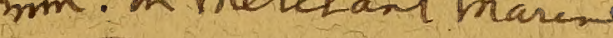

d Fusdenis

\title{
NATIONAL OCEANOGRAPHIC PROGRAM-1965
}

\section{HEARINGS}

BEFORE THE

SUBCOMMITTEE ON OCEANOGRAPHY

OF THEI

COMMITTEE ON

\section{MERCHANT MARINE AND FISHERIES}

\section{HOUSE OF REPRESENTATIVES}

\section{EIGHTY-EIGHTH CONGRESS}

\section{SECOND SESSION}

JUNE 23, 24, 25, AND 30, 1964

\section{Serial No. $88-23$}

Printed for the use of the

Committee on Merchant Marine and Fisheries

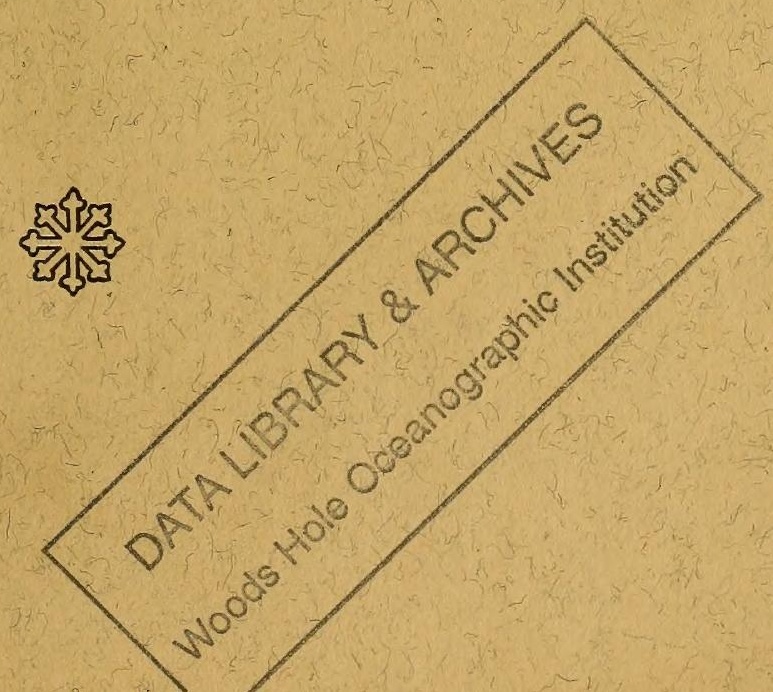





\section{NATIONAL OCEANOGRAPHIC PROGRAM-1965}

\section{HEARINGS}

BEFORE THE

\section{SUBCOMMITTEE ON OCEANOGRAPHY}

OF TEस

\section{COMMITTEE ON}

\section{MERCHANT MARINE AND FISHERIES}

\section{HOUSE OF REPRESENTATIVES}

\section{EIGHTY-EIGHTH CONGRESS}

SECOND SESSION

JUNE 23, 24, 25, AND 30, 1964

Serial No. 88-23

Printed for the use of the

Committee on Merchant Marine and Fisheries

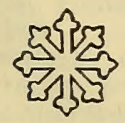




\section{COMMITTEE ON MERCHANT MARINE AND FISHERIES}

HERBERT C. BONNER, North Carolina, Chairman

EDWARD A. GARMATZ, Maryland THOR C. TOLLEFSON, Washington LEONOR K. (MRS. JOHN B.) SULLIVAN, WILLIAM K. VAN PELT, Wisconsin Missouri

T. A. THOMPSON, Louisiana FRANK M. CLARK, Pennsylvania THOMAS L. ASHLEY, Ohio JOHN D. DINGELL, Michigan L. MENDEL RIVERS, South Carolina ALTON LENNON, North Carolina THOMAS N. DOWNING, Virginia BOB CASEY, Texas

JAMES A. BYRNE, Pennsylvania CHARLES A. VANIK, Ohio HARLAN HAGEN, California EDITH GREEN, Oregon PAUL G. ROGERS, Florida FRANK A. STUBBLEFIELD, Kentucky JOHN M. MURPHY, New York JACOB H. GILBERT, New York

JoHN M. DREWRY, Chief Counsel Bernard J. ZiNcke, Counsel Ned P. EveretT, Assistant Counsel WILLIAM B. WINFIELD, Chief Clerk PAUL S. BAUER, Consultant

SUBCOMMITTEE ON OCEANOGRAPHY

ALTON LENNON, North Carolina, Chairman

JOHN D. DINGELL, Michigan BOB CASEY, Texas CHARLES A. VANIK, Ohio EDITH GREEN, Oregon PAUL G. ROGERS, Florida JACOB H. GILBERT, New York
THOMAS M. PELLY, Washington ROBERT F. ELLSWOR'H, Kansas STANLEY R. TUPPER, Maine CHARLES A. MOSHER, Ohio HASTINGS KEITH, Massachusetts. 


\section{CONTENTS}

Hearings held on- $\quad$ Page

June 23, 1964

June 24, $1964 \ldots \ldots \ldots \ldots$

June 25, 1964

June 30, $1964 \ldots \ldots \ldots \ldots$

Statement of-

Dubach, Harold W., deputy, National Oceanographic Data Center - -

Hornig, Dr. D. F., Director, Office of Science and Technology, and Chairman, Federal Council of Science and Technology _........

Maxwell, Dr. Arthur E., head, Geophysies Branch of the Office of Naval Research and Chairman of the Interagency Committee on Oceanography Panel on International Programs

McKernan, Donald L., Chairman, Interagency Committee on Oceanography, Instrumentation, Equipment, and Facilities Panel_......-

Nygren, Comdr. Harley D., U.S. Coast and Geodetic Survey, Acting Chairman, Ocean Surveys Advisory Panel, Interagency Committee on Oceanography _... . . . . . .

Stewart, Dr. Harris B., Jr., Deputy Assistant Director, U.S. Coast and Geodetic Survey in the Office of Oceanography

Treadwell, Capt. T. K., U.S. Navy, Chairman, Ships Panel of the Interagency Committee on Oceanography

Wakelin, Hon. James H., Jr., Assistant Secretary of the Navy (Research and Development) and Chairman of the Interagency Committee on Oceanography of the Federal Council of Science and Technology

Wallen, Dr. I. E., Assistant Director for Oceanography, Museum of Natural History, Smithsonian Institution, and Chairman, Research Panel, Interagency Committee on Oceanography _........

Additional information supplied by -

Commerce Department-

Chronological background of operations research study of ocean

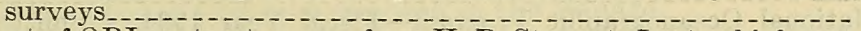
Cost of ORI contract, nemo from H. B. Stewart, Jr., to chief, program planning staff.

Investigation of geophysical data holdings....

Operations Research, Inc., biographies of consultants attached to

Systems development division, chart listing personnel dated April 18,1963

Ocean Science News article dated June 11, 1964, re retirement of Secretary Wakelin Stewart, Dr. Harris B., Jr.-

Panikkar, N. K., director, Indian Ocean Expedition of India, letter dated May 31, 1964_............................

Shepard, Frances P., professor of submarine geology, Scripps Institution of Oceanography, letter dated May 18, 1964_...-

Steele, S. B., acting public affairs officer, U.S. Information Service, letter dated May 21, 1964

Wijesekera, R. O. B., Ceylon Association for the Advancement of Seience, letter dated May 22, 1964

Willis, Frances E., American Ambassador, letter dated June 8, 1964

Yang, Theresa, letter dated March 15, 1964

Treadwell, Capt. T. K.-

Operation of oceanograpgic vessels, tables........

Shipping and geophysical companies approached by the Navy Oceanographic Office re ocean surveys................. 
Additional information supplied by-Continued

Wakelin, Hon. James H., Jr.-

Agencies participating in the national oceanographic program, chart _._.

Balance of oceanographic research effort in the United States..-

Highlights of ICO and panel meetings, calendar year 1963....

ICO contracts with private institutions, table $\ldots . . . . . . . . .$.

Interagency Committee on Oceanography advisory panels, chart.-

Interagency Committee on Oceanography, chart ............

Legislative bodies applicable to ICO member agencies' oceanography programs, fold-in table _................ Facing

Oceanographic ships at private institutions, table........

Past and present status of security classification of oceanic

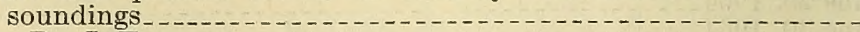

Wallen, Dr. I. E.-

Geochronology of Marine and Fluvial Sediments, from Science magazine, June 19, 1964, by Elizabeth Rona _............

Scientific background of drilling program as presented in a proposal to the National Science Foundation _.

Material submitted by Dr. J. Herbert Hollomon, Chairman of the Interdepartmental Committee for Atmospheric Sciences of the Federal Council for Science and Technology Relative to Air-Sea

Interaction Research Planning.

Appendix 2

Bibliography of Oceanographic Publications, submitted by Hon. James H. Wakelin, Jr., Assistant Secretary of the Navy.

Appendix 3
University Curricula in Oceanography, submitted by Hon. James $\mathrm{H}$. Wakelin, Jr., Assistant Secretary of the Navy.

Appendix 4

Aquatic Sciences in the Great Lakes Area, submitted by Hon. James

Page

H. Wakelin, Jr., Assistant Secretary of the Navy, and prepared by Robert B. Abel, executive secretary, Interagency Committee on Oceanography, including other documents on same topic.

Appendix 5

Oceanography-The 10 Years Ahead, submitted by Hon. James $\mathrm{H}$. Wakelin, Jr., Assistant Secretary of the Navy, including letter of transmittal to Speaker McCormick dated July 26, 1963, and signed by Dr. Jerome B. Wiesner.

Appendix 6

National Oceanographic Program-Fiscal Year 1964, submitted by Hon. James H. Wakelin, Jr., Assistant Secretary of the Navy.

Appendix 7

National Oceanographic Program-Fiscal Year 1965, submitted by Hon. James H. Wakelin, Jr., Assistant Secretary of the Navy, including letter of transmittal dated March 19, 1964, addressed to Speaker MeCormack and signed by President Johnson.

Appendix 8

Annual report of the National Oeeanographic Data Center-Fiscal Year 1962, submitted by Mr. Harold W. Dubach, Deputy, NODC.

Appendix 9

Annual Report of the National Oceanographic Data Center-Fiscal Year 1963, submitted by Mr. Harold W. Dubach, Deputy, NODC.

Appendix 10

U.S. Oceanography A Bold New Venture, article appearing in the Deputy Assistant Director, U.S. Coast and Geodetic Survey, in the Office of Oceanography.

Appendix 11

Man and the Sea, by Joel W. Hedgpeth, a series of lectures delivered 689 over KPFA, Berkeley, Calif., April 7-13, 1964. 


\title{
NATIONAL OCEANOGRAPHIC PROGRAM-1965
}

\author{
TUESDAY, JUNE 23, 1964 \\ Hodse of Representatives, \\ Committree on Merchant Marine and Fisheries, \\ SUbCommittee on OCEanography, \\ Washington, D.C.
}

The subcommittee met at $10: 15$ a.m., pursuant to call, in room 219, Cannon House Office Building, Hon. Alton Lennon (chairman of the subcommittee) presiding.

Mr. Lennon. Pursuant to notice given to the members of the Subcommittee on Oceanography, the subcommittee is convened.

I would like to make this short opening statement for the record and for the benefit of our distinguished guests here this morning.

The purpose of these hearings is to examine the national oceanographic program for fiscal year 1965 , which was transmitted to the Speaker of the House on March 19, 1964, by the President. Copies of this program have been distributed to the members of the Subcommittee on Oceanography. (See app. 7, p. 567.)

This year, the administration has presented the oceanographic program with a horizontal budget structure. This enables the Congress to examine the program as a complete entity rather than attempting to analyze the vertical budgets of the many different agencies involved in the study of the marine sciences. It is the procedure called for in the bill which originated in this committee, H.R. 6997. The legislation has passed the House and now reposes in the Senate.

We are indeed fortunate to have as our first witness Dr. D. F. Hornig who is the Director of the Office of Science and Technology and is Chairman of the Federal Council of Science and Technology. Dr. Hornig, in addition to these duties, is Science Adviser to the President. He will be followed by Dr. James H. Wakelin, Jr., Assistant Secretary of the Navy for Research and Development, who is also Chairman of the Interagency Committee on Oceanography.

Other witnesses involved in the functional planning of the fiscal 1965 oceanograhic program will follow.

Dr. Hornig, this is a great honor and a pleasure to this committee to have you here with us today and we look forward to your testimony and with a much closer relationship than we have had the privilege of enjoying in the past.

I ask you, sir, do you have other members of the ICO with you here, and I do not believe there are but two chairs to your right or left, so I suppose you would want them to sit where they are.

Dr. Hornig. Dr. Wakelin, of course, is Chairman of the ICO and we have a number of members of the ICO. 
Mr. Lennon. Yes, sir; the members of the committee have been furnished with a witness list and the subject for discussion that you were gracious enough to furnish the committee some several days ago.

Dr. Hornig. I also have with me Dr. Wenk, who is Executive Secretary of the Federal Council for Science and Technology and a member of my staff.

Mr. Lennon. You have a prepared statement, I believe, sir, which has been furnished to members of the subcommittee, and if you will just proceed we will be delighted to hear from you, sir.

\section{STATEMENT OF DR. D. F. HORNIG, DIRECTOR, OFFICE OF SCIENCE AND TECHNOLOGY, AND CHAIRMAN, FEDERAL COUNCIL OF SCIENCE AND TECHNOLOGY}

Dr. HorNIG. Mr. Chairman and members of the committee, I appreciate this opportunity to appear before your Subcommittee on Oceanography to discuss the relationship of this field to our national welfare. This is the first occasion on which the Director of the Office of Science and Technology has been able to discuss with you the oceanographic program and the manner in which the program is developed and administered.

I especially welcome your invitation to develop a series of presentations from the executive branch that will describe how the oceanographic research activities of some 20 bureaus are brought together in reasonably coherent fashion. All of these activities are carried on by the separate departments and independent agencies that have statutory missions related to the sea. As a consequence, the program has been primarily described to the Congress on an agency-by-agency basis. I believe, however, that it is vital that appropriate congressional committees examine the scope of such interagency programs in terms of the aggregate goals and the total national effort to achieve them.

I recall that it was your subcommittee that took initiative to examine the potential of oceanography to contribute to the Nation's needs very soon after publication of the National Academy of Sciences proposals for a 10-year program of Federal support to strengthen this enterprise. H.R. 6997, which was reported out by your committee and passed the House of Representatives last year, would identify oceanography as a field deserving of a congressional policy action. In calling for the development of a comprehensive, long-range plan and coordination in oceanography, this bill gained the support of my predecessor, Jerome B. Wiesner, in his letter to Chairman Bonner last June. This legislation has not yet been acted on. I should like to lend my support to its enactment, for I believe that it will help us better to achieve a coordinated, comprehensive, and effective national program in oceanography.

\section{OCEANOGRAPHY AND ITS CONTRIBUTION TO NATIONAL GOALS}

Before discussing further the Federal oceanography program, I should like to describe what we mean by oceanography and how this field of science is relevant to practical matters of importance to the Nation. 
The ocean covers more than 70 percent of the surface of the earth; for the most part it is the common property of the nations of the world and the common resource of the technologically advanced nations. Slow accumulation of observations made by explorers, and recently oceanographers, has given us a useful general picture of the ocean, but one inexact and almost totally lacking in detail. We know quite a lot about the gulf stream, the warm northward moving river which lies off our east coast and which carries heat and life to the countries of northwest Europe. This region has been more intensively studied than any other in the world's ocean, but we have only recently learned that there lies below the gulf stream another stream flowing with less speed in the opposite direction. We know that spectacular variations or meanders occur in the gulf stream, but why this is so or what consequences result we do not know.

The sea sustains plant and animal life in great abundance; we have identified many of the forms of life which reside near the ocean surface, although much more is to be learned; but we know very little about the living population at great depths. We recognize that there is a truly enormous potential food supply available in the ocean; but we are properly cautious about its management and exploitation, because we have so far learned so little about the food chains which lead through various forms of life from plankton to the edible fish.

Recent advances in technology have given us new instruments with which to study the ocean floor and the layers of sediment which reveal much about the history of the earth. These include acoustic refraction techniques, gravity meters of high precision, sensitive magnetometers, precision depth recorders, deep-coring facilities, and ocean bottom photography. We look forward to fascinating and important discoveries relating to the structure and history of the ocean floor, but the extent of the ocean is so great and the skill required in the use of these instruments so great that many mysteries will remain hidden for a long time.

The effects of the atmosphere on the ocean and of the ocean on the atmosphere are both obvious and subtle, catastrophic, and gentle. Fort short time periods these effects may be studied independently; but for longer periods the ocean and the atmosphere must be considered to be a single system. For example, a warm ocean gives up heat to the atmosphere with the consequence that winds are created; the winds create waves and spray, and the resulting mixing and evaporation cools the ocean. Further chains of events can be traced, but we must recognize that we don't know much in a quantitative sense about these processes. Here lie some of the critical difficulties in weather prediction for periods of weeks or months. To make substantial progress in this area we shall need carefully planned investigations.

The solution of the scientific problems which reside in the sea requires varied talents. Physicists, chemists, mathematicians, biologists, mechanical and electrical engineers all are needed in oceanographic research. Each of the scientific problems I have discussed is important to a number of practical problems which, in fact, determine the Nation's interest in oceanography and account for the recent large increases in budgetary support. Without a clear recognition of the scientific problems and an honest determination to attack them, we cannot hope to solve the practical problems; and we should 
find it impossible to hold and attract the capable, energetic scientists, engineers, and technicians which the agencies and research laboratories require.

From this discussion of the nature of oceanography, it should be clear that oceanography is not one field but a combination of fields. Classical disciplines and newer interdisciplinary sciences become closely coupled because the interests involved all relate to the sea.

Insofar as the Federal Government is concerned, the complexity that arises out of the variety of scientific categories is paralleled by the complexity that arises from the variety of practical interests which we have in the sea. The ocean is a military arena which, in an era of undersea warfare and sea-based deterrents, must be understood by the Navy. The Bureau of Commercial Fisheries in carrying out its statutory functions must inventory fish stocks; it must understand the factors which promote their growth and distribution; and it must employ this understanding to improve the effectiveness of the catch. And I might add-to insure that there is a catch and to know where we can find it in the future.

The Bureau of Sports Fisheries and Wildlife has concern for the conservation and utilization of our living resources as they contribute to ocean-related recreation. The Geological Survey and the Bureau of Mines are interested in determining the distribution and richness of mineral resources on or below the ocean floor and the means by which they can be exploited-both on the shallow Continental Shelf in the near future, and in the deeper ocean in the more distant future. The Coast and Geodetic Survey has the important task of charting the oceans, measuring not only bottom topography but also currents, temperatures, gravity, and magnetic fields. The Weather Bureau seeks to understand better how the ocean behavior influences weather and climate, and how such scientific information may be employed to improve weather prediction and, perhaps a long way off, to modify climate. The Atomic Energy Commission must understand processes within the ocean to determine how it may safely deposit radioactive waste, and the Public Health Service has a corresponding obligation to study adverse effects of pollutants on fish and other marine life, which form part of the human food chain. The Coast Guard is responsible for protecting life and property at sea. It requires an understanding of storm and iceberg hazards. The Coastal Engineering Research Center of the Army Corps of Engineers maintains an interest in the damaging effects of waves and weather on our shores and means by which these effects may be corrected or moderated. The Smithsonian Institution and the National Science Foundation have exceedingly vital roles in relation to the broad understandings of the ocean, to help insure that important areas of research are not overlooked as a result of concentration on the individual mission responsibilities of the various agencies.

Although the State Department maintains no research program of its own, it has a direct interest in the potential of oceanography to contribute to our foreign policy. The phenomena which we are observing are, of courses, global, and international cooperation in scientific expeditions has become a well-established medium for the more rapid and effective study of the oceans. Through such scientist-to- 
scientist communication, a small but significant mechanism of informal diplomacy fosters world understanding and achievement of our foreign policy aims. Research directed at understanding and exploiting both the ocean and the atmosphere offer the best possible opportunity for practical cooperation among nations and for developing stronger awareness throughout the world that our futures are bound together. In a direct way, U.S. efforts in oceanography contribute to the direct benefit of other peoples. The exploitation of the living resources of the sea can help meet protein deficiencies of hundreds of millions of people, although I must say that we have moved very slowly in doing so; I hope in this year we will be able to do a little more. The worldwide observation of storms, tsunami, and other devastating acts of nature may help save lives beyond our shores.

Because the study of the sea involves many interests and is approached from many points of view, programs are supported by many agencies. As a consequence, mechanisms have had to be developed to coordinate these programs in order that they add up to a single national program and $\mathbf{I}$ should like to discuss these mechanisms briefly.

\section{PLANNING AND COORDINATION THROUGH THE FEDERAL COUNCIL FOR SCIENCE AND TECHNOLOGY}

The Federal Council for Science and Technology was established in March 1959 by Executive Order 10807 to assist the President by $(a)$ providing more effective planning and administration of the Federal program; (b) identifying research needs, including areas requiring additional emphasis; $(c)$ achieving more effective utilization of scientific and technical resources and facilities of Federal agencies, including the elimination of unnecessary duplication; and $(d)$ furthering international cooperation in science and technology.

Functioning somewhat as a science cabinet, the Council includes policy rank officials from the eight departments having major programs in research and development, with observers from Department of State, Federal Aviation Agency, and the Bureau of the Budget. As special assistant to the President I serve on the Federal Council. Following the precedents of Presidents Eisenhower and Kennedy, President Johnson has asked that in that capacity I serve as Chairman.

It is important to recall that the authority and responsibilities of individual departments constitute the dominant basis for the conduct of Federal research and development. Each department with its own special and complex requirements, operating under statutory authority from the Congress, must be free to sponsor imaginative and creative research if its programs are not to become sterile. In the field of marine biology, for example, the National Science Foundation and the Smithsonian Institution are concerned with exploring a wide range of fundamental problems and in supporting the training of marine biologists, while the Bureau of Commercial Fisheries seeks to understand the distribution and habits of fish; the Navy investigates the effects of marine organisms on sound propagation, and the Public Health Service tries to assure the quality of the food taken from the sea. In some cases, the interests of the separate agencies overlap, and 
this circumstance has both advantages and disadvantages. However, there is a growing recognition of common interest among the agencies. None of the agencies, for example, are in a position to sponsor all of the fundamental research on which their programs depend. Each, therefore, draws increasingly on the fruits of research sponsored by sister agencies; each thus contributes to the other. Apart from this common pool of scientific information, each of the agencies must draw on scientific resources, particularly manpower, that cut across organizational lines.

In seeking to foster communication and cooperation among the agencies, the Council seeks to obtain greater efficiency and economy for the effort as a whole. These comments apply to not only oceanography, but to this very general problem of Federal programs which cut across many agencies.

In the task of coordination, the close relationship between the Federal Council, the Office of Science and Technology, and the President's Science Advisory Committee, and their close proximity to the White House, all help greatly in the conversion of plans into actions. Because of policy level agency representation in the Council, actions jointly agreed upon are in most cases implemented effectively and directly.

Issues which come before the Council fall generally into three categories: $(a)$ the development of Government-wide plans and programs; (b) problems of Federal management in which we consider efficient utilization of resources and the assurance of program quality; and (c) the development of Government-wide policies relating to nongovernmental programs and institutions and to international activities.

These issues are developed through studies by the President's Science Advisory Committee, the National Academy of Sciences, and the Executive Office of the President. But, by and large, the sharpening of issues, the collection of facts, and the generation of recommendations are carried out through the committee structure of the Council itself.

The Council at the present time has committees on oceanography, water resources research, atmospheric sciences, materials research and development, high energy physics, behavioral sciences, natural resources, scientific and technical information, scientific personnel, patent policy, international affairs, and long range planning. The particular case we are talking about today is the coordination of oceanography.

\section{GOVERNMENT-WIDE PROGRAMIS IN OCEANOGRAPHY}

It should be clear that all Federal science and technology cannot be coordinated by the Council. In fact, the Council has been highly selective in choosing topics for analysis and continued review. The Council operates with a minimum of staff, administrative superstructure, and protocol. In a few instances, however, the need for continuing coordination has warranted the development of full-time staffs in the committees themselves, and the Interagency Committee on Oceanography is one such example. 
In turning now to the program in oceanography and the manner in which its development and coordination have been carried out through the Council, I should recall a very brief history.

In 1959 a broad study undertaken by the National Academy of Sciences at the request of a number of Federal agencies was set forth in a report entitled "Oceanography, 1960-70." The study recommended doubling of the then annual effort of about $\$ 35$ million over a period of about 10 years. Senate Resolution 136 unanimously supported these recommendations to expand oceanography and the first of a series of bills was introduced in both the House and the Senate to strengthen Government-wide planning and coordination. In 1959, soon after its own establishment, the Federal Council appointed an Interagency Committee for Oceanography which has since been the primary mechanism for basic program planning.

In the spring of 1961, President Kennedy sent a special budget message to the Congress calling for a step increase in oceanographic funding, partly to accelerate a new ship construction program and training of manpower. That year, too, the Council released its first annual report on oceanography setting forth an integrated program and budget. Such a report has been developed and made available to the Congress each year since, and I will subsequently discuss the manner in which these reports are developed in more detail.

I think the members of this committee have seen the pink report that the chairman alluded to which analyzes the 1965 program in oceanography.

\section{LONG-RANGE PLANS}

Last summer a long-range, 10-year plan was developed to provide a broad perspective for an effective and expanded scientific study of the sea, set forth in this green report which I believe you have also seen.

Research objectives were identified, the relation of these objectives to the national welfare was discussed, and estimates were made of the funds, facilities, and manpower needed for their accomplishment. Reviewed, endorsed, and published by the Federal Council, this plan has served to illuminate the relationship between the agency programs and the general goals. The long-range plan was formally transmitted to the Congress July 26, 1963.

The 10-year plan represents the best judgment of Federal officials as to the size and internal priorities of the agencies' research programs. It is a view of a landscape at one point in time. As our understanding grows and the landscape is seen more clearly, more detailed plans must be made and the previous plans revised. Consequently, one of the first projects that I expect to assign to the ICO next year is the development of a new long-range plan that takes into account the experience we have gained and profits from it.

THE FISCAL YEAR 1965 OCEANOGRAPHIC BUDGET PROPOSALS

The development of the annual program in oceanography is the specific responsibility of the Interagency Committee on Oceanography, and I shall indicate briefly the steps which the Interagency Committee follows each year in preparing the program. 
The Interagency Committee, incidentally, operates through a series of specialized panels, and the panel chairmen have been invited to appear as subsequent witnesses before your committee. They will be able to tell you how each spring they draw up a set of plans that represent a combination of mission needs and scientific opportunities. These plans are first sifted and reviewed by the ICO and then evaluated both by OST staff and by a panel of outside consultants, convened by the Office of Science and Technology, and representing a variety of subject matter disciplines and institutional experience. They attempt to insure that these programs are not "more of the same," that they reflect fully new opportunities in scientific research, and the full potential of engineering technology.

Finally, the ICO proposals, together with the consultants' critique are submitted to the Council, acting in plenary session. With Council review and endorsement, the program then adopted serves as a guide, both to the Bureau of the Budget and to individual agencies in the development of budget proposals which are finally reflected in the President's annual budget message to the Congress. The national oceanographic program for fiscal 1965 was incorporated as special analysis $\mathrm{H}$ in the President's budget message to the Congress. Full details were set forth in the Federal Council report that was transmitted by the President to the Congress, that is he pink one, on March 19, 1964. Copies were sent to the committee.

The document includes a summary description of the program and its interpretation, and a detailed account of the parts of the program and its cost.

It is important to recognize here that any field of science or any other field of Government activity undergoes an excruciating set of reviews. Inevitably, the aggregate of budget proposals exceeds the funds available. Choices have to be made, and in this competition for funds justification must be based not only on the importance of the objectives but on the scientific resources available, particularly of skilled manpower, and the quality of the leadership. In his January 21 message on the fiscal 1965 budget, President Johnson enunciated a set of guidelines and principles expressing his determination to keep costs under tight control. It is in this framework that the $\$ 138$ million oceanographic budget was submitted.

The $\$ 138$ million in this proposal represents an 11-percent increase over the fiscal 1964 appropriations. To sustain momentum in the developing program, the budget was carefully tailored to foster growth in research and training, providing $\$ 73$ million in this category compared with $\$ 64$ million last year and some $\$ 52$ million for fiscal year 1963. To do this, ship construction was accordingly slowed.

In transmitting this year's oceanographic program to the Congress. President Johnson stated-

this proposed growth is an absolute minimum if the country is to achieve its objectives in oceanic research which had been previously enunciated by both President Kennedy and the Congress.

We are somewhat disappointed to find that some elements of this program, as was the case with the fiscal 1964 oceanography program, have not received support by the Congress and this illustrates a problem which I especially wish to call to this committee's attention. Different parts of the oceanographic budget are considered separately 
by several committees of Congress; in this process the coherence of the program may not be visible to the separate committees, and the integrity of the program may be weakened when some parts of it are cut without regard to the effect on the whole. I believe that this is one of the important problems which Congress and the Executive jointly face in attempting to create and execute wise policy in managing programs which extend through many agencies.

May I note, incidentally, that although the overall growth rate has been slowed, this level of support more than meets the targets initially set by the National Academy of Sciences in their report of 1958. It is also consistent with the 1960 study conducted by the House Science and Astronautics Committee which indicated that to meet the goals which the Congress then felt significant, the program over the decade of the 1960 's should increase by a factor of about t.

In assessing where we stand in oceanography, it is important to note that if the Congress acts favorably on the fiscal 1965 prograrr, the Federal Government will have invested \$134 million in new ships over the previous 5-year period. For the first time in this Nation's history we shall have a fleet explicitly designed for oceanographic research and surveys. We will also have invested $\$ 38$ million in new shore facilities.

Most important, in 5 years, the annual support for research will have grown by almost a factor of 3 .

These funds, to be sure, are not a large fraction of the Federal research and development budget, but their size and rate of growth must be measured in terms of the exceedingly small nucleus of activity from which this whole enterprise began. The capabilities of Government, university, and industrial laboratories have so increased that the world leadership which the United States has demonstrated in many fields of science is also sustained in oceanography.

Neither dollars nor numbers of ships are the proper yardstick of progress, however, rather, what matters are the scientific and engineering accomplishments in the oceans, but I will leave description of some of the exciting new discoveries and prospects resulting from this research to the panel chairmen of the ICO.

I know also that the Congress is interested in the quality of its management. I believe that the efforts of the Federal Council and the ICO to plan wisely, to develop balance of support between fields, to assess the relative emphasis to be given research, ships, and manpower, and to take steps to minimize duplication of effort, help to insure that the funds which the Congress has appropriated are prudently used.

Federal support of science is motivated because in the long or short run, science serves mankind. What will be discovered and how such discoveries will contribute to our national welfare is often unforeseen. I should like to assure this committee of the determination of the administration to support scientific research and to make as sure as is possible that we are working with maximum effectiveness on the most important problems. We can then hope to meet new challenges as they arise with confidence and wisdom.

Mr. Chairman, I will be glad to answer questions.

Mr. Lennon. Thank you, Doctor.

Mr. Pelly? 
Mr. Pelur. Well, Mr. Chairman, I do not want to delay hearing the panel members that are going to follow but I would certainly feel remiss if I did not compliment the doctor on his informative report. It is one of the finest bits of testimony that I think I have heard as a member of this committee.

Dr. Hornig. Thank you.

Mr. Lennon. Mr. Casey?

Mr. CASEY. Doctor, does the Interagency Committee on Oceanography now report to the Federal Council? In other words, is it kind of an advisory committee in the Federal Council?

Dr. Hornig. Yes; the ICO is set up as one committee of the Federal Council; so its reports and recommendations are evaluated by the Federal Council.

Mr. CASEY. I do not want to take too much time but I wonder if you could maybe clear up the difference between the Federal Council and the Office of Science Technology and the Science Advisory Committee. Are they more or less related? Do you have some of the same members serving on all three of these committees?

Dr. Hornig. I think this may be the best way to put it: All of these functions serve in an advisory capacity to the President. The Office of Science and Technology is the staff office within the Executive Office of the President; the Federal Council is a representative body of the Federal agencies which works with the Office of Science and Technology and provides advice from within Government; the President's Advisory Committee provides advice from outside of the Government. It also works with the Office of Science and Technology, but it produces the outside input.

Mr. CASEY. That clears it up sufficiently for me. I will not spend any more time on that.

I do want to compliment you on your statement and even though this committee's bill which the chairman and others of us introduced to show our support has passed the House and as the chairman stated, it reposes in the Senate. I believe that the interest that developed in this bill-we had another bill before as you recall, and had the same luck-in fact, I think the other one was passed and was vetoed.

Dr. HorNig. Yes.

Mr. CASEY. That it has stimulated interest in oceanography and I think not only outside of the Government but in the executive branch and I believe we are getting some of the fruits today of the purpose of the bill even though it has never really seen the final signature of the President and actually become part of the law.

I want to compliment you and the members of the subcommittee and the others that have worked with this committee on developing a bill that would be compatible to the executive department in setting forth the guidelines and following some of the ideas that have been worked out jointly by some of the committee and the executive department and going ahead with it even though it is not part of the law. I think we are accomplishing something, we really do not need the law if we continue to maintain this type of cooperation. I do believe we need the law for the purpose of informing our colleagues in the Congress of the need for this support and the support of these programs that you people are undertaking. 
Dr. Hornig. I think what you have said is very correct. I think we have gradually, through the work of your committee and through the work of the Interagency Committee, built up interest and understanding in this program.

Mr. CASEY. We have kind of a public relations job with the rest of the Congress who are not familiar with the work and the horizons that you are opening up in the future of the programs that can be undertaken, and the benefits that will result of continued effort in this field. I think that is where our problem is. If we can get them awakened to that. You do not ask for as much money as we spend on one pad down at Canaveral. I think the benefits we will reap from this are unlimited.

Dr. Honnig. I think the long-range aspects are very great and, of course, we have just begun the buildup. It is really only a few years old, and we are going to have to wait a while for some of the anticipated benefits.

Mr. Casey. You do not need all that money right now, you could not absorb it. I know you could use more money than you are going to get. I think that is typical of most all agencies. I think what we need to do is when someone complains about some oceanography program, well, they say, this is a tremendous amount of money, why, I think it relates to some of our other scientific programs and the possible results, I do not think this is exorbitant, I do not think it is wasteful.

Thank you, Mr. Chairman.

Mr. Lennon. Mr. Ellsworth?

Mr. Ellsworth. Thank you, Mr. Chairman. I, too, would like to compliment you, Dr. Hornig, on your very fine statement and I would like to second what Mr. Pelly and others on the subcommittee have said to you.

I do not really have any questions but I would like to make a couple of comments on your statement.

First of all, with respect to page 7, your comment that the phenomena which we are observing are, of course, global, I look forward to hearing later in testimony from some of the men who are going to follow, further comment on that. I think this is one of the real problem areas, critical problem areas. Not only so far as international cooperation is concerned but so far as rights and responsibilities are concerned when it comes to commercial exploitation of the resources of the ocean. So I was glad to have that comment in there and I look forward to having further details on some of these areas brought out in later testimony.

Then I want to comment also on page 16 where you point out that different parts of the oceanographic budget are considered separately by several committees of Congress and in this process the coherence of the program may not be visible to the separate committees and the integrity of the program may be lost. I think this is a tremendous problem. It is a problem that the bill which is pending over in the Senate is partly aimed at. It is a problem that Mr. Casey touched on, and I want to express the hope that the Executive Office of the President and the whole administration-now that the civil rights debate is over over there-can get behind this bill and urge its early passage by 
the Senate so it can be signed into law by the President and I think that will be helpful. It will not solve the problem but it will be helpful in preserving the integrity of the oceanographic program when it is presented to the Appropriations Committee for funding.

Dr. Hornig. I think that is correct. One of the reasons that the Federal Council has produced these reports is so that each of the congressional committees in considering its part can have the opportunity to see what the total program looks like.

Mr. Ellsworth. Thank you, Mr. Chairman.

Mr. Lennon. Mr. Rogers?

Mr. Rogers. Thank you, Mr. Chairman.

$\mathbb{I}$, too, want to join in saying that your statement has been very helpful to the committee.

I am concerned about the statement you made on page 16 , too. Do you foresee that probably as we develop in this field that is going to be necessary, probably to have one overall agency to develop this field or do you foresee just a continuation of the Interagency Committee?

Dr. Honnig. I am not sure that I can give you a final answer to that question. This is a problem which comes up in many areas of Government. I mean that a number of different scientific programs cut through many agencies, and also are considered by many committees of the Congress. It certainly is not true that in each case the answer is to create another agency. I think this is why it is a problem.

Te approach oceanography from many points of view and, for instance, the Navy has a different attitude toward it than the Bureau of Commercial Fisheries. This is, I think, a healthy state of affairs as well as being a source of this problem we are discussing. I think it would be wrong to generate a mechanism which did not allow the free play of these multiple points of view and multiple reasons for interest. I think that feature ought to be preserved because it is a source of strength.

Mr. Rogers. You do not think that could be preserved if you had one agency to administer this program?

Dr. Honvia. I think that would depend on how it was set up and administered. I do not have a firm opinion on this.

Mr. Rogers. I was thinking, we have the space agency now that handles the majority of the problems there, and I certainly feel that oceanography has the potential of our space program as we develop it and it was my thinking that some of the problems that you have discussed on page 16 probably could be met if we had an overall program more closely coordinated and administered by an agency under the jurisdiction, say, of your Oceanography Committee.

Dr. Horsig. I think there is no question that a single agency, either an existing one or a new one reporting to the President, could meet this problem better. The question is whether one would not end up overdoing it and weaken some of the ties of scientific research to the practical problems which would stay outside of it. That is, there would be a new and difficult problem to relate the research effort to the practical problems associated with missions necessarily retained by the agencies?

Mr. Rogers. Let me ask you now, your Interagency Committee, they make a recommendation as to what should be done in this field to your Federal Council? How is this determined? Are there so many 
votes that each department has, or how does this agency come to make these decisions to recommend to you and then how do you decide it?

Dr. Hornig. I will leave it to Dr. Wakelin to discuss the operation of the Interagency Committee itself.

Mr. Rogers. All right, the Federal Council.

Dr. HornIG. The Federal Council is a small body and operates informally, by consensus rather than by formal votes.

Mr. Rogers. What do you mean by consensus? You mean there is no way-suppose there is a disagreement? You mean no one ever disagrees?

Dr. HonNIG. This would be an unusual body if that were so.

Mr. Rogers. I would think so.

Dr. HorNig. I think the situation with regard to oceanography is that the Interagency Committee on Oceanography is a strong committee. The Federal Council presumes that the major technical disputes over program details are resolved.

Mr. Rogers. You would pretty much go along with the recommendation?

Dr. HonNIG. That is right. Normally there is

Mr. ROGERs. Unless there is some overriding reason?

Dr. HonNig. That is right.

Mr. Rogens. Have you ever turned down, since you have been here, recommendations that you can recall, just to give us an example?

Dr. Honnig. I will leave this to Mr. Wakelin. I have been here only since February and have not, in fact, been through this debate on this particular program yet.

Mir. Rogers. You have no votes, then, within the Federal Council, if there were a disagreement?

Dr. HonNig. In my experience we have never had to have votes. We have made recommendations where there were dissenting members, yes, but-

Mr. Rogers. What is the outcome in that situation?

Dr. Hornig. Since the Federal Council is basically an advisory committee to the Chief Executive, dissents on program scope or balance are noted, and this then must be debated and resolved when the President's budget is put together.

Mr. Rogers. Noted to whom? In other words, I am trying to determine who makes these decisions. Would this fall upon you as director to make the decision if there is any disagreement within your council?

Dr. Honnig. Yes, I and the Bureau of the Budget make recommendations to the President.

Mr. Rogers. Within the budgetary limitations?

Dr. Hornig. Yes.

Mr. Rogers. Who in the Bureau of the Budget? Do you have a representative that is an observer or a member of your Council?

Dr. Hornig. No one person; my entire office works closely with the Bureau of the Budget.

Mr. Rogers. You have no one specific person to work with in the Budget?

Dr. Honnig. No; not in general.

Mr. Rogers. Well, how do they keep informed? Do they have an observer with you? 
Dr. HonNig. My staff and Mr. Gordon's staff are in very close contact. We are at opposite ends of the same corridor.

Mr. Rogers. Do they attend your Council meetings? I know in one-I guess on the Interagency Committee they do have an observer.

Dr. Honvig. The Bureau of the Budget has an observer present at the Federal Council meetings.

Mr. Rogers. Staats is the observer? I believe you have him listed here for the Federal Council.

Dr. Hornig. Yes.

Mr. Rogers. Does he generally attend himself or have a representative go in his place?

Dr. Hornig. No, he is usually there himself.

Mr. Rogers. So that there is close liaison between the two?

Dr. Hornig. Yes.

Mr. Rogers. And you would say then the real decisions are made by Staats and by you if there is a disagreement within the Council?

Dr. Hornig. Major controversies between agencies are settled by the President. But I would like to emphasize the essential role of the ICO. Normally there is a discussion process in which we try to resolve most of these issues at as early a stage as possible, and leave only major budget issues for final budgetary discussions.

Mr. Rogers. I understand that. But I would think the very critical problems would be those which come to the Council where there is some major disagreement which would have to be resolved and I was interested to know who in the final analysis would resolve these differences. As I understand your testimony, it is after general discussion with the Council, no specific vote would be taken but any disagreements would be noted, but it would be resolved by you in conjunction with conferring with the Bureau of the Budget. Would this be correct?

Dr. Honnig. That is essentially correct. I do want to note historically this is a correct statement. In fact, this careful review mechanism the ICO has adopted, including calling in the outside consultants by OST and making their advice available to ICO has produced a situation where I am not aware of the Federal Council's having overruled the ICO any time in the recent past.

Mr. Rogers. Now, in your advisory council. Who appoints that advisory council outside of the Government?

Dr. Hornig. That is appointed by me, or my office, but with consultation of ICO.

Mr. Rogers. Is this rotated?

Dr. Hornig. Each year we appoint an ad hoc committee.

Mr. Rogers. An ad hoc committee?

Dr. Hornig. Yes.

Mr. Rogers. People who are in the business or from what-

Dr. HornIG. We try to make it a representative group of able people in the field who can look at the ICO program and ask hard questions if there are questions to be asked. The responsibility, of course, has to remain within the Government.

Mr. ROGers. I understand.

Now, do you have a certain term of years or is it just a 1-year term that you appoint these people to? 
Dr. HorNig. Normally this committee is just called together for limited periods in August and April.

Mr. Rogers. Yes, I understand. I know you are new and you should feel free to ask any of your aids. I am going to conclude in just 1 minute, Mr. Chairman.

So, your advisory committee perhaps meets once a year, the ad hoc committee?

Dr. HonNIG. That is right.

Mr. Rogers. How often does your Federal Council meet?

Dr. Hornig. Well, the Federal Council meets once or twice a month.

Mr. Rogers. Once or twice a month. And do you have actual participation by the people listed here in your book on national oceanographic program, fiscal year 1964, I believe you have listed them, or do they have representatives?

Dr. Hornig. For the most part they attend. It depends on the seriousness of the issues that are coming up at any given meeting.

Mr. RogERs. I wondered what participation you get?

Dr. Hornig. All of these members attend at least a considerable part of the meetings of the Federal Council.

Mr. Rogers. Does this take a full day's time, would you say?

Dr. HorNig. No, the Federal Council normally meets for about 3 hours.

Mr. Rogers. And you review these programs and recommendations made to you by the various committees?

Dr. HonNIG. That is right.

Mr. RoRERs. And then you act after you have heard your advisory ad hoc group, or do you wait for their advice before taking any action, or how is that cordinated with your decisions?

Dr. Hornig. Well, in this case the program is not normally presented to the Federal Council until after the ICO has compared notes with the outside advisory group and taken its reactions into account. The Federal Council sees both the original proposals from ICO and the extensive critique prepared by the outside panel.

Mr. RoGers. Does the outside panel report directly to you or is it just a coordinated report with the $\mathrm{ICO}$ ?

Dr. Horvig. The panel reports to me, but results are usually discussed first with the ICO. It is not a question of deciding whether someone is right or wrong; the objective is to develop the best possible program. The consultants make their criticisms and remedies available by discussion with the ICO.

Mr. Rogers. And you say, of course, we can disscuss with Mr. Wakelin how they determine priorities within the ICO, which are generally accepted by the Federal Council?

Dr. Hornig. That is correct.

Mr. Rogers. Thank you, Mr. Chairman.

Mr. Lennon. Thank you, Mr. Rogers.

Mr. Tupper has left, Mr. Mosher?

Mr. Mosher. Mr. Chairman, of the many very interesting, important, and significant comments that Dr. Hornig has made in his statement, my special attention is called to this sentence on page 7 :

Research directed at understanding and exploiting the ocean and the atmosphere offer the best possible opportunity for practical cooperation among nations and for developing stronger awareness throughout the world that our futures are bound together. 
Dr. Hornig, in the previous sentence you refer to the informal arrangements, scientist-to-scientist communication which fosters this opportunity.

Are there available also more formal arrangements? Is there any international formal machinery by which this remarkable opportunity might be exploited further?

Dr. HorNiG. Well, there are a variety of arrangements. There is a joint Indian Ocean Expedition, for example, which has been going on for 3 years; there is a tropical Atlantic survey which is a multination survey; UNESCO has an International Oceanographic Commission which fosters cooperation in this area.

Mr. Mosher. Do you feel that this country is taking the initiative and leadership to the greatest extent possible to encourage this type of mechanism?

Dr. Hornig. I think we have done quite well. We continue to look for newer and better ways to help both ourselves and others by pooling efforts. When you say "the greatest possible," these are strong words.

Mr. Mosher. Yes.

Dr. HoRNIG. I think we can always do better than we are doing.

Mr. Mosher. Well, in general, do we get a cooperative response? Just to be specific, for instance, what about the Russians, our greatest rivals in many world activities; are there cooperative arrangements in these areas with the Russians?

Dr. HoRnig. The answer is "Yes"; and I think this has been a fairly model area, as many of the geophysical sciences have been. The Russians have participated in the Indian Ocean Expedition, they have had research vessels in the Indian Ocean. I think some of the people-you might return to this question-some of the people who are working more closely and immediately in oceanography can be more specific than I have been.

To the best of my knowledge they have participated actively and willingly in these international arrangements.

Mr. Mosher. And this legislation that reposes in the Senate, although it is not directed immediately to this international activity, it would lay a better basis, would it not, for our participation in it?

Dr. HorNig. I think so.

Mr. Mosher. That is all, Mr. Chairman.

Mr. Tiennon. Thank you, Mr. Mosher.

Mr. Gilbert?

Mr. Gilbert. I have no questions, Mr. Chairman. I merely wish to thank the doctor for his testimony and his presentation before the committee this morning.

Mr. Lennon. Thank you, Mr. Gilbert.

Mr. Keith?

Mr. KeIтн. Thank you, Mr. Chairman.

On page 17 you make reference to the capabilities of Government, university, and industrial laboratories.

I represent the Woods Hole Oceanographic Institute. I wondered what category that would fit into or do you need a fourth category?

Dr. HorNIG. I think this will be most clearly resolved by adding the words "independent research organization." I think in my mind I lumped them with universities when I wrote the sentence in question.

Mr. KeirH. Thank you. 
On page 16 you amended your text to read, at the third line from the bottom, "The Federal Government will have invested \$134 million in new ships over," and you inserted, "the previous 5-year period."

Dr. Hornig. I do not think that differs from my prepared testimony. By the "5-year period," I mean through this year.

Mr. Krith. I was just wondering if there was an extraordinary development in the previous 5 -year period over the preceding 5 years?

Dr. Hornig. Oh, yes. At the time of the National Academy study in 1959 , we were really very deficient in the number and quality of ships we had available and this fact was widely publicized. Now, in these last few years, we have really built up a fleet of specialized oceanographic vessels. So our capabilities - that is what this investment renresents-have been very considerably expanded.

Mr. KeIтH. Are we relatively in a better position vis-a-vis the Russian effort than we were 5 years ago, or have their efforts paralleled ours?

Dr. Hornig. I think 5 years ago there were really very much better off than we. They had built a number of fairly large, specifically designed oceanographic vessels, and my impression is, and this can be checked by other witnesses, that we have gone a long way toward closing that gap.

Mr. KerrH. Thank you.

On the top line of that same page, 16, you say, following from the previous page-

Te are somewhat disappointed to find that some elements of this program, as was the case with fiscal year 1964 oceanography programs, have not received support by the Congress-

et cetera. Will these areas or these elements be specifically developed by successive witnesses or do you want to comment briefly on what elements you have in mind?

Dr. Horrig. I hope they will be since the other witnesses represent the various areas in the program specifically.

I have a table, just one moment.

Mr. Lenvon. Will the gentleman yield to me at that point?

I would think that the respective representatives from the severaI agencies on the ICO would be in a better position to say what success they had with their respective subcommittees on appropriations in these categories and perhaps directed it.

Mr. KeITH. It does not make any difference to me who comments on the question, but in view of the fact he states some elements of the program have not received support from the Congress

Mr. Levnon. I was saying some of the representatives of the ICO who in turn appeared before the various appropriations subcommittees could say how successful they were in obtaining the funds for their orerall program for oceanography. I think they could. I would hope they can. That would be one of their responsibilities, in my judgment, at least.

Dr. Hornig. Perhaps we can leave it that way. I assume they will, but I will see that this committee gets a detailed statement.

Mr. Kratre. Thank you, Mr. Chairman.

Mr. Lennon. Doctor, this subcommittee had a very pleasant relationship with your predecessor during the previous 5 years that Dr. Wiesner served. I give him credit to a considerable degree for the 
informal conferences that this committee had with him in our efforts to work out a bill that would be acceptable to the Congress or at least to the House as it later developed, and to the executive branch of the Government.

Now, I note on the second page of your statement that you, as the Chairman of the Federal Council for Science and Technology, and Director of the Office of Science and Technology, support the bill H.R. 6997 that passed the House last year and is now reposing in the Senate. More particularly in the Committee on Commerce of the Senate.

Is that support shared by the other members of the Federal Council for Science and Technology?

Dr. Hornig. Yes, so far as I know. I cannot speak for all the individuals, but as a body the answer is "Yes."

Mr. Lennon. May I ask what you as the Director of the Office of Science and Technology and as Chairman, as an individual of the Federal Council for Science and Technology, have so far done to indicate to the Senate Committee on Commerce your unqualified support of the legislation that was approved by your predecessor and I might say approved by the Bureau of the Budget and at that time approved by the then President of the United States?

Dr. HorNig. Well, I have engaged in verbal discussion; I am not sure whether we have communicated anything in writing or not before I was appointed in January.

Mr. Lannon. Would it be appropriate, inasmuch as you have so stated for the record your feeling with respect to the legislation, tc consider the propriety of asking the Federal Council to, by resolution or by communication to the distinguished gentleman from Washington, Senator Magnuson, your views with respect to this legislation? The gentleman from Washington has indicated to me early this year, and here it is now late June, that they wanted to have some hearings from some of the interested parties in the Great Lakes area. I think it would be helpful if you think this legislation is wise and is objective and the goal we are all seeking, I think it would be most helpful. Ordinarily, I think it is your duty if you have a feeling of confidence in the legislation to ask the Council to express in writing to the members of the Commerce Committee of the Senate, your support of the legislation.

Let us either abandon any idea of getting the bill passed and have them say they will not support it, or get something meaningful from them rather than continue to pass the buck.

Let me turn - and I cannot pursue it, Mr. Keith, because I asked you not to pursue it, because I felt that the members of the ICO respective agencies could better explain their difficulties with respect to obtaining what they hoped from the budget.

I think all of us understand what you mean when you say on pages 15 and 16 that you are disappointed that some elements of the program have not received support by the Congress, and this illustrates a problem which I especially wish to call to this committee's attention.

I was thinking in that instance that if the particular person on the ICO representing, say, the Bureau of Commercial Fisheries, or representing the Department of the Interior, would appear with the agency - the Bureau of Commercial Fisheries or the Bureau of Sport Fisheries-before the subcommittee that is considering their part of 
the budget and be prepared to state to that subcommittee the effect of the failure of that appropriate Subcommittee on Appropriations to give the consideration to the particular part of the budget that the Department of Interior was asking for. Do you see what I am driving at?

Dr. Hornig. I certainly do.

Mr. Lennon. In other words, what is the ICO committee for if it cannot be of assistance to the various agencies they represent on the ICO when they go to the particular Subcommittee on Appropriations? Then we would hope to obtain a situation different from what you have indicated that does develop here, because it is a fact, we know it, that your Subcommittee on Appropriations, when they mark up a bill and send it to the full committee, that is that. And unless the Subcommittee on Appropriations gets the total picture of the oceanographic program as related to that particular facet of the oceanographic budget, that is the end of it, because there is nothing done about it in the full committee. I think we will all admit that.

Dr. Hornig. I think Secretary Wakelin may be able to comment further on that, too.

Mr. Lennon. We are looking forward to his testimony.

We have with us, Doctor-and we do appreciate this very helpful information you have given this committee-our technical consultant to this committee, Mr. Paul Bauer, who has followed this program continuously since the midfifties, so to speak.

Mr. Bauer, do you have any questions you would like to ask Dr. Hornig at this time?

Mr. BAUER. Thank you, Mr. Chairman. I have a few.

As I read your testimony so far this morninig, Dr. Hornig, you seem to indicate that the hydrosphere and the atmosphere are indivisible parts of the study of the same unit, to wit, the ocean. Is that correct?

Dr. Hornig. 'That is right; they are closely related.

Captain BAUER. If that is the case, why is there a duplication of ICO by the Interdepartmental Coordinating Committee on Atmospheric Sciences? It seems to me that would be logically a question of a subcommittee of the Interdepartmental Committee on Oceanography if we mean by a study of the ocean that we must, of course, at the same time study the atmosphere, because without the winds we would have no wind driven currents, we would have no Gulf Stream, and so on.

Why do we have two agencies talking essentially about the same thing?

Dr. Honnig. I think the answer here is real easy. The ocean is very big and the atmosphere is very big, and I think there are strong interactions between them. But there are many problems of the atmosphere that do not involve the ocean; there are many problems of the ocean whiah, while they may be subtly connected with the atmosphere, do not have any primary involvement with the atmosphere. As with many topics, it is convenient to deal with them as separate convenient or logical parts. This does then involve us in the problem, as the Academy pointed out, that the area of air-sea interaction was a neglected area as a consequence of separate specialized treatment. I think we are now trying to do something about that, but I think the separation is basically correct since they are each very large units; they 
are about as big as we can handle one at a time. I think that Secretary Wakelin would concur with me on this, that it is a convenient means, both administratively and scientifically, of organizing science.

Mr. BAUER. Consider the air-sea interface, who would consider that, the ICO or ICAS ? The problem of the air-sea interface?

Dr. Honnig. Both. In addition, there was delegated to the Department of Commerce a responsibility to focus attention on this interaction area that had been neglected, and to do this in consultation with both the ICO and the Interdepartmental Committee on Atmospheric Sciences, ICAS.

Mr. BAUER. I notice in your budget breakdown on pages 19, 20, and 21 of the fiscal year report, that you have allocated $\$ 208,000$ to the Weather Bureau; $\$ 25,000$ to the Coast and Geodetic Survey, and this is all for air-sea interface problems; $\$ 998,000$ to the Bureau of the Commercial Fisheries; $\$ 60,000$ to the Coast Guard; $\$ 2,734,000$ to the Office of Naval Research; $\$ 856,000$ to the Navy's Office of Oceanography; $\$ 500,000$ to the Navy's Bureau of Ships; $\$ 200,000$ to the U.S. Army; and $\$ 300,000$ to the National Science Foundation.

Recapping the situation it puts Commerce in at $\$ 233,000$; Interior $\$ 998,000$; the Navy $\$ 499,000$; the Army $\$ 200,000$; the National Science Foundation $\$ 300,000$; and the Treasury Department $\$ 60,000$.

Why was the Department of Commerce picked to head up this program with the apparent appropriations as shown on pages 19, 20, and 21 of your report? In other words, the Navy, it seems to me, has the largest appropriation for the study of air-sea interface, even the Interior Department has more than the Department of Commerce. How did the Department of Commerce get in the picture?

Dr. Hornig. On scientific problems one cannot say that leadership must necessarily follow dollars. One looks to where one has a group of able people that have authority to fit into the Government-wide organization. This was discussed by all the agencies through both ICO and ICAS committee structure. I think it is perfectly true that the leadership might have been centered in a number of places but it had to be centered somewhere. The competence existed in Commerce; the other agencies were agreeable, and this was where it was settled.

Mr. BAUER. Who is most concerned with the problems of the air-sea interface, the Navy or the Department of Commerce?

Dr. Hornig. I think there is plainly a concern on both sides. I thing that the Navy has very large responsibilities and perhaps on this score scientifically-no, I do not think I would be willing to draw any distinctions-I would rather say that the Nary has important interests, the Department of Commerce, which is primarily the Weather Bureau in this case, has interests, too; and on an interaction problem it was generally decided, by consensus largely, that this was a good place to put it. I would not be willing to get into a debate as to which of the two might more appropriately have done it.

Mr. BAUER. I was not trying to create a debate, sir. It seems to me that with the ASWEPS program, for example, it is vital for the Navy to know all it can about the air-sea interface, and also the question of forecasting of preferred ship routing and wave structure.

Dr. HornIG. There is nothing in this interaction program which discourages the Navy or anyone else from exerting a maximum pos- 
sible effort in the region of air-sea interaction. The sense in which it was delegated to Commerce was that they are to keep track of what everyone does, help coordinate these efforts, and full gaps in programs left unfilled by other agencies.

I should also add that as regards these budgetary figures you mentioned, what is not written down here are components of the atmospheric sciences budget that also contribute to the interaction program. The Department of Commerce has a coordinating and planning role. The Navy has a vigorous program and is certainly encouraged to carry on a vigorous program.

(Documentation of the above subject may be found in app. 1, p. 155.)

Mr. BAUER. Thank you, sir.

There is one further situation that occurs to me.

This program that you have talked about is the nonclassified program of oceanography; is that correct?

Dr. HorNig. That is correct.

Mr. BAUER. How much is the classified program in round figures?

Dr. Hornig. There is a very substantial classified program but I think I would like to defer to Secretary Wakelin when he is before you.

Mr. BAUER. What I am getting at is, Do you have the classified program of oceanography come within the cognizance of the ICO and the Federal Council as the total program?

Dr. HoRNIG. In general, not within the cognizance of ICO.

Mr. BAUER. In other words, it is only a part of the total national oceanographic program which is considered by the ICO?

Dr. HoRNIG. That is correct.

Mr. BAUER. Are there any parts of the classified program that will benefit the unclassified program?

Dr. HoRnig. The answer to that is "Yes," and I think again Secretary Wakelin can elaborate a little.

Mr. Bader. For the record I would like to point out that the classified fiscal 1965 program was $\$ 386.5$ million, and the unclassified program is about one-third of that.

Now, there is one other consideration I think the committee would like to have cleared up, and that is when we talk about the unclassified oceanographic program, how much of this program existed before by the line functions of, say, the Department of Interior, Bureau of Commercial Fisheries, the Hydrographic Office of the Navy, that is now in the oceanographic program? In other words, are these figures able to show us the growth or lack of growth of the program since the National Academy of Sciences report?

Dr. Honvig. I think these figures give a reasonably good representation. There was some redefinition. Surveys, which had not been included previously in oceanography, rere included in later definitions of scope; this changed the figures a little, but I think the figures for the last few years give a reasonably accurate representation.

Mr. BAuEr. Now, one further question and I shall conclude.

In the national oceanographic program have you taken account in any way of the capabilities of industry? I am referring particularly to the geophysical industry. In other words, as a nation, our program, it seems to me, should include the capabilities of the geoplysical industry and other industries that have to do with the marine sciences. 
Dr. Hornig. Certainly in the development of instrumentation the answer is yes. Industry does, of course, carry on geophysical explorations outside of the Federal sponsorship. I think Secretary Wakelin again will come back to the question of undersea engineering or ocean bottom exploration where I do not think we have done as much as we ought to. I think there is a big role for industry in this essentially engineering enterprise.

Mr. BAUER. Thank you, Mr. Chairman.

Mr. Lennon. Thank you, Doctor.

Now, will Assistant Secretary of the Navy, Mr. James Wakelin, Jr., who is the Chairman of the Interagency Committee on Oceanography and I believe, sir, you and Dr. Hornig are accompanied today by Dr. H. J. Carlson, a member of the ICO, representing the National Science Foundation; Asst. Surg. Gen. Harry G. Hanson, representing the Public Health Service of the Department of Health, Education, and Welfare; Rear Adm. H. A. Karo of the U.S. Coast and Geodetic Survey of the U.S. Department of Commerce; Mr. D. L. McKernan, Bureau of Commercial Fisheries in the Department of Interior; Dr. R. Rollefson, who represents the State Department; R. B. Abel, executive secretary, ICO; and Rear Adm. W. D. Shields, also a member of the Committee on Oceanography; are you representing the Coast Guard, Admiral Shields?

\section{Admiral Shields. Yes.}

Mr. Lennon. Of course, I recognize you now.

Dr. I. E. Wallen, the Smithsonion Institution, and Dr. J. N. Wolfe of the Atomic Energy Commission.

Mr. Secretary, we are old friends. We are delighted to have you here. This will be perhaps your last appearance before this committee and to underscore my feelings we express our regret at Washington losing you, I would like to ask unanimous consent to include in the record at this point a tribute paid to Dr. Wakelin by the Ocean Science News, volume 6, No. 15, at the second paragraph, and I will ask one of the clerks if he will hand it to the lady and ask unanimous consent to include it in the record at this point. I think it is a tribute to the gentleman. You have done a fine job.

(The document mentioned follows:)

[From the Ocean Science News, June 11, 1964]

Assistant Secretary of the Navy (R. \& D.) Dr. James H. Wakelin, Jr., has resigned for personal reasons and will leave his post probably around the middle of July-depending on just when the Senate gets around to confirming his successor. This highly important post will be taken over by Dr. Robert W. Morse, dean of the college, Brown University, Providence, R.I. Dr. Morse, a physicist (ultrasonics, low temperature and solid state physics), has served as a consultant to the Nary on AST and underwater acoustics, and is president-elect of the Acoustical Society of America. He's 43 ; married; three children.

Ocean Science News wishes to take this opportunity to express its regret that the Navy and oceanography will shortly lose a proponent in official Washington as strong, intelligent and as effective as Dr. Wakelin has been. As Chairman of the Interageacy Committee on Oceanography he has guided this unique organization to a high degree of effectiveness. In his job with the Navy he has successfully urged and guided that service toward a much greater understanding of its operational environment. We want to add our voice to the chorus of applause for a job very well done, indeed. We wish Dr. Wakelin all the best in whatever his new venture turns out to be and hope it will be related to man's effort to explore and exploit the oceans-an effort that needs more, not fewer, such men. Concurrently, we look forward to Dr. Morse carrying on a now-established fine tradition in these jobs. 
Mr. Lennon. You have a prepared statement?

Mr. W AKELIN. Yes, sir.

Mr. Lennon. Will you proceed with the understanding, sir, if we do not complete your statement today we wondered if it would be possible for you to resume and continue it tomorrow at 10 ?

Mr. WAKELIN. Yes, sir.

Mr. Lennon. Thank you, sir.

Go ahead.

STATEMENT OF HON. JAMES H. WAKELIN, JR., ASSISTANT SECRETARY OF THE NAVY (RESEARCH AND DEVELOPMENT) AND CHAIRMIAN OF THE INTERAGENCY COMIMITTEE ON OCEANOGRAPHY OF THE FEDERAL COUNCIL OF SCIENCE AND TECHNOLOGY

Mr. WAKelin. Mr. Chairman and members of the committee; may I express for the Interagency Committee on Oceanography members our appreciation for this opportunity to outline for you the last 2 years' progress of the national oceanographic program and our hopes and aspirations for the fortheoming fiscal year 1965.

My appearances before you today will be my last to testify on our oceanographic work. I plan to relinquish the Office of the Assistant Secretary of the Navy for Research and Development next month, and I can think of no more fitting time or place for my final appearance as ICO Chairman than before this committee which has for 4 years spearheaded congressional interest in the marine sciences.

The origin and development of the national oceanographic program have nowhere been outlined as comprehensively as in your own excellent committee reports. Consequently, I will not attempt to duplicate previous material in this discussion but will limit myself to a description of our progress since our last meeting and a summary of our plans for fiscal year 1965 .

For your information, Mr. Chairman, the following persons will appear before your committee to discuss in detail various parts of our program:

Dr. I. E. Wallen, Chairman, Oceanographic Research Panel, Smithsonian Institution.

Comdr. Harley Nygren, Acting Chairman, Ocean Survey Panel, Coast and Geodetic Survey.

Dr. Arthur E. Maxwell, Chairman, International Program Panel, Office of Naval Research.

These gentlemen will discuss our oceanographic efforts. The following will describe supporting activities:

Capt. T. K. Treadwell, Chairman, Oceanographic Ships Panel, Office of the Chief of Naval Operations.

Mr. Donald L. McKernan, Chairman, Instrumentation and Facilities Panel, Bureau of Commercial Fisheries.

Dr. Woodrow Jacobs, Director, National Oceanographic Data Center.

Since our last meeting, 28 months ago, on the 27 th of February 1962, the ICO has undergone a few organizational changes. There have been numerous changes in the composition of our committee and our panels and, for your reference, I would like to furnish the latest roster of committee, panel, and consultant personnel.

(The information mentioned follows:) 


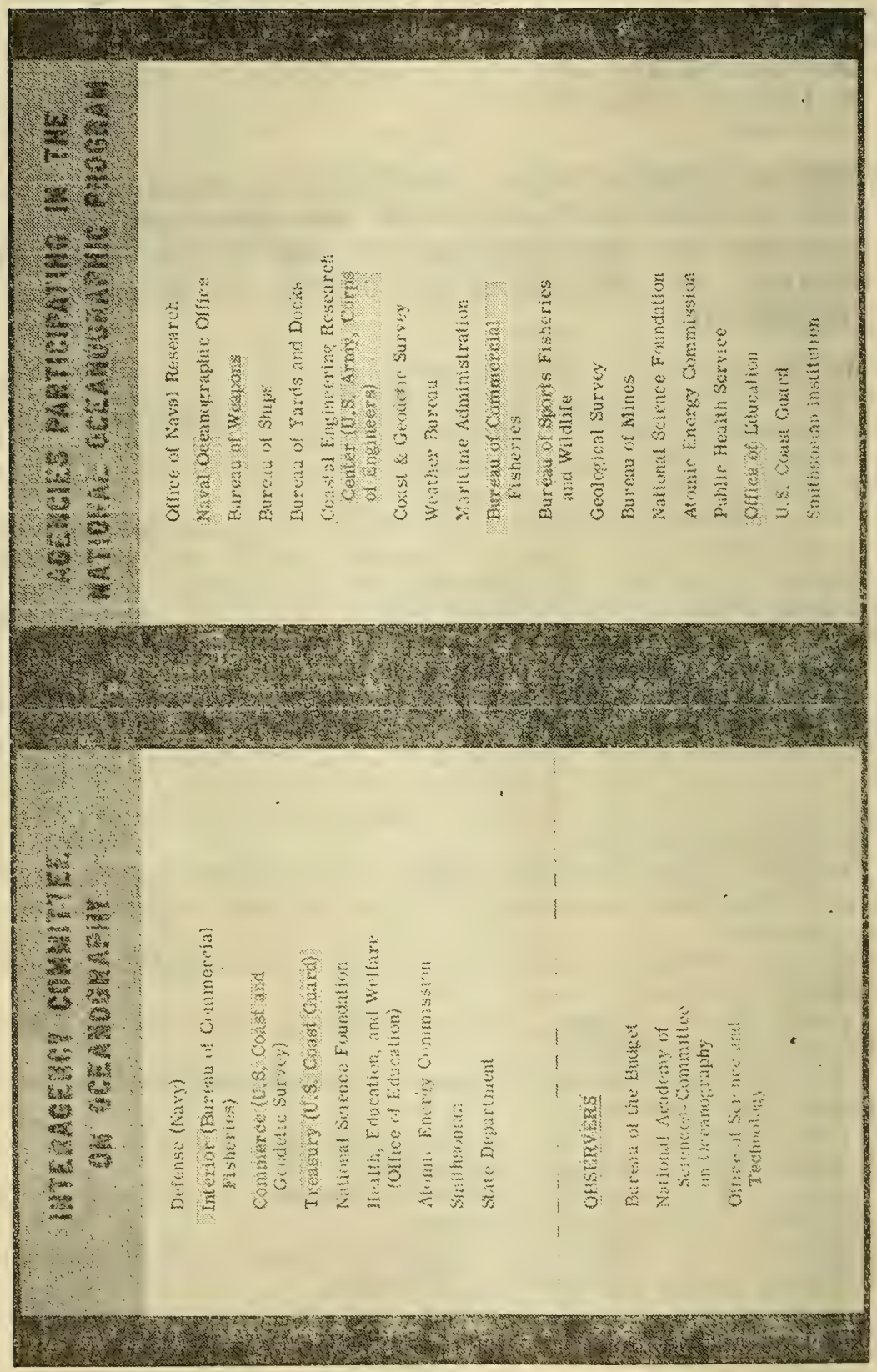




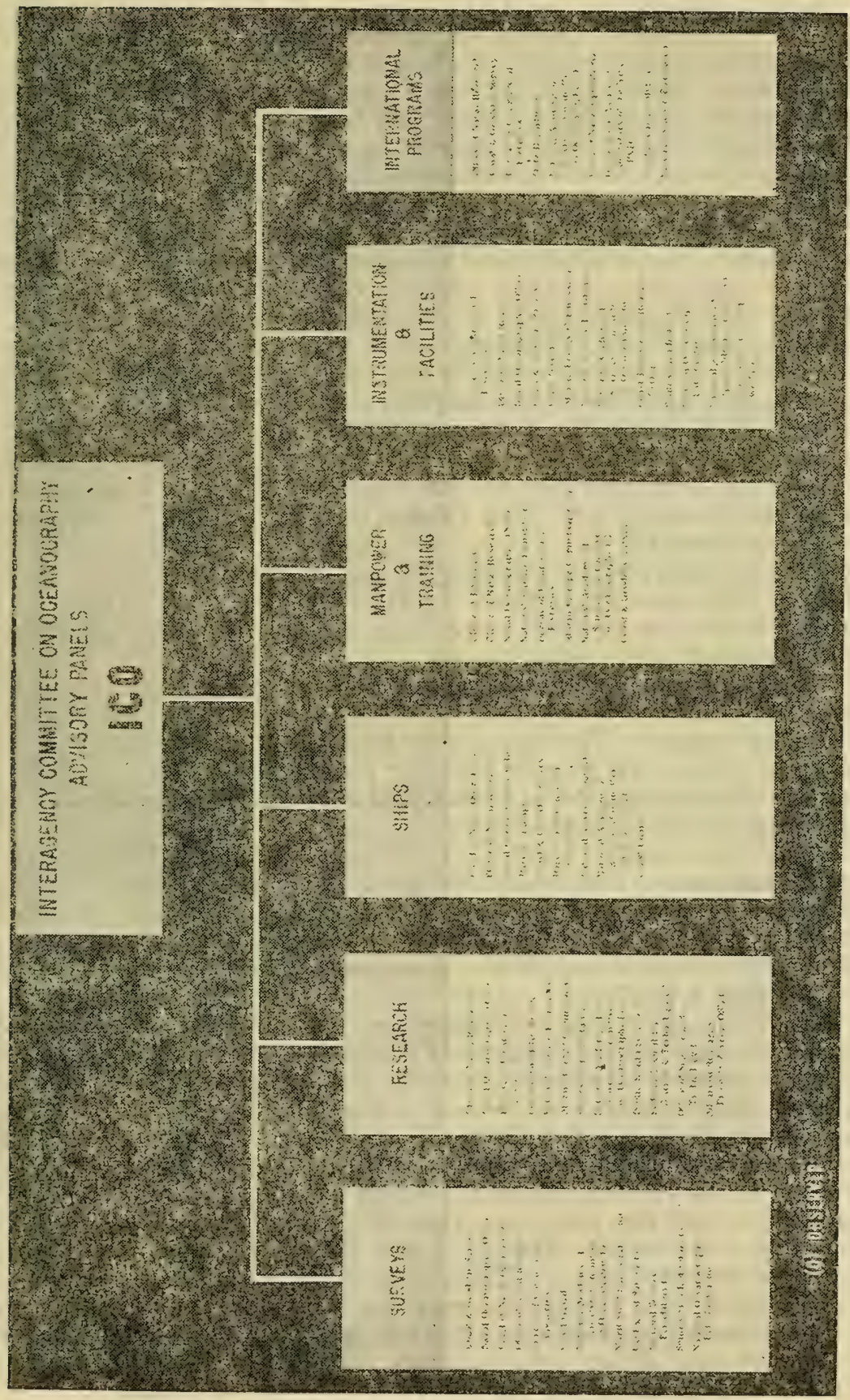


Mr. WaKelin. You may remember that you inquired specifically about the positions of the Smithsonian Institution and the Army. Corps of Engineers in the ICO scheme. Since our last meeting with. you, the Smithsonian Institution has been given full membership on the committee, and Dr. I. E. Wallen is its permanent representative. The Army, as part of the Defense Department, is represented on the full committee by myself as chairman; however, Mr. Joseph Caldwell of the Coastal Engineering Research Center has been added to the ICO Working Group. As I will expand on later in this statement, the Department of State has been given full membership on the ICO.

You will recall also that at our last meeting your committee gave particular emphasis to our need for central staff support to carry out the ever-increasing functions and responsibilities which attend our growth. In accordance with your suggestion in this regard, the ICO has set up such a staff. The composition of our staff reflects the typical interagency cooperative attitude that the ICO personifies. For instance, salary funding is provided by the Office of Naval Research, the Bureau of Commercial Fisheries, the Public Health Service, the Oceanographic Office, and the Coast and Geodetic Survey. Personnel billets have been provided by the Coast Guard, the Oceanographic Office, the Oceanographic Data Center, the Public Health Service. and the Naval Research Laboratory. The major portion of supplies and services are provided as a matter of fact by the Office of Naval Research as the operating arm of the ICO chairman, but at least 15 of the ICO member agencies have from time to time provided much valuable assistance to us in this area.

As you can readily imagine, the importance of a national program in oceanography is being brought increasingly to the attention of the American public. The number of books and articles is increasing at a high rate. To provide the best possible reference to this large volume of literature, the ICO last year compiled and issued our Pamphlet No. 9, Bibliography of Oceanographic Publications. We have listed herein 500 selective titles including treatises, textbooks, dictionaries, directories, bibliographies, periodicals, maps, films, histories, biographies, and nontechnical books and articles under 36 subject headings. We have also indicated the reading level and content. I should like to introduce this with your permission.

(See app. 2, p. 171.)

Mr. W AKELIN. A couple of years ago, at the suggestion of Dr. John Lyman of the National Science Foundation, the ICO began a compilation of university curriculums in oceanography to provide information about training programs in the marine sciences. Our purpose was to provide information for students, to increase the exchange of information among the schools, and to aid employers of personnel trained in the various disciplines which comprise oceanography. We have described the programs and facilities of each institution and have listed the courses that are taught, the names of the faculty members, the degrees that are offered, descriptions of courses, and the person to contact for further information. The demand for this publication exceeded our forecasts by at least an order of magnitude and the document now enjoys international distribution. I should like to submit this document for the record with your permission.

Mr. Lennon. We will go off the record for just a minute. 
(Discussion off the record.)

Mr. Lennon. On the record.

Without objection, that will be included in the record at this point. (See app. 3, p. 201.)

Mr. WAKELIN. In referring to the demand for this or any of our publications, I should mention that the ICO is becoming almost uncomfortably aware of our recognition by the reading public, particularly when it is evidenced in the some 10,000 letters we receive each year covering a wide variety of questions and comments. We are apparently becoming a focus of attention for those who would like to know how to get jobs in oceanography, how the oceans affect their particular way of life, where business might be conducted in oceanography, or just plain questions about things going on in the ocean.

However, the one question which seems to be occurring more than any other, to our interest and pleasure, is that concerning a career in oceanography. In response to literally hundreds of questions regarding school and professional careers in oceanography, the ICO has compiled a book entitled "Opportunities in Oceanography" which we expect to be published sometime next month. I should like to offer our prepublication copy for your information at this time.

We have tried to attract the student at an early level and to describe therein how he looks at oceanography in high school, how he might prepare himself throughout his undergraduate years, where, when, and how he will study oceanography at the graduate level, the various methods of obtaining financial assistance in getting through school, problems connected with his academic and professional careers, professional societies he may join, and finally and most importantly, the probable shape of his professional career. Based on our experience, we are anticipating a tremendous demand for this book and will be delighted to furnish additional copies for the members of your committee. We expect this, Mr. Chairman, to be ready in about 2 weeks. Dr. Wallen of the Smithsonian Institution brought this copy in for us for you to look at. While I cannot, in fact, submit this for the record, I should like to submit it for the committee to look at prior to its publication in finished form.

Mr. LenNon. We will be glad to look at it.

Mr. W AKELIN. The ICO possesses a convenient organizational mobility for carrying out many assignments. For instance, in answer to a recent congressional request, we were able to compile a critical listing of all the activities in the aquatic sciences in the Great Lakes area. Through our communications structure, we were able to do this with a minimum of effort even though the ICO does not formally consider the Great Lakes within its geographic cognizance. With your permission, I should like to introduce a copy of this report for the record.

(See app. 4, p. 369.)

Mr. WAKELIN. I had mentioned that the ICO has acquired a small working stafi. I think it is fitting here to describe for you the nature of the assignments of the individual staff members. It was never our intention to centralize our operation in anything like a bureaucratic manner; however, there is one point in the ICO operation which critically depends upon availability of trained manpower on a continuing basis. 
As you pointed out at our last meeting, the panels, which carry the real brunt of the ICO policy-formation load, themselves depend upon people who have other primary jobs in the Government. Although they can advise, formulate policy, and address themselves to needs, they generally do not possess anyone to "do the work." Accordingly, as the ICO has acquired new staff, each has been assigned permanently to one or more panel chairmen. This will prove helpful to the panels who will thus be able to draw conclusions and make recommendations secure in the knowledge that they can follow through and complete their staff action in a reasonable period of time. In addition, continuity of communications and organization is maintained not only within any particular panel but among the panels to the extent that they need to work together. We have found this last aspect of staff assignment to be particularly valuable in that our panel memberships change frequently.

The ICO is attempting to consolidate its facilities as well as its administration. As space has become available with the withdramal of naval elements from the Navy yard and the Navy yard annex, a number of our agencies, individually and through staff coordination, have been able to acquire space there. By the end of this month, one corner of the Navy yard will be shared by the oceanographic components of the Bureau of Commercial Fisheries, the Oceanographic Office of the Navy Department, the instrumentation and data centers, Coast Guard, Coast and Geodetic Survey, Geological Survey, Smithsionian Institution, and the ICO staff itself. We look forward to this colocation as one further step in the tightening of inteagency cooperation and communication in oceanography.

In recognition of the rapidly growing role of oceanography in our international relationships, the State Department, as I indicated earlier in my statement, has been given full membership in the committee. At the time of our last meeting, this Nation was committed to the International Indian Ocean Expedition, and we were planning the International Cooperative Investigations of the Tropical Atlantic. Both of these programs have flourished and their success has encouraged the international community to plan and implement several other joint ventures. Dr. Arthur Maxwell, Chairman of our Panel on International Programs, will discuss the status and accomplishments of these programs and will more comprehensively outline the rationale which tends to focus attention on oceanography as an increasingly useful element in international diplomacy.

In earlier hearings, your committee pointed clearly to the overriding need for a unifying long-range plan and a set of goals to guide onr national effort in oceanography. In the year following 1963, the ICO completed and published what we believe to be the first long-range plan designed to unite the efforts of the many Federal agencies contributing to this program. It is entitled, "Oceanography: The Ten Years Ahead," approved and forwarded to Congress by Dr. Wiesner on July 26,1963 . I have it here and with your permission I would like to introduce it also for the record.

Mr. Lennon. Without objection it will be inserted in the record following your remark.

(See app. 5, p. 425.) 
I should emphasize that this is not an executive planning document in a stepwise programatic sense; this would have been most unrealistic and would have created more problems than it solved. Rather, as stated in the document itself, we have tried to provide a bridge between scientific discovery and application and to indicate a desirable balance of eftort among the institutions in universities, government, and industry who undertake this work.

As I pointed out earlier, your committee also suggested that no accomplishment of the ICO could exceed in total value that of establishing strong and clear national goals in oceanography. This publication, "Oceanography: The Ten Years Ahead," reflects the considerable attention we have paid to this sector of the planning spectrum in that we have drafted our plan within the framework of a statement of national goals.

We have listed the support of basic science as the primary goal since it is the reservoir from which all applications must be drawn. This is not sheer altruism. Te know from experience in war, in tough economic competition, and in man's fight for a life free of poverty and disability, that research pays. It is the Federal Government that, in oceanography as well as in other fields, has strengthened basic research to provide the reservoir of knowledge needed to satisfy specific practical objectives. It must thus assume some responsibility for training and educating highly skilled manpower that it consumes, including the sponsorship of basic research undertaken by graduate students and by their faculty advisers.

We have naturally listed defense first among the areas of application. This is, of course, in line with our national outlook in all fields. It has become widely accepted that we, like the other major nations of the world, have a heavy stake in the preservation of peace. In the current world situation, military strength is a necessary element in our way of life. This must be a national capability so strong that the fact of its availability to the free world is a deterrent to major infractions of the peace of the cold war.

Within our defense team, the Navy's domain is the world oceanfrom its deepest depths up through the air-sea interface and into the skies and space above. During peacetime, one of its most important missions is maintaining the freedom of the seas so that we and other nations of the world may enjoy the advantages of waterborne commerce and transportation so vital to our growing economy. During wartime, it must, in addition, deny this freedom to the enemy. The Polaris deterrent, antisubmarine and mine countermeasure forces, carrier attack and amphibious forces-all depend for safe, effective operation on accurate knowledge of the ocean environment. Development of nuclear-propelled submarines makes submerged operation for long periods of time possible, and this creates under the sea an extensive area for naval operations, and one that must become familiar to us.

Next, we have problems of resource management and the control of marine wealth in the world oceans, particularly concerning the world fisheries, their importance to mankind and the interrelationships between the fish populations and the oceanographic environment. Fish are an important source of protein for the diets of many peoples of the world, but we know very little about their growth patterns and 
habits of particular fish, reasons for their migration, or of means to increase stocks and catches.

Ocean water, and especially the ocean bed, may be the source of minerals that the world must exploit when ores and fossil fuels now found on land are depleted. These resources are now unknown in richness and distribution. Extensive, sophisticated surveys may be required to inventory this potential. We have examined problems of protecting the public from the many threats posed by the sea, including pollution, storms, seismic activity, and erosion, while at the same time acknowledging the oceans' beneficial and aesthetic character and its impact on recreation. Finally, we have recognized here the sea's limitations as an atomic waste absorber and its function in relation to the making of weather.

An important function of the long-range plan is to permit the formulation of the individual annual programs in more coherent fashion. We are thus enabled each year to take stock of ourselves and to see where we stand in the context of the 10-year effort.

Mr. Chairman, I think it worthwhile to note a significant change in our approach to the program planning process, which has occurred since our last meeting. At that time, our young committee was concerned with initiating a program of national importance. Prior to that time, the salient problems we had were:

(a) A lack of resources-ships, labs, men, tools, and money;

(b) Lack of awareness at the departmental level of the rela-

tionship of oceanography to individual agency roles and missions:

(c) Spotty communications among and within agencies; and

(d) No strong definition of long-range goals.

At the time of the hearings the ICO was in the midst of tackling: and reducing these problems, as reflected in our annual issuance of the national oceanographic program documents. As evidence of this, I would like to introduce ICO Pamphlet No. 11, national oceanographic program, fiscal year 1964.

(See app. 6, p. 495.)

You will note that this pamphlet, like its predecessors, approaches the problem of program organization via the avenue of function, in terms of effort - that is research, surveys, international cooperation, and support-that is, design and construction of instruments, facilities, and ships, and development of trained manpower. Now, note the arrangement of our pamphlet No. 15, the program document for the forthcoming fiscal year 1965 .

(See app. 7, p. 567.)

This is the first annual plan prepared since publication of the longrange plan, and it begins to be oriented toward the goals we have laid out. I would like to invite your attention to this document for a few moments. In it we have tried to follow the theme of our long-range plan and to organize our resources to exploit the diverse ways in which the oceans contribute to the Nation's security and welfare. In planning our oceanographic effort, we have categorized our research into the following:

(a) Physical properties and motion of the sea: We are aiming for improrements in ship design, more efficient commerce, antisubmarine warfare advantages, and better disaster control. 
(b) Ocean-atmosphere interrelationships: The objectives relevant to this category include both weather and ocean prediction.

(c) Biological properties: More effective exploitation of the ocean's living resources is the most important goal in this section.

(d) Structure and history of the sea floor: We envision research application to antisubmarine warfare problems, mapping requirements, and development of mineral and other resources.

(e) Modification of the sea: Undesirable and dangerous effects of pollution of coastal and estuarine waters on food resources and on recreational areas are already well known and are likely to increase unless checked by wise planning. The potential danger of release of radioactive material in the ocean also needs thorough and continuing study. In each of these cases, research of various kinds is essential.

The ocean also can be deliberately modified in local areas in order to achieve certain desirable results: beach erosion can be controlled, surface waves minimized, et cetera. At present, achievements of this sort are slow in forthcoming, but research directed toward increased useful modification of the sea is needed.

A topic of great concern to the ICO concerns deep research vehicles. A very few scientists have for a long time proclaimed an urgent need for the means by which man can descend to take personal charge of operations in the deep sea environment. These voices went mostly unheeded, for, as you know, man responds best to challenge and for many year's, challenge was lacking. The tragic loss of the submarine Thresher, however, has awakened many of us to our inability to cope with such disasters. Two weeks ago I was privileged to preside at the dedication of Alvin, the first deep research vehicle designed and constructed in this country.

Tp to this time, the only American-owned vehicle capable of operating at the depth where the Thresher was lost was the bathyscaph Trieste I-now remodeled as Trieste II. The future looks somewhat better; we hope that Aluminaut and Deep Star will be completed this year. Significantly, both of these rehicles have been designed and constructed by industrial firms without Government support.

A matter which has concerned the ICO almost from its inception is the achievement of the proper balance between effort and resources to which $I$ alluded briefly at the start of my discussion.

A productive research program requires adequate resources in many areas. If the program is to maintain a healthy growth, this growth must be maintained in phase among the ships which are the laboratories of oceanography, scientists to man the ships and conduct the research programs, facilities to support the ships and to train the scientists, and tools with which the scientist can conduct his experiments. The ICO is aware of the need for the establishment of useful ways of relating resources to effort so that we can more intelligently develop our program plans. Some of these indexes are difficult to evaluate.

We know, for instance, that about four persons are required ashore to support a man at sea; that it requires about $\$ 30,000$ to support a research oceanographer; that about one-fourth of our research funds go merely to fuel, crew, and to repair our ships, and that it takes about 6 years past the baccalaureate for an oceanographer to attain 
his $\mathrm{Ph}$. D. TVe have arrived at a pretty fair relationship betreen ship a vailability and miles of surveys completed; nonetheless, this is an area, popularly known as operations research, where we can see considerable room for further refinement.

This brings me to the most important single problem facing the ICO. I will assume the liberty of speaking in complete candor, with your permission, $\mathrm{Mr}$. Chairman.

We certainly believe that we have resolved most of the communications problems in the executive branch of the Government. Our agencies and departments have achieved harmonious working arrangements in oceanography at all levels. However, our coordination seems to lose its effectiveness once the program passes to Congress for review.

I should like to introduce, with your permission, Mr. Chairman, a chart depicting all of the various congressional committees and subcommittees, both substantive and appropriations, to which our member agencies report.

(The chart mentioned faces this page.)

As nearly as we can tell, there is little communication among these 30-plus committees, and no matter how well coordinated our program may be, in the final analysis each of the agency participants in the national oceanographic program must defend its own segment of that program to a separate congressional committee.

Yet, ours is a truly Government-wide program. We commonly cut across agency and departmental boundaries and have become increasingly skilled in utilizing programs and resources in common. Tonetheless, the collective strength we enjoy in the establishment of a national program can be weakened appreciably by reduction of individual agency and department programs with the result that the entire effort suffers. None of our past attempts to solve this problem has met with success. In previous discussions, your committee discussed with Dr. Wiesner the possibilities of improving intra-House communications. Earlier this year, in my appearance before the Armed Forces Appropriations Committee, Senators Russell and Saltonstall both expressed their sympathy for our plight and their recognition of the need for a focal point of oceanographic activity within the Congress.

This, then, is our major problem, and we are very much afraid that it will lead to program stagnation. For instance, the fiscal year 1964 President's budget of $\$ 156$ million was reduced to the fiscal year 1963 level of $\$ 124$ million by congressional committee action. Based on evidence developed thus far, the future of our fiscal 1965 program does not look much better.

The fact is we are developing an oceanographic capability in the United States, and we are concerned that we may not be able to completely realize this potential. As more sophisticated instrumentation is developed, it also becomes more expensive to operate. Education costs, ship operating costs, and salaries are still rising. Yet we are confronted by level funding. Consequently, the highly publicized national oceanographic program may actually be starting downhill. 


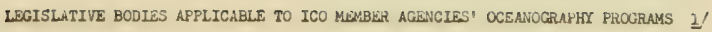

\begin{tabular}{|c|c|c|c|c|c|c|c|c|}
\hline \multirow[b]{3}{*}{ ¿GENCIBS NND BUREAUS } & \multicolumn{4}{|c|}{ HCUSE OF REFRESENTATIVES } & \multicolumn{3}{|c|}{ SENATE } & \\
\hline & \multicolumn{2}{|l|}{ SUBSTAUTIVE } & \multicolumn{2}{|l|}{ APERUPRIATION } & \multicolumn{2}{|c|}{ SUBST NNTIVE } & \multicolumn{2}{|c|}{ APPROFRIATION } \\
\hline & Sub-Conmititee & Coumittee & Sub-Comittere & Complitiee & Sub-Comnittes & Comittee & Sub-Cominittee & compltiter. \\
\hline \multicolumn{9}{|l|}{ DEFENSE } \\
\hline Navy & Research \& Development & Armed Services & Defense & Appropriations & $N / A$ & Arsed Services & Defense & Appropriations \\
\hline Arm & RIver \& Harbors & Public Works & Publ1c Works & do & $\begin{array}{l}\text { Rood Control - } \\
\text { Ruvers \& Harbors }\end{array}$ & Pubzic Works & Public Works & do \\
\hline \multicolumn{9}{|l|}{ COMMRRCE } \\
\hline $\begin{array}{l}\text { Coast \& Geodetic } \\
\text { Survey }\end{array}$ & $\begin{array}{l}\text { CG, Cras, and } \\
\text { Navigation }\end{array}$ & $\begin{array}{l}\text { Merchant Marine } \\
\text { and Fisheries }\end{array}$ & $\begin{array}{l}\text { State, Justice, } \\
\text { Commerce, \& Judiciary }\end{array}$ & do & $\begin{array}{l}\text { Merchant Marine } \\
\text { and Fisheries }\end{array}$ & Commerce & $\begin{array}{l}\text { State, Justice, } \\
\text { Commerce, \& Judiclary }\end{array}$ & do \\
\hline Weather Bureau & Coamerce \& Pinanco & $\begin{array}{l}\text { Interstate \& } \\
\text { Foreign Commerce }\end{array}$ & do & do & $\mathrm{N} / \mathrm{A}$ & do & do & do \\
\hline Maritime Adm. & Merchant Marine & $\begin{array}{l}\text { Merchant Marine } \\
\text { and Fisheries }\end{array}$ & do & do & $\begin{array}{l}\text { Merchant Marine } \\
\text { and Fisheries }\end{array}$ & do & do & do \\
\hline \multicolumn{9}{|l|}{ INTERIOR } \\
\hline $\begin{array}{l}\text { Buroau of } \\
\text { Commercial } \\
\text { Fisheries }\end{array}$ & $\begin{array}{l}\text { Fisherles \& wild - } \\
\text { life Cons. }\end{array}$ & do & $\begin{array}{l}\text { Dept. of Interior and } \\
\text { Releted Agencios }\end{array}$ & do & do & do & $\begin{array}{l}\text { Dept. of Interior \& } \\
\text { Related Agencios }\end{array}$ & do \\
\hline \multirow{2}{*}{$\begin{array}{l}\text { Bureau of Sport } \\
\text { Fisheries \& } \\
\text { Wildlifo }\end{array}$} & do & \multirow{2}{*}{ do } & \multirow[t]{2}{*}{ do } & \multirow{2}{*}{ do } & \multirow[t]{2}{*}{ do } & \multirow[t]{2}{*}{ do } & \multirow[t]{2}{*}{ do } & \multirow[t]{2}{*}{ do } \\
\hline & Scosnography & & & & & & & \\
\hline \multirow[t]{3}{*}{$\begin{array}{l}\text { Geological } \\
\text { Survey }\end{array}$} & Mines \& Mining & \multirow{3}{*}{$\begin{array}{l}\text { Interior and } \\
\text { Insular Affairs }\end{array}$} & \multirow{3}{*}{ do } & \multirow{3}{*}{ do } & $\begin{array}{c}\text { Irrigation \& } \\
\text { Beclamation }\end{array}$ & \multirow{3}{*}{$\begin{array}{l}\text { Interior and } \\
\text { Insular Affairs }\end{array}$} & \multirow{3}{*}{ do } & \multirow{3}{*}{ do } \\
\hline & Public Lands & & & & Fublic Lands & & & \\
\hline & $\begin{array}{l}\text { Irrigation \& } \\
\text { Reclamation } \\
\end{array}$ & & & & $\begin{array}{l}\text { Minerals, Materials } \\
\text { \& Fuels }\end{array}$ & & & \\
\hline Buresu of Mines & Mines and Mining & do & do & do & $\begin{array}{l}\text { M1nerals, Materials } \\
\text { \& Fuelo }\end{array}$ & do & do & do \\
\hline \multirow[t]{3}{*}{$\begin{array}{l}\text { MATIONAL SCIENCE } \\
\text { FOUNDATION }\end{array}$} & $\begin{array}{l}\text { Science, Research \& } \\
\text { Developpent }\end{array}$ & \begin{tabular}{|l} 
Science \& \\
Astronaut1cs
\end{tabular} & \multirow[t]{3}{*}{ Independent offices } & \multirow[t]{3}{*}{ do } & \multirow[t]{3}{*}{$N / A$} & \multirow[t]{3}{*}{$\begin{array}{l}\text { Labor \& Public } \\
\text { Nelfare }\end{array}$} & Independent offices & do \\
\hline & Oceanography & Merchant Marine \& & & & & & & \\
\hline & $\mathrm{N} / \mathrm{A}$ & $\begin{array}{l}\text { Select Corim. on } \\
\text { Covt. Regearch } \\
\end{array}$ & & & & & & \\
\hline ATOMIC ENERGY COMM. & 2/ & 2) & 21 & do & 2) & 2f & 2) & do \\
\hline & & & Public Works & & & & Public Works & \\
\hline $\begin{array}{l}\text { HEALTH, EDUCATION AND } \\
\text { WELFARE }\end{array}$ & & & & & & & & $\because \ldots$ \\
\hline $\begin{array}{l}\text { Fublie Health } \\
\text { Sorvlce }\end{array}$ & Publlc Health \& Saftey & $\begin{array}{l}\text { Interstate \& } \\
\text { Foreign Comnerce }\end{array}$ & Labor, HEW \& Related & do & Health & $\begin{array}{l}\text { Labor and Publie } \\
\text { Welfare }\end{array}$ & Labor, HEW \& Related & \\
\hline & Rivers \& Harbors & Public Worka & Agencies & & $\begin{array}{l}\text { Special Sub-Comm, } \\
\text { on Air and Water } \\
\text { Pollution }\end{array}$ & Public Works & Agencies & do \\
\hline $\begin{array}{l}\text { office of } \\
\text { Education }\end{array}$ & Special Education & $\begin{array}{l}\text { Education \& } \\
\text { Labor }\end{array}$ & do & do & Education & $\begin{array}{l}\text { Labor and } \\
\text { Public Welfare }\end{array}$ & do & do \\
\hline$\overline{\text { TREASUAY }}$ & & & & & & & & \\
\hline Coast Guard & $\begin{array}{l}\text { CG, cacs, \& } \\
\text { Navigation }\end{array}$ & $\begin{array}{l}\text { Merchant Marine } \\
\text { and Fisheries }\end{array}$ & $\begin{array}{l}\text { Depts of Treasury \& } \\
\text { Post Office \& Bxecutiro } \\
\text { Office }\end{array}$ & do & $\begin{array}{l}\text { Merchant Marine } \\
\text { and Fisheries }\end{array}$ & Commerce & $\begin{array}{l}\text { Dept s. of Treasury \& } \\
\text { Post Office \& Bocutivo } \\
\text { Office }\end{array}$ & do \\
\hline SKITHSONLAN & Oceanography & do & $\begin{array}{l}\text { Dept. of Inter1or \& } \\
\text { Related Agencies }\end{array}$ & do & Smithsonian & $\begin{array}{l}\text { Rules \& } \\
\text { Administration }\end{array}$ & $\begin{array}{l}\text { Dopt. of Interior \& } \\
\text { Related Agencies }\end{array}$ & do \\
\hline
\end{tabular}

1/ The substantive sequence is not always applicable as progrum suthorization frequently is implied in an organiration's charter 

In consideration of the potential involved, we consider this a most depressing outlook. I would like to introduce some evidence in support of this potential.

The budiget of the U.S. Gorernment for the fiscal year ending June 30,1965 , shows a 1965 estimated source of receipt to the U.S. Treasury of $\$ 260$ million for "rent on Outer Continental Shelf lands" which is twice the budget for the entire national oceanographic program.

This concludes my statement, Mr. Chairman, and I am open to your questioning, and that of the committee. I have also brought with me a copy of the film "Oceanography: Science for Survival" which describes the organization, the objectives, and the activities of the ICO. I will be delighted to show it at any time during these hearings, at your convenience.

After you have concluded your questions, I would like to introduce Dr. I. E. Wallen, chairman of the research panel who will expand on our general ICO effort and highlight some of the accomplishments in the research area.

Thank you very much, sir.

Mr. Lennon. Doctor, the ICO pamphlet No. 11, national oceanographic program, fiscal year 1964, without objection, will be included in the record following Dr. Wakelin's statement. The chart that you referred to on page 17 which you asked permission to be included in the record, without objection that will be included in the record following your statement.

Now, could we go off the record?

(Discussion off the record.)

Mr. Lennon. On the record.

We'll begin with Mr. Pelly.

Mr. PeuLy. Thank you, Mr. Chairman.

I would like to associate myself with the statement that you made at the beginning of the testimony of Secretary Wakelin; I think you have placed in the record something of the recognition of his accomplishments and I certainly want to state for my part, Dr. Wakelin, it has been a great pleasure for me to see what you have done in the way of coordinating the oceanographic efforts of the various agencies of Government. I do not think there is anyone that is familiar with this work that would not admit that a large part of the success has been due to your own personal efforts in this respect. I think your service in Government is something which speaks for itself. You are going to have a very prominent place in the annals of oceanography because I think you have set the program up on a sound basis and maybe you are dissatisfied with the fact that there is not more money forthcoming and feel you have not been fully successful, but I think you have organized our national effort on a sound basis and you have all the various heads of these agencies working closely together. It has been a real pleasure to me to observe your work and I only want to say how much I regret the fact that you are not going to be before this committee in the future. It has been a number of years of service that you have given to the Government and you certainly have contributed a great deal.

Mr. WaKelin. Thank you very much. 
I might say it has been a great privilege for me to be Chairman of the ICO and we have had, I think, an unusually wonderful group of members and alternates. I have known of no committee in my career in which we have kept as closely to objectivity as it is possible to keep and have remained friends and have admired one another's accomplishments in the other agencies. It has been a wonderful experience for me and I regret having to step down from this position and to leave my friends.

Mr. Pelly. Thank you, Mr. Chairman.

Mr. Lexnon. Doctor, let me ask you. There were some questions that I wanted to ask when the others finished. I will yield to you, Mr. Keith, if you cannot be here tomorrow because I understand that Dr. Wakelin could be back.

Mr. KeIth. Two of my questions can go over until tomorrow.

Mr. Lennon. What about you, Mr. Rogers?

Mr. Rogers. Yes, sir.

Mr. Lenvos. I think counsel wants to ask a couple of questions and it will take a little time to develop them.

Then, gentlemen, if you can conveniently come back, we will adjourn until tomorrow morning at 10.

(Whereupon, at 12:10 p.m., the hearing was adjourned, to reconvene at 10 a.m., Wednesday, June 24,1964 .) 


\title{
NATIONAL OCEANOGRAPHIC PROGRAM-1965
}

\author{
WEDNESDAY, JUNE 24, 1964
}

\author{
HoUse OF RepresentattVes, \\ SUbCOMMITTEE ON OCEANOGRAPHY OF THE \\ Committee on Merchant Marine and Fisheries, \\ Washington, D.C.
}

The subcommittee met at 10 a.m., pursuant to call, in room 219, Cannon House Office Building, Hon. Alton Lennon (chairman of the subcommittee) presiding.

Mr. Lennon. The subcommittee will resume its hearings.

I see that Dr. Wakelin is here. I do not recall at the conclusion of the hearing yesterday that any member of the committee had an opportunity to question you. Mr. Ellsworth, do you care to open with some questions?

Mr. Ellsworth. Thank you. I have not yet completed reading Dr. Wakelin's statement, so I pass at this time. I may say, though, I notice from the first page of his statement that he is planning to relinquish his office as Assistant Secretary of the Navy next month. I want to take this opportnunity to wish him smooth sailing in whatever course he charts for the future and express appreciation to Dr. Wakelin for the fine work he has done in our Government over a period of three administrations, and particularly for the wonderful cooperation he has given to this committee, especially with regard to legislation that the House has passed.

I will say further that it has been a real personal pleasure to become acqainted with Dr. Wakelin-and once again, smooth sailing on your future course.

Mr. Lennox. I assure you that those sentiments are shared by all the members of this committee who have been privileged to work with Dr. Wakelin over the years.

Mr. Keith. I would like to join in the sentiments which you, as the committee chairman, have expressed. I have not been on this subcommittee very long. I have found it most interesting, particularly representing, as I do, the Woods Hole Oceanographic Institution. I have gotten to know Dr. Wakelin from his visits to that institution. We have profited from his extensive knowledge on this subject. I am learning a lot.

I note in your testimony that there was $\$ 260$ million paid for rent on the Outer Continental Shelf lands. It may not be appropriate to this discussion, but I would like to have you just briefly describe the sources of this revenue.

This appears on page 18 of your testimony. 
STATEIIENT OF DR. JAIVES H. WAKELIN, JR., ASSISTANT SECRETARY OF THE NAVY (RESEARCH AND DEVELOPNENT) AND CHAIRMAN, INTERAGENCY COMIMITTEE ON OCEANOGRAPHY OF THE FEDERAL COUNCIL FOR SCIENCE AND TECHNOLOGYResumed

Dr. WAKELIN. This is in the budget of the U.S. Government for fiscal year 1965 . It appears on page 65 under the general heading, "Administrative Budget Funds, Miscellaneous Receipts."

Under a heading entitled "Rents, Rent on Outer Continental Shelf Lands," is the figure we have quoted here in my statement for a projection into fiscal year 1965 of the expected returns from rent on Outer Continental Shelf lands. The 3 years, 1963, 1964, and 1965 are following : 1963 actual, $\$ 359$ million; estimate for $1964, \$ 174$ million; estimate for $1965, \$ 262$ million.

I would presume, although I know nothing about the details of the rent arrangements, or where they are located, that these are mostly for petrochemical explorations, and removal of petrochemicals from the Continental Shelf.

Mr. KeItr. As I mentioned earlier, this is not exactly appropriate to a review of oceanography as such.

WTe are very much concerned in our district with the oceanographic resources that are being tapped by the Russians. I received a plone call over the weekend from a Capt. Albert Dahl, who says that the Russians are so densely populating the off shore lobster fishing grounds that they cannot get through with their own boats. At some time I want to discuss with you further means of controlling the tapping of those resources in the absence of any payment of rent from foreign interests who are exploiting them. I do not believe it is appropriate to this discussion, but I would like to alert the public in general, and you in particular, to the need for further legislation in this area.

Dr. Wakelin. Being a native of your State, Mr. Keith, I have a high degree of personal interest in this particular problem.

Mr. Кеттн. Everyone does who likes lobster.

Thank you, Mr. Chairman.

Mr. Lennon. Thank you, Mr. Keith. We are delighted to have with us this morning the ranking member of the minority of the full committee, who has over the years demonstrated a great deal of interest in this matter. He has been a help to this committee. We relcome him to this hearing.

Would you like to question the witness?

Mr. Tollefson. Thank you, Mr. Chairman.

I did not hear the witness' testimony yesterday. I have a couple of questions in mind that are very, very general, and they will sound amateurish to you.

In 1959, one of our subcommittee went over to the Orient. TVe were in Japan and we met with Diet members interested in fisheries and shipping, and likewise met with Japanese departmental people having to do with fisheries. One of the things that struck me quite forcibly was the fact in those fishery meetings there was almays a 
representative of the Japanese Government, or more than one, interested in oceanographic matters. I got the impression that the fisheries people and the oceanographic people in Japan work very closely together.

I asked them if that were not the case, and they said yes, they had worked very closely together for a long period of time.

I got the impression that the Japanese have been engaged in oceanography work for a long period time and probably in some respects were ahead of us.

Could you comment on that?

Dr. WAKELIN. I can very generally, Mr. Tollefson.

Our impression of the earlier work in Oceanography in Japan is that it derives from their particular interest in fishing. They are interested in the food supply for their islands. For this reason I believe their interest in the whole ocean area, both physical and chemical oceanography, stems from the food interest they have for their people. This is somewhat different than the earlier starts we have made in this country. TVe have had three different segments in general in our program, quite distinct from the Japanese interest in food, and that is in physical oceanography, in marine biology, and in whatever air and sea interactions are involved in the meterological aspects. These have not been as closely associated with the food resources of the sea.

We work very closely with Mr. McKernan's group in the Department of Interior. He has educated us to the requirement for oceanographic information with respect to the natural resources, the living resources of the seas, and I think now that our particular program in fishing resources is more nearly geared to the use of oceanography as the Japanese have developed it than it was prior to 1959 or 1960.

Mr. Tollerson. You answered the next question I was going to ask, and that is, whether or not our Fish and Wildlife people are working with other Government oceanographic personnel on oceanography matters. I am glad to hear you say they are.

Now, is there an exchange of the information between say the Japanese and our Government people, and likewise, is there an exchange between our Government and other governments?

Do you work with other governments? Is there an exchange of information?

Dr. WAKelin. Yes, there is. There are roughly two mechanisms for exchanging information. The formal mechanism among governments is through the Intergovernmental Oceanographic Commission, which is affiliated with UNESCO. I believe there were 37 nations who started this IOC in 1961 in Paris, and I think the membership has increased to about 50 .

IVhile there are a number of cooperative enterprises in which the IOC has been engaged, such as the Indian Ocean Expedition and the Tropical Atlantic Expedition, their particular budget for research is rather small in comparison with the budget of the participating nations. However, there is a free and open exchange of information on natural resources, on physical and chemical oceanography, and on meteorological aspects that affect and control the sea. 
I might also add, sir, that Mr. McKernan, whose interests is primarily in the living marine resources of the seas, headed our delegation to the Intergovernmental Oceanographic Commission just a few weeks ago in Paris. He may wish to elaborate on that further when he comes to the stand.

Mr. Tollefson. We will bear down on him.

Dr. WAKELIN. I have not completed one other aspect.

The National Science Foundation is the agent of this Government for a cooperative study, with Japan, of research and investigative projects in which we may both be interested in the Northern Pacific. This is apart from the IOC.

Mr. Tollefson. Just one more question.

Legislation emanating from this committee having to do with oceanography sought to coordinate the various Government oceanographic efforts. Has that legislation been working well?

Dr. Warkeln. The legislation, as I understand it, has not passed the Senate, if you are talking about H.R. 6997.

Mr. Tollefson. I have forgotten the number.

Dr. Wakelin. We in the Interagency Committee on Oceanography strongly endorsed the bill as providing a means to coordinate better efforts among the agencies involved in our program. We hope it will pass both Houses and be enacted into law.

Mr. Rogers. Again, I want to say to Secretary Wakelin how much we have appreciated his good services over the years. We know of your fine work. Certainly you are to be commended and congratulated for getting this field going in a much faster manner than it was when you came.

Dr. WAKELIN. Thank you, sir.

Mr. Rogers. You have certainly given it great impetus. I think we need to do much. This has been indicated by your testimony.

You discuss the problem you have in the Congress, Congress not getting an entire picture of this, which I think is a great problem in finding support for an oceanographic program which is as extensive as it should be.

What is your feeling about trying to set up a department where we would bring all of the activities of research for oceanography together, even though it would have the various phases of it?

\section{Rogers.}

Dr. WakeLIN. That is a difficult question to answer in specifics, Mr.

\section{May I attempt one?}

The current bill which has been passed by the House and which emanates from this particular committee, H.R. 6997, I believe is adequate for the support and coordination of work which is done cooperatively among the agencies and departments of our Government which have a mission in the general field of the oceans, or a particular need for oceanographic information. There are other problems which we are going to have to face to which this bill, while it embraces the cooperative programs of a number of departments, may not be the correct answer in the long run. I am talking first about the programs 
that fall between departments and between missions and, second, about roles that we are just beginning to face now.

We talked yesterday about some of the problems in the air-sea interaction field which are common to the whole realm of meteorology and to the domain of oceanography and the interaction of the sea and atmosphere which acts as a tremendous heat engine. There is really no one agency that is responsible for this, and for this particular reason Dr. Weisner, with Dr. Hollomon's and my support, suggested that the Department of Commerce be named as the coordinating agency for programs included in both the Interdepartmental Committee on Atmospheric Sciences and the Interagency Committee on Oceanography.

That is one example of a field that falls between particular roles and missions of the departments.

The second field in which we have a vital interest in the Navy is ocean engineering. While the Navy Department is not responsible for the domestic use of engineering derices in the sea, it does have a military mission, including recovery of objects from the ocean and personnel rescue and recovery. Apart from this, there is a whole general field of ocean engineering which will open up for our whole free enterprise system an industry concerned with the capability of working in and exploiting the seas. This is not a single agency or single department job.

Thirdly, there is the field of deep research vehicles which allows you to get down into the domain and begin to work in it apart from the engineering devices that these rehicles may incorporate, or carry. Here, again, we are all interested in deep research vehicles, not only for a military purpose, but for the furtherance of our ability to work in and become a part of the sea environment at great depths.

It seems to me that while H.R. 6997 is eminently adequate for those roles and missions that are quite clearly defined, we are going into a new area now where we need the cooperation and the help of industry in engineering and in deep research vehicle technology. We do not necessarily believe the ICO to be the best mechanism for this, but I do not think that a separate department which would excise from each of the agencies their own jobs in oceanography, together with those that fall between the agencies, is the answer either.

Perhaps what we need is a mechanism by which the "between agency" tasks can be pulled together in parallel with your legislation from this committee. Does that in part answer the question?

Mr. Rogers. Yes, I understand your feeling.

Let me ask you this: How often does your Interagency Committee meet?

Dr. WAKELIN. The full Committee meets on the average of about once a month. The panels within the Committee, Mr. Rogers, meet more often than that in the detailed review of their programs.

Mr. Rogers. I see.

Do they have a regular set schedule for meeting or not? 
Dr. Wareuin. Usually the schedule is set by the deadlines that we have to meet in the program preparation, of either a program, a plan, or a budget. There are usually no set dates.

Mr. Rogers. And who calls the meetings of your various panels?

Dr. WAKELIN. The panel chairman calls the meeting:

Mr. Rogers. Do you designate a chairman?

Dr. WAKELIN. Yes, and I convene the meetings of the Interagency Committee on Oceanography.

Mr. Rogers. You have developed some staff for your Interagency Committee?

Dr. Wakelin. Yes.

Mr. Rogers. This is good. What does that consist of?

Dr. WAKELIN. I think that I receired that in my statement. IIr. Abel here is the secretary of the ICO, and I believe he has on his central staff three in addition to himself.

WTould you like to elaborate on that? May I defer to Mr. Abel?

Mr. ABEL. I have three assistants. They are funded cooperatively by a number of agencies.

Hopefully, they will be assigned to the panels on a semi-permanent basis so that they can carry out the work of the panels.

Mr. Rogens. Your three people would be assigned to perhaps two or three panels?

Mr. ABEL. Yes.

Mr. Rogers. You have six panels?

Mr. Abel. Yes.

Mr. Rogens. So each would take care of two panels?

Mr. A Ber. Well, depending on the work the panels are assigned to at any given time. There is a seasonal approach to this.

Mr. Rogers. Do you devote all your time to this work?

Mr. Abel. Yes.

Mr. Rogens. And these three assistants devote all their time to this work?

Mr. ABel. Yes.

Mr. Rogers. How much time would you say members of the Interagency Committee devote to your work?

Dr. WAKELIN. I would like to use myself as an example.

As you know, I have other responsibilities in the Department of the Navy.

Mr. Rogers Very definitely. That is what I am concerned about.

Dr. Whelin. And perhaps, if $\mathrm{I}$ can give you an idea of the fraction of my time, it might be representative of the other members, but I cannot speak specifically for them.

I would presume, in looking over the time I have spent on the ICO and ICO matters, either with the Committee, with the panel chairman, with the ICO executive secretary, with my special assistant for oceanography, Commander Snyder, or the Federal Council for Science and Technology, that is the order of at least 25 or 30 percent of my time, 
averaged out over a year. That is inordinately large, but stems I think from my personal interest in the problems of oceanography and the interest of the Navy Department in the science and technology of the oceans.

Mr. Rogers. I would presume, perhaps, that other members who are not the chairman would not have to spend that much time on the Interagency Committee?

Dr. WAKELIN. I cannot answer that in detail. I would like to offer an estimate that probably at least 20 percent of their time--I would think at least 20 percent of their time.

Mr. Rogers. Do you operate your ships, oceanographic ships, by contract or by personnel in the departments of government?

Dr. Wakelin. In the Navy Department, we operate our ships by two different means: One, naval-staffed vessels in oceanography through the Naval Oceanographic Office; and two, those that are still owned by the Government but assigned to institutions are operated by them in their research work under contract, usually to the Office of Naval Research.

Mr. Rogers. And of all of the oceanographic ships, how many would you say operate by contract?

Dr. WA KELIN. Mr. Rogers, do you by any chance have the fiscal year 1965 budget? Page 44, I believe, gives you a rundown of those ships, starting with the Conrad, built in 1963, down through the 1966-built date.

The first is Lamont Geological Observatory. The next four are Navy. The next one is Navy. Scripps, University of Washington3 out of those 10 projected there are operated under contract.

Mr. Rogers. What about those above?

Dr. WaKeLIN. Those above are all operated by the Oceanographic Office.

Mr. Rogers. None of those are contracted?

Dr. Wakelin. No.

Mr. Rogers. Do you also contract with institutions who may own their own ships to do the work?

Dr. WaKeLIN. Yes, we do.

Mr. Rogers. What would be the extent of that work?

You may not have this at hand.

Dr. WAKELIN. I do not. I can supply it for the record.

There are many private institutions who have what we call boats up to and including maybe 100 to 200 feet long, or maybe shorter than 100 feet, who do special jobs in oceanograph. We can get you that for the record, Mr. Rogers.

Mr. Rogers. I would appreciate it if we could have that for the record.

(The information referred to follows:) 


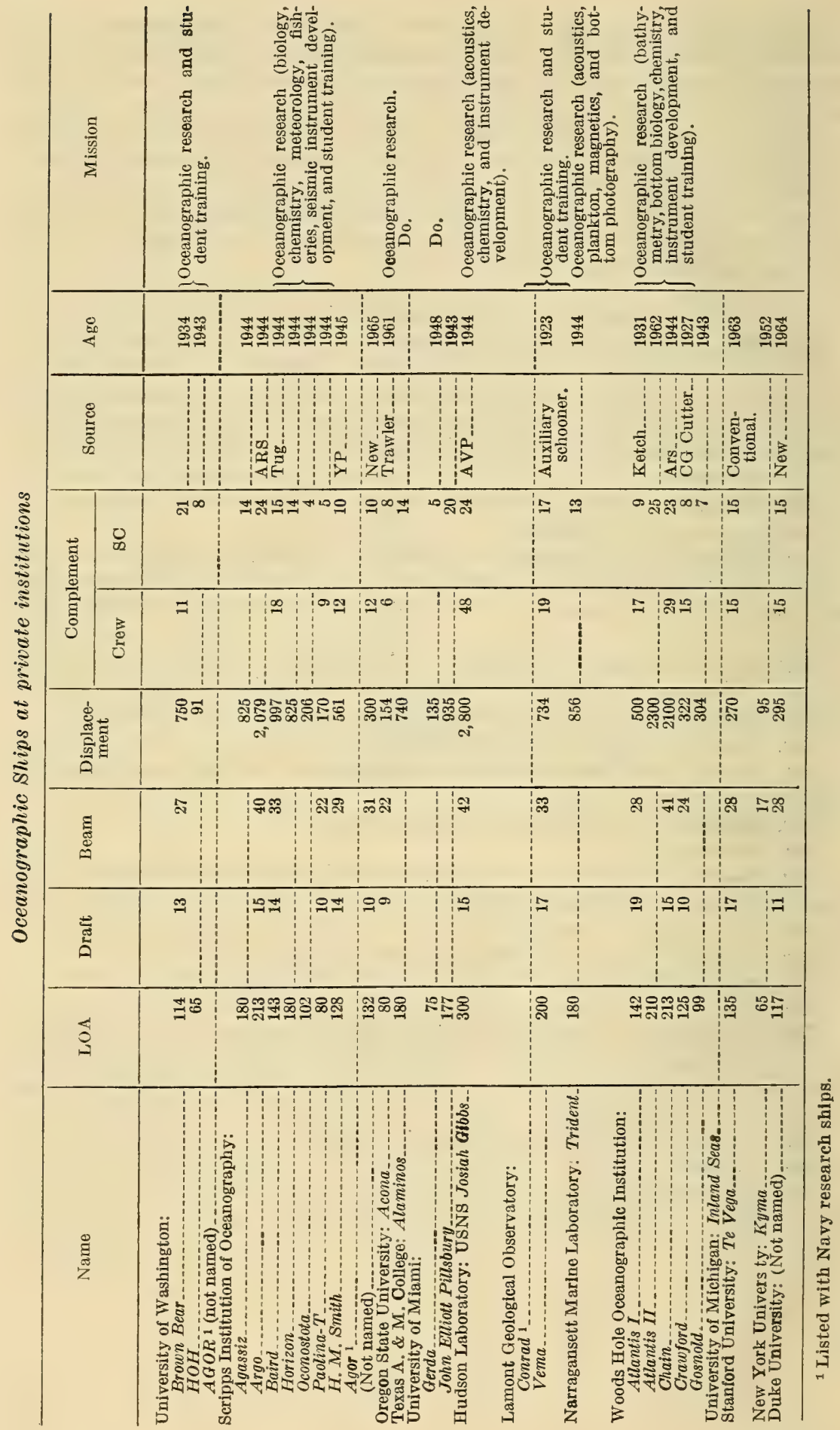


Mr. Rogers. In operating the Interagency Committee, what is your procedure in the settling of diversity of opinion?

Dr. WAKELIN. Are you referring to the procedural methods we use?

Mr. Rogers. Yes.

Dr. WAKeLIN. May I go through and describe very briefly how we develop a given subject, how it gets to the Committee, and what happens after that?

Mr. Rogers. Yes.

Dr. WAKELIN. In the beginning of a plan, such as a budget plan, the agencies who are represented on the ICO suggest to the whole ICO plan for the succeeding year. This, then, is given to a given panel, either the research panel, instrumentation panel, or ships panel, for their detailed study. Then when these proposals have all been analyzed, and when the panel chairmen are ready to discuss this with the full Committee we meet to discuss the plan in general.

In typical fashion, for example, in last year's budget, the agency submitted a figure for oceanographic support of the order of $\$ 200$ million. We reduced this in the ICO to $\$ 175$ million before submitting the plan formally to the Federal Council. In the procedures leading up to this reduction, each of the steps that were taken in the full Committee were taken more or less by vote. It was the sense of the Committee if there were strong objections, that particular project or particular part of the plan was sent back to the panel for resolution of objections that might have been made by one member or another.

It is usually the case that any program which goes to the Federal Council has the unanimous support of the ICO before it leaves the ICO.

Mr. ROGERs. It must have unanimous support?

Dr. WAKeLIN. This is not a condition, but in general I think we try to resolve differences of all matters largely of scientific and technical judgment by a sense of the Committee, and if someone on the Committee has a very firm feeling against it, it is usually sent back until it is resolved.

Mr. Rogers. Suppose there is some diversity of opinion that is not resolved, but it is felt the project should be approved. Would you have the authority to say, we will submit it to the Federal Council?

Dr. WAKELIN. I have taken that authority.

Mr. Rogers. You have been able to do that?

Dr. Wakeurn. Yes. I think the Committee has supported me.

For example, last year in the program several of us felt it was important to put into our 1965 plan a project in connection with deep holes. I am not talking about the Mohole, but getting samples in the deep oceans. This was a matter of considerable controversy in the ICO.

Finally, I suggested that we should submit this, since it did not seem to have unanimous approval of all the members of the ICO, to the Federal Council and inform them this was a matter that $I$ wished to call to their attention, and wished to get their approval on regardless of the fact there were several members who had adverse opinions about it.

Mr. Rocens. You do not use a procedure of letting each department have a vote? 
Dr. WAKELIN. No, we do not. In the last 2 years, at least, we have made drastic reductions as a committee to the whole program, affecting all of us.

inr. Rogens. Let me ask you this: How do you decide the percentage that should be allotted of the funds to each department involved?

Dr. WAKenIN. This is based largely, not on the prorated dirision of funds as funds, but on the substance and importance of the projects submitted by the agency. In several cases, we have exceeded those requests given to us by an agency by ICO action.

For example, we have added substantially in the last several years to the Department of the Interior's budget request to the Federal Council by Committee action and cutting out various other parts of the program, feeling their project was more important to the whole plan in this time period than were others that were in competition with it.

Mr. Rogers. So there is no specific breakdown?

Dr. Wakelin. There is no relationship, I am happy to say, between what an agency had last year and what they can submit for approral next year. I think this should be done on the substance of the program, and not on a fund basis.

Mr. Rogers. Has the pattern been that the funds pretty much follow the pattern of what the Department had the year before?

Dr. WaKelin. They have.

Mr. Rogers. That has pretty much matched?

Dr. WAKELIN. It has.

Mrr. Rogens. What three departments would you say have the major funding?

Dr. Wakelin. I would say the Department of Defense, the Department of Commerce, and the National Science Foundation, I think in about that order.

Mr. Rogers. You have an advisory group, an ad hoc group?

Dr. Wakelin. Yes.

Mr. Rogers. Of nongovernmental people?

Dr. Wakelin. They are selected by the President's science adviser, acting as Director of the Office of Science and Technology.

Mr. Rogers. Does the Interagency Committee make recommendations to him for his consideration in the selection of those ad hoc committees?

Dr. WAKELIN. I think in several cases we have suggested individual members as knowledgable in particular areas, but in general the framerork of the whole Committee choice has been up to Dr. Wiesner and now up to Dr. Hornig without much direct coupling from us.

Mr. Rogens. What use does your Committee make, or have you made, of the advisory ad hoc committees?

Dr. Warkelin. We have made a great deal of use of their recommendations. They have pointed out in several cases what we consider to have been weaknesses in our program. They have been most helpful to us. There are two areas in which they stress the real need for an alteration of emphasis.

One was in the shore facilities. As you recall, it takes about four men to support one afloat. While we are building a substantial number of ships, we in general have not kept up with the shore facilities that are going to be adequate for the program in the far future. TVe have to do more in this area. Since we did not, at the time they 
revierved our program last year and the year before, put in suficient funding for shore facilities, they recommended we give much more attention to this, and we have taken their advice.

In the area of research and surveys, there has been a long diseussion between the research people and those engaged on surveys. It is partly a semantic argument and partly a misunderstanding. The research scientists in oceanography are not usually interested primarily in surveys; they are interested in precise research data.

The survey people are interested more in a broad look into an area, like the Indian Ocean, rather than going particularly to one spot and doing an intensive job in research there. By bringing the tro groups together, the survey group with the research people, through the National Academy of Sciences, who are engaged in research work in oceanography, we have clarified a lot of differences, we have coordinated programs so surveys and research work on a given ship, or group of ships, and can go along together in a more harmonious manner. This was also pointed out as a misunderstanding by the ad hoc panels for the last 2 years. They have been most helpfril to us, and we have felt that a good outside look at our program has been healthy from the whole point of view.

Mr. Rogers. Yes. As I understood from previous testimony, the Advisory Committee really works with your panels and with your Interagency Committee, more than it does with the Federal Council.

Dr. Wakelin. Well, a typical case in point would be the review of our 1964 program last summer. This took a period of abont a reek of very intensive examination by the ad hoc panel meeting with each of the panels in detail.

Mr. Rogers. I see. And then they give their adrice and then it comes before the Interagency Committee?

Dr. WaKelin. They give their advice really to Dr. Wiesner and the Federal Council. They pointed out the weaknesses and the strengths of the program.

Mr. Rogers. Could you tell me about what amount of money is being expended on the beach erosion problem and wave action problem? Are we intensifying that greatly?

Dr. WAKELIN. It is not a substantial part of our program, Mr. Rogers. I can give you a figure for-

Mr. Rogers. It looks to me like it is about $\$ 500,000$.

Dr. Wakelin. The 1965 budget includes about $\$ 800,000$ for the Corps of Engineers for work in beach erosion and for the Coastal Engineering Research Center.

As I recall-I think my memory is within an order of magnitude of correctness - this has been about the level of effort for the last 2 years in beach erosion.

Mr. Rogers. There has been no increase in that?

Dr. WAKELIN. There has not been any substantial increase in beach erosion work in our program.

Mr. Rogers. Do you feel this is a proper phase of oceanographybeach erosion studies?

Dr. WAKELIN. Yes, sir; I do. I feel that the influence of the ocean on the shoreline, the influence of coastal waters on the relocation of land, sand, and so forth, the effect of waves in remaking, in a large measure, long areas of our shoreline is something tre should spend, I think, more than $\$ 800,000$ a year on. 
Mr. Rogers. I would agree with you.

Dr. WAKELIN. I am speaking as an individual.

Mr. Rogers. I would agree with you wholeheartedly because I know the problem we are having up and down our coastline is tremendous, and the damage is so very great.

Dr. WAKELIN. Yes.

Mr. Rogers. I would hope that the Interagency and the Federai Council would assign a little higher priority to these studies.

I commend you for your work, Mr. Secretary.

Mr. Mosher. No questions.

Mr. Casex. No questions.

Mr. Lennon. Dr. Wakelin, the ICO has been in existence now around 5 years, has it not?

Dr. WAKELIN. Yes.

Mr. Lennon. Are there minutes kept of the several meetings of the $\mathrm{ICO}$ ?

Dr. Wakzlin. Complete minutes.

Mr. Lennon. Are minutes kept of various panel discussions?

Dr. Wakelin. Yes, sir.

Mr. Lexwos. It would be interesting to the committee in following this matrer if we could have inserted in the record of the hearings a summary, not of what transpired or took place at either of the ICO meetings, or the panel meetings, but a summary by calendar years showing the progressive increase in ICO meetings and panel meetings over the past 5 years.

I know that was one of the things we were concerned with early in our hearings-the objective that the committee was seeking.

(The following material was subsequently received for the record:)

\section{Highlights of ICO and Panel Meetings, Calendar Year 1963}

\section{ICO MEETINGS}

March 1: Lengthy consideration was given to many phases of the long-range plan. Also discussed were the fiscal year 1965 national oceanographic program, the Manpower and Training Report, the Ocean Survey Plan, and international programs.

April 18: The working group preparing a report on the ICO and ICAS joint sponsorship of air/sea interface research described its preliminary findings. One of the problems encountered by the group in drafting its program was the dissimilarity of approach used by oceanographers and meteorologists. The relationship between ICO and the Navy Instrumentation Center was reviewed. Other agenda items included U.S. representation to the forthcoming IOC Bureau meeting and the ICO long-range plan.

June 3: Portions of this session were filmed for inclusion in the ICO morie, "Oceanography--Science for Survival." Items discussed were the fiscal vear 1965 budget preview, the executive session with the Subcommittee on Oceanography of the House Committee on Merchant Marine and Fisheries, ICO staff augmentation, and a proposed letter of ICO support for the nomination of Marston Sargent to replace Dr. Wooster at UNESCO. The concept of a quarterly report cataloging oceanographic research projects, through the Science Information Exchange of the Smithsonian Institution, was debated. The possibility of a joint NASCO-ICO meeting was considered.

August 8: The fiscal year 1965 recommended budget was discussed at length in connection with Bureau of the Budget ceilings imposed upon BCF, Navy, USGS, and USBM. NSF described a $\$ 7$ million deep coring (ocean floor) program it may sponsor. The relationship of the National Oceanographic Data Center to the ICO was again considered. Secretary Wakelin suggested that non-Navy ICO member agencies provide the extra billets needed to augment the ICO staff. 
September 30: A joint ICO-NASCO meeting examined the long-range national oceanographic program, the fiscal year 1964 NOP, and the NASCO report on "Investment in Oceanographic Research."

November 8: A letter to Dr. Wiesner was approved (with subsequent modification) wherein ICO recommended the establishment of a staff, to be located at the Department of Commerce, to coordinate the further identification of the unique problems involved and to stimulate the necessary agency activities in the field of air/sea interface research. The roles of deepsea research vehicles (DRV), air/sea interface research, and facilities were discussed in relation to their adequacy in the fiscal year 1965 national program. The proposed revision of current oceanographic ressel legislation was presented by the Coast Guard. Other agenda items included the fiscal year 1965 budget document, marine biology, the forthcoming Hawaii meeting, National Oceanographic Data Center and its Advisory Board, State Department and international programs, and the National Science Foundation canvass of the oceanographic community. Bureau of Commercial Fisheries trade winds zone oceanography program was presented to the ICO for its endorsement as a national program. The matter was referred to the research and surveys panels for evaluation. NASCO's report on "National Investments in Marine Research and Derelopment" was considered.

\section{PANEL MEETINGS}

(a) Instrumentation, Equipment and Facilities Panel:

February 17: The major item of discussion was the fiscal year 1965 budget. A report was given on the progress of an ad hoc committee studying the potential ICO use of the Navy Instrumentation Center.

March 20: The ad hoc committee reported the need for a national oceanographic instrumentation center, assisted by an advisory board, for the design, research and development, calibration, maintenance, and repair of oceanographic instruments. The center, the nucleus of which would be the existing Navy center, would meet the needs of the national oceanographic program.

March 27: Agenda items included the fiscal year 1965 budget, ICO-ICAS air/sea interface problems, and the instrumentation center.

July 9: The potential need for the Tongue Point, Oreg., facility was debated.

November 15: The facilities portion of the fiscal year 1965 budget was reviewed, at the request of the OST, and critical needs were pinpointed in ONR, Commerce, NSF, and Interior.

(b) International Programs:

February 13: U.S. representatives to the forthcoming Moscow meeting of IOC (May 6-8) were selected. U.S. "Declared National Programs," prepared for the IOC meeting, were discussed. Proposed U.S. representatives were selected for the ICITA meeting in Paris, July 2; IOC Communication Panel meeting, Paris, July 6-12; and the WMO meeting in Geneva in late 1963.

July 24: Debate centered around the forthcoming IOC working group meetings on communications. A candidate was proposed for the position of Deputy Director of the UNESCO office of oceanography. Data exchange problems were discussed.

August 7: The consultative committee to the IOC was discussed.

September 10: Proposed delegates were selected for forthcoming international meetings, including: IOC, Paris, October 28-31; Kuroshio Studies, Tokyo, October 29-31; Indian Ocean Coordinators Meeting, Paris, January 22-24; Data Exchange Working Group, Paris, January 27-28; and IOC, Paris, June 1964. Other agenda items included data exchange, problems of providing personnel for UNESCO programs, ICITA review, and "Declared National Programs."

October 1: Position papers prepared for the forthcoming IOC meeting were discussed.

(c) Manpower and Training Panel :

September 18: Discussion centered around a draft of the questionnaire to be mailed to all members of the Federal and non-Federal oceanographic community, the purpose of which is to accurately assess the current manpower situation.

(d) Oceanographic Research Panel :

January 7: The major agenda item was a discussion of the long-range plan. 
March 13: The Bureau of Commercial Fisheries proposed Trade Winds Zone investigation was considered from the standpoint of possible ICO endorsement as a national program. Other items debated were the fiscal year 1965 program and current effort in buoy component research. A subpanel's progress on air/sea interface research was heard (this subpanel met on January 30-31, March 6, May 23, July 17, September 18, and October $2-3)$.

August 14: The panel reviewed the fiscal year 1965 draft document just prior to its submission to the Office of Science and Technology's Ad Hoc Panel. The NSF's proposed $\$ 7$ million ocean floor long coring program was weighed for possible inclusion in the national program.

August 21 A subpanel was chartered for the purpose of analyzing radioactivity research to delineate it for accurate breakdown by ICO research objectives (this subpanel met on October 14).

October 4: The fiscal year 1965 program was reappraised in the light of the report of the OST'S Ad Hoc Panel. A subpanel was chartered to study the scientific application of deep-sea research vehicles (DRV) within the framework of the fiscal year 1965 program and the long-range plan (this subpanel met on October 9,16, 23, and 30 and November 6 and submitted its final report to the panel on November 27). The final report of the subpanel on air/sea interface research was discussed at length.

October 24: The fiscal year 1965 research budget was restudied, in view of recent Budget reductions in other functional areas. NASA's manned orbiting lab (MOL) was explained to the panel by a NASA representative.

October 31: A lengthy briefing on Anti-Submarine Warfare Environment Prediction System (ASWEPS) was heard for the purpose of evaluation of the program for possible inclusion in the National Oceanographic Program. (e) Oceanographic Ships Panel:

February 1: Fiscal year 1964 shipbuilding plans and ship operating scheclules were contemplated at length.

October 22: Relative priorities in the fiscal year 1965 ship construction program were debated in view of possible adverse action by BuBudget.

(f) Ocean Survey Advisory Panel:

January 7: Discussion revolved around the requirements and procedures for running an operations research (OR) analysis of the gorernments' ocean surrey activities. The panel decided to request preliminary oR proposals, from outside gorernment, then seek final proposals from the best responses.

January 10-11: The panel explained the 1963 field season government agency survey plans to four consultants from the non-Federal oceanographic community. Detailed season plans for each ship were examined.

April 11: A bidders conference was held.

April 25: The panel selected six companies, from the preliminary proposals, from which it sought final proposals.

June 10: The six final proposals were evaluated and the contract for the OR study awarded to Operations Research, Inc., of Silver Spring, IId.

September 26: The panel prepared for the forthcoming joint meeting of ICO-NASCO survey panels. Air/sea interface research and the Upper Iantle Project also were discussed. A subpanel was chartered to investigate the significance of the biological communities' needs in terms of the surreys plan.

September 27: A joint meeting of ICO-NASCO survey panels pinpointed two major problem areas : the inadequate input to the survey planning mechanism from the non-Federal oceanographic community, and the difficulties encountered in publication of data gathered on Federal surveys. Also discussed were the oR analysis and air/sea interface problems.

(g) ICO Working Group:

Mav 15: The main item of interest was the Spring previer of the fiscal sear 1965 program. Also discussed were progress of the air/sea interface subpanel and ICO staff augmentation. The impact of DSSRG and its relationship to ICO was considered.

August 2: The fiscal year 1965 program was restudied prior to submission to the OST's Ad Hoc Panel. Arrangements were made for panel chairmen to brief the Ad Hoc Panel during the latters' period of evaluation of the fiscal year 1965 program.

October 25: The major issue involved was the method of revising the fiscal year 1965 document to more nearly coincide with the format of the long-range plan, as suggested by the OST Ad Hoc Panel.

(h) Data Center Advisory Board. 


\section{REPORTS}

I. Completed during calendar year 1963 :

ICO publication No. 7 -... National Plan for Ocean-Wide Surveys.

ICO publication No. 9... Bibliography of Oceanographic Publications.

ICO publication No. 10_- Long Range National Oceanographic Plan.

ICO publication No. 11_- National Oceanographic Program, fiscal year 1964.

ICO publication No. 12.- Oceanographic Ship Operating Schedules.

ICO publication No. 14_- University Curricula in Oceanography 1963-64. Aquatic Sciences in the Great Lakes Area.

II. In progress :

ICO publication No. 8_... A Career in Oceanography.

ICO publication No. 15.- National Oceanographic Program, fiscal year 1965.

ICO publication No. 16_- Oceanographic Ship Operating Schedules, fiscal year 1965.

Mr. LenNon. I am glad to hear you say it is your judgment that the legislation reported out of this full committee, and subsequently to the full committee of the House, meets at present the objectives of the ICO and the Federal Council.

You disturb me, however, with your statement, or your remarks at the conclusion of your statement, that the oceanographic effort may be falling off, so to speak. I do not recall the exact terminology you used, but it appeared in the latter part of your statement.

What is your suggestion-I guess you are in a better position now since you are leaving the Navy Department to give us an opinion--as to how that might be helped by either this committee, or any individual of the committee, or the Congress?

What is the way to correct that diminution of funds for the oceanographic effort?

Dr. WaKelix. This is the only committee with which we, as members of ICO, have been connected which has taken an overall look at our national program. TThen I have been before Mr. Nahon's committee, their interest in oceanography has always been very intense, but as part of the antisubmarine warfare R. \& D. program, which is, of course, appropriate to the Department of the Navy.

It would help us greatly if we could tell the national oceanographic program story to more committees of the House and the Senate who would look with us at the total program and not at the particular agency for whom an appropriation or a hearing is engaged.

IIr. Lennon. Doctor, is it the practice for a department or agency or bureau to bring to the Federal Council, and then subsequently to the ICO, its projected figures for a particular fiscal year in the field of oceanography?

Dr. WAKELIN. Yes.

Mr. Lennon. In other mords, it goes in their respective requests for a budget, but then they come back to you for your consideration and allocation of the total?

Dr. Wakelis. No; when this finally goes through the Federal Council for approval, the next stage is a review by the Burean of the Budget of the submissions of each of the agencies and departments who comprise the program. This is another area in which we have been most fortunate in having Mr. E. L. Dillon, of the Bureau of the Budget, work with us throughout the entire vear, so he knows the whole story of the national program as well as the agencies submitting their requests through their secretaries and directors to the Bureau of the Budget. 
You will recall, Mr. Chairman, that the 1965 program was submitted to the Congress, to the House, and to the Senate, by the Presidentthe long-range program was submitted by Dr. Wiesner. President Johnson submitted on the 19th of March of this year, both to the Senate and to the House, this program in oceanography [indicating the 1965 fiscal year document]. I think you referred to that in your opening remarks.

Mr. Lennon. What was that figure?

Dr. WAKELIN. \$138 million.

Mr. Lennon. That was the figure for the budget?

Dr. WAKELIN. Yes.

Mr. Lennon. And that was actually less than the budget figure for fiscal year 1964 ?

Dr. Warelin. We submitted a program to the Congress in 1964 of $\$ 156$ million.

Mr. Lennon. And for fiscal year 1965 ?

Dr. WAKELIN. \$138 million, and fiscal year 1964 was \$156 million.

Mr. Lennox. You can hardly charge the Congress with the responsibility of that cut, can you?

Dr. Wakelin. No, sir; but the $\$ 156$ million was reduced to about $\$ 124$ million in congressional hearings.

Mr. Lennon. You went to the budget with $\$ 175$ million?

Dr. WAKELIN. That is correct.

Mr. Lennon. It was reduced from $\$ 175$ million by the Bureau of the Budget to $\$ 138$ million. It was reduced by Congress from $\$ 138$ million to what?

Dr. Wakelix. To $\$ 124$ million last year. I do not know what it is going to be this year, because all the hearings are not completed, or the actions of committees are not complete.

Mr. Lennon. That are the House figures? The House has passed all their appropriation bills except foreign aid.

While you are looking that up, the point I am making is. your biggest cut for your oceanographic effort came from the Bureau of the Budget as distinguished from the cuts made by the Congress; is that not so?

Dr. Wakelin. Yes, sir. The Bureau of the Budget did look at the whole program as this committee does. The other committees involved in other activities of our whole program do not look at the whole program.

IIr. Lennon. As I have indicated, the Bureau of the Budget figure for fiscal year 1965 is $\$ 138$ million. The Honse has passed 11 appropriation bills and there is only one yet to consider and I ronder how you fared on your $\$ 138$ million?

Dr. Wakelin. In the Navy I can say that we sustained a 5-percent cut in research, development, test, and evaluation, across the board. It remains to be determined whether that cut will be 5 percent in oceanography and antisubmarine warfare or whether this will be taken into other areas. TVe still have to reapportion that cut across the board in research, development, test, and eraluation, in which most of our oceanographic program resides.

Mr. Ellsworth. Will the gentleman yield?

Mr. Lennon. Yes. 
Mr. Eulsworth. Do I understand that this cut took place here in the House A ppropriations Committee, or where?

Dr. WAKELIN. The cut we are talking about?

Mr. Elusworth. The 5-percent cut.

Dr. Wakelin. The cut took place in the House Armed Serrices Committee $(a)$ authorization and $(b)$ appropriations.

Mr. Lennon. Did it take place in the House Armed Services Committee or Subcommittee on Appropriations?

Dr. WAKELIN. The $\$ 73$ million was removed by authorizaiton and another $\$ 8.5$ million by the Appropriations Committee.

Mr. Lennon. Dr. Wakelin, who appears before the respective authorization and then subsequently Subcommittee on Appropriations to defend the budget for oceanography?

Dr. WAKELIN. I do, for the Navy.

Mr. Lennon. For the Navy?

Dr. Wakelin. Yes, sir.

Mr. Lennon. The members of the ICO who appear before the respective Subcommittees on Appropriations representing the sereral departments and agencies and bureaus?

Dr. WAKELIN. Yes, sir.

Mr. Lennon. You are in a position to present the authorization to the appropriate committee on the total oceanographic effort?

Dr. Wakelin. Which I have done.

Mr. Lennon. In spite of that, you say that the $\$ 78$ million cut in the authorization and subsequently $\$ 8.5$ million in the appropriations Navy.

Dr. WAKELIN. \$73 million and \$8.5 million; yes, in R.D.T. \& E.,

Mr. Lennon. As Chairman of the ICO, do you know what the experience of the other interested members appearing before the respective subcommittees on Appropriations and authorizations has been?

Dr. WAKELIN. Our estimate now, across the board, as of this morning, is of the order of $\$ 7$ million cut out of $\$ 138$ million.

The Bureau of Commercial Fisheries sustained, I think, a 10 percent cut. There were smaller cuts in Geological Survey and Sport Fisheries. The Science Foundation is undetermined. We do not know the final apportionment within the Science Foundation, how their budget will be figured and their cut.

I would estimate that of the Navy program, which we have before you now for discussion, $\$ 65.5$ million, something of the order of $\$ 3$ million to $\$ 5$ million would be cut out of that as a result of the acrossthe-board cut that we sustained in the authorization and appropriations.

Mr. Lennon. Of the House figure, what percentage of the cut of the $\$ 138$ million is now reflected in the House appropriation bill up to this point? You have almost all of the House appropriation bills passed in the House and, in other words, what of the $\$ 138$ million that was in the budget is left now as a result of House action?

Dr. WAKELIN. How much is left? About $\$ 131$ million.

Mr. Lennon. That is a $\$ 7$ million cut?

Dr. WAKELIN. Yes, sir. 
Mr. Lennon. The Bureau of the Budget cut $\$ 37$ million and the House cut you $\$ 7$ million, so I think you ought to set the record straight. You were not critical of the House? You spoke disappointingly of the Congress and I think you ought to speak disappointingly of the Bureau of the Budget.

Dr. WAKELIN. Yes, sir.

Mr. Lenrox. Our percentage of the cut is not what we wanted it to be, but it is certainly better than the $\$ 37$ million cut of the Bureau of the Budget.

Dr. WAKELIN. We have had many discussions with members of the Bureau of the Budget and we understand they have serious problems in the apportionment of the national funding among many of these national programs, as well as other particular agency programs.

Mr. Lennon. Mr. Bauer?

Mr. BAUER. Doctor, there are several questions I will ask you that perhaps will require submission of material for the record that I know you do not have with you now.

However, I think for the record it would be very helpful for the committee if you would describe this new Naval Institute of Oceanology as it is now being formed.

If you cannot do that, perhaps the admiral can tell us the purpose.

Dr. WAKflin. Mr. Bauer, the purpose generally is to combine the research programs of the Office of Naval Research, principally those in the area of geophysics under the direction of Dr. Arthur Maxwell, which concerns itself primarily with educational and research institutions under contract to the Navy with part of the oceanographic program conducted by Admiral Knoll's group in the Naval Oceanographic Division (OPNAU).

The reason for combining these is to get a closer association of our in-house naval research on oceanography as conducted by the Oceanographic Office with those institutions which are under contract for research in this field to the Office of Naval Research. The idea of the Institute of Oceanology was to coordinate better by locating in one place the two parts of the program.

Perhaps if Admiral Knoll does testify before the committee he rould like to amplify these statements.

In general, we are trying to combine the in-house and contract rork under one colocated group, better to take advantage of their mutual interests in the field of oceanography.

Mr. BAUER. In other words, am I correct in assuming that you would also include some features of aerology?

Dr. WAKELIN. Yes, sir; as well as a considerable part of the program in the air-sea field. This would be included in the Institute of Oceanology.

Mr. BAUER. It would be correct to say that this is an approach to the stucly of the entire environment of the ocean; is that correct?

Dr. WAKELIN. This is an approach toward the consolidation of programs in the Navy, both with respect to meteorology and oceanography ; yes, sir.

Mr. BAUER. You contemplate including hydrobiology?

Dr. Wakelin. We have not specifically included that in Dr. Maxwell's ONR plans. I would certainly think it should be considered a part of this at a later time. 
Mr. BAUER. What is the present status of security classification of ocean surveys?

Dr. WAKELIN. I'm sorry I do not have that information with me. I will be happy to send it to you as soon as I return to my office.

Mr. BAUER. Doctor, while you gather that information, would you also supply for the record a résumé on in-house versus sponsored oceanographic research?

Dr. WaKeLIN. I will be happy to include this résumé along with the other request.

(The following information was subsecuently received for the record:)

\section{Past and Present Status of Security Classiftcation of Oceanic Soundings}

Prior to 1942 all oceanic soundings were incorporated on unclassified charts, and sent to the International Hydrographic Bureau.

The need for protection of ship movements, plus protection of data which could be used by enemy submarines, resulted in the classification of oceanic soundings, during the war years. In February 1951 the classification of these secret and confidential soundings was reduced to restricted. When the restricted eategory was eliminated in 1952, these soundings were upgraded to confidential.

Since then, restrictions have been progressively relaxed. In 1958, soundings in the Antarctic, Gulf of Mexico, and Caribbean were declassified. In other areas, only depths greater than 300 fathoms were classified. In 1959, those in the Southern Hemisphere south of latitude $30^{\circ}$ south were additionally declassified.

In mid-1959, the National Academy of Sciences Committee on Oceanography recommended that "all oceanographic information, including oceanic soundings and other survey information be unclassified, with the exception of certain data collected in strategic regions or by clandestine means." This was amplified to mean that soundings taken with no better than celestial or loran A accuracy, or on sounding lines spaced more than 10 miles apart, would be unclassified. Also to be unclassified were all detailed surveys made by the PDR (precision depth recorder), all positions of sea-mounts, all bathymetric charts at scales smaller than $1: 2,000,000$, all soundings south of $20^{\circ}$ south latitude, and the whole Indian Ocean.

The Navy in early 1960 concurred in part with the NASCO group recommeudations, and it was decided that soundings spaced closer than 10 miles, precisely positioned (loran $\mathbf{C}$ or equivalent) would be classified. The Hydrographer was directed to sanitize such data for release at 10-mile spacing.

In early 1962 this was further relaxed to classify only precision soundings at closer than 5-mile line interval. This resulted in a declassification of a large quantity of the stock of classified soundings. These ground-rules are still in force. This policy is considered adequate and reasonable for the present, but is certainly not unchangeable. It has, as noted in the foregoing, been arrired at through an evolutionary process, and this will doubtless continue. It is the Navy's policy to cooperate in every way with other agencies and scientists who desire data, consistent with the current dictates of military security.

\section{Balance of Oceanographic Research Effort in the United States}

During the formative years (fiscal years 1960-63) of the national oceanographic program, the Interagency Committee on Oceanography (ICO) was advised by the National Academy of Sciences, through its committee on oceanography (NASCO), ${ }^{1}$ that a productive national program of oceanography required, more than any other element, a significant growth in its basic research sector. This research need referred primarily to the university laboratories, who felt that: $(a)$ that they had achieved a potential of facilities which would allow modest acceleration in their research effort; $(b)$ that the basic knowledge, which had been acquired by that time, indicated numerous and exciting possibilities for further good and productive research; and $(c)$ that from all points of

${ }^{1}$ National Academy of Sciences publication, Qceanography, 1960-70. 
View of our national interest, it was well past the time when this Nation could and should afford to step up its program of oceanographic research, as a matter of practical exploitation.

The ICO responded by paying particular attention to encouragement of basic research in prenaration of its annual national programs; primarily through the mechanisms of the Office of Naval Research, which doubled its oceanographic research support from 1960 to 1964, and the National Science Foundation, which tripled its research support during the same period. Not only were the recognized centers of oceanographic research in the United States considerably aggrandized but at least half a dozen new laboratories were established in the countrr. In addition, a number of small colleges instituted courses in oceanographr and undertook a small degree of productive research with partial Gorernment support.

This growth was extremely encouraging not only to its practitioners, but to the Government scientific administrators who play such a large part in its attainment. Howerer, it is possible that some balance was lost in this drive for funding since a special panel of experts later convened by the assistant to the President for Science and Technology reported that the Federal inhouse research program appeared to be somewhat undernourished by comparison. This observation may have resulted from a comparison of program budget data for the period 1960 to 1965. In 1960, research supported by Federal Government grants and contracts to academic and industrial laboratories amounted to about $\$ 17$ million: at the same time the aggregate effort mounted by Government laboratories amounted to some $\$ 10$ million. Although at first glance this would seem to favor the private laboratories, the large number of academic and industrial laboratories should be recognized. as compared to Federal laboratories prosecuting oceanographic projects. In 1965 funds for sponsored research in academic and industrial laboratories amount to approximately $\$ 40$ million whereas inhouse research is in the neighborhood of $\$ 29$ million.

Within the Federal laboratories, the largest users of research funds are the Oceanographic Office of the Navy (\$5 million), and the complexes of fisheries research laboratories (about $\$ 12$ million), and Navy laboratories (about $\$ 5$ million). Although there are exceptions to the rule, it may generally be assumed that funds given to university laboratories support mainly basic research while Federal laboratories are engaged in projects of application to the mission of the parent agencs. During the formative years of the national oceanographic program, almost no research funds passed from the Government to industry except in an indirect manner (i.e.. design and fabrication of instruments for university research contractors, etc.). However, in fiscal year 1965 nearly \$2 million is scheduled for industry on direct Federal contract for research excluding the Mohole project. At the same time an increasingly large share of the research (including instrumentation design) budget passes indirectly to industry through Federal and non-Federal laboratories. It is estimated that at the present time industry receires over $\$ 10$ million in research and instrumentation contracts annually - a healthy trend.

\section{Mr. BA DER. Thank you, sir.}

Mr. Lennon. Thank you, Dr. Wakelin.

We appreciate your attendance here this morning and we certainly wish you well and regret that you will not be back in your capacity as the head of ICO. Our only hope is that your successor will be as dedicated, knowledgeable, and interested as you have demonstrated over the years.

Dr. WAKeLrN. Thank you very much, Mr. Chairman.

Mr. Lennon. It is indicated here that our next witness is Mr. Donald L. McKernan, Chairman, Interagency Committee on Oceanography, Panel on Instrumentation and Facilities. We have had him here before us many times and I might say he wears a number of hats.

We are glad to have him here again in this official capacity. 
STATEMENT OF DONALD L. MIKERNAN, CHAIRMAN, INTERAGENCY COMMITTEE ON OCEANOGRAPHY, INSTRUMENTATION, EQUIPMENT, AND FACILITIES PANEL

Mr. McKernan. Mr. Chairman, I greatly appreciate the honor today of appearing before you as a member of the Interagency Committee on Oceanography and as its Chairman on Instrumentation and Facilities.

Before proceeding with my remarks, Mr. Chairman, I want to take this opportunity on behalf of the Department of the Interior to echo the sentiments expressed by a number of members of this committee for the wonderful work of, and the fine opportunity it has been for us in the Department to work with a public spirited citizen such as Secretary Wakelin.

We in the Department think it is going to be difficult for our Government to replace a man of his dedication and foresight.

We think his contribution to the Nation is going to be recognized, perhaps in future years, even more than it is today. It has been a privilege for me to work with him and observe his dedication and understanding of the problems of oceanography as they relate to our Department.

This has been greatly appreciated by the Secretary of the Department of the Interior and those of us in the Department who have been working with him.

Mr. Chairman, I have a statement of several pages in length but in order to save time you might want to put the statement in the record and allow me to comment briefly on my impressions of the progress and the problems remaining in the general field of coordinating the instrumentation work of the ICO.

I am at your disposal, Mr. Chairman.

Mr. Lennon. Mr. McKernan, we have heard your off-the-cuff discussions before and I think perhaps it would be as effective and as informative if you did just that with the understanding you can go through your prepared statement and use any part of it you would like. However, you can put the full statement in at the conclusion of your remarks.

Mr. McKernan. Thank you, Mr. Chairman.

Before starting, I would like to refer the committee to page 4 of my statement. The present membership of the committee is indicated there.

I am very fortunate, Mr. Chairman, in having a number of these people, or their alternates, present with me today so that, if the committee wishes to ask more specific questions requiring intimate technical knowledge of the field of instrumentation, I am sure there are people in the room who can do a creditable job in answering such questions.

Mr. Chairman, as I see the problems of instrumentation, they are something like this: All of us in the Interagency Committee on Oceanography are deeply aware of the costs of putting ships to sea. These are expensive platforms and they are becoming most costly every year. 
We recognize that this means that we must improve our techniques for measuring the properties of the ocean and increase our effectiveness in understanding the sea, if we are going to spend the funds allotted us in the most efficient manner.

Therefore, this whole matter of instrumentation and of mechanizing the instruments aboard ship, and of getting the most accurate measurements possible for the greatest number of scientists in various disciplines, is of the utmost importance.

Essentially then, the Panel on Instrumentation and Facilities is devoted to the task of (1) attempting to recognize the problems of instrumentation which occur in measuring rarious physical, chemical, and biological properties of the sea and $(2)$ seeing how we can resolve these problems and make the necessary measurements most effectively and with increasing efficiency.

As I see the task of this Panel, it is essentially to pinpoint these problems and to try to provide some leadership and stimulus in finding solutions for them.

The Panel has devoted a good deal of time to this and I rould suppose that in the matter of time each of us associated with the Instrumentation and Facilities Panel as given a significant amount of his daily effort to the task. I have been fortunate in having one or two specialists on instrumentation within the Bureau of Commercial Fisheries who have put in about one-half of their time on instrumentation and associated ICO duties.

The Panel has attempted to find out what each agency is doing in the field of instrumentation research in order that we do not duplicate one another. In the field of instrumentation, the matter of duplication of effort is perhaps more serious or could be more serious than in most other areas. For example, many marine scientists want to measure temperature accurately and record temperature measurements along with a number of other parameters in the ocean. Therefore, it is very important that good communication, especially between these various scientists, be achieved. We have attempted to do that and in this field I think we have achieved considerable success. Mr. Chairman.

We have tried to encourage the cooperation and coordination of work in various fields, such as the development of buoys which can monitor various properties in the ocean.

We have worked very closely with the National Academy of Science Committee on Oceanography in studying particular instrumentation problems.

As I believe was mentioned in response to a question asked of Dr. Wakelin just before I came on the stand, Mr. Chairman, we have been fortunate in having some of the Nation's best instrument people as advisers on our Panel.

Mr. Allyn Vine of the Woods Hole Oceanographic Institution is a recognized authority in this field. He has been an adviser on our Panel and attends a considerable proportion of our Panel meetings. He consistently has been available when we have special problems.

I am sure that the committee understands from the testimony of the tro preceding witnesses that there are many problems remaining and that coordination is not completely effective and probably never will be, but from my point of view as a member of the ICO, in addition to being Chairman of this very important Panel, our accomplishments are significant and of importance to the Nation. 
Even so, there has arisen from our meetings and from our increased communications with one another an awareness of additional and unsolved problems in the area of review and coordination of instrumentation research and development especially.

For example, the matter Mr. Rogers mentioned about choosing priorities and critically reviewing each Department's instrumentation and facilities programs. I think it would be a mistake for us to come before this committee and indicate that we have accomplished the ultimate in striking priorities or critically reviewing programs. I think all of us and all of the panels are still struggling mightily with the problem of both reviews and priorities. However, as a first step, we have improved communications between departments and laboratories in the field.

For example, Mr. Chairman, in the case of instruments, many of us feel, and in fact perhaps all of us feel, that greater interagency coordination in standardization and calibration of instruments is needed, first on a national scale and ultimately, I might add, on an international scale.

I could give as an example the Indian Ocean where ships of many nations have been engaged in physical and biological oceanographical research. If the measurements they obtain are going to be useful in plotting physical and biological properties of the Indian Ocean and studying the way these currents affect the living organisms of the ocean, obviously the instruments used to take these measurements must be calibrated one with another.

If good calibration or standardization of measurements is not achieved, then it is very difficult to combine the data from the ships of various nations. Therefore, this matter of inter-calibration and standardization of equipment and methods is of extreme importance in multiship operations.

We have not been totally successful, even in our country, in this regard, but I would offer for the committee that we have been so much more successful than we ever have been in the past that our progress is good. But, it is our aim to go a good deal further in the field of standardization and calibration of instruments.

I believe planning for future instrumentation and facilities research and development has progressed very well. We have plans developed, not only for this year and next year, but tentative plans for several years. These are not firm, hard plans, yet, Mr. Chairman, but on the whole they show interest by all agencies engaged in ocean research to get together and to think about problems of instrumentation and facilities in the future.

Of course, we are being pressed to do the job better by current limitations of our budget. I am sure that the efforts will stimulate us to even greater efforts.

I mentioned the matter of improved communications as being one of the greatest accomplishments of our panel on instrumentation, and I think other panel chairmen would say the same thing in other fielòs of oceanography. The matter of knowing what the Navy and the Coast Guard plus various private and university laboratories are doing in the field of instrumentation is of the utmost importance and saves the time and effort of highly skilled scientists in all agencies involved. 
The matter of stimulating effort in this field and of providing the kind of leadership necessary to encourage cooperation in this particular field has not been perfectly worked out yet. I am somewhat dissatisfied with my own efforts in this regard and I believe that other members in my panel feel the same way. This comes about because of the compromises we must make between panel duties on one hand and the duties of our regular positions on the other. Even so, with all these limitations, it seems to me that the Interagency Committee on Oceanography and its panels and advisory groups of university and industrial scientists provide about the best mechanism I can think of for producing the kind of leadership, planning, and cooperation Government and scientists must put forward in this general field of instrumentation and facilities.

The whole problem of our national effort in instrumentation and facilities, in my view, is not going ahead as fast as I would like to see it, nor as fast as we had planned. Not all of this is due to the lag in the budgetary process. Part of it is due, perhaps, to the high goals we set for ourselves and part of it is due, perhaps, to the other urgent problems of the day that have arisen as we have moved into the field. Even so, it seems to me that the progress in the field of instrumentation has been rather remarkable in the last 5 years. Not all of this, of course, is due to the Interagency Committee on Oceanography and its work, but I believe that it can take credit for a good deal of the interest in both industry and in Government and the coordination between industry and Government, as well as within Government, that has occurred.

In the future, Mr. Chairman, there will be a challenge for marine scientists everywhere, and especially for those in our own country, to keep our eminence in the field of marine instrumentation. There is also a challenge in developing new instruments to take advantage of the fundamental knowledge of the sea in order to mine the seas, both for minerals and for living resources. There needs to be renewed emphasis on the ocean-engineering phase of our national oceanography program in the very near future. This appears to be the next step in our national effort.

Tre have been giving some thought to the problems of ocean engineering. Many of us are planning on a small scale to more into this particular field of especially applying the fundamental knowledge we are gaining of the world ocean to the problems of practical importance in defense, fishing, mining, commerce, and weather to a greater extent than in the past.

Mr. Chairman, I very briefly have given you my general impression of our progress since I last appeared before you in the field of instrumentation and facilities and I will be very pleased to answer questions on either my brief statement or on my written testimony.

Thank you, Mr. Chairman.

Mr. Lennon. Thank you, Mr. McKernan.

Gentlemen of the committee, Mr. McKernan, as you all know, is from the Bureau of Fisheries and I hope all of you will take the time to read his fine statement in its entirety.

Without objection, your prepared statement will be placed in the record immediately following your testimony.

Mr. McKernan. Thank you, Mr. Chairman.

Mr. Lennon. Are there any questions, Mr. Casey? 
Mr. Casey. Yes, Mr. Chairman.

I notice the primary purpose, or one of the primary purposes, you mention in your statement is the standardization of equipment, calibration, and so forth, as well as better methods of testing calibration. In this exchange, you also mentioned international exchange of information. You mentioned briefly proposed instrumentation is a classified file limited to Government personnel only.

Do we have any developments that are considered of such importance to the national defense that they should be highly classified?

Mr. McKernan. Mr. Casey, there is a type of work, of course, that is done by the Navy, of a classified nature which inrolves defense aspects of oceanography. This is not at the present time under the purview of the Interagency Committee on Oceanograplyy. Our exchange of information and exchange of calibrated instruments are those of an unclassified nature. We benefit from these exchanges as Tell as other countries.

It is true that the exchange of information is not equal at the present time among all countries, but there is developing quite an actire exchange of information between ourselves and other countries, including the United States and the U.S.S.R. This is of an unclassified nature in respect to instruments and facilities in our case and also includes unclassified data.

Mr. Caser. I notice we have a joint project with other nations, including the U.S.S.R. in the Indian Ocean. I presume the objectives that are being pursued there and the instrumentation that is bein developed in conjunction there is something that is of general use to peacetime purposes?

Mr. McKernan. In my own field of fisheries, there is little known about the fisheries of the Indian Ocean. Interestingly enough, there is a great interest by the U.S. fishing companies in the fishery resources of the Indian Ocean. There are several major U.S. companies that are establishing stations in the Indian Ocean at the present time and some of these are using data which is coming out of the Indian Ocean expedition.

By the way, the Russian scientists have done a great deal of fishery exploration there, and we are still trying to pry data loose from them on this.

Mr. CASEY. I was going to ask you that. There has been a lot in the papers on that and they have developed this possibly more highly than we have in the commercial fisheries field, including instrumentation of the ships they have where they make their catch and do everything to it they possibly can do on shore, so that when they come in, some of it is already canned and some of it is being prepared for fertilizer as well as edible products. Have you had an opportunity to review any of this instrumentation?

Mr. McKernan. Yes, we have had an opportunity to see some of this. We have had a good opportunity to discuss this matter with Russian scientists and in several areas of the world we are exchanging information rather completely with them on these particular matters.

For example, there has been an international expedition in the tropical Atlantic, and the Soviet Union and the United States, as well as other countries, have rather freely exchanged fisheries and hydrographic information that has been collected on this particular pro- 
grani. It has been a rather successful international effort. It may lead to additional successful efforts because I think it has reduced suspicion and so forth among many nations. It is pretty obvious to me that we cannot afford to do everything that needs to be done every where. If we can encourage other nations who are also interested in the sea for various purposes to carry on part of these particular studies, and then allow us to examine their data, and if we are smart enough and sharp enough we will use this to our advantage, both for our national defense and, in my own case, for utilizing the resources of the sea and improving the standing of our commercial fishing industry.

Mr. CASEY. Do we have any national goal in oceanography such as wo had in the space program?

Mr. McKernan. Yes; these have been generally spelled out, Mr. Casey, in our published programs. In our national oceanographic programs of various kinds, we have rather clearly spelled out the goals of our country in oceanography.

Mr. Caser. Do we have any of the kind of thing that has caught the public fancy, such as the space program has? As you well know, the space program could not begin to get the support it now has unless it caught the public fancy as it did with its boldness in new exploration and arlienture as well as the defense aspects and the scientific aspects. Of course, NASA is supposed to be purely a peacetime effort, purely for scientific knowledge and to broaden man's horizon, but by the same token we all know it has a very definite place in defense.

Of course, the Defense Department is in this to a great extent and the manned orbital laboratory is going to be a defense project or a NASA project.

Mr. MCKERNAN. We think the objectives in oceanography are the most exciting objectives in any of the fields in which our Government is carrying out research and development.

We put this in various forms in our publications on oceanography, such as the long-range oceanographic program from 1963 to 1972 . This, briefly stated, is the national goal: to comprehend the world ocean, its boundaries, its properties, and processes, and to exploit this comprehension in the public interest and for the enhancement of our security, culture, national posture, and our economic growth.

Mr. CAser. Do you have any films or anything like that other than this publication? In other words, I am interested in trying to get some real stimulus behind this program because $I$ think it is that important. I really do.

Mír. McKernan. I share with all of our committee members in being very pleased at your interest. Yes, we do have some films and we have developed film strips. There is a film that was mentioned, I beliere, by Secretary Wakelin that we would like to show if the committee has time before it adjourns this hearing. I think it is a very good one.

Mr. CAsex. There are 435 men who occupy seats here and who get called on for speeches before civic clubs, ladies' clubs, and business groups and I think if you would let them know that some of those films are available, there might be a little free publicity.

Mr. McKersin. I think that is a very good idea and I am sure that those of us on the committee, and perhaps Mr. Abel will take this adrice to heart, Mr. Casey. 
Mr. CASEY. Thank you.

Mr. Lennon. Mr. Pelly?

Mr. Pelly. Thank you, Mr. Chairman.

Mr. Lennon. Off the record a minute.

(Discussion off the record.)

Mr. Pelly. Mr. Chairman, I will ask my question afterward because it deals more with an item of personal interest in fisheries.

Mr. Lennon. He will be around. Thank you, Mr. Pelly. That is very helpful.

Mr. Keith?

Mr. Keirн. Thank you, Mr. Chairman.

Mr. McKernan, I am interested in your reference to more shorebased facilities. I believe you made a recommendation for more of these on page 16 of your testimony?

Mr. McKernan. Yes, sir.

Mr. Кеттн. You say-

* * * Existing oceanographic centers need to be expanded so as to extend the capabilities of their personnel. Large new marine technological institutes specializing in the various engineering aspects need to be established. An example of such a base is the proposed Interior Oceanographic Base at Tiburon, Calif., now occupied by skeleton planning groups from three agencies. Emphasis here will be in scientific research, engineering research, surveys, and monitoring. Logistics, data handling, monitoring, and instrumentation will also be undertaken.

I am a little concerned about your survey in this booklet headed "University Curriculum." There is a tremendous amount of educational talent available to oceanographers throughout the length and breadth of this country. It would seem to me that since these institutions are meagerly funded at the moment, to start another oceanographic base might just spread even thinner the funds available. Perhaps further development of such places as Scripps, TVoods Hole, and the University of Rhode Island, American University, and the University of Washington would be better.

At any rate, I would like to have you speak for just a moment, if you would, on why we need to have an entirely new base when we have existing facilities that perhaps could be further strengthened?

Mr. McKernan. Of course, this matter of strengthening our existing facilities is a matter of concern to us with the emphasis now on economy. We are not proposing an immediate implementation of this particular plan. This is an example, in a way, of our dream. We see the need for larger centers very near the ocean that can handle certain kinds of instruments and certain kinds of data very efficiently. For example, one of the plans we had for this particular base-incidentally, it is a Navy base, a part of which, at least, has practically been turned over now and which we are simply operating with a skeleton staff-we can see information about the ocean in the eastern Pacific or eventually throughout the entire Pacific being put into computers and used in predicting ocean weather as well as the atmospheric weather on the west coast of our United States much more accurately, from the Aleutian Islands, perhaps south to the Equator.

We have done this on an experimental basis at the present time and we find that there are techniques becoming available to us which show tremendous promise for improving the predictability of fish catches and concentrations of fish along our coasts as well as the 
ability for better weather prediction, long-range weather prediction, and such things.

Mr. Kеiтн. Thank you, Mr. McKernan. I will pursue this later.

What I am primarily concerned about is the possibility of duplication, a thinning of our effort, a vitiating of our effort, and therefore, the ability to handle the problem.

Mr. McKernan. We are considering this, Mr. Keith. We certainly will keep this in mind.

Mr. Kerth. Thank you.

Mr. Lennon. I might say, Mr. Keith, as Chairman of that particular panel on Facilities, Equipment, and Instrumentation, Mr. McKernan's prime responsibility is to see that there is no duplication in any of these fields.

Mr. BAUER. In your statement on page 13 you mentioned that we have a prototype of a national center for testing, calibration, and standardization of oceanographic instruments in the Navy Oceanographic Instrumentation Center. What are the current plans of your Panel with respect to the development of a national center that you have mentioned?

Mr. McKernan. It is the Panel's intention to establish a National Instrumentation Center. The plan is as follows:

(1) Study the operation of the present Naval Oceanographic Instrumentation Center and the degree to which it meets the needs of other agencies.

(2) Establish a National Oceanographic Instrumentation Coordination Unit, primarily an information exchange office, with the Navy Instrumentation Center providing instrumentation services on a national level.

(3) With increased experience and, if agreement among agencies can be obtained, expand the Navy Center so that it is truly national in character.

(4) If such agreement cannot be reached, request funds to establish a separate national center under the auspices of the Interagency Committee on Oceanography.

It is not intended that individual agencies ever be prevented from developing specialized instrumentation capabilities to meet particular mission requirements. The operational procedures of the Coordinating Unit are being developed in the form of the information exchange system described on pages 6 and 14 of my prepared statement.

Mr. BAUEr. It has been of concern to this committee for some years, as you know, as to the method for utilizing ships-of-opportunity, and by that I mean vessels that are under the American flag sailing the high seas of the world. Does the Panel have any plans for completing a suit capable of instrumenting these ships-of-opportunity?

Mr. McKernan. Yes, the Panel is preparing instruments which can be used on ships-of-opportunity. The problem here is trofold. The first task is to provide instruments designed to require very little time, no special skill, and no alternation of vessel operation; they must also provide data of unquestionable quality. The second is to insure that the oceanographic centers ashore are capable and organized to receive and handle the data so gathered; some work on the design and programing of the equipment of their data centers is required. 
The Panel plans to use indicating rather than recording devices until automatic position indicating equipment is available. It is hoped that these will come with the advent of the data relaying satellites which may be operational by 1970. At that time the satellites will interrogate the shipboard recorders and relay the ship's position and observed data back to the data center. The instrument suit for ships-of-opportunity was described on pages 405 and 406 of the "Proceedings of the Gorernment-Industry Oceanographic Instrumentation Symposium." Our progress to date in obtaining this instrumentation has been as follows:

Item 3. Electronic bathythermograph with associated winch-wire boom-recorder-readout assembly: It has been found that the industry funded and developed expendable bathythermograph mentioned on pages 10 and 11 of my prepared statement may do the job as well and require far less shipboard equipment and skill.

Item 4. An automatic recording sea-surface temperature probe: A standard sea-surface temperature indicator is being developed through the cooperative efforts of the Naval Oceanographic Office, Coast Guard, Weather Bureau, and Bureau of Commercial Fisheries. Data from this device will be entered into the quartermaster's logbook along with the ship's position and pertinent meteorological data. Operational evaluations are underway now and more are contemplated in the nezt fiscal year.

Item 5. Meteorological instruments: The Weather Burean already has in use on ships-of-opportunity the following instruments:

(a) Wind direction and relocity indicators (still in limited use).

(b) Barographs or barometers.

(c) Air temperature indicators. air.

(d) Various instruments for measuring the moisture content of the

The other four devices listed in the proceedings; that is (1) the sounding set, (2) the precision depth or graphic recorder, (6) the towed magnetometer, and $(7)$ the shipboard wave height measuring or recording device are not yet in stages applicable to ships-of-opportunity.

Work on these four derices is being held in abevance until other work is completed. The Naval Oceanographic Office is developing instrument suits for oceanographic survey ressels and for the shipboard oceanographic synoptic observational networks. It is hoped that the instruments dereloper for these other uses may lead to devices applicable to ships-of-opportunity. Progress depends on individual agency priority and on the availability of funds.

Mr. Lennon. Thank you rery much, Mr. McKernan, for your presentation.

Mr. MoKernan. Thank you.

(Mr. McKernan's prepared statement follows:)

Statement of Donald L. McKermat, Chairman, Interagency Committee on Oceanography, Instrumentation, Equipment, and Facilities PaNel

Mr. Chairman and members of the subcommittee, I am very happy to ha re the opportunity to describe the progress the Instrumentation, Equipment, and Facilities Panel has made since our meeting 2 years ago. The principal objectives of this Panel are (1) To give impetus to the development of instruments and instrument ssytems for oceanographic research and surveys, (2) to encourage coopera- 
tion and coordination in these areas by the entire oceanographic community, and (3) to coordinate the development of shoreside facilities.

The investment in oceanographic instrumentation has grown substantially in recent years. You might ask, "Why do we require this new equipment and what are we doing with it?" The present-day scientists requires new and sophisticated instruments to determine the nature of the seas and their boundaries, to conduct work on and in the seas and to exploit them more effectively. For his studies the scientist needs samples of the water, the bottom, and marine life. He requires new instruments to investigate special phenomena, such as weather, earthquakes, and tsunamis, and the effects of storms on our shores. An understanding of these will lead to a keener comprehension of the forces at work on our planet, improved prediction and warning networks, and eventually, possibly, some control. The latter will not be easy to accomplish. Military, construction, and other engineers are using a great variety of new instruments in an immediately practical way to defend our shores and shipping lanes, to build bridges, worldwide cable networks, tunnels, and to drill oil wells, to fish, navigate, salvage, search, and rescue, to secure our coasts from erosion, and to protect life and property against the sea.

It is often necessary to wrestle heavy gear and equipment over the side, in all types of reather, sometimes at the risk of the instruments, and indeed of life and limb. So they must be exceedingly durable and able to withstand such hazards. Many times the available equipment cannot measure as precisely as desired, or its reliability cannot be depended upon. For esample, scientists of the Bureau of Commercial Fisheries compared tuna food caught in a net to that found in the tuna stomachs. They found little correlation between what the tuna has eaten and what the net has collected. Why? Improper sampling techniques may have been used-the tuna food organisms can avoid the net. More accurate plankton nets and midwater trawls must be designed, and this is being done.

A geologist samples the bottom of the ocean. He brings up a few pounds of material containing a valuable mineral. How representative is this sample of that section of the bottom? At present the answer is expensive to obtain.

We had difficulty in locating the Thresher which sank in deep water. Navy's search and rescue operations require an entirely new and specialized field of instrumentation. The Public Health Service, concerned with pollution, must detect and measure very dilute amounts of pollutants, such as pesticides and radioactive materials. This requires very exact methods and specialized instrumentation.

The master of a passenger vessel wants to make the quickest and safest passage possible. Which route would be optimum for avoiding adverse currents, sudden storms, or heavy seas? We must have instruments that will give us instantaneous observations of weather and ocean conditions for large areas of the oceans. Both reports and predictions are necessary.

These are just a fer of the reasons why oceanographers go to sea, and why they need instruments. The immediate need for accurate and reliable instruments is great. Improved instruments that require less maintenance, less attention, and perform several operations at the same time, will release scientists from routine tasks and make their hours more productive. Autonation has barely come to oceanographic instrument design.

These are some of the problems that have occupied us. Mr. Chairman. I hope to tell you briefly some of the ways we have gone about solving them, what we've accomplished, and what we're planning for the future.

\section{PANEL MEMBERSHIP}

All Government departments and agencies having an interest in oceanographic instrumentation are represented on this Panel. Liaison with non-Federal scientists is maintained through observers from the National Academr of Sciences' Committee on Oceanography. In general, the Panel members are the top instrument specialists of their organization.

For the record, present membership of the ICO Instrumentation. Equipment, and Facilities Panel is as follows:

Army : Coastal Engineering Research Center, observer, Leo C. Williams. Atomic Energy Commission, Armold B. Joseph; alternate, Dr. John. N. Wolfe. 
Commerce :

U.S. Coast and Geodetic Survey, Anthony J. Goodheart; alternate Theodore V. Ryan.

Bureau of Standards, observer, Mr. Joshua Stern.

Health, Education, and Welfare: Public Health Service, Dr. James L. Verber; alternate, Dr. Allen Hirsch.

Interagency Committee on Oceanography, observer, Mr. Robert B. Abel.

Interior: Bureau of Commercial Fisheries, Donald L. McKernan, Chairman; alternate, Dr. Julius Rockwell, Jr.

National Academy of Sciences, Committee on Oceanography : observer, Allyn C. Vine; alternate, Richard C. Vetter.

National Oceanographic Data Center: observer, Dr. Woodrow C. Jacobs.

National Science Foundation: Dr. Richard G. Bader.

Office of Naval Research, Feenan D. Jennings.

Nary Oceanographic Office, Gilbert Jaffe, alternate, Capt. T. K. Treadwell. Smithsonian Institution : observer, Dr. H. A. Fehlmann.

Treasury : U.S. Coast Guard, Lt. Comdr. Richard M. MIorse.

\section{WAYS OF ACCOMPLISHING OBJECTIVES}

During the past 2 years a formal procedure for an annual review of the instrumentation and facilities section of the national oceanographic program has been inaugurated. We have found this annual process to be not only a rather good program review, but also an excellent mechanism for information exchange and coordination among Panel members.

Another important means of coordination is accomplished at Panel meetings when experts are invited to brief the Panel on subjects of general interest. Recently a group from NASA's Goddard Space Flight Center explained one method bs which data could be relayed from ocean platforms back to data centers via satellites.

Still another method is through small ad hoc working groups assigned to study special aspects of instrumentation and report to the Panel at intervals. One recently appointed group is gathering information on buoys, another on data collecting satellites, a third is determining how ocean engineering is serving and can better serve the oceanographic community.

Because of recent progress and developments, some emphasis has been directed to providing and encouraging an information exchange system to keep us informed of accomplishments, progress, and plans in oceanographic instrumentation and facilities. Following are projects of rarious Panel members to facilitate information exchange and coordination:

(a) Descriptions of oceanographic instruments that have been made and used (Encyclopedia of Oceanographic Instruments).

(b) A file of specifications of oceanographic instruments (those that have been made).

(c) Descriptions of oceanographic instruments that are being dereloped (inhouse and contracted).

(d) Proposals to develop oceanographic instruments (a privileged file for Federal use only).

(e) Descriptions of instrument needs.

(f) List of existing noncommercial marine science laboratories.

(g) List of planned noncommercial marine science laboratories.

\section{ACCOMPLISHMENTS OF THE PANEL}

Two years ago, during my testimony before this subcommittee, mention was made of the Gorernment-Industry Oceanographic Instrumentation Symposium held in August of 1961. Since that time the proceedings of this symposium have been published and are for sale. Copies are arailable here for the members of this subcommittee. Nearly all of the general concepts and principles set forth in this publication are still current as are most of the data.

Staff members have found the proceedings a useful medium for introducing a company to oceanographic instrumentation. Partly as a result of this and partly as a result of the Panel's contacts with industry, some firms have aggressively exploited their oceanographic capabilities, and are now working in this field. 
The proposal and capability file estabiished for the Panel by the National Dceanographic Data Center has been increasing steadily in size. Lists of titles of proposals in this privileged file are distributed semiannually to Panel members and to others in the Federal Government who need this information. The file has recently been transferred to the Navy Oceanographic Instrumentation Center. In the future a copy of each proposal sent to the Federal Government on oceanographic instrumentation will be forwarded to that office.

This file, now comprising some 300-odd proposals, prorides raluable source information for Federal administrators and engineers who are embarking on new programs, and who need to locate companies with specific and highly specialized capabilities. As it now exists, this file is quite useful; when it is fully implemented it will be a major factor in reducing redundancy in the development of oceanographic instruments and will provide a coordinated and easily accessible source of information on the rast array of engineering skill and potential of American industry.

The exchange of useful oceanographic data between agencies and nations in our international programs is dependent upon the standardization of equipment. The Nary Oceanographic Instrumentation Center has an established procedure for testing and calibrating precision deep sea reversing thermometers and is performing this service for its own scientists and those of the Bureau of Commercial Fisheries, Coast and Geodetic Survey, Coast Guard, Naval Research Laboratory, and the Lamont Geological Observatory (Columbia University). The calibration of salinometers is now being undertaken for the Coast Guard. The Nary Oceanographic Office's instrument specifications are being used by other agencies for procurement purposes.

The ever-increasing number of instances of cooperation and integration of efforts by member agencies is considered a significant accomplishment of this Panel. Some examples follow :

1. In the derelopment of its acoustic flowmeter the Coast and Geodetic Survey used the test facilities of the Coastal Engineering Research Center of the Army Engineers. During these tests CERC not only materially assisted the Coast and Geodetic Service in an experimental project, but became acquainted with a system of potential ralue in their studies of erosion and its effect on breakwaters and jetties. This very sensitive device can measure minor current fluctuations in turbulent areas, thus permitting a better understanding of the eroding tendencies of currents along our shores and in our harbors.

2. The Public Health Service is now represented on our Panel. With other member agencies, it undertook a joint review of available instruments to measure and analyze currents. The knowledge thus gained permitted the undertaking of a significant study on the dispersion of pollution by deep currents in Lake Michigan.

3. Coast Guard's recent cooperative participation in oceanography has been largely stimulated by its membership in ICO. Some examples related to the work of this Panel include: Establishment and support of meteorological buoys in the Gulf of Mexico for the Weather Bureau and the Bureau of Naral Weapons, use of sereral ocean station ships for special studies by the staff of the Antisubmarine Weapons Environmental Prediction System (ASWEPS) of the Naval Oceanographic Office, and evaluation of an electronic bathythermograph and a sonic wave height sensor in cooperation with the same Office.

4. A recent project, illustrative of the type of informal cooperation encouraged by the Panel, is the development of the expendable bathythermograph. This type of device is cast over the side of a moving vessel and sends back signals from which can be derived a plot of temperature against depth. The need for such a device was included in one of the lists of required instruments in the proceedings of the Panel's instrumentation symposium. As a result, companies undertook its development with their own funds.

By the end of the next fiscal year, operational eraluations of these expendable BT's will have been completed by the Navy Oceanographic Instrumentation Center, the Bureau of Commercial Fisheries, the Bureau of Ships, and possibly by the Coast and Geodetic Survey. Although the requirements of each of these agencies are slightly different, it is hoped they ean be met by one instrument. which can be easily and cheaply produced. If so, a substantial advance will have been made over the conventional bathythermograph which has been serving the oceanographic community unchanged for the past 27 years.

The end point of this development will be an automatic system than can function from all types of oceanographic platforms : buoys, ships, eren aircraft. 
5. In some cases it is more desirable for agencies to monitor work done by one agency while concentrating their development efforts elsewhere. The development of large, multipurpose, telemetering buoys by the Office of Naral Research is recognized by the ICO as the Government's primary buoy development effort.

The progress in this single, large contract is reported at intervals to the members of a Guidance Committee, representing Government, academic institutions, and private industry. Such meetings insure that all pertinent information is incorporated into the design of a truly multipurpose buoy.

When completed it will become the basic unit for the large synoptic buoy networks to monitor a great variety of parameters vital to the forecasting of sea conditions and long-range weather phenomena essential for national defense, commercial fisheries and other research and operational programs.

6. Other buoy developments are proceeding for small or highly specialized applications, such as the submerged stable instrument platform of the Coast and Geodetic Survey and the jointly sponsored Office of Naval Research-Bureau of Commercial Fisheries-Scripps Institution of Oceanography lightweight current and temperature recording buoys.

This Panel has encouraged the concept of locating major Government oceanographic laboratories near academic institutions or as interagency complexes, whenever this is in the best interest of all concerned. Usually, there are many advantages: Academic stimulation, cooperative use of vessels, libraries, laboratories, and other expensive facilities and equipment, participation in joint research activities, free exchange of scientists and technicians, etc.

Oceanographic Jaboratories generally use and assist the facilities of other groups in their local areas. Visits and cooperative programs are encouraged between scientists from more distant laboratories, from educational institutions, industry, and also foreign countries. For example, the Bureau of Commercial Fisheries Biological Laboratory at San Diego has been working closely with the Naval Electronics Laboratory and a local company in an attempt to develop a sonic fish locating and identifying device.

The new BCF Laboratory, now under construction on the Scripps campus, will provide Laboratory and office space for the Geological Survey and the InterAmeriean Tropical Tuna Commission.

Four bureaus in the Department of the Interior, Geological Survey, Bureau of Mines, Bureau of Sport Fisheries and Wildlife, and Bureau of Commercial Fisheries are planning the establishment of an Interior Oceanographic Center at Tiburon, Calif., which has the enthusiastic support of the local scientific community.

In January 1963, the Navy formally dedicated its Oceanographic Instrumentation Center, here in Washington. This facility, established with ICO support, is being studied as the prototype of a national center for testing, calibrating, and standardizing oceanographic instruments.

\section{FUTURE PLANS}

The major task before the Panel in the future will be to continue coordinated planning to define immediate and long-range needs for major oceanographic facilities and equipment and to accelerate the Government's oceanographic instrumentation and ocean engineering programs.

The development of adequate test and valuation techniques is becoming increasingly important. Industry is now not only developing good instruments but also preparing programs on how to use them to excellent adrantage. Not long ago we were making our own instruments; now, we buy them from industry and assist in their development.

A large part of our effort in the immediate future will be the development of detailed test and eraluation procedures to aid the designers and manufacturers. This vital and necessary part of instrument development is expensive in both time and funds. The capability of industry has been well demonstrated. Funds are required in amounts greater than previously realized, both for in-house liailiaison, consumer evaluation, and for development and product engineering by industry.

Ocean engineering is another important aspect of the Panel's future work. A special working group is exploring the role and responsibility of Government in this area of oceanography. We are beginning to recognize the need-indeed, the necessity-for a greater capability by this Nation for operating in and ex- 
ploiting the oceans much more actively and efficiently. We may note that various segments of industry and the academic community hare already started to point the way.

An adequate information exchange system is vital to coordination at all levels from the working scientists and engineers, through the procurement and managerial staffs, to the top policymakers. We plan to continue and expand our efforts along the lines previously mentioned.

The Panel intends to foster the development of interagency instrument systems. Examples of these are:

(a.) National or international oceanwide buoy networks.-Worldwide monitoring systems are necessary to provide synoptic data on weather and ocean environment for predicting and ultimately controlling weather, for more efficient exploitation of our fisheries, and to improve military surveillance and ocean transportation.

(b) Satellite systems.-To relay the data from buoys and other ocean platforms to national and international data centers. The use of satellites to relay data, automatically monitored information and platform location, not only will tie in with the above buoy networks but will aid in the protection of human lives, reporting the position of vessels, life rafts, aircraft, and icebergs. Though expensive, such systems would result in savings in search-for-rescue alone nearly equal to their cost. The feasibility of this technique was dramatically demonstrated by the BCF ressel, the Geronimo, which transmitted oceanographic data to the National Oceanographic Data Center via Syncom satellite.

(c) Sensors.-These very small but key parts of all observational systems are a most critical technical area, requiring further development.

(d) Undersea structures and devices.-With the increasing accessibility of the mesodepths and greater knowledge about the riches they contain, whole new families of devices are coming into being: Small submersible workboats, remote control manipulators, undersea structures, and inhabited stations. Communication, and monitoring networks, mining techniques, midwater and deep fishing methods must be developed. We must increase our effort in the underwater realm.

(e) More shorebased facilities are vital for this effort.--Educational institutions have been meagerly funded. Whole new campuses are required, sea-grant colleges if you will, to train the coming generations in ocean technology, aquacultural engineering, undersea navigation, three-dimensional seamanship, and deep water mining techniques. Existing oceanographic centers need to be expanded so as to extend the capabilities of their personnel. Large new marine technological institutes specializing in the various engineering aspects need to be established. An example of such a base is the proposed Interior Oceanographic Base at Tiburon, Calif., now occupied by skeleton planning groups from three agencies. Emphasis here will be in scientific research, engineering research, surveys, and monitoring. Logistics, data handling, monitoring, and instrumentation will also be undertaken.

This Panel is proud to have had a role in the national oceanographic effort. We believe we have made substantial progress. We are attempting to provide leadership and help coordination in this area of ocean science and technology for all segments of the oceanographic community.

Mr. Lennon. Our next witness is Dr. Arthur E. Maxmell, Chairman of the Interagency Committee on Oceanography Panel on International Programs.

Doctor, we certainly would like to stay here as long as you need to read your statement but I wonder if, in the interest of time, having dictated this statement, and spent a great deal of time in research on it, if you want to read it in its entirety or do you want to go through it and comment on it and put the statement in the record?

I am a little bit afraid that today, for sure, we will get a quorum call right after 12 o'clock. 
STATEMENT OF DR. ARTHUR E. MAXWELL, HEAD, GEOPHYSICS BRANCH OF THE OFFICE OF NAVAL RESEARCH AND CHAIRMAN OF THE INTERAGENCY COMMITTEE ON OCEANOGRAPHY PANEL ON INTERNATIONAL PROGRAIIS

Dr. Maxwell. If it is agreeable to you, Mr. Chairman, I would be pleased just to submit my statement for the record.

Mr. Lennon. We will assume the committee members, even though they are not all here, are going to read it and study it.

Go ahead and do whatever you want to do.

Dr. Maxweld. I would be pleased to submit it for the record and comment on it, and perhaps be available for questions in order to save time.

Mr. Lennox. If there is no objection, Dr. Maxwell's prepared statement will immediately follow his testimony today.

Dr. Maxwell. Mr. Chairman and members of the committee, it is a great pleasure to be here before you again. Personally, I feel that this is one of the most important panels of the Interagency Committee on Oceanography and I think this is particularly so in listening to the committee hearings so far where we have alluded to a great number of questions in regard our international programs.

I think you will also find as we go along that the programs of the Research and Survey Panels all gradually feed into our international programs. I do not think I need to go into any great detail as to why the international aspects of oceanography are so important.

Secretary Wakelin and Mr. McKeman have mentioned many of these and the fact that the oceans are so large and that they belong to no one are facts certainly obvious to all of us. Nonetheless, I think it is true that our international programs must have some sort of theme to them and they must be serving an economic interest and policy matters in order to be useful for the Government and in order to be supported by our Government.

Some of the items that are of particular significance with regard to international cooperation are the various kinds of scientific studies that require the cooperation of many nations. For example, air-sea interaction has been discussed many times this morning and yesterday. If we are to look into the air-sea interaction program, we find that this is a program of global nature and it requires observations from a global area. These cannot be done very easily by any single nation and cooperation of many nations makes it very desirable.

In 1961 our cooperation in international programs in oceanography was considerably enhanced by the formation of the Intergovernmental Oceanographic Commission under the auspices of UNESCO. Since that time, there have been three meetings of the Commission and five meetings of its Bureau. The last meeting of this Commission ended only last Friday.

Mr. MeKernan, your last witness, was the chairman of the U.S. delegation to this meeting. There are two programs which have been 
mentioned several times before these hearings which are formal programs of the Commission. These are the International Indian Ocean Expedition and the International Cooperative Investigations of the Tropical Atlantic.

The International Indian Ocean Expedition started out as an international program developed by the Special Committee on Oceanographic Research, a nongovernmental group, but this was taken over by $\mathrm{ICO}$ at its first meeting in 1961.

The second program, the one on Tropical Atlantic, was one initiated in the United States by the ICO itself. The program looked promising as a national program and, as such, it was submitted to the Intergovernmental Commission for its consideration. It was adopted and has broken down the program into three parts; Equalants I, II, and III, which have already been completed.

The first two of these were carried out in the spring and fall of 1963 and the last was completed only this spring. We have been particularly fortunate in this in that the United States has had a member of the Bureau of Commercial Fisheries as the International Coordinator for this program. In general, the program has thrived under our leadership.

To give you some estimate of the magnitude of these international programs, the Indian Ocean Expedition has had participation by some 40 ships from about 12 different countries. In addition, eight other countries participated with scientific assistance. The U.S. effort in this expedition has been approximately one-third of the total effort and through the end of next year when the Indian Ocean Expedition officially ends, we will have sent approximately 14 cruises to the area and the total cost of these will run in the neighborhood of $\$ 20$ million.

Again, I would like to repeat this is about a third of the total effort in the International Indian Ocean Expedition.

Returning now to the tropical Atlantic, we find in Equalant I, that there were 14 vessels taking part from 7 nations; three were from the United States, three from the Soviet. Union, and other countries that participated were Argentina, Brazil, the Republic of Congo, Nigeria, and the Republic of the Ivory Coast.

In Equalant II, 11 vessels participated from 8 nations and during Equalant III, there were 8 vessels from 6 nations.

As Mr. McKernan told you, one of the very successful things about this expedition was the fact that all of the data collected on Equalants I and II have been received in World Data Center $\mathbf{A}$ located here in Washington. These data have been published in a data report and were made arailable last week to the Intergovernmental Ocean Commission.

In terms of the volume of this raw data amounts to approximately 4 inches thickness. This is a tremendous effort and I do not think there has been any other instance where countries working together in international programs have been able to submit their data so rapidly and make it available for everybody to look at.

In addition to the two programs under the IOC that I have mentioned, there is a third program, the Cooperative Study of Kuroshio adopted only last week as an intergovernmental program.

At the present time the United States has not decided its extent of participation in this. This is still under study by our Government, by the various agencies within the IOC. 
In addition to these formal cooperative programs, there are numerous other informational programs of an international nature. I think perhaps one of the best known is the cooperative work of the Lamont Geological Observatory of Columbia University with South America that has been carried out over the past decade.

Lamont has worked closely with the Hydrographic Office of the Argentine Navy and, as a matter of fact, the results of this cooperative work have provided the basis for establishing and effective oceanographic program in Argentina. This is also true for countries such as Brazil. Chile, and Peru.

Our panel has been in existence since 1962 and its purpose really is twofold: First, to insure that U.S. participation in the Intergovernmental Oceanographic Commission and other international programs proceeds in an aggressire, judicions, and timely manner; and (2) that the panel provides a forum whereby the various U.S. activities in international oceanographic programs have a common meeting point.

This enables the ICO to have a single point where it can be aware of all aspects of U.S. participation in international programs.

To date, most of the efforts of our panel have been restricted to responsibilities the United States has in the Intergovernmental Oceanographic Commission.

This involves making sure we are properly represented by our delegation to the Commission and insuring that the delegation is well prepared. This entails the development of a U.S. position on agenda items of the Commission meetings.

I think it is fair for me to state at this time that the United States in all of the meetings of the Commission and the Bureau has had represenation that has been outstanding and it has been better prepared than any other country attending these sessions. In so doing, it has been able to exert very effective leadership within the Commission.

In addition to the mechanism of the Intergovernmental Commission for coordinating international programs in oceanography, there also exists a nongovernmental group. This is the Scientific Committee on Oceanographic Research under the auspices of the International Council of Scientific Unions. This special committee, SCOR, as it is called, acts as the scientific adviser and conscience to the Intergovernmental Commission. It is this advisory group that looks over the scientific programs of the Commission and also advises the Commission on what it should do.

In the United States, under the National Academy's Committee on Oceanography, there also exists a special committee, the U.S. National Committee to SCOR. This group provides the U.S. input to SCOR and what this does is to allow for a parallel structure both in the Government and outside the Government in national and international programs. As such, this allows complete participation of all scientists throughout the country, those who are working for the Government and those working for the universities.

As I have mentioned, most of the past work of our panel has been in connection with the Commission, making sure we are prepared for this activity. Looking a little to the future, we find several problems facing us that we would like to look into in a little more detail. The first is the problem of international conventions of the sea. This is a very complicated problem as there are many international laws and national laws of various countries that apply. We are trying to 
develop a feeling for this whole problem so that our ideas can eventually be submitted to the Intergovernmental Commission.

Further, there are a number of groups in the country interested in the various international aspects of oceanography. These include the Office of the Foreign Secretary of the National Academy of Sciences, the Office of International Scientific Affairs of the Department of State, and the International Panel of the Federal Council for Science and Technology, as well as our own Panel.

In the near future, we hope to bring all of these people together to discuss problems of oceanography in the international sense and to determine, if possible, whether we are really proceeding in the most aggressive fashion and proper leadership as we should in this area.

With that, Mr. Chairman, I would like to be arailable to answer any questions you might have.

Mr. CaSex (presiding). Thank you, Doctor.

Doctor, how much of the total oceanographic funds are spent in international efforts?

Dr. Maxwell. Mr. Casey, I would say in the neighborhood of less than $\$ 10$ million annually goes into international oceanographic programs. It is difficult to put a firm figure on this since part of these programs are of a formal nature and part of them informal arrangements made between various institutions throughout the country. For example, it is difficult to keep track of what part of a cruise, let us say in the northern Atlantic, is international when it is working with a group from the United Kingdom.

Mr. CAser. You heard the statement of Mr. McKernan that Russia is ahead of us in some aspects of commercial fishing and that they have had no luck in getting any exchange on techniques and data that they have in this regard.

Do you have other phases in which Russia is holding out on the exchange of data?

Dr. Maxweld. IVe have through the International Governmental Commission developed a scheme of exchange of oceanographic information. This has not worked as well as we would have liked but we are receiving data from the Soviet Union on their oceanographic programs. In particular the data so far received has been from the tropical Atlantic investigations.

In addition we have statements from them saying they will submit data from cruises in the Indian Ocean and other cruises they have declared as a part of their national program.

Mr. CASEY. Have they given any data that is new or something we have not been able to obtain for ourselves? Have they given us anything other than a confirmation of something we have already discovered or gotten from some other more friendly country?

Have they given us anything of real benefit to us?

Dr. Maxwell. In the case of the tropical Atlantic, they gave us the data they collected at that time and these data are new data and very useful to us. The program we had in this area involved the Soviets carrying out a significant, finite part. If we did not have information on this, we would have had a gap in our knowledge. They provided this and they have provided it completely in that instance. We have not received data from other areas of the world as successfully as we have from this particular area. 
Mr. CASEY. Does this data have a practical application, or is it of a general scientific nature?

Dr. Maxwell. The data is of a scientific nature, but it has its practical applications.

One of the reasons for our undertaking this study of the tropical Atlantic was to learn more of the fishing conditions off the rest coast of Africa. The data will be very useful in this problem. They are not only data on the physical and chemical properties of the ocean, but biological data and fishing data as well.

Mr. CASEY. Would you say we are getting sufficient return on what we might be exchanging with them?

In other words, are we getting an equal amount back, or are we doing more than we should?

Dr. Maxwel.. On a quid pro quo basis, I would say we are not getting back what we are putting in, but I think we must keep in mind these agreements have only been entered into fairly recently, in the last year or so. The Soviets have promised to send some of their data. Other countries have submitted data in much greater quantities than we, at least per capita. Canada has been one of the largest contributors to the data center.

There are other nations with which we have good relations in oceanography; for example, the United Kingdom, and some of the South American countries, who have not submitted any information.

Mr. Caser. Are we trying to show leadership and good faith in trying to get the others to live up to the agreement, or are we holding back?

Dr. Maxwell. We are trying to do this, but we are keeping a careful eye on what is going on in the situation to make sure these other countries live up to their agreements in this area, and to insure that we are not the only one putting data in.

Mr. CASEY. How long do you think we should go on seeing if they live up to the agreement?

Dr. Maxwell. We have had also from the Soviets a finite time by which they will submit data. I think we should see if they meet their schedules. They have said they would submit some other data sometime in the month of July. This commitment was made after they submitted earlier this year a list of declared national programs.

I might explain about these declared national programs. Once a country declares certain national programs it has underway, it carries with it an obligation to send the results of these programs into the world data centers. It has only been recently that the Soviets declared a large number of these programs with the full intention of sending the data to the world data centers.

Mr. CASEY. Going through your statement rapidly, I notice that the Second World Conference on Oceanography is probably going to be held in Russia ; is that correct?

Dr. Maxwell. That is correct.

Mr. CASEY. In 1966. Where was the first one held?

Dr. Maxweul. It was held in 1959 in the United Nations in New York. This was under the sponsorship of the American Association for the Advancement of Science and UNESCO.

The Commission, at its third session last week, approved the Soviets' offer to hold the next International Oceanographic Congress in the 
Soviet Union under the auspices of UNESCO. This wil be held probably in 1966-the spring of 1966.

Mr. CaSeY. Do you think their cooperation merits that sort of an honor?

Dr. Maxweld. With regard to their participation in the Commission, certainly along with ourselves, they have been one of the leaders in this field and have encouraged many other countries to develop programs, both national programs, and international programs in oceanography. I think the Soviets are making a genuine effort in this field to cooperate with us. We have learned a lot from them. We have had an exchange of personnel between our ships and their ships. I think this is good for oceanography for the two countries to do this.

I think they deserve the recognition of holding the second congress in the Soviet Union.

Mr. CASEY. Thank you very much, Doctor.

Tomorrow we will hear from Dr. Wallen and Commander Nygren, and Captain Treadwell and Dr. Jacobs.

We will resume our hearings tomorrow morning at 10 o'clock.

(Dr. Maxwell's prepared statement follows:)

Statement by Dr. Arthur E. Maxweld, Head, Geophysics Branch of the Office of Naval Research, and Chatrman of the Interagency Commitree on Oceanography Panel on International Programs

Mr. Chairman and members of the committee, it is a great pleasure to appear before you as Chairman of the Panel on International Programs. Personally, I feel that this is one of the most important panels of the Interagency Committee on Oceanography.

The oceans like the atmosphere are amenable to international cooperation because events which happen in one portion may have far-reaching effects at remote locations and great distances. For example, changes in the oceanic circulation off the coast of Florida may produce a profound effect at a later time off the coast of Norway. This, plus the facts that the sheer size of the ocean and that it belongs to no particular nation, makes it particularly conducive to international scientific cooperation. In spite of these factors, scientific cooperaivis in oceanic research will be practical only when the sums of the scientific, economic, and political benefits are useful. Obviously, the science would not be good unless the scientific programs are sound and yet sound programs may not likely be supported unless they serve the government's needs in economics or politics. Nonetheless, experience has shown over the past decade or so that many scientific programs in oceanography fulfill these requirements. Many instances can be cited where international cooperation in oceanic research has been useful. For example, it has speeded up the exploration in areas where little has been known. The International Indian Ocean Expedition and the International Cooperative Investigations of the Tropical Atlantic are both examples of this type of program. We would have had no more than cursory information on either of these areas had it not been for these cooperative programs in which many nations participated. Likewise, inrestigations of this type have provided a mechanism for the intercalibration of techniques whereby standardized methods are introduced and observations taken by one country may be compared directly with another.

Further, there are many scientific studies which can be accomplished only through the concerted efforts of many nations since no single nation has either the manpower or resources to earry out the program singularly. Some examples of these kinds of scientific programs are the study of air-sea interaction which involves the exchange of energy and material between the atmosphere and the ocean. Often these studies require synoptic or nearly simultaneous measurements made over very large areas of the earth's surface. obviously, to obtain the data required for studies of this nature, the participation of many countries is required. Similarly, fluctuations in sea level which occur 
on a global scale must be measured on a global scale. Also, since these changes are of a secular or long period nature, a long-time series of observations, often in remote areas, is required. Again, these observations would tax the resources of any single country and could be carried out more easily through international cooperation. Studies of a biological nature are also amenable for international cooperation. The determination of the kinds and amount of fish contained in the ocean, as well as how rapidly these are consumed and reproduced, is one of prodigious effort requiring a considerable period of time. This will be so even with international cooperation and painstakingly so if it were to be undertaken by individual countries. Another area in which many countries hare individual efforts and in which these efforts could be made much more efficient is the mapping of the topography of the ocean floor. Cooperative programs in this instance would prevent duplication of efforts and would also provide an interchange of techniques and interpretation.

Still another area in which international cooperation has been useful is that of data exchange. This was particularly demonstrated during the period of the International Geophysical Year in which world data centers were estab. lished. These data centers allowed for the free exchange of information between all countries.

In addition to data exchange, cooperative programs in oceanography have also provided a mechanism for the exchange of scientists and ideas. This has proved to be particularly useful between countries such as the United States and the Soviet Union, where normally there is a minimum of such exchange. Further; along these ines, there results from these exchanges an increased understanding among oceanographers. If this understanding is pursued on a broad enough basis, it could conceivably produce a marked effect on international relations. Similarly, oceanographic research ships, as they visit various countries, in a way act as ambassadors of good will and understanding, particularly since their mission is one that is deroted to increasing the welfare of mankind.

Although cooperative programs in oceanography have been carried out to one extent or another for many decades, the most significant effort of this kind was undertaken during the International Geophysical Year in 1957-58. This was organized by the special committee for the IGY under the auspices of the International Council of Scientific Unions with most of the large maritime countries participating in the program. Upon the completion of this international endearor, SCOR, a special committee of ICSU, examined possible areas of research in which this cooperative spirit could be continued. The result was the initiation of the international Indian Ocean expedition. Although this program was conceived in 1958, ship operations did not commence until 1961, and they will extend through the end of 1965. In 1961 the newly formed Intergovernmental Oceanographic Commission of the United Nations Educational, Scientific, and Cultural Organization (UNESCO) assumed responsibility for the coordination of the International Indian Ocean Expedition (IIOE). The IIOE represents the first formal international program of several to be sponsored by the IOC. This program was drawn up to provide for a concerted study of one of the least known oceanic areas in the world-the Indian Ocean. Underlying theme of the program was to determine the effect the changing monsoon winds had upon the ocean circulation and, in turn, what effect this had on the biological productivity. The scientific program was broken into four broad areas of interest. The first concerned itself with the problem of the ocean basin. For example, how does the bottom of the Indian Ocean compare with bottom features of other oceans and what were the geological forces that shaped the basin? The second broad area of interest covered the chemical and physical description of the waters and the dynamics of their motion. The third major field of interest concerned the liring populations in the Indian Ocean, both plant and animal. In particular, there has been much effort to determine the productivity of this area. The last broad area of research involved the interaction between the ocean and atmosphere, especially the difference of conditions between the two monsoon seasons. This effort included not only studies from surface ships but also involred the use of fixed ocean buoys and meteorological aircraft. In this connection an International Meteorological Center was established in Bombay which w:Il be continued at the end of the expedition.

By the end of 1965 over 40 ships from about 12 countries will have participated. In addition, eight other countries will have provided scientific assistance. The U.S. effort in this program amounts to approximately one-third the total and 
has entailed approximately 14 cruises to the area at an estimated total cost through 1965 of $\$ 20$ million.

The second major international program to be sponsored by the Commission was the International Cooperative Investigation of Tropical Atlantic. Initial impetus for the program came from the United States. This endeavor was divided into three efforts designated Equalants I, II and III. During Equalant I, 14 vessels took part from 7 nations. Of these 14 ships, 3 were from the United States and 3 from the Soviet Union. Other countries that participated were Argentina, Brazil, Republic of Congo, Nigeria, and the Republic of Ivory Coast. In Equalant II, 11 vessels participated from 8 nations and during Equalant III there were 8 vessels from 6 nations. Equalants I and II were carried out in the spring and fall of 1963, respectively, and Equalant III has been completed only in the past month. One of the noteworthy achievements of this cooperative investigation has been the rapid assimilation of data at World Data Center $\mathbf{A}$, located in Washington, D.C. All of the data from Equalants I and II have been receired and published and a good part of the data from Equalant III is in hand. The total cost to the United States in this program was about $\$ 3$ million all of which came out of regularly sponsored programs.

Another program under the auspices of the IOC is the proposed investigations of the Kuroshio and adjacent regions off the coast of Japan. This program, now in its planning stage, has been initiated primarily through the efforts of Japan, Korea, Philippines, and the U.S.S.R. The extent of U.S. participation is still not known at this time. In addition, several cooperative oceanographic programs exist between the United States and Japan which have resulted from bilateral agreements between these two nations entered into by the Prime Minister of Japan and the President of the United States.

Aside from the formal programs mentioned above, there are numerous informal oceanographic programs between the United States and other countries which have been carried out over many years. Perhaps the most significant of these has been the cooperative effort between the Lamont Geological Observatory of Columbia University and many South American countries. This work has been particularly fruitful with Argentina, Chile, Peru, and Brazil. For the past decade, Lamont has worked very closely with the Hydrographic Office of the Argentine Navy and this interest has provided the basis for most of the oceanographic research now going on in that country. Similarly, the Woods Hole Oceanographic Institution has worked very closely with the National Institute of Oceanography of England in the northern Atlantic and Indian Oceans and with the French in the Mediterranean Sea. Likewise, the Scripps Institution of Oceanography has carried out many cooperative programs in the North Pacific with Japan and Canada. Noteworthy of mention are the Norpac expeditions of 1955 and the Eastropic expedition of 1956. At the present time, informal cooperative programs between the United States, Peru, and Ecuador are underway to study the El Nino phenomenon which occurs randomly off the west coast of Central and South America. Also, the French bathyscaph Archimede is presently engaged in the exploration of the Puerto Rican Trench as part of a joint United States-French program.

Coordination of the U.S. participation in these many international oceanographic programs is carried out primarily through the Interagency Committee on Oceanography. Under the ICO exists a Panel on International Programs established in 1962. The purpose of this Panel is twofold: (1) to ensure that U.S. participation in the Intergovernmental Oceanographic Commission and other international programs proceeds in an aggressive, judicious and timely manner; and (2) that the Panel provides a forum whereby the rarious U.S. activities in international oceanographic programs have a common meeting point. This allows the ICO to be aware of all aspects of U.S. participation in international oceanographic programs. To date, the primary effort of the Panel has been devoted to the U.S. responsibilities in the Intergovernmental Oceanographic Commission. This has entailed the selection of U.S. delegations and the development of the U.S. positions on the agenda items to be discussed at the Commission meetings. There have been three sessions of the full Commission and five meetings of its Bureau in the 4 years of its existence. It is my pleasure to report that at all of these meetings, the United States has been far better prepared than any other of the 51 member countries. This has enabled the United States to assume the position of effective leadership in this important Intergovernmental Commission. 
Parallel to the governmental structure for coordinating international programs there exists, under the auspices of the National Academy of Sciences Committee on Oceanography (NASCO), a U.S. National Committee to SCOR which as you recall is the Scientific Committee on Oceanic Research of the International Council of Scientific Unions (ICSU). SCOR acts as the scientific advisor and conscience to the Intergorernmental Commission in much the same manner as the NASCO does to our ICO. Therefore, this provides for this interaction between university and governmental scientists both at the national and international levels.

As I have mentioned, there have been three meetings of the IOC - the last of these terminated only last Friday, June 19. At this third session, 17 resolutions were adopted. To give you an idea of the activities of the Commission, I shall mention some of the more salient resolutions. In the long run perhaps the most significant was the acceptance of a draft of the General Scientific Framework for World Ocean Study. I have taken the liberty of using some of the material from this draft in my opening remarks. This document is intended to provide the basic framework around which future programs of the Commission can be designed in order that logical international programs for the study of the ocean can be developed. As I have already mentioned, the Commission adopted the cooperative study of the Kuroshio and adjacent regions as an official program. The Commission also approved of the U.S.S.R. proposal for a Second World Oceanographic Congress to be held in the Soriet Union in 1966 under the sponsorship of UNESCO. Further, the Commission recommended that all member states adopt the recent recommendation approved by the general assembly of the Intergovernmental Maritime Consultative Organization (IMCO) concerning the marking and identification of oceanographic stations. This is particularly significant because it may, in future years, provide the basis for international conventions concerning research in the open ocean. Another important resolution recommended that member states assist each other in encouraging and developing national programs in marine research.

The Commission elected Dr. Panikkar of India its new Chairman, along with Dr. Lacombe of France and Dr. Sugiwara of Japan as Vice Chairmen. These officers will serve from the present time till the end of the next meeting of the Commission which will be in Paris in 1965. The following member states were appointed to the Consultative Council of the Commission-Argentina, Australia, Brazil, Canada, Germany, Poland, United Arab Republic, United Kingdom, Ukraine, United States of America, and U.S.S.R.

Although in the coming months the Panel on International Programs of the Interagency Committee on Oceanography will spend a large share of its time on matters connected with the Intergovernmental Oceanographic Commission, other matters of international importance are coming to the forefront. Some of these will include discussions on how the United States can effectively exploit the natural resources of the sea such as fish and minerals and discussions on the international conventions which may apply thereto. Further, in order that the United States maintain leadership in world oceanography the Panel has considered calling a small conference which would include, besides the Panel members, the National Academy of Sciences Committee on Oceanography, the International Panel of the Federal Council for Science and Technology, Office of the Foreign Secretary of the National Academy of Sciences, Office of International Scientific Affairs of the Department of State, and appropriate members of the, Agency for International Development (AID). The main purpose of this conference would be to insure that future U.S. international programs in oceanography are as effective as possible from the scientific, economic, and political aspects.

I appreciate the opportunity to appear before you today and I will be pleased to answer any questions you may have.

(Whereupon, at $12: 05$ p.m., the committee adjourned, to reconvene at 10 a.m., Thursday, June 25, 1964.) 



\title{
NATIONAL OCEANOGRAPHIC PROGRAM-1965
}

\author{
THURSDAY, JUNE 25, 1964 \\ Hodse of Representatives, \\ Subcominttee on Oceanography of the \\ Committee on Merchant Marine and Fisheries, \\ Washington, D.C.
}

The subcommittee met at 10 a.m., pursuant to call, in room 219 , Cannon House Office Building, Hon. Alton Lennon (chairman of the subcommittee) presiding.

Mr. LenNon. Gentlemen, we will resume the hearings.

I understand we are to have a film this morning and with the help of some of you gentlemen and some of the members of the committee staff, we will move right along with that.

We apologize for the delay but we had a markup this morning on a couple of bills in executive session.

Proceed.

(A film was shown.)

Mr. Lennon. We are delighted to have with us this morning, Dr. I. E. Wallen, Chairman of the Research Panel and Assistant Director for Oceanography, from the Smithsonian Institution.

We are delighted to have you, Dr. Wallen, and if you have a written or prepared statement, fine. You may proceed.

If you care to, in the interest of time, you can include your statement in the record and hit the high spots. You can put your statement in the record at the conclusion of your verbal statement and we will then ask questions.

What is your choice?

STATEMENT OF DR. I. E. WALLEN, ASSISTANT DIRECTOR FOR OCEANOGRAPHY, MUSEUM OF NATURAL HISTORY, SMITHSONIAN INSTITUTION, AND CHAIRMAN, RESEARCH PANEL, INTERAGENCY CONIMITTEE ON OCEANOGRAPHY

Dr. WALlen. Thank you, Mr. Chairman.

I will take advantage of your latter offer and talk off the cuff.

Mr. Lennon. Thank you, sir. Go right ahead.

Dr. Wallen. Mr. Chairman and members of the committee, I am talking for the Research Panel of the Interagency Committee on Oceanography. It has been the responsibility of this Panel to attempt to coordinate research efforts of the various Federal departments to make sure that there is in fact interagency cooperation in research.

I have listed in my statement some examples of cooperation in research and have listed the members of the Research Panel. I will 
talk briefly about the kinds of operations the committee engages in; which might be summarized by saying that we have operated through subpanels. We established a subpanel in biology which has examined the field of marine biology, helped to define the field, and helped to choose that part of marine biology we wanted to consider as a part of the oceanographic program.

After this decision was made, we were able to incorporate the results of this Panel in the 10-year plan so that we have not prepared a specific report.

Another subpanel was formed to meet a different kind of a problem. We established a panel on radiobiology because there was some question as to the adequacy of communications among the various agencies. Some of the people had raised questions concerning the desirability of declassification of some of the projects. So, this Panel was asked to consider the problem.

As a result of their considerations we were able to define rather clearly the roles of the U.S. Public Health Service, the Atomic Energy Commission, the National Science Foundation, and the Navy. Those agencies which had the primary interest in this field.

There, again, we did not require a report of the subpanel.

Another panel of which we did require a report was established to consider undersea research vehicles. We had received, particularly as a result of the loss of the Thresher, considerable stimulus to consider ocean engineering. You saw in the film and have otherwise heard of the Deep Submergence System Review Group which considered particularly the engineering problems involved in getting to depths in the ocean.

It was the job of the Research Panel to try to pick out those kinds of research which could only be done with these vehicles. We hoped to set the standards which the engineers should meet in order to develop the vehicles.

We expect to have copies of this report on undersea vehicles within the next 2 months.

Another recently established subpanel is concerned with microbiology. Microbiology is of particular interest to us because of the applications of pharmaceuticals, poisons, toxins, wastes, plankton organisms, bacteria, and so forth, as they affect humans.

We are asking the microbiology panel to go through this field of science, pick out those parts of the field that are oceanographic in nature and determine what the level of effort is at the present time. They should make recommendations with regard to how the oceanographic program may more adequately treat this field.

Now if I might go beyond the organization of panel into the subject matter of research and oceanography, I have listed some examples of the effectiveness of oceanographic research in developing new information.

Perhaps I can take advantage of the fact that my formal statement has been presented for the record, Mr. Chairman, and talk about some other things not in my statement.

One of them that I might start with is a study of circulation off of the mouth of rivers. We have known for a long time that river discharge into the ocean must have a substantial effect on the sea. For example, it affects us by increasing the production of organisms in 
the ocean in that area and we think we know the reason; that is, that those chemical elements, organic material, washed in from the land are of value to the organisms of the sea and provide the life material for their bodies.

We were very much concerned in learning how far into the ocean these kinds of effects might be felt. So, in a joint project between the Navy, the National Science Foundation, and the Atomic Energy Commission, a rather major study was undertaken off of the Columbia River with the result that we were able to trace Columbia River water for as much as 450 miles away from the mouth of the river.

This was a particularly interesting study for two reasons; No. 1, because of its oceanographic implications; No. 2, it gave us a chance to test atomic energy equipment to determine how far we might be able to identify the waste materials in the Hanford reactors.

As I indicated, it was possible to identify very minute quantities of materials in the orders of parts per 10 billion off of the Columbia River, approximately 450 miles.

Another thing that I might mention as an example, which is not included in my statement, is the recent advance in fisheries, particularly the discovery of the large fishery potential in connection with upwelling in the ocean. Oceanographers now spend a substantial portion of their time studying the location of currents and the reasons for upwelling. Cp-welling means that those organisms - that is to the biologists-those organisms that die on the surface of the ocean and fall to the depths of the ocean are releasing their elements toward the bottom of the ocean, haring picked them up near the surface.

So, in order to get a cycle established to return these nutrients, it is necessary to hare the bottom water brought to the surface. In those areas where ocean bottom water comes to the surface of the ocean, we have greatly increased productivity. We can harvest fishes in larger number and we can find greater varieties of organisms.

The Indian Ocean Expedition discovered such an area for the first time off the coast of Thailand and Indonesia at certain times of the year. This is connected, no doubt, with the monsoons. We are able to recommend to the governments of these countries that it would be desirable to investigate the possibility of establishing fishing industries in the area.

In oceanography, in the physical part, we have been able to identify various contributing currents to the gulf stream. Up until this time, as far as the map was concerned, the gulf stream began approximately at the coast of Florida and continued just off New England and was known to lead east.

Its sources and contributing currents were not well known but recent data has certainly given us a much better understanding of the sources of the gulf stream from the central Atlantic, the equatorial current, which itself was only recently discovered, and from the circulating currents that run through the Gulf of Mexico and, of course, from those currents that run along the northern coast of South America.

Another recent derelopment which I think is of interest, is the use of computers in environmental studies. For a long time, ecologists and biologists interested in organisms and their relationship to the environment were very much disturbed at their inability to handle the large amounts of data that could be accumulated. It was impos- 
sible to make a major study of a biological area in order to say that this group of organisms occurs here and has commercial value.

Or, that this group of organisms occurs here and may be of value for pharmaceuticals.

Or, this maybe occurs here and may be hazardous; this occurs here and may be harmful to fouling; this produces bioluminescence.

In order to approach this problem, we have finally been able to devise a system of incorporating the data onto punchcards and then putting them into electronic computer's. Recently it has been possible to complete a study of the distribution of organisms.in the Gulf of California. We expect to do much more of this in the future.

From the geological standpoint, we have recently discovered large numbers of sea mountains, and have found a rather definite relationship between fishes and these undersea structures. This, of course, is of value again to fisheries because of the possibility to accumulate the fishes in commercial quantities in and around these sea mounts.

I might add just a few things, too, in the field of interagency cooperation in research. The one that I mentioned concerned the cooperation of the Atomic Energy Commission, the National Science Foundation, and the Navy in supporting a single ship for the most part, but with supporting vessels in the area off the Columbia River.

I might also call attention to the joint use of vessels by various agencies. For example, the University of Miami, which operates iis ship from support from the Office of Naval Research and the National Science Foundation, made a cruise to the tropical Atlantic area. It did this in cooperation with the Coast Guard, with a Woods Hole oceanographic vessel, with scientists from the Smithsonian In titution, sicentists from the University of Miami, and the Bureau of Commercial Fisheries.

The Bureau of Commercial Fisheries and the Public Health Service have operated for a long time in the areas of pollution and waste control, and have in fact had in existence for several years, even longer than the Interagency Committee on Oceanography, a committee between the two agencies which considers the problem of joint interests, of making it possible for the Public Health Service to operate on $\mathrm{Bu}$ reau of Commercial Fisheries and Bureau of Sports Fisheries vessels and working up the data in cooperation so that that information of special value to public health is given to the Public Health Service and the information that may be obtained on the distribution of organisms and their possible importance to man is taken by the Bureau of Commercial Fisheries and Sport Fisheries and Wildlife.

In the Antarctic program of the National Science Foundation, support has been given to the Weather Bureau, to the Smithsonian Institution, to the Navy, and to many other Government organizations, including of course the Coast Guard for its work in that area.

One of the programs we face in research is, How do we gather data on a long-term basis from a single place? We have had reasonably successful cooperation, and I think reasonably successful only because our success in engineering has not been sufficient to meet onr needs in sciences yet, in the development of buoy programs. We find buoys being supported through the instrument panel of ICO, buoys being supported by the research panel of ICO, and the development of buoys is of course a very important lead in our ability to take data less expensively over long periods of time. 
Perhaps that is enough deviation from my talk.

I might mention in closing a little bit about Project Mohole. Project Mohole has had so much publicity that the Interagency Commitee has been forced to give it some consideration. I did want particularly to point out that we are aware of the progress of Project Mohole and very much interested in it. However, from the standpoint of oceanography, we are interested not in Mohole because of its ability to take a sample from the center of the earth, or at least from a deeper part of the earth, but we are interested in it because it gives us an oceanographic capability that we cannot now meet.

We support Project Mohole by attempting to develop a long coring: capability. That is, a capability for taking cores that are 1,000 feet or longer in length. The length of the cores in the national oceanography program are generally determined by the length of life of the bit that is attached to the drilling device. As long as the bit lasts, we continue to take a core, and with present bits this means we can penetrate to something of the order of 1,000 feet.

Another very interesting problem which I thought I might mention in closing has to do with a discovery in the Indian Ocean that during apparently a large part, if not all of the year, there exists in a major part of the ocean in the Arabian Sea a large area that is devoid of oxygen. This means that no organisms can live on the bottom of the ocean. It means that those organisms that live in the middle of the ocean are restricted, but it means that because there is a lack of oxygen there must be something to take the oxygen out. The lack of oxygen is related, apparently, to the production of a large amount of organic material. The organic materials are the nutrients that provide the basis of life in the sea, so the surface of the Arabian Sea is really teem-. ing with life, tremendous numbers of fishes, tremendous quantities of other marine organisms.

It would be very interesting to speculate, which is all it is, on the reason why this oxygenless area has persisted, apparently, long after there has been substantial introduction of organic material into the area. It is certainly interesting to speculate how it might be possible to distribute this organic matter, or to find other so-called pools of organic matter in the ocean that could serve as a fertilizer and thus increase the production of fishes beyond the hundreds of billions of pounds that were discussed in the film.

'Thank you very much, Mr. Chairman. I will be pleased to answer' questions.

Mr. Lennon. Thank you, Dr. Wallen.

We are delighted to have the chairman of the full committee who is enthusiastic about the whole program.

Chairman Bonner, do you have any questions?

Mr. Bonner. No questions.

Mr. Mosher. I am not sure it is relevant, but his reference to this area of the sea devoid of oxygen reminds me of the problem we have in Lake Erie which is becoming devoid of oxygen. What do you do to replace oxygen?

Are there any techniques in a relatively small area such as Lake Erie? Are there any techniques by which there is hope we can overcome the pollution problem there?

Dr. Wallen. The easiest way which could be practiced in a smaller lake would be to flush out that water and get rid of the excess organic 
material, or to dilute it. In Lake Erie, where there is continual addition of organic material, perhaps not dangerous, but as pollutants, there is not an awful lot that can be done.

Mr. Mosmer. I suppose the control of pollution would ultimately rejuvenate the lake?

Dr. WALLin. Yes; that is correct.

Mr. Mosfier. That would be the best way to attack that problem?

Dr. Walden. A reduction in pollution will certainly reduce the loss of oxygen or will increase the amount of oxygen production. There is a complicating factor, and that is, having reached a level of pollution where there is very substantial organic matter present, the organic matter is used for further production of organisms which themselves die and add to the oganic material, and you have a cycle that lasts for a long period of time so the results are not immediately felt. Certainly it is true in the long run.

Mr. Lennow. How long have you served as Chairman of the Research Panel?

Dr. Wallen. For 2 years.

Mr. Lennon. Subpanels are organized within your panels to make special studies of special objectives or projects?

Dr. WALLEN. Yes.

Mr. Lennow. And when that function is finished, then that panel phases out and it is directed to some other specialty in the research program?

Dr. WALlen. That is correct.

Mr. Lennon. That is the practice of the other panel chairman in $\mathrm{ICO}$, is it not?

Dr. WALLEN. Yes.

Mr. Lennow. They establish subpanels to make special studies to report back to the panel who in turn reports back to the ICO?

Dr. Wallen. Yes.

Generally, when a problem arises, it may arise within the panel, or in the ICO, or even in the Federal Council. If a problem is referred from the Federal Council to the ICO, it may be referred to the Research Panel which may then establish a special subpanel to meet the problem.

Mr. Lennon. During this 2-year period there have been, necessarily, reasonably substantial changes in the personnel of your Panel?

Dr. WALLEN. That is correct. ICO.

Mr. Lennon. That would be true of the other several panels of the

Tell me quite frankly, Doctor, during this 2 years that you have been Chairman of this particular Panel, do you believe there has been a greater degree of coordination in this field of oceanography, progessively a better degree of coordination than in the last few years?

Dr. WALlen. Yes, sir; I certainly do.

As an example, it seems to me that even the Panel itself does not have to meet so often nowadays, that we more or less automatically pick up the phone and ask those people who are involved whether they have programs in the area in which we propose to work. It is not necessary to wait until the problems arise in order to solve the problems. 
Mr. Lennon. You mention your degree of research programs was related to the engineering capability of another panel.

Dr. WALLEN. Yes; that is correct.

Mr. Lennon. Particularly in the field of buoys.

Dr. Wallen. Our method of procedure may be of interest to you. Generally, in the area of instruments, facilities, and equipment, when a scientist conceives of a new piece of equipment, we consider that research in the development of that piece of equipment is a part of the research program.

Mr. Lennon. So you find, I would assume, there are times when your Research Panel confers with the Panel of the Facilities Panel, particularly in the field of engineering as related to buoys and other facilities?

Dr. Wallen. Yes, sir.

Mr. Lennon. Mr. Baner, do you have any questions at this time?

Mr. Bader. Yes, Mr. Chairman.

Dr. Wallen, have any developments occurred in deep ocean coring during the past year?

Dr. Wallen. Yes, there have been a number of developments. The representatives of major oceanographic institutions have made proposals for the construction and operation of a new or converted drilling vessel. The National Science Foundation, which has had the principal responsibility for responding to these proposals, believes that there is strong scientific justification for an extensive deep drilling program. Because of the great expense in the construction or conversion of an appropriate vessel, it is expected that the approved proposal will provide for joint use of the deep drilling vessel to serve several oceanographic institutions.

Information provided as the scientific background of a drilling program was presented by the University of Miami to the National Science Foundation. This was extracted from their proposal by Dr. F. F. Koczy of the University of Miami. With the approval of the Chairman, I should like to insert a copy of Dr. Koczy's statement for the record.

In the issue of Science magazine of June 1964, Dr. Elizabeth Rona of the Oak Ridge Institute of Nuclear Studies, has presented a summary of a conference on the geochronology of marine fluvial sediments. This paper is an excellent summary of the progress on the use of radioactivity in dating marine sediments. I should like to request permission to insert a copy of Dr. Rona's paper in the record at this time. The ICO is hopeful that it will be possible for the National Science Foundation or other ICO agency to receive approval for funding through the Bureau of the Budget and the Congress for undertaking a program of drilling of deep cores.

Mr. LenNon. If there is no objection, this material may be inserted immediately after your statement.

Captain Bauer, would you continue?

Mr. BAUER. Thank you. Another question I would like to ask refers to your testimony concerning the movement of radioactivity through the Columbia River. Has the radiation shown an deleterious effects on organisms beyond the mouth of the Columbia River? 
Dr. Wallen. The answer is "No." Rather extensive studies by scientists at the General Electric Laboratories at Hanford, Wash., at the University of Washington Laboratory of Radiation Biology, and at the Oregon State University have been made on samples of many kinds of organisms from the ocean mouth below Portland and extending for several hundred miles at sea. Traces of zinc 65, chromium 5l, and occasionally other isotopes that are believed to have origmated in the Columbia River have been found in some organisms. The quantities of radioisotopes in marine animals are so low as to be barely detectable. Our existing knowledge of radioactivity and its effects indicates that there must have been no deleterious effect.

Mr. Baver. My next question is this: Is the Bureau of Commercial Fisheries investigating radiobiological effects on fisheries?

Dr. Wallen. Yes. The Bureau of Commercial Fisheries has worked rather closely with the Atomic Energy Commission for the past several years to study the potential effect of radionuclides on commercial fisheries in the sea. In cooperation with the $\mathrm{AEC}$, the Bureau began work in 1950 at its Biological Laboratory in Beaufort, N.C., to investigate the relationship between radioactivity and fisheries. The Beaufort Laboratory has generally been supported approximately 50-50 by the Atomic Energy Commission and the Bureau of Commercial Fisheries. The program has expanded over the years and, in March 1963, it was raised to the status of an independent radiobiological laboratory, which is directed by Dr. Ted Rice. The personmel of the Laboratory have been cleared for atomic energy information and thus are permitted to carry on experiments that simulate the actual releases of atomic energy materials from projects visualized by the Atomic Energy Commission. The Laboratory has studied the extent of occurrence of radionuclides in the environment as a result of atomic or other contamination of the ocean. They have studied accumulation rates by marine organisms for various radionuclides, the extent of retention of various radioisotopes, and the level at which these radioisotopes seem to produce an effect. With the chairman's permission, I should like to enter for the record the annual report of the Radiobiological Laboratory from the Department of the Interior to the Atomic Energy Commission. This document is dated April 1, 1964, and reviews the scientific accomplishments of the Laboratory during the preceding 12 months.

Mr. Lennon. We will place this report in the subcommittee files. Captain Bauer, do you have further questions of Dr. Wallen?

Mr. BAUER. 'This concludes my questions, Mr. Chairman.

Mr. Lennon. The subcommittee wishes to thank you, Doctor, for a very excellent and informative statement.

('The prepared statement of Dr. Wallen and the material mentioned follow herewith:)

Statement By Dr. I. E. Wallen, Assistant Director for Oceanography, MuSeUar of Natural Eistory, Smithisonias Institution, and Chairman Research Panel, Interagency Comaittee on Oceanography

Mr. Chairman and members of the committee, on behalf of the members of the Research Panel of the Interagency Committee on Oceanography, I am pleased at this opportunity to report on research achievements in oceanography during the last 2 years.

Since the hearing of February and March 1962, there has been some turnover in membership of the Research Panel. Additional members were added in order 
to more competently judge the effectiveness of oceanographic reserach. The jpresent members of the Panel, including myself, are the following :

Mr. Boyd E. Olson, U.S. Naval Oceanographic Office.

Dr. A. E. Maxwell, Office of Naval Research (ONR), Geophysics (formerly (Chairman).

Dr. S. R. Galler, ONR, Biology Branch.

Dr. Robert A. Frosch, Advanced Research Projects Agency.

Dr. Roland Smith, Bureau of Commerical Fisheries.

Mr. Gilbert Corwin, U.S. Geological Survey.

Mr. Theodore Ryan, Coast and Geodetic Survey.

Dr. Richard G. Bader, National Science Foundation.

Mr. Bernard Berger, Public Health Service.

Mr. Arnold Joseph, Atomic Energy Gomission.

Dr. Donald Pritchard (National Academy of Sciences, observer).

Dr. Frank Gifford (Weather Bureau, observer).

During our last report to you we stated that a subpanel had been established to consider the Federal program in the area of biological oceanography. This subpanel was not asked to submit a special report. Its efforts were incorporated into the 10 -year plan, which has been distributed to you by Dr. Hornig, and in the annual national oceanographic program documents, Interagency Committee on Oceanography Pamphlets No. 11 and 15, which were provided by Dr. Wakelin.

Four additional subpanels have been established in the last 2 years to review the Government's plans in oceanography at the task level. This is in accordance with the perspectives given you 2 years ago by Dr. Arthur Maxwell.

Two of the subpanels have served their function and have gone out of existence. A Subpanel on Radiobiology considered the relationships between radio:activity research in the Atomic Energy Commission and that of the Public Health Service, National science Foundation, and other potential sponsors of research in this area. As a result of several-meetings adequate coordination was effectively undertaken within the agencies, and the Subpanel has been disbanded.

A second subpanel was established to consider the development of underseas research vehicles. This subpanel prepared a report which is presently being reviewed and edited and should be available within the next 2 months. This report will be concerned with the types of research that may be accomplished with undersea vehicles. It will not consider the many problems of engineering of the vehicles, which more propery will be discussed by a later speaker.

A Subpanel on Microbiology has recently been established to consider that field of study. The plan here, Mr. Chairman, is to attain an understanding of the occurrence of useful antibiotics and other pharmaceuticals from the ocean. The Subpanel will, of course, be concerned with the occurrence and transmission of waterborne diseases and parasites in the ocean.

One of the more complex topics that we have been forced to consider is that of :air-sea interaction. We feel that an understanding of the energy exchange between the ocean and atmosphere has tremendous implications for the prediction and control of weather. We are well aware of the necessity of cooperation with atmospheric scientists and have developed a joint panel with the Interagency Committee on Atomspheric Sciences. This panel has made a preliminary report through the Research Panel to the Interagency Committee on Oceanography and -directly to the Interagency Committee on Atmospheric Sciences.

Although we have been concerned with whether an apparent two-headed monster, such as this, could function, we have recently established that it is entirely practical for such a committee to prepare planning documents will full joint cooperation between the two parent committees. The funding for research for air-sea interaction, in my opinion, has become responsive to the requirements of the meteorologist and of the oceanographer.

Two years ago, Mr. Chairman, we discussed the objectives and plans of the Research Panel. I will not repeat these. I should like rather to talk about the accomplishments in oceanographic research.

At the outset I must state that we have only begun to receive data leading to an understanding of major oceanographic problems. All of the accomplishments that I mention, although they are significant steps forward, are simply examples of the return which we can expect from a continuing research effort. I will orient my presentation to the five categories of oceanographic research which are listed by Dr. Wakelin on page 14 of his statement.

The first one of these is physical properties and motion of the sea. I would like to start this part of my presentation by telling a story. Dr. Allyn Vine of 
the Woods Hole Oceanographic Institution prevailed on the Chief of Naval Operations in 1961 to send a message to a nuclear submarine returning from the South Atlantic. This message requested that the submarine, on reaching a point $1^{\circ}$ south of the Equator assume a $45^{\circ}$ angle at 300 feet depth and maintain a heading of $0^{\circ}$ north for 5 minutes. Although puzzled by such a strange order the submarine skipper attempted to do this and found that it was impossible. The Woods Hole scientists had correctly located the submarine in the massive Equatorial current and countercurrent so that pressures on the upper end of the submarine were in one direction and in the lower end of the submarine in the opposite direction. Since that time the equatorial undercurrent has been found to transport about 30 million cubic meters of water per second in a highspeed eastward flow.

Having confirmed the existence of a current, similar to the already known Cromwell Current in the Pacific, the scientists were quite eager to determine whether or not a similar current existed in the equatorial area of the Indian Ocean. They have been surprised to discover, during the International Indian Ocean Expedition, that although there were strong currents from time to time in the Indian Ocean, no steady eastward flow was evident. Studies for many years will be necessary to define and to describe the actual flows of these giant marine rivers. It is not unlikely that other large volume, large area ocean currents will be discovered. Many smaller areas of oceanic flow are being located on a continuing basis.

The second research category, that of ocean-atmosphere interrelationships, is a most significant one. Here again I would like to cite an example. It has been reported by Dr. Jerome Namias of the Weather Bureau that the unusual weather experienced in much of the Northern Hemisphere may be traced to the phenomena of energy storage and exchange. Oceanographic data located a very large temperature anomaly in the North Pacific in the summer of 1962 . The temperature a veraged as much as $7^{\circ}$ higher than usual at the surface of the ocean. Hindsight tracing of the origin and path of the hurricane which hit Seattle in the fall of 1962 shows that it came directly across, and was apparently related to, the area of anomalous oceanographic temperature. These temperatures persisted throughout much of the winter and seemed to be definitely related to the especially cold weather along the eastern coast of the United States and through Western Europe. These types of anomalies are not common, and our conclusions are tentative. We should be prepared to study the next one more completely when it occurs. Such interpretations cause us to be very strongly interested in weather in the ocean.

With regard to category 3 , biological properties, the oceanographic community is well aware of the potential production of food from the ocean. Biologists are concerned that we are at a rery primitive hunting stage when it comes to predicting the location of marine organisms and why they are there. Over the. period of historical time, many scientists had become convinced by fishing experience that all of the commercially harvestable fishes must be found in the upper 1,000 feet of the ocean. Xet within the past 2 years, with the development of better fishing gear, the Bureau of Commercial Fisheries Laboratory in Seattle. has collected fishes in commercially exploitable abundance at a depth of 3,600 feet near the mouth of the Columbia River. Assistance from the United States, and also from a Norwegian fisheries project, has resulted in the derelopment of a $\$ 25$ million shrimp fishery off the south coast of India. This, of course, is really fishery oceanography and not biological oceanography as we normally think of it.

Biological oceanographers have reached conclusions, based on data collected in different places by different persons, that the sound reflection and interference layer in the water, often called the scattering layer, may be clue to squid, to jellyfishes, to lantern fishes, or to plankton. Biologists are particularly interested in undersea vehicles because, for the first time, they promise that an observer can combine registration of a sound scattering layer on an echo sounder with observation and identification of the kinds of organisms producing the echo. trace.

The abundances, kinds, and distributions of biological organisms are so poorly known that our predictions of the numbers and kinds of marine organisms that would be available for exploitation by humans varies throngh billions of pounis, or even more. It is in this area that we are now concentrating our greatest efforts in terms of trained manpower. However, our results are not really spectacular because of the limited backlog of biological ship time. 
The fourth category-structure and history of the sea floor-has enjoyed rather great advances in experimental methods during the past few years. Isotope fractioning techniques for determining the rates of accumulation of marine sediments have been applied to bottom materials from the Pacific, Atlantic, and Indian Oceans. Sediment deposition in the South Pacific is believed to be in the order of 0.3 to 0.6 millimeters per thousand years, an extremely low rate, which is probably related to the relatively low percentage of land in the Southern Hemisphere. By comparison, sedimentation in the North Pacific and in the South Atlantic occurs at a rate of a few millimeters per thousand years and in the North Atlantic it may be a few centimeters per 1,000 years. Data from the Indian Ocean has been more variable.

During the cruises of oceanographic vessels, an echo sounder usually makes traces indicating the more prominent features of the sea bottom. In recent years the stepped-up oceanographic ship activity has resulted in the discovery of many previously unknown sea mounts-submerged peaks arising from the ocean floor. In the Indian Ocean the Russian research vessel Vityaz found that several of the previously located peaks were actually part of an unrecognized undersea mountain range which extended for more than 2,000 miles, stretching from the Bay of Bengal toward the Antarctic seas.

Such echo tracings are not completely reliable. In February of this year geologists from the Scripps Institution for Oceanography found that they were grossly mistaken in their interpretation of the shape of Scripps Canyon (off San Diego) from echo soundings. Using a diving saucer, rented from France and flown to California by Navy plane, the scientists were surprised to learn more about Scripps Canyon in 5 days than they had in the hundreds of trips across as well as from the sediment cores taken from the area.

Although Project Mohole is not considered to be oceanography, the development of a capability of taking cores of 1,000 feet or longer has occurred throngh oceanographic efforts. Oceanographers are very eager to obtain a vessel that will enable them to take long cores throughout the world ocean. Such cores will provide much new information on the structure and history of the earth.

With regard to research category 5, the modification of the ocean, we have many ideas but essentially no accomplishments. In addition to weather prediction on possible control, one of the most interesting developments in this area is the appearance of a new technique of the use of rhodamine and other dyes to simulate the distribution and mixing rates of radioactive and sewage wastes, which may be introduced into the ocean. Such studies can provide theoretical information of great value in prediction of the effects of detonation of nuclear devices or of accidental venting of nuclear reactors into the ocean. Experiments with dyes are completely safe to conduct and a sufficient number have been completed to justify a special conference on dye distribution, which is planned for August 26-28 of this year.

If I may, Mr. Chairman, I would like to conclude with two especially interesting discoveries. The first concerns the transmission of sound in water. Not long ago the Lamont Geological Observatory exploded a 1-pound charge of TNT in the Indian Ocean. Listening devices off Bermuda were able to pick up the sound of this explosion some 3 hours and 45 minutes later, thus confirming a theory of sound transmission which had little support and is still very poorly understood.

To the biologist a fascinating discovery in the Indian Ocean concerns a very large area in the Arabian Sea which is productive of biological organisms near the surface yets offers a tremendous puzzle. Apparently no organisms live on the bottom in this area, and for a substantial distance above the bottom, because the zone is devoid of oxygen. This oxygenless zone occasionally may approach the surface, to cause tremendous kills of biological organisms. We would like to know whether, why, and how this occurs. It would certainly be interesting to know the source of the organic matter which uses up the oxygen, particularly since the land masses adjoining the area are mostly desert.

Although many papers have been published as a result of research in oceanography, which has been encouraged by our committee, the results appear in perhaps a thousand journals and in large numbers of Government reports. They are not easy to locate. The Interagency Committee on Oceanography has initiated a project to develop a bibliography of publications, stemming from the national oceanogxaphy program during calendar years 1962 and 1963 as well as subseqennt years. This bibliography should be available within the next few months. 
Scientific Background of Drilling Program as Presented in a Proposal to. the National Science Foundation

\section{(Excerpts selected by F. F. Koczy from proposal written by C. Emiliani, June 1964)}

The earth is a geophysical, geochemical, and biological system of such complexity that less is known about its structure, composition, and dynamics than about those of most other celestial bodies. The complexity of the earth as a planet rests essentially upon a threefold basis: (1) its mass, large enough to. have permitted the differentiation of a core, mantle, and crust, and the production and retention of a substantial hydroatmosphere; (2) its heat balance, permitting surface water to exist in all three phases; and (3) its angular velocity and axis orientation resulting in a diurnal cycle of convenient frequency. A perhaps unavoidable consequence of these things has been the development of life, a phenomenon of considerable interest even from a purely physicochenical point of view.

Whereas processes operating over short-time intervals (up to a few hundred years) are easily studied by direct observation, those operating over longer time intervals can be understood only if, in addition to direct observation (when feasible), their effects through periods of time proportionate to their durations are. studied. Many of these effects are recorded in the sections of sedimentary rocks available in the upper crust.

The thickness of soft sediments in "normal" ocean areas; that is, in the areas between the foot of the continental slopes and that of the midoceanic ridges, ranges from about 300 meters in the Pacific to about 10,000 meters in areas of the Atiantic.

Three main types of sediments occur on the ocean floor. The most common is Globigerina-ooze, covering about 48 percent of the ocean floor and consisting essentially of a clay matrix with embedded abundant shells of planktonic Foraminifera, skeletal elements of Coccolithophoridae, diatom valres, and skeleta of Radiolaria (see appendix). The clay matrix consists of the finest continental cetritus brought to the ocean by rivers and wind and distributed by ocean currents. Magnetic spherules of cosmic origin are also abundant.

The second type of sediment is red clay, covering about 38 percent of the ocean floor. Red clay consists of the same matrix as Globigerina-ooze, but the calcareous elements (foraminiferal shells and Cocclithophoridae platelets) have been removed by solution. This solution occurs on the portions of the ocean floor which are deeper than about 4,800 meters in the Atlantic and 4,300 meters in the Pacific. Before glaciation of Antarctica and subsequent cooling of the ocean bottom water (that is before a few million years ago) solution was probably restricted to depths greater than those at which it occurs today.

The third type of deep sea sediments is silica-ooze, consisting again of the usual clay matrix, but including large amounts of siliceous shells of Diatoms and Radiolaria. Diatom ooze is common at high southern latitudes in both the Atlantic and the Pacific, while Radiolaria ooze is restricted to a belt along the central and eastern equatorial Pacific.

Deep sea sediments provide a record which, although most likely not continuous at any given place, is believed to be far more complete, for the time interval covered, than that provided by marine sediments outcropping on land. Furthermore, deep sea sediments integrate the changing picture at the surface of the earth over very great areas, while epicontinental marine sediments are greatly influenced by conditions in the immediate neighborhood. Finally, cosmic elements are remarkably concentrated in deep sea sediments, while they are enormously diluted in epicontinental sediments and nearly impossible to find and isolate.

These considerations suggest that deep sea sediments are especially useful for rate studies; that is, for the study of the first and second derivatives, with respect to time, of a large number of geophysical, geochemical, and biological processes of regional, worldwide, and cosmic significance. The factors involved are the influx of various mineralogical and geochemical phases from the continents and also from the water column above (by direct precipitation); the influx of biological phases from the water column above and the formation of such phases in situ: and the influx of cosmic elements from outer space (principally cosmic spherules, but also cometary material which may be detectable by solid-source mass-spectrometry). 
The study of the Pleistocene cores has provided a remarkable (but still incomplete) picture of the Pleistocene epoch. Thus, a continuous temperature record for the past 375,000 years was reconstructed using Urey's method of istotopic paleotemperature analysis. $\mathrm{C}^{14}$ and $\mathrm{Pa}^{231} / \mathrm{Th}^{230}$ measurements have provided a partial time scale for these reconstructions, showing that the temperature variations were quasi-periodical, with a quasi-periodicity of about 40,000 years. An important observation is that the apparent agreement between $\mathrm{C}^{14}$ and $\mathrm{Pa}^{231}$ / $\mathrm{Th}^{230}$ data over the entire range of $\mathrm{C}^{1 \pm}$ dating shows that cosmic ray flux has not changed markedly during the past 60,000 zears.

While the study of Pleistocene deepsea cores has greatly clarified the history of the Pleistocene, the study of longer columns of deep sea sediments should clarify the history of earlier geological periods. Geophysical measurements and geological-paleontological observations suggest that the deep sea sediments may represent only the past 100 million years of the earth's history. It appears possible, in fact, that the older sediments may hare been swept away by the upper branches of conrection cells in the mantle. Even so, 100 million years is a time interval which compares favorably with the duration of many geophysical, geochemical, and biological phenomena to be studied. Furthermore, areas of the central and western Pacific and the eastern Indian Ocean, and especially areas on the concave side of island arcs (such as the Caribbean) and portions of the ancient Tethys (Gulf of Mexico, Caribbean, Mediterranean) may hare remained undisturbed by the activity of convection currents in the mantle for more than 100 million years. Older Mesozoic and even Paleozoic or PreCambrian sediments may be preserved in some of these areas.

In general, section of unconsolidated deep sea sediments up to 1,000 meters thick have been noticed in the Atlantic Ocean, and sections about 300 meters thick occur over much of the Pacific. Sampling of such sediment thicknesses requires the usage of a drilling vessel. Preliminary tests conducted off Guadalupe Island in the eastern Pacific and in the Caribbean have demonstrated the feasibility of the operation.

In addition to the rate problems mentioned above, coring through the deep sea sediment cover will clearify many important problems related to the origin, structure, and evolution of the ocean basins. Thus, for instance, cores through the deep sea sediment cover of the Atlantic Ocean should provide a conclusive test for the contention that this ocean opened up about 100 million years ago by drift of the Americas with respect to Europe and Africa. If this contention is correct, shallow water sediments of Mesozoic age should be found underneath younger pelagic sediments.

For a proper approach to the problems mentioned, stratigraphic sections of deep sea sediments as complete as possible are necessary. TTo basic difficulties, however, are opposed to such completeness. First, as shown by the study of the cores obtained with the piston corer, unconformities are common in deep sea sediments eren in areas considered "stable". Second, coring techniques will not yield a 100 percent recovery of the sediment encountered. The latter dificulty may be minimized by collecting pairs of cores from any given location, rather than single cores. The former may be minimized by suitable geographical dispersion of the coring locations. Continuous stratigraphic records may then be reconstructed by intercorrelating the cores thus obtained. The problem of intercorrelation is a difficult one, however, requiring the simultaneous usage of unrelated parameters. An example of the method, involving Pleistocene cores, is shown in figure 1 .

The dating of the stratigraphic record obtained from the deep sea floor is a problem of fundamental importance for the interpretation of all measured parameters. Dating may be achieved essentially in two ways:

(1) K/A dating of volcanic ash layers which may be encountered at different levels within the sediments; and (2) correlating the sedimentary record with marine epicontinental deposits outcropping on the continents and related to the established geological time scale.

The first method implies the occurrence, within the sampled deen sea sediments of volcanic ash layers, and the usefulness of this material for $\mathrm{K} / \mathrm{A}$ dating (neither one of these two things is assured). The second method involves classical paleontological method, which while not as exact as successful $\mathrm{K} / \mathrm{A}$ dating of ash layers, will still provide a fairly adequate time scale. For the all imnortant purpose of assuring a time scale (at least by the paleontological method), Globigerina-ooze sediments of the tropical and subtropical North Atlantic, the. 
Gulf of Mexico-Caribbean, and the Mediterranean are most suitable. These sediments, in fact, contain fossil species of Foraminifera which have been studied in detail in the neighboring epicontinental deposits.

\section{WORK ACCOMPLISHED}

Preliminary to the major LOCO efforts of the future, a limited operation was carried out from November 27 to December 17, 1963, using the drilling vessel Submarex of Global Marine Exploration Co. (Los Angeles). This vessel is a converted PC with a length of 173 feet 8 inches, a beam of 23 feet, and a displacement of 298 tons. The vessel is equipped with a skid-mounted Howard Turner drilling rig and a 42 -foot mast. Standard 2\% inch drill tubing in 20foot lengths is employed. The maximum drilling depth is about 2,500 feet.

The restricted drilling range of the vessel (2,500 feet) posed a severe limitation to a program of pelagic drilling and coring, because pelagic sediments generally occur at depths greater than 7,500 feet. A critical analysis of the submarine topography and geology of a region including the continental margin between Cape Hatteras and the Florida Straits, the Bahamas, the Gulf of Mexico, and the Caribbean led us to focus our attention on two small areas of the western Caribbean, between Jamaica and Nicaragua, as possible locations where pelagic sediments might occur at depths less than 2,000 feet. These are the northern slope of Rosalind Bank, and the area between Pedro Bank and the island of Jamaica. Preliminary to the drilling operation, these areas were investigated using the recently acquired Rayflex electrosonic profiler on board our $R / V$ Gerda. Short gravity cores were also obtained. The results indicated favorable bottom topography and possibly also favorable sediments.

The Submarex was equipped in Miami with the necessary drilling equipment and left dock on November 27 bound for the Rosalind Bank site (location A: $17^{\circ} 15^{\prime} \mathrm{N}, 80^{\circ} 35^{\prime} \mathrm{W}, 650$ feet of water) where the R/V Gerd $\alpha$ was waiting to direct the drilling vessels to an exactly chosen place and to assist in the anchoring operations.

After three unsuccessful attempts due to the limited capability of the vessel and the gear together with the unfavorable weather, the submarex was moved to a fourth location (D) between Walton Bank and the island of Jamaica $\left(17^{\circ} 40^{\prime} \mathrm{N}\right.$, $77^{\circ} 58^{\prime} \mathrm{W}, 2,000$ feet of water). The drill string penetrated to 185 feet below the sea floor and a total of 68 feet of cores were recovered. Indurated sediments were encountered at 180 feet. The piston core failed to work, but a standard corer built on board was successful. The topmost 18 feet could not be cored, probably because too soft. We plan to reoccupy location $D$ with the $R / V$ Pillsbury at the beginning of February (1964) and sample the top 50 feet using standard piston coring techniques. The Submarex returned to Kingston on December 17 for demobilization.

A preliminary analysis of the sediments recovered has been made. From near the surface to 180 feet the sediment appears to be a sort of "Globigerina ooze" light gray in color because of finely disseminated $\mathrm{MnO}_{2}$. It differs from normal Globigerina ooze mainly because bethonic foraminifera are more abundant, representing an estimated 5 percent of the total foraminiferal population. The benthonic foraminifera are of bathyal type and no material redeposited from shallow water has been noticed.

Among the pelagic Forminifera, Globigerinoides sacculifera and Globigerinoides rubra predominate throughout. Right-coiled specimens of Globorotalia multicamerata are abundant at 152 feet below the ocean floor, rare at 138 feet, and absent above. Left-coiled specimens of Globorotalia truncatulinoides and right-coiled specimens of Globorotalia menardii occur at 152, 138, and 94 feet (together with predominant specimens oppositely coiled) but are absent at 85 feet and above. Globigerina eggeri, Globigerina inflata, Orbulina universa, and Pulleniatina obliquiloculata occur throughout, often in abundance. Globigerinoides sacculifera fistulosa is absent.

The above micropaleontological observations, and others, indicate that the section present at location $D$ represents a portion of the Pliocene-Pleistocene time. Globorotalia multicamerata has been described as restricted to the Miocene in the Caribbean, but this may result more from the scarcity of Pliocene outcrops of suitable facies rather than from a true chronological restriction.

The indurated sediments encountered at 180 feet consist of shells of predominantly benthonic Foraminifera and shell fragments of benthonic mollusks loosely cemented together by a calcareous matrix. The fossils are poorly preserred and it has not yet been possible to establish their age. Preliminary 
$0^{18} / 0^{16}$ analyses of the shell material have given isotopic of plus 1.5 percent with respect to the Chicago standard PDB-1. This would indicate a bottom temperature only slightly higher than existing today (about $7^{\circ}$ C.).

\section{APPENDIX}

For those not familiar with biological terminology, a few pertinent comments are given in the following:

(a) Foraminifera: An order of marine protozoans. Single-celled animals, most of which deposit $\mathrm{C}_{\mathrm{a}} \mathrm{CO}_{3}$ shells. Dimensions of the shells : $200 \mu$ to $1,000 \mu$. Foraminifera may be benthonic (living on the bottom, from the shoreline to the greatest oceanic depths) or planktonic (freely floating at, or near the ocean surface). The shells of planktonic Foraminifera fall to the bottom when the animal reproduces. Most of the foraminiferal shells in Globigerina ooze sediments are planktonic, the bethonic ones amounting to only 1 to 2 percent. Planktonic Foraminifera evolved about 150 million years ago, and have been very abundant since. Planktonic foraminiferal species number about 2,000 living and 100,000 fossil.

(b) Coccolithophoridae: Planktonic marine protophyta. Single-celled plants depositing $\mathrm{C}_{2} \mathrm{CO}_{3}$ platelets all around their bodies. Diameter of the platelets: about $5 \mu$ to $10 \mu$. Coccolithophoridae evolved about 150 million years ago and provide an important food source for planktonic Foraminifera.

(c) Diatoms: Planktonic and benthonic, marine and fresh water protophyta. Single-celled plants depositing two valves consisting of hydrated $\mathrm{S}_{1} \mathrm{O}_{2}$. Maximum diameter of the valves : about $50 \mu$.

(d) Radiolaria : Planktonic marine protozoa. Single-celled animals depositing shells consisting of hydrated $\mathrm{S}_{1} \mathrm{O}_{2}$. Diameter of shell : about $250 \mu$. One family deposits $\mathrm{S}_{\mathrm{r}} \mathrm{SO}_{4}$ shells.

The taxonomy of Foraminifera has been studied in detail during the past 100 years. Although much remains to be done, a fairly satisfactory stratigraphy for the Cretaceous-Cenozoic (the past 100 million years) of the Tethys (the ancient sea stretching from the Caribbean through the Mediterranean to Indonesia) and adjacent regions has been established on the basis of Foraminifera. Planktonic Foraminifera, in particular, are useful for correlations of marine deposits in distant regions.

The taxonomy of Coccolithophoridae, Diatoms, and Radiolara has been studied much less than that of Foraminifera. Therefore, these organisms are less useful than Foraminifera for stratigraphic purposes.

[From Science magazine, June 1964]

\section{Geochronology of Marine and Fluvial Sedments}

For more than 100 years, scientists have been trying to develop methods to determine the onset and duration of the Pleistocene epoch. Analysis of continental deposits is not reliable for this purpose because such disturbances as faulting, erosion, and glaciation leave only discontinuous records. Deep sea sediments, however, offer a possibility of determining sedimentation rates and absolute ages of recent geological periods. The extremely slow deposition of minerals under the protective laver of thousands of meters of sea water makes these sediments suitable material for dating. Included in the techniques for dating marine sediments are the micropaleontological method (Science 139, 728 (1963) ), and a method based on the radioactive decay of members of the two uranium families in the sea. The former method depends upon the characterization and distribution of Foraminifera as a function of depth within the sediments. The appearances of Foraminifera are related to the temperature of their environment and are correlated stratigraphically. The latter method is based on the concept that uranium is soluble in sea water; the daughters Th $^{230}$ and $\mathrm{Pa}^{231}$ are insoluble and are concentrated in the sediments in a distribution which is not in equilibrium with their respective parents, $U^{234}$ and $U^{235}$. Still another method, which is sometimes useful for obtaining sedimentation rates, is the ratio of $\mathrm{Th}^{230}$ to $\mathrm{Th}^{232}$. Here, $\mathrm{Th}^{232}$ decays very slightly during the Pleistocene epoch, while $\mathrm{Th}^{232}$ decays with a 76,000 -year half-life. After deposition this ratio is assumed to vary only because of the shorter half-life of $\mathrm{Th}^{230}$.

Although these methods are used in many laboratories in the United States and abroad, many controversial issues exist, such as problems of sample col-

$$
35-377-64-7
$$


lection and preparation, counting techniques, and the interpretation of results. A Conference on the Geochronology of Marine and Fluvial Sediments was held at the Oak Ridge Institute of Nuclear Studies, October 17 to 19, 1963, with the purpose of discussing these questions, in order to establish items of agreement, to seek explanations of points of disagreement, and to discuss the validity of the basic assumptions on which various dating methods rest. The meeting, limited to 50 participants, was dedicated to Hans Pettersson (Goteborg, Sweden) who was in attendance. In 1937 he suggested that Th $^{230}$ is precipitated (unsupported by its parent uranium) from the ocean onto the bottom, thus laying the conerstone for thorium dating of the sediments. Emphasis was put on discussions and free intercourse of ideas. Six invited papers and 15 contributed papers were presented by scientists from leading institutions in this field.

The method of dating by the ratio of $\mathrm{Th}^{230}$ to $\mathrm{Pa}^{231}$ is based on the assumption that $\mathrm{Th}^{230}$ (commonly called ionium) and $\mathrm{Pa}^{231}$ are removed simultaneously from sea water soon after formation (authigenic materials) and are thus separated from their respective parents, $U^{234}$ and $U^{235}$. In the sediments, each isotope decars with its own half-life of 76,000 years and 32,500 years, respectively. Provided the ratio of the uranium parents in sea water has remained constant for at least several hundred thousand years, the ratio of $\mathrm{Th}^{230}$ to $\mathrm{Pa}^{231}$ can be used for estimating deposition rates over periods of at least 200,000 years. The validity of this method rests on a few assumptions which were considered by the participants.

The longest and most involved discussions centered around the problem of separating authigenic thorium and protactinium isotopes from those isotopes of allogenic origin. It is obvious that some of these isotopes originate from allogenic minerals, such as volcanic ash, meteorites and continental detritus. E. D. Goldberg (Scripps Institution of Oceanography) presented data on samples prepared by leaching with $6 N \mathrm{HCl}$ and compared these results with those obtained by bringing the whole sample into solution by fusion methods. He found that the ratios of $\mathrm{Th}^{230}$ to $\mathrm{Th}^{232}$ were higher in the leached than in the fused samples. This is an indication that a harsher treatment brings the detrital thorium into solution. F. F. Koczy (Marine Laboratory, Miami) and most of the other participants believed that leaching (even mild leaching) dissolves some detrital thorium. Paul Antal (Marine Laborator5, Miami) found that $\mathbf{T h}^{230}$ was more refractory to acid leaching in deeper segments of a sediment core. He attributed this to a diagenetic induration, a process in which amorphous precipitates are converted into chemically resistant minerals. If this diagenesis causes a reduced leaching yield of $\mathrm{Th}^{230}$, a large error in dating will result. Less leaching indicates apparently older ages for the sample.

The detrital contribution of thorium is most serious if ratio of $\mathrm{Th}^{230}$ to $\mathrm{Th}^{232}$ is used for sedimentation rates; the detrital contribution of $\mathrm{Th}^{230}$ is hard to assess. Goldberg showed, however, that dating methods with the ratios of $\mathrm{Th}^{230}$ to $\mathrm{Pa}^{231}$ and $\mathrm{Th}^{230}$ to $\mathrm{Th}^{232}$ gave the same results if proper geological considerations are observed. Sackett has shown, however, that the ratio of $\mathrm{Pa}^{231}$ to $\mathrm{Th}^{230}$ in the top of the cores is seldom equal to the predicted ratio. He attributes this result to the mixing of the sediments, which would upset the ratio of $\mathrm{Th}^{230}$ to $\mathrm{Th}^{232}$, but less seriously affect the ratio of $\mathrm{Th}^{230}$ to $\mathrm{Pa}^{231}$.

The general consensus was that the best method is the dissolution of the total sample and subsequent correction for the isotopes of detrital origin. Different approaches for arriving at this correction were discussed. Elizabeth Rona et al. (Oak Ridge Institute of Nuclear Studies) are investigating the validity of using the ratio of $\mathrm{Th}^{230}$ to $\mathrm{Pa}^{231}$ for dating in the Gulf of Mexico. They reported on the analysis of samples (thorium, protactinium, and uranium) along the Mississippi River, the principal contributor of sediment material to the gulf. Using the ratios $\mathrm{Th}^{230}$ to $\mathrm{Th}^{232}$ and $\mathrm{Th}^{230}$ to $\mathrm{Pa}^{231}$, they hope to make corrections on the sediments of the open gulf for terrestrial contributions of these isotopes. Thurber found activity ratios of $\mathrm{Th}^{230}$ to $\mathrm{Th}^{232}$ in the Xlississippi and other gulf coast waters to be about 1, although this ratio varied considerably in other bodies of water.

Aaron Kaufman (Lamont Geological Observatory) discussed this problem from a different aspect. He determined the isotopic ratios of thorium, radium, and uranium on 25 selected samples of the flurial carbonate sediments in the Great Basin. These sediments were also dated by $\mathrm{C}^{14}$ age procedures. In nearly every case, in which the $\mathrm{Ra}^{226}$ and $\mathrm{Th}^{230}$ were in equilibrium, the data lead to the assumption that the initial activity ratio of $\operatorname{Th}^{230}$ to $\operatorname{Th}^{232}$ is 2.2. Thus, one can use the $\mathrm{Th}^{232}$ data for these selected samples to convert $\mathrm{Th}^{230}$ to authigenic 
$\mathrm{Th}^{230}$. Applying this correction, the ages derived from the ratio of $\mathrm{Th}^{230}$ to $\mathrm{U}^{238}$ are found to be equal to 80 percent of the $\mathrm{C}^{14}$ ages.

Disequilibrium of members of the uranium family can be used to date fossil marine carbonates. The principle of the method is that uranium is in low, but measurable, concentrations in modern shells, whereas $\operatorname{Th}^{230}$ is below the limit of detection. As the shells get older, $\mathrm{Th}^{230}$ grows in them, and the ratio of $\mathrm{Th}^{230}$ to $\mathrm{U}^{238}$ is then a measure of the age of the fossil shell. Results of analysis of 12 fossil sediments were presented by Herbert Potratz (Washington University, St. Louis) and Richard Blanchard (U.S. Public Health Service). Ages, based on the ratio of $\mathrm{Th}^{230}$ to $\mathrm{U}^{234}$, agreed in most instances with ages estimated on stratigraphy. Wallace Broecker (Lamont Geological Observatory) found that fossil coral without calcite shows uranium concentrations close to the level contained in living coral. However, recrystallized coral samples, compared to their living equivalents, are deficient in uranium. Broecker reported that unrecrystallized material could apparently be dated with reliability to 300,000 years, and by using the ratio of $\mathrm{U}^{234}$ to $\mathrm{U}^{238}$ even beyond this range.

Until recently, the ratio of $U^{234}$ to $U^{238}$ has been assumed to be equal to 1 . Several cases of disequilibrium between these two isotopes have been reported recently. To assess the authigenic origin of $\mathrm{Th}^{230}$ and to correct for uraniumproduced $\mathrm{Th}^{230}$, the concentration of its parent $\mathrm{U}^{234}$ must be known. Deviation of the uranium ratio from 1.0 was discussed. Goldberg reported that the ratio for water from the Atlantic, Pacific, and Indian Oceans is 1.14 \pm 0.01 : a Red Sea sample showed a ratio of $1.18 \pm 0.01$. Ratios of $U^{234}$ to $U^{238}$ were determined on lake and river samples by David Thurber (Lamont Geological Observatory). He found isotope fractionation resulted in activity ratios of $U^{234}$ to $U^{238}$ that were greater than 1 , in nearly all cases being greater than 1.2 and ranging as high as 6.

Considerable isotope fractionation was reported by John Rosholt (U.S. Geological Survey, Denver) in roll features (uranium-bearing fluvial sandstone) in Shirley Basin, Wyo. In these samples, the $\mathrm{U}^{23 t}$ is found to be deficient in altered ore sands by as much as 70 percent, while calcite ore sand shows only a slight deficiency. A small amount of uranium in unaltered sand, above and below the roll feature, does not show isotopic fractionation. The reasons for fractionation in the samples were discussed by Rosholt, and several mechanisms were proposed. Any environment which contains intimately mixed sediment and hydrological phases for a sufficient length of time may lead to the enrichment or depletion of $U^{234}$ in one phase or another. Thurber suggested that the recoil of the nuclides during alpha decay makes the daughter $\mathrm{U}^{234}$ nuclide more available to weathering than the parent $\mathrm{U}^{233}$. Subsequent preferential leaching leads to the deficiency or enrichment of $\mathrm{U}^{234}$.

Methods of chemical separation of nuclides in dating were discussed in some detail. Two approaches to the determination of the ratio of $\mathrm{Th}^{230}$ to $\mathrm{Pa}^{231}$ were presented. William Sackett (Lamont Geological Observatory) used a direct chemical separation of protactinium and thorium. Goldberg in a few experiments and Ronas group in all experiments used an indirect method which involves separating thorium chemically and then counting the $\mathrm{Po}^{215}$ a daughter of $\mathrm{Th}^{227}$. This isotope $\left(\mathrm{Po}^{215}\right)$ can be well characterized by its alpha emission of 7.35 million electric-volts energy in alpha spectroscopy. In both cases, a thorough knowledge of thorium and protactinium chemistry is necessary. Harold Kirby (Monsanto Research Corp., Miamisburg, Ohio) discused the chemical similarities and differences of these two elements; the latter far outnumbered the former. Protactinium can be separated from thorium by the hydrolysis of protactinium in strong hydrochloric acid, in which process the thorium remains in solution. There different behavior in ion exchange and solvent extraction techniques is also exhibited. Kirby concluded by stating that the wet chemical behavior of thorium and protactinium denies the existence of an actinide series of elements because protactinium and thorium have little in common with each other or with the elements of higher atomic number, from uranium on. This dissimilarity of the chemistry of thorium and protactinium raises the speculation as to whether the two isotopes, once reaching the ocean bottom, behave in the same way in the sediments. Richard $\mathrm{Ku}$ suggested that uranium and possibly thorium may migrate in the sediments.

The use of isotopes as tracers for yield determinations was also discussed, and it was pointed out that the lack of exchange between the tracer anc the isotope, whose yield has to be determined, may lead to serious errors. 
All the participants used either gridded ionization chambers or solid-state detectors for determining the alpha spectra of their samples. Equally good results were obtained with both detectors provided that infinitely thin and homogenous samples were available. The method of choice for the preparation of thin samples is usually electrodeposition. Stephen Kim (Oak Ridge Institute of Nuclear Studies) discussed how he used dilute hydrochloric acid and ethanol as an electroplating solution. He varied temperature, $p \mathbf{H}$, current, and time of electrodeposition and found that under the best conditions very thin samples can be prepared with a yield of 80 to 100 percent for uranium, thorium, and protactinium.

It is apparent that dating of marine sediments by the ratio of $\mathrm{Th}^{230}$ to $\mathrm{Pa}^{231}$ cannot be extended beyond a ferv hundred thousand years. Peter Deines (Pennsylrania State University) outlined a program in which $\mathrm{Be}^{10}$ is used. It is formed in the atmosphere by cosmic rays and has been detected in deepsea sediments through its $\beta$ activity. It has an approximate half life of 2.7 by $10^{6}$ vears. The change in concentration of this isotope in profiles of cores whose age fell beyond the limit of $\mathrm{Th}^{230}$ measurement can be used to date sediments with ages ranging to millions of years. The concentration of $\mathrm{Be}^{10}$ in the sediments is very low, and it is obvious that methods of ultrahigh sensitivity have to be used. Deines described a mass spectrograph now under construction that is designed to reach this sensitivity. With this instrument determination of $\mathrm{Be}^{10}$ will be 10 to 1000 times as great as is possible by measurement of its radioactivity and dating sediments of ages up to 20 million years may be possible.

The conference was stimulating, ideas were exchanged, and information shared. Some of the controversial issues--the use of whole sample versus leaching techniques, correction for allogenic thorium and protactinium, and the need for determinations of isotope fractionation in dating the samples-were clarified. Among the problems that still remain unsolved are the varying results obtained in similar samples and sample preparation by different methods and measurement. It was generally agreed that it may be possible to clarify controversial issues by the preparation and interlaboratory distribution of samples, such as red clay marine carbonates and marine limestones. These samples will be distributed among laboratories which are active or interested in dating marine sediments. Results of these investigations should be presented at a later date, possibly at a conference to be convened as a follow-up of this meeting.

Elizabeth RoNa,

Oak Ridge Institute of Nuclear Studies, Oak Ridge, Tenn.

Mr. Lennon. Our next witness will be Comdr. H. Nygren, Chairman of the Surveys Panel program.

We are delighted to have you. Do you have a prepared statement?

STATEMENT OF COMDR. HARLEY D. NYGREN, U.S.C. \& G.S., ACTING CHAIRMAN, OCEAN SURVEYS ADVISORY PANEL, INTERAGENCY COMMITTEE ON OCEANOGRAPHY

Commander Nrgren. It is nine pages. I would be happy to condense it.

Mr. Lenron. We will put the full text of your statement in the record immediately following your testimony:

Commander Nrares. With your permission I will emphasize the areas of the statement that describe the accomplishments of the Panel, the operations of the Panel, and avoid the other.

I think it is well to note that I am only the Acting Chairman of the Surveys Panel in the absence of Dr. Stewart, the permanent Chairman. I am here because he is unable to be here. The statement lists the members of the Panel. It gives a little background information in its formation. I will not repeat that.

One of the specific accomplishments of the Panel since the hearings of 1962 is represented by ICO Pamphlet No. 7, the national plan for ocean surveys, which was issued in May of 1963. This plan was pre- 
pared as a framework within which the specific survey program for each year could be formulated. It describes the purposes and objectives of the plan, the facilities and personnel to be required, the scope of the work, the types of investigations and the disposition of the data. It also describes the data to be collected and includes the tentative ship construction schedule. This plan is reviewed and revised by the Panel whenever necessary.

In any national program it is essential that the requirements as well as advice of the nongovernmental oceanographic centers be effectively considered in making up the annual national program. Communications from without the Government are effected by a combination of formal and informal means.

On a formal basis, the Panel meets with the NASCO Panel on Oceanwide Surveys at least once a year, usually in connection with the preparation of the annual national program. More directly, the ICO Panel includes NASCO representation.

In recent months, this representation was recommended for increase from one to three scientists, and from the class of observer to member, representing three major centers for oceanographic research in the United States. You may recall from the list of Survey Panel participants that the Executive Secretary of NASCO, with offices in Washington, D.C., is an alternate member. Owing to his proximity and rapport with the NASCO Panel, he is in day-by-day communication with the ICO group.

At one of the recent joint meetings, the NASCO Oceanwide Survey Panel heard statements from each agency on its current survey operations, funding, and accomplishments, and is presently considering a detailed study of the technical data. NASCO has now agreed to reexamine its recommendation for Oceanwide Surveys in the light of these recent survey accomplishments. They will also evaluate our performance in response to their plan. The Ocean Surveys Advisory Panel is accumulating performance and cost data for their use in making this evaluation.

Through the ONR and NSF representatives on the Panel, these two activities, which together fund a very large percentage of the oceanography conducted by academic institutions, bring to the Panel a detailed knowledge of the plans and works in progress carried on outside the Federal agencies. Of course, the benefit is extended both ways-numerous cases arise in which the institutions can conduct work aboard Federal agencies' survey ships, thus avoiding costly duplication.

For example, on the recent Equalant I cruise, conducted under the International Cooperative Investigations of the Tropical Atlantic (ICITA), ONR-supported scientists from New York University were able to conduct detailed studies of a recently discovered equatorial undercurrent when the U.S.C.\& G.S. ship Explorer transited the equator on an oceanographic cruise. Costs to ONR for the shipboard accommodations for the four scientists embarked was the nominal messing bill.

In another ocean, at this monent, University of Hawaii biologists and geologists and geophysicists from the Universities of California and Southern California, and the U.S. Navy, as well as metereologists from the Weather Bureau, using equipment from the Universities of 
Michigan and Wisconsin, and biologists from the Department of Interior all are now being accommodated on the U.S.C.\& G.S. ship Pioneer which is conducting a multiphase oceanographic survey in support of the international Indian Ocean expedition. These two cruises just cited illustrate the genuine working communications between agency scientists and administrators in the oceanographic committee at large. Copies of the reports to date have been brought from the Panel's files.

These summary statements distill the contents of detailed reports on instrumentation, survey ship design, and buoy networks. The Panel has continued to work closely with the contractor, and has received periodic progress reports from him.

The Ocean Surveys Advisory Panel has also been concentrating on other problems. One was the compilation of the agencies' plan for 1966 under the heading of "Ocean Surveys." Program statements have been received from all member agencies and will shortly be reproduced and distributed within the Panel following which a meeting will be held to discuss coordination of these operations. The various bureaus have been examining their own internal requirements in order to properly fit them into the ICO budgetary categories. Some agencies, having no money allocated to surveys, have in the past been doing survey type work under the heading of "Research."

A better definition of the objectives of the work has caused some revision in the reporting of funds to ICO for fiscal year 1966. After the meeting of the Panel, the smooth version of this part of the national ocean survey program for fiscal year 1966 will be prepared for ICO. This will then become part of the national oceanographic program pamphlet for 1966 .

The Panel recently considered a very carefully developed proposal for a study of the region which supports the extensive tuna fishery of the central Pacific. This plan, recognizing the role of physical oceanography in the sporsor's mission, requires facilities in excess of the BCF's in-house capability. Accordingly, the Panel has brought to all interested Federal agencies the sponsor's proposal. Those aspects of the program that can be aided by coopertion of the other agencies are currently being studied.

I have attempted to present a concise picture of what the Ocean Surveys Advisory Panel does through the use of a few specific examples.

As you can well imagine, perhaps its most effective work is the day in, day out informal communication that exists between the Panel members, and the members of the other Panels with closely related functions; for example, the Research and Ships Panels. Indeed, it is extremely difficult and not particularly desirable to segregate the functions of these three Panels. Fortunately, communications are good. Panel members are, in the main, scientists or engineers and administrators who have long been identified as experts in their respective fields. I believe the mutual respect and rapport that has prevailed has resulted in an effective method for managing the Federal oceanographic program.

Thank you for your interest. I would be pleased to attempt to answer questions you may care to ask.

Mr. Lennon. Thank you, sir. 
Mr. Tollefson. No questions.

Mr. Rogers. Commander, what is the overall budget for your Panel?

Commander Nygren. Surveys for 1965, sir, were $\$ 25,114,000$.

Mr. Rogers. Would you name the top three departments that will spend that money; in other words, the major portion of the money for the top three departments.

Commander NyGREN. The Department of Commerce-

Mr. Rogers. How much is that?

Commander Nygren. It is on page $40 ; \$ 9,101,000$.

Mr. Rogers. And the next one?

Commander Nygren. Of course Defense had $\$ 14,704,000$.

Mr. Rogers. Is that mainly Navy?

Commander Nygren. Yes, sir.

Mr. Rogers. Any Army?

Commander NyGren. The Army has $\$ 1$ million.

Now, there is no figure broken out of that for ocean surveys for the Army.

Mr. Rogers. No ocean survey is being conducted by the Army?

Commander Nygren. No, sir.

There is a matter of definition that has come up as to what is survey and what is research. Some agencies have no money for surveys, but actually some of the work they are doing amounts to survey type work-for instance, exploratory fishing.

Mr. ROGERs. Do you coordinate these reports?

Commander Nraren. Yes, sir.

Mr. Rogers. You get all of these various reports even though they are not designated as surveys?

Commander Nygren. Panel members have been discussing how better to define these categories, sir. It is a problem of what you are going to call something.

Mr. Rogers. What I was wondering, do you actually get the reports? Are they brought in by Panel members?

Commander Nrgres. Yes. The Panel at the present time is obtaining these figures from the various agencies to make the 1966 presentation.

Mr. Rogers. And how long has your Panel been established?

Commander Nrgres. This Panel has been established since the ICO was established. This is an outgrowth of the task group B appointed in 1959 .

Mr. ROGERs. Do you work closely with an ad hoc committee?

Commander Nygren. Yes. We had a meeting with the National Academy of Sciences Committee. The ad hoc committee that was discussed the other day of the Federal Council has not met with the Ocean Surveys Panel. The Chairman of the Ocean Surveys Panel has met

Mr. ROGERS. With the ad hoc committee?

Commander Nrgren. Yes.

Mr. Rogers. Is that the normal procedure, that he takes the Panel recommendation and discusses it with the ad hoc committee?

Commander Nrgren. Or vice versa.

Mr. Rogers. They make the recommendations to you?

Commander Nygren. Yes, sir.

Mr. ROGERS. Rather than going over your program? 
Commander Nrgren. The ad hoc committee examines the total program for the coming year for all panels. This is presented by the Panel Chairman at the time this ad hoc committee is convened. This is then discussed in that context.

Mr. Rogers. How often does your Panel meet?

Commander Nygren. It has not met as often recently as it did previoulsy. I would estimate it has met approximately once a month for many, many months. Recently we have, in the last 3 months, had one meeting. We have had numerous interchanges by telephone. It has not been possible in the last few months to get Panel members together as a group.

Mr. Rogers. Has your program been acted on? Is there any need to get them together?

Commander Nygren. Not really; no, sir.

One reason we had to get together was to discuss the ocean surveys problem in general with the National Academy of Sciences Committee, and at that time we did have a joint meeting with them. We presented to them some of the problems we had, and what we propose to do as a group.

Mr. Rogers. Who is the Chairman of your Panel?

Commander Nrgren. Dr. Harris Stewart, and has been for some time.

Mr. Rogers. Is it on his initiative that the Panel is called together?

Commander Nygren. Yes. Sometimes this is suggested by other Panel members, of course, if there is something urgent.

Mr. Rogers. Who is the staff member for the Panel?

Commander Nygren. Dr. Shykind assists the Surveys Panel.

Mr. Rogers. When is the next meeting scheduled?

Commander Nygren. The Acting Chairman is about to step down from the chair, and he will call a meeting very shortly. We have to have a meeting in order to prepare this presentation for the 1966 program. We should have this meeting very shortly. The Chairman will call it. I have not done so as yet.

Mr. ROGERs. When you set up a program of things that need to be done, how do you supervise this?

Commandker Nrgren. The problem that faces the Ocean Surveys Panel is a little peculiar in that the ocean surveys recommendations of NASCO have not really been carried out as yet. They recommended that 20-some ships be built for ocean surveys work. We have yet to take delivery of the first ship under these recommendations.

Mr. RoGERs. When were the first recommendations made?

Commander Nrgren. 1959. No ship has been delivered as yet.

Mr. Rogers. Are there any to be delivered in the near future?

Commander Nygren. Yes. We will take delivery of two next year for the Coast and Geodetic Survey. We have had two Coast Guard ships diverted to this work. The ocean survey work as envisioned by UNASCO has not reached full fruition, so we have a situation where the great bulk of the money listed as surveys in this program is mission-oriented surveys. They will be the nautical charting surveys, or the surveys of the Navy which are not necessarily in response to the National Academy's recommendation. They were going on before the recommendations were made. They are very definitely oceanography. They are applied oceanography. 
Mr. Rogers. And can be used in your program?

Commander Nygren. Yes, sir.

Mr. Rogers. So the work is being done then?

Commander Nrgren. The work is being done as it has always been done, and we are attempting to meet some of the recommendations of the National Academy with the equipment that is today available.

There is a percentage of the survey dollars which is ocean survey in response to NASCO's recommendations. Most of it is not-most of it is what we have chosen to call mission-oriented surveys.

Mr. Rogers. What $I$ am wondering is, is this just carrying on a Navy program and getting funding from somewhere else, or is this funding from the Navy, or what?

Commander Nrgren. The ocean surveys work?

Mr. Rogers. Yes.

Commander Nygren. No. The Navy's requirements are based on military requirements. This is entirely different. The Coast and Geodetic Survey problems are separate. The National Academy did recommend that the ocean survey plan be set up and be followed. This we are attempting to do as part of the national program.

To date, the only agency that has been able to divert ship time specifically to this has been the Coast Survey. The Nary ultimately contributes to this body of knowledge as it is declassified. There is no question about this. Their surveys are not tailored to the recommendations of the National Academy.

Mr. Rogers. This $\$ 14$ million, does that come from the Navy budget?

Commander NrGReN. I would rather you direct that question to Captain Treadwell, who follows me, who will be able to discuss the Navy funding much better than I.

Mr. Rogers. I thought you might know generally the funding of your Panel.

Commander Nygren. This comes from the Navy budget. If you want to pursue -

Mr. Rogers. It is carrying on a Navy function and it is funded by the Nary?

Commander Nrgren. Yes.

Mr. Rogers. So there is no money coming from other agencies, or some other source; it is a Navy source?

Commander Nygren. Yes.

Mr. Rogers. And it is carrying on a Navy function that can contribute, but it does not necessarily fall within the national plan set up by the National Academy of Sciences?

Commander Nygren. May I suggest Captain Treadwell can better answer this. I say this not to be evasive, but it is a matter of definition again.

What is the ultimate objective of this work?

Mr. Rogers. The only two ships that are really carrying out the plan are the Coast and Geodetic Survey ships?

Commander Nygren. Yes. And as of today, there is no ship assigned to this.

Mr. Rogers. I thought you said you had pulled a couple off.

Commander Nygren. One has been sent to the Indian Ocean, and one had to be diverted to Alaska in response to the earthquake damage, so today there are no ships on the ocean survey plan as such. 
Mr. Rogers. The recommendations of the Panel are not now being carried out?

Commander Nygren. Of the National Academy's Panel, yes. We are attempting to carry these out in the future. The ships that were diverted were not ships originally justified for this type of work. They were hydrographic ships.

Mr. Rogers. This gets back to something I am concerned aboutwhether we have sufficient authority in this Interagency Committee to really do anything and get it done.

As I understand it, the Panel has recommended a certain program, but somehow we have not gotten around to it since 1959. There is some contribution, maybe, in an offhand way, but what you have really recommended that is needed to be done on ocean surveys has not yet been done.

Commander Nygren. Yes, sir, and part of that is because of the fact there is such a long leadtime in the preparation of equipment, facilities, and so forth.

Mr. ROGERS. When were your recommendations first made?

Commander Nygren. 1959 was when the National Academy made its recommendation.

Mr. Rogers. How about your Panel? How long have you been trying to get this done?

Commander Nygren. I think this Panel fell right in line.

Mr. ROGERS. Immediately?

Commander Nrgren. Yes.

Now, the first ship that was authorized for this, I believe, was in 1962. There has been relatively little time loss. It takes time building the ship and staffing it.

Mr. ROGERs. And then what supervision do you have over the program once you have set up your recommendations and they have been accepted?

What does the Panel do to see it is carried out, or does that fall within your authority?

Commander Nrgren. The Panel has no authority. It is an advisory panel. The ICO has no authority. It is an advisory group.

Mr. Rogers. All you can do is make recommendations and hope they are carried out?

Commander NrGRen. That is correct.

Mr. Rogers. If they are not, there is nothing you can do?

Commander Nygren. I do not know that there is nothing we can do, but we have no authority to take any executive action as a panel. That is correct.

Mr. Rogers. Can you bring it to the attention of anyone who has authority?

Commander Nrgren. Yes; this is done.

Mr. Rogers. What avenue of command would you go through?

Commander Nrgren. The Panel would point out to the Interagency Committee itself that certain action was required. The Interagency Committee would then act on this recommendation. The Panel itself acts through the ICO in every case.

Mr. Rogers. I understand that. Then he would have to go to the Federal Council?

Commander Nygres. Well, not in every case ; no, sir. 
The agency heads on the ICO have their own executive authority and can put recommendations into effect as they see fit.

Mr. Rogers. Have you ever had to do this?

Commander Nrgren. It is possible, sir, but in my limited experience I do not know.

Mr. ROGERS. Thank you very much.

Thank you, Mr. Chairman.

Mr. BAUER. Commander, there are several things I would like to discuss.

First, just what do we mean by "surveys"? Am I correct in my thinking that there are really two classes of surveys?

One is of a large-scale nature where you explore some area of ocean which has never been touched before to find out if there is something interesting, and one is a small-scale operation.

Are those the two types of survey?

Commander Nygren. One would be called a reconnaissance-type survey, and the other would be a detailed survey.

I think the problem is defining what is a survey effort and what is a research effort at sea. Not so much as differentiating between different types of surveys.

Mr. BaUtr. You do have to have the reconnaissance survey first to find out what you want to look at with the magnifying glass?

Commander NxGren. Yes. That was the purpose of the NASCO recommendations for ocean surveys.

Mr. BAOER. Really, our capability with respect to surveys depends upon the availability of ships that are capable of carrying on surveys; is that correct?

In other words, without the ship you cannot carry on a survey; is that right?

Commander Nyaren. Yes.

Mr. BAUER. Now, with respect to the Navy's $\$ 14$ million, I have been given to believe that these ships for the foreseeable future will be working on special military projects and would not be available for general reconnaissance surveys; is that correct?

Commander Nrgren. I would rather you directed that question to Captain Treadwell.

Mr. BAUER. I shall be very happy to.

That leaves the Coast Survey as the only source of vessels in the Government that are in the survey business; is that correct?

Commander Nrgren. Yes. If you accept the fact that the contributions from the Coast Guard and the Bureau of Commercial Fisheries which are by no means negligible are not within this predetermined type of survey.

Mr. BAUER. True, but as far as concentrating on survey operations, the Coast Survey is the only one?

Commander Nygren. Yes.

Mr. BAUER. With respect to reconnaissance survey, have we made as much use of ships as we can?

It seems to me if you can get information at a certain geographical location within a certain accurancy at a particular time, that information should be capable of being fed into a computer and you could come out with general information that would help the overall reconnaissance type of survey. 
Commander Nrgren. Yes. I am sure the Navy has a large program designed to take advantage of ships, of opportunity.

Mr. BAUER. Is your Panel familiar with this program?

Commander NYGReN. We are aware of the fact that is within their plans; yes, sir.

Mr. BaUER. Does the Coast Survey contemplate using any of the ships of opportunity in the production of hydrographic data for the Coast Survey?

Commander NyGren. We will accept hydrographic information from whatever source we can.

Mr. Bauer. Has the Coast Survey gone and looked for it?

I am particularly interested in the survey of the Gulf of Mexico. The oil industry there has had very good geodetic control and know to a matter of feet bathymetry, the salinity, the temperature of the water, the magnetics, the gravity and the subbottom structure. That is their business. They have been doing this on the Continental Shelves of the world for some years. Currently the oil industry and the geophysical industry have over 100 ships at sea. It is of concern to me to find out whether or not we are tapping that source of information. This is being done all over the world. There are 28 ships in one company's fleet in the North Sea. There are some ships in the Persian Gulf, off the coast of Africa, South America, as well as the Gulf of Mexico and the Pacific coast.

Are we using this information to get the knowledge of the bathymetry, magnetics, gravity, salinity, and temperature at a particular time and a known position?

Commander NyGres. We have within the Coast and Geodetic Survey contacted 16 geophysical survey and research corporations within the last 2 years. We have examined the data in some of their files. We have been invited to examine it in other cases. I do not mean to imply we have scrutinized with a fine eyeglass the holdings of all 16 companies. However, we have been in contact with these 16 companies. Our regional officers are under instructions now to continue these contacts.

Mr. BAUER. With respect to that source of information, I have a chart here which is somewhat out of date, prepared by the former oceanographer of the Nary, showing the areas here with the green spaced lines as being areas of the oceans of the world where we do not have what is called bathymetry. The fine crosshatched lines show areas of good bathymetry. The pink shows areas of the world's oceans where we have a modern knowledge of the vertical temperature structrue, and the red areas show areas where we have good coverage.

On this chart, the Hydrographer of the Navy overlaid at the request of the staff the preferred steamship lines of the American merchant marine which our country subsidizes.

You will see these steamship lines plying on regular voyages cover a lot of the white area where we have nothing on oceanic structure. I am just wondering whether or not that type of a platform for survey purposes could not be used.

Has your Panel given any thought to the use of this source of what one might call ship bottoms?

Commander Nygren. This Panel in the period I have observed has not concerned itself with the methodology of obtaining the data. 
There have been, and are now, some projects going on to upgrade the instrumentation available to merchant ships.

One of the problems in obtaining data from ships of opportunity is the quality of the data, and there is a rather serious problem in the National Oceanographic Data Center at the present time with large volumes of substandard data that must be evaluated before it can be used.

So I am aware, and this was discussed in some detail in the Eastern Pacific Oceanographic Conference, of an effort to upgrade the instrumentation for such things as surface temperatures and salinities as obtainable from ships of opportunity.

We also realize, and have not pursued this further in the panel, that the Navy has this extensive program of obtaining data from ships of opportunity. Our feeling has been this was being explored.

Mr. Bayer. Who is going to make the charts of the oceans of the world, the Coast Survey or the Navy?

Commander Nygren. The Navy has the responsibility within the U.S. Government of publishing the navigation charts of the waters exclusive of the territorial waters of the United States, and certain other areas. The data obtained from any source is turned over to the Navy and they publish these charts.

Mr. Bauter. The Coast Survey's charter was changed by this committee some years ago, as I remember, to allow them to go anywhere in the world?

Commander Nrgen. We do so, and our data is transmitted to the Navy in the areas where it is their responsibility for publication.

I may also remind you we publish data furnished to us by the Navy in the form of world magnetic charts. This is a longstanding integrated operation between the Coast Survey and the Navy.

Mr. BAUER. That is with respect to the publication. I am trying to find out how we are going to get at an ocean survey of the oceans of the world as far as our country is concerned. I do not see from the testimony this morning, Mr. Chairman, that we are making very much progress in using ships of opportunity.

Would Captain Treadwell be able to talk to ships of opportunity better than you perhaps?

Commander Nygren. He certainly should be able to discuss it better than $I$.

Mr. Bauer. How about the Continental Shelf? That has always been the Coast Survey's medium, shall we say?

Commander NyGReN. Yes, sir.

Mr. BAUER. Are we using the data from the oil industry and the geophysical industry?

Commander NyGReN. We are examining the data at the present time so as to ascertain what is available, what its quailty is. Part of the problem, Mr. Bauer, is, there is no mechanism for publishing much of this data at the present time, and this is an admitted weakness in the oceanographic program. The problem of processing and publishing data from the surveys, or from the research efforts, is an area that requires more study.

Mr. BAUER. In other words, the program should be funded for more production; is that your theory?

Commander Nraren. This is one of the areas where we need stimulation. 
Mr. BAUER. How far behind the taking of the boat sheet in your surveys of the coastal waters of the United States are you before the production of the finished chart involving all of that data-how many years?

Commander Nrgren. Until all that data is applied, you have a substantial lag. The critical information is immediately applied to the charts so there is no danger, or hazard, to navigation. Less critical information is not applied. The charts of the Coast and Geodetic Survey we are speaking of.

Mr. Bauer. Yes.

Commander Nygren. I believe we have quoted a figure in the past, some cases it might be 5 to 6 years before the complete information from the surveys is applied to the chart. However, this is a matter of economy of operation. It is undesirable to spend a great deal of time and money putting relatively insignificant data on the chart. The critical information goes on immediately.

Mr. BAUER. What is the timelag on critical data?

Commander Nrgren. The boat sheets are received in the office. They are photostated. This is put on the charts as soon as possible. This is a matter of weeks or months, and this again depends on the degree of criticality of the data. If something is discovered that is obviously a hazard to navigation and a danger to life and so forth, this information is transmitted to mariners. The mariner puts it on his own chart in this case.

Mr. BAuEr. I am aware of the great work the Coast Survey and Admiral Karo have done, particularly in this northeast storm recharting of coastline which was substantially changed, and also the work being done as a result of the Alaskan earthquake.

However, this question of survey goes over and beyond the question of safety of navigation, does it not?

Commander Nygren. Yes, sir.

Mr. BAUER. If we wanted to find out what the continental structure is-we will say the Hudson Canyon and various canyons that exist on the continental slopes of the country and the world--then we would have to wait 6 years before that information would be available?

Commander Nygren. No, sir. I would not want to let that stand in the record. This is a matter of relative priority. We cannot do everything on a first priority basis. We have to weigh the needs of the consumer in this case. As a small example, but one that might be well mentioned, this report for the Equalant I, which was mentioned by various previous witnesses, was printed and published by the Coast and Geodetic Survey and has been released in a matter of weeks because it was considered to be an element of considerable priority. We have issued provisional charts of areas in a matter of a very few weeks or months where it was a high priority necessity.

Mr. BAOER. For example, the survey that was made by the Coast Guard off the Siberian coast 2 years ago, and the Bering Sea area, that material has been published, has it not? Was this survey by the Coast Guard coordinated by the Survey Panel of the Interagency Committee under the Coast Guard, or more or less did it do it on its own?

Commander Nygren. The Coast Guard, of course, did it within its own authority and the authority of the Navy Department. The Sur- 
vey Panel was thoroughly informed of its intentions as far as possible at the time. If you remember, this was a well coordinated activity in that there were participants of universities, the Navy Department, and the Coast Guard on the actual ship itself.

So, it was part of a national oceanographic program without a bit of doubt.

Mr. BAUER. I am quite surprised they were not driven off the Soviet coast. They were within 20 miles of the Soviet coast, were they not?

Commander Nrgren. I have heard that figure, yes, sir.

Mr. BAJER. Mr. Chairman, I think that is all I have, except one more question.

Was this Operations Research, Inc., hired to devote its attention to ocean surveys or to the operations of the Coast and Geodetic Survey?

Commander Nrgres. The ocean survey, without respect to any given agency. This was the national plan they were to look into and they have been forced-

Mr. BAUER. The authority of the survey?

How many oceanographers do they have in the Operations Research Co.?

Commander Nrgren. On their permanent staff, I don't believe they have any oceanographers.

They have a staff of consultants they call on for this, as well as using information furnished to them by the staffs of the various agencies.

Mr. BAUER. As I remember past hearings, the original ocean survey plan was written by Captain Hendricks of the Hydrographic Office, is that right? Then it was presented to the ICO and, as I remember, Dr. Stewart, of the Coast Survey, was made the head of the Survey Panel and came up with a recommendation of how to conduct the survey of the oceans of the world.

If my memory serves me correctly, the National Academy of Sciences committee frowned more or less on Dr. Stewart's efforts. Then the plan went back into a situation of further consideration on the part of someone. Is it fair to say that we have not advanced very far since the original work of Dr. Stewart?

Just how do we stand? I cannot see that we are getting ahead at all on ocean surveys, unless I do not understand the testimony.

Commander Nygren. We have a general plan and we have completed a substantial part of the prototype surveys in the North Pacific and from this we can evaluate the adequacy of the plan as NASCO has agreed to do. We can evaluate our performance under the plan and when we do go ahead into a more full-scale production, as we obtain more ships, we will have had a chance to eliminate any weaknesses in the plan or performance under the plan.

We have been going through a fairly effective tooling-up process for this.

Mr. BAUER. That is all I have.

Thank you, Mr. Chairman.

Mr. RogERS. I was interested in this company. When was this company hired and what was it hired to do?

Commander Nrgres. It was hired to conduct an operations research type analysis of the national ocean survey plan.

Mr. Rogers. This is no oceanographic company?

Commander Nygren. Mr. Chairman, that is a good question. 
Mr. Rogers. There is no oceanographic company?

Commander NyGren. That is a good question, whether there should be an oceanographer in the company itself. This is an operations research type job where they evaluate information and methods. There is a feeling that to have an oceanographic competence of their own would possibly bias them. Obviously, they cannot do a job unless they are given information. They have quite specifically said that the output would be only as good as the input.

People have been working with them to see that they were given the right information.

There is the other philosophy that says only an expert can evaluate this type of work and I think, myself, that the decision went the right way, provided the company has been able to get proper input from the scientific people, and we feel it has.

Mr. Rogers. You may be right that a company should not know anything about the field it evaluates, but $I$ am not sure $I$ agree with that. However, that may be correct.

I would be interested in having a little information on the company for the record, and I realize you may not have this here.

Commander Nrgren. Yes, sir.

Mr. Rogers. Information as to its personnel and officers? How long has this company been in existence, do you know?

Commander Nygren. I do not know but I would not want to indicate it was not competent to discuss oceanographic problems. They have had other contracts in the field. This was taken into consideration when their proposal was evaluated and they have done considerable work in this area.

Mr. Rogers. I would like to know when the corporation was formed and something about the contracts it has had in this field.

Commander Nygren. Yes, sir.

Mr. Rogers. The extent of these contracts and the time element involved?

Commander Nygren. Yes, sir.

Mr. Rogers. And the consultants used by this company.

Commander Nygren. Yes, sir.

Mr. Rogers. You say they call in consultants?

Commander Nygren. Y Yes, sir.

Mr. Rogers. Oceanographers and so forth?

Commander Nygren. Yes, sir. They have a consulting firm of naval architects that has been furnishing them information on vessel design and vessel capability.

Mr. Rogers. They do not know anything about that either, so far as their own experts are concerned? They have experts in that field?

Commander Nygren. They have no naval architects on their staff.

Mr. Rogers. No naval architects or oceanographers?

Commander Nygren. I do not believe so. 
Mr. Rogers. It might help us to know the competency of the people involved in actually doing this contract work and the amount of the contract.

Commander Nrgren. Yes, sir. (The information follows:)

U.S. Department OF COMIMERCE, Coast and Geodetic Survey, July 1, 1964.

To: Chief, program planning staff.

From: Deputy Assistant Director, Office of Oceanography.

Subject: Cost of ORI contract.

The contract with Operations Research, Inc., for "Services to conduct an operations research study of the national ocean surveys program" (contract No. CGS-1138 (neg.) invitation No. 2892) is for the amount of $\$ 280,108$. It was signed on June 18, 1963, with the work thereunder to commence on July 1, 1963, and to be completed in 18 months.

H. B. Stewart, Jr.

\section{Chronological Background of Operations Research Study of Ocean Survexs}

As early as April 1962, the Ocean Surveys Panel of the Interagency Committee on Oceanography discussed the practicality of carrying out an operations research study of ocean surveys. In July of 1962, an ad hoc panel of consultants to the OST, chaired by Dr. Howard Wilcox, recommended that the operations research technique be applied to the ocean survey program. At the August 20, 1962, meeting of the Federal Council for Science and Technology action was recommended. Item 4-2, page 9, of the minutes of that meeting reads as follows:

"ICO should immediately develop survey objectives, plans, and systems analysis with procedures to review and update them as new techniques and information become available. Planning should be accomplished by the ICO Ocean Surveys Panel."

About that same time the Assistant Secretary of Commerce for Science and Technology also urged that the operations research and systems analysis approach be made to Coast an Geodetic Survey's activities. This was reported in the September 12 letter from the Chief Scientist, U.S. Coast and Geodetic Survey, to the Director.

The Ocean Surveys Panel of the ICO discussed operations research at some length in January 1963. By now the Bureau of the Budget approval of the operations research approach was obvious by the fact that during October 1962 , at the Bureau of the Budget level $\$ 300,000$ had been added to the Coast Survey's fiscal year 1964 proposed budget specinically for operations research studies. Dr. Wenk of the Federal Council for Science and Technology in December 1962, or January 1963 , in discussions with ICO members specifically urged that these studies be initiated immediately so that their results could be used in the formulation of oceanographic budgets for fiscal year 1965. The ICO Surveys Panel continued discussions through January 1963. By then it was known that the Coast and Geodetic Survey felt that such a study could be funded by that agency with fiscal year 1963 funds. During several survey panel meetings the format of a request for proposals was developed and sent to all agencies concerned for comments. The final request for proposals was sent out on April 1, 1963, requesting that management proposals be received prior to April 23. These proposals were evaluated by the Coast Survey and nine other agencies by April 29 and the six companies selected for final submission were notified on May 1. Each was requested to submit final technical proposals by June 3 . These were similarly evaluated in writing by each Survey Panel member, and the final decision was made by the Coast and Geodetic Survey on June 11,1963. 


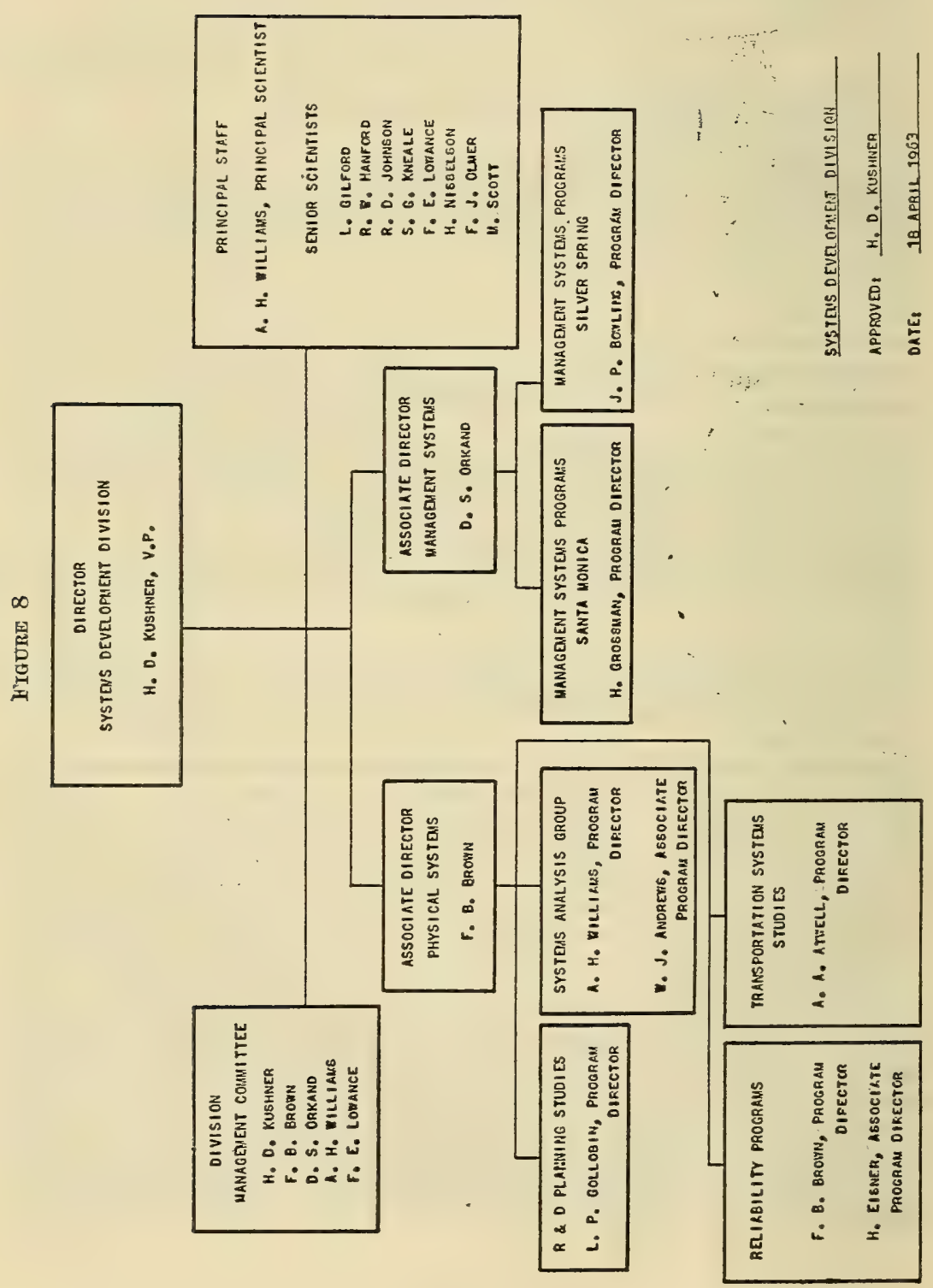


Operations Research, Inc.

\section{Staffing}

V. STAFFING AND SCHEDULE

5.1 The organization of the study effort is planned as a project of the Systems Development Division of ORI, directed by Harvey D. Kushner. The organization chart of this group is shown in figure 8. The ORI study team will be supported by a team of experienced oceanographers who will be available to perform and/or participate in specific subtasks of the program. These will be drawn from the staff of Marine Advisers, Inc., and will be led by Paul L. Horrer. Additional senior consulting help will be drawn upon for special problem assignments and for participation in technical review of the project tasks. Technical direction and the staff group from which project team members will be drawn are the following. Brief biographies of the principal team members are included in this section. More detailed résumés are appended to the proposal.

Overall technical director, Harvey D. Kushner, vice president.

5.2 Overall technical direction of this program will be by Mr. Kushner, director of the Systems Development Division of ORI. Mr. Kushner is a graduate of the Johns Hopkins University School of Engineering. He was an associate marine engineer with the Bureau of Ships, U.S. Navy Department in the Scientific and Performance Branch of the Ship Design Division. He participated in and was responsible for preliminary design studies of a variety of new ship propulsion and machinery systems. At the Central Research Laboratory of Melpar, a division of Westinghouse Airbrake Co., he was a member of the technical staff of the fluid dynamies group.

With ORI since 1955, he has directed operations research studies of a wide range of naval systems associated with surface and undersea warfare. He has directed studies of sonar systems, including development of analyses of the influence of oceanographic conditions on sonar and acoustic weapon performance. Currently he is directing a study for the Committee on Undersea Warfare of the National Academy of Sciences that is to support a panel study by the Academy of the Navy's research and development program for torpedo weapon systems.

\section{PROJECT LEADER, HAROLD NISSELSON, SENIOR SCIENTIST}

5.3. Mr. Nisselson is a mathematical statistician who is especially qualified by experience to direct the proposed program. As a mathematical statistician in the Office of the Assistant Director of the Bureau of the Census for Research and Development he planned and directed a number of special statistical research projects. These projects included methodological research programs in data collection, analysis, and evaluation techniques. On special assignment to the office of Charles Hitch, Assistant Secretary of Defense-Comptroller, he participated in the development of management information systems and the use of sampled data systems. His experience is unique in the design of large-scale data collection programs, in the establishment of quality control procedures, and in the evaluation of data requirements and data program performance.

\section{PROJECT TASK TEAMS}

5.4. The proposed study is organized in project subtasks which will be staffed by personnel with special qualifications for the particular assignments. These task teams will be drawn mainly from the following group of staff members whose biographies are included at the end of this section.

Dr. Frank Brown, Program Director and Associate Director, Systems Development Division: Physicist, experienced in system reliability analysis, system performance analysis, and meteorology.

Dr. Merit Scott, senior scientist: Physicist, experienced in naval weapon systems analysis, ship systems studies, and particular oceanographic factors affecting the Polaris weapon system.

Frank Falci, senior staff: Naval architect, experienced in ship system design and operational analyses of naval systems.

Dr. William J. Andrews, Associate Program Director, Systems Analysis: Physicist, experienced in navigation systems analysis, including those for Polaris system application.

Dr. Girard L. Ordway, senior staff: Physical chemist, experienced in system error analysis, in programing for automatically handling communications traffic for the naval command control ship system, information retrieval systems. 
Dr. Norman Zachary, senior scientist: Mathematician, experienced in dataprocessing systems, information retrieval, and large-scale computer operations.

Fred S. Zusman, senior staff : Mathematician, experienced in system error analyses, mechanized information retrieval systems, data-processing systems.

Leon Gilford, senior scientist: Mathematical statistician, experienced in largescale survey design, reliability analysis and quality control procedures for data collection programs, design of measures of effectiveness for complex data collection programs.

John McCutcheon, mathematician: Experienced in development of equipment performance monitoring systems.

Stanley R. Kalin, research engineer: Experienced in systems analysis, reliability, and quality control.

Donald S. Orkand, Associate Director, Management Systems: Statisticianeconomist, experienced in management systems analysis and development of personnel requirements information systems (for Bureau of Naval Personnel).

Robert J. Byer, Management Systems engineer: Training in naval architecture and marine engineering combined with management systems background, experienced in management control procedures, including cost and schedule control.

T. Arthur Smith, senior staff : Economist, experienced in analysis of management systems, management information requirements:

Robert W. Boody, Management Systems engineer : Experienced in master planning and scheduling, management system analysis.

5.5. Support of the task teams with specialized oceanographic experience will be provided by the staff of Marine Advisers, Inc., of La Jolla, Calif. Staff members who will participate in the project include the following: Paul L. Horrer, president, oceanographer ; Joseph W. Joy, oceanographer.

5.6. Additional consulting support in special tasks will be drawn from appropriate senior individuals with special experience in oceanographic research and surveys. The following individuals have tentatively indicated their willingness to consult for such special problems.

Dr. Warren Woster, professor of oceanography, Scripps Institute of Oceanography: Dr. Woster will be available after September 1963, when he returns from his present assignment as Director of the Office of Oceanography at UNESCO in Paris.

Dr. Finn Michelson, associate professor of naval architecture, University of Michigan: Dr. Michelson's experience in ship design ranges from ship design and construction in Norway to the design of a research vessel for the Bureau of Commercial Fisheries for the Great Lakes:

Dr. H. Wysor Marsh, Jr., director, Marine Electronics Department, AVCO : Dr. Marsh is a theoretical physicist currently directing research on acoustic properties of the ocean for the Office of Naval Research. He was formerly Chief of the Research Division of the Naval Underwater Sound Laboratory and codirector of the Project AMOS program to measure acoustic propagation characteristics of the ocean.

Morris Schulkin, consulting physicist: Mr. Schulkin has recently been associated with the Marine Electronics Department, AVCO Corp. He was, with WVysor Marsh, responsible for the Project AMOS program of the Naval Underwater Sound Laboratory. He was formerly Chief of the Radio Meteorological Branch of the Bureau of Standards and is broadly experienced in meteorology and oceanography.

Mr. Rogers. One other question in following up on this business of using ships of opportunity.

Is that a proper field for the Panel to get into?

Commander Nygren. Perfectly proper for the Panel to consider this; yes, sir. In general, we have not been concerned in methodology and so forth but this is a perfectly appropriate subject.

Mr. Rogers. I thought you were pleading for ships and platforms upon which to-

Commander Nygren. We are getting information from ships of opportunity now, sir. We are not-

Mr. Rogens. According to information on the chart here, it is not being exploited as it might. I presume that is true according to the charts you have there? 
Commander Nygren. Mr. Chairman, it all depends on what we are looking for. There is such a tremendous spectrum of properties we want to sample that a ship of opportunity would not have-for example, gravity meters, magnetometers, and this type of equipment.

Mr. Rogers. Would it be difficult to get that on these ships?

Commander NyGren. It would be extremely difficult to get that on there in the numbers required and with the staff that is required. It is difficult to get it on the survey ships we have now, much less the hundreds of ships of opportunity. However, some properties such as sea-surface temperatures which are significant, are easily obtained by this method and soundings to a certain extent are useful when obtained from competent mariners.

This information is coming in and is being utilized.

Mr. Rogers. You feel it is being done to the utmost?

Commander Nygren. No, sir; I think we can do more and I think we are doing more. This is one of the problems actively attacked right now.

Mr. Rogers. Where is the difficulty in getting the equipment to put on ships of opportunity? Where would that bottleneck be?

Commander Nygren. Part of it was the availability of the equipment itself. It has been going through a developmental process of various types. The Navy now has some equipment designed for this program which could better be described by somebody from the Navy.

I understand the program has come along quite well and when this has passed through the developmental phase and goes into production, they will be ready to go into full-scale operation with it.

$\mathrm{Mr}$. Rogers. For instance, who has the responsibility of contacting the oil companies, the ships that are making these surveys? Where does that responsibility lie?

Commander Nygren. This is being handled by two different agencies who are interested at the present time. The Navy, I understand, has an exchange agreement with these companies but this was worked out with the Society of Geophysical-the SEG, Society of Exploration Geophysicists. This exchange agreement could be discussed a little better by somebody from the Navy.

Mr. Rogers. All right.

Commander Nrgren. Within the Coast Survey, we have put the responsibility on regional offices to contact the geophysical companies in their areas and find out what their holdings are, where the quality is, and what their capabilities are. As I mentioned, we have contacted 16 companies in the last year and a half to find out what they have.

Mr. Rogers. I understood you had gone through some of their files but not-

Commander Nygren. It is in various degrees, yes. We have contacted 16 companies on this matter.

Mr. Rogers. Does that, in effect, cover the major companies involved, these 16 you mentioned?

Commander NrgreN. It may cover the major ones, but by no means covers all of them. This program is continuing. This is a standing order and going on at the present time.

There are many problems involved, such as the fact many companies will not turn loose data. It is, perhaps, of a proprietary nature, or procured under contractual terms that do not permit them to do this, 
and others will make it available. It is not of such a distribution or accuracy so that we can use it, so it all has to be evaluated on a case-bycase basis.

Mr. Rogers. Would you let us have the list of companies contacted. and those who have indicated willingness to cooperate, and those who have indicated an unwillingness to cooperate?

Commander Nygren. I do not think anybody has indicated an unwillingness to cooperate. They have put reservations in as to how their cooperation may be limited.

Mr. Rogers. I would think, then, you would indicate whatever difficulties might have arisen with the companies if you cannot use the material they have?

Commander Nygren. Yes, sir. What percentage of the 16 I would be able to get this information from, is something I cannot answer.

Mr. Rogens. I realize you would have to give this for the record as soon as that can be gathered.

Commander NyGRen. Yes, sir.

(The requested information follows:)

\section{Investigation of Geophysical Data Holdings}

In January 1964, U.S. Navy and U.S.C. \& G.S. representatives met to explore means of expanding the existing data exchange processes and improving communications with industry. Both agencies have worked with the Society of Exploration Geophysicists in establishing contact.

In November 1962, the Navy approached 26 geophysical and oil companies for available data. As a result, charts showing magnetic, gravity, seismic, and bathymetric information throughout the world have been received. Generally, all requests made by Navy have been honored. As a recent example of a special request fulfilled by industry, urgently needed gravity data have been supplied to the Navy to meet specific missile range requirements; in return Navy has fulfilled approximately 50 requests from industry for gravity, magnetic, and bathymetric data.

Coast and Geodetic Survey has been concerned with the data holdings on the Continental Shelves of the United States. All regional and district offices have been directed to maintain liaison with geophysical and oil companies to determine their survey capability and the suitability and availability of bathymetric and geophysical data. As requested by the committee, a list of individual and industrial firms with which C. \& G.S. has been in contact to date follows:

(1) Dr. Lynn S. Hoover: Recommended several individuals who had knowledge of geophysical data holdings.

(2) Texaco, Mr. Martin Standard, New Orleans: Advised on methods and procedures for inspecting data. Discussed obtaining selected data, and explained some problems of datums, etc., that would make some of the data of lessened value for absolute purposes.

(3) California Oil Co., Mr. George Jones: Discussed possibilities of obtaining gravity and magnetic data. No hydrographic data was available.

(4) Shell Oil Co., Mr. Robert Dayton: Discussion at same time as that with Mr. Jones.

(5) Committee for Cooperation With Governmental Agencies, Society of Exploration Geophysicists, Mr. F. Gilman Blake, Jr. : A meeting of the committee was attended. The existing data exchange arrangement with the Naral Oceanographic Office was explained by S.E.G. and a desire to extend this cooperation to C. \& G.S. was expressed. The C. \& G.S. observer addressed the meeting and explained the C. \& G.S. missions and requirements. In response to a question, the observer stated that "we had no desire to duplicate surveys in any geophysical discipline on bathymetric operation, and that our appropriations were so limited that we would welcome knowledge of existing data which could be utilized in our programs and thus allow us to conserve funds" (R. A. Earle, November 6,1963$)$. Through personal contacts at this meeting several companies presented maps showing some of the gravity and magnetic coverage. 
The speech prepared for presentation is attached. Mr. Blake was furnished copies of a letter explaining the position and requirements of C. \& G.S. and copies of the minimum standards of accuracy for hydrographic surveys. These were distributed by him to potential data holders in order that each might analyze his own data for possible use by C. \& G.S. and communicate this to C. \& G.S.

(6) Tidelands Exploration Co.: Offered to sell hydrographic data from their files. These data were in an area for which C. \& G.S. surveys were considered to be adequate. An examination disclosed that their geographic distribution was such as to mak'e them of insufficient value to justify purchasing.

(7) Capt. Paul S. Bauer: Discussed availability of oil exploration data in Gulf of Mexico and its utilization by C. \& G.S. This was one subject among others concerning charging activities.

(8) United Geophysical Co., Mr. Walter Mitchell : C. \& G.S. requested a meeting at a future date to discuss data holdings.

(9) Geotechnics \& Resources, Inc., Mr. William H. Atwood : C. \& G.S. explained the contract between the California Co. (representing several oil companies) and the Government for extending the basic horizontal survey station network of the United States through the offshore oilfields. Discussed reasons for the contract and benefits to accrue to the Government and the oil companies, and the exploration firms.

(10) Seismograph Service Corp., Mr. H. Curtin: General discussion of services and equipment the company could and would furnish.

(11) Aero Service Corp., Mr. Homer Jensen: A visit was made to the Philadelphia office of Aero Service. Data holdings were examined and discussed. The amount and type of data that can be released was made known and will possibly be utilized in the world magnetic charts.

(12) Gulf Research \& Development Co., Pittsburgh: Gulf briefly outlined magnetic data holdings available.

(13) Operations Research Inc., Harvey D. Kushner: After being offered assistance of the Society of Exploration Geophysicists and ORI sent them two questionnaires. Their replies will be considered and included in the reports ORI will make to C. \& G.S. and ICO under their ocean survey plan contract.

(14) Jersey Production Research Co., Mr. K. H. Burns: Mr. Burns expressed a desire to cooperate with the C. \& G.S. and referred our request to Humble Oil \& Refining, their domestic operating affiliate.

(15) The California Co., Mr. J. A. Harris: Mr. Harris reported on availability of data in his files. This reconnaissance data was inspected by the New Orleans district offices.

(16) Standard Oil Co. of Texas, Mr. E. J. Smith, Jr.: Mr. Smith invited a representative to discuss their data holdings.

(17) Offshore Raydist, Inc., Mr. G. A. Roussel : Company was requested to furnish information on distribution, equipment, and costs of their services in the Sabine Pass area. Future discussions will be held.

(18) Sidney Schafer \& Associates, Mr. Schafer: Holdings of gravity data for the Gulf of Mexico region were described by M. Schafer. Detailed surveys would not be released, but some of the data might. An index of holdings and a copy of the specifications were obtained. No magnetic data was held.

(19) Lorac Service Corp., Mr. H. W. Hutchison: Lorac furnished details of their existing services and costs for offshore survey work. C. \& G.S. replied that it would contact the company to negotiate agreements if the need arose in the future.

The analyses of data holdings and company capabilities will be continued. To date, several conclusions are becoming apparent.

Some of the companies state that they can make surveys to C. \& G.S. specifications. This has not been confirmed because the exploration surveys on which they have been engaged are not to these standards, and need not be for geophysical purposes.

The available data holdings represent a valuable source of some types of information. In every case, the data must be examined for accuracy and distribution. Some of the reasons why data examined was not adequate or available follow:

(1) Data are of a proprietary nature, procured under contracts which prohibit its release.

(2) Values of gravity and magnetics are not based on a standard datum. 
(3) The survey area is not considered to be one of critical need for charting purposes.

(4) Positional errors are unknown or excessive.

(5) Bottom features in some cases are not adequately delineated.

(6) Equipment is uncalibrated.

(7) Properties measured are not required by the present publication schedule.

(8) No tide or velocity corrections were applied to soundings.

While these properties may not affect the value of the surveys for purposes of geophysical exploration, they do make them of less value for some charting purposes.

(The speech mentioned above follows:)

ОстовеR 17, 1963.

GentLemen : I appreciate the opportunity of being at this meeting and will try to limit my remarks so as not to take too much of your time.

As most of you realize the Coast and Geodetic Survey has for nearly 150 years been responsible for doing all survey work needed for the production of nautical charts, tide and current tables, and magnetic charts; and for the establishment of precise geodetic control, both horizontal and vertical, including needed gravity and astronomical data. For the last 40 jears we have also been responsible for obtaining seismic data, both teleseismic and strong motion, for the study of earthquakes and their effect on structures, manning the seismic seawave warning system in the Pacific, etc.

During the past 5 years a great deal more emphasis has been placed on scientific research, thus our Bureau has not only established an Office of Research and Development with a staff of many noted scientists, but more and more precise data in all geophysical and bathymetric disciplines have been needed.

In consequence of this and in view of our active participation in many national and international programs, such as the IGY some years ago, and more recently in programs which are now being implemented for the upper mantle, the World Oceanographic Survey, and the International Quiet Sun Year projects; we have approached Congress for additional funding. At some hearings before congressional committees, Government agencies have been criticized for wasting funds in obtaining basic survey data which already exist in geophysical and oil company files.

Our Bureau has no desire to duplicate surveys in any geophysical discipline or bathymetric operation, but in order to utilize said data, we must know whether it exists and whether it is in a usable form; for example, is the control accurate enough for our purposes, has it been reduced to datum, whether it covers large enough areas for our broad scientific needs in depicting the magnetic and gravitational fields, etc.

In the past, the oil and geophysical companies have on occasion released enough data for our programs; for example, when making a gravity map of the Southwest about 10 years ago we were allowed to utilize oil company files to obtain enough data to depict the gravitational field in that area at 10 milligal spacing. Our present plan for the upper mantle project envisions a gravitational map of the United States at 5 milligal spacing, or obtaining gravity data at approximately 10-mile intervals. Unquestionably a lot of data exist in this discipline which could be utilized in certain areas of the country if it was releasable. Similarly, we need a lot more data in geomagnetism for magnetic charting and for independent research studies, and this follows in other areas. We have contracts with various geophysical companies for supplying data, for furnishing men and equipment, for developing instrumentation, etc., but our Bureau does not have information on surveys or on facilities which exist and which might be utilized in our programs.

This, gentlemen, is my basic question: How can we obtain information on existing data which is releasable and which could be utilized in our basic programs? Before answering questions I might state that our Bureau has awarded a contract to Operations Research, Inc., to study and recommend the best methods of proceeding with a long-range national ocean survey plan.

This research program covers the field, not just my Bureau's participation in such a program.

I would now be glad to answer questions and also obtain some ideas on how I can get information on my question. 
Mr. Rogers. Thank you very much.

The House is about to go into session and Captain Treadwell, rather than begin at this late point, if it is agreeable to you, would you be present Tuesday?

If so, the committee will adjourn until 10 o'clock Tuesday.

(Commander Nygren's prepared statement follows:)

Statement of Chdr. Harley D. Nygren, U.S.C. \& G.S., Acting Chatrman of the OCEAN SURvers Advisory PaNel, Interagency Comimitee on OCEanOGRAPHY

I am Cmdr. Harley D. Nygren, U.S.C. \& G.S., Chief, Program Planning Staff, in the Office of the Director, U.S. Coast \& Geodetic Survey. In Dr. Stewart's absence, as his alternate for the Coast and Geodetic Survey, I am here to present a résumé of the functions of the Ocean Surveys Advisory Panel.

Chaired by Dr. Harris B. Stewart, of the Coast and Geodetic Survey, and comprised of members representing the USWB, NOO, OPNAV, ONR, BCF, U.S. Coast Guard, NASCO, MARAD, U.S. Geological Survey, NSF, Smithsonian, and NODC, this Panel is the outgrowth of Task Group B appointed in 1959 by Dr. James Wakelin, Jr., as Chairman of the Subcommittee on Oceanography for the Standing Committee on Science of the Federal Council for Science and Technology. A complete listing of members, alternates, and observers is as follows. I will not read this in detail into the record.

Commerce :

(U.S.C. \& G.S.) : Dr. Harris B. Stewart, Jr., Chairman.

Alternate: Comdr. Harley D. Nygren.

Navy :

(WXB) : Mr. Morton Rubin.

(NAVOCEANO) : Comdr. R. C. Atkinson.

(OPNAV) : Lt. Comdr. R. B. Reed.

Interior:

(ONR) : Dr. A. E. Maxwell.

(BCF) : Mr. Joseph E. King.

Alternate: Mr. Roland F. Smith.

Treasury :

(USCG) : Capt. W. F. Cass.

Alternate: Lt. Comdr. R. M. Morse.

NASCO:

(Ocean-Wide Surveys Panel) : Dr. Warren S. Wooster ; (two to be designated).

Alternate: Mr. R. C. Vetter.

MARAD :

USGS :

Observer : Mr. Vito Russo.

NSE :

Observer : Mr. Gilbert Corwin.

Observer: Dr. John Lyman.

Alternate: Dr. George Sprugel, Jr.

Smithsonian :

NODC :

Observer : Dr. H. A. Fehlmann.

$\mathrm{ICO}$ :

Observer : Dr. Woodrow Jacobs.

Observer : Mr. Robert B. Abel.

The Panel's original function was to analyze and report on the oceanographic ship requirements of Federal agencies which were to conduct the ocean survey program recommended in chapter 9 of the NASCO report titled, "Oceanography 1960-70." This report is now out of print; however, I believe the subcommittee received a copy during the 1962 hearings. As the ICO was formalized, Task Group B became the Ocean Surveys Advisory Panel with the following major responsibilities :

(a) Within the framework of the long-range national oceanographic plan, prepare annually a coordinated plan for the conduct of the ocean surveys program. 
(b) In support of the above, develop data on ship requirements and operating costs for the several agencies involved.

(c) Review proposals for oceanographic surveys requiring across-the-board support by Federal agencies. Establish ad hoc subpanels for coordination of interagency participation.

(d) Coordinate U.S. participation in international oceanographic surveys and reports.

It may be of interest to describe how the Ocean Surveys Advisory Panel fulfills its responsibilities to insure the best possible scientific return for the expenditure of resources and funds. The programs are developed upon the general guidelines provided in the NASCO report. These, of course, require interpretation and revisions based on the progress of the surveys and technology in general. The individual agencies' programs reflect primarily the missions of the agencies, and the scientific competency of their staffs.

One of the specific accomplishments of the Panel since 1962 is represented by ICO Pamphlet No. 7, National Plan for Ocean Surveys, issued in May 1963. This plan was prepared as a framework within which the specific survey program for each year could be formulated. It describes the purpose and objectives of the plan, facilities and personnel to be required, scope of the work, types of investigations and disposition of the data. It also describes the data to be collected, and includes a tentative ship construction schedule. This plan is reviewed and revised by the Panel whenever necessary.

In any national program it is essential that the requirements as well as advice of the nongovernmental oceanographic centers be effectively considered in making up the annual national program. Communications from without the Government are effected by a combination of formal and informal means:

On a formal basis, the Panel meets with the NASCO Panel on Ocean-Wide Surveys at least once a year, usually in connection with the preparation of the annual national program. More directly the ICO Panel includes NASCO representation.

In recent months, this representation was recommended for increase from one to three scientists, and from the class of observer to member, representing three major centers for oceanographic research in the United States. You may recall from the list of Survey Panel participants that the executive secretary of NASCO, with offices in Washington, D.C., is an alternate member. Owing to his proximity and rapport with the NASCO Panel, he is in day-by-day communication with the ICO group.

At one of the recent joint meetings, the NASCO Ocean-Wide Survey Panel heard statements from each agency on its current survey operations, funding, and accomplishments, and is presently considering a detailed study of the technical data. NASCO has now agreed to reexamine its recommendation for oceanwide surveys in the light of these recent survey accomplishments. They will also evaluate our performance in response to their plan. The Ocean Surveys Advisory Panel is accumulating performance and cost data for their use in making this evaluation.

Through the ONR and NSF representatives on the Panel, these two activities, which together fund a very large percentage of the oceanography conducted by academic institutions, bring to the Panel a detailed knowledge of the plans and works in progress carried on outside the Federal agencies. Of course, the benefit is extended both ways-numerous cases arise in which the institutions can conduct work aboard Federal agencies' survey ships, thus avoiding costly duplication. For example, on the recent Equalant $I$ cruise, conducted under the International Cooperative Investigations of the Tropical Atlantic (ICITA), ONR-supported scientists from New York University were able to conduct detailed studies of a recently discovered equatorial undercurrent when the U.S.C. \& G.S. ship Explorer transited the Equator on an oceanographic cruise. Costs to ONR for the shipboard accommodations for the four scientists embarked was the nominal messing bill.

In another ocean, at this moment, University of Hawaii biologists and geologists and geophysicists from the Universities of California and Southern California, and the U.S. Navy, as well as meteorologists from the Weather Bureau using equipment from the Universities of Michigan and Wisconsin, and biologists 
from the Department of Interior all are now being accommodated on the U.S.C. \& G.S. ship Pioneer which is conducting a multiphase oceanographic survey in support of the International Indian Ocean Expedition. These two cruises just cited illustrate the genuine working communications between agency scientists and the outside scientific community. Through the interchange of agency plans by members of the Surveys Panel, very substantial economies are effected by sharing survey ship capabilities, as well as technological advances. These comments apply to survey vessels of the U.S. Navy, and ships of other ICO members also. I believe a brief enumeration of several tasks recently undertaken by the Panel might be an effective way of presenting another aspect of its work:

An independent evaluation of the NASCO-recommended ocean survey program, considering ship facilities, instrumentation, sampling density, reporting, etc., was deemed highly desirable in view of the magnitude of the proposed program. Modern statistical methods and operations research procedures for calculating the optimum density of sampling, ship speed, personnel stafing, etc., have been called upon. Although funded by the Coast and Geodetic Survey, the specifications for the study were prepared by the Panel, and the qualifications of the prospective operations analysts were formally graded by the Panel. The choice of contractor was made from the group selected by the Panel. The 18-month study now about half completed, has been based on data solicited and received from not only Federal agencies engaged in this work, but from a broad spectrum of scientists and administrators in the oceanographic committee at large. Copies of the reports to date, have been brought from the Panel's files. These summary statements distill the contents of detailed reports on instrumentation, survey ship design, and buoy networks. The Panel has continued to work closely with the contractor, and has received periodic progress reports from him.

The Ocean Surveys Advisory Panel has also been concentrating on other problems. One was the compilation of the agencies' plans for 1966 under the heading of "Ocean Surveys." Program statements have been received from all member agencies and will shortly be reproduced and distributed within the Panel following which a meeting will be held to discuss coordination of these operations. The various bureaus have been examining their own internal requirements in order to properly fit them into the ICO budgetary categories. Some agencies, having no money allocated to surveys, have in the past, been doing survey type work under the heading of research. A better definition of the objectives of the work has caused some revision in the reporting of funds to ICO for fiscal year 1966. After the meeting of the Panel, the smooth version of this part of the national ocean survey program for fiscal year 1966 will be prepared for ICO. This will then become part of national oceanographic program pamphlet for 1966.

The Panel recently considered a very carefully developed proposal for a study of the region which supports the extensive tuna fishery of the central Pacific. 'This plan, recognizing the role of physical oceanography in the sponsor's mission, requires facilities in excess of the BCF's in-house capability. Accordingly, the Panel has brought to all interested Federal agencies the sponsor's proposal. Those aspects of the program that can be aided by cooperation of the other agencies are currently being studied.

I have attempted to present a concise picture of what the Ocean Surveys Advisory Panel does through the use of a few specific examples. As you can well imagine, perhaps its most effective work is the day in, day out informal communication that exists between the Panel members, and the members of the other Panels with closely related functions; for example, the Research and Ships Panels. Indeed it is extremely difficult and not particularly desirable to segregate the functions of these three Panels. Fortunately, communications are good. Panel members are, in the main, scientists or engineers and administrators who have long been identified as experts in their respective fields. I believe the mutual respect and rapport that has prevailed has resulted in an effective method for managing the Federal oceanographic program.

Thank you for your interest. I would be pleased to attempt to answer questions you may care to ask. 
EXPLANATION OF ABRREVIATIONS USED IN COMMANDER NYGREN'S STATEMENT

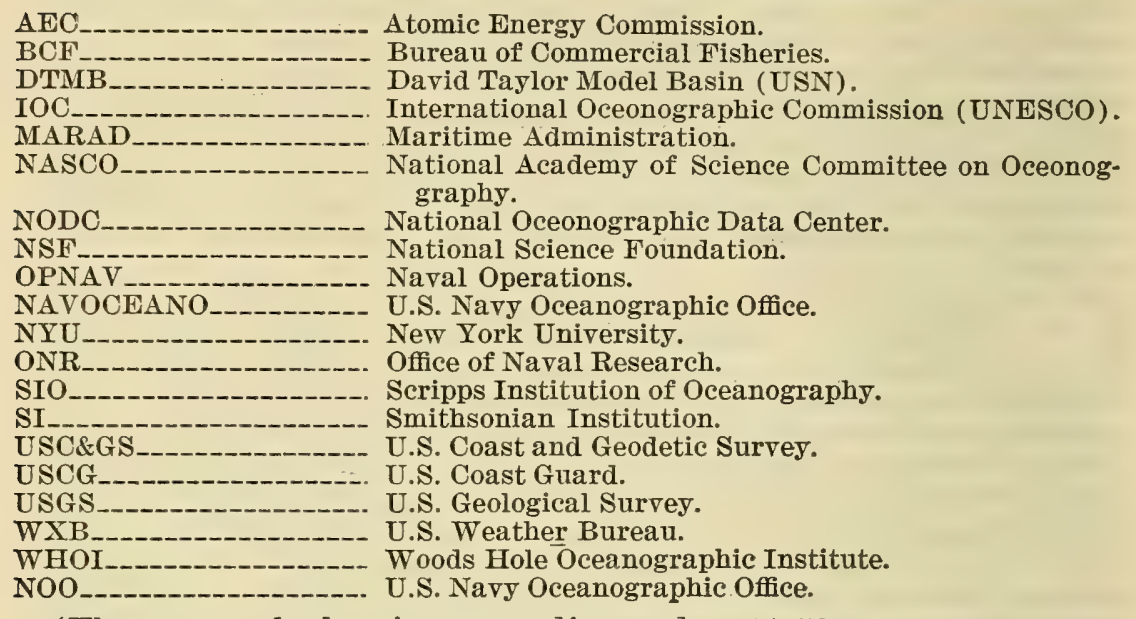

(Thereupon, the hearing was adjourned at 11:59 a.m. to reconvene at 10 a.m., Tuesday, June 30, 1964.) 


\section{NATIONAL OCEANOGRAPHIC PROGRAM-1965}

TUESDAY, JUNE 30, 1964

House of Representattves,

Committee on Merchant Marine and Fisheries, SUbCOMmitee ON OCEanography, Washington, D.C.

The subcommittee met at $10: 15$ a.m., pursuant to adjournment, in room 219, Cannon House Office Building, Hon. Alton Lennon (chairman of the subcommittee) presiding.

Mr. Lennon. The committee will come to order.

The hearings will be resumed at this point.

We have with us today, Capt. T. K. Treadwell, who is the Panel Chairman on Ships and Facilities to support the fiscal 1965 oceanographic program.

Captain, we are delighted to have you. We apologize for the absence of so many members of the subcommittee, but we run into these inevitable conflicts with other committees where they are in executive session, voting out bills, and taking other official activity.

You have a prepared statement, sir. Is it your desire to read the statement in full, or to go through and comment on the more pertinent points and then put the statement in the record? Whatever is your choice, we will be glad to accede to your request, sir.

\section{STATEMENT OF CAPT. T. K. TREADWELL, U.S. NAVY, CHAIRMAN, SHIPS PANEL OF THE INTERAGENCY COMMITTEE ON OCEAN- OGRAPHY}

Captain Treadweld. Mr. Chairman, the statement consists principally of a large number of tables which I think would be better entered in the record.

Mr. Lennon. I see your statement is not as long as I guessed when I picked it up. Suppose you stay with the statement and then take as much time as you like.

Captain Treadwell. The textual part summarizes the table. I think if I stuck with that and then answered questions following it?

Mr. Lennon. You may proceed.

Captain TreadwELL. I greatly appreciate the opportunity to be here on behalf of the ICO's Ships Panel.

This Panel is made up of representatives from the major agencies involved in ship construction and operations-Commerce, Interior, National Science Foundation, Navy, and Treasury. Its membership includes a wide range of experts, oceanographers, hydrographers, ship designers, safety experts, and ship operators. 
Perhaps the most important achievement of this Panel is a continuing interchange of technical information on ships, equipment, and operations. Technical personnel are often prone to follow their own line of work too closely and forget that there are other people with similar problems. As with all segments of ICO, we bring together people with mutual interests. This interchange results in several things, some of which are informal, some formal. As an example of the first we have the detailed exchange of information on how certain design features are working out, or how particular equipment is performing. An example of formal work, on the other hand, is the annual review of agency shipbuilding programs, and making recommendations concerning them to the ICO. Another is the preparation of an annual summary of ship operations which is developed by the Panel, covering ship operations which are scheduled for the coming year. I have the current 1965 copy of this available for the committee's use. It contains principally details which probably would not be suitable for insertion in the record but it is available for your inspection.

Mr. Lennon. Thank you, Captain, we are happy to have that document.

Captain Treadweld. This preparation of an annual ship operation summary permits considerable cooperative usage of ships and greatly decreases the possibility of duplication.

Decisions regarding shipbuilding are particularly critical, and require a great deal of soul searching on the part of the agencies and the Panel. The initial cost alone is a tremendous capital investment-over the first 5 years of our formal national oceanographic program, 27 percent of all funds have been spent on ship construction or conversion. Operating costs, when totaled over the expected useful life of 20 to 30 years, adds an even larger amount. As a result, probably no other part of the national program receives such scrutiny at all levels-within the agencies, the ICO, the executive offices, and the Congress.

Two other factors also make our decisionmaking particularly difficult. First is the long leadtime required for ship construction; frequently 3 to 4 years are required between the submission of a budget request and the actual placing of a ship in operation. Coupled with this lag is the unfortunate fact that oceanographic techniques, instrumentation, and equipment are making rapid strides, far more rapid than we can get the ships built; in effect, making up for long past years of neglect. How, then, can one assure that a ship designed and built today will not be obsolescent, or at least of limited usefulness, by the time it becomes operational? If I may cite just one example, when the designs for the Navy AGOR (research ship) class were drawn up 5 or 6 years ago, no one foresaw clearly the impact that buoys, aircraft, deep-diving vehicles, and improved instrumentation would have. We all try as best we can, to look into the future. The Navy is currently restudying the AGOR design, with a view to modifying it to follow these new trends. The Coast and Geodetic Survey also has completed a study which resulted in major design changes to their large survey ship. As we accumulate operation experience with new vessels, we will be able to speak with more assurance about what improvements should be made. 
As we complete 5 years under a coordinated national program in oceanography, it would be useful to see where we stand in our shipbuilding program. The attached tabulations show, for the major Federal agencies concerned, their inventory of research and survey ships, identifying those built or converted under the national program. Included also is the program now under consideration by Congress for fiscal 1965. The allocation of research ships to the various universities and private institutions is also included, since these organizations are an integral part of the national effort. I might summarize these tables briefly:

The Navy now has 18 survey and research ships operational, or in the pipeline, exclusive of those which it has provided for private laboratories. Six of these are new construction funded during the past 5 years, and two more are in the proposed 1965 program. Most of the new construction survey ships are slated to replace older, obsolete hulls, so that even this vigorous shipbuilding program will not produce great additional capability.

The Coast and Geodetic Survey had 14 ships operational, including 2 small wire drag boats. Under the national program nine more are under design or construction, seven of which will replace existing ships. Coast Survey is requesting one class I (large) ocean survey ship in the 1965 program.

The Coast Guard has 15 ships with oceanographic capability, much of which was developed during the last few years. None of these were constructed specifically as oceanographic ships, but rather are ocean station vessels, buoy tenders, and icebreakers which perform oceanographic work. Coast Guard has asked for funds in the 1965 program to conduct a design study for a vessel to replace the Evergreen, a buoy tender with oceanographic capability.

The Bureau of Commercial Fisheries has 14 ships larger than 100 tons in operation or on the way, of which 5 were built during the national program period. Another ocean research ship is requested in the 1965 program, again, to replace an older vessel.

The National Science Foundation, finally, has provided funds for the construction of 12 ships and numerous small boats. In fiscal 1965, they propose to fund the construction of a small vessel for biological research.

Mr. Chairman, that completes my prepared statement. I would be happy to answer any questions the committee might have.

Mr. Lennon. Thank you, Captain, for your very comprehensive statement.

Mr. Ellsworth, any questions?

Mr. Ellsworth. Thank you, Mr. Chairman. I have no questions. It was a very fine statement and I appreciated having it.

Mr. Lennon. Mr. Tupper?

Mr. Tupper. No questions, Mr. Chairman.

I will read this very carefully. I apologize for being late.

Mr. Lennon. Captain, what would you say that our national posture is compared with other nations as to the number of ships that are actually today engaged in the various facets of oceanographic work?

Captain TreadweLL. I would say that compared to most large maritime nations we are in very good shape. The major ones who have large oceanographic programs have also mounted similar building and 
research programs to support whatever they see to be their national aims. I don't think we have to take our hat off to any other nation, with the possible exception of the Russians. The Russians have a very substantial program, and they have been working at it for a number of years. They have a vigorous ship-of-opportunity program, I am sure, to get information from their trawlers and fishing vessels. I would say that they are probably your closest competitor.

Mr. Lennon. In lead time in years, how much advantage does Russia have, or putting it in a more direct question, how long have they been engaged in the oceanographic research compared with our program of oceanographic research?

Captain Treadwell. I do not know exactly, Mr. Chairman, but their major advances in this came to my attention at about the same time that the United States first began to become aware of the potentialities. I think that this increasing awareness of the importance and value of oceanography occurred almost simultaneously worldwide, in the immediate postwar period.

Mr. Lennon. Are you saying in your judgment that we have enough, or enough as reasonably projected for the near future, in oceanographic ships or ships capable of oceanography research in the various fields of oceanography?

Captain Treadwell. I would say that the shipbuilding program to date has been generally commensurate with the funding of the remainder of the program. They have not been too far out of line. It is always very tempting to cut a ship out of the oceanographic program. It is a large chunk of easily identifiable cash which can be trimmed, and you do not see the detrimental effect of this trimming for some time in the future.

I think that the place where our lack of advance on the shipbuilding program will show up is perhaps 5 to 10 years in the future. Then many of the older ships which we have in stock right now will begin to break down, as they are beginning to do already. If we have not planned and built the ships to replace them, 5 years from now we are gong to be in serious difficulty.

Mr. Lennon. Captain, with the Navy and the Coast and Geodetic Survey and Coast Guard and the Bureau of Commercial Fisheries and the Department of the Interior engaged in the meaningful objectives of oceanography in their respective fields, is there any degree of duplication or overlapping that is unnecessary?

Captain Treadwell. No, sir; none has come to my attention. Duplication in surveys and in research is, I believe, very largely eliminated at the panel and the ICO level. With regard to duplication in the shipbuilding program itself, I do not foresee that within the near future anyone is going to have enough ships so that duplication would be likely.

Mr. Lennow. How long have you served as chairman of this particular panel, Captain?

Captain Treadwell. About 2 years, sir.

Mr. Lennon. And how many meetings of your panel group would you say have taken place during this period of 2 years?

Captain Treadwell. I would guess we have met formally about 14 to 20 times in the last 2 years. Our work, of course, is very seasonal, in the preparation of the annual shipbuilding program and in the prepa- 
ration of the oceanographic ship-operating schedules. During other times of the year there is more need for informal contacts rather than formal panel meetings.

Mr. Lennon. Does your panel have occasion to meet from time to time with other panels who are interested in other closely related objectives?

Captain Treadwell. We have never met formally with them as two panels. We quite frequently attend the other panels' meetings to insure, particularly with the research and with the ocean survey panels, that their needs are being met in the shipbuilding program.

Mr. Lennon. Does your recommendation of your panel go to the ICO or to the respective agency involved, or to both?

Captain Treadwell. It goes to both. It goes formally to the ICO, and it goes back both through the panel representatives and the ICO representatives to the agency concerned. So, we wind up, hopefully, both with an agency-approved program and with an ICO-approved program.

Mr. Lennon. Mr. Bauer, who is the consultant to the full committee and assigned to this committee and hearings of this nature, we are glad to have you, sir. I wonder if you and chief counsel, Mr. Drewry, have any questions you would like to ask of the captain?

Mr. BAUER. I have several, Mr. Chairman, that were more or less referred by the previous witness at the last meeting, Commander Nygren, inasmuch as Captain Treadwell is in a better position, being in the Navy.

The question is, is the availability of naval vessels for ocean surveys more or less precluded for the near future by virtue of the necessity of Navy survey vessels engaging in special surveys of interest only to the Navy?

Captain Treadwell. Yes, as far as having ships set specifically aside to do nothing except general charting of the oceans. I do not foresee within the next year or so that any Navy ships can be so assigned. We had a ship in the 1964 budget which was earmarked for this work; it was cut out by the Senate, for, I am sure, very good reasons.

I think I should make it clear, though, that the Navy, along with all other agencies, although they have no ships specifically assigned to the oceanwide survey program, do, in fact, contribute very heavily to it.

To take the Navy as a specific example, practically everything that we do contributes to the program. There is so much of the ocean which is unknown that you can go out there and survey almost anywhere and be generating new information. Even our classified work, once it can be downgraded or sanitized to the point where it is available for general distribution, does contribute to the program.

We also have a very active program for ships of opportunity, the utilization of nontechnical ships, which contributes to this.

Mr. BAOER. Captain, you have quite a program, do you not, in the Navy, for utilizing ships of opportunity? I would like you to talk to that.

Captain Treadwell. Yes, sir.

As a matter of fact, if it were not for the ships of opportunity, the Navy would be even further behind than it is in its survey program.

One of the main sources of ship of opportunity data in the Navy, 
which people do not often think about, is the use of fleet ships. For 10 to 15 years we have had an active program having combatant and auxiliary ships take soundings and bathythermographs, plus current data, weather reports, all the related information that they can get, and send it in to the Navy.

Last year, for example, over 8,000 voluntary reports came in from this sort of ship of opportunity. These were divided among Navy, Coast Guard, MSTS, merchant marine, fishermen, people who are all aware of the benefits that they can get by providing this information into the common pool.

In addition to that, we have had specific projects such as in the mine force in the 6th Fleet in the Mediterranean, called Project Flood. Under Project Flood, Navy puts on board mine craft packages of instrumentation to take soundings, temperature, salinity, current, and bottom samples. We provide a man ahead of time to train the ship's crew to use these, and the data is sent back.

Right now we have about 10 ships working on it; they are providing a tremendous amount of information in the holiday areas in the Mediterranean.

The Navy has also very recently approached the merchant marine through the American Merchant Marine Institute, to get participation in a bathythermograph program by tankers and cargo ships.

With the assistance of the Merchant Marine Institute we approached 40 of their member companies, asking them to use Navysupplied instrumentation and provide us the data. So far we havewell, it was only started very recently, but we have heard from three companies which have responded favorably. Only one has said no.

If we can get this program going we will begin to tap the merchant marine.

Mr. Baver. Have you explored any exchange of data agreements with the geophysical industry?

Captain Treadwell. With the commercial companies?

Mr. Bauer. Yes.

Captain Treadwell. Yes, sir. The Navy has had for about almost 3 years now a working agreement which was negotiated through the Society of Exploration Geophysicists. This agreement is with the various oil companies and exploration companies who produce principally gravity, magnetics, and subbottom geophysical work. We received - the figure slips my mind-but a tremendous amount of our stock of geophysical data has come in through these commercial sources.

As one particular case in point, we recently had a request by the Pacific Missile Range for some gravity data, and we were able to fill this from commercial sources, without tieing up Navy capability to getit.

Mr. Bauer. Does the Coast and Geodetic Survey know of this program?

Captain Treadwell. Yes, sir; they are aware of it, and as Commander Nygren mentioned the other day, they are instituting a similar program.

Mr. BAUER. That is all I have, Mr. Chairman.

Mr. Lennon. Mr. Drewry? 
Mr. Drewry. Captain Treadwell, you mentioned the allocation of ships to various universities as being part of the overall program.

Following up what Mr. Bauer was just bringing out, and in view of the lack, or shortage, of ships available exclsively for survey work, would it be feasible to call upon the geophysical industry on a contract basis to perform survey work and collect oceanographic data when their vessels are conducting mineral exploration surveys in various areas of the world where oceanographic data is inadequate? This would be in addition to the data which the industry normally acquires in connection with their geophysical surveys. Would it not be feasible, relatively simple, and less costly for the Government to work through the geophysical industry which is presently operating dozens of ships all over the world with crews trained in just the type of techniques required in an oceanwide survey program? It would seem to me an advantage to the national oceanographic program to encourage participation by industry as a functioning part of it. Of course I presume there is area planning on your survey work so you don't want to bother about contracting for survey data in an area where you have already acquired what you need to know, especially if there is some other area that has not been surveyed at all.

Has there been anything done in this direction?

Captain Treadwell. As far as I know, Mr. Drewry, there has not been anything in that direction for a couple of reasons. $I$ think the idea is basically sound. However, the areas which the geophysical companies are interested in from a minerals exploration standpoint are only by coincidence the same areas that, say, the Navy, or Commercial Fisheries, or anyone else would be interested in from another viewpoint. Where these two areas coincide certainly we should take advantage of it. The other point is that to a very large extent we are getting so much of the information we need free, just from their sense of public duty, that we would be a little reluctant to pay them to do what might not be very much more.

Mr. Drewry. I put that point in my question because I understood from some previous witness that one difficulty with calling upon the geophysical industry for data which they have already collected is that they do not collect some types of data in the same way or in the same scope that you would want in the overall program. That is what I had in mind. If that is a fact that they do not collect adequate data then it would seem logical that if you can use what they do collect it would be a rather less costly way to take advantage of what we need right now while we are starting off on this program to get every possible platform that is in existence to get the information while you are waiting for the ships to be built and the money for the new ships to be appropriated.

Captain Treadweur. That is a very good point. For example, they do not ordinarily take things like biological observations because they have no commercial interest in it. That is a very good point and well work looking into.

Mr. Drewry. I am also interested in the subject of the merchant ships. I had not heard about it from any of the merchant marine companies. What is the scope of what you have discussed with them?

Captain Treadwell. We have asked several of their member companies to put on board bathythermographs and send the data back to us. 
The cost of the equipment and the cost of installation would be paid for by the Navy, the observations themselves would be made by the regular crew on board ship. So far, the only point of discussion is whether or not this can be done by the crew without going into additional cost for the company concerned. But I believe that this can be worked out.

Mr. Drewry. Now, you say you have talked to three companies and they have shown interest. Do you have any objection to mentioning the names of the companies?

Captain Treadwell. I do not have them here. I can provide them for the record. As I say, we approached them through the Merchant Marine Institute and they recommended about 40 member companies as a pilot project. We have written to these 40 companies and of the 5 responses we have received, 4 were favorable and 1, unfortunately, was unfavorable. I can provide further information on that.

Mr. Drewry. I would like to have that, Mr. Chairman, if I may.

(The following data was supplied as requested:)

Shipping and Geophrsical Companies Approached by the Navy Oceanographic OfFice With Respect to Ocean Surveys

The following companies have been approached :

Alcoa Steamship Co., Inc.

American Export, Isbrandtsen, Inc.

American Oil Co.

American Trading \& Production Corp.

Atlantic Refining Co.

Bethlehem Steel Co., Marine Division.

Bloomfield Steamship Co.

California Steamship Co. (2 offces)

The Calmar Steamship Co.

The SEFOR Cargo Ships, Ine.

Central Gulf Steamship Corp. ( 2 offices)

Chemical Transporters, Inc.

City Service Tanker Corp.

Farrell Lines, Inc.

Grace Lines, Inc.

Gulf \& South American Steamship Co., Inc.

The Hess Oil \& Chemical Corp.

The Hudson Water Cruiser Corp.

Humble Oil \& Refining Co.

Keystone Shipping Co.

Keystone Tank Ship Corp.

The Kurz \& Co.

The Lykesbrother Steamship Co.

Marine Navigation Steamship Co., Inc.

Moore-McCormack Lines, Inc.

The Mystic Lines, Inc.

The National Bulk Carriers, Inc.

Taco Tankers, Inc.

Prudential Lines, Inc.

The Pure Oil Co.

Sobine Towing \& Transportation Co., Inc.

Shipping Enterprises Corp.

Sinclair Refining Co.

Socony Mobile Oil Co., Ine.

T. J. Stevenson Co., Inc.

The Sun Oil Co. 
Texaco, Inc.

Tidewater Oil Co.

Trinidad Corp.

United Fruit Co.

United States Lines

Mr. Drewry. I am interested in this point because I have talked personally with a number of people in the American shipping industry and they show a rather wide degree of interest in doing whatever they can to cooperate. It still sounds a little bit like a mystery to them, but they would like to know what they can do. With some 300 ships among the subsidized lines alone that are crisscrossing all of the oceans of the world on routes where they could deviate as much as 100 miles on either side of their normal route without delaying their occupation, it would seem to me that there is a valuable source of survey assistance there that could be tapped.

Captain Treadwelt. That is correct.

Mr. Drewry. On the question of cost, I have talked to at least one maritime labor leader, a vice president of one of the nonlicensed unions, who expressed interest in it and foresaw no problem, as long as this was in connection with the national program, of causing any extra cost burden by virtue of the payment for the personnel who are on the ships who might do the reading. In fact, we got an indication they would like to do it. The duties of a seaman sometimes leave a little time on his hands.

Captain Treadwell. We also have found the merchant marine, or anybody else, very cooperative once their connection with the program and the possible benefits of it were clearly pointed out.

This really is the key point, to show how this will ultimately benefit them.

Mr. Drewrry. There is enough work that has to be done that there is no reason to expect that a program of this sort, this type of use of ships of opportunity, would in any way conflict with the work of those institutions and agencies that are regularly engaged in oceanographic work, is there?

Captain Treadwell. No; no possibility of that within the foreseeable future. The ocean is a very big place.

Mr. Drewry. That is all, Mr. Chairman.

Mr. Lennon. Do you have some other comments, Captain?

Captain Treadweld. No, sir; I do not believe I have anything further. Oh, I am sorry, I do have a piece of information concerning the one company which was reluctant to cooperate. This was simply because they did not want to slow down to a speed of 15 knots. They felt that this would interfere with their operation.

Mr. Lennon. You mean figuratively or literally?

Captain Treadwell. Literally.

Mr. Lennon. Captain, we appreciate your fine statement, and without objection your attached statistics and tables shall be included in the record as a part of your statement, and without further objection, if the information requested by Counsel Drewry could be furnished for the record, sir?

(The material mentioned follows:) 


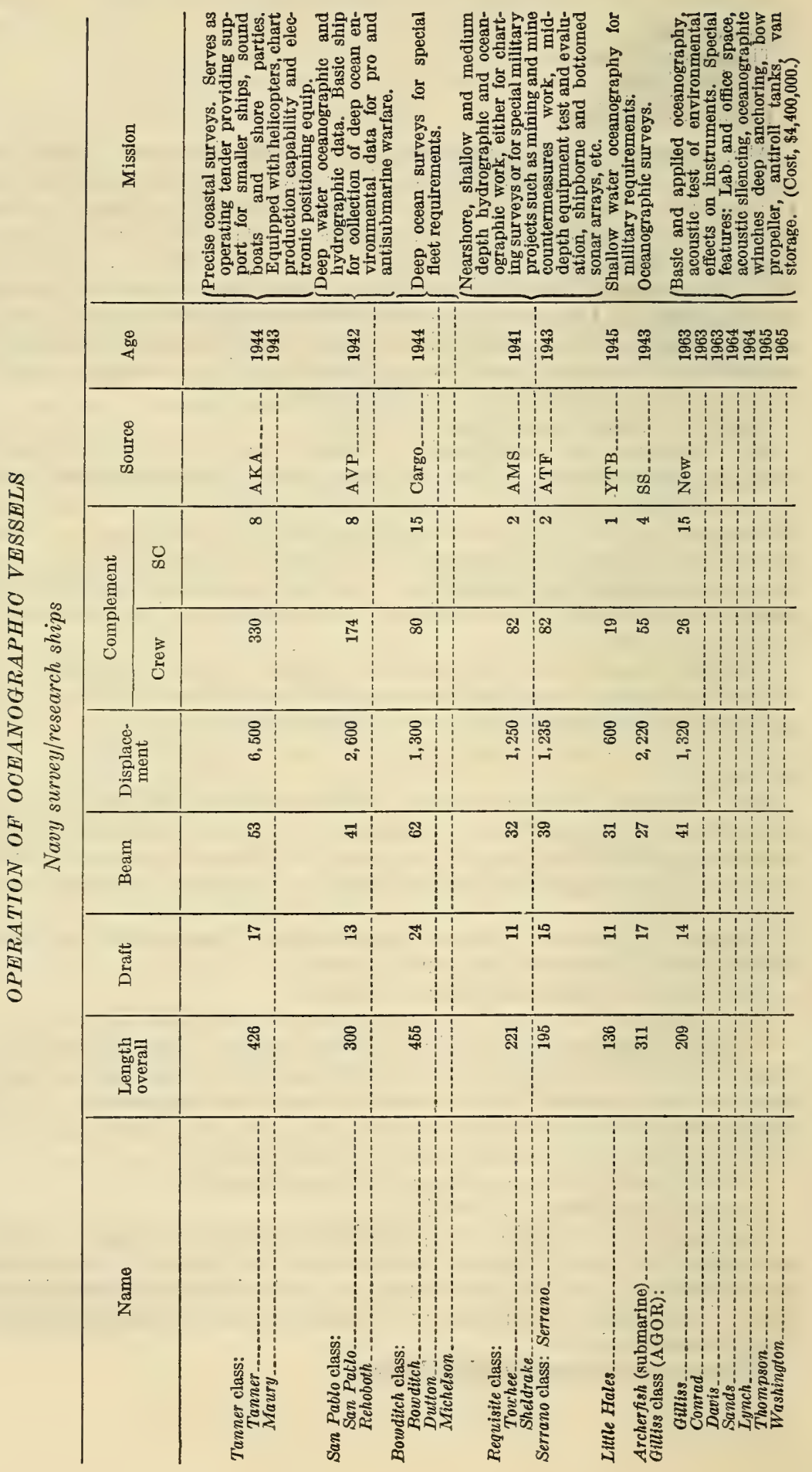


NATIONAL OCEANOGRAPHIC PROGRAM-1965

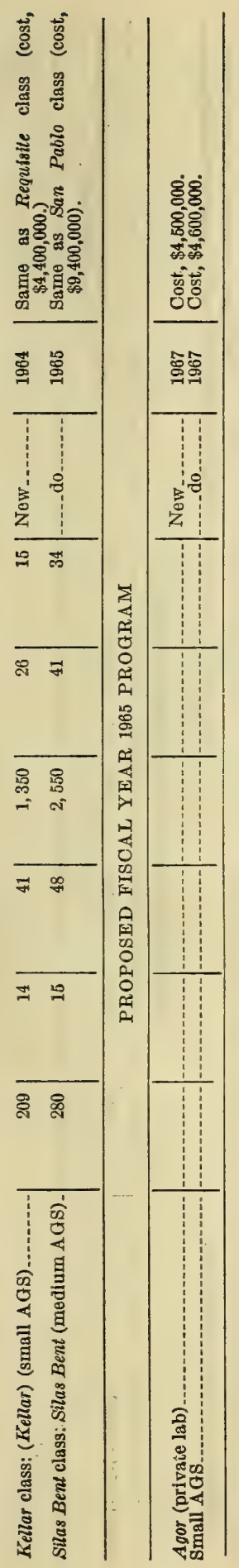




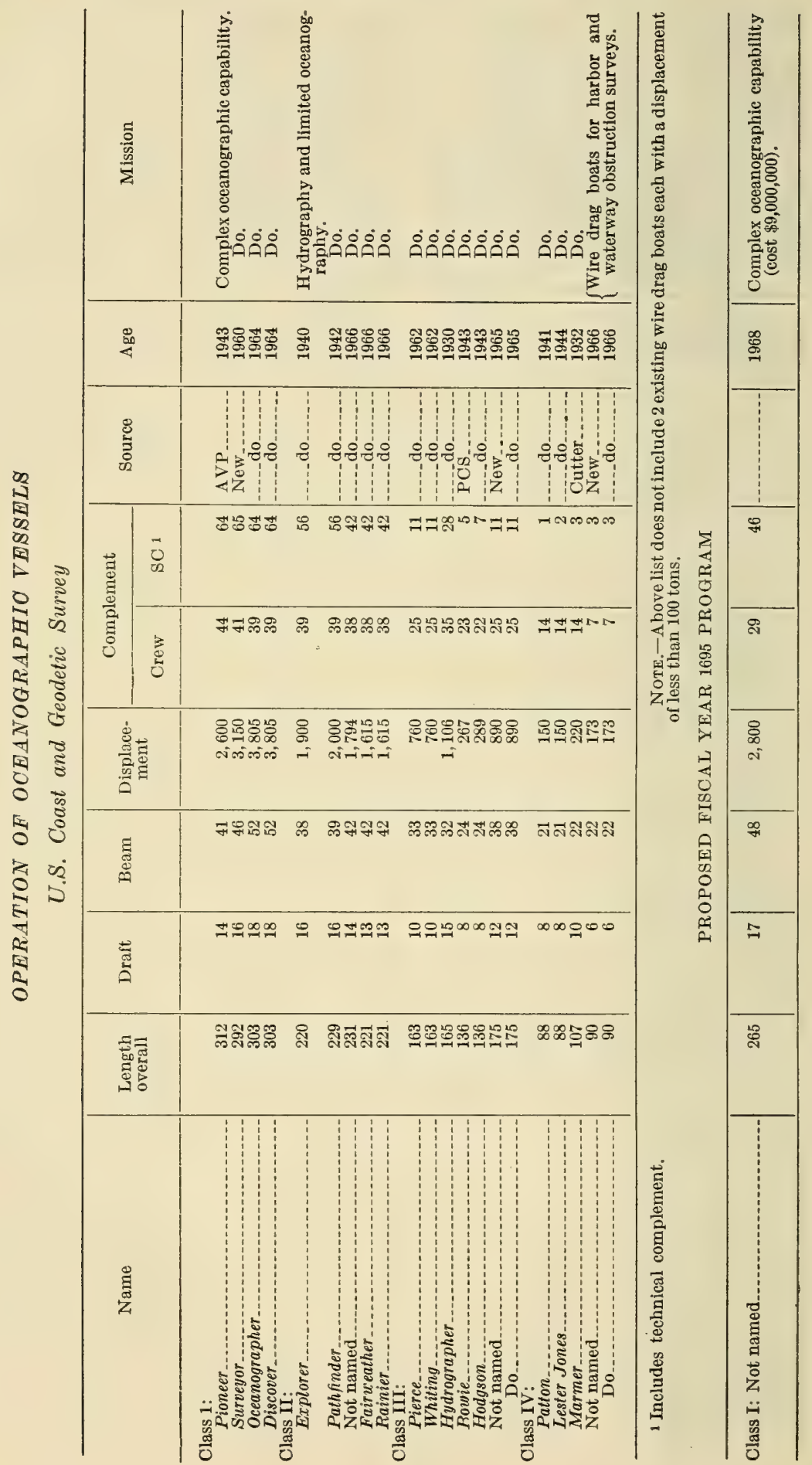




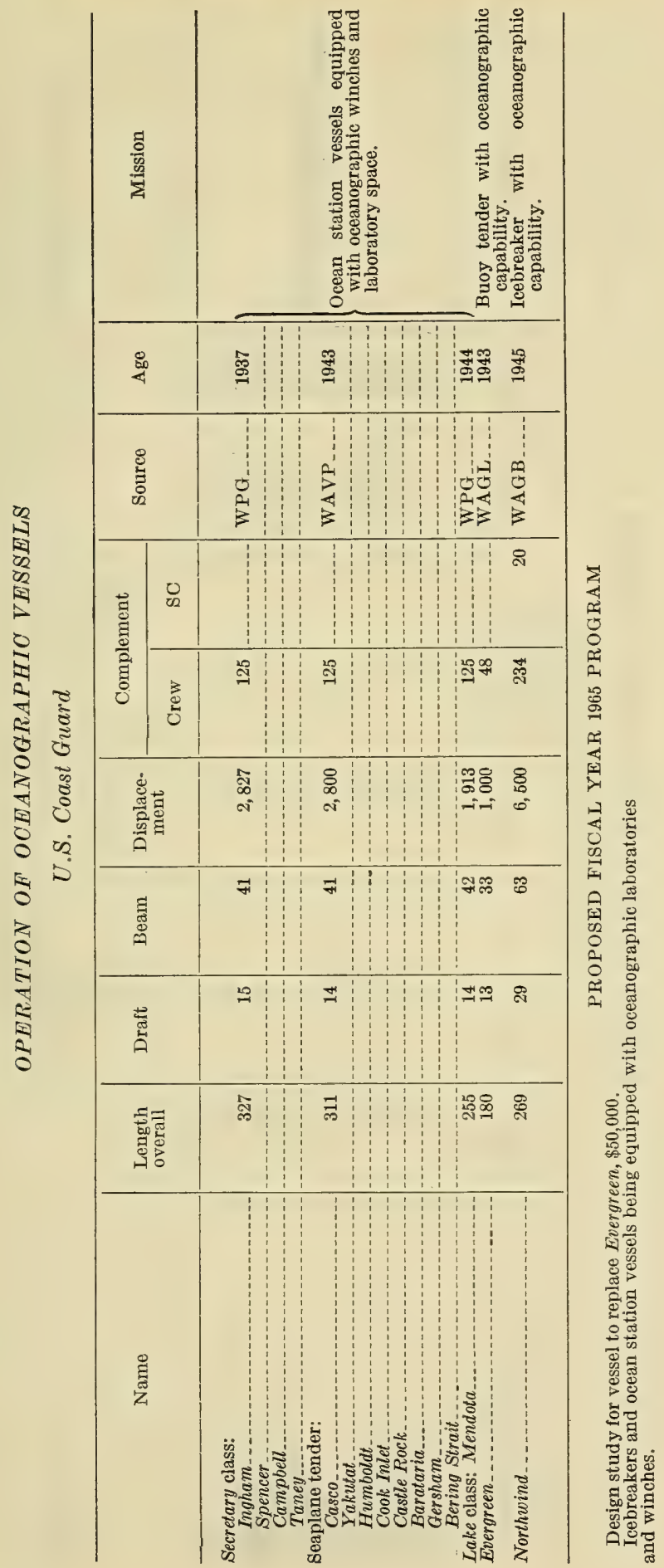




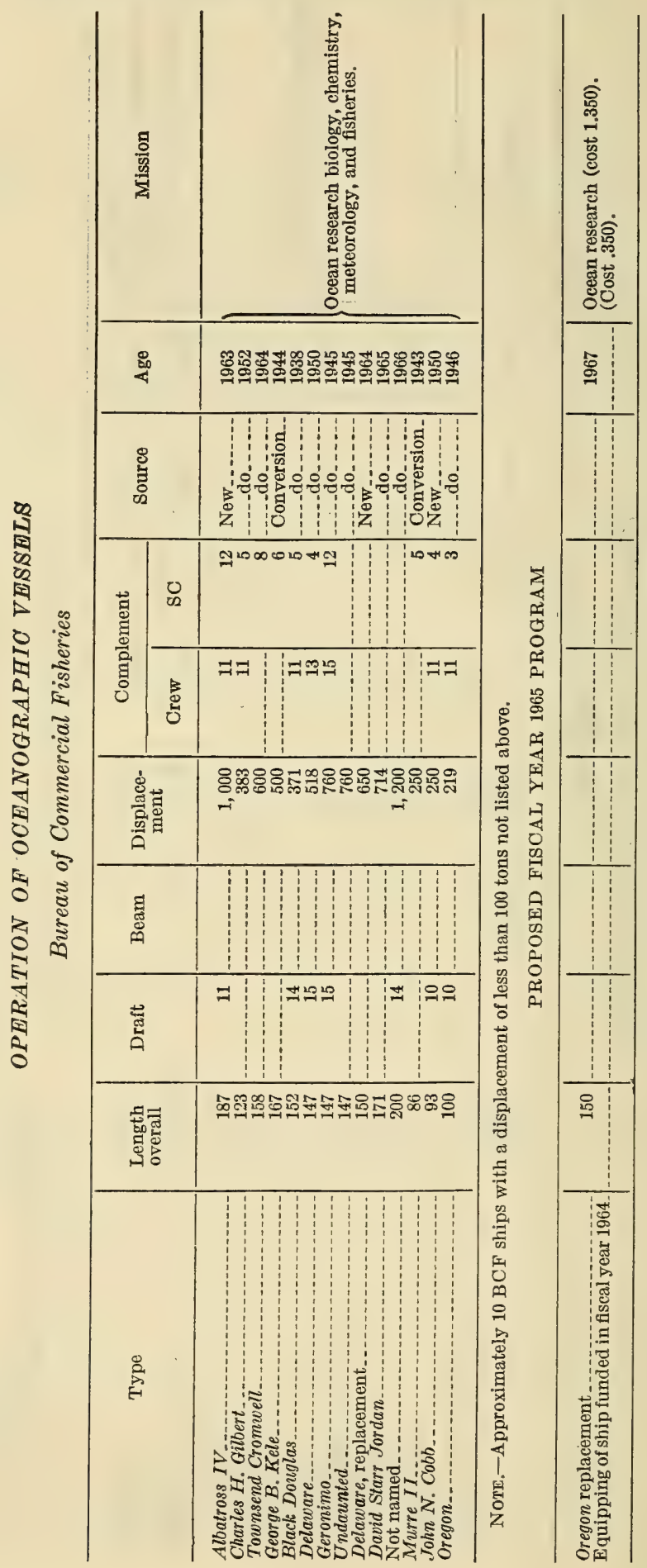




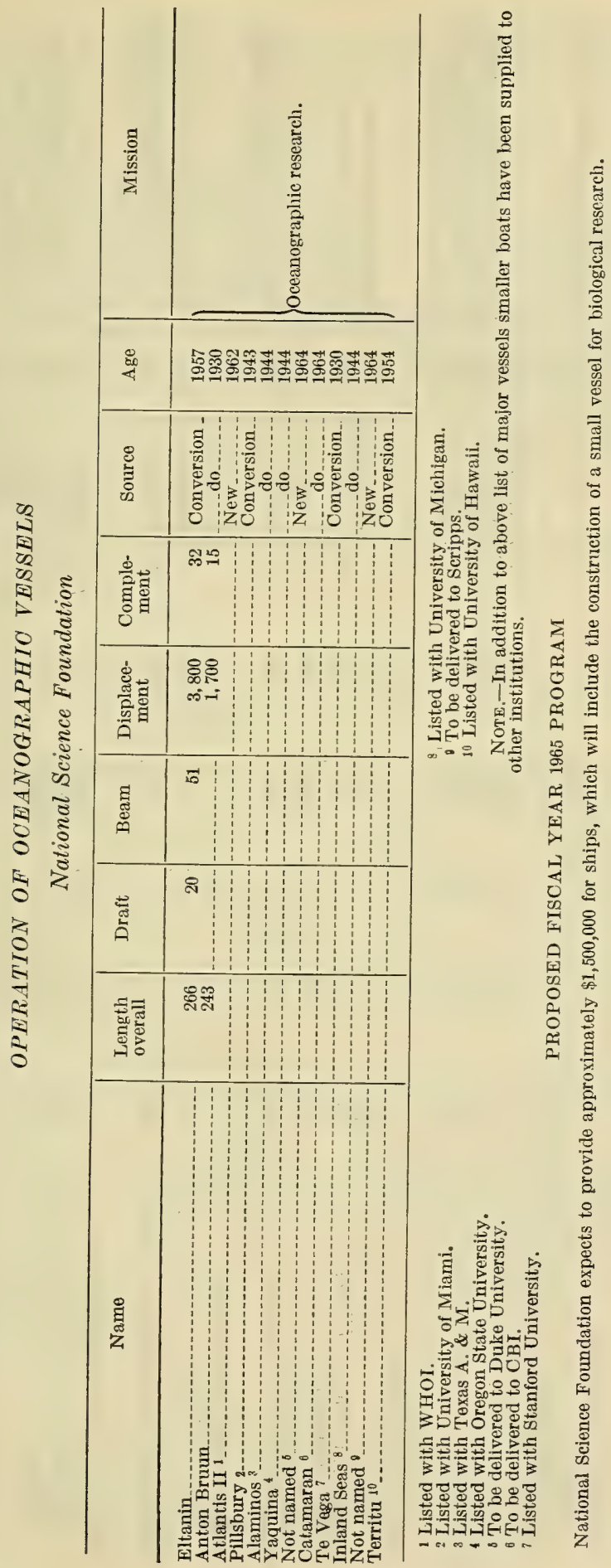




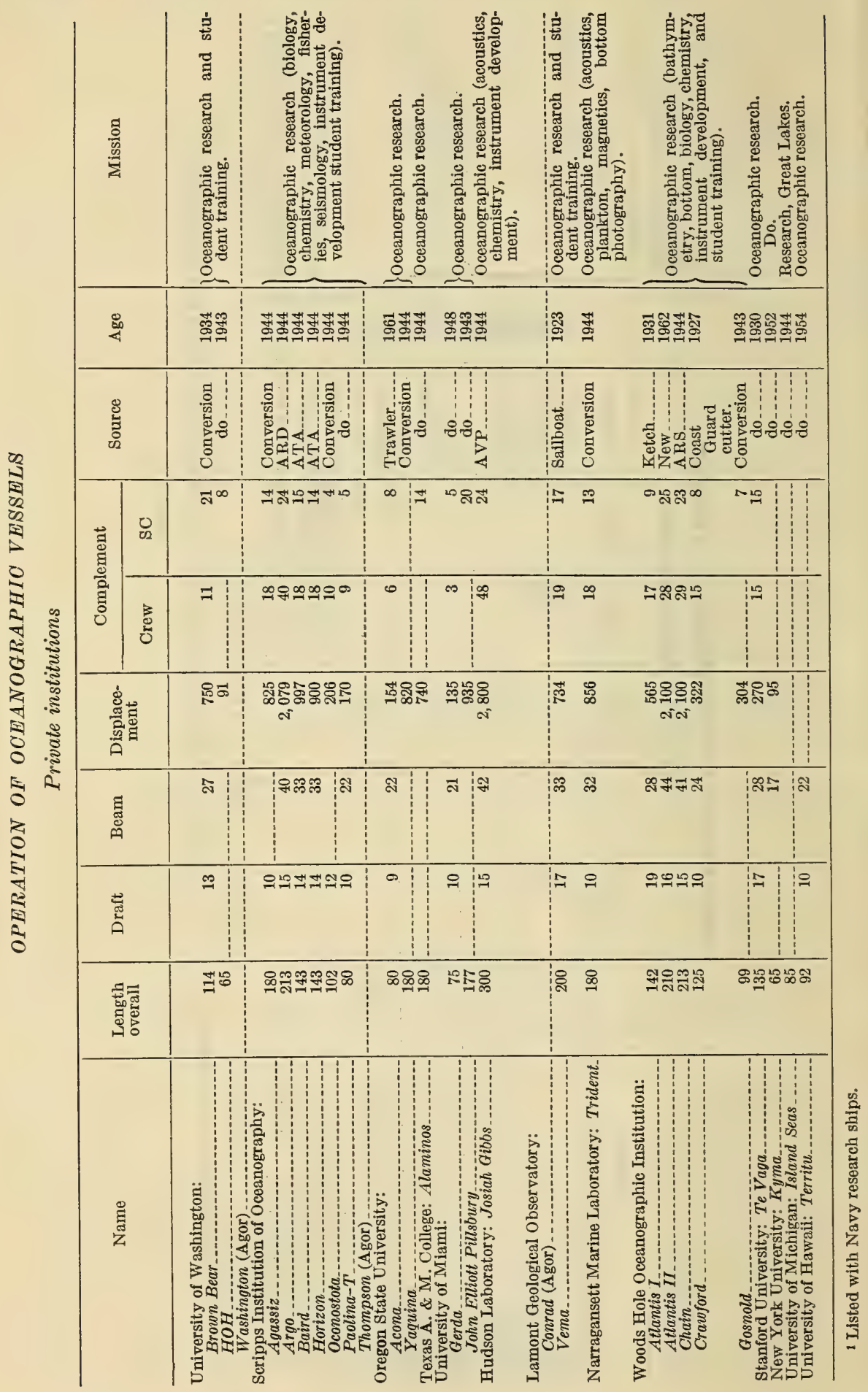


Mr. Lennon. Our next witness is, in the absence of Dr. Woodrow Jacobs of the National Oceanographic Data Center. I wonder who is here to make the presentation for Dr. Jacobs? I lunderstand he is hospitalized.

Mr. Dubacr. I am Harold Dubach. I am the deputy and D. Jacobs has been ill for about 2 months.

Mr. Lennon. We are glad to have you. Would you give your full name to the reporter and we assume you will use the statement that is now being handed to the members of the committee. You may have had some part in the preparation of this statement and for that reason it is very probable that you would like to go through and pick out the parts that you would like to lay specific emphasis upon and then, of course, Dr. Jacobs' full statement will be included as part of the hearing'record. Whatever is your choice.

Would you want to take it in its entirety or go through it and pick out the highlights of it? Of course, the whole text of it will be put in the record.

Mr. Dubacr. I believe I would prefer just to hit some highlights, if I may.

Mr. Lennon. All right, lay specific emphasis on the things you think we ought to be advised of:

\section{STATEMENT OF HAROLD W. DUBACH, DEPUTY, NATIONAL OCEANOGRAPHIC DATA CENTER}

Mr. Duвасн. If you will recall in the last report, the Data Center's governing body is an advisory board on which sit representatives of each of the sponsoring agencies and two representatives of the National Academy of Sciences. In January of 1964, Dr. John Lyman replaced Mr. Howard Eckles as Chairman of this Board. Also, since the last report to your committee, changes have been made in the representation by the Atomic Energy Commission and the National Academy of Sciences. Mr. Joseph and Dr. Kask have replaced Dr. Schultz and Dr. Shaefer who are the respective representatives of those agencies. I should also like to mention that in fiscal year 1964 the Coast Guard became one of the NODC sponsors. During fiscal year 1965 three other agencies have indicated their desire to become sponsors of NODC. These are the Geological Survey, Coastal Engineering Research Center, and the Department of Health, Education, and Welfare. Our sponsors in fiseal year 1965 will then total 10. Each year the NODC prepares a summary of its work and accomplishments as an annual report which is presented to the advisory board and submitted to the sponsoring agencies. With your permission, Mr. Chairman, I would like to submit the annual reports for fiscal years 1962 and 1963 for the record.

Mr. Lennon. Without objection, that will be included as as part of your statement in the record.

(See apps. 8 and 9, p. 623 and p. 655.)

Mr. Duвach. Recording our accomplishments: In the 3 years since the inception of the NODC we have been working toward a greater adaptability of processing systems already in use, as well as attempting to diversify into fields not presently being processed with any great degree of uniformity in the United States. 
Working toward this goal of ready accessibility, we have begun to convert the previous punched card system for physical-chemical station data into a new magnetic tape system. This will enable us to assemble these data so that we may retrieve the valuable temperature, salinity, density, and sound velocity information at a more rapid rate than ever before. We have, therefore, initiated a program of digitizing these data into a magnetic tape system of uniform units which will enable us, with the aid of a computer, to provide information in a few hours which would otherwise take months or years to tabulate.

Our present archive contains physical and chemical data from about 260,000 oceanographic stations which is contained on over 5 million punched cards. When these data are distributed over the world's oceans in all seasons, one can see that there are many areas of the world where little or no data are available. We are attempting to fill some of these gaps through a vigorous acquisition program and exchange with other nations. These data are being processed and archived at the rate of three-quarters of a million punchcards each year.

Our archives of bathythermograms, or BT's as we know them, now contain approximately 850,000 analog temperature records for depths up to 900 feet. We are continuing to process approximately 30,000 each year from survey ships or other vessels for which there is an urgent and immediate need. Emphasis has been placed on digitizing $\mathrm{BT}$ data and putting it into a form that will make it available for computer programs. Proceeding with a new system, we have digitized approximately 50,000 of the existing archives of 850,000 analog temperature records on a pilot project basis. Over 2 million data points are involved and are contained on approximately 250,000 punched cards. Since the system has been examined and approved by members of the oceanographic community, we plan to step up production during the coming year, processing into a magnetic tape storage system what will be the equivalent of more than 100,000 observations. Because new data are being received at the rate of about 90,000 observations per year, this effort is still far short of what will be required to complete the ultimate goal of digitizing the entire backlog and keeping up with the contemporary inflow.

A variety of other data are received in manuscript and other forms. Standard storage-retrieval systems and determination of standard recording forms have yet to be determined for these data. Nevertheless, these data are organized in a logical manner, usually geographically and by data type and date, and are available to the oceanographic community on demand in their existing form, which is usually a manuscript log-type form. Development of appropriate storage-retrieval systems for these data will proceed as our research and development of systems for data types now in work are completed.

In January of this year, we began geological and biological production on a pilot study basis. Core, grab, and dredge data from approximately 2,100 geological stations have been put into the geological storage-retrieval system for test purposes. Similarly, approximately 1,200 biological stations, represented by 5,000 punchcards, have been entered into the biological storage-retrieval system also for testing purposes. 
To summarize the chief contributions of the Data Center since its inception, I would emphasize three points:

First, through our efforts there has been increasing emphasis on the use of standardized procedures in recording and reporting. In the past, oceanography has been plagued by a multitude of recording forms and incompatible observation and reporting procedures. The NODC fortuitously has turned out to be the catalyst that has brought the diversified oceanographic interests together to do something concrete about this long-standing problem. The Data Center will continue to sponsor and cooperate in these endeavors.

Second, from the beginning, the Data Center has emphasized the application of quality control procedures to the data processing techniques, so that the scientist is assured of receiving the highest quality data possible under the circumstances.

Third, we have emphasized personal service. Services include providing technical information, educational materials, and advice beyond that represented by the simple provision of hard data.

Then just a word about our services. Regarding our service to the oceanographic community, the NODC has been called on many times to furnish statistically summarized and analyzed oceanographic data for industrial, private, and Government organizations which need information on the environment for various applications and uses.

I would like to give you some idea as to the volume of the reimbursable work performed at the NODC. During fiscal year 1961 our reimbursable funds amounted to about $\$ 3,000 ; 2$ years later during fiscal year 1963 , they increased to over $\$ 200,000$. It must be pointed out, however, that these figures include governmental and nongovernmental requests for services. Details on the services supplied are given in the annual report, previously submitted.

At this time I would like to submit for introduction into the record some of the other publications produced by the Data Center.

Mr. Bauer. Mr. Chairman, I suggest that the inclusions in the record be by reference rather than by printing.

Mr. PeLcy (presiding). Without objection, that will be included by reference only and made available.

Mr. Dubach. Yes, sir. I think that these are referenced in the full context that represents Dr. Jacobs' statement.

Now I would like to outline briefly our progress in research and development.

We have developed a holding-recall system for indexing core, grab, and dredge samples. Additionally, a system for handling the chemical analyses of sea bottom materials has been completed and currently is being circulated for approval of the oceanographic community. In work is the development of a system for handling the physical properties of sediments. Significant advances have been made in the development of holding-recall systems for hydrobiological data. Developed - and approved by our Interagency Advisory Board-to date are holding-recall systems to handle environmental data, phytoplankton primary productivity, phytoplankton pigment data, zooplankton data, and benthos data.

Progress is being made in the field of physical-chemical data as well. A holding-recall system has just been completed for drift bottle 
data. The NODC has worked very closely with Mr. Dean Bumpus of the Woods Hole and Dr. John Norcross of the Virginia Institute of Marine Sciences. Also under development are schemes for handling nearshore oceanographic data, instrument-measured current data, and nonnutrient chemical data.

It should be pointed out that all holding-recall systems are developed in concert with the oceanographic community. Extremely gratifying is the cooperation the NODC has received from the oceanographic community which is reflected in their willingness to serve on the various ad hoc committees formed in conjunction with our developmental work.

Quality control of oceanographic data is the third item I would like to touch on.

Now that the NODC has had the experience of nearly 3 years of working with various types of oceanographic data in a multitudinous variety of formats, we can rationally approach the problem of developing and implementing automated quality controls. I do not mean to imply that until this time there has been no application of quality control, but practically all of it has been applied subjectively. With our present backlogs of data and our present and future acquisition effort, we would be naive to believe that we could continue to apply subjective quality controls. To have applied automated quality controls at the outset of our operation would also have been naive since no end products had been defined and we had practically no guidelines for total systems. Now we feel we are ready to begin with an automated system.

Shortly, we expect to have in operation a computer program which will check some items of a routine nature which at the present time are monitored by our oceanographers. This will then give additional time for these oceanographers to assess the scientific plausibility of the data. One of the first attempts at automated quality control that we will implement shortly is a program which will check the quality of work done by contractors who are digitizing the BT work for the NODC. This will not only insure that a major contractor is capable of performing quality work, but will also provide a quality check as the work progresses.

We are making some inroads on the problem of quality control of oceanographic station data. We have machine plotted all the temperature-salinity relationships for the historical data for the Indian Ocean and are currently funding for a similar analysis for the Pacific Ocean. From these plots we are generating envelopes of acceptable limits which for the time being will be used in our subjective quality control program. This is to serve as a first step in the generation of a mathematical computer for the subjective approach.

Just about a year ago we were able to demonstrate very dramatically how quality control can pay off through rapid communication systems. During the Equalant I and II phases of the international cooperative investigations of the tropical Atlantic known as ICITA, in 1963, the NODC received, on a daily basis, meteorological and oceanographic messages from ships participating in the surveys. During these surveys, we accomplished what we believe to be a "first" in oceanographythat is, the radio receipt of a complete oceanographic station within a matter of hours after the station had been occupied. These were then 
continually received at the rate of one per day. Receipt of data at the present time may vary from as much as 1 month to several years after the data are taken. The basic reduced data were fed to a computer and the computations for density, dynamic depth, specific volume anomaly, and sound velocity were made as were interpolations of these values for internationally accepted standard depths. This in itself demonstrated that an oceanographic program for almost instantaneous receipt of data was feasible. As the surveys progressed, the NODC developed an evaluation message which was communicated back to the ship at sea. During the Equalant II, both an American vessel and an Argentine vessel daily transmitted oceanographic data to the NODC. The messages returned to these ships consisted of an evaluation of the observed data against the historic data and served as a means of intership comparison of data. It is interesting to note that the observed data received from both ships showed a bias of very small magnitude in the same direction. The implication of this was that both ships were collecting high quality data.

The finale of this experiment in quality control and communications occurred on September 19, 1963, during a combined operation of the Washington Laboratory of the Bureau of Commercial Fisheries, NASA, and the NODC. On that day, with time available on the Syncom II satellite communication system, the BCF ship, Geronimo, radioed station data to the Kingsport which was the Syncom surface station, which in turn communicated the data to Washington via Syncom II. The data were computed and evaluated by the NODC and salinities were found to deviate significantly from what would be the expected norm for the area. In other words, either a hitherto undiscovered oceanographic phenomenon was occurring in the area or something was wrong with the chemical analysis. Shortly after the Geronimo received the evaluation message - which was returned in about an hour - the oceanographers aboard that ship found that their salinometer was malfunctioning.

With your permission, Mr. Chairman, I would at this time like to introduce for the record copies of the messages and some of the press reports of this experiment. In December 1963, Dr. Spilhaous, who is well known in the oceanographic community, presented it in his "Our New Age" syndicated strip which appeared in the Washington Post and other newspapers.

Inasmuch as it costs so much to occupy a single oceanographic station, any program which can give a scientist an instantaneous evaluation and quality control of the data he has just taken pays for itself many times over. Once the scientist has left the station, he can never be really sure whether the data he has obtained are worthless or may reveal some new secret of the sea unless he goes back to the same spot and repeats his observations - and this at times at great cost.

The NODC is constantly striving to insure the quality of the data both at the collection source and at the shoreside processing facility.

One final word, if I may, on the NODC plans for the future.

One of the major objectives of the NODC is the adoption by the oceanographic community at large of standardized coding forms; for this reason, in designing coding forms for use by NODC in data processing, the cooperation of as wide a spectrum as possible of the oceanographic community has been enlisted. NODC will continue to advance 
this objective and the use of standardized forms will facilitate data processing and thus enhance the early usefulness of the data to scientists.

Another objective concerns the development of new and exotic instrumentation, producing new and different types of data output. The NODC will continue to work with the Navy's Instrumentation Center, and the Interagency Instrumentation Panel, and others concerned with the development of new instrumentation to insure that the data products on one hand and data processing and archiving facilities on the other hand are coordinated.

NODC will continue to develop its capabilities for handling physical and marine biological and geological-geophysical data in cooperation with leading scientists in all fields, and with respect to both digital data and nondigital information.

NODC will continue to develop quality control procedures designed to enhance the quality of its data products.

The NODC must discover funding procedures and manpower resources to reduce the accumulated backlog of oceanographic data, the bulk of which was inherited at the time of its establishment in January 1961.

NODC will strive to improve its communication systems with the leading oceanographic laboratories and organizations in the United States and to expand its exchange programs with foreign organizations. It will continue through Intergovernmental Oceanographic Commission and the World Data Center system to improve acquisition and exchange of data. Regular exchange of data began in 1961 with activities in some 18 countries; now our exchange program includes activities in some 40 countries.

NODC will continue to explore better means of information retrieval, mechanical, photoelectronic, manual, and combinations thereof, which will speed up the availability of data and information to the user.

This concludes my report, Mr. Chairman, and I am now available for any questions you may have.

Mr. Pelly. Thank you, Mr. Dubach. I was wondering when you were referring to the problem of funding procedures and of manpower resources reducing the backlog, how are you, as against the backlog which you inherited in 1961? Have you reduced the backlog, or are you just keeping up with the present data that comes in, or are you actually making progress?

Mr. Dubach. I think in some areas we are holding our own. By this I would restrict this to the station data and in some measure BT data. In the areas like geology and biology these have never been touched in any volume before and so we are beginning to make a little impact in these areas.

Regarding station data, when we started business in 1961 there was an estimated 300,000 oceanographic stations of which we had roughly 100,000 in our files. As you can see from the record we have now 250,000 , approximately, but the volume has increased; there are now estimated to be around 350,000 to 400,000 oceanographic stations. Our first priority in all of our processing is applied to contemporary data over historic data simply because, from the response in the oceanographic community, this is where the current interest lies primarily. I 
am not implying that there is no interest in historic data. There is some, and when there is this interest exhibited we proceed to give precedence to historic data in selected areas to fill the gap and provide the service that is needed.

Mr. PeLly. In other words, you are trying to take care of the area where there is the most demand?

Mr. Dubach. Yes, sir.

Mr. Pelly. Thank you. Mr. Bauer, I think, has several questions he would like to ask.

Mr. Bauer. Thank you, Mr. Chairman.

Now, as I understand the structure of the NODC, you are under the management control of the Oceanographer of the Navy; is that correct?

Mr. DUBACH. He is our administrative executive.

Mr. BAUER. Who supplies the money for the salaries?

Mr. DUBACH. All of the sponsors jointly fund the NODC operation and as I understand the budget, it is not compartmentalized into salaries, contracts, and so forth and so on. This is in essence a pooled resource from which salaries are drawn, from which contracts are drawn, from which supplies are drawn, and so forth and so on.

Mr. BAUER. Now, that leads, of course, to the situation of how is your personnel billet structure handled? Are the billets taken out of the Navy Oceanographic Office or are the billets created for NODC in the civil service structure, because oftentimes it is more difficult to get a personnel allowance than it is money.

Mr. Duвach. The billets are assigned by the Navy.

Mr. BAUER. In other words, the operation of NODC although funded by the joint venture, we'll say, still take personnel billets from the Navy's Oceanographic Office, is that not correct?

Mr. Dubach. That is correct.

Mr. BAUER. Is that not more or less a constraint upon the growth of the Navy's Oceanographic Office?

Mr. Dubach. Well, I do not know about the Navy Oceanographic Office. All I can speak for would be the NODC, but we have had no problem in this regard in our working togetherness with the Oceanographer, he has been most helpful in this regard.

Mr. BAUER. I am wondering why the billet structure was not handled the same way as the pay structure. At least an individual billet structure established for NODC. Do you know of any reason why that was not done?

Mr. Dubach. I do not know, Mr. Bauer.

The charter does not specify this; all it specifies is the money ratios and I do not know the details of why it was set up this way.

Mr. BADER. Now, just how does NODC fit into the ICO structureor does it?

Mr. Dubach. Originally, as I understand it, there was a Data Processing Panel in the ICO. Once this Panel had completed its work I believe the ICO released its authority over the Panel and from that day on an Advisory Board was established which acts more or less as a governing board for the Director of the NODC.

Now, many of the people who sit on this Advisory Board also sit on the ICO group. 
Mr. BAUER. Is there any reason why the ICO could not act as the advisory board of the NODC?

Mr. Duвach. I think this would have its problems because we get down to some very fundamental decisions in data processing and how we are doing, where we go from here, and this type of thing. I do not know that the ICO would want to become this intimately involved with day-to-day working operations and policy guidance.

Mr. Bauer. It could be handled in the same way that the Ships Panel is handled, could it not?

Mr. Dubach. I suspect, I do not know. I would have to defer this question to the ICO.

Mr. BAUER. Now, what does the management control by the Oceanographer of the Navy consist of ?

Mr. Dubach. Pretty much housekeeping types of problems. They do our bookkeeping work for us; they do our hiring and this type of thing-our personnel work for us. This prevents a duplication of effort in having a separate little administrative office set up to do this particular job. They take care of our space requirements and all of these types of things. Plus we go through Navy channels for adherence to regulations - this type of thing-Government regulations. have?

Mr. BACER. And they also give you the billet structure that you

Mr. Dubach. Yes, sir.

Mr. Bauer. That is all I have, Mr. Chairman.

Mr. Drewry. No questions.

Mr. Pelly. Then we will thank you for giving us a very informative report.

(Mr. Dubach's prepared statement follows:)

Statement of Harold W. Dubach, Deputy Director, National

Oceanographic Data Center

My name is Harold Dubach and I am substituting for Dr. Jacobs of the National Oceanographic Data Center (NODC) who is recovering from an extended illness of some 6 weeks. I would like to submit his statement for inclusion in the record at this time. I will attempt to cover what I believe are the highlights.

\section{INTRODUCTION}

As you will recall from the last report, the Data Center's governing body is an Advisory Board on which sit representatives of each of the sponsoring agencies and two representatives of the National Academy of Sciences. In January of 1964, Dr. John Lyman replaced Mr. Howard Eckles as Chairman of this Board. Also, since the last report to your committee, changes hare been made in the representation by the Atomic Energy Commission and the National Academy of Sciences. Mr. Joseph and Dr. Kask have replaced Dr. Schultz and Dr. Schaefer who are the respective representatives of those agencies. I should also like to mention that in fiscal year 1961 the Coast Guard became one of the NODC sponsors. During fiscal year 1965 three other agencies have indicated their desire to become sponsors of NODC. These are the Geological Surrey, Coastal Engineering Research Center, and the Department of Health, Education, and Welfare. Our sponsors will, in fiscal year 1965, total 10. Each year the NODC prepares a summary of its work and accomplishments as an anal report which is presented to the Advisory Board and submitted to the sponsoring agencies. With your permission, I would like to submit the annual reports for fiscal year 1962 and 1963 for the record. 


\section{ACCOMPLISHMENTS}

First, let me present our production accomplishments. In the 3 years since the inception of NODC, we have been working toward the greater adaptability of processing systems already in use, as well as attempting to diversify into fields not presently being processed with any great degree of uniformity in the United States.

Working toward this goal of ready accessibility, we have begun to convert the previous punched card system for physical-chemical station data into a new magnetic tape system. This will enable us to assemble these data so that we may retrieve the valuable temperature, salinity, density, and sound velocity information at a more rapid rate than ever before. We have, therefore, initiated a program of digitizing these data into a magnetic tape system of uniform units which will enable us, with the aid of a computer, to provide information in a few hours which would otherwise take months or years to tabulate.

Our present archive contains physical and chemical data from about 260,000 oceanographic stations contained on over 5 million punched cards. When these data are distributed over the world's oceans in all seasons, one can see that there are many areas of the world where little or no data are available. We are attempting to fill some of these gaps through a vigorous acquisition program and exchange with other nations. These data are being processed and archived at the rate of three-quarters of a million punched cards each year.

Our archives of bathythermograms (BT's) now contain approximately 850,000 analog temperature records for depths up to 900 feet. We are continuing to process approximately 30,000 per year from survey ships or other vessels for which there is an urgent and immediate need. Emphasis has been placed on digitizing BT data and putting in into a form that will make it available for computer programs. Proceeding with a new system, we have digitized approximately 50,000 of the existing archives of 850,000 analog temperature records on a pilot project basis. (Over 2 million data points are contained on approximately 250,000 punched cards.) Since the system has been examined and approved by members of the oceanographic community, we plan to step up production during the coming year, processing into a magnetic tape storage system what will be the equivalent of more than 100,000 observations (half a million punched cards). Because new data are being received at the rate of about 90,000 observations per year, this effort is still far short of what will be required to complete the ultimate goal of digitizing the entire backlog as well as keeping up with contemporary inflow.

A variety of other data are received in manuscript or other forms. Standard storage-retrieval systems and determination of standard recording forms have yet to be determined for these data. Nevertheless, these data are organized in a logical manner, usually geographically by data type and date, and are available to the oceanographic community on demand in their existing form. Development of appropriate storage-retrieval system (s) for these data will proceed as our research and development of systems for data types now in work are completed.

In January of this year, we began geological and biological production on a pilot study basis. Core, grab, and dredge data from approximately 2,100 geological stations have been put into the geological storage-retrieval system for test purposes. Approximately 1,200 biological stations (represented by 5,000 punch cards) have been entered into the biological storage-retrieval system also for testing purposes.

To summarize the chief contributions of the Data Center since its inception, I would emphasize three points :

First: Through our efforts there has been increasing emphasis on the use of standardized procedures in recording and reporting. In the past, oceanography has been plagued by a multitude of recording forms and incompatible observing and reporting procedures. The NODC fortuitously has turned out to be the catalyst that has brought the diversified oceanographic interests together to do something concrete about this longstanding problem. The Data Center will continue to sponsor and cooperate in these endeavors.

Second: From the beginning, the Data Center has emphasized the application of quality control procedures to the data processing techniques we use, so that 
the scientist is assured of receiving the highest quality of data possible under the circumstances.

Third: We have emphasized personal service. Services include providing technical information, educational materials, and advice beyond that represented by the simple provision of "hard" data.

\section{SERVICES}

Regarding our service to the oceanographic community, the NODC has been called on many times to furnish statistically summarized and analyzed oceanographic data for industrial, private, and Government organizations which need information on the environment in which their instruments will be operated.

I would like to give you some idea as to the volume of the reimbursable work performed at the NODC. During fiscal year 1961 our reimbursable funds amounted to about $\$ 3,000$; during fiscal year 1963 , they increased to over $\$ 200,000$. It must be pointed out, however, that these figures include governmental and nongovernmental (industry, private institutions, etc.) requests for services. Details on the services supplied are given in the annual report.

With your permission, I would like to introduce for the record some of the publications produced by the Data Center since our last report to you.

\section{RESEARCH AND DEVELOPMENT}

Now I would like to outline briefly our progress in research and development.

We have developed a holding-recall system for indexing core, grab, and dredge samples. Additionally, a system for handling the chemical analyses of sea-bottom materials has been completed and currently is being circulated for approval of the oceanographic community. In work is the development of a system for handling the physical properties of sediments.

Significant advances have been made in the development of holding-recall systems for hydrobiological data. Developed (and approved by our Interagency Advisory Board) to date are holding-recall systems to handle environmental data, phytoplankton, primary productivity, phytoplankton pigment data, zooplankton data, and benthos data.

Progress is being made in the field of physical-chemical data as well. A holding-recall system has just been completed for drift bottle data. The NODC worked very closely with Mr. Dean Bumpus of the Woods Hole Oceanographic Institution and Dr. John Norcross of the Virginia Institute of Marine Sciences. Also under development are schemes for handling near shore oceanographic data, instrument-measured current data, and nonnutrient chemical data.

It should be pointed out that all holding-recall systems are dereloped in concert with the oceanographic community. Extremely gratifying is the cooperation the NODC has received from the oceanographic community which is reflected in their willingness to serve on the various ad hoc committees formed in conjunction with our developmental work.

\section{QUALITY CONTROL OF OCEANOGRAPHIC DATA}

Now that the NODC has had the experience of nearly 3 years of working with various types of oceanographic data in a multitudinous variety of formats, we can rationally approach the problem of developing and implementing automated (computer) quality controls. I do not mean to imply that until this time there has been no application of quality control, but practically all of it has been applied subjectively. With our present backlog of data and our present and future acquisition effort, we would be naive to believe that we could continue to apply subjective quality controls. To have applied automated quality controls at the onset of our operation would also have been naive since no end products had been defined and we had practically no guidelines for total systems. Now we feel we are ready to begin.

Shortly, we expect to have in operation a computer program which will check some items of a routine nature which at the present time are monitored by our oceanographers. This will then give additional time for these oceanographers to assess the scientific plausibility of the data. One of the first attempts at automated quality control that we will implement shortly is a program which will check the quality of work done by contractors who are digitizing bathythermograms for the NODC. This will not only insure that a major contractor is capable of performing quality work, but will also provide a quality check as the work progresses: 
We are making some inroads on the problem of quality control of oceanographic station data. We have machine plotted all the temperatiure-salinity relationships (based on historical data) for the Indian Ocean and are currently funding for a similar analysis for the Pacific Ocean. From these plots we are generating envelopes of acceptable limits which for the time being will be used in our subjective quality control program. This is a first step in the generation of mathematical models for the computer which will eliminate the subjective approach.

Just about a year ago we were able to demonstrate very dramatically how quality control can pay off through rapid communication systems. During the Equalant $I$ and $I I$ phases of the international cooperative investigations of the tropical Atlantic (ICITA) in 1963, the NODO received, on a daily basis, meteorological and oceanographic messages from ships participating in the surveys. During these surveys, we accomplished what we believe to be a first in oceanography-i.e., the radio receipt of a complete oceanographic station within a matter of hours after the station had been occupied. These were then continually received at the rate of one per day. (Receipt of data at the present time may vary from 1 month to several years after the data are taken.) The basic reduced data were fed to a computer and the computations for density, dynamic depth, specific volume anomaly, and sound velocity were made as were interpolations of these values for internationally accepted standard depths: "This in itself demonstrated that an oceanographic program for almost instantaneous receipt of data was feasible. As the surveys progressed, the NODC developed an evaluation message which was communicated back to the ship at sea. During the Equalant II, both an American vessel and an Argentine vessel daily transmitted oceanographic data to the NODC. The messages returned to these ships consisted of an evaluation of the observed data against the historical data and served as a means of intership comparison of data. It is interesting to note that the observed data received from both ships showed a bias of very small magnitude in the same direction. The implication of this was that both ships were collecting high quality data.

The finale of this experiment in quality control and communications occurred on September 19, 1963, during a combined operation of the Washington Laboratory of the Bureau of Commercial Fisheries, NASA, and the NODC. On that day, with time available on the Syncom II satellite communication system, the BCF ship, Geronimo, radioed station data to the Kingsport (the Syncom surface station) which, in turn, communicated the data to Washington via Syncom II. The data were computed and evaluated by the NODC and salinities were found to deviate significantly from what would be the expected norm for the area. In other words, either a hitherto undiscovered oceanographic phenomenon was occurring in the area or something was wrong with the chemical analysis. Shortly after the Geronimo received the evaluation message (which was returned in about an hour), the oceanographers aboard that ship found that their salinometer was malfunctioning.

With your permission, I would at this time like to introduce for the record copies of the messages and some of the press reports of this experiment. In December 1963, Dr. Spilhaus presented it in his "Our New Age" syndicated strip which appeared in the Washington Post and other newspapers.

Inasmuch as it costs so much to occupy a single oceanographic station, any program which can give a scientist an instantaneous evaluation and quality control of the data he has just taken pays for itself many times over. Once the scientist has left the station, he can never be really sure whether the data he has obtained are worthless or may reveal some new secret of the sea unless he goes back to the same spot and repeats his observations-and this at great extra cost.

The NODC is constantly striving to insure the quality of the data both at the collection source and at the shoreside processing facility.

\section{NODC PLANS FOR THE FUTURE}

One of the major objectives of the NODC is the adoption by the oceanographic community at large of standardized coding forms; for this reason, in designing coding forms for use by NODC in data processing, the cooneration of as wide a spectrum as possible of the oceanographic community has been enlisted. NODC will continue to advance this objective; the use of standardized forms will facilitate data processing and thus enhance the early usefulness of the data to scientists. 
Another objective concerns the development of new and exotic instrumentation, producing new and different types of data output. NODC will continue to work with the Navy's Instrumentation Center, and the Interagency Instrumentation Panel, and others concerned with the development of new instrumentation to insure that the data products on one hand and data processing and archiving facilities on the other hand are coordinated.

NODO will continue to develop its capabilities for handling physical and marine biological and geological-geophysical data in cooperation with leading scientists in both fields, and with respect to both digital data and nondigital information.

NODC will continue to develop quality control procedures designed to enhance the quality of its data products.

NODC must discover funding procedures and manpower resources to reduce the accumulated backlog of oceanographic data, the bulk of which was inherited at the time of its establishment (January 1961).

NODC will strive to improve its communication systems with the leading oceanographic laboratories and organizations in the United States and to expand its exchange programs with foreign organizations. It will continue to work through the Intergovernmental Oceanographic Commission (IOC) and the World Data Center system to improve acquisition and exchange of data. Regular exchange of data began in 1961 with 18 countries; now our exchange program includes activities in 40 countries.

NODO will continue to explore better means of information retrieval, mechanical, photoelectronic, manual, and combinations thereof, which will speed up the availability of data and information to the user.

This concludes my report, Mr. Chairman, and I am now available for any questions you may have.

Mr. Peluy. The next and final witness as I understand it is Dr. Stewart of the Coast and Geodetic Survey.

Dr. Stewart, would you come forward? Will you identify yourself for the reporter?

Dr. StewarT. Thank you, Mr. Chairman. I am Dr. Harris B. Stewart, Jr., Deputy Assistant Director of the U.S. Coast and Geodetic Survey in the Office of Oceanography.

\section{STATEMENT OF DR. HARRIS B. STEWART, JR., DEPUTY ASSISTANT DIRECTOR, U.S. COAST AND GEODETIC SURVEY IN THE OFFICE OF OCEANOGRAPHY}

Dr. STEWART. My appearing here today with no prepared statement was occasioned by the fact that I have within the past week returned from the Indian Ocean where I was acting as chief scientist aboard the U.S. Coast and Geodetic ship Pioneer, taking part in the International Indian Ocean Expedition, and it was the belief that this committee might be interested in a very brief, on the order of 5 minutes, summary of some of the things that have actually been going on at sea relative to this International Indian Ocean Expedition.

The Pioneer left San Francisco on the 11th of February. I joined the ship in Manila. From Manila we worked down through the South China Sea, touching briefly at Jesselton on Borneo. Then into Singapore, up through the Malacca Straits to Penang, on the Malay Penninsula, working back and forth across the Andaman Sea, up through the Bay of Bengal to Calcutta, then down to Columbo, Ceylon, where I left the ship. The ship is now just leaving Djakarta in Indonesia and will work her way across the Pacific arriving at San Francisco in early August.

The work done can be briefly summarized. The ship worked from the upper atmosphere where the meteorological balloons finally 
petered out, down through the surface waters where plankton tows and productivity measurements were made as part of the biological program of the International Indian Ocean Expedition, on down through the deeper water where our water sampling profiles were tied in with the international effort to understand the circulation and distribution of variables in the equatorial regions of the Indian Ocean. The work we did in the eastern Indian Ocean tied in with work of other ships from other countries and from the United States farther to the west.

The main part of our work, however, was involved in geology and geophysics. This involved sediment coring, rock dredging, bottom photography, diving, work with heat probes or geothermal probes, continuous echo sounding or hydrography. It included special work with a subbottom acoustic device for penetrating the bottom and giving us returns from layers below the bottom.

It included the whole gambit, really, of oceanographic activities.

I think probably one thing that seldom is heard about in the Indian Ocean operations, one thing which we felt was quite important and one thing I think this committee might be most interested in, was some of the international cooperation and the means we used to try and improve the scientific image of the United States in that part of the world, particularly in southeast Asia.

We had aboard from other agencies in the United States people from the Weather Bureau, the Geological Survey, the Naval Oceanographic Office, the National Oceanographic Data Center, and a doctor from the Public Health Service. So, you see the things that have been talked about here, this cooperation among the ICO agencies, this also goes on at the wet deck level at sea.

We also had personnel from the Scripps Institution of Oceanography, from the University of Hawaii, doing work both for the University of Hawaii and for the Bureau of Commercial Fisheries, a man from the University of Southern California, and at each major port we picked up local marine scientists to work with us to the next port. We had a fisheries man from the Philippine Fisheries Commission; we had a man from the Philippine Bureau of Coast and Geodetic Survey; we had the director of the Geological Survey of Malaysia ; these were people actually aboard taking part in the scientific work of the expedition.

We had a man from the Fisheries Research Laboratory of Malaysia at Penang. We had one of the directors of the Survey of India aboard. We had a man from Andhra University in India, and just as I left we were getting a man from one of the marine research laboratories of Indonesia. When the Pioneer visited Djakarta in Indonesia this past week, we took up to 50 scientists and other interested people out for 1 day aboard the ship to demonstrate what we were doing.

In each port we would hold up to 2 days of scientific seminars. When the ship tied up, instead of having the men scatter about the town as tourists, we would hold scientific seminars with the local scientists; we would hold open house aboard ship in which scientists and interested people and schoolchildren and government officials could come aboard and would be given a guided tour of the ship. We also had a reception aboard one night for government officials. 
We would hold in each port a press conference in which we would tell the people what we were doing and why we were doing it and how this could perhaps contribute to their well-being.

And this whole aspect was made possible primarily through the very close cooperation with and very hard work by the separate offices in each country of the U.S. Information Service which did really a spectacular job so far as we were concerned.

But I think this was one aspect of this expedition that in the past ships really have not concentrated on very much-this letting the people in the areas where our ships are working know why we are there and what we are doing and take them along with us to work along with us so that the work we are doing does not just come back to the United States, but, in fact, filters out to the other countries and perhaps helps them in their fisheries problem and their meteorological problem and their basic scientific problems.

I have, which I would like to leave with the committee, two copies of the brochure of which we had some 6,000 aboard which were handed out to everyone that came aboard, letting them know something of what the expedition is about.

I would also like to leave for possible insertion in the record if I may, Mr. Chairman, copies of six letters that have come back to the Coast and Geodetic Survey, one, for example, from the American Ambassador to Ceylon; one from the Director of the Indian program in the Indian Ocean; one from the U.S. Information Service in Calcutta; one from the Ceylon Association for the Advancement of Science; one from the Scripps Institution; and one from a very young girl in the Philippines who visited the ship, a 13-year-old schoolgirl who wrote to say thanks.

I think these things give you some idea of the international aspects of an expedition like this and how it can be used to help burnish up the American scientific image in a part of the world that is currently in a lot of trouble.

Also, I would appreciate having included in the record an article that appeared in the December 1963 issue of the Journal of the Explorers Club. In it I tried to summarize briefly what the U.S. oceanographic program is all about and why it is of importance to the United States. I feel that this will make a contribution to the testimony which the committee is assembling.

That is the end of my statement, sir.

Mr. Pelly. Fine, Doctor, the material will be made a part of the record.

(The letters mentioned follow herewith and the article mentioned may be found in app. 10, p. 683.)

The Foreign Service of the United States of America,

AMERICAN EMBASSY,

Colombo, Ceylon, June 8, 1964.

Hon. LUTHER H. Hodges,

Secretary of Commerce,

Washington, D.C.

DeAr Mr. SECRETARY: As you are aware, the USCGS ship Pioneer, under the command of Capt. E. B. Brown, visited Colombo from May 19 to 25, 1964, during its current voyage as a participating ship in the International Indian Ocean Expedition. We at the Embassy were very favorably impressed by the ship, the ship's officers, and the scientific staff aboard. In striking contrast to some adverse, unsubstantiated comment of the ship and its mission in the leftist press a few 
weeks before its arrival, we felt that all of the men aboard the Pioneer gave Colombo the most impressive display of scientific interest and knowledge that it had seen for quite some time.

In my opinion the visit of the Pioneer made an outstanding contribution to a better understanding in Ceylon of the true purposes of the International Indian Ocean Expedition as well as to a better appreciation of the constructive role that the U.S. Government plays in international organizations in general and in the Indian Ocean Expedition in particular.

Dr. Harris B. Stewart, Jr., Deputy Assistant Director, Coast and Geodetic Survey, who was acting as chief scientist aboard the Pioneer when she arrived in Colombo, led a most erudite and informative seminar which was attended by many of Ceylon's leading scientists in the fields of geology and biology. Undoubtedly the seminar, along with the reception and open house held aboard the Pioneer, helped much to further amity and understanding between Ceylon and the United States.

Capt. E. B. Brown was most cooperative with the Embassy. He took great care to assure that the advance planning required for the visit was coordinated with the Embassy at every step. Throughout the Pioneer's stay here he also made a significant contribution to the success of the visit by his splendid overall direction.

Sincerely yours,

Fratees E. WILLIS, American Ambassador.

INDIAN OCEAN EXPEDITION, Council of SCIENTTFIC ANd INdUSTRIAL RESEARCH, New Delhi, May 31, 1964.

Dr. H. STEWART,

Care of Ship Pioneer, U.S. Coast \& Geodetio Survey,

San Francisco, Calif.

DeAr Dr. STUART: Although it is likely that we may meet in Paris in connection with the Intergovernmental Oceanographic Commission meetings, may I write and thank you for your kind letter.

It was a very exciting experience to many of our Indian colleagues to be associated with the U.S. group of scientists during the short time your ship spent at Calcutta. We are also extremely happy that the seminar was a success and that it has kindled many new ideas in our young scientists. I have also personally very much enjoyed the oceanographic company we had during the time we were together in Calcutta.

Please accept our most cordial greetings and thanks on behalf of the Indian National Committee on Oceanic Research and myself.

With kindest regards.

Yours sincerely,

N. K. PANIKKar.

U.S. INFORMATTON SERICE, Calcutta, May 21, 1964.

Admiral H. ARnold Karo,

Director, U.S. Coast and Geodetic Survey,

Department of Commerce, Washington, D.C.

Dear Admiral Karo: The recent visit of the USCGS ship Pioneer contributed greatly to the achievement of our mutual objectives you so aptly expressed when you said (the objectives) "*** to bring closer that day of universal peace and understanding for which we all strive."

I have heard high praise of the crew and scientists from many of the visitors to the ship. Helpful and cooperative, Capt. Edward Brown was an able ambassador for the United States and the Coast and Geodetic Survey.

Drs. Stewart, Shepherd, and Dietz were a pleasure to work with. Dr. Stewart was especially effective both in his shipboard press conference and in the lecture hall. He has the ability not only to communicate ably with reporters who lack even the most elementary knowledge of his subject but also to stimulate his scientific peers. I could mention other individuals but because I do not want this letter to become a mere catalog, I will name only Professor Dietz, for the Indian geologists, the outstanding scientist; clearly he was known 
and respected as a man of stimulating theories, theories that the Indians thronged to hear.

This visit more than fulfilled the expectations that arose when we first conlceived of the project more than a year ago. We would welcome other such ships. We are submitting a full report to the U.S. Information Agency, Washington, D.C., a copy of which I hope you will see.

Sincerely yours,

\section{S. B. STEELE, Acting Public Affairs Officer.}

\section{Ceylon Association for the Advancement of Science,}

Dr. HARRis B. Stew ART, Jr., Colombo, May 22, 1964.

U.S. Coast and Geodetic Survey.

Dear Dr. Stewart: The Council of the Ceylon Association for the Advancement of Science, and the Ceylon Committee for the Indian Ocean Expedition wish me to convey to you, Captain Brown, and the other members of the Pioneer their sincere thanks for the most interesting and instructive seminar. The Ceylonese scientists who were present at the seminar learned a great deal from the lectures delivered at the seminar and were very enthusiastic about the work of the Pioneer.

For me personally it was an honor and a privilege to have been associated with you and the staff of the Pioneer.

May I be permitted to add that I deeply appreciate the kind references you made and that I shall treasure the lovely medal you were so kind to honor me with.

Good luck to the Pioneer and bon voyage.

With kindest regards.

Sincerely yours,

\section{R. O. B. WIJESEKERA.}

MAX 18, 1964.

The DIRECTOR,

U.S. CoAst \& Geodetic SuRvey,

Washington, D.C.

DeAr Admiral Karo: It has been a great pleasure for me to have accompanied one leg of the Pioneer Indian Ocean Expedition and to have been with the group during the week in Calcutta. I think the Survey will be proud of the results of this expedition. It is not only accomplishing important scientific results but is also adding much to the prestige of the United States by the fine cooperation with USIS in getting across to the nations visited the purposes of the work. The fine series of lectures, seminars, and press conferences, combined with the friendly social gatherings in Calcutta certainly left a splendid impression on the Indian scientists and engineers. Thanks to Dr. Stewart's carefully made arrangements and advance notices, geologists and geophysicists from all over India came to attend the meetings and to see the ship and equipment. It was just the sort of international exchange that is so badly needed to increase our prestige. What an ideal combination of having Captain Brown in command and Dr. Stewart as chief scientist. They both make such a good team and their spirit is so contagious.

I was glad to get to sea because I am afraid that Dr. Stewart would wear himself out with his constant activities during the visit to Calcutta. He never seemed to have any time to himself at all. Since we sailed he has had a slightly more restful time but stands long night watches following closely all of the activities and contributing in so many ways to the success of the work in the Bay of Bengal. It is a pleasure to see how eagerly every one in the crew cooperates in the work when they have the kind of leadership that exists here.

Iuch has been accomplished in unraveling the mysteries of the interesting valleys and canyons in the Bay of Bengal. It was unfortunate that there was no better means of obtaining positions during the work out beyond shore control. I hope some day when controls are made available that one of the Survey ships can return and really make an accurate map of this interesting bay. Also it will be better when Survey ships are better equipped for coring, dredging, etc. Much valuable time is lost by the difficulty of holding the ship in position during coring or in proceeding slowly ahead during dredging. I realize that these difficulties were unavoidable for the present cruise and that this is just a start in 
equipping the Coast and Geodetic Survey vessels for a more active part in oceanographic research.

Let me congratulate you on this fine beginning of what I hope will become a major contribution to international oceanography.

Thank you again for the opportunity to participate.

With kind regards.

Sincerely yours,

Frances P. Shepard,

Professor of Submarine Geology,

Scripps Institution of Oceanography.

\section{Manila, Philippine Islands,} March 15, 1964.

To Captain Brown, Dr. Stewart, Officers and Crewmembers of the Pioneer, Especially "Sir Sweat."

DEAR SIRS: In behalf of my friends, I sincerely wish to thank you for your kindness in allowing us to tour your ship. If you only knew how much we enjoyed and profited from this. We honestly believe that you are the kindest and most patient foreigners we've ever met.

I know that we were a bunch of giggling, immature adolescents causing so much trouble for poor Mr. Sweat. We do apologize and hope that the next time you come, you would see us a bit more grown up.

There were many of us who went there quite ignorant. We had heard of oceanography and we mistakenly thought of it as inferior to solar physics, bio-, etc. I mean what is so important about the old sea? We thought that it was a dull, unadventurous job-sort of like taking a white collar job. But we know now that it is not. I know that Dr. Stewart would be very glad to hear this-I overheard one of the boys telling another that you have convinced him about oceanography and that he might study that for college. We may not all turn out oceanographers but you have planted in us that desire to search, to be curious and the desire to learn.

So despite all the trouble we've caused you, I hope that this might make you feel good.

Again I wholeheartedly thank you. We shall all miss you-may God bless you all.

Sincerely yours,

Theresa YaNG.

Mr. PELLY. I think your appearance here this morning has really brought out this whole matter of oceanography up to date. You have practically come right out of the field and made this very interesting explanation. I certainly hope that other members of the committee will read what you had to say because I think it gives a definite feel of the whole program.

As I recall at the time when this project was first started there was some doubt on the part of some foreign countries as to whether they wanted our cooperation and intrusion into those waters and I think from what you say that you are certainly making this whole program understood and I for one can say I have enjoyed your little brief summary here very much and I thank you for it.

Mr. Bauer or our counsel may wish to ask some questions, so do not go away.

Mr. BAder. I have no questions.

Mr. Pelly. It would seem, then, that you would bring to a very interesting conclusion the hearing here this morning. We appreciate your presence and the presence of other witnesses.

The record will remain open for a reasonable length of time for any additions or statements that others may wish to include.

I wish to thank all the witnesses for their appearances. The meeting is adjourned.

(Whereupon, at $11: 30$ p.m., the hearing was adjourned.) 



\section{APPENDIX 1}

MATERIAL SUBMITTED BY DR. J. HERBERT HOLLOMON, CHAIRMAN OF THE INTERDEPARTMENTAL COMMITTEE FOR ATMOSPHERIC SCIENCES OF THE FEDERAL COUNCIL FOR SCIENCE AND TECHNOLOGY RELATIVE TO AIR-SEA INTERACTION RESEARCH PLANNING 



\section{FEDERAL COUNCIL FOR SCIENCE AND TECHNOLOGY INTERDEPARTMENTAL COMMITTEE FOR ATMOSPHERIC SCIENCES U.S. DEPARTMENT OF COMMERCE \\ WASHINGTON. D.C. 20230}

July 8,1964

Honorable Herbert C. Bonner

Chairman, Merchant Marine and

Fisheries Committee

U.S. House of Representatives

Washington, D.C.

Dear Mr. Bonner:

In view of my responsibilities as chairman of the Interdepartmental Committee for Atmospheric Sciences of the Federal Council for Science and Technology and the unique responsibility that has been assigned to the Department of Commerce relative to air-sea interaction research planning, I am providing you with a summary of the developments leading to this assignment together with the pertinent background documents.

You will note that the emphasis of the Department of Commerce assignment lies in the areas of coordination, and in identifying and filling in the cracks in an overall Federallysupported program which is to be developed in full agreement with all participating agencies and on the basis of earlier recommendations of the National Academy of Sciences-National Research Council. This program assignment to the Department of Commerce specifically provides for individual agencies conducting their own research consistent with their statutory missions.

If I can be of any further assistance in this matter, please don't hesitate to let me know.

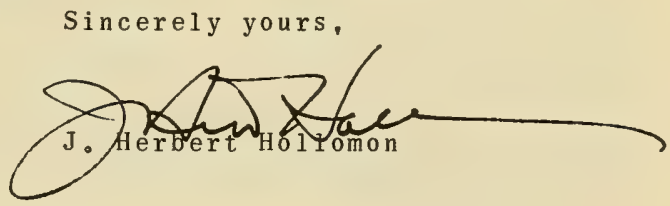




\author{
FEDERAL COUNCIL FOR SCIENCE AND TECHNOLOGY \\ INTERDEPARTMENTAL COMMITTEE FOR ATMOSPHERIC SCIENCES \\ U.S. DEPARTMENT OF COMMERCE \\ WABHINGTON, D.C. 20230
}

\title{
AIR-SEA INTERACTION PLANNING
}

In the spring of 1960 the National Academy Committees on Oceanography and Atmospheric Sciences jointly appointed a panel to study the area of mutual concern -- research on the interactions between. the air and the sea.

The joint panel under Dr. George S. Benton of John Hopkins University, produced NAS-NRC Publication 983, "Interaction Between the Atmosphere and the Oceans", in January 1962. This report made six recommendations:

1) Techniques must be developed for various measurements in the boundary layer of the atmosphere and the ocean.

2) Investigation of the physics and chemistry of the interfacial zone and the effect of its properties on exchange mechanisms must be pursued.

3) Special area studies should be undertaken to provide experimental facilities for field tests of equipment.

4) Systems of fixed stations instrumented for atmospheric and oceanographic observations must be established.

5) Marine meteorological observations from ships should be improved in quality and extended in scope.

6) Automatic recording, processing, reduction and storage of data should be employed wherever appropriate.

The Interagency Committee on Oceanography (ICO) and the Interdepartmental Committee for Atmospheric Sciences (ICAS) reviewed this report and endorsed the identification of and emphasis on the problems of research. In a joint letter to Dr. Wiesner of 24 September 1962, it was recommended that the Academy draft a specific program of implementation to be included in the Academy's

-report on oceanography and atmospheric sciences to be further considered by ICO and ICAS for inclusion within their total national programs. 
At the same time, ICO and. ICAS, appreciating the importance of this research area, commenced discussions which led to the formation in December 1962, of a Joint Ad Hoc Panel on Air-Sea Interaction. This panel was given an initial task of developing a program, the initial phases of which could be implemented in FY 1965. A draft report was completed by March 1963, which delineated research needs in the micro-meso- and macroscale areas, estimated instrumentation and system requirements, and recommended the establishment of a National Air-Sea Research Institute to coordinate, guide, and conduct air-sea research programs. The report called for $\$ 18.8 \mathrm{million}$ in FY 1965 and $\$ 14.3 \mathrm{milli}$ in in FY 1966. It was considered by ICO and ICAS in April 1963 as incomplete and in need of further identification of programs and deficiencies as well as priorities.

Further effort by the panel produced a report in 0ctober recommending a National Program consisting of highest priority and most significant items and calling for a FY 1965 budget of $\$ 4.4$ million. This report emphasized the need for an effective interagency coordination mechanism including a small, full-time staff competent in both meteorology and oceanography, and administratively assigned to one federal agency. Its budget was largely for instrumentation and data processing, but included also some micro- and mesoscale research support. This report was accompanied by a recommendation from the chairman.' Dr. Jacobs, that in view of the operational and research experience of the Dept. of Commerce (Weather Bureau and Coast E Geodetic Survey) in both meteorology and oceanography, that Department should take immediate action to establish a full-time staff to proceed with the planning and implementation of an effective air-sea research program. It also set forth certain steps needed to be taken to enable meteorology and oceanography to proceed together toward common goals; i.e. integration of observational procedures and networks, development and procurement of common instrumentation. creation of a compatible data analysis and dissemination system. and coordination of area studies of air/sea transfer processes.

The program as recommended was only partially endorsed by ICO and ICAS, but the need for a coordination mechanism was recognized and a joint ICO-ICAS letter was forwarded to Dr. Weisner in December 1963 recommending that Commerce be assigned the responsibility "to coordinate the further identification of the unique problems involved" and "should develop a coordinated air-sea interaction program with other interested agencies...". The joint panel was to be made permanent to monitor the program for I CO and ICAS. 
Dr. Wiesner approved this concept and assigned to the Department of Commerce the primary responsibility for leadership in the important field of air-sea interaction.

When implementation plans of the Department of Commerce were presented to ICAS and ICO, some differences of policy developed as to whether responsibility for development of the overall air-sea program should lie with the Department of Commerce or with the ICO-ICAS joint panel acting for ICO and ICAS. Two alternative plans were presented to the Federal Council by the' ICAS Chairman, Dr. Hollomon, in February 1964, as a result of which Dr. Hornig amplified Dr. Wiesner's instructions and assigned to theiDepartment of Commerce the responsibility for developing a Federally-supported a $\mathrm{r} / \mathrm{sea}$ interation program in consultation with the participating agencies through their representatives on a joint ICO/ICAS air-sea interaction panel.

Agencies continue to be responsible for funding, conducting, and otherwise managing their portions of the program consistent with their statutory missions. Such portions are those either initially proposed by an agency for support, or added by mutual agreement between between the agency, Department of Commerce, and the joint panel. The Department of Commerce will undertake funding needed to fill out the remaining important components of the total program plan consistent with its statutory missions. Area studies of transfer processes represent. one such component. 


\section{NATIONAL OCEANOGRAPHIC DATA CENTER}

WASHINGTON 25, D.C.

Code 2000-WGJ/cal

18 October 1963

To: Dr. J. Herbert Hollomon

Chalrman, Interdepartmental Committee

on Atmospherlc Sciences

U. S. Department of Commerce

Washington, D. C. 20230

Dr. James H. Wakelin, Jr.

Chairman, Interagency Conmittee on Oceanography

U. S. Department of the Navy

Washington, D. C. 20350

Dear Dr. Hollamon and Dr. Wakelin:

I am writing to you on a matter of considerable urgency which I hope can soon be resolved in the national interest.

The importance of the investigation of alr-sea processes has been repeatedly emphasized by atmospheric sclentists and oceanographers who have been conducting research in these interdependent flelds.

Atmospheric sclentists and oceanographers are agreed that an augmented and coordinated program for investigating the processes of alr-sea interaction should be one of the major objectives in the fleld of geophysics during the next decade. If oceanography and meteorology are to progress significantly beyond their present states of development, it is essential that further knowledge be gained of the exchange of energy, momentum, and material substances across the air-sea interface.

The 1962 report of the National Academy's Joint Panel on Alr-Sea Interaction (NAS-NRC Publication 983) emphasized the need for further investigation into the processes of the air-sea interaction.

In response to this need, a jolnt ICO/ICAS Ad Hoc Panel on OceanAtmosphere Research was established under my chalmanship: (I) to study the problem, (2) to recommend an Ocean-Atmosphere Research Program, and (3) to prepare a budget for this program for FY-1965 and the years immediately following. The Panel submitted a first draft of its report in March 1963, and presentations on the substance of the report have been made to the ICO, ICAS, and the 
Federal Council for Sclence and Technology, the Jolnt NASCAS/NASCO Panel on Alr-Sea Intęractions, and the OST Ad Hoc Advisory Committee on Oceanography. All of these groups have agreed on the requirement to Implement an aggressive Ocean-Atmosphere Research Program along the Iines proposed by the Joint ICO/ICAS Panel. The Ad Hoc Advisory Committee on Oceanography further stated, "We belleve it is essent1al that a start on such a program be made in FY-1965."

The major obstacle in the way of Implementing the Ocean-Atmosphere Research Program is the complexity of the federal structure which controls the activities required to support such a program. At the present time, the meteorological and oceanographic activities required to support an effective alr-sea research effort are spread through some twenty-one federal agencies. And, since the program involves a team effort between the atmospheric scientist and oceanographer, an additional problem is the coordination of two observational and research mechanisms which have unt1l now been only incldentally related to each other. If we are to develop an adequate national and internat1onal program of ocean-atmosphere research, we must take bold and difficult steps in the flelds of meteorology, oceanography, and possibly hydrology to:

1. Integrate observational procedures and networks;

2. Develop and procure common instrumentation;

3. Create a compatible data analysis and dissemination system; and

4. Plan for and implement coordinated area studies based on all avallable methods of measuring vertical transfer.

However, unless an effective centralized coordinating mechanism is established, it is feared that the a1r-sea research effort will be consigned to failure.

In vlew of the operational and research experience of the Department of Commerce (Weather Bureau and Coast and Geodetic Survey) in both oceanography and meteorology, 1 t 1 s proposed that the Department of Commerce take 1mmediate action to establish a full-time staff within the Department to proceed with the planning, and Implementation by FY-1965, of an effective alr-sea research program.

Sincerely yours,

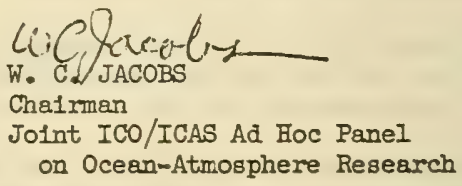


FEDERAL COUNCIL FOR SCIENCE AND TECHNOLOGY

EXECUTIVE OFFICE BUILDING

WASHINGTON 28, D.C.

December 4, 1963

MEMORANDUM FOR

Dr. Jerome B. Wiesner

SUBJECT: Air/Sea Interaction Research

The oniy identifiable air/sea interaction programs within the Federal Government have been set forth in the FY 1963 and 1964 National Oceanographic Programs and have been essentially a description of departmental or agency oceanographit programs that could be identified as contributing to the air/sea interaction research objective. There has not been developed an integrated air/sea interaction research program with specific objectives toward which progress could be evaluated.

The efforts of the Joint Ad Hoc ICO/ICAS Air/Sea Interaction Research Panel to devolop just ouch a program have continued alnce ita worleing draft report distributed to the Council at its meeting of April 23, 1963. Another report is now at hand recommending a minimum essential program for FY 1965. This report has been accepted by ICAS and is under consideration by ICO and ICAS.

Essential steps which must be accomplished in the fielda of meteorology. oceanography, and possibly hydrology are:

1. Integration of observational procedures and networks.

2. Development and procurement of common instrumentation.

3. Creation of a compatible data analysis and disemination Bystem.

4. Coordination of area studies of air/sea transfer processes.

In order to make progre'ss along these lines and to insure the development of an adequate National Air/Sea Interaction Research Program, a single agency should be assigned the responsibility now to coordinato the further identification of the urique problems involved and to stimulate the necessary agency activities in this field. In view of its special interest and research experience in both meteorology and oceanography (Weather Bureau and Coast and Ceodetic Survey). the Department of Commerce should be 
assirned this resoonsibility and should develop a coordinated air/sea interaction prograin with other interested agencles which when considered with tice mingion-orienied programs of all other agencies concerned will rounci out a comprehensive national piogram.

It is planned to make permanent the Jolut ICO/ICAS AIr/Sea Interaction Regearch Paxel to monitor and insure that the Air/Sea Interaction Research Program will be implemented by the various responoible Governent ageacios.

James H. Wakelin, Jx. Chairman, Interagency Committee on Oceanography
J. Herbert Hollomon

Chairman, Interdepartmental

Committee for Atmospheric Sciencer 
C
EXECUTIVE OFFICE OF THE PRESIDENT Office of Science and Technology

Washington, D.C. 20506

December 5, 1963
C

0

MEMORANDUM FOR

Dr. James H. Wakelin, Jr.

Chafrman, Interagency Committee on Oceanography
Dr. J. Herbert Hollomon

Chairman, Interdepartmental Committee for Atmospheric Sciences

FROM: Jerome B. Wlesner

I am glad to have your memorandum dated December 4, 1963 on A1r/Sea Interaction Research. The expressed inten. tIon of ICO and ICAS to develop a coherent research program in this important area is most encouraging; and the Air/Sea Interaction Panel, the two Federal Council committees and their chafrmen are to be commended.

I hope that it will be possible to find strong scientific leadership for this new program and that 1 will be possible to begin promptly the planning for the coordinated program. The atmosphere and ocean are coupled mechanical and thermodyriamic systems, and the air/sea interaction program should contribute toward a deeper appreclation of this elementary fact and toward more effective cooperation in other parts of the meteorology and oceanography programs. 


\author{
FEDERAL COUNCIL FOB SCIENCE AND TECHNOLOGY \\ Executive office Building \\ Washington, D.C.
}

19 Decenber 1963

HEHORANDUH FOR:

\author{
Dr. J. Herbert Hollomon \\ Assistant Secretary of Commerce \\ SUBJECT: Central Responsibility for Air-Sea Interaction \\ Prograin
}

Following the recommendations of the ICO and ICAS, as stated in the memorandum to me of December 4 from you and Dr. Wakelin. I am glad to assign to the Department of Comerce the priary responsibility for leadership in the important field of air-sea interaction. The Department should coordinate those activities of the various agencies in this field which contribute to a coherent national program, it should stimulate interest and understanding of the parts of the program which need strengthening. and it should carry out the adainistrative management of area studies of airsea transfer in which universities, research institutions, and Government agencies may participate.

Jerome B. Wiesner

ce: Dr. James H. Wakelin, Jr., Chairaan, I CO 


\section{EXECUTIVE OFFICE OF THE PRESIDENT \\ OFFICE OF SCIENCE AND TECHNOLOGY \\ WASHINGTON}

6 March 1964

MEMORANDUM FOR:

J. Herbert Hollomon, Chairman, ICAS

James H. Wakelin, Chairman, ICO

SUBJECT: Air-Sea Interaction Program

At its meeting 'on.February 25, 1964, the Federal Council discussed questions related to the responsibility of the Department of Commerce for the air-sea interaction program. The Council supported the designation of special responsibility in this area to DOC as an experiment to be reviewed at the end of one year. The Council further agreed to the following specific statement of this responsibility as it appears in the minutes:

"Planning Responsibilities for Interagency Air/Sea Interaction Research

1. The Department of Commerce is responsible for coordinated planning of the Federally-supported air/sea interaction program.

2. This program will be developed in consultation with the participating agencies through their representatives on a joint ICO/ICAS air/sea interaction panel.

3. The program developed by DOC will be submitted jointly to ICO/ICAS for review.

4. These air/sea interaction plans will be submitted to the Federal Council for Science and Technology for endorsement as components of National Programs in Oceanography and Atmospheric Sciences.

5. Agencies are responsible for funding, conducting, and otherwise managing their portions of the program, consistent 
with their statutory missions. Such portions are those either initially proposed by an agency for support, or added by mutual agreement between the agency, DOC, and the joint panel.

6. DOC will undertake funding needed to fill out the remaining important components of the total program plan consistent with its statutory missions. Area studies of transfer processes represent one such component."

The intention of the Council is to stimulate activity and provide effective leadership and coordination of the air/sea interaction program. I am glad to endorse the Council's statement, which should serve to. amplify Dr. Wiesner's earlier memoranda on the subject and should clarify the relationship of DOC to the other agencies in this area.

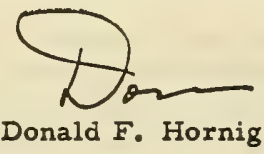


FEDERAL COUNCIL FOR SCIENCE AND TECHNOLOGY INTERDEPARTMENTAL COMMITTEE FOR ATMOSPHERIC SCIENCES U.S. DEPARTMENT OF COMMERCE

WABHINGTON, D.C. 20230

$$
\text { June } 19,1964
$$

$\mathrm{C}$

Dr. Franklin A. Gifford

Chairman, Joint ICO/ICAS Air-Sea

Interaction Panel

U.S. Weather Bureau

Washington, D.C.

Dear Dr. Gifford:

At their April meetings the Interagency Committee for Oceanography and the Interdepartmental Committee for Atmospheric Sciences approved the following membership for a Joint ICO/ICAS Air-Sea Interaction Panel:

Dr. Franklin A. Gifford, USWB, Chairman

Dr. Donald P. Martineau, Office of Naval Research

Mr. Thomas Austin. Bureau of Commercial Fisheries

LCDR Richard M. Morse, U.S. Coast Guard

Dr. Fred White, National Science Foundation

Dr. W. C. Jacobs, National Oceanographic Data Center

Dr. R. V. Thomann, Department of Health, Education

and Welfare

An additional member, Mr. Arnold B. Joseph, Division of Biology and Medicine of the Atomic Energy Commission, has now been approved.

Your panel is charged with providing assistance to the Department of Commerce in the development of the Federally-supported air-sea interaction program. You will keep the program under continuous review and recommend to the ICO and the ICAS the appropriate components of the National Programs in Oceanography and Atmospheric Sciences.

James H. Wakelin, Jr.

Chairman, Interagency

Committee on Oceanography
J. Herbert Hollomon

Chairman. Interdepartmental

Committee for Atmospheric

Sciences 


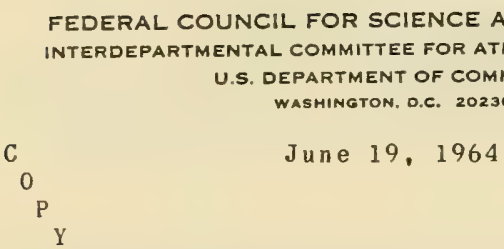

Dr. W. C. Jacobs

Chairman, Joint ICO/ICAS Ad Hoc Panel on Air-Sea Interaction

National Oceanographic Data Center

Washington, D. C.

Dear Doctor Jacobs:

The Joint ICO/ICAS Ad Hoc Panel on Air-Sea Interaction, of which you are Chairman, is hereby dissolved as a formal agency of the Interagency Committee for Oceanography and the Interdepartmental Committee for Atmospheric Sciences.

You and your panel are to be commended for the tremendous undertaking represented by your "Working Draft National Program, Ocean-Atmospheric Research" of March 1963, and your "National Program, Ocean-Atmospheric Research, Fiscal Year 1965" of 0ctober 4, 1963. Both documents have accomplished much toward identifying the unique problems in the air-sea interaction area and providing the basis for further agency programing.

It is hoped that the members of your panel will be available as individuals to assist the new Joint ICO/ICAS Air-Sea

Interaction Panel and the Sea-Air Interaction Laboratory of the Department of Commerce in the development of the Federally-supported program.

James H. Wakelin, Jr. Chairman. Interagency Committee on Oceanography
$J$. Herbert Hollomon

Chairman. Interdepartmental

Comittee for Atmospheric Sciences 


\section{APPENDIX 2}

BIBLIOGRAPHY OF OCEANOGRAPHIC PUBLICATIONS SUBMITTED BY HON. JAMES H. WAKELIN, JR., ASSISTANT SECRETARY OF THE NAVY 



\section{BIBLIOGRAPHY OF OCEANOGRAPHIC PUBLICATIONS}

INTERAGENCY COMMITTEE ON OCEANOGRAPHY of the FEDERAL COUNCIL FOR SCIENCE AND TECHNOLOGY United States of America 


\title{
FEDERAL COUNCIL FOR SCIENCE AND TECHNOLOGY
}

\author{
JERONE B. WIESNER, Chaiman \\ OFFICE OF SCIENCE AND TECHNOLOGY
}

\section{HAROLD BROWN \\ Director of Defense Research and Engineering DEPARTMENT OF DEFENSE \\ J. HERBERT HOLLOMON \\ Assistant Secretary for Science and Technology DEPARTMENT OF COMMERCE}

BOISFEUILLET JONES

Special Assistant to the Secretary for Health and Medical Affairs DEPARTMENT OF HEALTH, EDUCATION AND WELFARE

ROGER REVELLF

Secretary

DEPARTMENT OF THE INTERIOR

RAGNAR ROLLEFSON

Director, Office of Intemational Scientific Affairs (Observer)

DEPARTMENT OF STATE
GLENN T. SEABORC, Chaiman ATOMIC ENERGY COMMISSION

ALAN T. WATERMAN

NATIONAL SCIENCE FOUNDATION

JAMES E. WEBB

Administrator NATIONAL AERONAUTICS AND SPACE ADMINISTRATION

WILLARD COCHRANE

Director, Agricultural Economics DEPARTMENT OF AGRICULTURE

ELMER B. STAATS

Deputy Director
BUREAU OF THE BUDGET (Observer)

N. E. HALABY

FEDERAL AVIATION AGENCY (Observer)

EDWARD WENK, JR.

Technical Assistant to the Director

OFFICE OF SCIENCE AND TECHNOLOGY

(Executive Secretary)

\section{INTERAGENCY COMMITTEE ON OCEANOGRAPHY}

\author{
JAMES H. WAKELIN, JR., Chairman \\ Assistant Secretary of the Navy \\ (Research and Development) \\ RADM. H. ARNOLD KARO \\ $U$. S. Coast and Geodetic Survey \\ DEPARTMENT OF COMMERCE \\ Bureau of Commercial Fisheries \\ DEPARTMENT OF INTERIOR \\ RADM. R. D. SCHMIDTMAN \\ DEPARTMENT OF THE TREASURY \\ RAGNAR ROLLEFSON \\ Office of Intemational Scientific Affoirs \\ DEPARTMENT OF STATE \\ HARVE J. CARLSON \\ NATIONAL SCIENCE FOUNDATION \\ HARRY G HANSON \\ Public Health Service \\ DEPARTMENT OF HEALTH, EDUCATION AND WELFARE \\ JOHN N. WOLFE \\ ATOMIC ENERGY COMMISSION

\section{E. WALLEN} \\ Museum of Natural History \\ SMTTHONIAN INSTITUTION \\ ROBERT B. ABEL \\ Office of Naval Research \\ DEPARTMENT OF THE NAVY \\ (Secretary)
}




\section{FOREWORD}

The Interagency Committee on Oceanography of the Federal Council for Science and Technology plans and coordinates programs in the science of oceanography sponsored by government agencies. As part of its area of activity, the Committee is interested in assuring that the supply of scientists and engineers is sufficient to accomplish the programs planned for future years. The Committee has published this selected bibliography to provide a source of readly available information about marine science to students and other potential scientists.

The Committee is grateful to Mark W. Pangborn, Jr. of the U. S. Geological Survey and those who assisted him in the compilation of this bibliography. 


\section{TABLE OF CONTENTS}

Section

1. General Oceanography

2. Physical Oceanography: Sea Water, Waves, Tides, and Currents

3. Pollution of the Ocean

4. Sediments and Stratigraphy

5. Geology of the Sea Bottom and Coasts

6. The Mohole

7. Islands and Coral Reefs

8 Legal Aspects of the Sea

9. Navigation

10. History of Navigation

11. Chart Making and History of Chart Making

12. General Oceanographic Procedure, Techniques, Instrumentation, and Equipment

$\begin{array}{ll}\text { 13. Survival at Sea; Safety, Health } & 10 \\ \text { 14. Diving } & 10\end{array}$

A. General

$\begin{array}{ll}\text { B. Bathysphere and Bathyscaph Diving } & 10 \\ \text { C. Helmet and Hose Diving } & 10\end{array}$

D. Skin and Scuba Diving 11

15. Submarine Archaeology and Treasure Diving 12

16. Underwater Photography 12

17. Marine Meteorology 13

18. Resources of the Sea (excluding fisheries) 13

19. Marine Biology and Ecology 13

20. Seaweed 14

21. Fishes 14

22. Fisherles and F1shery Research 15

23. Sea and Shore BIrds 16

24. Whales and other Sea Mammals 16

25. Seashore Life 16

26. Shells; Mollusks 17

27. Education and Careers in Oceanography 18

28. Dictionaries 18

29. Directories 19

30 History of Oceanography 19

31. Biographies of Oceanographers 19

32. Oceanographic Expeditions 20

33. General Maps of the Oceans 21

34. F13ms and Film Strips

$\begin{array}{ll}\text { 35. Bibliographies on Oceanography and Related Subjects } & 22 \\ 36 . & \text { Periodicals on Oceanography and Related Subjects }\end{array}$ 
This reading list of 500 selected titles has been prepared to help the student and general reader locate information about the ocean in its many aspects. It lists technical treatises, college textbooks, dictionaries, directories, bibliographies, periodicals, maps, films, histories, biographies, and non-technical books and articles under 36 subject headings, with reading level and contents indicated. Only titles in English are listed. Older books are generally omitted unless they are of exceptional interest.

Further information on physical oceanography, including tides, waves, currents, and charts of our coastal waters, may be obtained from: Director U. S. Coast and Geodetic Survey, Washington 25, D. C.

Further information on the geology of the coasts and sea bottom, may be obtained from: Director, U. S. Geological Survey, Washington 25, D. C.

Further information on the plants and animals that live in the oceans and along the shore, may be obtained from: Comissioner, U. S. Fish and Wildife Service, Washington 25 , D. C.

Single copies of this bibliography are available from: Interagency Committee on Oceanography, Building T-3, Room 1714, 17th and Constitution Arenue, Washington 25, D. C. 
1. GENERAL OCEANOGRAPHY

\section{A. Techintcal}

Oceanogring: an introctuction to the narine sclences, Jercme W1111ans. Boston, Ifttle, Brown, 1962. 242 p. $\$ 8.00$. college textbook.

The Oceass; the1x physics, chentstry, and general blology, Harold ULrik Sverdrop and others. New Iork, Prent1c-Hall, 1962. 1087 p. $\$ 20.00$. technical treat18e.

Oceanography; 1nvited lectures presented at the International Ocennographic Congress, edfted by Mary Sears. Washington, 1961. 645 p. (Anericen Assoctation for the Advancement of Sctence. Publication no. 67). \$14.75. Thity articles by experts on wide range of oceanographic problems.

Proceedings of the Sympostum on Aspects of Deep Sea Research. edited by W1ll1am Stelling ron Arx. Washington, 1957. 181 p. (National Acadent of Sciences-National Research Council. Publication no.473). $\$ 1.75$

Ocean Geography for Oceanographers, Cuchlaine A. M. KIng. New York, St. Martin's Press, 1963. 336 p. In press.

Gulf of Mexdco; its orlgin, waters, and marine Ilfe, edited by Paul Simon Galtsoff. Washington, G.P.O., 1954. 604 p. (U.S. Fish and Wildiffe Servlce. Flshery bullet1n 89). $\$ 3.25$ from Government Printing Office.

\section{B. For the Adult Lavman and High School} Student (ageg I4 up)

This Great and W1de Sea; an introduct 1 on to oceanography and marine biology, Robert Ervin Coker. New York, Harper, 1962. 325 p $\$ 2.25$. Reprint of a very easy college text, 1947 .

The Sea, Leonard Engel. New York, TIme, Inc., 1961. $190 \mathrm{p}$. (IIFE nature l1brary). \$3.25. This beautiful book feature's many colored pictures and 11 ne maps, and w11I be enjoyed by both adults and children.

The Sea Around Us, Rachel Loulse Carson. Rev.ed. New York, Oxford University Press, 1961. 237 p. \$5.00. A famous best-seller dealing mostly with physical and geological oceanography.

The Sea and 1ts Mysterles, John S. Colman. New York, Norton, 1950. 285 p. \$3.75. Conclse summary.
Cosets, Waves and Weather, for Nev1gators. John Quincy Stenurt. Boston, GInn, 1945.

Tho Arctic Oeean, P. A. Gordleqko. (Sc1ent1fie Awariem, rol.204, n0.5, Wo 1961, pp.88-102). An secount of Ruesten inteotigation.

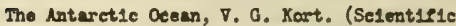
Anoricen, vol.207, no.3, Sept. 1962, pp.11328). Result of Rusalan research.

Frontiers of the Sea; the story of oceanographic exploration, Robert C. Coren. Gerden C1ty, New York, Doubledsy, 1960. 307 p. \$4.95. P1ne; this and the next seven titles enphasize the reaench now bolng on.

Turn to the Sea, Athelstan Frederick Spllhaus. Washington, National Academy of Sclences-Nat1onal Research Counc1l, 1959. $4 \mathrm{p}$. Pamphlet on the importance of studyIng the ocerns.

Conquest of the Sea, Cord-Christian Troebst. New Iork, Harper, 1962. 269 p. \$4.95. An account of the see 28 a possible seat of milftary action, and es a source of minerals, power, and food, and of the research needed to understand the sea.

Ocesn Sclence and Nat1onal Security; report of the Cormittee on Sclence and Astronautics, U. S. House of Representatives, $86 \mathrm{th}$ Congress, 2d Session. Wash1ngton, G.P.O., 1960. 180 p. (Report no. 2078, serisl H).

Oceanography, 1960 to 1970. Washington, National Academy of Sclences-National Research Council, Comittee on Oceanography, 1959-1962. 12 parta. Free. Describes the personnel, sh1ps, equipment, and research needs of oceanography over the next ten years.

Nat1onal Oceanograph1c Program, F1scal Year 1963. Washington, 1962. 31 p. (U. S. Interagency Commlttee on Oceanography: ICO pamphlet no. 3). Free.

Exploring the Secrets of the Sea, W1llian J. Cromie. Englewood Cliffs, New Jersey, Prent1ce-Hall 1962. 300 . \$5.95. Fine on the present atate of our knowledge of the ocean and how that knowledge has been gatned.

The Global Sea, Harr1s Bates Stewart, Jr. Princeton, New Jersey, Van Nostrand, 1963. $128 \mathrm{p}$. In preparation. A sumuary of recent advances in oceanography and why a knowledge of the ocean is important to our ilfe on land. 
ine Woods Hole Marine Biological Laboratory, Frank Rattray Lillie. Chicago, University of Chicago Press, 1944. 284 p. On the history and activities of a famous research organization.

\section{For Children Ages 10 to 14.}

Secrets of the Sea; oceanography for young scientists, Howard Jonah PIncus. Columbus 16, Ohio, American Education Publications, Education Center, 1960.31 p. $\$ 0.25$ Information-packed pamphlet; includes career data.

The Ses for San, William Maxwell Reed and Wilfrid S. Bronson. Rev. by Paul F. Brandwein. New York, Harcourt, 1960. 243 p. $\$ 4.95$.

The Sea Around Us, Rachel Louise Carson. Special edition for young readers, adapted by Anne Terry White. New York, Golden Press, 1958. 165 p. \$4.95. Finely illustrated.

1001 Questions Answered About the Oceans, Jan Hahn. New York. Dodd, Mead, 1963. $\$ 6.00$. In press.

The Golden Picutre Book of Sea and Shore; tide pools, Shells, small animals, the big and little creatures of the ocean; tides, currents, 1slands, and other wonders of the sea, Marion Bergner Carr. New York, Golden Press, 1959. 57 p. \$0.79. Easy book, features pictures.

The Wonderful World of the Sea, James Fisher: Garden City, New York, Garden City Book's, 1957. 68 p. $\$ 3.45$. Attractive picture book, stressing man's relations to the sea.

All About the Sea, Ferdinand C. Lane. New York. Random House, 1953.148 p. $\$ 1.95$.

Easy.

The Young Pathfinder's Book of Oceans, Streams, and Glaciers, William D. Clarke. New York, Hart Publ.Co., 1961. 128 p. \$3.95. This volume deals almost entirely with oceanography.

Turn to the Sea, Athelstan Frederick Spilhaus. Adapted for young readers by Eileen Daly, Racine, Wisconsin, Whitman Publ.Co., 1962. 59 p. \$0.59. This and the next five titles deal with the need for oceanographic research, and describe the techniques and gadgetry used in such research.

All about Underseas Exploration, Ruth Brindze New York, Random, 1960 . 145 p. \$1.95
Undersess; the challenger of the deep frontier, Cors Cheney and Ben Partridge. New York, Coward-McCann, 1961. 125 p. \$2.95.

The Challenge of the Sea, Arthur Charles Clarke. New York, Holt, 1960.167 p. $\$ 3.95$.

In the Deep Blue Sea, Elizabeth Morgan. Englewood Cliffs, New Jersey, Prentice-Hall, 1962. 72 p. $\$ 2.95$. Easy.

The Wonders of Underwater Exploration, Irwin Stambler. New York, Putnam, 1962. 128 p. $\$ 1.95$.

2. PHYSICAL OCEANOGRAPHY: SEA WATER, WAVES, TIDES, AND CURRENTS.

An Introcuction to Physical Oceanography, William Stelling ron Arx. Reading, Mass. Addison-Wesley, 1962. 422 p. \$15.00. Pages 19 to 4 deal with the geological background, the remainder with sea water and its movement. college textbook.

Physical Dceanography, Albert Defant, New York, Pergamon Press, 1961. 2 rols. \$35.00. Very technical treatise.

Dynamical Oceanography, Joseph Proudman. New York, Wiley, 1953. 409 p. \$8.50. Technical.

The Sea; 1deas and observations. Vol.1, Physical Oceanography, M. N. Hill and others. New Iork, Wiley, 1962. 664 p. \$25.00. Technical; summarizes what we have learned since about 1940 .

Proceedings of the JNESCO Symposium on Physical Oceanography. Tokyo, 1955. Tokyo, UNESCO and Japan Society for the Promotion of Science, 1957.292 p. $\$ 4.50$. Technical: forty-six articles on instrumentation, currents, work in progress.

Conference on Physical and Chemical Properties of Sea Water, Easton, Maryland... Washington, 1959. 202 p. (National Acadenry of Sciences-National Research Council. Publ. no. 600$)$. \$2.00. Technical.

Chemistry and Fertility of Sea-Water, Hildebrand Wolfe Harvey, New York, Cambridge University Press, 1955. 244 p. \$5.50. Replaces his "Recent Advances in the Chemistry and Biology of Sea-Water." Technical.

Realms of Water; some aspects of its cycle in nature. Philip Henry Kuenen. New York, Wiley, 1955.327 p. $\$ 6.50$. Pages 21-88 cover water in the sea; a little technical. 
Water, Miracle of Nature, Thanaon King. New York, Collier Books, 1961. 238 p. \$0.95. Pages 30-62 discuss water in the sea

The Anatorny of the Atlantic, Henry Stommel. (Scientific American, vol.192, no.1, Jan. 1955, pp.30-35). Currents, temperature, saltiness.

Hydrodynamics of Oceans and Atmospheres, Carl Henry Eckart. New York, Pergamon Press, 1960. 290 p. \$9.00. Technical.

The Atmosphere and Sea in Motion; scientific contributions to the Rossby memorial volume, Bert Bolin. New York, Rockefeller Institute Press, 1959. 509.p. \$15.00. Technical.

Interaction Between the Atmosphere and the Oceans; report to the Committee on Atmospheric Sciences and the Committee on Oceanography, the Joint Panel on Air-Sea Interaction. Washington, 1962. 43 p. (National Acaderry of Sclences-National Research Council. Publ. 983). O.P. Technical.

Interaction of Sea and Atmosphere; a group of contributions, by Alfred Clarence Redfield and others, Boston, 1957.75 p. American Meteorological Society. (Meteorological ironographs, vol.2, no.10).

Waves and Tldes, Robert Christopher, Hamlyn Fussell and D. H. Macmillan. London, Futchinson's Scientific and Technical Publications, 1952. 348 p. A little technical in spots.

Water Waves; the mathematical theory with application, James Johnston Stoker. New York, Interscieace, 1957. 567 p. \$12.00. Technical.

Wind Waves at Sea, Breakers and Surf, Henry Bryant Bigelow and W. T. Edmondson. Washing ton, G.P.O., 1947. 177 p. (U. S. Fydrographic office. Publ. no.602). \$2.80. from Hydrographic Office, Washington, D. C.

Ocean Waves and Kindred Geophysical Phenomena, Vaughan Cornish. Cambridge, England, University Press, 1934. 163 p. pp.1-49 deal with ocean waves; pp.86-120, with tidal bores.

Ocean Waves, Willard Bascom. (Scientific American, vol.201, no.2, August 1959, pp. $74-843$.

Tides and Tidal Streams; a manul complled for the use of seamen, Harold Dreger Warburg. New Yark, Cambridge University Press; 1922. 95 p. \$3.75. Somewhat technical.
Tidal Hydraulics, George Bigelow Pillsbury. Washington, G.P.O., 1940.283 p. (U. S. Corps of Engineers. Professional paper no. 34). Technical.

The Tide, Harry Aaron Marmer. New York, Appleton, 1926. 282 p. Semitechnical.

The Tides, and Kindred Phenomena in the Solar System, George Howard Darwin. San Francisco, Freeman, 1962. 378 p. \$2.75. Reprint of an 1897 series of lectures; not very technical.

Ebb and Flow; the tides of earth, air, and water, Albert Defant. Ann Arbor, University of Michigan Press, 1960. 121 p. \$1.25. Deals mainly with ocean tides; very fine.

The Tides, Thomas D. Nicholson. (Natural History, vol.68, 1959, pp.326-33).

The Margins of the Restless Ocean, Hubert A. Bauer. (Naturgl History, vol.68, 1959 pp.470-76). Effect of the tides on the land.

The Glant Tldes of Fundy, Paul A. Zahl. (National Geographic Magazine, rol.112, no.2, Aug. 1957, pp.153-92). Easy, many pictures.

Watch the Tldes, David Greenhood, New York, Hollday, 1961 . \$2.75. Fine for younger ch1ldren.

Tsunamis, Joseph Bernstein. (Scientiflc American, vol.191, no.2, August 1954, pp.6064). About so-called "tidal waves."

Cosstal Currents Along the Atlantic Coast of the United States, Frank Joshus Haight. Washington, G.P.O., 1942. 73 p. (U. S. Coast and Geodetic Survey. Special publ. no.230). 0.p. The Coast Survey has issued many pamphlets on currents, temperature, and salinity of our coasts, bays, and harbors.

The Gulf Stream; a physical and dynamical description, Henry Stammel. Berkeley, University of California Press, 1958. $202 \mathrm{p}$. $\$ 6.00$. Technical.

The Ocean River, Henry Chapin and F. G. Smith, 2d ed. New Tork, Seribner, 1962. 325 p. \$1.65. All about the Gulf Stream and its effects on man.

The Gulf Stream, Ruth Brindze. New York, Vanguard, 1945 . 63 p. $\$ 2.50$. For Children 10-14.

The Gulf Strean, Ruth Brindze, New York, 
The Circulation of the Oceans, Walter Munk. (Scientific American, vol.193, no.3, Sept. 1955, pp.96-104). World scope.

The Cromwell Current, Jahn A. Knauss.

(Scientific American vol.204, no.4, April 1961, pp.105-16). About a great submarine current in the central Pacific.

The Peru Current, Gerald S. Posner. (Scientific American, vol. 190, no.3, March 1954, pp.66-71). About a current that comes up the west coast of South America.

The Circulation of the Abyss, Henry Stommel. (Scientific American, vol. 199, no.1, July 1958, pp. 85-90). About currents in the bottom of the Atlantic Ocean.

\section{POLIUTION OF THE OCEAN}

The Hazards of Atomic Wastes; perspectives and proposals on oceanic disposal, Alton Frye Washington, Public-Affairs Press, 1962. 45 p. $\$ 1.00$.

Radioactive Waste Disposal into Atlantic and Gulf Coastal Waters; a report from a working group of the Committee on Oceanography. . Washington, 1959. 37 p. (National Academy of Sciences-National Research Council. Publ. 655): 0.p. This and the next four publications are a little technical.

Radioactive-waste Disposal into the Sea; report of the Ad Hoc Panel convened by the Director General of the IAEA, under the chairmanship of Henry Brynielsson in Feb. 1960. Vienns, 1961. $174 \mathrm{p}$. (International Atomic Energy Agency. Safety series, no.5).

Disposal of Low-level Radioactive Waste into Pacific Coastal Waters; a report of a working group of the Comittee on Oceanography. . . Washington, 1962. 87 p. (National Acadeny of Sciences-National Research Council. Publ. 985). \$2.00.

Considerations of the Disposal of Radioactive Wastes from Nuclear-powered Ships into the Marine environment, the Conmittee on the Effects of Atomic Radiation on Oceanography and Fisheries... Washington, 1959. (National Academy of Sciences-National Research Council. Publ.658). 0.p

A Study of the Disposal of Chemical Waste at Sea, Alfred Charles Redfield and L. A. Walford. Washington, 1951. $52 \mathrm{p}$. (National Academy of Sciences-National Research Council. Publ. 201). \$1.00.

\section{SEDIMENTS AND STRATIGRAPHY}

Sedimentary Rocks, Francis John Pettijohn. 2d ed. New York, Harper, 1957.718 p.

$\$ 12.00$. Detailed college textbook.

Manual of Sedimentary Petrography, William Christian Krumbein and F. J. Pettijohn. New York, Appleton, 1938. 549 p. $\$ 6.50$. Advanced college text; old, but contains the best analysis of loose sedimentary deposits.

Principles of Sedimentation, William Henry Twenhofel. 2d ed. New York, McGran-Hill, 1950. $673 \mathrm{p}$. $\$ 11.00$. Advanced college text on how sediments are deposited in water.

A Treatise on Sedimentation, William Henry Twenhofel. 2d ed. New York, Dover, 1962. 2 vols. \$4.70. Reprint of a 1936 classic; technical.

Stratigraphy and Sedimentation, William Christian Krumbein and L. L. Sloss. San Francisco, Freeman, 1951. 497 p. $\$ 5.00$. Integrates stratigraphy and sedinentation; a $2 d$. ed. is in preparation.

Principles of Stratigraphy, Carl Owen Dunbar and John Rodgers. New York, Wiley, 1957. 356 p. \$10.00. Advanced, yet very clear college text on how to read geologic history from water-laid deposits.

Stratigraphic Principles and Practice, James Marvin Weller. New York, Harper, 1960.

725. p. $\$ 10.00$. Advanced college textbook.

Recent Marine Sediments: a symposium. . Parker Davies Trask, Rev,ed. Tulsa, 1955 736 p. (Society of Economic Paleontologists and Mineralogistis. Special publ. no, 4). $\$ 5.00$. Technical

Recent Sediments, Northwest Gulf of Mexico; a symposium sumarizing the results of work carried on in Project 51 of the Americen Petroleum Institute, 1951-1958, edited by Francis Parker Shepard and others, Scripps Institute of Oceanography. Tulsa, American Association of Petroleun Geologists, 1960. 394 p. \$7.00. Technical.

5. GEOLOGICAL OCEANOGRAPHY: GEOLOGY OF THE SEA BOTTOM AND COASTS.

\section{A. Technical.}

Coastal and Submarine Morphology, Andre Gutlcher. New York, Wiley, 1958. $274 \mathrm{p}$. $\$ 6.50$. College textbook. 
Marine Ceology, Philip Henry Kuenen. New York, Wiley, 1950.568 p. $\$ 9.50$. College textbook.

Submarine Geology, Francis Parker Shepard. New York, Harper, 1948. 348 p. \$6.00. College textbook.

The Floor of the Ozean; new light on old mysteries, Reginald Aldworth Daly. Chapel Hill, N.C., University of North Carolina Press, 1942. 177 p. Somewhat dated in spots.

Glaciological Research on the North Atlantic Coasts, Hans W: son Ahlmann. London, 1948. 83 p. (Royal Geographical Society. RGS research series, no.1)

Beaches and Coasts, Cuchlaine A. M. King. London, Arnold, 1960. $403 \mathrm{p}$.

Shore Processes and Shoreline Development, Douglas Wilson Johnson. New York, 1919. $584 \mathrm{p}$. In part replaced by King's book, listed above.

Salt Marshes and Salt Deserts of the World, Valentine Jackson Chapman. New York, Interscience, 1960.392 p. \$14.50. Geology and ecology.

Coastal Changes, William Washington Williams. london, Routledge, $1960.220 \mathrm{p}$. On the geological and engineering aspects of shore protection; slight British slant.

The New England Acadian Shoreline, Douglas Wilson Johnson. New York, Wiley, 1925. $608 \mathrm{p}$.

Atlantic Submarine Valleys of the United States and the Congo Submarine Valley, Arthur.Clifford Veatch and P.A. Smith. New York, 1939. 101 p. (Geological Society of America. Special paper no. 7). $\$ 4.80$.

The Sea off Southern California; a modern habitat of petroleum, Kenneth Orris Emery. New York, Wiley, 1960. 366 p. \$12.50.

Submarine Topography off the California Coast; canyons and tectonic interpretation, Francis Parker Shepard and K. O. Fnery. New York, 1941. 171 p. (Geologica) Society of America. Special paper no. 31). 0.p.

Sunken Islands of the Mid-Pacific Mountains, Edwin L. Hamilton. New York, 1956. 97 p. (Geological Society of America. Memoir 64). $\$ 2.50$.

The Floor of the Oceans, Bruce C. Heezen and others. Vol.1, The North Atlantic.
Text to accompany the Physiographic diagram of the North Atlantic. New York, 1959. 122 p. (Geological Society of America. Special paper no. 65). Map, $\$ 1.50$; text, $\$ 4.50$.

\section{B. Nontechnical.}

The Earth Beneath the Sea, Francis Parker Shepard. Baltimore, Johns Hopkins Press, 1959. 275 p. \$5.00. Fine book on the geology of the coasts and sea bottom.

The Ocean Floor, Hans Petterseon. New Haven, Yale University Press, 1954. 181 p. \$3.75.

Under the Deep Oceans; twentieth Century Voyages of discovery, Thomas Frohock Gaskell. New York, Norton, 1960. 239 p. \$3.75 Mainly an account of sea-bottom geolog rather than the story of the Challenger's 1950 voyage.

The Last Geographic Frontier; the sea floor, Edwin L. Eamilton. (Scientific Monthly, vol.85: 1957, pp.294-314).

The Changing Level of the Sea, Rhodes $W$. Fairbridge. (Scientific Anerican, vol, 202, no. 5, May 1960, pp.70-79). Effects of glaciation on sea level.

The Magnetism of the Ocean Floor, Arthur D. Raff. (Scientific American, vol. 205, no.4, Oct. 1961, pp.146-56).

Seismic Shooting at Sea, Maurice Ewing and Leonard Engel. (Scientific American, vol. 206, no.5, May 1962, pp.116-26). How the sea floor is studied.

The Paciflc Floor, Robert S. Dietz. (Scientific American, vol. 186, no.4, April 1952, pp. 19-23).

Fractures in the Pacific Floor, Henry $W$ Menard. (Scientific American, vol. 193. no.1, July 1955. pp.36-41).

The East Pacific Rise, Henry W. Menard. (Sclentific Amertcan, vol. 205, no.6. Dec. 1961, pp. 52-61).

The Trenches of the Pacific, Robert $L$. Fisher and Roger Revelle. (Sclentific American, vol. 193, no.5, Nov. 1955, pp.3641).

An Introduction to the Geology and Mineral Resources of the Continental. Shelves of the Americas, James Van Alen Trumbull and others. Washington, G.P.O., 1958. 92 p. (U.S. Geological Survey. Bulletin 1067). Sold only by the Superintendent of Documents, Government Printing office, Washington 25 . D. C., for $\$ .75$. 
Submarine Physiography of the U.S. Continental Margins, G, F. Jordan, Washington, G.P.O., 1962. 28 p. (U.S. Coast and Geodetic Survey. Technical bulletin, no. 18). \$0.20.

The Continental Shelf, Henry C. Stetson.

(Scientific American, vol. 192, no.3, March 1955, pp.82-86). U. S. Coasts.

The Origin of Submarine Canyons, Bruce C. Heezen. (Scientific American, vol.195, no.2, Aug. 1956, pp.36-41).

The Physical Geography of Beaches and Coastlines, Ronald Kay Gresswell. London, Fult on Educational Publications, 1957. 128 p. Most interesting and useful, despite its British slant.

Beaches, Willard Bascom. (Scientific American, vol. 203, no.2, Aug. 1960, pp.80-92).

Our Changing Atlantic Cosstline, Nathaniel T. Kenney. (National Geographic Magazine, vol. 122, no.6, Dec. 1962, pp.860-87). The effects of the storm of March 7, 1962, on the cosst between Long Island and Cspe Hatteras.

Florida Dunes and Scrub; vegetation and geology, Herman Kurz. Tallahassee, 1942. 154 p. (Florida. Geological Survey. Geological bulletin, no.23). Coastal geology and ecology.

Oregon's Sidewalk on the Sea, Paul A, Zahl. (National Geographic Magazine, vol. 120, no.5, Nov. 1961, pp.208-34). Biology, agate collecting.

The Fiord Region of East Greenland, Loulse Amer Boyd. New York, 1935. 369 p. (American Geographic Society. Special publ. no.18). Finely illustrated account of a glaciated coast.

The Cosstline of England and Wales in Pictures; James Alfred Steers. Cambridge, Eng., University Press, 1960 . 145 p. Splendid picture book; although they are concerned only with the British cossts, this and the following charming volume may intrigue American readers.

The Sea Coast, James Alfred Steers. London, Collins, 1953. $276 \mathrm{p}$.

\section{THE MOHOLE}

A Hole in the Bottom of the Sea; the story of the Mohole project, Willard Bascom. Garden City, New York, Doubleday, 1961. 352 p. \$4.95. All about the hole to be drilled into the sea bottom, where the earth's crust is thinnest, to determine the nature of the original rock making up the earth's interior.

The Mohole, Willard Bascom. (Scientific American, vol. 200, no.4, April 1959, pp. 41-49).

Scientists Drill at Sea to Pierce Earth's Crust, Samuel W. Matthews. (National Geographic Magazine, vol. 120, no.5, Nov. 1961, pp.686-97). Easy, with many pictures

Experimental Drilling in Deep Water at $\mathrm{La}$ Jolla and Gusdalupe Sites. Washington 1961. 183 p. (National Academy of Sciences-National Research Council. Publication no. 914). $\$ 3.00$.

Design for a Deep Ocean Drilling Ship. Wash1ngton, 1962. 173 p. (Nat fonal Academy of Sciences-National Research Council. Publication no.848). 0.p.

7. ISLANDS AND CORAL REEFS.

Atoll Environment and Ecology, Herold Jacob Wiens. New Haven, Yale University Press, 1962. 532 p. \$15.00. Geology, geography, and natural history of a large number of tropical islands.

Handbook for Atoll Research, Francis Raymond Fosberg and M. H. Sachet. Washington, 1953. 129 D. National Research Council. Pacific Science Board. Atoll research bulletin, no.17). How to investigate, collect, and photograph.

Coral Island; portrait of an atoll, Marston Bates and D. P. Abbott. New York, Scribner, 1958. 254 p. \$4.95. Charming account of a scientific survey of Ifaluk, in the Caroline Islands.

Coral Reefs and Atolls, John Stanley Gardiner. London, Macmillan, 1931. 18I p.

The Coral Reef Problem, William Morris Davis. New York, 1928, 596 p. (American Geographical Society. Special publication no.9). Somewhat technical but informative survey of the world's coral reefs; emphasizes geology.

The Structure and Distribution of Coral Reefs, Charles Robert Darwin. Berkeley, University of Calffornia Press, 1962. 214 2 . \$1.95. A classic, first published in 1842 . since proven correct by' recent research.

A Year on the Great Barrier Reef; the story of corsis and of the greatest of their creations, Charles Maurice Yonge. New York, Putnam, 1930. $246 \mathrm{p}$. This and the next two 
references are fine accounts of the great Australian reef and of the creatures that live thereon.

Wonders of the Great Barier, Theodore Cleveland Roughley. New York, Scribner, 1947.282 p. $\$ 5.00$.

The Great Barrier Reef and Adjacent Isles, Keith Gilleit and Frank McNeill. Rev.ed. Sydney, Coral Press, 1962. 209 p. Magnificently illustrated.

On Australia's Coral Ramparts, Paul A. Zahl. (National Geographic Magazine, vol. 111, no.1, Jan. 1957, pp-1-48). Easy, with fine pictures.

Questions of the Coral Reef's, Norman D. Newell. (Natural History, vol.68, 1959 , p. $.118-31)$.

Biology of the Corals, Norman D. Newell. (Natural History, vol.68, 1959, pp.226-35).

Atlantic Reef Corals; a handbook of the common reef and shallow-water corals of Bermuda, Florida, the West Indies and Brazil, Frederick George Walton Smith. New York. Farrar, Strauss, 1948. $112 \mathrm{p}$.

Florida's Coral City Beneath the Sea, Jerry Greenberg. (National Geographic Magazine, vol. 121, no.1, Jan. 1962, pp. 70-89). This and the next title deal with the John Pennekamc Coral Reef State Park.

Key Largo Coral Reef; America's first undersea park, Charles M. Brookfield. (National Geographic Magazine, vol. 12l, no.1, Jan. 1962, pp.58-69).

Geology of the Isles of Shoals, Katherine Stevens Fowler-Billings. Concord, New Hampshire State Planning and Development Commission, 1959.51 p. About a group of islands just off the New Hampshire coast.

Topographic map, Acadia National Park and vicinity, Hancock County, Maine. . 1:31, 680. Washington, U. S. Geological Survey, 1942. 0.p. Text on verso: The Geoiogy of Mount Desert Island, George McLane Wood. This is the only example of fiord coastline in the eastern United States.

Sea Islands of Georgia; their geologic history, Count Dillon Gibson. Athens, Georgia, University of Georgia Press, 1948. $73 \mathrm{p} . \$ 2.00$.

The Ocean Island (Inagua), Gilbert C. KIingel. Garden City, New York, Doubleday-Anchor, 1961. 415 p. \$1.45. Natural history of a Caribbean island.
Galapagos, World's End, Charles William Beebe. New York, Putnam, 1928. 443 p. Natural history of the island group.

The Galapagos Islands; a history of cheir exploration, Joseph Richard Slevin. San Francisco, 1959 . 150 p. (California Academy of Sciences. Occasional papers, no.25).

An Island is Born; Oahu roars up from the deep. . Nora Dowell Stearns. Honolulu, Honolulu Star-Bulletin Co., 1935. 115 p.

Geologic Map and Guide of the Island of Oahu, Hawail. . Harold Thornton Stearns. Honolulu, 1939. "75 p. (Hawail Division of Hydrography, Bulletin 2). This and the next title are a little technical, but very informative.

Geology of the Hawaiian Islands, Harold Thornton Stearns. Honolulu, 1946. 106 p.

(Hawaii. Division of Hydrography. Bulletin 8).

The Explosive Birth of Myojin Island, Robert S. Dietz. (National Geographic Magazine, vol. 105, no.1, Jan. 1954, pp.117-28). About the 1952 eruption in the Pacific, south of Tokyo.

A New Volcano Bursts from the Atlantic, John Scofield. (National Geographic Magazine, vol. 113 , no.6, June 1958, pp.73557). In the Azores Islands, 1957.

Tristan da Cunha: death of an Island, P.J. G. Wheeler. (National Geographic Magazine, vol. 121, no.5, May 1962, pp.679-95).

Volcanic eruption of 1961.

Lost Continents; the Atlantis theme in history, science, and literature, Lyon Sprague DeCamp. New York, Gnome Press, 1954. 362 p. $\$ 5.00$.

Legendary Islands of the Atlantic; a study in medieval geography, William Henry Babcock. New York, 1922. 196 p. 'American Geographical Society. Research series, no.8). Includes information on Atlantis.

8. LEGAL ASPECTS OF THE SEA

The Public Order of the Oceans; a contemporary international law of the sea, Myres Smith McDoug2l and William T. Burke. New Haven, Yale University Press: 1962. 1226 p. \$12.50.

The Continental Shelf, Martinus Willem Mouton. The Hague, Nijhoff, 1952, $367 \mathrm{p}$. 
The Tidelands 0il Controversy; a legal and historical analysis, Ernest R. Bartley. Austin, University of Texas Press, 1953. 312 p. \$5.00.

Shore and Sea Boundaries, with Special Reference to the Interpretation and Use of Coast and Geodetic Survey Data, Aaron Louis Shalowitz, Washington, G.P.O., 1962-63. 2 vols. (U.S. Coast and Geodetic Survey. Pulbication 10). Vol. 1, \$3.50. from Government Printing office; vol.2, in press. About boundary problems associated with the submerged lands cases.

\section{NAVIGATION}

American Practical Navigator, Nathaniel Bowditch, Washington, G.P.0., 1958. 1524 p. (U.S. Hydrographic office. H.O. Publication no.9). Sold by the Hydrographic Office or the Government Printing office, for \$6.25. A comprehensive manual of useful data.

Dutton's Navigating and Piloting, Benjamin Dutton, edited by John Clayton Hill, II, and others. Annapolis, Maryland, United States Naval Institute, 1958. 771 p. \$8.00. This and the next two titles are college textbooks, comprehensive, with much mathematics.

Marine Navigation, Philip Van Horn Weems and C. V. Lee. 2d ed. Annapolis, Md. Weems System of Navigation, Inc., 1958. 455 p. $\$ 7.50$.

Basic Marine Navigation, Bart Jan Bok and F. W. Wright. $2 \mathrm{~d}$ ed. Boston, Houghton Miffin, 1952 . 424 p. $\$ 6.75$.

Primer of Navigation. . George Webber Mixter. 4th ed., rev. by Donald McClench. Princeton, New Jersey, Van Nostrand, 1960. $553 \mathrm{p}$. \$9.50. Introductory text, comprehensive, but with a minimum of mathematics.

Navigation, Henry Brinton and P. Moore. London, Methuen, 1961. 72 p. This and the next two titles are easy and non-mathematical.

Narlgation the Easy Way, Carl Daniel Lane and John Montgomery. New York, Norton, 1949. \$4.75

Little Ship Astro-navigation, M. J. Rantzen. New York, Philosophical Library, 1952. 160 p. $\$ 4.75$.

A Guide to Ocean Navigation, Frank Edgar Knight. New York, St. Martin's Press, 1959. 177 p. Features a historical, rather than a practical, approach to the art of navigation. $\$ 4.25$.
Nautical Almanac, for the year. . . Published annually by the Nautical Almanac Office, U.S. Naval Observatory, Washington, D.C. Sold only by the Government Printing office, for $\$ 2.00$. Contains the astronomical data needed to navigate on the high seas.

United States Cosst Pilots. New editions are published from time to time by the U.S. Coast and Geodetic Survey, Washington 25 , D. C. 8 vols. Sold only by the Coast and Geodetic Survey and its outlets. Provides information on coasts and harbors that is not included on the Coast charts.

Coast Charts. New editions of these maps of our coasts and harbors are published from time to time by the U. S. Coast and Geodetic Survey, Washington 25, D. C. Sold only by the Coast and Geodetic Survey and its outlets.

Catalog of Nautical Charts and Related Publications. New editions of this catalog are published from time to time by the U. S. Coast and Geodetic Survey, Washington 25 , D. C. Free from the Coast and Geodetic Survey. This catalog lists Coast Charts, Coast Pilots, and other publications useful in cruising along the U.S. coasts; tells how and where to buy them.

Catalog of Nautical Charts and Publications. New editions of this catalog are published from time to time by the U. S. Navy Hydrographic Office, Washington 25, D. C. Free from the Hydrographic office. This catalog lists Nautical Charts, Sailing Directions, and other publications useful in sailing the high seas; tells how to buy them.

The Boatman's Manual; a complete manual of boat handling, operation, maintenance and seamanship, Carl Daniel Lane. Rev. ed New York, Norton, 1951.596 p. $\$ 6.50$. This and the next two titles provide information useful for the week-end sailor, on such matters as rigging, equipment, navigation, weather, communication, and business.

Seamanship, a practical manual. Charles Frederic Chapman. New York, Motor Boating, 1951. 258 p. (Motor Boating's ideal series, vol.19). $\$ 2.00$.

A Beginner's Guide to the Sea, Frank Knight. New York, St. Martin's Press, 1955: 234 p. $\$ 2.75$.

The Experts' Book of Boating, edited by Ruth Brindze. Englewood Cliffs, New Jersey, Prentice-Hall, 1959. 291 p. \$5.95. Experts discuss 21 topics, such as cooking: sails, 
navigation, and boat handling.

\section{HISTORY OF NAVIGATION.}

A History of the Practice of Navigation, J. B. Hewson. Glasgow, Brown, Son, and Ferguson, 1951. 270 p. Scholarly and detailed.

The Sky and the Sailor; a history of celestial navigation, Harold A. Calahan. New York, Harper, 1952. 262 p. \$4.00.

A History of Marine Navigation, Per Collinder. New York, St. Martin's Press, 1955. 195 p. $\$ 4,25$. Easy.

The Haven-finding Art; a history of navigation from Odysseus to Captain Cook, Eva Germaine Rimington Taylor. New York, Abelard-Schuman, 1957. 295 p. \$6.00. Easy; includes a good bibliography.

The Evolution of Celestial Navigation, Charles Louis Petze, Jr, New York, Motor Boating, 1948. 104 p. Not chronological, but arranged by subject; abundantly illustrated.

The Art of Navigation in England in Elizabethan and Farly Stuart Times, David Watkin Waters. New Haven, Yale University Press, 1958. 696 p. $\$ 12.50$.

\section{CHART MAKTNG AND HISTORY OF CHART MAKDNG}

Navigational Observations. 2d, ed, (U. S. Navy Hydrographic Office. Publ. no. $606 \mathrm{~A}$, Hydrographic Observer's Manual). Washington, G.P. O., 1956. 30 p. Sold by the Hydrographic office for $\$ 0.50$. How the mariner can help the Hydrographic office keep its charts up-to-date.

Nautical Chart Manusl, H. R, Edmonston. Lth ed. Washington, U. S. Coast and Geodetic Survey, 1956, 81 p. Sold by Coast and Geodetic Survey, for \$3.00. A11 about the rules and practices, format, terms, and symbols that appear on its charts.

Hydrographic Manusl, Karl B. Jeffers. Washington, G.P.O., 1960. 283 p. (U. S. Coast and Geodetic Survey. Publication 20-2). Sold by Government Printing office for $\$ 2.00$. This and the following book describe how hydrographic surveys are made; technical.

Hydrographic Manual, Kenneth T. Adams. Rev. ed. Washington, G.P.O., 1942. 940 p.

(U, S. Coast and Geodetic Survey. Special publieation no, $y_{4} 3$ ), O.P. Contains much information not in publication 20-2.

Manual of Coastal Delineation from Aerial Photographs, Philip G. McCurd. Washington, 1947. 143 p. (U.S. Navy Hydrographic office. Publ. no. 592). Sold by the Hydrographic office for $\$ 1.50$. On making coast charts from air photos.

Wire Drag Manual, Kenneth S. UIm. Washington, G.P.O., 1959. 103 p. (U, S. Coast and Geodetic Survey. Publ. 20-1). Sold by the Government Printing office for $\$ 0.35$. How the Coast Survey locates wrecks, reefs, and rocks.

Surveys of the Seas; a brief history of British hydrography, Mary Blewitt. London, Macgibbon \& Kee, 1957. 168 p. Handsomely illustrated and most interesting.

Marine Cartography in Britain; a history of the sea chart to 1855, Adrian H. W. Robinson. Leicester, Eng., Leicester University Press, 1962. $222 \mathrm{p}$.

12. GENERAL OCEANOGRAPHIC PROCEDURE, TECHNIQUES, INSTRUMENTATION, AND ERUIPMENT.

Sources of Limnologicsl and Oceanogrephic Apparatus and Supplies, 1959: Anerican Society of Limnology and Oceanography, Special publication, no.1. (Limnology and Oceanography, vol.4, 1959; pp.357-65).

Oceanography and Marine Blology; a book of techniques, Harold Barnes. New York, Ma cMillan, 1959.218 p. $\$ 7.00$. Nontechnical summary of techniques and equipment, including photography.

Apparatus and Methods of Oceanography. Part 1, Chemical, Harold Barnes. New York, Interscience, $1959.341 \mathrm{p} . \$ 5.75$. This and the next six books are rather technical.

Instruction Manual for Ocesnographic Observations. 2d. ed. Washington, 1955. 210 p. (U. S. Navy Hydrographic Office. Publ. no. 607). Sold by the Hydrographic office for $\$ 12.00$. How oceanographic data is collected by the Navy.

Processing Oceanographic Data, E, C. LaFond. Washington, G.P.O., 1951 . 114 p. (U. S. Navy Hydrographic Office. Publ. no. 614). Sold by the Hydrographic office for $\$ 7.00$.

Symposium on Dceanographic Instrumentation. . John D. Isaacs and C. O'D. Iselin. Washington, 1952. 233 p. (National Academy of SciencesNational Research Council. Publ. no. 309). $0 . P$. 
Marine Sciences Instrumentation. . Vol.1, A collection of papers presented at the Marine Conference. . Woods Hole, 1961 edited by Roy D, Gaul. New York, Plenum Press, 1962. 354 p. $\$ 12.50$.

Oceanography Vessels of the World; a joint publication of IGY World Data Center A for Oceanography and the National Oceanographic Data Center, compiled by Luis R. A. Capurro and others. Washington, printed by U. S. Naval Oceanographic Office. 1961. 1 vol. (National Oceanographic Data Center general series, Publication G-2). Sold by the Oceanographic Office for $\$ 4.50$.

Proceedings, Government-industry Oceanographic Instrumentation Symposium, sponsored by the Interagency Committee on Oceanography. .

1961. Edited by Julius Rockwell. Washington, Miller-Columbian Reporting Service, 1962. 482 p. $\$ 6.00$.

13. SURVIVAL AT SEA: SAFETY, HEALTH.

The Raft Book, Harold Gatty. New York, George Grady Press, 1943. 152 p. Survival and navigation book for castaways.

Know-how in the Surf, John Bloomfield. Melbourne, Angus and Robertson, 1959. 205 p. Safety on the beach.

Dangerous Marine Animals, Bruce W. Halstead. Cambridge, Maryland, Cornell Maritime Press, 1959. $146 \mathrm{p}$. $\$ 4.00$. About creatures that sting, bite, or are poisonous to eat.

Sea Pests; poisonous or harmful sea life of Florida and the West Indies, Craig Phillips and W. H. Brady. Coral Gables, Florida, University of Miami Press, 1953. 78 p.

Proceedings of the Underwater Physiology Symposium, January 10-11, 1955, Washington, D. C... - Loyal G. Goff, editor. Washington 1955. 153 p. (National Acaderry of SciencesNational Research Council. Publ. 377). Collection of articles on oxygen toxicity bends, respiratory problems, etc. O.P.

A Survey Report on Human Factors in Undersea Warfare. the Committee on Undersea Warfare. Washington, Nationa? Academy of Sciences-National Research Council, 1949. 541 p. $\$ 3.00$.

Underwater Medicine, Stanley Miles. Philadelphia, Lippincott, 1962.328 p. $\$ 10.00$. On underwater physiology, hazards, safety, medicine.
14. DIVING.

\section{A. General}

Man Under the Sea, James Dugan. New York Collier Books, 1963. 332 p. \$1.50. In press. Originally published in 1956, this is an informal history of man's varied underseas activities: submarine archaeology, treasure search, undersea warfare, mineral prospecting, submarines, etc.

Famous Underwater Adventurers, Frederic Wagner. New York, Dodd, Mead, 1962. 159 p. $\$ 3.00$. Good brief biographies of Robert Gulton, Simon Lake, William Beebe, the Piccards, Cousteau, and seven other experts, for ages $10-15$.

\section{B. Bathysphere and Bathyscaph Diving}

Half Mile Down, Charles William Beebe, New York, Harcourt, 1934. 334 p. About the Beebe-Barton descent to 2500 feet, off Bermuda, in 1934.

2000 Fathoms Down, Georges S. Houot and Pierre Henri Willm. New York, Dutton, 1955. 192 p. \$4.75. Enthusiastic account of dives in a French bathyscaph, 1947 to 1953.

Seven Miles Down; the story of the bathyscaph Trieste, Jacques Piccard and Richard S. Dietz, New York, Putnam, 1961. $256 \mathrm{p}$ $\$ 5.00$. First-hand account of the dive of January 23, 1960, and of the dives.leading up to it.

Man's Deepest Dive, Jacques Piccard. (National Geographic Magazine, vol.118. no.2, Aug. 1960, pp.224-39). About the dive of January $23,1960$.

Four Years of Diving to the Bottom of the Sea, Georges S. Houot. (National Geographic Magazine, vol.113, no.5, May 1958, pp. i 1431). This and the next three items deal with French bathyscaph dives, in the Mediterranean.

Two and a Half Miles Down, Georges S. Houot. (National Geographic Magazine, vol. 106, no.1, July 1954 , pp.80-86).

Diving Through an Undersea Avalanche, Jacques-Yves Cousteau. (Nationsl Geographic Magazine. vol. 107, no.4, April 1955 pp. $538-42$ )

To the Depths of the Sea by Bathyscaphe, Jacques-Yres Cousteau. (National Geogrephic Magazine, vol.106. no.1, July 1954, pp.67-79)

\section{Helmet and Hose Diving.}


Deep Diving and Submarine Operations; a manual for deep sea divers and compressed air workers, Robert Henry Davis. 6th ed. London, Siebe, Gorman, 1955. 693 p. On the history and techniques of deep diving.

Diving Manual, U. S. Department of the Navy. Washington, G.P.O., 1960.456 p. How the Navy does it. Sold by the Government Printing office for $\$ 4.25$.

Marine Salvage Operations, Edward Michael Brady. Cambridge, Maryland, Cornell Maritime Press, 1960.237 p. $\$ 8.50$.

Down to the Ships in the Sea, Harry Grossett. New York, Lippincott, 1954. 256 p. Fine life of a veteran helmet diver. Other writers on salvage include Edward Ellsberg and David Masters.

Deep Down Under, John Joseph Floherty. Philadelphia, Lippincott, $1953.146 \mathrm{p}$. \#3.75. A career book, for boys 12 to 15 , on the engineering and salvage accomplishments of professional divers.

\section{Skin and Scuba Diving.}

Basic Scuba, self-contained underwater breathing apoaratus, Fred M. Roberts.

Princeton, New Jersey, Van Nostrand, 1960. 386 p. \$8.50. This and the next title are good basic books, stressing equipment, physiology, swimming, and safety.

The New Science of Skin and Scuba Diving. . by the Conference for National Co-operation in Aquatics. Rev.ed. New York, Association Press, 1962. 208 p. $\$ 2.95$.

The Skin Diver; a complete guide to the underwater world, Elgin Ciampi. New York, Roland Press, 1960. 315 p. \$6.00. Fine. This and the next three titles are broader in scope than the two listed above, if less detailed, and include information on underwater activities, such as spearfishing, photography, and wreck exploration. Many similar but not always satisfactory books are not listed here.

130 Feet Down; handbook for hydronauts, Hank and Shaney Frey. New York, Harcourt, 1961. 274 p. $\$ 6.50$

Underwater Diving Manual; the British SubAqua Club official instructions on underwater swimming techniques, George F. Brookes and A. V. Broadhurst. Newton Center, Mass. Charles T. Branford, 1961. 239 p. \$5.00.

Our World Underwater, William M. Stephens. New York, Lantern Press, 1962. 252 p. \$4.95.
A History of Self-contained Diving and Underwater Swimming, Howard E. Larson. Prep. for the Office of Naval Research under the auspices of the Committee on Undersea Warfare. Washington, 1959. 50 p. (National Academy of Sciences-National Research Council. Publ. no. 469). \$1.50.

Skin Diver's and Spearfisherman's Guide to American Waters. . Hilbert Van Nydeck Schenck, Cambridge, Maryland, Cornell Maritime Press, 1955.56 p. $\$ 1.75$. Strong on locations.

The Silent World, Jacques-Yves Cousteau. New York, Harper, 1953. 266 p. \$5.00. This and the next three books deal with the pioneering work of the French skin divers Cousteau, Huout, and Tailliez; lack of space prevents the listing of many more titles on skin diving and pearl fishing.

The Living Sea, Jacques-Yves Cousteau and James Dugan. New York, Harper, 1963. \$5.95. In press. Sequel to The Silent World, describing Cousteau's adventures since 1951.

Undersea Explorer; the story of Captain Cousteau, James Dugan. New York, Harper, 1957. $143 \mathrm{p}$. \$2.95. For ages 10 to 15 .

To Hidden Depths, Philippe Tailliez. New York, Dutton, 1954. 188 p.

Lady with a Spear, Eugenie Clark. New York, Harper, 1953. 243 p. \$4.50. Fine and informative; the exploits of a lady marine biologist.

Fish Men Explore a New World Underseas, Jacques-Yves Cousteau. (National Geographic Magazine, vol. 102, no.4. Oct. 1952. pp.431-72).

Diving Saucer Takes to the Deep, JacquesYves Cousteau. (National Geographic Magazine, vol. 117, no.4, April 1960, pp.570-86). About a midget 2-man submarine for underwater exploration.

Diving for Science, Lymn Poole. New York, Whittlesey, 1955 . $160 \mathrm{p} . \$ 2.75$. On the techniques and especially the scientific uses of skin diving, in fisheries investigation, the search for minerals, cave stidy, and underwater photography, for ages 10 to 14.

Underwater Work; a manual of scuba commercial, salvage and construction operations, John E. Cayford. Cambridge, Maryland, Cornell Maritime Press, 1959. 217 p. \$5.00. Scuba, not helmet and hose. 
15. SUBMARTNE ARCHAEOLOGY AND TREASURE DIVING.

The Treasure Diver's Guide, John Stauffer Potter. Garden City, New York, Doubleday, 1960. 501 p. \$9.50. Mainly a list of wrecks, arranged by aréa; includes information on how to identify wrecked galleons and on other aspects of submarine archaeology. Not always accurate, but the only thing of this sort available.

Deep Water Archaeology, Frederic Dumas. London, Routledge and Kegan Paul, 1962. 71 p. Practical handbook by an expert.

Ships, Shoals, and Amphoras; the story of underwater archaeology, Suzanne De Borhegyi. New York, Holt, 1961 . 176 p. \$4.95. A dependable, informal history.

History Under the Sea, Mendel L. Peterson. Washington, G.P.O., 1954. 16 p. (Smithsonian Institution. Publication 4174 ). A Smithsonian archaeologist tells how to explore wrecks and preserve relics.

History Under the Sea, Mendel L. Peterson. Washington, G.P.O., 1963. 200 p. (Smithsonian Institution Publication). In press; an amplification of the item above.

Finding History Under the Sea, D. A. Heller. (Natural History, vol.64, no.9, Nov. 1955 , pp.492-95). About Peterson's explorations with link and the Criles, concerning which see the next two titles listed below.

Sea Diver; a quest for history under the sea, Marion Clayton Link. New York, Rinehart, 1959.333 p. \$4.95. Vivid account of skin diving for wrecks in the Carribbean. Only a few of the best books and articles on treasure diving can be mentioned here.

Treasure-Diving Holidays, Jane and Barney Crile. New York, Viking, 1954. $263 \mathrm{p}$. $\$ 4.50$.

Diving for Pleasure and Treasure, Clay Blair, Jr. Cleveland, World, 1960. $248 \mathrm{p}$. \$4.95. Searching for the Monitor and for wrecks off the coast of Mexico.

4,000 Years Under the Sea, Philippe Diole. New York, Messner, 1954. 237 p. \$4.50. Classic on submarine archaeology in the Mediterranean area.

1,600 Years Under the Sea, Ted Falcon-Barker. New York, McKay, 1960. 225 p. \$4.50. Operations near Epidauros, Greece.

Oldest Known S.lipwreck Yields Bronze Age
Cargo, Peter Throckmorton. (National Ceographic Magazine, vol. 121, no.5, May 1962. pp.697-711). Concerns the remains of a ship sunk about 1000 B.C. off the west coast of Turkey.

Thirty-three Centuries Under the Sea, Peter Throckmorton. (National Geographic Magazine, vol. 117, no.5, May 1960, pp.682-703). About wrecks off the Turkish coast.

Fish Men Discover a 2,200-Year-0ld Greek Wreck, Jacques-Yves Cousteau. (National Geographic Magazine, vol.105. no.1, Jan. 1954, pp.1-36). About a wine-ship sunk near Marseilles.

Exploring the Drowned City of Port Royal, Marion Clayton Link. (National Geographic Magazine, vol.117. no.2. Feb. 1960, pp.15183). Port Royal was submerged diring the Jamaica quake of 1962

I Found the Bones of the Bounty, Luis Marden. (National Geographic Magazine, vol.112, no.6, Dec. 1957: pp.725-89)

\section{UNDERWATER PHOTOCRAPHY.}

A. Guide to Underwater Photography, Dimitri Rebikoff and Paul Cherney. 2d ed. New York, Greenberg, 1955 . 113 p. \$1.95. The first four titles deal with shallow-water photography, the next three with deep-water photography.

Underwater Photography, Hilbert Van Nydeck Schenck and $H$. W. Kendall. Cambridge, Maryland, Cornell Maritime Press, 1957. 126 p. \$3.50.

Underwater Photography and Television, Ellis Royal Cross. New York, Exposition Press, 1954 . 258 p. $\$ 6.00$.

Camera Under the Sea, Luis Marden. (National Geographic Magazine, vol. 109, no.2, Feb. 1956, pp.162-200).

Exploring Davy Jones's Locker with Calypso, Jacques-Ives Cousteau. (National Geographic Magazine, vol. 109, no.2, Feb. 1956, pp.14961). Testing the new Edgerton deep-sea camera at the end of a two-mile line.

Calypso Explores an Undersea Canyon, Jacques-Ives Cousteau. (National Geographic Magazine, vol.113, no.3, March 1958, pp.37396).

Photographing the Sea's Dark Underworld, Harold E. Edgerton. (National Geographic Magazine, vol.107, no.4, April 1955, pp.52337). 
Underwater Television, W. R. Stamp. (Scientific American, vol. 188, no.6, June 1953, pp. 32-37).

\section{MARDNE METEOROLOGY.}

Oceanography for Meteorologists, Harald Ulrik Sverdrup. New York, Prentice-Hall. 1942. $246 \mathrm{p}$. Technical.

Meteorology, with marine applications, William I. Donn. 2d. ed. New York, McGrawHill, 1951. 465 p. $\$ 7.00$. Easy college text, for layman, student, and mariner.

A Mariner's Meteorology, Charles Greham Halpine and Halton Hagen Taylor. Princeton, New Jersey, Van Nostrad, 1956. 371 p. $\$ 8.00$. Textbook for Naval Academy Midshipmen.

Oceanography for the Navy Meteorologist. Norfolk, U.S. Navy Weather Research Facility, 1960. 128 p. (Navieps 50-1P-547). Technical and specialized.

Atlantic Hurricanes, Gordon E. Dunn and Banner J. Miller. Baton Rouge, Iouisiana State University Press, 1960. $290 \mathrm{p}$. $\$ 10.00$. Technical.

Hurricanes, Their Nature and History: particularly those of the West Indies and the southern coasts of the United States, Ivan Ray Tannehill. 9th ed. Princeton, New Jersey, Princeton University Press, 1956. 308 p. $\$ 4.50$.

Hurricane, Marjory Stoneman Douglas. New York, Rinehart, 1958.393 p. $\$ 5.95$. A most readable history of American hurricanes.

Weather of the San Francisco Bay Region, Harold Thompson Gilliam. Berkeley, University of California Press, 1962. 72 p. $\$ 1.50$ How the ocean affects San Francisco's weather.

18. RESOURCES OF THE SEA (excluding fisheries, for which see section 22).

The Sun, the Sea, and Tomorrow; potential sources of food, enerey, and minerals from the sea, Frederick George Walton Smith and Henry Chapin. New York, Scribner, 1954. $210=$

Ocean Harvest; the future of oceanography: Helen Wolff Vogel and Mary L. Caruso. New York, Knoof, 1961. 144 p. $\$ 3.00$. The ocean as a potential source of food, minerals, and fresh water, for ages 10 to 24.
Raw Materials from the Sea, Edward Frankland Armstrong and L. M. Miall. Leicester, England, Constructive Publications, Itd. 19L5. 164 p. On the sea as a source of minerals and fresh water.

Minerals on the Ocean Floor, John L. Mero. (Scientific American, vol.203, no.6, Dec. $1960, \mathrm{pp} .64-72$ ).

Calypso Expl ores for Underwater 0il, JacquesYves Cousteau. (National Geographic Magazine, vol.107, no.2, Aug. 1955: pp.155-84). Easy.

Fresh Water from the Ocean, for Cities, Industry, and Irrigation, Cecil Byrne Ellis. New York, Ronald Press, 1954. 217 p. \$6.00. A little technical.

Salt-water Purification, K, S. Spiegler. New York, Wiley, 1962. 167 p. $\$ 9.50$. Sumarizes the present state of the art, technical in spots.

19. MARINE BIOLOGY AND ECOLOGY.

Treatise on Marine Ecology and Paleoecology, Joel Walker Hedgpeth and Harry S. Iadd. New York, 1957. 2 vols. (Geological Society of America. Memoir 67). $\$ 22.50$. Technical.

Marine Ecology, Hilary B. Moore. New York, Wiley, 1958. 493 p. \$9.50. College textbook.

Zoogeography of the Sea, Sven Petrus Ekman. London. Sidgwick and Jackson. 1953. $417 \mathrm{p}$. Technical.

The Biology of Marine Animals, Joseph Arthur Colin Nicol. New York, Interscience, 1960. T07 p. \$14.00. Technical.

Aspects of Deep Sea Biology, Norman Bertram Marshall. New York, Philosophical Library. 1954. 380 p. $\$ 10.00$. Technical.

Creatures of the Deeo Sea, KIaus Gunther and Kurt Deckert. New York, Scribner, 1956. 222 p.

Symoosium on Marine Microbiology, Carl t: Oppenheimer. Springfield, Illinois, Thoms, 1963. 928 p. In press.

Marine Microbiology; a monograph on hydrobacteriology, Claude Echraim -obell. Waltham. Mass., Chronica Botanica, 1946. $240 \cong$. Technical.

Nature Adrift; the story of marine plankton. ¿ames Fraser. Chester Springs, Pennsylvania, 
Dufour Editions, 1962. $\$ 8.95$. In press.

The Open Sea; its natural history; Part 1, The world of plankton, Alister Clavering

Hardy. Boston, Houghton Mifflin, 1957. 335 p. \$6.50. Hardy's books are expert and most readable.

The Open Sea; its natural history: Part 2, Fish and fisheries, with chapters on whales, turtles, and animals of the sea floor, Alister Clavering Hardy. Boston, Houghton Mifflin, 1959.322 p. $\$ 7.50$

The Underwater Guide to Marine Iife, Carleton Ray and Elgin T. Ciampi. New York, A. S. Barnes, $1956.338^{\circ}$. 83.15 . Intended for the skin diver; ecology, biology, descriptions of cammoner forms of life.

The Seas; our knowledge of life in the sea and how it is gained, Frederick Stratten Russell and C. M. Yonge. 2d ed. New York, Warne, 1936. 379 p. $\$ 5.00$. Marine biology.

A Biography of the Sea; the story of the world ocean, its animal and plant populations, and its influence on human history, Richard Carrington. New York, Basic Books, 1960, 285 p. $\$ 5.00$. Mainly marine biology.

The Ocean, Francis Downes Ommanney. New York, Oxford University Press, 1949. $245 \mathrm{p}$. $\$ 2.00$. Mainly marine biology.

Under the Sea, Maurice Burton. New York, Watts, 1962.256 p. $\$ 4.95$. Natural history of marine animals; easy.

The Oceanic Iife of the Antarctic, Robert Cushman Murphy. (Scientific American, vol 207, no.3, Sept. 1962, pp. 186-210).

The Kingdom of the Octopus; the life history of the Cephalopoda, Frank Walter Lane. New York, Sheridan House, 1960.300 p. \$7.50. Paperback, New York, Pyramid Books, 1962. 287 p. $\$ .75$

The Case of the Sea-serpent, Rupert Thomas Gould. London, Philip Allan, 1934. 291 p. The author weighs the pros and cons.

20. SEAWEED.

How to Know the Seaweeds; an illustrated manual for identifying the more common marine algae of both our Atlantic and Pacific coasts. . ., Elmer Yale Dawson. Dubuque, Iowa, W. C. Brown, 1956. 197 p. $\$ 2.25$.

Marine Algae of the Northeastern Coast of
North America, William Randolph Taylor. 2d ed. Ann Arbor, 1957. 509 p. (University of Michigan studies, Scientific series, vol. 13). Technical

Seaweeds at Ebb Tide, Muriel Lewin Guberlet. Seattle, University of Washington Press, 1961, 198 p. \$2.95. For identifying Pacific coast algae.

Seaweeds and Their Uses. Valentine Jackson Chapman. New York, Pitman, 1952. 287 p. All about seaweed, except identification.

21. FISHES.

Ichthyology, Karl Frank Lagler and others, New York, Wiley, 1962. 545 p. In press. College text.

Ecology of Fishes, G. V. Nikolsky. New York, Academic Press, 1962. \$12.00. In press. Technical

The Physiology of Fishes, Margaret Elizabeth Brown. New York, Academic Press, 1957. 2 vols, each $\$ 14.00$. Detailed, technical account of fish metabolism and behavior.

A History of the Fishes, John Roxbrough Norman. $2 d$ ed. New York, Hill \& ang, $463 \mathrm{p}$. Anatorry, physiology, ecology, geological history, and relations to man. $\$ 6.00$.

A Study of Fish, Chapman Pincher. New York, Duell, Sloan and Pearce, 1948. 343 p. Fish anatomy and physiology.

The Ways of Fishes, Leonard Peter Schultz and Edith M. Stern. New York, Van Nostrand. 1948. 264 p. $\$ 6.00$

The Life Story of the Fish; his morals and manners, Brian Curtis. New York, Dover, 1962. 293 p. \$1.50. Fish anatomy, physiology, and behavior

Living Fishes of the World, Eral Stannard Herald. Garden City, New York, Doubleday, 1961. 303 p. $\$ 12.50$. A systematic survey, with numerous fine photographs, many in color.

F1shes; a guide to fresh and salt-water species, Herbert Spencer Zim and Hurst $H$ Shoemaker. New York, Golden Press, 1959. $160 \mathrm{p}$. (Golden nature guide). \$1.00. Well-illustrated guide to 278 comoner species.

Field Book of Giant Fishes, John-Roxbrough Norman. New York, Putnam, 1949. 375 p. Fine Euide to whales, dolphins, and fishes over six feet long; an earlier edition was 
called "liant fishes, whales, and dolphins."

Marine Game Fishes of the World, Francesca Raimonde Ia Monte. Garden City, New York, Doubleday, 1952.190 p. \$3.95. Finely illustrated identification book.

Field Book oi Marine Fishes of the Atlantic Coast, from Labrador to Texas; being a short description of their characteristics and habits with keys for their identification, Charles Marcus Breder, Jr., and C. W. Coates. New York, Putram, 1948. 332 p. \$5.00.

Marine Game Fishes of the Pacific Coast, from Alaska to the Equator, Lionel Albert Walford. Berkeley, University of California Press, 1937. 205 p.

Common Ocean Fishes of California, Phil Morgan Roedel. Sacramento, 1953. $184 \mathrm{P}$. (California Department of Fish and Game. Fish bulletin no. 75).

Handbook of Hawaiian Fishes, William Alonzo Gosline and Vernon E. Brock. Honolulu, University of Hawail Press, 1960. 372 p. $\$ 11.00$. Identification book.

Shark, Thomas Helm. New York, Dodd, Mead, 1961. 260 p. \$4.00. Personal experiences shark fishing, plus accounts of shark attacks and facts about sharks.

Shark Attack, Victor Marcus Coppleson. Sydney, Angus and Robertson, 1958. $266 \mathrm{p}$.

The Search Beneath the Sea; the story of the Coelacanth, James Leonard Brierley Smith. New York, Holt, 1956. 260 p. \$3.95. How a primitive type of fish, believed extinct for 70 million years, was discovered off the coast of Madagascar.

Some Fublications on Game-fish and Sport Fishing, The Branch of Fish Hatcheries, $U$. S. Bureau of Scort Fisheries and Wildlife. Washington, 1962. 11 p. (U.S. Fish and Wildlife Service, Leaflet FL-4ل4), Free, Lists more than 100 titles.

Modern Angling Bibliography; books published on angling, fisheries, fish culture, from 1881 to 1945, John Fitzgerald Hampton. London, Jenkins, $1947.99 \mathrm{p}$.

A Bibliography of Fishes, Bashford Dean. Enlarged and edited by Charles Rochester Eastman. New York, Russell and Russell, 1962. 3 vols. $\$ 50.00$

22. FISHERIES AND FISHERY RESEARCH.
World Sea Fisheries, Robert Morgan. New York, Pitman, 1956. 307 p. \$6.95. General book on fishing regions, plankton, techniques, etc.

Atlantic Ocean Fisheries, George Borgstrom and Arthur J. Heighway. London, $F$ ishing News (Books), 1961. $336 \mathrm{p}$. Up-to-date survey of the commercial fishing situation.

Fishing Resources of the United States, Lionel Albert Walford, Washington, Public Affairs Press, 1947. 134 p. \$5.00. Mainly marine fisheries; many maps and diagrams showing occurrence of important food fishes. Also issued as Senate Document 51 , U. S. 79 th Congress, lst Session.

Let's Take a Trip to a Fishery, Sarah Regal Riedman. New York, Abelard-Schuman, 1956. $127 \mathrm{p} . \$ 2.75$. This and the next title describe American fishery activities for ages 10 to 14 .

Harvest of the Sea, Walter Buehr. New York, Morrow, 1955. 96 p. \$2.75.

Fishery Science; its methods and applications, George Armyntage Rounsefell and W. H. Everhart. New York, Wiley, 1953. 444 p. $\$ 9.50$, Somewhat technical.

Papers Presented at the International Technical Conference on the Conservation of the Living Resources of the Sea, Rome, 18 April to 10 May 1955. New York, 1956. $371 \mathrm{p}$. (United Nations. Document $\mathrm{A} / \mathrm{Conf}$. 10/7; Sales no.: 1956.II.B.1). Technical.

Fish as Food, George Borgstrom. New York, Academic Press, 1961-62. 2 vols. Vol.1, $\$ 24.00$; vol.2, $\$ 25.00$. Technical work on production, biochemistry and microbiology, nutrition, sanitation, and utilization.

Principles of Fisheries Development, C. J. Bottemanne. Amsterdam, North-Holland Publishing Co., 1959. 677 p. \$10.00. Detailed reference book.

Fisheries Hydrography; how oceanography and meteorology can and do serve fisheries, Ilmo Hela and Taivo Laevastu. London, Fishing News (Books), 1961. 137 p. Most informative, with fine illustrations.

Living Resources of the Sea; opportunity for research and expansion, Iionel Albert Walford. New York, Ronald Press, 1958. 321 p. \$6.00. On techniques, equipment, and resources worth investigating.

Marine Products of Commerce; their acquisition, handling, biological aspects and the science and technology of their preparation and 
preservation, Donald Kiteley Tressler and James M. Lemon. 2d ed. New York, Reinhold, 1951. 782 p. $\$ 20.00$. Veritable encyclopedia on salt and other marine chemicals, algae, pearls, sponges, coral, fishes, shellfish, sea mammals.

List of Films and F1lmstrips on Fisheries and Related Subjects. Rev.ed. Rome, Food and Agricultural Organization of the United Nations, Fisheries Division, 1960. 162 p.

\section{WHALES AND OTHER SEA MAMMALS.}

Follow the Whale, Ivan Terence Sanderson. Boston, Little, Brown, 1956. 423 p. \$7.00 A history of whaling, with an extensive bibliography.

Whales, Everhard Johannes Slifper. New York, Basic Books, 1962. 475 p. \$12.50. Physiology, anatomy, and history of whales; detailed.

A11 About Whales, Roy Chapman Andrews. New York, Random, 1945 . 448 p. $\$ 1.95$. For ages 12 to 16.

Whaler's Eye, Christopher Ash. New Iork, Macmillan, 1962 . 245 p. \$7.50. Picture book about life with a modern whaling fleet in the Antarctic.

The Sea-hunters; the New England whalemen during two centuries, 1635-1835, Edouard A. Stackpole. Philadelphia, Itppincott, 1953. 510 p. $\$ 7.50$.

Yankee Whalers in the South Seas, Addison Beecher Colvin Whipple. New York, Doubleday, 1954. $304 \mathrm{p}, \$ 3.95$.

Whales and Whaling, Paul Budker. London, Harrap and Co., Ltd, $184 \mathrm{p}$

Dolphins; the myth and the mammal, Antony Alpers. Boston, Houghton Mifflin, 1961. 268 p. $\$ 5.00$.

Man and Dolphin, John C. Lilly. Garden City, New York, Doubleday, 1961.312 p. \$4.95. Paperback: New York, Pyramid Books, 1962. 191 p. \$.75. On the high intelligence and ability to communicate shown by the dolphin, or porpoise.

Porpoises and Sonar, Winthrop Niles Kellogg. Chicago, University of Chicago Press, 1961. 177 p. \$4.50. Paperback: \$1.50. How the remarkable mammal navigates.

Seals, Sea Lions, and Walruses; a review of the Pinnipedia, Victor Blanchard Scheffer.
Stanford, Califormia, Stanford University Press, 1958. 179 p. \$5.00. Technical.

The Seals, Sea Lions, and Sea Otters of the Pacific Coast, Karl Walton Kenyon and V. B. Scheffer. Washington, Government Printing Office, 1955. 34 p. (U.S. Fish and Wildlife Service. Circular 32).

The Pacific Walrus; a review of current knowledge and suggested management needs, John Leo Buckley. Washington, 1958. $29 \mathrm{p}$. (U.S. Fish and Wildlife Service. Special scientific report: wildlife, no. 4I).

Seals and Walmuses, Louis Darling. New York, Morrow, 1955. 63 p. \$2.75. For ages 10 to H. $^{2}$

Saga of the Grey Seal; introducing the natural history of the grey seal of the North Atlantic, Ronald Mathias Lockley. New York, Devin-Adair, 1955. 149 p. \$4.00.

The Hunting of the Silver Fleece; epic of the fur seal, Fredericka I. Martin. New York, Greenberg, 1946. 328 p.

24. SEA AND SHORE BIRDS.

Birds of the Ocean; a handbood for voyagers, Wilfrid Backhouse Alexander. Rev.ed. New York, Putnam, 1954. 306 p. World scope; emphasis on identification.

Sea-birds; an introduction to the natural history of the sea-birds of the North Atlantic, James Fisher and R. M. Lockley. Boston, Houghton Mifflin, 1954. $320 \mathrm{p}$. $\$ 6.00$. Not an identification book.

Audubon Water Bird Guide; water, game, and large land birds, eastern and central North America from southern Texas to central Greenland, Richard Hooper Pough. Garden City, New York, Doubleday, 1951. 352 p. \$3.95. Identification, range, habits, etc.

A Gathering of Shore Birds, Henry Marim Hall. New York, Devin-Adair, 1960. 242 p. $\$ 10.00$. On the natural history of 57 North American species.

25. SEA AND SHORE ITHE.

The Edge of the Sea, Rachel Louise Carson. Boston, Houghton Mifflin, $1955.276 \mathrm{p}$. $\$ 3.75$. This and the next two titles are appreciation books, written to introduce the uninitiated reader to shore life. 
Between the Tides, Philip Street. New York, Philosophical Iibrary, 1953. $175 \mathrm{p}$. Mild British slant.

Life of the Shore and Shallow Sea, Douglas P. Wilson. $2 \mathrm{~d}$ ed. London, Nicholson \& Watson, 1951. 213 p. Mild British slant.

The Sea Shore, Charles Maurice Yonge, London, Collins, 1949. 311 p. (New Naturalist series). Meaty explanation of shore biology and ecology; British slant.

Natural History of Marine Animals, G. E. MacGinitie and Nettie MacGinitie. New York, McGraw-H111, 1949. 473 p. \$9.50. Easy college textbook, emphasizing coastal invertebrates.

The Biology of the Sea-shore, Frederick William Flattely and D. L. Walton. New York, Macmillan, 1947. 336 p. College textbook.

1001 Questions Answered About the Seashore, Norman John Berrill and Jacquelyn Berrill. New York, Dodd, Mead, 1957.305 p. $\$ 5.00$. For ages 10 to 14.

Sea and Share, Clarence John Hylander. New York, Macmillan, 1950.242 p. \$3.00. All about coastal life, for children 10 to 14.

Living Tide, N. J. Berrill. Boston, Dodd, Mead.

Exploring the Seacoast, John Perry and Jane Greverus Perry. New York, Whittlesey, 1961. 305 p. \$3.50. Varlous scientific activities, for ages 10 to 14 .

Nature Study at the Seashore; exploring with Four camera, Percy A. Morris. New York, Ronald Press, 1962. 294 p. \$6.00.

Seashores; a guide to animals and plants along the beaches, Herbert Spencer Z1m and Lester Ingle. New York, Simon \& Schuster, 1955. 160 p. $\$ 1.00$. Well-illustrated guide to recognizing 450 commoner forms of iife.

Beginner's Guide to Seashore Life, Leon Augustus Hausman. New Tork, Putnam, 1949. 128 p. $\$ 2.00$. Easy recognition book.

Field Book of Seashore Iife, Roy Waldo Miner. New Tork, Putnam, 1950. 888 p. \$7,00. How to recognize the common invertebrates of the Atlantic coast, from Nora Scotia to Cape Hatteras.

Iffe in the Shtfting Dunes; a popular field guide to the natural history of Castle Neck, Ipswich, Massachusetts, with attention to the unusus ecological relationships peculiar to such an area, Laurence B. White. Boston, Museum of Science, 1960.85 p. $\$ 1.75$.

The Bay; a naturalist discovers a universe of ilfe above and below the Chesapeake, Gilbert c. Klingel. New York, Dodd, Mead, 1951. $278 \mathrm{p}$.

One Hundred Hours Beneath the Chesapeake, Gilbert C. Mingel. (National Geographic Magazine, rol. 107, no.5, May 1955, pp.68196.). Underwater Iffe near Gwynn Island Maryland.

Marine Life in Texas Waters, Clyde Theodare Reed. Houston, Anson Jones Press, 1941. 88 p. (Teras Academy of Sclence. Publications in natural history, Non-technical serles).

Between Pacific Tides, Edward Flanders Ricketts and Jack Calvin. 3d ed, rev. by Joel Walker Hedgpeth. Stanford, Callfornia, Stanford University Press, 1952. 502 . Appreciation book on Pacific cosst biology and ecology. $\$ 6.95$.

Animals of the Seashore, Murlel Lewln Guberlet. Portland, Oregon, Binfords \& Mort, 1962. In press. Describes 200 conmon creatures of the Pacific Northwest coasts.

Common Seashore Life of the Pacific Northwest, Lynwood Sinith. Ed. by Vinson Brown. Healdsburg, California, Naturegraph Co., 1952 65 p. $\$ 1.75$

Introduction to Seashore Iife of the San Francisco Bay Region and the Cosst of Northerm Californda, Joel Walker Hedgpeth. Berkeley, Californta, University of Callfornta Press, 1962. 136 p. \$1.95.

Common Seashore Life of Southern California, Joel Walker Hedgpeth. Healdsburg, Californta, Naturegraph Co., 1961.64 p. $\$ 1.75$.

Seashore Treasures, Charles Howard Edmondson. Palo Alto, Calffornia, Pacifle Bookś, $1949^{\circ}$ 144 p. Martne life of the Hawailan coast.

\section{SHELIS: MOLIUSKS.}

Introducing Sesshells; a colorful guide for the jeginning collector, Robert Tucker Abbott. New York, Van Nostrand, 1955.70 p. $\$ 2.50$ Fine. This and the next two titles tell how to collect and appreciate shells; they are not identification books.

Sea Treasure; a guide to shell collecting, Kathleen Yerger Johnstone. Boston, Houghton Miffin, 1957. 242 p. \$4.00. Fine. 
Shell Collector's Handbook, Alpheus Hyatt Verrill. New York, Putnam, 1950. 228 p. $\$ 5.00$

Sea Shells of the World; a guide to the better-known species, Robert Tucker Abbott, and Herbert S. Zim. New York, Golden Press, 1962. $160 \mathrm{p}$. \$3.50. This and the next six titles are mainly identification books.

The Shell Book; a popular guide to a knowledge of the families of living mollusks, and an aid to the identification of shells native and foreign, Julis Ellen Rogers. Rev.ed. Boston, C. T. Branford, 1951. 503 p. $\$ 6.50$.

American Seashells, Robert Tucker Abbott. New York, Van Nostrand, 1954. 541 p. \$12.50. Detalled and definitive.

How to Know the Amerlcan Marine Shells, Robert Tucker Abbott. New York, New American Library, 1961. 222 p. (Signet Key book, KT375). \$.75.

A Field Guide to the Shells of our Atlantic and Gulf Coasts, Percy A. Morris, Rev,ed. Boston, Houghton Miffin, 1951. $220 \mathrm{p}$ (Peterson field guide series). \$4.50.

Shells of the New York C1ty area; a handbook of the land fresh water and marine mollusks ranging from Cape Cod to Cape $\mathrm{May}$, Morris K. Jacobson and W1lliam K. Emerson. New York, Argonaut Books, distributed by Citadel Press, 1961. 142 p. $\$ 4.00$.

A Field Guide to the Shells of the Pacific Cosst and Hawat1, Percy A. Morris. Boston, Houghton Mifnin, 1952. 220 p. (Peterson field guide series). $\$ 4.50$.

Mollusks; in introduction to their forms and functions, John Edward Morton. New York, Harper, 1960. 232 p. \$1.40.

Oysters, Charles Maurice Yonge. Iond on, Collins, 1960. 209 p. (The new naturalist series). Chaming book on the natural history of the delectible bivalve.

27. EDUCATION AND CAREERS DN OCEANOGRAPHY.

Universfty Curricula in Oceanography, Academic Year 1962-63, Washingt on, 1962. $111 \mathrm{p}$. (U.S. Interagency Comittee on Oceanography. ICO pamphlet, no.6). O.P.

Education and Recruitment of Oceanographers in the -United States; . A report by the Comultee on Education and Recruitment, the American Soclety of Limnology and Oceano-
Eraphy, Inco.; Alfred C. Redfleld. Ann Arbor, Michigan, 1960. 23 p. (Supplement to Limnology and Oceanography. vol.6).

Your Future in Oceanography, with the U.S. Navy Hydrographic Office and other Federal establishments. Rev.ed. Washington, U.S. Civil Service Comission, 1961. 22 p.

There's Adventure in Marine Science, Julian May. New York, Hawthom Press, 1959. 160 p. $\$ 2.95$. Career fiction, for ages 10 to 14 .

Steady as You Go; Jack Powell's adventure with the U.S. Coast and Geodetic Survey, Robert. F. A. Studds. New York, Dodd, Mead, 1956. $306 \mathrm{p}$. Career fiction for boys 12 to 15 , demonstrating jobs with the Cosst and Geodetic Survey.

High, Wide, and Deep: sclence and adventure with the Cosst and Geodetic Survey, John Joseph Floherty. Philadelphia, Ilppincott, 1952. $154 \mathrm{p}$. $\$ 2.75$. Careers described for boys 12 to 16 .

Deep Sea, High Mountain, Elllott B. Roberts. Boston, Iittle, Brown, 1961. 275 p. \$3.75 True adventures of Coast and Geodetic Survey men; fine career information for boys 12 to 16

28. DICTIONARIES,

Tide and Curreat Glossary, Paul Schureman. Rev, ed. Washington. Government Printing Office, 1949. Lo p. (U.S. Coast and Geodetic Survey. Special publication no.228). Sold by Goverkment Printing office for $\$ .15$.

Waves, Tides, Currents, and Beaches; glossary of terms and list of standard symbols, Robert L. Wiegel. New Iork, Counc1l on Wave Research, The Engineering Foundation, 1953. $113 \mathrm{p}$.

Glossary of Oceanographic Terms. Washington. 1960. 12 p. (U.S. Navy Hydrographic Office. Special Publication, SP-35.

Navigation dictionary. Washington, 1956. 253 p. (U.S. Navy Hydrographic Office. H. O. Publication, no.220). Sold by the Hydrographic Office, for $\$ 2.00$.

A Dictionary of Nautical Terms, A. G. Course. London, Arco Publications, 1962. $216 \mathrm{p}$.

A Functional Glossary of Ice Terminology. Washington, 1952.88 p. (U.S. Navy Hydrographic office. H. 0. Publication, no.609) 
Sold by the Hydrographic Office, for $\$ .80$. Deals mainly with sea ice.

Standard Encyclopedia of the World's Oceans and Islands, Anthony Huxley. New York, Putnam, 1962. 383 p. \$10.95. Gazetteer of over 2000 names of seas, island, bays, straits, capes and other related topographic features.

29. DIRECTORIES.

International and National Organizations of Oceanographic Activities, Richard C. Vetter. Washington. National Academy of Sciences-National Research Council, Committee on Oceanography, 1959. 47 p. 0.p.

An International Directory of Oceanographers, Kenneth Orris Emery and Mary Sears. 3d ed. Washington, National Academy of Sciences-ivational Research Council, Committee on Oceanography, 1960. 177 p. 0.p.

International Aspects of Oceanography; oceanographic data and provisions for oceanographic research, Thoms Wayland Vaughan. Washington, National Academy of Sciences, 1937.225 p. Dated, but contains much historical information of interest.

Directory of the Public Acquaria of the World, Spencer Wilkie Tinker and Marian omura. Preliminary ed. Honolulu, Waikiki Acquarium, University of Hawaii, 1962. 28 p.

Directory of Hydrobiological Laboratories and Personnel in North American, Robert W. Hiatt. Honolulu, University of Hawaii Press, 1954. 324 p. $\$ 3.75$.

World Directory of Marine Iaboratories, The American Institute of Biological Sciences. New York, Reinhold, 1963. In press.

30. HISTORY OF OCEANOGRAPHY.

A Study of the Oceans, James Johnstone. $2 d$ ed. New York, Longmans, 1926. 215 p. Mainly a concise history of oceanography.

Founders of Oceanography and Their Work; an introduction to the science of the sea, William Abbott Herdman. New York, Longmans, 1923. 340 p. The first half of this book, pages 1 to 144 , is a history of oceanoeraphy, as told in the lives of some rreat researchers.

Searchers of the Sea; pioneers in oceanography, Charles Michael Daugherty. New York, Viking, $1961.160 \mathrm{p}, \$ 3.00$, Biographica sketches of 15 prominent oceanographers, for ages 10 to 15 .

The Coast and Geodetic Survey, 1807-1957; 150 years of history, Aaron Joseph Wraight and E. B. Roberts, Washington, Government Printing Office, $1957.90 \mathrm{p}$. $\$ .35$.

Charting our Sea and Air Lanes, Stuart E. Jones. (National Geographic Magazine, vol. 111, no.2, Feb, 1957, pp. 188-209). Sketch of the history of the Cast and Geodetic Survey.

Oceanography, 1960 to 1970: Part 11 - A History of Oceanography: a brief account of the development of oceanography in the United States. Washington, National Academy of Sciences-National Research Council, Committee on Oceanography, 1962. 28 p. Free.

Seas, Maps, and Men; an atlas-history of man's exploration of the oceans, George Edward Raven Deacon. Garden City, New York, Doubleday, 1962. 297 p. \$9.95. Tells the story of some of the great ocean exploring expeditions, then describes some of the great discoveries in marine biology, submarine archaeology, and physical and geological oceanography.

\section{BIOGRAPHIES OF OCEANOGRAPHERS.}

Yankee Stargazer; the life of Nathaniel Bowditch, Robert Elton Berry. New York, Whittlesey, 1941. 234 p. Bowditch, 1773 1838 , made the art of navigation truly scientific.

Navigator; the story of Nathaniel Bowditch, Alfred Boller Stanford. New York, Morrow, 1927. 308 p. Fictionized biography.

Sextant and Sails; the story of Nathaniel Bowditch, Robert Elton Berry. New York, Dodd, Mead, 1943. 231 p. For ages 12 to 16.

Down to the Sea; a young people's life of Nathaniel Bowditch, the great American navigator, Louise Hall Tharp. New York, McBride, 1942. $242 \mathrm{p}$. For ages 12 to 16.

Carry on, Mr. Bowditch, Jean Lee Latham. Boston, Houghton Mifflin, 1955. 251 p. $\$ 3.25$. A fine fictionized biography, for ages 10 to 14 .

Matthew Fontaine Maury: the pathfinder of the seas, Charles Lee Latham. Annspolis, United States Naval Institute, 1927. 264 p. Scholarly life of Maury, 1806-1873, founder of oceanography, early head of the 
Hydrogrephic Office of the Navy Department, and the Admiral Rickover of his time.

Natthew Fontaine Maury; scientist of the a. Frances Ieigh Willians. New Brunsick, New Jersey, Patgers University Press, 163. $\$ 10.00$. In press.

Datthew Fentaine Maury and Joseph Henry; - larsists of the Civil War, Patricia Nan. 308 p. \$5.95. Easy.

Matther Fontaine Maury; trail maker of the sea, Hildegarde Hawthorne. New York, Langmans, 1943. 226 p. Fictionized biography, easy.

Trail Blazer of the Seas, Jean Lee Latham. Boston, Hought on Mifflin, 1956. $245 \mathrm{p}$. \$2.75. Fine fictionized biography of Maury, from birth to about 1858, for ages 10 to 14.

The Chequered Career of Ferdinand Rudolph Hassler, first Superintendent of the United States Coast Survey; a chapter in the histary of science in America, Florian Cajor1. Boston, Christopher, 1929. 245 p. Swiss-bort Hassler, 1770-1843, had his troubles with a penn-pinching Congress.

Alexander Dallas Bache; sclentist and educator, 1806-1867, Merle Middlet on Odgers. Philadelphia, Iniversity of Pennsylvania Press, 1947. 223 p. \$2.75. Bache was Director of the Coast Survey from 1843 to 1867 .

Letters and Recollections of Alexander Agassiz, with a sketch of his life and work, George Russell Agassiz. Boston, Houghton Mifflin, 1913. 454 p. Agassiz, 1835-1910, son of Louis Agassiz, was a faned marine biologist.

The Hidden Coasts; a biography of Admiral Charles Wilkes, Daniel Mac Intyre Henderson. New York, Sloane, 1953. 306 p. \$5.00. Scholarly life of Admiral Winkes, $1798-$ 1877, of Civil War fame, who led an important charting and scientific expedition to the Antarctic and Pacific Oceans.

\section{OCEANOGRAPHIC EXPEDITIONS.}

Titian Ramsay Peale, 1799-1885, and his Journals of the Wilkes Expedition, Jessie Poesch. Philadelphia, $1961.214 \mathrm{p}$. (American Philosophical Society. Memoir 52). \$6.50. Fine account by the scientific illustrator who accompanied Wilkes.

\begin{abstract}
Yanke Harverors in the Shogun's Seas; records of the United States Surveying Expedition to the North Pacific Ocean, 18531856, Allan Burnett Cole. Princeton, New Jersey, Prineeton University Press, 1947. 165 p. \$2.50
\end{abstract}

The Voyage of the Challenper, Herbert $S$. Bailey, Jr. (Scientific Awerican, vol.188, no.5, May 1953, pp.88-94). The mumerous old publications of this fanous expedition are not listed here.

The Last Cruise of the Carnegle, John Harland Paul. Baltimore, Willians and Wilkins, 1932. 331 p. The Carnegie was lost by fire in 1929. This and the next five titles deal with expeditions which specialized in sea-botton geology and physical oceanography.

Westward Ho with the Albatross, Hans Pettersson. New York, Dutton, 1953. 218 p. $\$ 4.00$. About an important Swedish voysge of $1947-1948$.

Exploring the Deep Pacific, Helen Raitt. New York, Norton, 1956, 288 p. \$3.75. About the Scripps Institute Capricorn expedition of 1952-1953.

Challenger; the I1fe of a survey ship, George Stephen Ritchie. New York, AbelardSchuman, 1958, 270 p. $\$ 5.00$. Adventures of a new Challenger, 1931-1953, mapping the coast of Africa and studying the sea bottom.

Oceanographic Cruise Report, U.S.C.\&G.S. Ship Explorer--1960, Seattle, Washington, to Norfolk, Virginia, February 2--April 27, 1960. Washington, Government Printing Office, 1962.162 p. $\$ 3.00$.

Iffe on an Ice Floe, Ivan Papanin. New York, Messner, 1939. 300 p. Enthusiastic account of nine months that four Russian scientists spent drifting on an Arctic Ocean ice island, making oceanographic observations.

The Galathea Deep Sea Expedition, 1950 1952, Ant on Frederick Bruun. New York, Macmillan, 1956.296 p. \$8.00. Not a daily account of life aboard ship, but a fine picture of research procedures. This and the remaining titles in this section deal mainly with marine biology.

Round the World with Galathea, Hakon Mielche. London, Hodge, 1953. 24l p. Fine daily account of life aboard ship.

The Shoals of Capricorn, Francis Downes Ommanney. New York, Harcourt, 1952. 322 p. 
Charming journal by a marine biologist working among the reefs of Mauritius and the Seychelles.

The Voyage of the Petula, Frank Evans. London, Hall, 1957.189 p. Vivid picture of marine biology activities aboard a small research vessel, in the Atlantic.

Beyond the Pack Ice, Peter Digby. London, Jenkins, 1954 . $186 \mathrm{p}$. How Mr. and Mrs. Digby studied plankton along the coasts of Greenland .

Kon-Tik1, Thor Heyerdahi. Chicago, Rand McNally, 1950 . 304 p. \$5.00. Paperback: New York, Permabook, 1960.240 p. \$.35. Justly famous book about a voyage on a raft, attempting to demonstrate that the South Pacific Islands were settled by colonizers from South America; truly captures the feel of tropic seas!

Kon-Tik1. Thor Heyerdahl; a special edition for young people. Chicago, Rand MoNally, 1960. 165 p. \$4.95. For ages 10 to 14 , loaded with photographs and maps.

Sea of Cortez; a leisurely journal of travel and research, John Steinbeck and Edward Flanders Rickets. New York, Viking, 1941. $598 \mathrm{p}$. The story of a collecting voyage to the Gulf of California, told as only Steinbeck can tell it.

The Log from the Sea of Cortez; the narrative portion of the Sea of Cortez, John Steinbeck and Edward Flanders Ricketts. New York, Viking, 1951.282 p. $\$ 4.00$. Paperback: Viking, 1962. $282 \mathrm{p} . \$ 1.45$. Includes a short biography of marine biologist Ed Ricketts, by his friend Steinbeck.

Book of Bays, Charles William Beebe. New York, Harcourt Brace, 1942. 302 D. How Beebe investigated marine life along the Central American coast. Other Beebe books on coast and reet life include "The Arcturus adventure," "Nonsuch, land of water:" "Zaca venture," and "Beneath tropic seas."

33. GENERAL MAPS OF THE OCEANS (excluding coast and sailing charts, for which see section 3 )

Physiographic Diagram, Atlantic Ocean. . . Bruce C. Heezen and Marie Thar:. New York, Geological Society of America, 1957-62. Sheet 1 (1957. \$1.50) covers the North Atlantic between latitudes 17 degrees and 50 degrees North, scale about 1:5,000,000. Sheet $2(1961, \$ 2.00)$ covers the remainder of the Atlantic and the west coast of South America, scale about $1: 10,000,000$.
Atlantic Ocean, scale $1: 20,000,000$. Washington, National Geographic Society, 1955. $\$ 1.00$. Colored bathymetric map, Mercator projection.

Pacific Ocean, scale $1: 36,432,000$. Washington, National Geographic Society, 1062. (Atlas plate 61 ). $\$ .5 \mathrm{C}$. Colored bathymetric map, Mercator projection.

The World, scale 1:12,233,000. Washington, 1961. (U.S. Navy Hydrographic Office, Chart no. 15,254). \$12.00. A large, 12-sheet colored bathymetric map, Mercator projection. with the sea-bottom relief show in considerable detail.

Chart of the World, scale 1:39,000,000. Washington, 1961. (U.S. Navy Hydrographic Office. Chart no. 1262A, 10 th ed.). \$.70. Colored bathymetric map, Mercator projection.

Ice Atlas of the Northern Hemischere, Washington, 1946. 106 p. (U.S. Hydrographic Office, Publication no. 550). Sold by the Hydrographic Office for $\$ 8.00$. Shows distribution of sea ice.

34. FILMS AND FIIM STRIPS.

The Bahamas, where limestones Erow today. 1952. 41 mins., sound, color. Humble Oil Co., Public Relations and Advertising Department, F. 0. Box 2180, Houston 1. Texas. Technical film on how modern limestones are formed.

Beach and Sea Animals. 1957, 11 mins., sound, black \& white or color. Encycloredia Britannica Films, 1150 wilmette Ave., Wilmette, Illinois, Beautiful film on Atlantic coast life, suitable for almost any age.

Challenge of the Ocears. 1960,29 mins. sound. black \& white or color. Mciraw-Hill Text-Films, 330 West 4 2nd Street, New York 36, New York. Sponsored by the National Research Council. On oceanographic instruments and methods of study, with some results, suitable for ages 12 up.

Island Adventure. 1956. 28 mins., sound. color. Texaco Comrany, Public Relations Division. 135 East L2nd Street, New York 17, New York. On the construction and equipping of an oil drilling island on the California coast, suitable for ages 15 up.

Island Oddities. 195226 mins., sound, color. Esso Standard Oil. Marketins Decartment, Hutchinson River Farkway, Selham. New York. Beautiful film on coastal life in the Bahama Islands, suitable for almost any age. 
Ocean Tides--Bay of Fundy. 1956, 15 mins., sound, color. Encyclopedia Britannica Films, 1150 Wilmette Ave., Wilmette, Inlinois. Good account of the features of huge tides, suitable for ages 12 up.

Offshore Venture. 1958, $\mathcal{I}_{4}$ mins., sound, color. Humble Oil Co., Public Relations and Advertising Department, P.O. Box 2180 , Houston 1, Texas. On finding and producing offshore oil, suitable for ages 15 up.

Problem at Port Washington. 1951, 10 mins., sound, black \& white. U.S. Armiy Corps of Engineers, Technical Liason Division, Chief of Engineers, Department of the Army, Washington 25, D.C. How the Corps of Engineers tests models of breakwaters at Port Washington, Wisconsin; suitable for ages 12 up.

Project Mohole, report no.1. 1959, 19 mins., sound, color. Educational. Testing Service, 20 Nassau Street, Princeton, New Jersey. iddling film about the Mohole, of some interest to ages 14 up.

Recent Carbonate Deposits of the Florida Keys. 1947, 38 mins., sound, color.

Magnolia Petroleum Co., c/o Humble Oil Co., Public Relations and Advertising Department, P.0. Box 2180, Houston 1, Texas.

Rendezvous in the Reef. 1951. 28 min.. sound, color. Esso Standard Oil, Marketing Department, Futchinson River Farkway: Pelham, New York. Fine submarine photography concerning fish life in the Bahamas.

Station 307. 1954. 19 mins., sound, black \& white. Radiant Films, 247 West 42 nd Street, New York 36, New York. "The Jacques Cousteau oceanographic team explores the botton of the Persian.Gulf at a station of a large submarine geological survey for British Petroleum Co.; suitable for ages 15 up.

Tides and Currents, 18 mins., sound, black \& white. U.S. Coast and Geodetic Survey. Motion Picture Service, Washington 25, D.C. On the causes, types, and measurement of tides and currents; suitable for ages 15 up.

What's Under the Ocean. 1960, 13 mins., sound, black \& white or color. Film Associstes of California, 11014 Santa Monica Blvd., Los Angeles 25, California. Briefly describes the work of skin divers, bathyscaphs, and oceanic research vessels; suitable for ages 10 to 16

Blueprint for Discovery--Probing for the
Earth's Deepest Secrets. 1962, 26 or 40 mins., sound, color. Victor J. Jurgens Motion Picuure Productions, Old Military Road, lake Placid, New York. Official film report of Project Mohole, produced for the National Science Foundation; suitable for ages lit up.

Sighty Currents of the Sea, LIFE filmstrip, "Pew portrait of our planet" series. E? frames, color, with teaching guide. LIFE Filnstrios, Time \& Life Building, Rockefeller Center, New York 20, New York.

Deep Frontier; an introduction to oceanography. Film strip and record, 18 mins., 82 frames, color. U.S. Department of Interior. Bureau of Commercial Fisheries.

35. BIBLIOGRAPHIES ON OCEANOGRAPHY AND REIATED SUBJECTS.

A Reader's Guide to Oceanography, Jan Hahn. Woods Hole, Massachusetts, Woods Hole Oceanographic Institution, $1961.10 \mathrm{p}$. Free.

A Preliminary Bibliography of Books on the Seashore, Oceanography, and Related Subjects, Joel Walker Hedgpeth. La Jolla, California, 1953. $69 \mathrm{p}$. (Scripps Institution of Oceanography. SIO Reference 53-13). Annotated listing of 550 titles.

Books of the Sea; an introduction to nautical literature, Charles Lee Lewis. Annapolis, United States Naval Institute, 1943. 318 F. o.p.

Pacific Island Bibliography: Floyd M.

Cammack and Shiro Sato. New York. Scarecrow Press, 1962. 421 p. \$10,00.

Is land Bibliograchies: Micronesian botany, land environment and ecology of coral atolis vegetation of tropical Pacific islands, Marie-Helen Sachet and F. Raymond Fosberg. Comp. under the auspices of the Pacific Science Board. Washington 1955. 577 p (National Acaderny of Sciences-National Research Council. Publication 335). \$6.00.

Annotated Bibliography of Geologic and Soils Literature of Western North Pacific Islands, prepared under the direction of the Chief of Engineers, U.S. Army, by the Intelligence Division, Office of the Engineer, Headquarters, U.S. Army Forces, Far East, and Eighth U.S. Army, with personnel of the U.S. Geological Survey. N.F.: 1956. 884 p.

A Bibliography of Bibliographies of the South Pacific, Ida Leeson. Published under the auspices of the South Pacific Comission. 
New York, Oxford University Press, 1954. 61 p. $\$ 1.95$.

A Bibliographical Sourcebook of Compressed Air Diving and Submarine Medicine, Ebbe Curtis Hoff and Leon Jack Greenbaum. Washington, Research Division, Project $\mathrm{X}-427$, Bureau of Medicine and Surgery, Navy Department, 1948-1954. 2 vols. (NAVMED 1911; NAVMED P-5033).

Oceanography of the North Pacific Ocean, Bering Sea and Bering Strait; a contribution toward a bibliography. Mary C. Grier. Seattle, University of Washington Press, 1941. 314 p. $\$ 4.00$

References on the Physical Oceanography of the Western Pacific Ocean, Mary C. Grier. Washington, 1946. 174 P. (U.S. Navy Hydrographic Office, H. O, Publication, no. 238). $\$ 2.40$.

36. PERIODICALS ON OCEANOGRAPHY AND RELATED SURJECTS.

Lack of space prevents listing more than a few periodical titles.

Shore and Beach, published monthly by the American Shore and Beach Preservation Association, Washington, D.C. Contains articles on coastal geology, geography : and engineering.

Offshore, published monthly by International Trade Publications, Conroe, Texas. Concerned mainly with petroleum.

Oceanus, published quarterly by the Woods Hole Oceanographic Institution, Woods Hole, Massachusetts. Contains nontechnical articles on oceanography and on Institute activities.

Sea Frontiers, published monthly by the International Oceanographic Foundation, Miami, Florida. The column, "Science of the sea in books, " reviews both popular and technical books dealing with the sea. Contains nontechnical articles.

Deep-sea Research, published quarterly by Pergamon Press, Iondon, England. Technical.

Journal of Marine Research, published irregularly by the Sears Foundation for Marine Research, Bingham Oceanographic Laboratory, Yale University, New Haven, Connecticut. Technical.

Journal of the Marine Bi.logical Association of the United Kingdom, published quarterly by the Association, Flymouth, England. Technical.

Limnology and Oceanography, published quarterly by the American Society of Limnology and Oceanography, Lawrence, Kansas. Technical.

Atoll Research Bulletin, published irregularly by the Pacific Science Board of the National Academy of Sciences-National Research Council. Washington, D.C. Devoted to the geology, geography, natural history, and anthropology of the Pacific Islands; mostly technical.

Pacific Sciences; a Quarterly Devoted to the Biological and Physical Sciences of the Pacific Region, published by the University of Hawaii Press, Honolulu, Hawaii.

Scientific American, published monthly by the Scientific American Publishing Co., New York, New York. This general, nontechnical scientific journal contains many fine articles on oceanography; some of the best, 1947-1962, are listed in this bibliography.

Skin Diver Magazine, published by Skin Diver Publications, Lymwood, California. Popular journal for the skin or scuba-diving hobbyist.

Underseas Technology - published monthly by the Sheffield Publishing Co., Washington, D.C.

Ocean Science News, published 36 times per year by the Nautilus Press, Washington, D.C. A news letter on oceanographic activities. 


\section{APPENDIX 3}

UNIVERSITY CURRICULA IN OCEANOGRAPHY SUBMITTED

BY HON. JAMES H. WAKELIN, JR., ASSISTANT SECRETARY OF THE NAVY 



\section{UNIVERSITY CURRICULA}

IN OCEANOGRAPHY

ACADEMIC YEAR

1963-64

INTERAGENCY COMMITTEE ON OCEANOGRAPHY' of the

FEDERAL COUNCIL FOR SCIENCE AND TECHNOLOGY United States of America 
FEDERAL COUNCIL FOR SCIENCE AND TECHNOLOGY

JEROME B, WIESNER, Chairman Director

Office of Science and Technology

HAROLD BROWN

Director of Defense

Research and Engineering

Department of Defense

5. HERBERT HOLLOMON

Assistant Secretary for

Science and Technology

Department of Commerce

BOISFEUILLET JONES

Special Assistant to the Secretary

for Health and Medical Affairs

Department of Health, Education

and WeIfare

JOHN C, CALHOUN

Science Adviser to the Secretary

Department of the Interior

RAGNAR ROLLEFSON

Director, Office of International

Scientific Affairs (Observer)

Department of State

EDWARD WENK, JR.

Technical Assistant to the Director office of Science and Technology (Executive Secretary)

INTERAGENCY COMMITTEE ON OCEANOGRAPHY

JAMES H, WAKELIN, JR, , Chairman

Assistant Secretary of the Navy (Research and Development)

RADM, H, ARNOLD KARO

U,S. Coast and Geodetic Surver

Department of Commerce

DONALD L. MCKERNAN

Bureau of Conmereial Fisheries

Department of Interior

RADM. R. D. SCHMIDTMAN

U.S. Coast Guard

Department of the Treasury

RAGNAR ROLLEFSON

Office of Intemational Scientific Affairs

Department of State (Observer)

ATHELSTAN F. SPILHAUS

Committee on Oceanography

National Academy of Sciences (Observer)
GLENN T, SEABORC

Chairman

Atomic Energy Comission

ALAN T. WATERMAN

Director

National Science Foundation

JAMES E, WEBB

Administrator

National Aeronautics and

Space Administration

WILLARD COCHRANE

Director, Agricultural Economics

Department of Agriculture

ELMER B. STAATS

Deputy Director

Bureau of the Budget (Observer)

N, E, HALABY

Administrato

Federal Aviation Agency (Observer)
HARVE J. CARLSON

National Science Foundation

HARRY G, HANSON

Public Health Service

Denartment of Health,

Education and Welfare

JOHN N. WOLFE

Atonic Energy Commission

\section{E. WALLEN}

Museum of Natural History

Smithsonian Institution

ENOCH L. DILLON

Bureau of the Budget (Observer)

ROBERT B, ABEL

fice of Naval Research

Department of the Navy

(Secretary) 


\title{
UNIVERSITY CURRICULA IN OCEANOGRAPHY
}

\author{
ACADEMIC YEAR 1963-64
}

Interagency Committee on Oceanography

of the

Federal Council for Science and Technology

Printed by the

U. S. DEPARTMENT OF HEALTH, EDUCATION, AND WELFARE

Public Health Service 


\section{FOREWORD}

The Interagency Committee on Oceanography, under the direction of the Federal Council for Science and Technology, is responsible for developing annually a National Oceanographic Program to coordinate the efforts of all government agencies in meeting the long-range goals of the United States in marine science. In reviewing the vastly expanded oceanographic programs of the next few years, the Interagency Comnittee has become concerned with the necessity for planning to insure that the supply of trained manpower will be adequate to accomplish the work proposed. The recommendations of the ICO and its Panel on Manpower and Training for augmenting the number of scientists being trained for oceanography are embodied in ICO Pamphlet Number Eight, soon to be released.

This catalog, University Curricula in Oceanography, is designed to supplement ICO Pamphlet Number Eight by making available information about existing training in the marine sciences. It is hoped that the catalog will be an aid in promoting full use of existing opportunities and facilities.

The ICO is deeply grateful for the cooperation of the many faculty members of listed institutions who generously supplied the information in this report. 
TABLE OF CONTENTS

FOREWQRD $\ldots \ldots \ldots \ldots \ldots \ldots \ldots \ldots \ldots \ldots \ldots \ldots \ldots \ldots \ldots \ldots \ldots \ldots \ldots \ldots \ldots \ldots$

INTRODUCTION...................................... 1

LISTINGS OF UNIVERSITY CURRICULA:

Agricultural and Mechanical College of Texas.............. 7 Graduate School, U.S. Department of Agriculture.............. 13

*University of Alaska.............................. 16

*The American University.............................. 17

California Institute of Technology...................... 19

University of Chicago............................. 20

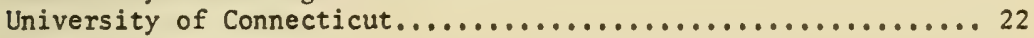

Columbia University.............................. 27

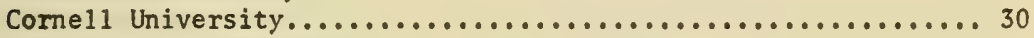

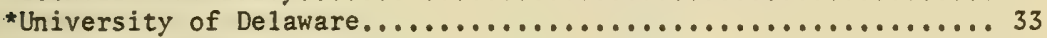

*Duke University.................................... 35

*Florida State University........................... 38

University of Georgia............................ 40

Harvard University................................ 42

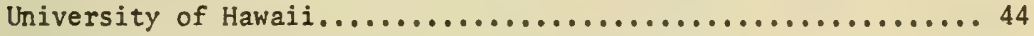

University of Houston........................... 53

Humboldt State College........................... 55

Johns Hopkins University......................... 59

Louisiana State University......................... 63

Massachusetts Institute of Technology.................. 64

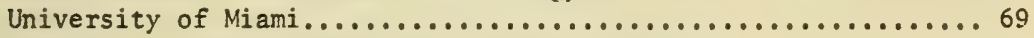

University of Michigan............................ 76

U.S. Naval Postgraduate School........................... 79

New York University............................. 82

State University of New York Maritime College............... 88

University of North Carolina....................... 90

Northeastern University............................ 93

Oregon Institute of Marine Biology.................... 94

Oregon State University........................... 96

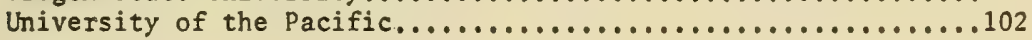

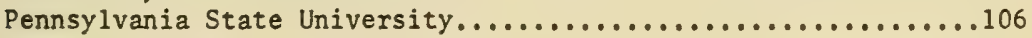

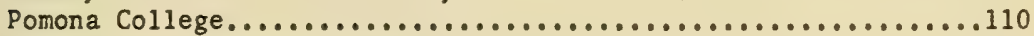

University of Puerto Rico............................111

Rensselaer Polytechnic Institute............................

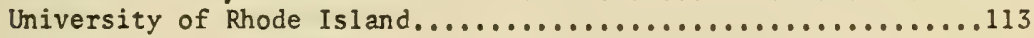

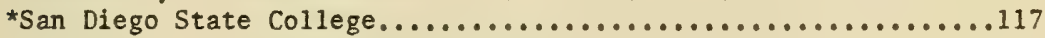

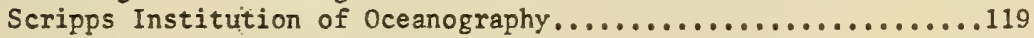

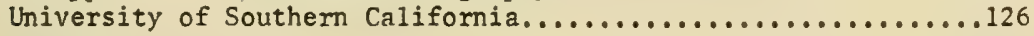

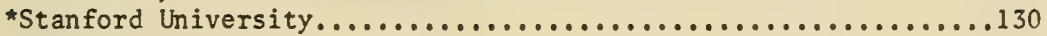

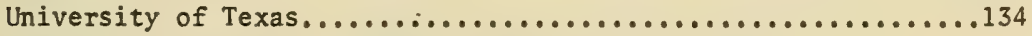

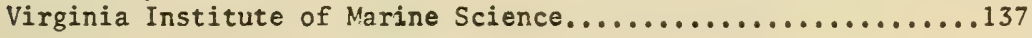


Walla Walla College..................................... 143

*University of Washington...............................144

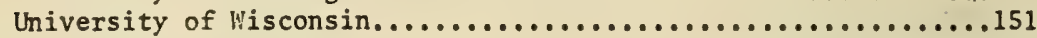

*Yale University .................................. 155

ALPHABETICAL FACULTY LIST. . . . . . . . . . . . . . . . . . . . . . 157

*Because no revisions were furnished the ICO staff before the publication deadline, this entry is reprinted from the 1962-63 edition of University Curricula in Oceanography. 


\section{INTRODUCTION}

This catalog is a compilation of courses offered in the marine sciences at American colleges and universities. In addition to providing information to students, its purpose is to increase the exchange of information among the schools, and between them and employers of ooeanographic manpower.

The term "oceanography" is used in this publication in its broadest sense, meaning the application of science to the study of the sea. Courses described are not restricted to those designated "oceanography" by the institutions offering them, but include all courses dealing with study of the marine environment.

Only those schools which grant a degree specifically in the field of marine sciences are listed as granting degrees under the section entitled "Degrees Offered" under each school entry. However, nearly all the institutions apply listed course work for credit towards an advanced degree. Some universities consider it most beneficial for a scientist to be trained to the doctorate level in one of the classical disciplines of science before he concentrates his attention entirely upon the marine environment. The omission in this catalog of degrees in fields other than specifically marine science does not in any way imply that the Interagency Committee on Oceanography considers the system of training which culminates in a degree in "oceanography" superior to that which channels training through traditional scientific disciplines.

The following information is included for each listed institution.

1. A brief description of programs and facilities at each institution.

2. The name of the department in which listed courses are taught.

3. The name, acadenic rank, and highest degree held by all faculty members teaching courses listed or supervising student research.

4. Degrees offered in oceanography or related marine science.

5. A list of courses, including course number, title, teacher, and description.

6. The person to be contacted for further information.

In addition to the individual listings for each institution, an alphabetical listing of all faculty members is appended. 
Many students and faculty advisors have written the Committee inquiring about the preparation necessary for entry into the field of oceanography. It should be noted that nearly all institutions award only graduate degrees in marine science, and batchelor's degree is requisite for beginning students in this field. The following excerpt from the bulletin of the University of Miami Institute of Marine Science sets forth typical requirements for undergraduate preparation. ("Oceanography" is used in its narrow sense at Miami, including only physical and chemical oceanography and omitting biological and geological oceanography, which are called Marine Biology, Marine Geology, and Fisheries).

\section{UNDERGRADUATE CURRICULA}

The department receives many inquiries concerning proper undergraduate preparation for entrance to its graduate program. To guide students, several undergraduate programs are suggested for preparation in Fisheries, Marine Biology, Oceanography, and Marine Geology. Other disciplines are not considered since each university has its own set of requirements designed to give students broad exposure to the liberal arts.

Students interested in pursuing marine science should select an undergraduate major in one of the basic scientific disciplines. The undergraduate college should be selected on the basis of curriculum and staff strength in that major. In the biological sciences Zoology is much preferred to Botany as an undergraduate major but, hopefully zoology students will include basic botany courses in their curriculum. Within the general scope of the program suggested below, prospective marine biology students most interested in experimental biology should take care to be well prepared in chemistry, biochemistry, and mathematics. Students interested in systematics, anatomy, etc., should strengthen their zoology, genetics and related course program.

Prospective marine geologists should acquire strong backgrounds in Mathematics, Chemistry and Physics.

The student should at the same time be careful to satisfy the graduation requirements of his own University. Students should consult their Department for assistance on individual programs.

University College science courses that lack laboratories are not acceptable substitutes for the basic science courses. Students may wish to spend one summer at a marine laboratory in order to have a more firm basis for decision concerning their future career in marine science.

In the suggested curricula on the following pages, courses are designated as "required" (those believed to be essential) and "suggested" (those which should be taken if the student's program can include them). 
A student may be admitted to graduate standing in this department without having had some of the required courses, but he will ordinarily not be allowed to take a mester's degree until he has completed all of them, either before or after admission to the Graduate School.

Courses listed as "suggested" should be taken whenever the student's program permits, but he will ordinarily not be obliged to take them in order to obtain the master's degree. He may, however, be asked to take some of the "suggested" courses if he continues for the Ph.D. degree.

Exceptions to these requirements may be made at the discretion of the department and the student's advisory committee. The reading knowledge of two languages is required of graduate students before the $\mathrm{Ph}$. D. degree can be achieved, Good undergraduate preparation in at least one language is strongly urged. Spanish ordinarily is not an acceptable substitute for French or German or Russian.

Undergraduate courses taken by a graduate student do not contribute credits toward his advanced degree at the University of Miami.

The courses designated as "required" are marked with an asterisk.

MARINE BIOLOGY

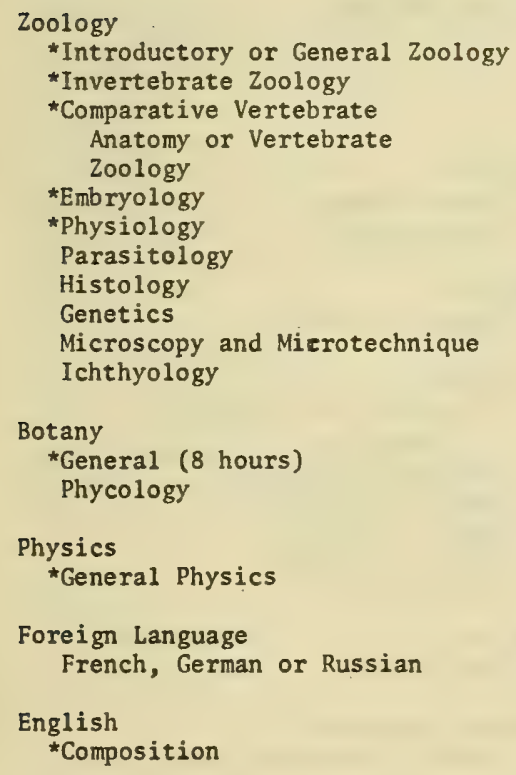

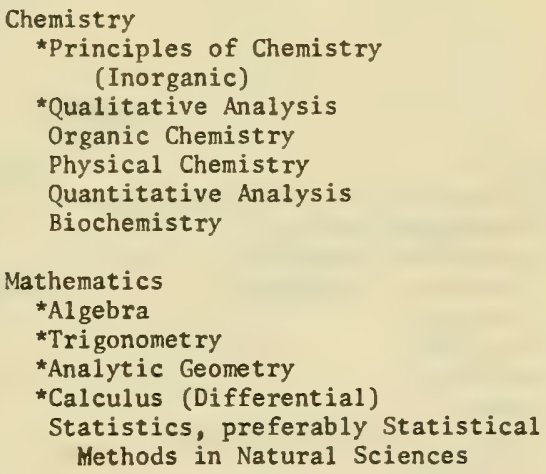


MARINE GEOLOGY

Physics

*General Physics (2 semesters)

Thermodynamics

Modern Physics

\section{Chemistry}

${ }^{*}$ Chemistry (2 semesters)

Physical Chemistry

Qualitative Analysis

Quantitative Analysis

\section{Mathematics}

*Al gebra

*Trigonometry

*Analytical Geometry

${ }^{*}$ Calculus

\section{Zoology}

*Introductory or General
Geology

${ }^{*}$ General Geology

*Paleontology

*Petrology

*Optical Mineralogy

*Field Geology

*Structural Geology

Stratigraphy

Sedimentation

Marine Sciences

Introduction to Matine Biology

Introduction to Oceanography

English

${ }^{*}$ Composition

Foreign Language

French, German or Russian 


\section{Agricultural and Mechanical College of Texas}

\section{DEPARTMENT OF OCEANOGRAPHY AND METEOROLOGY}

The program of marine sciences at the A\&M College of Texas consists of the work of the Department of Oceanography and Meteorology, which offers curricula leading to the M.S. and the Ph.D. degrees in oceanography, and of pertinent courses offered in other departments such as Biology, Wildlife Management, and Geology and Geophysics. An effort is made to maintain a balance between the biological, chemical, geological, and physical aspects of oceanography, both in teaching and in research. Facilities include two buildings on the campus, a shore laboratory in Galveston, platform facilities offshore from Panama City, Florida, the 180' fully equipped oceanographic research vessel ALAMINOS, and two $65^{\prime}$ vessels for inshore work. To date 45 students have completed M.S. degrees and 28 have completed Ph.D. degrees in oceanography.

\section{Instructional Staff:}

DALE F, LEIPPER, Ph.D., Professor and Head of Department DONALD W. HOOD, Ph.D., Professor of Chemical Oceanography LOUIS S. KORNICKER, Ph.D., Professor of Geological Oceanography HUGH J. McLellan, Ph.D., Professor of Physical Oceanography WILLIS E. PEQUEGNAT, Ph.D., Professor of Biological Oceanography ROBERT O. REID, M.S., Professor of Physical and Meteorological Oceanography

WILLIAM H. CLAYTON, Ph.D., Associate Professor of Physical Oceanography

JOHN D. COCHRANE, M.S. Associate Professor of Physical and Meteorological Oceanography

GUY A. FRANCESCHINI, Ph.D., Associate Professor of Meteorological Oceanography

SAMMY M. RAY, Ph.D., Assoc. Professor of Biological Oceanography ERNEST E. ANGINO, Ph.D., Assistant Professor of Geochemical Oceanography

SAYED Z. EL-SAYED, Ph.D., Assistant Professor of Biological Oceanography

EDWARD R. IBERT, Ph.D., Instructor of Chemical Oceanography WORTH D. NOWLIN, M.S., Instructor of Physical Oceanography GEORGE L. HUEBNER, Ph.D., Senior Research Scientist, Oceanographic Instrumentation

RICHARD M. ADAMS, M.S., Administrative Scientist

Degrees offered:

Master of Science in Oceanography

Doctor of Philosophy in Oceanography 
Undergraduate Courses:

201. SEA AND AIR SCIENCES

ADAMS

Oceanography and meteorology as scientific career fields. Features of the natural environment which affect man's daily 1 ife and activities. A survey course open to all college students.

401. INTRODUCTION TO OCEANOGRAPHY

STAFF

The various aspects of oceanography with emphasis upon those pertinent in the Gulf of Mexico. The principles upon which the disciplines of the subject are based. The unity of the marine sciences and their importance to man. The relations between oceanography and the fields of biology, chemistry, engineering, geography, geology, mathematics, meterology, and physics. Opportunities in oceanography.

\section{Graduate Courses:}

\section{SURVEY OF METEOROLOGY AND OCEANOGRAPHY}

A survey course in meteorology and oceanography designed for teachers of secondary school science.

603. SEA LABORATORY TECHNIQUES

STAFF

Practice in techniques used regularly aboard ship and in collecting field data. Cruise planning, navigational methods, collection of hydrographic, bathymetric and meteorological data, sediment sampling, biological sampling, and the collection of water samples for chemical analysis will be stressed.

610. PHYSICAL OCEANOGRAPHY

REID, LEIPPER, MC LELLAN

Survey of the physics of the sea; physical properties, transmission of light and sound in the sea, sea ice; heat budget of the sea and transformation of energy within the sea and at the boundaries; evaporation from the sea, description of water masses and their origin; the horizontal and vertical circulation of the seas; the applied dynamic and kinematic formulas for circulation in the sea; the concept of dynamic equilibrium of the different concentrations within the sea; introduction to waves and tides of the sea. 
Theoretical and quantitative aspects; equations of motion; equation of continuity; boundary conditions; distribution of properties in the presence of diffusion; heat budget; stability; dynamics and computation of ocean currents; wind currents; turbulence; friction.

612. THEORY OF OCEAN WAVES

REID, NOWLIN

Theory of simple harmonic surface waves; wave groups and group velocity, wave energy and energy propagationl dispersion. Theory of generation and decay of surface waves. Waves of large steepness, including solitary and enoidal waves. Modification of waves in shallow water, refraction; wave ray analysis and the phase diagram. Capillary waves; internal waves and shear waves.

613. ENGINEERING ASPECTS OF OCEANOGRAPHY

REID

Applications of oceanographic knowledge in engineering. Sea disturbances, astronomical tides, seismic sea waves, seiches, surging in harbors; wind generation of ocean waves. Practical wave forecasting; wave refraction diagram analysis; propagation of waves in shallow water, breaking waves. Principles of similitude, fluid resistance, wave forces on fixed and floating structures. Sediment movement; coastal erosion and stabilization. Harbor location and design; breakwater, and dike construction. Density currents in estuaries; diffusion and dispersal and pollutants.

614. DYNAMICS OF THE OCEAN AND ATMOSPHERE

REID

Advanced theory of the ocean dynamics, a comparison of the hydrodynamic and thermodynamic character of the ocean and the atmosphere; the mutual dependence of the dynamics and thermodynamics of the sea on those of the air and vice versa; some special theories from the mean equations of motion, gradient wind, jet stream, mutual adjustment of the mass field and velocity field in the sea; mutually coupled temperature variations of the sea and the air; wind driven currents; the general hydrodynamic problem of the ocean and of the atmosphere, and an investigation of its uniqueness; the maintenance of the general circulation. 
620. BIOLOGICAL OCEANOGRAPHY

PEQUEGNAT

Critical study of important contributions defining major biological divisions, provinces, and 1 ife zones of the oceans; effects of climate, chemical, and physical barriers, and phylogeny on zoogeography; factors relating to population cycles; productivity problems; ecological interrelationships of major groups of plants and animals in the sea.

621. BIOLOGICAL OCEANOGRAPHY OF THE GULF OF MEXICO

PEQUEGNAT

Detailed examination of selected aspects of biological oceanography which are of major importance to the Gulf of Mexico.

630. GEOLOGICAL OCEANOGRAPHY

KORNICKER

Topography and characteristic features of the ocean bottom; marine shorelines and processes operating in the coastal zone; nature of marine sediments; marine transportation and deposition of sedimentary materials; erosion of beaches.

631. GEOLOGICAL OCEANOGRAPHY OF

KORNICKER THE GULF OF MEXICO

Topography, stratigraphy, paleontology, and environments of the Gulf; littoral region and adjacent plains; forces acting on shorelines and bottoms; depositional surfaces, equilibria, equilibrium structures; tectonics; pleistocene history of region. Field trips.

640. CHEMICAL OCEANOGRAPHY

HOOD

The chemical composition and properties of sea water; the definition and calculation of salinity; the $\mathrm{pH}$, excess base, and carbon dioxide system in the sea; nutrients, their cycles, and their distribution; oxygen and other dissolved gases; chemistry of sedimentation; composition of organisms and organic constituents of sea water; marine corrosion; extraction of raw materials from the sea.

641. CHEMICAL OCEANOGRAPHY

HOOD

Detailed study of selected topics in chemical oceanography which pertain to the Gulf of Mexico; industrial utilization of sea water and chemical products obtained from marine plants and animals; water freshening; industrial corrosion problems; chemical aspects of photosynthesis and fertility of the sea; chemistry of estuarine waters. 
642. LABORATORY TECHNIQUES IN HOOD, ANGINO OCEANOGRAPHY

Detailed study will be made of methods of preparation and analysis of samples for biological, chemical, and geological investigations. The methods of analysis will concern oxygen, phosphate, silicate, nitrate, nitrite, salinity, carbon, sediment particle size, mineralogy, organic production and others.

643. GEOCHEMISTRY OF THE OCEAN KORNICKER, ANGINO

Geochemistry of the oceanic hydrosphere, biosphere, and lithosphere; these are related to the atmosphere; study of the elements within them.

644. GEOCHEMISTRY OF THE OCEAN KORNICKER, ANGINO

A detailed critical study of the geochemistry of sedimentation, the geochemical evolution of the ocean, the biogeochemistry of calcium carbonate and isotope geochemistry as related to the ocean.

651. METEOROLOGICAL OCEANOGRAPHY

REID, COCHRANE

The use of the conservative characteristics of the sea in forecasting meteorological and oceanographic phenomena. Calculation of ocean waves and swell, transformation of waves in shallow water, statistical summaries, modification of air masses in contact with the ocean, forecasting of fog and squalls, effect of the oceans upon climate of the world, meteorological tides.

\section{BOUNDARY LAYER PROBLEMS}

REID

Theory or radiative exchange of energy at the sea surface; the theory of turbulent flow over hydrodynamically rough and smooth surfaces with application to the evaluation of the fluid frictional stresses at the boundaries of the sea, the evaluation of wind stress, evaporation, etc; the micro-structure of temperature and coefficients.

681. SEMINAR

STAFF

Presented by students and based upon their research work and upon surveys of the 1 iterature. 
685. PROBLEMS

STAFF

A course offered to enable majors in oceanography to undertake and complete with credit in their particular fields of specialization limited investigations which do not fall within their thesis research and which are not covered by any other courses in the established curriculum. An example of the solution of a special problem in oceanography would be the work done in analyzing a special set of data collected on a cruise at sea. The course may also consist of a special series of problem discussions not given periodically, such as those offered by visiting scientists.

691. RESEARCH

STAFF

For thesis or dissertation.

For information contact

Dr. Dale F. Leipper, Head

Department of Oceanography and Meteorology

Agricultural and Mechanical College of Texas

College Station, Texas 
Graduate School, U. S. Department of Agriculture Washington 25, D. C.

The Graduate School offers an organized program of courses leading to a certified statement of accomplishment in oceanography. 20 semester hours of credit with a grade of " $\mathrm{C}$ " or better are required, including the following courses:

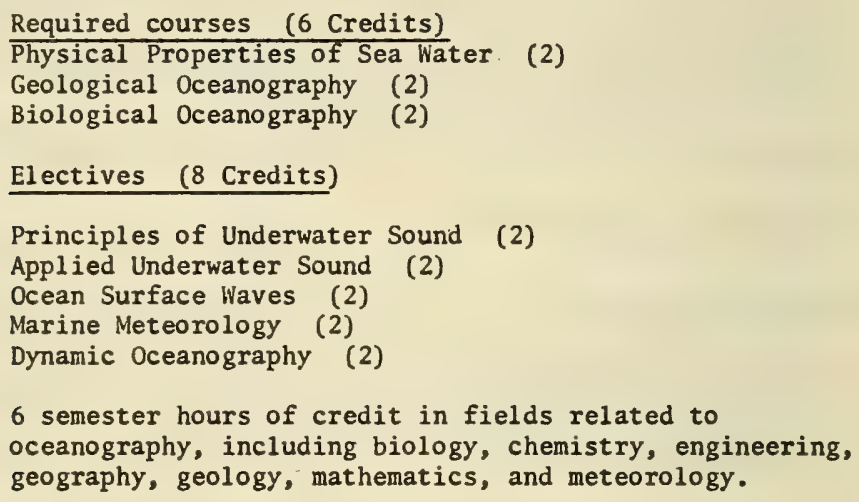

6 semester hours of credit in fields related to oceanography, including biology, chemistry, engineering, geography, geology, mathematics, and meteorology.

DEPARTMENT OF PHYSICAL SCIENCES

\section{Instructional Staff:}

HENRY STEVENS, Ph.D., Chairman

SAMUEL A. ARNY, B.S., Oceanographer, U. S. Naval Oceanographic office

M. D. BURKHART, M.S., Oceanographer, U. S. Naval Oceanographic Office

ROBERT ELDER, B.A., Physical Oceanographer, U. S. Naval Oceanographic office

JOHN J. SCHULE, JR., B.A., Division Director, Oceanographic Prediction Division, U. S. Naval Oceanographic Office

MORRIS SCHULKIN, M.S., Chief Scientist, Marine Electronics Office, AVCO Corporation

JOSHUA I. TRACEY, Ph.D., Geologist, Regional Geology, U. S. Geological Survey

\section{Degrees offered:}

None 
Undergraduate Courses:

5-360. GENERAL OCEANOGRAPHY BURNS

Characteristics of oceans and factors that control distribution of properties and of plants and animals. Biology, chemistry, geology and physics of the oceans.

Graduate Courses:

5-475. PRINCIPLES OF UNDERWATER SOUND

SCHULKIN

Fundamental principles of acoustics and application of these principles to underwater sound. Transmission of sound in the sea, including refraction, reflection, attenuation, and fluctuation.

5-476. APPLIED UNDERWATER SOUND

SCHULKIN

Applied theory and practice for those entering the field or working in related fields. Ray theory, normal mode theory, sound channels, noise and reverberation, measurement techniques, and elements of transducer design.

5-584. PHYSICAL PROPERTIES OF SEA WATER

MAGNITZKY

Examination of physical principles governing properties of sea water. Comparison of these properties with those of pure water. Definition and calculation of salinity and density. Distribution of salinity, temperature, and density.

5-655. OCEAN SURFACE WAVES

SCHULE

Measurable properties of ocean surface waves and the methods of observing and analyzing ocean waves. Demonstration of wave solution of hydrodynamic equations. Discussion of various sea surface models including their assumptions, solutions, and practical applications. Problems of propagation of waves in dispersive medium. Examples of various forecasting techniques.

5-658. GEOLOGICAL OCEANOGRAPHY

TRACEY

Topography and composition of ocean floor and coastal features together with underlying causes. Emphasis on dynamic processes and deductive reasoning required to understand ocean features now being extensively observed with modern instrumentation. 
5-662. MARINE METEOROLOGY

BURKHART

Introduction to fundamental principles of marine meteorology with special emphasis upon problems of marine climatologist and physical oceanographer. Descriptive and synoptic meteorology. Air mass analysis. Boundary processes. Radiation. Climatic principles.

5-664. DYNAMIC OCEANOGRAPHY SCHULE

Introduction to principles of vector analysis. Development of principles of conservation of mass and momentum. Vector equations of motion. Hydrostatic equations and density-pressure-depth relationship. Various current equations. Principles of turbulence. Equation of mean motion. Various approaches to problem of evaluating eddy stress terms.

5-666. BIOLOGICAL OCEANOGRAPHY

ARNY

Detailed examination of marine ecosystem, stressing community relationships and influence of the physiocochemical environment on marine life. Distribution of flora and fauna.

For information contact:

Dr. Henry Stevens

Chairman, Departmental Committee on the Physical Sciences Graduate School

U. S. Department of Agriculture

Washington $25, \mathrm{D} . \mathrm{C}$. 


\title{
University of Alaska

College, Alaska

\section{INSTITUTE OF MARINE SCIENCE}

The Institute of Marine Science has well-equipped research laboratories on the campus at College (Fairbanks), and access to workshops, library, computer center, and the usual university facilities. In addition, the Institute operates the Douglas Marine Station, near Juneau, with general purpose laboratories, radioisotope facilities, darkroom, and running sea water on the adjacent pier.

A Ph.D. program is to be offered in 1963, but course descriptions and a faculty list were not furnished before this catalogue went to press.

For information contact:

\author{
Dr. K. M. Rae, Director \\ Institute of Marine Science \\ University of Alaska \\ College, Alaska
}


The American University

Washington 16, District of Columbia

\section{DEPARTMENT OF EARTH SCIENCES}

\section{Instructional Staff:}

CAPTAIN PAUL S. BAUER, M.S., Adjunct Professor of Earth Sciences MATTHEW F. NORTON, Ph.D., Professor of Earth Sclences, Chairman ELIIS YOCHELSON, Ph.D., Lecturer

Degrees Offered:

Bachelor of Sclence and Master of Science in Earth Sclence with Emphasis in Oceanography.

Courses:

27.321 PAIEONTOLOGY

NORTON

Development of the major phyla as illustrated by fossils.

\subsection{STRATIGRAPHY AND SEDIMENTATION}

NORTON

Principles governing sedimentary processes, distribution of sedimentary rocks in time and space, physical and biological correlation, analysis of sediments, interpretations of sedimentary environments.

27.506 OCEANOGRAPHY

\section{BAUER}

Survey of the physics, chemistry and biology of the oceans; physlography and geology of ocean basins.

27.521 BIOLOGICAI PRINCIPLES IN EARTH SCTENCES YOCHELSON

Morphology and taxonomy with special reference to fossil evidences for evolution; ecology and functional morphology; reconstruction of food chains.

Evidence for and methods of reconstructing depositional environments of ancient sediments.

27.541 PHYSICAL PRINCIPIES IN EARTH SCIENCES

BAUER

Physical processes in the various spheres of the earth, their description, measurement, and probable cause. 
27.543 HYDROLOGY STAFF

Hydrologic cycle; ground water, surface water, hydrogeochemistry.

27.600 ADVANCED TOPICS IN EARTH SCIENCES STAFF

Study of a selected special topic or topics in Earth Sclences. 


\section{Californila Institute of Technology}

Pasadena, California

WILIIAM G. KERCKHOFF MARINE LABORATORY

While the California Institute of Technology offers extensive course work leading to the Ph.D. In blology and geology, it does not offer courses or degrees in marine science. The Division of Biology, under the chairmanship of Ray D. Owen, Ph.D., operates the Kerckhoff Marine Laboratory which offers facilities for teaching and research in marine zoology, embryology, and physiology. 


\section{The University of Chicago Chicego 37, IIIInols}

\section{THE DEPARTMENP OF THE GEOPHYSICAL SCIENCES}

The University of Chicago is expanding its activities in oceanography and hopes to offer more courses in marine science than at present. However, the principal emphasis will be on thorough preparation in basic disciplines with opportunities to apply them to marine research through affording students opportunity to participate in research at marine laboratories.

At the present time research at the University is being conducted on storm surges, near-shore oceanic circulation, interaction of waves and bottom, geochemistry of marine sediments, interactions between marine organisms and thelr environment and the organization of marine communities. Facilities at the University include a wave tank, flume, wind tunnel, paleoecology laboratory, sedimentology laboratory, geochemistry laboratories, hydrodymamics laboratory, electron probe, $\mathrm{x}$-ray diffraction equipment and several high speed computors (7090 IBM, 1620, MANIAC, UNIVAC). Fleld facilities are available at the Woods Hole Oceanographic Institution and the Pacific Marine Station.

Instructional Staff

SVERRE PEITERSSEN, Ph.D., Professor of Meteorology

GEORGE W. PLATZMAN, Ph.D., Professor of Meteorology

DAV FULTZ, Ph.D., Professor of Meteorology

ROBERT L. MIILER, Ph.D., Associate Professor of Marlne Geophysics and Geology

RAL.PH G. JOHNSON, Ph.D., Assoclate Professor of Paleontology

ROBERT A. BERNER, Ph.D., Assistant Professor

JOEL W. HEDGPEIH, Ph.D., University of the Pacific, Marine Station, Iecturer in Paleozoology

JOHN ZEIGLER, Ph.D., Woods Hole Oceanographic Institution, Lecturer in Marine Geology

Degrees Offered:

None in Oceanography. The M.S. and Ph.D. degrees in the Geophysical Sclences are offered with specialization in areas included in oceanography.

Courses Offered:

131, 132, INIRODUCTION TO THE GEOPHYSICAI SCIENCES

STAFF

133.

Broad problems of the planet, the earth's magnetic and gravitational fields, physical and biological oceenography, sediments, physicel processes and circulation in the atmosphere, climatology, erosion processes, volcanology, the earth's interior, and mountain-bullding. 
201.

General continuum principles; waves; potential flow and vortex motion; dynomics in moving coordinates; boundary-layer theory.

282, 283 DYNAMICAL PROBLEMS IN THE GEOPHYSICAL SCIENCES

PLATZMAN

Dynamical problems of the atmosphere and oceans.

301, 302 HYDRODYNAMICS I, II, III.

STAFF

303.

Integral momentum and energy principles; various topics in two-and three-dimensional potential flows including flow around objects and vortex motions; surface and internal gravity-wave motion, open-channel flow; dimensional analysis, viscosity, and the Navier-Stokes equations; topics in boundary-layer theory, thermal convection, hydrodynamic stability, or turbulence. Occasional laboratory work included.

\section{PALEOECOLOGY}

JOHNSON,

Consideration of the problems of terrestrial and OLSON marine paleoecology.

387. MARINE GEOLOGY

STAFF

388. MARINE GEOPHYSICS I.

MIIIERR

Surface and internal gravity wave motion; wind generation of waves and wave forecasting; wave refraction, diffraction.

389. MARINE GEOPHYSICS II

MIIJER

Coastal processes, sediment transport, and related topics.

481. RESEARCH IN MARINE GEOPHYSICS

MILTERR

482. RESEARCH IN STORM SURGES

PLATTZMAN

For Information Contact:

Chairman,

Department of the Geophysical Sciences

The University of Chicago

Chicago 37, Illinois 


\author{
$\frac{\text { University of Connecticut }}{\text { Storrs, Connecticut }}$
}

MARINE RESEARCH LABORATORY

No separate department offers work towards a degree in oceanography. The University considers that marine science is interdisciplinary in nature. Students who wish to prepare themselves for work in marine science will select a special field. A committee composed of a major advisor in this field and two associate advisers in related fields will determine requirements for each student on an individual basis.

Work in the marine sciences includes radiation biology (accumulation of nuclides, correlation of hydrographic and radiobiological factors), ecology (estuarine, larval, benthic), bacteriology (enumeration methods, cycles in estuaries), coastal climatology and oceanography (influence of weather on physical properties of sea water), phycology (growth, structure and distribution), and physiology (crustacean receptors, carbon dioxide fixation).

Besides the usual facilities available on the main campus at Storrs, the University maintains a year-round laboratory at Noank at the mouth of the Mystic River (U.S. Coast and Geodetic Charts 358,1211 ). Facilities include a two-story brick building with eight large laboratory rooms (most with salt water), common ancillary rooms, library, shop, etc, all provided with both special and common equipment; $30^{\prime}$ dragger, four skiffs with out board motors; a pick-up truck; rooming for about 25 .

\title{
Staff:
}

John S. Rankin, Jr., Ph.D., Director and Professor of Zoology

Edward G. Boettiger, Ph.D., Professor of Zoology

Robert C. Cleverdon, Ph.D., Professor of Bacteriology

David Dean, Ph.D., Assistant Professor of Zoology

Russeel P. Hunter, Ph.D., Professor of Wildlife Management

C. Albert Kind, Ph.D., Professor of Zoology

George R. Rumney, Ph.D., Associate Professor of Geography

Donald M. Skauen, Ph.D., Professor of Pharmacy

Francis R. Trainor, Ph.D., Assistant Professor of Botany

Ralph M. Wetze1, Ph.D., Associate Professor of Zoology

Degrees offered:

Master of Science and Doctor of Philosophy in various departments with specialization in marine science. 


\section{Courses :}

Geology and Geography

217. SEDIMENTATION

FRANKEL

Study of origin, transport, deposition and biogenesis of terrestrial, trasitional and marine sediments.

294. INTRODUCTORY OCEANOGRAPHY

RUMNEY

A physical geography of the sea. The character and distribution of bathymetric regions, physical and chemical properties and dynamic processes are presented, as well as the chief oceanic environments and forms of life. Field trips to the shore required.

Wildlife Management

285. ICHTHYOLOGY

HUNTER

A study of the structure and characteristics of fishes, their ecological relationships, life histories and economic importance. Enphasis on fresh water forms.

286. MARINE FISH AND FISHERIES

HUNTER

A study of the physical ahd biological factors affecting marine fisheries production. General oceanography, marine fishes and their ecological relationships are reviewed.

313. FISHERIES MANAGEMENT

314. FISHERIES MANAGEMENT TECHNIQUES

Zoology and Entomology

317. MARINE ECOLOGY

DEAN

The ocean as an environment, with special reference to shallow and estuarine regions; distribution of biota in relation to the physical and chemical environment. Field trips required.

The following courses in other fields are frequently taken by students specializing in marine science.

Bacteriology

300. SPECIAL PROBLEMS IN BACTERIOLOGY

STAFF

311. SEMINAR

STAFF 
321. BACTERIAL PHYSIOLOGY I

322. BACTERIAL PHYSIOLOGY II

Botany

281. INTRODUCTORY PHYCOLOGY

300. INVESTIGATION OF SPECIAL TOPICS

310. CYTOGENETICS

363. MINERAL NUTRITION OF PLANTS

369. APPLICATIONS OF ISOTOPIC TRACERS TO BIOLOGICAL RESEARCH

391. SEMINAR

\section{Chemistry}

235. MICROCHEMICAL TECHNIQUES

242. IDENTIFICATION OF ORGANIC COMPOUNDS

314-315. ADVANCED INORGANIC CHEMISTRY

332. INSTRUMENTAL ANALYSIS

345. PHYSICAL-ORGANIC CHEMISTRY

353-354. CHEMICAL KINETICS AND PHOTOCHEMISTRY

\section{Civil Engineering}

260. WATER AND SEWAGE TREATMENT

261. SANITARY ENGINEERING LABORATORY

271. ELEMENTARY SURVEYING

391. ADVANCED SANITARY ENGINEERING LABORATORY 398. STREAM SANITATION
CLEVERDON

CLEVERDON

TRAINOR

STAFF

NEWCOMER

KOONTZ

KOONTZ

WETHERELL

STAFF

STOCK

BOBBITT

WARD

ILMET, SMITH

WARING

TIPPY, WIDMER, SMITH

WIDMER, SMITH

STEPHENS, BREEN

WIDMER

WIDMER 
Geology \& Geography

263. METEOROLOGY AND CLIMATOLOGY

RUMNEY

305. SPECIAL PROBLEMS IN GEOLOGY

STAFF

325. SPECIAL PROBLEMS IN GEOGRAPHY

STAFF

Pharmacy

312. BIONUCLEONICS

SKAUEN

Physics

300. INDEPENDENT STUDY

STAFF

304. RESEARCH IN PHYSICS

STAFF

310. SEMINAR

BARTRAM

Wildlife Management

288. LIMNOLOGY

HUNTER

Statistics

300. INVESTIGATION OF SPECIAL TOPICS

STAFF

310. ADVANCED STATISTICAL METHODS

STAFF

340. STATISTICAL METHODS PECULIAR TO BIOLOGY

Zoology and Entomology

300. INDEPENDENT STUDY

STAFF

303. RESEARCH

STAFF

310. SEMINAR

STAFF

320. ABVANCED INVERTEBRATE ZOOLOGY

RANKIN, DEAN

323. THE PHYSIOLOGY OF DEVELOPMENT

CLARK

326. BIOCHEMICAL TECHNIOUES

KIND, COOK

335. COMPARATIVE PHYSIOLOGY

BOFTTIGER 
337. CELLULAR PHYSIOLOGY

BERNSTEIN

344. HELMINTHOLOGY

PENNER

353. PRINCIPLES AND METHODS OF SYSTEMATIC ZOOLOGY

SLATER

For information contact:

Dr. John S. Rankin, Jr., Director

Marine Research Laboratory

University of Connecticut

Storrs, Connecticut 
Columbia University

New York 27, New York

Graduate students in marine sciences at Columbia University normally enroll in the Department of Geology, those of marine biology enroll either in the Department of Zoology or of Botany. There is no separate Department of Oceanography. Emphasis is on providing for each graduate student adequate training in the fundamental sciences (chemistry, geology, physics, mathematics, and zoology) appropriate to his special field of interest. To provide this training, the student with his advisor may select from the entire list of course offerings in the Graduate Departments at Columbia University. Research facilities for graduate students in oceanography are available in laboratories and on ships of the Lamont Geological Observatory, a separate institute within Columbia University.

\section{Instructional Staff}

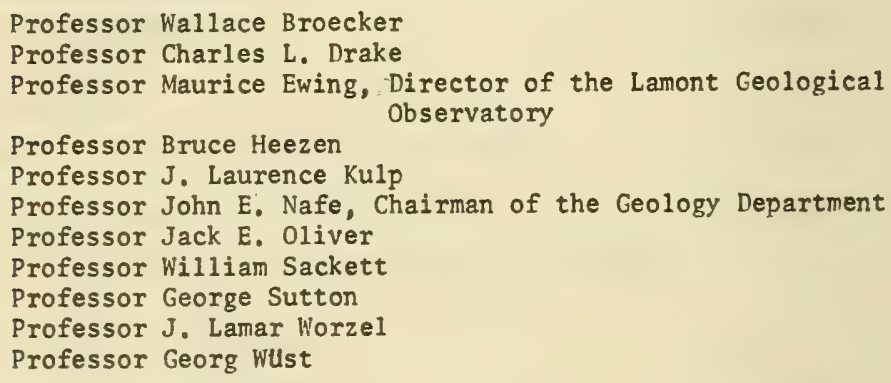

Degrees offered: Master of Arts in Oceanography Doctor of Philosophy in Oceanography

\section{Courses:}

Students commonly select courses from the following list. The list is not inclusive, nor is any particular course necessarily required. A complete description of these and other course offerings may be found in the bulletin of the Graduate Faculties of Columbia University, and of the School of Engineering and Applied Science.

\section{Chemistry:}

Advanced inorganic chemistry

Introduction to chemical nhysics

Chemical and statistical thermodynamics

Radio chemistry 
Geology:

Advanced geologic mapping

Mineralogy of metalic minerals

Mineralogy of non-metalic minerals

Principles of sedimentation

Experimental marine sedimentology

Paleozoic and later stratigraphy of North America

Principles of geomorphology I and II

Principles of structural geology

Geotectonics

Introduction to economic geology

Groundwater geology

Introduction to paleontology

Micropaleontology

Petrology of igneous rocks

Petrology of metamorphic rocks

Chemical equilibria in geologic systems

Atomic structure of minerals

Isotope geology

Geochemistry

Advanced geochemistry

Submarine geology I and II

Introduction to geophysics

Survey of geophysic prospecting

Basic dynamic meteorology

Dynamical weather prediction

General circulation of planetary atmosphere

Physical meteorology

Oceanography

Dynamic oceanography

Application of digital methods to geophysical problems

Upper atmoshpere physics

General geophysics (seismology)

General geophysics (gravity and magnetism)

Mathematics and Engineering Mathematics:

Advanced calculus for science majors

Differential equations

Partial differential equations

Applied mathematics I and II

Functions of a complex variable

Numerical solution of engineering problems

\section{Physics:}

Mechanics

Theory of electricity and magnetism

Thermodynamics

Mathematical methods of physics

Introduction to theoretical physics

Advanced laboratory 
Elektromagnetic theory. I and II

Analytical Dynamics I and II

Elasticity and hydrodynamics

Zoology:

General invertebrate $200 \operatorname{logy}$

General vertebrate 200 logy

Biometrics

Comparative physiology

Experimental embryology

General genetics

Genetics of microorganisms 


\author{
Cornell University \\ Ithaca, New York
}

Graduate students and a limited number of undergraduate students participate in long range research on the oxygen resources of coastal waters, and on the physiology of marine zooplankton, during the summer months and other academic recesses. Cooperative research with the Woods Hole Oceanographic Institution similarly provides opportunity for student experience. Academic facilities at Ithaca include an oceanographic laboratory equipped for analytical and experimental studies.

\title{
DEPARTMENT OF CONSERVATION
}

Instructional Staff:

GUSTAV A. SWANSON, Ph.D., Professor of Conservation; Head, Department of Conservation

JOHN P. BARLOW, Ph.D., Associate Professor Oceanography

ALFRED W. EIPPER, Ph.D., Assistant Professor of Fishery Biology

EDWARD C. RANEY, Ph.D., Professor of Zoology

DWIGHT A. WEBSTER, Ph.D., Professor of Fishery Biology

Degrees offered:

None in marine sciences, but the B.S. is given with a major sequence in marine ecology; and candidates for the M.S. and $\mathrm{Ph} . \mathrm{D}$. may major or minor in oceanography and marine ecology, fishery biology, or vertebrate zoology (ichthyology). Research projects including graduate student dissertation problems are continuously in progress in Long Island coastal areas, and others are conducted by arrangement with appropriate marine stations.

Courses offered:

22. ICHTHYOLOGY

RANEY

Evolution, relationships, structure, habits, ecology, and literature of fishes. Laboratory studies on structure and identification of fishes. Field studies on ecology and life histories.

122. ADVANCED ICHTHYOLOGY

RANEY

A continuation of Course 22, alternating with it. May be taken without Course 22 as prerequisite. 
173. FISHERY BIOLOGY

WEBSTER

Principles of fishery management, stressing dynamics of growth, populations, and production. Techniques of fishery management and the investigational aspects of fishery biology are also included.

175. FISHERY BIOLOGY LABORATORY

WEBSTER

Field and biometrical exercises in fishery management.

180. OCEANOGRAPHY

BARLOW

Physical and chemical aspects of the oceans, particularly as background for marine ecology; geography and geology of the ocean floor; currents, tides, distribution of temperatures. Laboratory work in processing oceanographic data.

181. MARINE ECOLOGY

BARLOW

The sea as an environment; the physical and chemical characteristics of marine habitats; the productivity of the sea; the relation of hydrography to fisheries and faunal distributions.

407. RESEARCH PROGLEMS IN OCEANOGRAPHY

BARL.OW

For information contact:

Dr. John P. Barlow

Department of Conservation

Cornell University

Ithaca, New York

\section{DEPARTMENT OF BOTANY}

Instructional Staff:

GEORGE C. KENT, Ph.D., Professor of Plant Pathology; Head, Department of Plant Pathology; Acting Head, Department of Botany

JOHN M. KINGSBURY, Ph.D., Associate Professor of Botany

Degrees Offered:

None in marine sciences. Appropriate thesis research problems dealing with marine algae may be undertaken by candidates for the M.S. or Ph. D. degrees under the direction of Professor Kingsbury. Problems requiring living materials which cannot be cultured ordinarily will be performed by arrangement at an appropriate marine station. 


\section{Courses Offered:}

\section{BIOLOGY OF THE ALGAE}

Structure, ecology, physiology, origins, economic importance and evolution in the groups of the bluegreen, green, yellowgreen, golder brown, and euglenoid algae are discussed. Evolutionary and ecological significance of different pigment systems are demonstrated. Biologically important characteristics of ponds and streams are brought out in relation to the algae populating them. Emphasis is placed also on particular biochemica physiological, or structural characteristics of algae of potential value in research on general biological problems. Living material of a large number of genera is provided in laboratory to illustrate lecture topics, to demonstrate and provide practice in techniques of isolation and culture, and to develop a working familiarity with the local algal flora.

\section{BIOLOGY OF THE ALGAE}

Although a continuation of Course 112, covering the groups of the diatoms, dinoflagellates, brown, and red algae and emphasizing the characteristics of the marine environment, this course is complete in itself and need not be preceeded by Course 112 . Photographic transparencies of living specimens are used extensively to supplement examination of preserved material in laboratory. Participation in an optional field trip to varied marine and brackish habitats on Cape Cod and Cape Ann, Massachusetts in late spring may be limited to 12 students.

\section{SPECIAL PROBLEMS IN PHYCOLOGY}

Students engaged in special problems or making special studies may register in this course. They must satisfy the instructor that their preparation warrants their choice of problem.

For information contact:

Dr. John M. Kingsbury Department of Botany Corne11 University Ithaca, New York 
$\frac{\text { University of Delaware }}{\text { Newark, DeIaware }}$

\section{DEPARTMENT OF BIOLOGICAL SCIENCES}

Instructional Staff:

W. ROBERT A. BAILEY, Ph.D., Associate Professor of Biological Sciences

ARNOLD M. CLARK, Ph.D., Professor of Biological Sciences

FRANKLIN C. DAIBER, Ph.D., Associate Professor of Biological Sciences

JAMES C. KAKAVAS, Ph.D., Associate Dean, School of Graduate Studies and Professor of Biological Sciences

EVA KONRAD, Ph.D., Assistant Professor of Biological Sciences

JAMES B. KRAUSE, Ph.D., Associate Professor of Biological Sciences

RICHARD A. NYSTROM, Ph.D., Assistant Professor of Biological Sciences

RAPHAEL R. RONKIN, Ph.D., Associate Professor of Biological Sciences

HORACE J. SAWIN, Ph.D., Research Professor of Biological Sciences and Geology

CARL N. SHUSTER, JR., Ph.D., Assistant Professor of Biological Sciences and Director, University of Delaware Marine Laboratories

G..FRED SOMERS, Ph.D., Chairman and Professor of Biological Sciences

MARENES R. TRIPP, Ph.D., Assistant Professor of Biological Scineces

PHILIP S. WOODS, Ph.D., Associate Professor of Biological Sciences

Degrees offered:

Master of Arts and Master of Science in Biological Sciences Doctor of Philosophy in Biological Sciences (Specialization in Marine Biology)

Upper Division Courses:

B427. INTRODUCTION TO BIOLOGICAL OCENAOGRAPHY SHUSTER

Saltwater ecosystems, with emphasis on Delaware Bay and the Atlantic Ocean.

B491. INTRODUCTION TO RESEARCH

STAFF

Original research. Problem selected in accord with student's interests and research activities in the Department 
Graduate Courses:

B505. COMPARATIVE PHYSIOLOGY

NYSTROM

Comparison of the reactions of different groups of animals to their environments with emphasis on mechanisms of adaptive significance; comparison of relationships between effector and integrative systems.

B512. SPECIAL PROBLEMS

STAFF

Original investigations in the biological sciences.

B527. SELECTED TOPICS IN OCEANOGRAPHY

STAFF

Seminar with field examination of techniques.

B528. MARINE INVERTEGRATES

SHUSTER

Advanced training in methods for studying the biology of specific marine organisms.

B530. ICHTHYOLOGY

DAIBER

Biology of fishes, including structare and function, reproduction, development, behavior, geographic distribution, and systematics.

B531. FISH ECOLOGY

DAIBER

Ecological principles as exemplified by fishes. Laboratory and field studies.

B560. ESTUARINE HYDROGRAPHY

STAFF

Analysis of estuarine systems: chemistry, physics, geology and biology.

B569. THESIS

STAFF

B570. RESEARCH

STAFF

Independent and original research in the biological sciences. Seminar participation.

B589. SEMINAR STAFF

Reports and discussion of selected topics and current developments in the biological seiences. 


\section{Duke University Durham, North Carolina}

DUKE UNIVERSITY MARINE LABORATORY - DEPARTMENT OF BOTANY AND DEPARTMENT OF ZOOLOGY

\section{Instructional Staff:}

J. R. BAILEY, Ph.D., Associate Professor of Zoology

C. G. BOOKHOUT, Ph.D., Director; Professor of Zoology

J. D. COSTLOW, JR., Ph.D. (Research and Thesis supervision only) Assistant Professor of Zoology

I. E. GRAY, Ph.D., Professor of Zoology

H. J. HUMM, Ph.D., Associate Professor of Botany

WANDA S. HUNTER, Ph.D., Associate Professor of Zoology

T. W. JOHNSON, Ph.D., Associate Professor of Botany

D. A. LIVINGSTONE, Ph.D., Associate Professor of Zoology

MURIEL I. SANDEEN, Ph.D., Assistnat Professor of Zoology

F. J. VERNBERG, Ph.D., Associate Professor of Zoology

Degrees Offered:

A separate degree is not offered in marine sciences, but in either the Botany or Zoology Department with a concentration of courses in Marine Biology and a thesis in the subject.

Courses:

Botany

207. MARINE MYCOLOGY

JOHNSON

Introduction to the structure, classification, culture, and physiology of marine and brackish water fungi. Special problems on groups or individual species. Lectures, laboratory, field trips, introduction to periodical literature, and individual investigations.

211. MARINE ALGAE

HUMM

Classification, taxonomy, morphology, distribution, ecology, and economic uses of marine algae; preparation of herbarium material. In addition to collection, field work will provide students an opportunity to observe associations of marine algae in situ by means of diving equipment, if they wish to use it.

Zoology

203. MARINE ECOLOGY

GRAY

A study of marine animals in relation to environment. Consideration of environmental factors, succession, rhythms, communities, intraspecific and interspecific, 
relations, productivity, conservation, problems, etc., concerned with animal life in the ocean. lectures, reviews, conferences, field and laboratory work.

The major groups of parasites will be considered in relation to different types of marine animals. Systemstics of the parasites present will be considered along with host-parasite relations and life cylces. A special problem will be selected by the student and completed during the last two weeks of the course.

214. OCEANOGRAPHY

\section{LIVINGSTONE}

An introduction to the study of the ocean. Consideration of its physical, chemical, biochemical, and geological processes. Lectures, laboratory, field trips, and introduction to periodical literature.

(Advanced courses in Oceanography planned for next year with new staff.)

216. LIMNOLOGY

LIVINGSTONE

A study of lakes, ponds, and streams, including their origin, development, geochemistry, energy balance, productivity, and the dynamics of the plant and animal communities living in them. Lectures, field trips, laboratory work.

238. SYSTEMATIC ZOOLOGY

\section{BAILEY}

The fundamental theory and practice involved in the collection, identification, and classification of animals.

249. PHYSIOLOGY OF INVERTEGRATF RECEPTORS, EFFECTORS, AND COORDINATION

SANDEEN

A study of sense organs, endocrine and nervous mechanisms, muscles, chromatophores and other effectors in selected invertebrate animals. Lectures, reports and laboratory.

250. PHYSIOLOGICAL ECOLOGY OF MARINE ANIMALS VERNBERG

A study of the physiological responses of marine animals in relation to certain environmental factors and evolution. Animals representing numerous phyla and from various habitats are studied. 
274. MARINE INVERTEBRATE ZOOLOGY

BOOKHOUT

A study of invertebrate animals that occur in the Beaufort region. A number of field trips will be made to a variety of habitats to study, collect, and classify animals in their natural environment. The structure and habits of living invertebrates, as well as their behavior under experimental conditions, will be studied in the laboratory.

278. INVERTEBRATE EMBRYOLOGY

BOOKHOUT

Lectures, readings, and laboratory work dealing with rearing, development, and life history of invertebrates.

351, 352. DEPARTMENTAL SEMINAR

STAFF

A weekly meeting of graduate students and faculty to hear reports and to discuss biological facts, theories, and problems.

353,354 . RESEARCH

STAFF

Students who have had proper training may carry on research under direction of members of the staff in various fields.

355,356 . SEMINAR

STAFF

One or more seminar courses in particular fields

are given each year by various members of the staff. 


$\frac{\text { Florida State University }}{\text { Tallahassee, Florida }}$

\section{OCEANOGRAPHIC INSTITUTE}

Instructional Staff:

TAKASHI ICHIYE, D.Sc., Assistant Professor of Physical Oceanography

R. W. MENZEL, Ph.D., Associate Professor of Marine Biology

CHARLES B. METZ, Ph.D., Professor of Marine Biology and Associate Director

\section{Degrees offered:}

M.S. and Ph.D. degrees are awarded through Biological Sciences, Geology, Chemistry, Meteorology and Physics with specialization in marine science.

\section{Upper Division Courses:}

Biology 430. SURVEY OF MARINE SCIENCE

MENZEL, OTHERS

A survey of the marine sciences including physical oceanography, bacteriology, algology, ecology, and marine zoology. Field work at the Marine Laboratory. Taught by invited guest scientist in summer, and by Oceanographic Institute staff in first trimester.

Meteorology 455. INTRODUCTORY PHYSICAL OCEANOGRAPHY

The physical, geological and chemical properties of the oceans and their containers, and the behavior of the oceans.

Meteorology 456. FIELD WORK IN OCEANOGRAPHY

Methods and equipment used in oceanographic field work are demonstrated and applied to field problems.

Graduate Courses:

Biology 545-6-7. PROBLEMS IN MARINE BIOLOGY MENZEL, OTHERS

Selected problems in marine biology. Offered in regular trimester and summer.

Geology 519. MARINE GEOLOGY

Origin and present form of the ocean basins; characteristics of oceanic crustal rocks; marine sediments, processes, and environments; current problems in marine geology. 
Geology 530. ADVANCED SEDIMENTOLOGY

GOODELL

Quantitative aspects of sedimentology; advanced techniques and procedures; analysis of sediment data.

Meteorology 555. ADVANCED PHYSICAL OCEANOGRAPHY-ICHIYE

Ocean waves, tides, currents, diffusion, turbulence, heat budget, transmission of energy.

Meteorology 591. DIRECTED STUDIES IN OCEANOGRAPHY-ICHIYE

Selected topics in physical oceanography.

Zoology 561-2-3. EXPERIMENTAL EMBRYOLOGY SEMINAR-METZ

Selected topics in embryology.

Additional related course work is available in the various science departments from cooperating faculty. 
The University of Georgia

Athens, Georgia

\section{MARINE INSTITUTE}

The university of Georgia Marine Institute, located at Sapelo Island, Georgia, is operated by the University in cooperation with the Sapelo Island Research Foundation. Laboratory facilities include radioisotope counting and handling equipment; spectrophotometers, constant-temperature rooms, running estuarine water, chromatographic equipment, and library. The 65-foot research vesse1, Kit Jones, is equipped with both hydrographic and trawling winches, loran naviagtion, sonic sounding, and interior laboratory space. It can accomodate four scientists for work along the coast and over the continental shelf.

Research now in progress at the Marine Institute includes the following. Studies of near-shore sedimentation processes. Geology of the continental shelf. Geochemistry of carbonate sediments. Flow of energy and elements through the ecosystems of the salt marsh, estuaries, and continental shelf waters. Relation of levelbottom communities to sediments. Translocation of materials in halophytic plants. Collection and processing of organisms for studies of the biochemistry of bioluminescence. Collection of organisms for studies of microbial metabolism of uronic acids. Collection of organisms for a study collection of the regional fauna and flora.

\section{Staff:}

Dirk Frankenberg, Ph.D. Assistant Professor of Zoology

Vernon J. Henry, Ph.D. Assistant Professor of Geology

John H. Hoyt, Ph.D., Assistant Professor of Geology

Orrin Pilkey, Ph.D. Assistant Professor of Geology

Lawrence R. Pomeroy, Ph.D. Associate Professor of Zoology

Kenneth L. Webb, Ph.D. Assistnat Professor of Botany

Associated members of the University faculty not members of the staff of the Marine Institute:

Milton J. Cormier, Ph.D. Assistant Professor of Chemistry

Leon S. Dure, Ph.D. Research Assistant

Robert G. Eagon, Ph.D. Associate Professor of Bacteriology

Eugene $\mathrm{P}$. Odum, Ph.D. Alumni Foundation Distinguished Professor of Zoology

William J. Payne, Ph.D. Associate Professor of Bacteriology and Head of the Department of Bacteriology

Donald C. Scott, Ph.D. Associate Professor of Zoology and Chairman, Marine Institute Advisory Board 
Degrees offered:

No degrees are offered in the marine sciences, but work toward graduate degrees in zoology, geology, and botany may be undertaken with research in marine science carried out at the Marine Institute.

Courses:

$\underline{\text { Zoology }}$

353. ECOLOGY

605. ICHTHYOLOGY

654. LIMNOLOGY AND OCEANOGRAPHY

656. MARINE BIOLOGY

807. ADVANCED INVERTABRATE ZOOLOGY

808. ADVANCED INVERTABRATE ZOOLOGY

854. PHYSIOLOGICAL ECOLOGY

855. ADVANCED ECOLOGY

\section{Geology}

609. MARINE GEOLOGY

603. INVERTEBRATE PALEONTOLOGY

605. SEDIMENTATION AND STRATIGRAPHY
Odum

Scott .

Pomeroy, Scott

Pomeroy

Thomas

Thomas

Odum

Odum

Henry

Henry

Hamblin

\section{For Information contact:}

Prospective visiting investigators should write to Dr. George H. Lauff, Research Coordinator, Sapelo Island Research Foundation, Sapelo Island, Georgia.

Prospective graduate students should write to the appropriate department head at the University of Georgia, Athens, Georgia. 


\author{
Harvard University \\ Canbridge, Massachusetts
}

COMMITTEE ON OCEANOGRAPHY

There is no separate department offering work toward a degree in oceanography. The University considers that specialization in marine science should be undertaken within one of the classical scientific disciplines, such as biology, geology, physics, or chemistry. The Committee on Oceanography will assist students who wish to prepare themselves for work in this special field, and will help them arrange joint programs of study when that is desired. Members of the Committee are:

FRANCIS BIRCH, Ph.D., Professor of Geology

GEORGE F. CARRIER, Ph.D., Professor of Mechanical Engineering

GEORGE L. CLARKE, Ph.D., Associate Professor of Zoology, Chairman of the Committee

RICHARD M. GOODY, Dr.Phil., Professor of Meteorology

FREDERICK V. HUNT, Ph.D., Professor of Physics

COLUMBUS ISELIN, S.D., Professor of Physical Oceanography

BOSTWICK H. KETCHUM, Ph.D., Lecturer on Biological Oceanography

GILES W. MEAD, PH.D., Curator of Fishes, Museum of Comparative Zoology

ALAN R. ROBINSON, th. D., Assistant Professor of Meteorology and Oceanography

RAYMOND SIEVER, Ph.D., Associate Professor of Geology

HENRY M. STOMMEL, A.M., Professor of Oceanography

E. BRIGHT WILSON, JR., Ph.D., Professor of Chemistry

Degrees offered:

None in oceanography. Students must qualify in one of the classical scientific disciplines.

Courses:

The following are courses in oceanography or closely related thereto. Other suggested courses for students wishing to specialize in marine science may be obtained from the bulletin "Instruction in Oceanography."

Biology

130. BIOLOGY OF FISHES

MEAD

The classification, structure, and natural history of fishes.

143. PRINCIPLES OF ECOLOGY

CLARKE

The basic interrelations of plants and animals with the physical and biological factors of the environment. The fundamental concepts of environmental biology. The control of growth, distribution, reproduction, and behaviro; develop- 
ment and organization of populations; energy flow and dynamic balance in communities; and productivity of natural areas and biological resources.

\section{PROBLEMS IN AQUATIC ECOLOGY}

\section{CLARKE}

Fundamental ecological relations of the aquatic environment with special consideration to problems of most recent interest in marine biology, oceanography, limology, fishery biology, and conservation.

\section{BIOLOGICAL OCEANOGRAPHY}

\section{KETCHUM}

The major problems in the development, seasonal changes, and variations of populations of aquatic organisma: Recent developments in aquatic biology will be emphasized and will include such subjects as photosynthetic production and its relationship to environmental conditions, the transfer of energy and elements through the food web, the biologically controlled distribution of elements in the sea, estuarine and coastal circulation in relation to the distribution of populations, the uses of radioisotopes for the study of oceanographic problems and biological effects of the contamination of the sea with radioisotopes.

333. MALACOLOGY

335. ICHTHYOLOGY

343. ECOLOGY AND OCEANOGRAPHY

345. GRADUATE RESEARCH IN BIOLOGICAL OCEANOGRAPHY
CLENCH

MEAD

CLARKE

KETCHUM

\section{Meteorology and Oceanography}

201. DYNAMICS OF ATMOSPHERES AND OCEANS

ROBINSON

Dynamics of rotating and convecting fluid systems with application to phenomena in the atmosphere and oceans.

202. SPECIAL TOPICS IN GEOPHYSICAL FLUID DYNAMICS ROBINSON

Advanced topics in theoretical meteorology and oceanography.

\section{PHYSICAL OCEANOGRAPHY}

STOMMEL

This course is primarily concerned with the general circulation of the ocean, and relates various hydrodynamical models to a fairly detailed amount of the observational material availabel for its description.

302. RESEARCH IN GEOPHYSICAL HYDRONAMICS

ROBINSON

303. READING IN GEOPHYSICAL HYDRODYNAMICS

ROBINSON 


\author{
University of Hawaii \\ Honolulu 14, Hawai
}

The University of Hawaii does not have a single all-inclusive department of oceanography which deals with all aspects of marine science, but because of the ideal location of the University of Hawaii several university departments are engaged in teaching and research on marine subjects.

Major facilities for marine research and teaching include the research vessels NEPTUNE I ( $83 \mathrm{feet}$ ) and SALPA ( $43 \mathrm{feet}$ ) and several small motorboats; Dept. of Zoology aquariums with running sea water at various temperatures; Hawaii Marine Laboratory at Coconut Island; Honolulu Aquarium at Waikiki; Geophysics Institute Laboratories; and the Hydrodynamics Laboratory at Kewalo Basin.

\title{
HAWAII INSTITUTE OF GEOPHYSICS
}

Instructional Staff:

George P. Woollard Ph.D., Director

Doak C. Cox, M.A., Geophysicist and Professor of Geology Other instructional staff members are listed under the Department of Meteorology and Oceanography and Department of Geology.

\section{Degrees offered:}

None. Research training is offered for graduate students seeking Degrees in physical, chemical and geological oceanography offered through other University Departments.

\section{HAWAII MARINE LABORATORY}

Instructional Staff:
A. Banner, Ph.D., Director
(see also Departments of Botany and Zoology)

Degrees offered:

None. Research training is offered for graduate students in biological oceanography and marine biology seeking degrees offered through the different University Departments of Biology. 


\section{Courses:}

It is intended to start with the Summer Institute in Marine Sciences, commencing in 1964 where a selection of six of the following graduate level courses would be taught each summer.

Botany

S-586 Biological Productivity of the Sea

S-000 Tropical Phycology

S-000 Marine Mycology and Bacteriology

S-000 Taxonomy of Phytoplankton

S-000 Experimental Marine Botany

S-000 Atol1 Ecology

\section{Chemistry}

S-580 Oceanographic Chemistry

\section{Geology}

S-470 Marine Geology

S-671 Nearshore Geology

S-672 Geology of Ocean Basins

S-000 Marine Invertebrate Paleontology

\section{Oceanography}

S-600 Physical Oceanography

Microbiology

S-000 Marine Protozoology

\section{Zoology}

S-606 Comparative Animal Behavior

S-620 Marine Ecology

S-000 Hawaiian Reef Organisms

S-646 Comparative Invertebrate Physiology

S-621 Physiological Ecology

S-000 Taxonomy of Zooplankton

S-000 Marine Parasites

S-000 Invertebrate Embryology

S-000 Experimental Embryology

S-622 Isotopic Tracers in Biology 
DEPARTMENT OF METEOROLOGY AND OCEANOGRAPHY

Instructional Staff:

Carl W. Adams, M.S., Assistant Professor of Meteorology and Oceanography

Richard A. Barkely, Ph.D., Chief, Oceanography

Investigation, Honolulu Biological Laboratory; Affiliate Graduate Faculty member.

Taivo Laevastu, Ph.D., Associate Professor of Oceanography Gunter Seckel, M.S., Oceanographer, Honolulu Biological Laboratory; Affiliate Graduate Faculty Member.

Degrees Offered:

Master of Science in Oceanography.

Upper Division Courses:

550 GENERAL OCEANOGRAPHY

ADAMS, (BANNER, BARKLEY, DOTY, MOBERLY, ZEITLIN)

Physical properties of the sea; distribution of temperature, salinity, density; radiation; waves, tides, currents and other motion; ocean-atmosphere inter-relationships; relationships of physical oceanography to marine geology, chemistry, biology and meteorology.

575 REGIONAL OCEANOGRAPHY LAEVASTU, SECKEL

Processes at the surface and formation of water types; formation of deep waters; water type and mass analyses; coastal and oceanic waters; water masses by natural regions and description of the characteristics of oceanic regions.

Graduate Courses:

600 PHYSICAL OCEANOGRAPHY BARKLEY

Dynamics of ocean currents, waves, tides and seiches, ocean-atmosphere interaction processes, methods of solving problems in physical oceanography.

601 OCEANOGRAPHIC FORECASTING

LAEVASTU, (COX WOOLLARD)

Forecasting of waves and surface currents; sea and weather routing of ships, meteorological services; application of various forecasts in navigation, fisheries and marine engineering. 
675 OCEANOGRAPHIC INSTRUMENTATION, LABORATORY RESEARCH AND FIELD WORK

Description and demonstration of oceanographic instruments and observation practices. Laboratory exercises and treatment of oceanographic data. Sea practice on research vessels arranged through the Department.

684 PROBLEMS IN OCEANOGRAPHY

LAEVASTU

Study of selected subjects in all fields of oceanography. Preparation of term papers required (review or analyses of available data).

In addition to the specific courses in oceanography, courses in meteorology treat some complementary subjects in oceanography (e.g., hydrodynamics, etc.)

\section{DEPARTMENT OF BOTANY}

Instructional Staff:

M. S. Doty, Ph.D., Professor of Botany

Degrees offered:

Master of Science in Botany

Doctor of Philosophy in Botany

Courses:

586 BIOLOGICAL PRODUCTIVITY OF THE SEA

DOTY, (LAEVASTU)

Qualities and functions of the sea; relationship to marine organisms.

681 PHYCOLOGY-CHLOROPHYTA

DOTY

Systematics, function, and utilization considered at an advanced level.

682 PHYCOLOGY-PHYTOPLANKTON

DOTY

Systematics, functions, and utilization considered at an advanced level.

683 PHYCOLOGY-MYXOPHYTA AND PHAEOPHYTA

DOTY

Systematics, functions and utilization considered at an advanced level. 
684 PHYCOLOGY-RHODOPHYTA

DOTY

Systematics, functions, and utilization considered at an advanced level.

\section{DEPARTMENT OF CHEMISTRY}

Instructional Staff:

Harry Zeitlin, Ph.D., Associate Professor of Chemistry

Degrees Offered:

Master of Science in Chemistry (research in problems related to the marine environment)

Doctor of Philosophy in Chemistry (research in problems related to the marine environment)

Courses:

580 OCEANOGRAPHIC CHEMISTRY

A theoretical and descriptive study of the chemistry of the oceans and practice in the standard analytical methods important to chemical oceanography.

DEPARTMENT OF GEOLOGY

Instructional Staff:

Theodore Chamberlain, Ph.D., Assistant Professor of Geology

Ralph M. Moberly, Ph.D., Assistant Professor of Geology

Degrees offered:

M.S. Degree in Geological Sciences

$\mathrm{Ph} . \mathrm{D}$. Degree in Geological Sciences

Courses:

470 MARINE GEOLOGY

CHAMBERLAIN

A survey of marine geologic processes and forms. Field work involving marine geologic equipment and techniques.

671 NEARSHORE MARINE PROCESSES CHAMBERLAIN

Waves, tides, currents, winds and their effects upon beaches and nearshore sediments. 
672 SEMINAR IN GEOLOGY OF OCEAN BASIN

MOBERLY

Structure, topography, sediments, and history of islands, ocean basins, and continental margins.

673 PRINCIPLES OF SEDIMENTOLOGY

CHAMBERLAIN

Physics of erosion, transportation and deposition. Statistical and other analytical procedures applicable to sediments.

674 SEDIMENTARY PETROGRAPHY AND STRATIGRAPHY

MOBERLY

Composition of carbonate and other sediments and sedimentary rocks; interpretation of their variation. Methods of study.

DEPARTMENT OF ZOOLOGY

Instructional Staff:

Albert H. Banner, Ph.D., Professor of Zoology, Director, Hawaii Marine Laboratory

George W. Chu, D.Sc., Professor of Microbiology and Zoology

Hubert W. Frings, Ph.D., Professor of Zoology William A. Gosline, Ph.D., Professor of Zoology Sidney C. Hsiao, Ph.D., Professor of Zoology Fred I. Kamento, Assistant Professor of Zoology Donald C. Matthews, Ph.D., Proffesor of Zoology Barry S. Muir, Ph.D., Assistant Professor of Zoology Ernest S. Reese, Ph.D., Assistant Professor of Zoology Albert L. Tester, Ph.D., Senior Professor of Zoology, Chairman of the Department.

Sidney J. Twonsley, Ph.D., Associate Professor of Zoology Pieter Van Weel, Ph.D., Professor of Zoology

Affiliate Staff:

Philip Helfrich, Ph.D., Assistant Director, Hawaii Marine Laboratory

John C. Marr, M.A., Area Director, Honolulu Biological Laboratory, U. S. Bureau of Commercial Fisheries Michio Takata, M.S., Director, State Division of Fish and Game 
Degrees Offered:

Master of Science in Zoology, including Marine Zoology

Doctor of Philosophy in Marine Zoology.

Upper Division Courses in Marine Biology:

425 MICROTECHNIQUE

MATTHEWS

Fixing, staining, mounting of tissues, entire animals and organs.

431 BIOMETRY

TESTER

Elementary statistical methods; confidence interval chi-square, t-test, normal distributions, regression, correlation.

432 ADVANCED BIOMETRY

TESTER

Analysis of variance and covariance, curvilinear regression, multiple correlation, design of experiments.

525-526 GENERAL ICHTHYOLOGY

GOSLINE

First semester: anatomy, physiology, ecology, distribution. Second semester: classification with reference to Hawailan species.

Graduate Courses:

603 ZOOGEOGRAPHY

Animal distributions; physiographic, climatic and historic factors.

606 COMPARATIVE ANIMAL BEHAVIOR

Physiological basis, ontogenetic and phylogenetic origins, and categories of behavior. A study of innate, learned, and social behavior with emphasis on the innate behavior of marine species. 
607 PHYSIOLOGICAL BASES OF ANIMAL BEHAVIOR

Sensory, neural, and endocrine determinants of animal behavior patterns and communication.

615-616 ADVANCED INVERTEBRATE ZOOLOGY

TOWNSLEY

Comparative morphology, development, taxonomy and phylogeny of invertebrate animals. Identification and classification of reef and shore fauna.

620 MARINE ECOLOGY REESE

Natural history, behavior, and relation of invertebrates and fishes to environment.

621 PHYSIOLOGICAL ECOLOGY

VAN WEEL

Physiological adaptations to environmental, physical, and biotic features.

622 ISOTOPIC TRACERS IN BIOLOGY TOWNSLEY

Chemical and physical features of radioactive isotopes used in biological work. Methods of detection; application to biological systems.

629 METHODS OF FISHERY INVESTIGATION MUIR

Determining age, growth, spawning success, and life history of fish; emphasis of marine species of the Pacific.

631 POPULATION DYNAMICS

Fundamentals of population growth, mortality and equilibrium. Consideration of mathematical models developed for various animal populations, including man.

646 COMPARATIVE INVERTEBRATE PHYSIOLOGY VAN WEEL

Life processes with emphasis on marine invertebrates.

691 SEMINAR IN MARINE ZOOLOGY STAFF

Reports on research or reviews of literature. 
Investigations and literature pertaining to fisheries biology; stress on problems relating to pelagic fisheries of the Pacific.

699 DIRECTED RESEARCH

Directed research and reading in various fields of $200 \log y$.

732 FISHERIES MANAGEMENT

MUIR

Methods of estimating vital statistics of fish populations. Optimum sustainable yields and management problems, particularly of marine fisheries. 


\author{
University of Houston \\ Houston, Texas
}

The University of Houston offers extensive course work in geology, the other basic sciences, and mathematics; but does not offer courses specifically in marine science except in support of the other fields. However, arrangements can be made for students who prepare themselves in the basic disciplines at Houston to take specialized courses and initiate thesis research at established marine laboratories. Since the University of Houston is particularly well located for studies of coastal sediments, emphasis is placed on instruction in sedimentation, sedimentary petrography, and invertebrate paleontology.

\title{
DEPARTMENT OF GEOLOGY
}

Instructional Staff: (for courses listed below)

Paul H. Fan, Ph.D., Professor

Harvey Blatt, Ph.D., Asst. Professor

Vernon E. Briard, Ph.D., Lecturer

Robert Greenwood, Ph.D., Assoc. Professor

Gene Ross Kellough, M.S., Lecturer

J. Robert Moore, III, M.S., Lecturer

E. H. Rainwater, M.S., Lecturer

Anthony Reso, Ph.D., Lecturer

Adam Thomas, B.S., Lecturer

DeWitt C. Van Siclen, Ph.D., Chairman \& Assoc. Prof.

Degrees Offered:

Bachelor of Science and Master of Science

Courses Offered:

333 GEOMORPHOLOGY

Fan

335 INVERTEBRATE PALEONTOLOGY

Reso

431 EARTH PHYSICS

Briard 


$\begin{array}{lll}436 & \text { INTRODUCTORY MICROPALEONTOLOGY } & \text { Kellough } \\ 460 & \text { PRINCIPLES OF STRATIGRAPHY } & \text { Fan } \\ 639 & \text { MARINE GEOLOGY } & \text { Moore } \\ 660 & \text { GEOCHEMISTRY } & \text { Greenwood } \\ 670 & \text { AIR-PHOTO GEOLOGY } & \text { Thomas } \\ 680 & \text { SEDIMENTATION } & \text { Blatt } \\ 682 & \text { SANDSTONE PETROGRAPHY } & \text { Blatt } \\ 683 & \text { CARBONATE PETROGRAPHY } & \text { Blatt } \\ 686 & \text { TECTONICS } & \text { Van Siclen } \\ 690 & \text { ADVANCED INVERTEBRATE } & \\ & \text { PALEONTOLOGY } & \text { Reso } \\ 692 & \text { ADVANCED MICROPALEONTOLOGY } & \text { Rainwater } \\ 694 & \text { PALEOECOLOGY } & \\ 696 & \text { ADVANCED STRATIGRAPHY } & \end{array}$

For Information Contact:

Dr. DeWitt C. Van Siclen

Chairman, Department of Geology

University of Houston

3801 Cullen Boulevard

Houston 4, Texas 


\author{
Humboldt State College \\ Arcata, California
}

The marine science program at Humboldt State College offers instruction and research in marine fisheries, physical, chemical and biological oceanography as well as the marine aspects of zoology, botany, and ecology. Project research is under way in the areas of water pollution, atomic waste disposal in the sea, water quality and flushing action of Humboldt Bay, as well as oceanographic and biological studies of the waters off the Humboldt coast. Present facilities include saltwater aquaria, water chemistry laboratory, ichthyology laboratories, zoology and botany classrooms and laboratories. A 40-foot research vessel equipped with standard oceanographic and biological instrumentation is also available. A marine sciences laboratory with a modern saltwater system will be constructed at Trinidad, California, in 1963-64.

\title{
DIVISION OF NATURAL RESOURCES
}

Marine Fisheries and Oceanography

Instructional Staff:

Ernest 0. Salo, Ph.D., Chairman, Division of Natural Resources, Associate Professor of Fisheries John W. DeWitt, M.S., Coordinator of Fisheries, Associate Professor of Fisheries

George H. Allen, Ph.D., Associate Professor of Fisheries Richard L. Ridenhour, Ph.D., Assistant Professor of Fisheries James A. Gast, Ph.D., Assistant Professor of Oceanography

Degrees Offered:

Bachelor of Science in Fisheries

Master of Science in Fisheries

Courses:

Fisheries

125 FIELD PROBLEMS

Individual work on specific problems involving marine fisheries and oceanography.

132 COMMERCIAL FISHERIES

RIDENHOUR

Enumeration, dynamics and age and growth of fish populations. 
$136 \mathrm{~A}$,

136B. ICHTHYOLOGY

ALLEN

Evolution, Distribution, migration, anatomy and physiology of fishes. Classification of groups that are of economic and recreational importance.

143 PROBLEMS IN WATER POLLUTION AND DeWITT SANITATION BIOLOGY

Scope, magnitude, nature and significance of water resources and pollution. Sources and nature of common pollutant materials. Detection, surveillance, and abatement of water pollution.

220 ADVANCED PRINCIPLES OF FISHERIES MANAGEMENT

STAFF

New and advanced theories, principles and techniques in fisheries management.

225 ADVANCED FIELD PROBLEMS

STAFF

Directed field experience in individual problems.

290

THESIS

STAFF

298 SEMINAR IN FISHERIES MANAGEMENT

STAFF

Oceanography.

100 GENERAL OCEANOGRAPHY

GAST

Introduction to general oceanography including the study of the ocean basins of the world; the chemistry of sea water; the causes of the major ocean currents, and the tides and waves.

101 BIOLOGICAL OCEANOGRAPHY

GAST, SALO

Studies of the basic biological production of the sea including theory and use of Carbon 14 and other radioactive tracers; qualitative and quantitative determinations of plankton production including analysis of the non-conservative elements involved.

Physical processes of the seas including theory and practice of current determinations, theory of waves and tides, distribution of variables in the sea and analysis of bottom sediments. 
103

CHEMICAL OCEANOGRAPHY

GAST

Determination of various constituents including some of the minor elements of importance in the physical, chemical, and biological processes of the sea.

Biology

40

ELEMENTARY BIOMETRICS

RIDENHOUR, SALO

Statistical methods as used in the study of biological populations.

DIVISION OF BIOLOGICAL SCIENCES

Instructional Staff:

William M. Lanphere, Ph.D., Chairman, Division of Biological Sciences

Warren J. Houck, Ph.D., Associate Professor of Zoology Fred Telonicher, A.B., Professor of Zoology

William C. Vinyard, Ph.D., Assistant Professor of Botany

Degrees offered:

Bachelor of Arts degree in Biology

Master of Arts degree in Biology

Bachelor of Arts degree in Botany

Bachelor of Arts degree in 20ology

Courses:

\section{Biology}

101 MARINE ECOLOGY

TELONICHER, HOUCK

The habits, classification, development, and adaptations of marine life, with particular reference to the ecology of the Humboldt coast.

199 INDEPENDENT STUDY

STAFF

299 INDEPENDENT STUDY

STAFF

Botany

112 INTRODUCTION TO PHYCOLOGY

VINYARD

Comparative morphology, taxonomy and ecology of the freshwater and marine algae. 
199 INDEPENDENT STUDY

212 ADVANCED PHYCOLOGY

Taxonomy, life histories, and relationships of the marine algae of the Pacific Coast.

299 INDEPENDENT STUDY

\section{Zoology}

112 INVERTEBRATE ZOOLOGY

TELONICHER

A study of animals without backbones, with special reference to the natural history and classification of the animals of the seashore.

199 INDEPENDENT STUDY

212 ADVANCED MARINE BIOLOGY

An advanced course dealing with problems in marine ecology, classification, and life histories.

299 INDEPENDENT STUDY

For Information Contact:

Dr. Ernest 0. Salo

Chairman, Division of Natural Resources

Humboldt State College

Arcata, California 
The Johns Hopkins University

Baltimore 18, Maryland

\section{DEPARTMENT OF OCEANOGRAPHY}

The Johns Hopkins University offers a broad program of advanced study and research in physical, chemical and biological oceanography. Facilities shared with the affiliated Chesapeake Bay Institute include modern chemical and biological laboratories, instrument development laboratory and shop, dark room, drafting and data reduction facilities. and library; the Annapolis field laboratory, where research vessels are docked, has an instrument laboratory, chemical preparation room, wood-and metal-working shop, storage and maintenance facilities.

A new oceanography building on campus is scheduled for completion in 1964. Additional space will permit extension of staff activities into geological oceanography and air-sea interaction studies. Funds have been obtained to build a 150-ton catamaran-hulled research ves̀sel.

Instructional Staff:

Donald W. Pritchard, Ph.D., Professor of Oceanography, Chairman. of the Department and Director of Chesapeake Bay Institute (physical oceanography; estuarine dynamics)

Raymond B. Montgomery, Sc.D., Professor of Oceanography (physical oceanography)

James H. Carpenter, Ph.D., Assistant Professor of Oceanography (chemical oceanography)

Blair Kinsman, Ph.D., Assistant Professor of Oceanography (physical oceanography; wind waves)

Walter Rowland Taylor, Ph.D., Assistant Professor of Oceanography (biological oceanography)

E. Dixon Stroup, M.S., Lecturer and Research Staff Assistant (physical oceanography)

Degrees offered:

Master of Arts in Oceanography

Doctor of Philosophy in Oceanography 
Courses:

Courses 303, 601-602, 616 and 624 are offered in alternate years with 603,605-606, 611-612 and 626. The latter are among the courses available in 1963-64.

General:

301 INTRODUCTION TO OCEANOGRAPHY-GENERAL

STROUP

A broad description of the marine environment including characteristics of sea water and theories of ocean currents. An elementary presentation especially for students in science and engineering: not applicable toward a minor in oceanography for the Ph.D. degree.

611-612 SEMINAR IN OCEANOGRA PHY

STAFF

Required of all students in the department.

614 ASPECTS OF MARINE GEOLOGY FOR OCEANOGRAPHERS

PRITCHARD

Directed reading and conference course.

615 RESEARCH PROBLEMS IN OCEANOGRAPHY

STAFF

Independent research for the $\mathrm{Ph} . \mathrm{D}$. dissertation. Open to candidates for the $\mathrm{Ph} . \mathrm{D}$. degree.

\section{Physical Oceanography}

601-602 PHYSICAL OCEANOGRAPHY

MONTGOMERY

Both geographic and hydrodynamic aspects of oceanography are stressed. Topics: instruments; relief of the ocean floor: observed distributions of temperature, salinity and currents; physical properties of sea water; heat and light; scalar and vector fields; kinematics; hydrostatics; momentum dynamics; vorticity dynamics; viscosity; Ekman's studies of currents; eddy flux; map projections. Practice is provided in analysis of oceanographic data.

605-606 WAVES AND TIDES

KINSMAN

Theory of surface and internal waves; wave forecasting; transformation of waves in shallow water. Tide theory; analysis and prediction of tides and tidal currents.

Modern theories of wind wave generation, dissipation and energy transfer on the ocean surface. 
Physical and chemical properties of estuarine waters, including the kinematics and dynamics of motion. Classification of estuaries by geomorphological and oceanographic parameters.

A review of the current literature on the theoretical aspects of physical and meteorological oceanography.

\section{Chemical Oceanography}

624 CHEMISTRY OF SEA WATER

\section{CARPENTER}

The composition of sea water; the carbon dioxide system; nutrients: laboratory work dealing with the chemical methods of analysis in routine use in oceanography; assembly and correlation of chemical data.

625 ADVANCED CHEMICAL OCEANOGRAPHY

CARPENTER

Detailed examination of the chemical and physico-chemical aspects of the nutrient systems, the interaction between the bottom and overlying water, and of minor constituents. Review of modern analytical methods with limited laboratory work.

\section{Biological Oceanography}

303 MARINE ECOLOGY

TAYLOR

General survey of the populations in marine and estuarine waters. The relationships of physical, chemical and biological factors of the environment to these organisms is discussed. Limited field work included. Permission of instructor required for undergraduate students.

616 BIOLOGICAL OCEANOGRAPHY

TAYLOR

Consideration of the sea and estuaries as biological environments. Emphasis is placed on marine microbiology, especially phytoplankton and zooplankton. Selected topics in algal physiology and nutrition, biochemistry of photosynthesis, primary productivity in marine waters, and bottom communities and their relation to the plankton are discussed. The course is designed for students intending to pursue advanced studies in the biological or chemical phases of oceanography. 
620 ADVANCED BIOLOGICAL OCEANOGRAPHY

TAYLOR

Directed reading and discussion of selected topics from current literature.

\section{MARINE MICROBIOLOGY}

Studies of marine and estuarine microorganisms including bacteria, fungi, and unicellular algae such as dinoflagellates and diatoms. Included are discussions of the morphology, taxonomy and certain aspects of physiology, biochemistry, nutrition and bioluminescence of these organisms. Laboratory and field work emphasize isolation and culturing techniques that are unique to the study of marine microorganisms.

A wide variety of pertinent courses is available in other departments, including meteorology, fluid mechanics, mechanics of perfect fluids, mechanics of viscous fluids, turbulence, mechanics of gravity waves, and geophysical fluid mechanics, all in the Department of Mechantes; limnology and properties and behavior of water, in the Department of Sanitary Engineering and Water Resources.

For Information Contact:

Susan S. Raup

Assistant to the Chairman

Department of Oceanography

Johns Hopkins University

Baltimore 18, Maryland 


\author{
Louisiana State University \\ Baton Rouge 3 , Louisiana
}

Louisiana State University does not offer courses in marine science at its Baton Rouge campus. Sumer courses in marine biology at Gulf Coast Research Laboratory, Ocean Springs, Mississippi, are offered to LSU students.

\title{
Coastal Studies Institute
}

The Coastal Studies Institute is not an academic department. Its research activities are oriented toward geographic, geologic, biologic, and ecologic basic investigations in various parts of the world. To a very limited extent advanced graduate students may be provided field experience necessary for doctoral degrees in academic departments. Areas of interest are likely to start in water no more than 5 fathoms deep and to extend inland only as far as land may be characterized as "coastal." More detailed information may be obtained from the Director, Coastal Studies Institute, LSU, Baton Roge 3, Louisiana. 
Massachusetts Institute of Technology

Cambridge 39, Massachusetts

Graduate education in oceanography is centered in the Department of Meteorology and the Department of Geology and Geophysics, but many pertinent subjects are offered by other M.I.T. departments. Students may also take subjects offered by Harvard University under the cooperative arrangements existing between the two institutions. Close scientific cooperation is maintained with the Woods Hole Oceanographic Institution and several of their senior scientific staff hold part-time appointments at M.I.T. Arrangements may usually be made for students to use the excellent experimental facilities and research vessels at Woods Hole when this is desirable. Special summer courses and summer research appointments are offered by the Woods Hole Oceanographic Institution on a competitive basis. Those interested in these opportunities should write to the Director of the Woods Hole Oceanographic Institution, Woods Hole, Massachusetts.

\section{DEPARTMENT OF -GEOLOGY AND GEOPHYSICS}

\section{Instructional Staff:}

Robert R. Shrock, Ph.D., Professor and Head of Department Columbus O'D. Iselin, D.Sc., Professor (part-time) of Oceanography

William S. Von Arx, Sc.D., Professor of Physical Oceanography Dayton E. Carritt, Ph.D., Professor of Chemical Oceanography Ely Mencher, Ph.D., Professor (part-time) of Geophysical Oceanography

William H. Dennen, Ph.D., Associate Professor of Mineralogy and Physical Geology

John W. Winchester, Ph.D., Associate Professor of Geochemistry

John W. Kanwisher, Ph.D., Assistant Professor of Biophysics

Degrees offered:

Master of Science in Oceanography

Doctor of Philosophy in Oceanography

\section{Courses:}

12.60 OCEANOGRAPHY I

STAFF

Introduction to different aspects of the oceans and their relations to the atmosphere, solid earth, and marine life. Lectures varying from term to term and given by staff members from both M.I.T. and the Woods Hole Oceanographic Institution. (Hersey, Iselin, Kanwisher, von Arx) 


\subsection{CHEMICAL OCEANOGRAPHY I}

Study of the chemical systems in the oceans; the composition of sea water; the density-chlorinitysalinity relationships; the carbon dioxide system; the nutrient systems; dissolved gases; the routes and rates of material and energy transfer between hydrosphere, biosphere, and geosphere. Discussion of the methods of measurement of the dissolved substances in sea water.

\subsection{SEMINAR IN CHEMICAL OCEANOGRAPHY}

Readings in the contemporary literature and discussion of several topics chosen to fit the backgrounds, fields of study, and interests of the participants. Topics in which chemical data are used in the interpretation of natural processes in the sea, such as carbon 14 dating in marine sediments in sea water; exchange of carbon dioxide (and other gases) across the sea surface; rates of physical, biological and geological processes in the oceans as inferred from chemical data; discussion of chemical species in natural fresh and salt waters.

The following courses in geology and geophysics are recommended by the Department for work towards a degree in oceanography:

$\begin{array}{ll}12.011 & \text { MINERALOGY I } \\ 12.012 & \text { MINERALOGY II } \\ 12.14 & \text { PETROLOGY } \\ 12.15 & \text { PETROLOGY LABORATORY } \\ 12.301 & \text { PHYSICAL GEOLOGY } \\ 12.302 & \text { HISTORICAL GEOLOGY } \\ 12.308 & \text { SEDIMENTATION AND STRATIGRAPHY I } \\ 12.309 & \text { SEDIMENTATION AND STRATIGRAPHY II } \\ 12.583 & \text { SEDIMENTOLOGY SEMINAR } \\ 12.811 & \text { GEOCHEMISTRY I } \\ 12.812 & \text { GEOCHEMISTRY II }\end{array}$

12.82 SPECTROCHEMICAL ANALYSIS
DENNEN

DENNEN

FAIRBAIRN

FAIRBAIRN

DENNEN

MENCHER

MENCHER

MENCHER

SHROCK, MENCHER

WINCHESTER

WINCHESTER

DENNEN 
12.831 ELEMENTS OF GEOPHYSICS I

12.832 ELEMENTS OF GEOPHYSICS II

12.833 GEOPHYSICAL LABORATORY
GREENEWALT, MADDEN

GREENEWALT, MADDEN

GREEREWALT

For Information Contact:

Dr. Robert R. Shrock

Head, Department of Geology and Geophysics

Room 24-302

Massachusetts Institute of Technology

Cambridge 39, Massachusetts

\section{DEPARTMENT OF METEROLOGY}

Instructional Staff:

Henry G. Houghton, Sc.D., Professor and Head of Department Jule G. Charney, Ph.D., Professor

Victor P. Starr, Ph.D., Professor

Delbar P. Keily, S.B., Associate Professor

Norman A. Phillips, Ph.D., Associate Professor

George Veronis, Ph.D., Associate Professor (part-time)

Degrees offered:

Master of Science in Oceanography

Doctor of Philosophy in Oceanography

Doctor of Science in Oceanography

Courses:

19.67 PLANETARY FLUID DYNAMICS

CHARNEY

Discussion of fluid dynamical problems on the planetary scale with examples drawn from the atmosphere, the oceans and the interior of the earth. Convectively driven circulations in rotating systems and high-speed computational methods for the solution of the governing equations.

19.83T PHYSICAL OCEANOGRAPHY

HOUGHTON

Structure and physical properties of the oceans. Methods of measurement and an outline of the observational information. Dynamics of oceanic current systems. Wind currents, waves and tides. 
19.84 DYNAMIC OCEANOGRAPHY

STARR, PHILLIPS

Hydrodynamics of planetary fluid flow. Restatement of various principles of classic fluid mechanics in a form useful in oceanography with special emphasis on the Coriolis and other effects of the earth's rotation. Classic theories of Ekman and others for ocean currents, and the energy balance for the oceans.

19.89 SPECIAL PROBLEMS IN OCEANOGRAPHY

STAFF

Reading, consultation, and original investigation on oceanographic problems.

The following courses in meteorology are regularly taken by students of oceanography:

19.003 ELEMENTARY METEOROLOGY I

AUSTIN

19.22 METEOROLOGICAL INSTRUMENT

KEILY

19.34 STATISTICAL METHODS IN METEOROLOGY

LORENZ

19.35 STATISTICAL PROBLEMS IN METEOROLOGY

LORENZ

19.44 SYNOPTIC METEOROLOGY II

SANDERS

19.51 SYNOPTIC LABORATORY I

SANDERS

19.601 INTRODUCTION TO THEORETICAL METEOROLOGY

PHILLIPS

19.62 DYNAMIC METEOROLOGY I

LORENZ

19.64 DYNAMIC METEOROLOGY II

STARR

19.72 PHYSICAL METEOROLOGY

HOUGHTON

The following courses in other departments are considered pertinent to the Department's program in oceanography:

18.60 INTRODUCTION TO FLUID MECHANICS

BENNY

18.62 HYDRODYNAMIC STABILITY AND TURBULENCE

LIN

1.65 FREE SURFACE FLOW

IPPEN

1.681 EXPERIMENTAL HYDROMECHANICS

HARLEMAN

1.682 EXPERIMENTAL HYDROMECHANICS

HARLEMAN

1.683 EXPERIMENTAL HYDROMECHANICS

HARLEMAN 
For Information Contact:

Dr. Henry G. Houghton Head, Department of Meteorology Room 24-514

Massachusetts Institute of Technology Cambridge 39, Massachusetts 


\author{
University of Miami \\ Coral Gables 46, Florida
}

\title{
INSTITUTE OF MARINE SCIENCES
}

The Institute embraces both the Marine Laboratory, which conducts research in marine science, and the Department of Marine Sclence, which provides academic instruction. The Laboratory employs a 176foot converted cargo vessel, a 78-foot research vesse1, a 36-foot catamaran, and several small motor vessels. Other facilities include extensive laboratory space, the Marine Blological Museum, a large library, etc.

Training is offered primarily to graduate students although a few strictly undergraduate courses are taught. Students who show research abllity and meet the necessary requirements may take part in Investigations being carried on as part of the Marine Laboratory's program.

\section{Instruct lonal Staff:}

EGENE CORCORAN, Ph.D., Assistant Professor of Marine Blochemistry

CESARE EMILIANI, Ph.D., Research Associate Professor of Marine Geology

LEONARD GREENFIELD, Ph.D., Research Assistant Professor

HOMER W. HISER, Ph.D., Research Associate Professor of Meteorology and Head, Meteorological Research Laboratory

CLARENCE P. IDYLL, Ph.D., Professor of Marine Blology and Chairman, Division of Fishery Sciences

EDNIN S. IVERSEN, Ph.D., Research Assistant Professor

ALBERT C. JONES, Ph.D., Research Assistant Professor

FRITZ F. KOCZY, Ph.D., Professor of Marlne Sciences, Chairman, Division of Physical Sciences

CHARLES E. LANE, Ph.D., Professor of Marine Sciences

SAMUEL P. MEYERS, Ph.D., Research Associate Professor

HILARY B. MOORE, Ph.D., Professor of Marine Biology and Assistant Director of the Marine Laboratory

CARL H. OPPENHEIMER, Ph.D., Research Associate Professor

HARDING OWRE, Ph.D., Research Assistant Professor

C. RICHARD ROBINS, Ph.D., Research Assoclate Professor and Chairman, Department of Marine Sciences

GENE A. RUSNAK, Ph.D., Research Associate Professor

F. G. WALTON SMITH, Professor of Oceanography and Director of the Institute of Marine Science

GILBERT L. VOSS, Ph.D., Research Professor of Marine Blology and Chatrman, Division of Biological Sciences

ROBERT H. WILLIAMS, Ph.D., Professor of Botany and Marine Sciences WARREN WISBY, Ph.D., Research Associate Professor 
Degrees Offered:

Master of Science in Fisheries, Marine Biology and Oceanography Doctor of Philosophy in Fisheries, Marine Blology and Oceanography

Courses:

\section{Flsheries}

G501. FISHERY BIOLOGY AND MANAGEMENT I

The sclence of fishery blology; methods of appraisal and Investigation of populations of aquatic animals of commercial and game importance; fishing methods; catch statistics; the sampling of fish and invertebrate populations; theory and procedures in tagging and in age and growth studies.

G502. FISHERY TECHNOLOGY

Preservation of fish; tests of quality; processing and transportation of fishery products.

G521. SALTWATER POLLUTION TECHNOLOGY

Methods of biological, chemical, and physical analysis of saltwater bays and estuaries for industrial and other pollut1on. The principal types of pollution and their effects upon marine life, with emphasis on the shellfish and scale fish populations. Preventive and corrective measures.

The following courses are open only to graduate students.

602. FISHERY SEMINAR

604. FISHERY BIOLOGY AND MANAGEMENT II

Continuation of Fishery 501. Studies of growth; migrations; Iife histories; natural fluctuations in abundances and dynamics of exploited populations; management of fisheries.

605. POPULATION ENUMERATION AND DYNAMICS

Advanced theory and methods of estimating the sizes of populations of invertebrates and fishes; effect of fishing on the abundance and yleld from animal stocks.

671,672,673,674,675. ADVANCED STUDY IN FISHERIES

Supervised reading and study in areas of special interest to advanced students. 
681,682. FISHERY RESEARCH

Advanced research. Research 600,700 toward master's thesis or doctoral dissertation.

\section{Marine Biology}

204. INTRODUCTION TO MARINE BIOLOGY

Introduction to the biology of the common marine animals and plants of the shore, coral reefs, and open ocean. Nature of the enviromment. Economic applications, Including commercial fisheries, and relations to other marine sciences. Laboratory study and field observations of subtropical marine organisms from diving helmets, shore collecting and dredging.

\section{GENERAL MARINE BIOLOGY}

Anatomy, classification, and identification of marine organisms, mainly as typified by Florida examples. The mechanism and physiology of reproduction, respiration, feeding, and locomot1on. Parasitism, symbiosis, and other aspects of the natural history of marine organisms. Study of the literature of current research in marine blology.

512. PHYCOLOGY

The morphology, taxonomy, physiology, and ecology of marine algae including phytoplankton.

531. MARINE MICROBIOLOGY

Taxonomy, physiology and ecology of marine microorganisms. Blochemical considerations and economic significance.

\section{MARINE BIOCHEMISTRY}

Blochemistry of organisms, water and sediment in the marine enviroment. Lecture, 3 hours; demonstrations.

The following courses are open only to graduate students.

602. MARINE BIOLOGY SEMINAR

621. TAXONOMY OF MARINE INVERTEBRATES

The classification, anatomy, and life histories of marine invertebrates. Detailed studies of a selected group from material collected in the Florida area. Lecture, 2 hours: laboratory, 4 hours; field trips. 
622. ECOLOGY OF MARINE ANTMALS

Types of environment in the ocean, with special reference to shallow tropical seas; the relation of distributious to the physical and chemical environment; effects of environmental changes; breeding cycles; plankton and food chains, causes of population fluctuations. Application of ecological techniques to local problems.

623. INVERTEBRATE EMBRYOLOGY

Early development of invertebrates including the protochordates, life histories, larval stages, and metamorphoses of the principal types and their evolutionary significance; larval adaptation, methods and techniques.

625. BEHAVIOR OF MARINE ORGANISMS

Sensory physiology; acuity and sensitivity of marine organisms, and their sensory adaptation to various marine environments. Sound production and its significance in communication; social behavior; predator-prey relationships. Field trips will stress comparative behavior of local species.

\section{PLANKTON}

The drifting organisms, the influence of environment factors upon them, their place in the conomy of the sea and freshwater habitats, and their relation to fisheries.

634. PHYSIOLOGY OF MARINE ORGANISMS

Osmotic regulation, behavior, feeding, metabolism, nerve and muscle function, endocrines, blood chemistry, excretion.

$671,672,673,674,675$. ADVANCED STUDY IN MARINE BIOLOGY

Supervised reading and study in areas of special interest to advanced students.

681,682. MARINE BIOLOGICAL RESEARCH

Advanced research.

686. BIOLOGY OF MARINE FISHES

Special emphasis on tropical species. Field work devoted to individual research in food habits, development, growth, behavior, physical and chenical tolerances, parasites, and physlology of local fishes. 
687. SYSTEMATICS OF MARINE FISHES

Classification and evolution of the major groups of fishes, with emphasis on the family level and higher. Current research and literature on modern groups. Speciation, zoogeography, methods. One credit problem in directed research and methods on local marine species optional. Research 600 , 700 toward master's thesis or doctoral dissertation.

\section{Oceanography}

203. INTRODUCTION TO OCEANOGRAPHY

An introduction to the physical nature of the ocean, its topography and circulation. Chemical nature of ocean water. Bottom deposits. Relation to biological, geographical, geological and economic problems, including fisheries.

501. GENERAL OCEANOGRAPHY

Physical properties and chemical composition of sea water, and relationships to activities of plants and animals; main features of the physics of the oceans; quantitative chemical and physical methods in the laboratory; use of oceanographic instruments in the field.

511. DESCRIPTIVE OCEANOGRAPHY

Theory of oceanographic measurements; preparation and direction of cruises; description of water masses in the ocean particularly the Gulf of Mexico, the Caribbean Sea and the equatorial Atlantic; the current system of the ocean.

531. RADAR METEOROLOGX

The essential fundamentals of radar; the operational and research uses of radar meteorological data, their derivation from radarscope interpretation, and actual radar operation.

533. DYNAMIC METEOROLOGY

The thermodynamic and hydrodynamic princlples for the understanding of the physical behavior of the atmosphere and its motions.

\section{GEOCHEMISTRY}

Distribution of chemical elements and significant compounds in nature, and their major and minor cycles. Geochemical processes in the lithosphere, the atmosphere, and the ocean. The chemical interrelations between organisms and their enviroment. 


\section{GEOPHYSICS}

The physical properties of the interior of the earth, with emphasis on seismology, magnetism and gravimetry. The interrelation between land, ocean and atmosphere. Lecture, 3

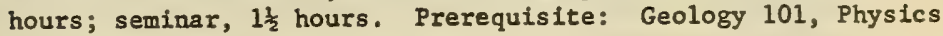
235, and permission of instructor.

551. MARINE GEOLOGY

Geological aspects of the oceans and their basins. Marine processes and features including sedimentation, erosion, shorelines, bottom topography, and geochemistry considered in relation to their present-day significance and the interpretation of the geological past.

581,582. SUPERVISED PROJECTS

Students engaging in certain approved field activities, such as active participation in expeditions under proper supervision, may register for credit.

The following courses are open only to graduate students.

601. MARINE SCIENCE SEMINAR

602. OCEANOGRAPHY SEMINAR

603. SPECIAL WORK

Special work to enrich the student's background according to qualification requirements.

610. CHEMICAL OCEANOGRAPHY

Ocean chemistry; relation to hydrodynamica1, physical, meteorological, geological, and blological problems. Special methods in quantitative determination of inorganic and organic constituents.

621. DYNAMIC OCEANOGRAPHY

Starting from principles of mechanics, dynamics and thermodynamics, deductions are made relating to the movement of the water of the ocean.

622. TIDES AND WAVES

General wave equation and the theory of tides; special application to all wave types in the ocean, including seiches and internal waves; prediction of waves, origin and decay of waves. 
630. ADVANCED SEDTMENTATION

Advanced studies in the processes and products of sedimentation with special emphasis upon the mechanics of sediment transport, deposition and subsequent modification. Includes studies of texture, structures and composition of ancient and modern sediments.

$671,672,673,674,675$. ADVANCED STUDY IN OCEANOGRAPHY

Supervised reading and study in areas of special interest to advanced students. 
University of Michigan

Ann Arbor, Michigan

\section{INTERDEPARTMENTAL COMMITTEE ON OCEANOGRAPHY}

Work in oceanography at the University of Michigan is not concentrated in a single department; student progress is supervised by the Interdepartmental Committee on Oceanography, which has cognizance over work toward advanced degrees and determines requirements for each student on an individual basis. The members of the Committee are:

John C. Ayers, Ph.D., Research Oceanographer, Chairman D. C. Chandler, Ph.D., Professor of Zoology

E. W. Hewson, Ph.D., Professor of Meteorology

J. T. Wilson, Ph.D., Professor of Geology

F. C. Michelson, Ph.D., Assistant Professor of Naval Architecture

Research and training in aquatic sciences is given by the Departments of Botany, Civil Engineering, Engineering Mechanics, Environmental Health, Fisheries, Geology, and Zoology, divisions of Ichthyology and Malacology of the University Museum, and by the Great Lakes Research Division of the Institute of Science and Technology. Also on campus and participating in research and training are the Institute for Fisheries Research (Michigan Department of Conservation), the Great Lakes Commission (an Interstate agency), the U.S. Bureau of Commercial Fisheries, and the Great Lakes Fishery Commission (a U.S.-Canada agency). The Great Lakes Research Division has three research vessels of 114 feet, 50 feet, and 34 feet used for research and training.

\section{DEPARTMENT OF ZOOLOGY}

\section{Instructional Staff:}

John C. Ayers, Ph.D., Research Oceanographer

C. F. Powers, Ph.D., Assistant Professor of Zoology

J. L. Hough, Ph.D., Professor of Geology

W. P. Graebel, Ph.D., Associate Professor of Engineering Mechanics

F. C. Michelson, Ph.D., Assistant Professor of Naval Architecture

\section{Courses:}

Lectures on the complex of environmental conditions which effect the biotic assemblages in the world's aquatic habitats. Emphasis on the modern concept that fresh and marine waters are essentially similar. 
444 FIELD INVESTIGATIONS IN LIMNOLOGY

Linnological studies of local lakes and streams. Interpretation of the interaction of environmental factors and the biota.

445 THEORETICAL CONSIDERATIONS IN APPLIED LIMNOLOGY

Lectures on modern theories relating to the study of aquatic ecosystems. Laboratory work includes field trips, use of limnological equipment, and methods of sampling, enumerating, and identifying organisms.

446 OCEANOGRAPHY LABORATORY

Discussion and laboratory dealing with selected topics in physical, chemical and biological oceanography.

526 ADVANCED STUDIES IN LIMNOLOGY AND OCEANOGRAPHY

Discussion. lectures, and laboratories on special topics in aquatic research.
A. Dynamics
B. Plankton
C. Coastal and Estuarine Processes
D. Other

527 EXPERIMENTAL LIMNOLOGY

Lecture, discussion, and laboratory on experimental methods of studying aquatic phenomena under both laboratory and field conditions.

531 ADVANCED OCEANOGRAPHY

675 CURRENT PROBLEMS IN LIMNOLOGY AND OCEANOGRAPHY

Discussion of current concepts and problems.

676 CURRENT PROBLEMS IN LIMNOLOGY AND OCEANOGRAPHY

Continuation of 675 .

313 OCEANOGRAPHIC TECHNIQUES

479 LIMNOLOGY

The study of lakes and streams, with stress on the physical, chemical, and biotic factors which determine their biological productivity. 


\section{ADVANCED LIMNOLOGY}

The study of lake metabolism and aspects of energy transfer through the aquatic ecosystem. Emphasis is placed on the role of algae and bacteria, with some work on zooplankton and benthic fauna.

677 CURRENT PROBLEMS IN LIMNOLOGY AND OCEANOGRAPHY

\section{E.M. 921 SEMINAR IN OCEANOGRAPHY}

For Information Contact:

Dr. John C. Ayers

Great Lakes Research Division

University of Michigan

1069 North University Building

Ann Arbor, Michigan 


\section{U. S. Naval Postgraduate School \\ Monterey, California}

\section{DEPARTMENT OF METEOROLOGY AND OCEANOGRAPHY}

The Naval Postgraduate School is a naval university for the advanced formal education of Naval officers. The school is located about a mile east of downtown Monterey on the site of the former Del Monte Hotel. Modern classroom and laboratory buildings have been constructed and are situated on a beautifully landscaped, pleasant campus.

The Department has laboratory facilities equipped with modern instrumentation, access to computing facilities, and is in the process of acquiring a 63-foot research vessel.

\section{Instructional Staff:}

WILLIAM DWIGHT DUTHIE, Ph.D., Professor of Meteorology, Chairman GLENN HAROLD JUNG, Ph.D., Associate Professor of Oceanography WARREN CHARLES THOMPSON, Ph.D., Professor of Oceanography JACOB BERTRAM WICKHAM, M.S., Associate Professor of Oceanography

Degrees offered:

Bachelor of Science, Master of Science

Doctor of Philosophy in Meteorology and Oceanography

\section{Courses:}

Mr-120(C). INTRODUCTION TO METEOROLOGY AND OCEANOGRAPHY

Distribution of the properties of the atmosphere and the oceans; the mean pattern of the general circulation and the seasonal and short-tern variations from the mean; methods of predicting atmospheric and oceanographic conditions.

OC-110(C). INTRODUCTION TO OCEANOGRAPHY

A survey course treating physical and chemical properties of sea water, marine blology, and submarine geology; the heat budget of the oceans; water masses and the general circulation; currents, waves, a nd tides.

Oc-211(A). OCEAN WAVE THEORY

Various solutions of the hydrodynamical equations of motion for surface and internal waves, with particular attention to short gravity waves and their properties; generation of waves by wind; empirical and theoretical wind-wave spectra. 
Oc-212(A). TIDES AND TIDAL CURRENTS

Theories of the astronomical tides; the tide-producing forces; tidal oscillations in ocean basins; geographical variation of the tides; analysis and prediction of tides; tidal datum planes. Meteorological tides. Seiches. Tidal currents.

OC-213(B). SHALLOW-WATER OCEANOGRAPHY

Types and characteristics of continental shelves, coasts and beaches; wave processes in shallow water; littoral currents and storm-tides.

OC-214(B). MARINE ENVIRONMENTS

The oceanography of partially enclosed water bodies; of estuaries, fjords, straits, river mouths, and harbors; and of enclosed seas.

OC-230(A). SPECIAL TOPICS IN OCEANOGRAPHY

The mechanics of simple water waves; ocean-wave spectra, statistical properties of ocean waves, wave forces, and wave pressures; the movement of ships in irregular seas; tides, tidal currents, and the forces associated with them; sea-water transparency and underwater visibility.

Oc-240(B). DESCRIPTIVE OCEANOGRAPHY

Properties of sea water; water masses, currents and threedimensional circulation in all oceans; distribution of temperature, salinity and oxygen; temperature-salinity relationship.

OC-243(A). DYNAMIC OCEANOGRAPHY

Turbulence and diffusion in the ocean; boundary layer flow; stability; dynamical models for the general circulation of the ocean and for special regions.

OC-310(B). GEOLOGICAL OCEANOGRAPHY

Physlography of the sea floor, especially the continental shelf and slope, coral reefs, submarine canyons, and seamounts; marlne processes that have shaped the ocean basins and coasts; character and distribution of sediment types and rates of deposition; origin of the ocean basins.

OC -330 (A). MARINE GEOLOGY AND GEOPHYSICS

Physical and engineering properties of marine sediments; geographical distribution of marine sediments; types of continental shelves and harbors; deposition and erosion 
on the sea floor; current scour around objects on the bottom; biological fouling organisms, distributions of foulers, and rates of fouling.

OC -410 (B). BIOLOGICAL OCEANOGRAPHY

Plant and animal groups in the oceans; character of the plankton, nekton, and benthos; marine biological environments; oceanographic factors influencing populations; the effect of organisms on the physical-chemical properties of sea water; organisms responsible for boring, fouling, sound and light production, and sound scattering.

OC $-510(B)$. CHEMICAL OCEANOGRAPHY

Chemical composition of sea water and sea ice; determination and distribution of salinity, density, dissolved gases, and plant nutrients; production of fresh water from sea water.

OC-612(B). ARCTIC SEA ICE

Arctic geography and oceanography; sea-ice observations, formation, properties, growth, deformation and disintegration; ice drift in response to winds and currents.

OC-613(B). ARCTIC SEA ICE AND ICE FORECASTING

Lectures same as in $0 c-612(B)$. Laboratory exercises on ice drift and ice growth.

Oc-621(B). OCEAN THERMAL STRUCTURE

Reviews variation of ocean temperature structure and processes involved; techniques in forecasting thermal structure illustrated by laboratory exercises; practice in developing forecast methods from actual air and sea data.

OC-640(B). OCEANOGRAPHIC FORECASTING

Prediction of ocean transports and advective effects from the atmospheric wind field using the hydrodynamical equations and digital computations; prediction of long-term variations in oceanographic conditions using methods of cross-correlation and spectrum analysis.

Oc $-650(C)$. OPERATIONAL OCEANOGRAPHY

Applications of oceanography in ASWEPS, Arctic, submarine, weather, and other Navy operations; radar propagation.

For Information Contact:

Bureau of Naval Personnel

Washington $25, \mathrm{D}$. C. 
New York University

New York 53, New York

\section{DEPARTMENT OF METEOROLOGY AND OCEANOGRAPHY}

Current research projects in which students participate include research in ocean waves, air-sea boundary processes, solar radiation balance, turbulent dye diffusion, the large scale ocean circulation, and the equatorial Atlantic. Extensive analogue and digital computing facilities are available, such as a CDC 1604, BECKMAN 210 and smaller units. A sixty-five foot research ship, the KYMA, equipped with $A C$ and DC power, radar, loran, gyrocompass, fathometer, Doppler navigator, deep sea winch, BT winch, dye diffusion gear, skin diving equipment, and data telemetry electronics is used for oceanographic investigations. Applications for graduate assistantships and graduate fellowships are available on request.

\section{Instructional Staff:}

JAMES E. MILLER, M.S., Professor of Meteorology, Chairman of the Department

GERHARD NEUMANN, Dr. Rer. Nat., Professor of Oceanography WILLARD J. PIERSON, JR., Ph.D., Professor of Oceanography JEROME SPAR, Ph.D., Professor of Meteorology

RICHARD M. SCHOTLAND, SC.D., Associate Professor of Meteorology BENJAMIN DAVIDSON, Ph.D., Associate Professor of Meteorology KATSUYUKI OOYAMA, Ph.D., Assistant Professor of Meteorology ANDREW F. BUNKER, M.A., Adjunct Professor of Meteorology SILVIO SIMPLICIO, M.S., Adjunct Professor of Meteorology ALBERT ARKING, Ph.D., Adjunct Assistant Professor of Meteorology

Degrees offered:

Master of Science in Oceanography

Doctor of Philosophy in Oceanography

\section{Undergraduate Courses:}

\section{INTRODUCTION TO THE GEOPHYSICAL SCIENCES I AND II}

An historical, descriptive, and physical survey of the earth as a planet, the interior and crust of the earth, the oceans, and the atmosphere. Fundamental concepts and methods of the geophysical sciences. Laboratory includes techniques of meteorological and oceanographic observation.

\section{DYNAMIC METEOROLOGY AND OCEANOGRAPHY I AND II}

Thermodynamics and hydrodynamics of the atmosphere and ocean. Radiation. The equations of fluid motion on a rotating earth. Convection. Wind, waves, currents, and tides. Turbulence in the air and sea. Boundary layer problems. 


\section{DESCRIPTIVE METEOROLOGY AND OCEANOGRAPHY I AND II}

The average state of the oceans and the atmosphere. World climates. General circulation of the air and sea. Geography and topography of the continents and ocean basins. Properties and distribution of the major air and water masses. Interactions between the sea and the air.

THEORETICAL GEOPHYSICS (Not to be given until 1964-1965.)

Theory of elastic and hydrodynamic wave motions in the earth, sea and air.

CLIMATOLOGY (Not to be given after 1963-1964.)

Factors controlling climate, statistical methods of climatology, climates of the continents and oceans.

INTRODUCTION TO OCEANOGRAPHY (Not to be given after 1963-1964.)

The fundamental principles of oceanography including methods of observation. Elements of dynamical oceanography, ocean currents, waves, and tides. Survey of the stratification and the general circulation of the oceans and of the most important adjacent seas; relation of physical oceanography to meteorology and marine biology.

APPLIED METEOROLOGY I AND II (Not to be given after 1963-1964.)

Application of meteorological principles to weather forecasting for aviation, industry, and the general public.

STATISTICAL METHOOS IN THE GEOPHYSICAL SCIENCES (Not to be given until 1964-1965.)

Applications of statistical methods to problems in meteorology, oceanography, and other branches of geophysics.

\section{Graduate Courses:}

\section{THE PLANET EARTH}

The average state of the lithosphere, hydrosphere, and atmosphere. The shape of the earth. Energy sources and exchanges. General circulation of the atmosphere and the oceans. Interactions and boundaries between $1 \mathrm{ithosphere,} \mathrm{hydrosphere,} \mathrm{and} \mathrm{atmosphere.} \mathrm{Air}$ masses and water masses. The climate of the atmosphere and of the oceans. Paleocl imatology. 


\section{PHYSICAL OCEANOGRAPHY}

Ocean basins and sea bottom. Physical and chemical properties of sea water. Sound and radiation in the oceans. Interaction between the ocean and the atmosphere. Exchange of heat and water between sea and air. The sea surface as a hydrodynamic interface.

LABORATORY WORK IN OCEANOGRAPHY (given at the Woods Hole Oceanographic Institution and on the New York University research vessel.)

Practical work with the more common oceanographic instruments such as Nansen bottles, bathythermographs, reversing deep-sea thermometers, sea samplers, current meters.

\section{OCEANOGRAPHIC INSTRUMENTS AND METHODS OF ANALYSIS}

Demonstration, description, and theory of instruments used to obtain oceanographic data. Methods of evaluation of records. Presentation and analysis of data.

WAVE MOTIONS IN THE ATMOSPHERE AND IN THE OCEAN

Theory of atmospheric and ocean waves and of large perturbations in the westerlies of temperature latitudes and in the tropical easterlies. Effect of the spheroidal shape of the earth. Tides.

\section{METHODS OF THEORETICAL METEOROLOGY AND OCEANOGRAPHY}

Meteorological and oceanographic fields. The equations governing these fields and their solutions. Boundary-value problems and eigenvalue problems in oceanography and meteorology. Incompressible and compressible flows. The theory of bores and pressure jumps. Theory of atmospheric and oceanic oscillations. Viscous flows. The diffusion of atmospheric and oceanic properties.

\section{GEOPHYSICAL RANDOM PROCESSES}

Applications of the theory of random processes to turbulence, wind-generated ocean waves, large scale atmospheric motions, short- and long-range weather forecasting, geomagnetic activity, microseisms, and radar storm detection. (Alternates with Analys is and Forecasting of Ocean Waves - spring term 1964, 1966...)

\section{GEOOYNAMICS}

The dynamics of geophysical systems with special emphasis on the atmosphere and oceans. Atmospheric thermodynamics. The hydrodynamic equations for a rotating earth. 


\section{STATISTICAL METHODS IN METEOROLOGY AND OCEANOGRAPHY}

Fundamental methods in statistical analysis. Climatological statistics. Application of statistical methods to weather forecasting and to research in meteorology and oceanography.

\section{SPECIAL TOPICS IN OCEANOGRAPHY}

Review of recent work on selected problems in oceanography.

DYNAMIC OCEANOGRAPHY

Dynamics of ocean currents. Conditions in stratified water. The circulation of the ocean. Ocean surface waves. Seiches. Tidal waves. Internal waves.

\section{ESTUARINE HYDROGRAPHY AND FLUSHING PROBLEMS}

Physical and chemical properties of the water masses of bays, estuaries, and other coastal regions. Dynamics of water movements. Diffusion and turbulence in natural bodies of water. Exchange of water with the open sea. Mixing of water masses and problems of water pollution.

\section{ANALYSIS AND FORECASTING OF OCEAN WAVES}

Discussion of modern methods for the analysis and prediction of the state of the sea surface. (Spring 1963, 1965...)

OCEANOGRAPHIC ASPECTS OF MAINTENANCE OF BEACHES, HARBORS, AND MARINE STRUCTURES

Application of information gained from oceanographic research, including ocean waves, currents, tides, storm tides, and other sea-level changes, to beach erosion problems, off-shore oil drilling, and harbor and marine structures.

DISPERSION OF POLLUTANTS IN THE ATMOSPHERE AND THE OCEANS

Fundamentals of meteorology, oceanography, and climatology as applied specifically to the dispersion of pollutants in the biosphere. The analytic principles of atmospheric propagation, diffusion, and deposition of weapon test debris and reactor effluents are treated. Oceanographic diffusion of materials and its implications for safe disposal of radioactive wastes are explored. 
THE OCEANS

Application of the principles of physical and dynamical oceanography to the individual oceans and their special problems. Description of the various oceans and seas.

\section{OCEANOGRAPHIC FIELD RESEARCH}

Practical work at sea with standard oceanographic instruments such as Nansen bottles, reversing thermometers, bathythermographs, current meters, bottom samplers, and specially designated equipment.

\section{ANALYSIS OF OCEANOGRAPHIC DATA}

Processing of oceanographic observations. Methods of evaluation of records. Presentation and analys is of physical and chemical observations.

\section{SELECTED PROBLEMS IN OCEANOGRAPHY}

Discussion and review of modern work in oceanography.

\section{RESEARCH METHODS IN METEOROLOGY AND OCEANOGRAPHY}

Lectures and applied work on such topics as selection and delimitation of the research problem, bibliographic research, preliminary experiments, controls and tests, the research record, statistical methods, and the writing of the final report.

\section{RESEARCH IN OCEANOGRAPHY}

Candidates for the master's degree in oceanography meet regularly with the staff advisers to whom they are assigned to report on the progress of their master's thesis.

\section{ADVANCED RESEARCH IN OCEANOGRAPHY}

Candidates for the degree of Doctor of Philosophy who have passed the preliminary examinations in oceanography meet regularly with the staff advisers to whom they are assigned to report on the progress of their doctoral dissertations. 
The following are related courses in meteorology frequently taken by students of oceanography:

WEATHER ANALYSIS

ATMOSPHERIC RADIATION

ATMOSPHERIC PHYSICS

ATMOSPHERIC TURBULENCE

WEATHER PREDICTION

RADIOMETEROROLOGY

THE ATMOSPHERES OF THE PLANETS

PHYSICS OF THE UPPER ATMOSPHERE

TROP ICAL METEOROLOGY

\section{SEMINAR}

Lectures, group discussion, and reports on modern developments in meteorology and oceanography, by the staff, graduate students, and visiting specialists.

For information contact:

Prof. James E. Miller

Chairman, Department of Meteorology and Oceanography New York University

New York 53, New York 


\section{State University of New York Maritime College Fort Schuyler, New York 65, New York}

Marine science training at S.U.N.Y. includes the use of a modern oceanography lab equipped with common oceanographic instruments such as Nansen bottles, reversing sea thermometers, bathythermographs, etc. Ample practice in taking oceanographic observations is offered during cruise periods aboard the training ship EMPIRE STATE IV.

\section{SCIENCE DEPARTMENT}

\section{Instructional Staff:}

MEIR H. DEGANI, Sc.D., Professor, Chairman of the Department CHARLES THOR, M.S., Associate Professor

Degrees offered:

Bachelor of Science (Meteorology and Oceanography)

\section{Courses:}

\section{OCEANOGRAPHY}

The fundamental principles of static oceanography; physical and chemical properties of sea water; topography and composition of the ocean bottom. Survey of dynamic oceanography, waves, currents, and tides.

\section{PHYSICAL OCEANOGRAPHY}

The ocean basins. The 3-dimensional distribution of physical and chemical properties of sea water and their periodic and aperiodic changes. Propagation of sound and electromagnetic waves. Ice in the sea.

\section{DYNAMIC OCEANOGRAPHY}

Basic hydrodynamic equations. Theory of currents in a homogenous and nonhomogenous ocean. Basic principles of general oceanic circulation.

\section{WAVES}

Interaction'between the ocean and the atmosphere. Surface, tidal and internal waves. Analysis and forecasting of ocean waves. Use of wave forecasting in ship routing. 
408 INSTRUMENTS AND OBSERVATION

Theory and design of oceanographic instruments. Collection and evaluation of data. Practical work in several of the common instruments such as Nansen bottles, reversing sea thermometers, etc.

$410 E$

Investigation of problems in oceanography of special interest to the merchant marine.

For further information contact:

Dr. M. H. Degani

Chairman, Science Department

State University of New York Maritime College

Fort Schuyler

New York 65, New York 


\section{University of North Carolina}

Chapel Hill, N.C.

There is no separate department offering work toward a degree in oceanography; however, a student may specialize in the marine sciences in the departments of botany, geology, or zoology. Facilities available for student training in marine research include: standard botany, geology, and zoology laboratories at Chapel Hill; coastal laboratory at Morehead City with research library, research collections, a 47-foot diesel powered research vessel, and 4 skiffs and run-abouts with outboard motors.

Recearch is being carried out on the following subjects: 1ife history, ecology, and taxonomy of marine and estuarine crustaceans, fishes, and mollusks; oceanographic and primary productivity studies of sounds and estuaries; laboratory studies of influence of environmental factors upon meristic structures of developing fishes; clay mineral, heavy minera1, and size studies of bottom sediments; geomorphic development of coastal features; foraminifera of coastal waters.

\section{Degrees Offered:}

None in oceanography. Master's and doctor's degrees in botany, geology, and zoology.

DEPARTMENT OF BOTANY:

Instructiona1 Staff:

M. H. HOMMERSAND, Ph.D., Assistant Professor

Courses :

114. ALGAE

HOMMERSAND

300. RESEARCH IN ALGOLOGY

HOMERSAND

312. SPECIAL TOPICS IN ALGOLOGY

HOMMERSAND

DEPARTMENT OF GEOLOGY:

Instructional Staff:

ROY L. INGRAM, Ph.D., Professor, Chairman JOSEPH ST. JEAN, Ph.D., Associate Professor

Courses:

106. INVERTEBRATE PALEONTOLOGY ST. JEAN 
111. SEDTMENTARY ROCKS

117. CLAY MINERALOGY

247. SEDTMENTATION

285. ADVANCED INVERTEBRATE PALEONTOLOGY

288. MICROPALEONTOLOGY

389. RESEARCH IN PALEONTOLOGY
INGRAM

INGRAM

INGRAM

ST. JEAN

ST. JEAN

ST. JEAN

DEPARTMENT OF ZOOLOGY:

Instructiona1 Staff:

C. E. JEKNER, Ph.D., Professor

D. P. COSTELLO, Ph.D., Kenan Professor

A. E. StIVEN, Ph.D., Assistant Professor

Courses:

106. GENERAL INVERTEBRATE ZOOLOGY

JENNER

108. GENERAL ECOLOGY

STIVEN

109. AQUATIC BIOLOGY

JENNER

146. MARINE ECOLOGY

JENNER

206. ADVANCED INVERTEBRATE ZOOLOGY

JENNER

209. EXPERTMENTAL INVERTEBRATE ZOOLOGY

COSTELLO

213. ADVANCED MARINE ECOLOGY

JENNER

331. RESEARCH IN INVERTEBRATE ZOOLOGY

JENNER

335. RESEARCH IN HYDROBIOLOGY

JENNER

340. RESEARCH IN MARINE ECOLOGY

JENNER

341. RESEARCH IN GENERAL ECOLOGY

STIVEN 
INSTITUTE OF FISHERIES RESEARCH at Morehead City:

\section{Staff:}

A. F。 CHESTNUT, Ph.D., Director and Professor

W. E. FAHY, Ph.D。, Associate Professor

A. B. WILLIAMS, Ph.D., Associate Professor

WILLIAM A. LUND, Ph.D., Assistant Professor

WILLIAM JOSEPH WOODS, Ph॰D。, Assistant Professor

H. J. PORTER, Instructor

\section{Courses:}

The Institute, although primarily a research organization, aids in the training of marine scientists by offering research courses in zoology, by directing graduate research, and by providing the facilities of its marine laboratory.

For Information Contact:

Chairmen of Departments of Zoology, Botany, and Geology. 


\section{Northeastern University}

Boston, Massachusetts

DEPARTMENT OF NATURAL SCIENCE:

Instructional Staff:

BERNARD C. GORDON, M.S.

J. ROSSON OVERCASH, Ph.D., Chairman of the Department

Degrees offered:

None; oceanography courses can be taken by majors in biology, mathematics, physics, and the social sciences.

\section{Courses:}

$17: 31$. OCEANOGRAPHY I

An introduction to the geology of the ocean basins and the physical and chemical properties of sea water. Special attention is given to the development of ocean currents and the important effects these currents have on the land masses of the world.

$17: 32$. OCEANOGRAPHY II

Emphasis is placed on the habitat zones and organisms of the sea. Phytoplankton, zooplankton, and nekton are discussed. Attention is given to the growing economic importance of marine resources for the expanding world populations.

NOTE: In both courses, field trips are taken to the Woods Hole Oceanographic Institute, Boston Fish Pier, and nearby museums .

For Information Contact:

B. L. Gordon, Department of Natural Science Northeastern University Boston 15, Massachusetts 


\section{The Oregon Institute of Marine Biology \\ Charleston, Oregon}

In affiliation with the University of Oregon

Eugene, Oregon

The Institute of Marine Biology is located on 100 acres of property along Coos Bay at Coos Head. Marine life is abundant and varied. The number and diversity of habitats accessible within a few minutes' drive of the station, and the fact that most of these have been relatively little altered by man, make rich invertebrate and fish faunas readily available to the student. Commercial fishermen bring unusual catches from deeper water to the station. Over 300 different kinds of marine algae have been listed from the region, and numerous fresh-water algae are also available.

The Institute buildings provide dormitories, dining hall, classrooms, and laboratories. There are six laboratory classrooms, with running salt water, study tables and benches, and lamps. The Institute's basic laboratory equipment is supplemented by equipment from the University campus. A working library is available.

The station has a 36 foot vessel for routine collecting in connection with class and research activities. Students occasionally make private arrangements to accompany Charleston fishermen on deepsea trips.

\section{Institutional Staff: (1963)}

VALENTINE J. CHAPMAN, Ph.D., Professor of Botany, University of Auckland.

IAN E. EFFORD, Ph.D., Assistant Professor of Fisheries, University of British Columbia.

HOWARD M. FEDER, Ph.D., Instructor in Biology, Hartnell College.

PETER W. FRANK, Ph.D., Associate Professor of Biology, University of Oregon; Acting Director of the Institute

HARRY K. FRITCHMAN, II, Ph.D., Instructor in Biology, Boise Junior College.

SHIRLEY SPARLING, Ph.D., Assistant Professor of Biology, University of California at Santa Barbara.

Degrees offered:

None. The University of Oregon awards credit for all courses, Courses offered (Summer only):

Bi 433. ALGAE。

CHAPMAN

Structure, function and ecology of representative algae, with emphasis on marine forms. 
Bi 461,462。 INVERTEBRATE ZOOLOGY.

FEDER

Survey of representative invertebrate groups, with emphasis on marine forms; morphology, systematics, ecology, and life histories.

Bi 476. BIOLOGY OF MARINE ORGANISMS.

FRITCHMAN, SPARLING, STAFF

An introduction to marine biology for college teachers who have had no firsthand experience in this field.

Bi 478. MARINE ECOLOGY.

EFFORD

An examination of general ecological problems, with special reference to marine invertebrates. Topics will include tidal zonation, patchiness and migration of plankton, zoogeography, community structure, population control, fouling organisms.

Bi 401, 501. RESEARCH

Bi 403, 503. THESIS

Bi 407,507 . SEMINAR

Bi 408. LABORATORY PROJECTS

For Information Contact:

Director

Oregon Institute of Marine Biology

Department of Biology

University of Oregon

Eugene, Oregon 


\section{Oregon State University \\ Corvallis, Oregon}

\section{DEPARTMENT OF OCEANOGRAPHY}

The department stresses a broad approach to oceanography in a research and graduate training program which integrates the biological, chemical, geological, geophysical, and physical aspects of marine science. A 30,000 square foot building under construction on the campus will be well equipped for all aspects of research and teaching. A 39,000 square foot laboratory at Newport ( 56 miles west of the campus) to be constructed during the next few months will house coastal aspects of oceanography as well as several allied sciences and will provide docking facilities for the Research Vessel ACONA. The ACONA will be replaced shortly with a 750-ton converted vessel.

Instructional Staff:

WAYNE V. BURT, Ph.D., Department Chairman and Professor, Oceanography

JOSEPH W. BERG, Jr., Ph.D., Professor, Geophysical Oceanography

PETER DEHLINGER, Ph.D., Professor, Geophysical Oceanography

PETER K. WEY, Ph.D., Professor, Chemical Oceanography

JOHN V. BYRNE, Ph.D., Associate Professor, Geological Oceanography

GERALD A. FOWLER, Ph.D., Assistant Professor, Geological Oceanography

HERBERT F. FROTANDER, Ph.D., Associate Professor, Biological Oceanography

JAMES E. McCAULEY, Ph.D., Associate Professor, Biological Oceanography

RICHARD Y. MORITA, Ph.D., Associate Professor (Joint with Microbiology)

JUNE G. PATTULLO, Ph.D., Associate Professor, Physical Oceanography

RICHARD W. SHAFER, Capt. USN (Ret.), Associate Professor, Physical Oceanography

ANDREW G. CAREY, Ph.D., Assistant Professor, Biological Oceanography

HERBERT CURL, Jr., Ph.D., Assistant Professor, Biological Oceanography

W. BRUCE MCALISTER, Ph.D., Assistant Professor, Physical Oceanography

CHARLES OSTERBERG, Ph.D., Assistant Professor, Chemical Oceanography

KILHO PARK, Ph.D., Assistant Professory, Chemical Oceanography

WILIIAM G. PEARCY, Ph.D., Assistant Professor, Biological Oceanography

LAWRENCE F. SMALL, Ph.D., Assistant Professor, Biological Oceanography 
WILBUR A. RINEHLART, M.S., Instructor, Geophysical Oceanography

ROBERT I. SMITH, M.A., Instructor, Physical Oceanography EULIZABEYH STRONG, B.A., Instructor, Physical Oceanography BRUCE WYATT, M.S., Instructor, Physical Oceanography

\section{Degrees Offered:}

Master of Science in Oceanography

Master of Science in General Science (no thesis required)

Doctor of Philosophy in Oceanography

Students may specialize in any of the following fields: Geophysics; Physical, Chemical, Biological, or Geological Oceanography

Undergraduate Courses:

Lower Division:

133. ELEMMENTS OF OCEANOGRAPHY

PATTULIO

Study of the development of the principles of oceanography by the men who have been pioneers in the field; background of and contributions by these pioneers; ships and equipment used from Polynesian times to the present.

331. INTRODUCTION TO OCEANOGRAPHY FROLANDER, BYRNE

Elective non-technical course designed to give the student broad general background. Emphasis on relationship between oceanography and other fields.

Upper Division:

420. GEOPHYSICAL EXPLORATION

BERG

Physical methods used in mining and oil prospecting, emphasizing geologic interpretation.

431. PHYSICAI LIMNOLOGY

SMAII

Physical and chemical processes in lakes and rivers; methods of making physical measurements; and some field work.

432. PHYSICAL OCEANOGRAPHY MCALISTER

Physical processes in ocean and estuaries; some field work. 
433. CURRENTS AND WATER MASSES

PATTULIO

Factors contributing to the origin and preservation of the water masses and currents of the oceans; distribution of variables in the sea.

434. ESTUARINE AND SHORELINE PROCESSES MCALISTER

A general study of estuarine and nearshore processes. Waves, surf and beach effects, tides and tidal currents; types and mechanism of estuarine circulation.

\section{BIOLOGICAL OCEANOGRAPHY}

\section{FROL_ANDER}

Physical, chemical, and biological factors characterizing the marine environment; factors, controlling plant and animal populations, methods of sampling, identification, and analysis.

442. MARINE PLANKTION

FROLAINDER

Floating plant and animal life in the sea; factors controlling population and production; regional distribution; methods of sampling; identification; nuisance forms.

443. MARINE MEKTION

PEARCY

Review of the swimming animals of the oceanic zones of the sea, including squid, fishes, and marine mamals; their vertical and horizontal distribution and abundance; food chain relationships, special problems of deep-sea life; methods of sampling.

444. MARINE PHYTOPLANKTION ECOLOGY CURL, SMALL

Floating plant life in the sea and estuaries; systematics, and distribution; physiology; populadynamics; effects of environmental factors; artificial cultivation; effect upon the environment and position in food webs.

445. MARINE PHYTOPLANKTION PHYSIOLOGY CURL

The life processes of plankton algae with special emphasis on energy-capturing processes, mineral nutrition, flotation mechanisms, cell division, and the evaluation of experimental procedures; problems of existence in the open ocean; artificial production of maximum yields. 
446. MARINE PRIMARY PRODUCTION

SMALI

A detailed examination of the experimental procedures used in measuring primary biological production. An cpportunity is afforded in acquiring skill in most procedures. Stress is laid on evaluation of experimental results and their interpretation.

480. MARINE GEOPHYSICS

\section{BERG}

Marine applications of geophysical methods including seismic, gravity, magnetic and others.

SEM. COMPUTER APPLICATIONS TO OCEANOGRAPHY RINEHART

Fortran language, use of IBM 1620 computer. Applications to marine geophysics, seismology, physical and biological oceanography.

\section{Graduate Courses:}

530. MARINE MICROBINLOGY

MORITA

Micro-organisms of ocean water, their ecology and economic importance.

551. CHEMICAL OCEANOGRAPHY

PARK

Chemical composition and properties of sea water; standard chemical methods for oceanographers; salinity; pH, dissolved gases, nutrients, carbonate cycle, geochemistry and extraction.

552. THEORETICAI CHEMICAL OCEANOGRAPHY PARK

Dissolved salts, oxygen and carbon dioxide in the sea, photosynthesis; organic matter; biogeochemistry of carbonates; marine corrosion, sorption reaction.

561. GEOLOGICAL OCEANOGRAPHY

BYRNE

Structure and morphology of the ocean basins; processes of marine erosion and deposition; sediment types and distribution; marine geological methods and applications. Course designed for non-geologists.

565. GEOLOGY OF THE OCEAN BASINS

BYRNE

Methods of geological and geophysical measurement in the ocean basins; topographic, geologic, and geophysical nature of the ocean basins and the major features occurring in them, their origin and development. 
566. MARINE SEDIMENTATION

BYRNE

Equipment and methods of sediment collection; nature and distribution of sediments in the various marine environments; physical and biological processes affecting sedimentation; chemical deposits; engineering application of marine sedimentation; recent marine sediments as a key to paleoecology.

571. MARINE HYDRODYNAMICS

MCALISTER

Mathematical treatment of motion in the ocean; methods for solving physical problems.

572. UNDERWATER SOUND

SMITH

Applications of sound transmission; factors affecting sound transmission in the sea; uses of sound; active and passive sonar, sofar, Swallow, sediment study, depth determination, navigation.

573. WAVES AND TIDES

MCALISTER

Cause, nature, measurement, analysis and prediction of surface waves, tides and tidal currents; tsunamis; storm surges.

580. THEORETICAI GEOPHYSICS, SOUND TRANSMISSION BERG

Fundamental relations between stress-strain, general theory of wave transmission, shallow water and deep water transmission, reflectivity, attenuation.

581. THEOREIICAI GEOPHYSICS, EARTH GRAVITY DEHLINGER

Internal constitution of the Earth, gravity field and gravity potential of the Earth, Earth ellipsoid, gravity measurements, (sea, land and space), isostasy, reduction of gravity measurements, gravity anomalies, deviations from isostatic equilibrium, convection currents, polar migrations.

582. THEORETICAL SEISMOLOGY

BERG

Fundamental elastic wave equation and solutions, including body and surface waves; layered half-space problem; effects of gravity, curvature, and viscosity; wave equations and solutions for plates and cylinders, wave propagation in medium with variable velocity. 
583. EARTHQUAKE SEISMOLOGY

DEHLINGER

Description of earthquakes; types of earthquakes; a seismograph theory; seismic ray paths; velocity determinations; shallow and deep earthquakes; magnitude and energies of earthquakes; locating earthquakes; microseisms; seismicity.

584. PHYSICS OF THE EARTH

DEHLINGER

Effects of confining pressure, temperature, time, and solutions on the properties of rocks; the earth and moon in the solar system; source materials and their reliabilities for determining the nature and composition of the earth; composition of the core, crust, and mantle of the earth; processes within the earth with special reference to their effect on earthquakes, isostasy, crustal structure, Island arcs, etc.

501. RESEARCH

STAFF

503. THESIS

STAFF

505. READING AND CONFERENCE

STAFF

507. SEMINAR

STAFF

For information contact:

Dr. Wayne V. Burt, Chairman

Department of Oceanography

Oregon State University

Corvallis, Oregon 


\section{$\frac{\text { University of the Pacific }}{\text { Stockton } 4 \text {, California }}$}

PACIFIC MARINE STATION, Dillon Beach, Cal ifornia

Pacific marine station provides opportunities for study and research in marine biology and related fields of science. Facilities include laboratories, library, research museum, darkrooms, and living accommodations. A 38 foot converted landing craft, BIOS PACIFICA, and a 26 foot whaleboat are available.

Undergraduate and graduate courses are offered during the summer sessions on a non-matriculation basis. These courses are accepted by many university departments in fulfillment of the requirement for study at a marine station as part of the advanced degree requirements. Usually two formal courses are offered during the seven week summer session, one of which is given by a visiting instructor from another institution. During the academic year there are opportunities for advanced study in problems of marine ecology and invertebrate zoology.

Students from other colleges who desire to study at Pacific Marine Station should plan to begin their program by attending classes at the Station during the summer session before taking up academic year residence at Dillon Beach, al though formal admission procedures may be deferred until the fall semester.

\section{Instructional Staff:}

JOEL W. HEDGPETH, Ph.D., Director, Professor of Zoology

JOHN S. TUCKER, Ph.D., Assistant Director, Ass istant Professor of Zoology

RALPH G. JOHNSON, Ph.D., Visiting Professor of Paleontology (summer sessions)

GILBERT C. HUGHES, III, Assistant Professor of Biological Sciences

EUGENE N. KOZLOFF, Ph.D., Visiting Professor

Degrees Offered:

Master of Science on the basis of a combination major with main campus departments.

\section{Courses:}

\section{Regular Session Courses}

112. INVERTEBRATE ZOOLOGY (Offered in spring semester only). HEDGPETH

The functional morphology, taxonomy, embryology, ecology, phylogeny and economic importance of the invertebrates. Lectures, laboratory field trips and individual reports. 
212, ADVANCED INVERTEBRATE ZOOLOGY (Offered by arrangement). HEDGPETH

213.

Lectures, conferences, laboratory studies, field trips, individual problems and reports dealing with the invertebrates at an advanced level; course 213 is an intensified examination of selected phyla and may be repeated for credit as subject matter permits.

\section{3, DIRECTED STUDIES}

STAFF

294.

Independent studies in problems of invertebrate zoology or marine ecology, planned with the instructor. Reading knowledge of at least one foreign language, preferably German or Russian is recommended.

895, GRADUATE SEMINAR

HEDGPETH

296.

297. GRADUATE RESEARCH

STAFF

298.

Advanced investigation in a selected problem in invertebrate zoology or marine ecology. The course may be re-elected as often as progress of the work warrants.

299. THESIS

STAFF

By appointment.

Summer Session Courses (1963)

S112. INVERTEBRATE ZOOLOGY

KOZLOFF,

The functional morphology, taxonomy, ecology and HEOGPETH phylogeny of the invertebrates. Lectures, laboratory, field trips and individual reports.

S124. MARINE BOTANY

HUGHES

Morphology, taxonomy and ecology of marine and estuarine algae, fungi, and seed plants with emphasis on the local flora. Lectures, laboratory, field trips, and individual projects.

S212. ADVANCED INVERTEBRATE ZOOLOGY

KOZLOFF, With special reference to marine invertebrates. 
Summer courses to be offered in any given year are selected from the following courses according to demand and the interests of visiting faculty members. (Include courses 5112,5124 , and 5212 in this 1 ist).

SIIO. AQUATIC ECOLOGY

Studies of the interrelationships of organisms and their environment with special reference to the sea, estuaries and fresh waters. Lectures and field trips, individual projects.

S126. ANIMAL TAXONOMY

Principles of classification, with laboratory and field work on the classification of selected groups of marine invertebrates.

SI27. ICHTHYOLOGY

Studies on the morphology, classification, life histories, ecology and economic importance of fishes with special reference to local species.

S135. OCEANOGRAPHY

The physics and chemistry of the ocean with special reference to biological significance. Lectures, field trips and problems.

SI37. MARINE PALEONTOLOGY

Lectures, readings and discussions on marine paleoecology and evolution with special reference to local living and fossil assemblages. Field trips.

S138. SHORE GEOLOGY AND LITTORAL PROCESSES

Topography and sediments of shorelines and coasts: study of the physical processes in the nearshore environment. Lectures, laboratory, field trips.

5145. ECOLOGICAL PHYSIOLOGY

The life functions of marine organisms with emphasis on their responses to the marine environment. Lectures, laboratory, field trips and special projects. 
S195. BIOLOGY SEMINAR

Conferences, readings and discussions on selected subjects.

5197, INVESTIGATIONAL BIOLOGY

5198.

Supervised individual studies on selected biological problems. The course may be re-elected as often as progress in the work warrants.

For information contact:

Dr. Joel W. Hedgpeth

Director, Pacific Marine Station

Dillon Beach, California 


\section{The Pennsylvania State University University Park, Pennsylvania}

Advanced degree programs at the University emphasizing the marine sciences stress the theoretical and instrumental analysis and interpretation of oceanographic data rather than field investigations. Students are encouraged to take full advantage of the University's outstanding physical facilities: mass spectrometers, $x-r a y$ and electron diffraction and fluorescence units, electron microprobe, emission spectrograph and computation equipment are available. Exceptional opportunities are offered students interested in hydrodynamics, acoustics and anti-submarine warfare techniques through the facilities of the College of Engineering and the Ordnance Research Laboratory. Opportunities for field work are afforded through cooperative arrangements with coastal marine laboratories.

Courses in the marine sciences are offered by the Departments of Geology and Geophysics, Geochemistry and Mineralogy, and Meteorology.

\section{Instructional Staff:}

H. L. BARneS, Ph.D., Ass istant Professor, Geochemistry

T. F. BATES, Ph.D., Professor of Mineralogy

G. W. BRINDLEY, Ph.D., Professor of Solid State Technology

R. T. DUQUeT, Ph.D., Assistant Professor of Meteorology

J. C. GRIFFITHS, Ph.D., Professor of Petrology

L. F. HERZOG, Ph.D., Associate Professor of Geophysics

B. F. HOWELL, JR., Ph.D., Professor of Geophysics

M. L. KEITH, Ph.D., Professor of Geochemistry

P. D. KRYNINE, Ph.D., Professor of Petrology and Sedimentation

J. L. LUMLEY, Ph.D., Associate Profiessor of Aeronautical Engineering

H. A. PANOFSKY, Ph.D., Professor of Meteorology

R. F. SCHMALZ, Ph.D., Assistant Professor of Geology

J. N. WEBER, Ph.D., Assistant Professor of Geochemistry

\section{Degrees Offered:}

The University does not offer a program leading to advanced degrees in the marine sciences. Course offerings at the advanced undergraduate $(400)$ and graduate $(500$ and 600$)$ levels may be credited toward degrees in Geochemistry, Geology, Geophysics, Meteorology and Mineralogy, and advanced degree programs in these fields may be pursued with a strong emphasis in the marine sciences. The University offers Master of Science and Doctor of Philosophy degrees in all of these fields. 
Advanced Undergraduate Courses:

ENGR

431 DIGITAL COMPUTER PROGRAMMING

Principals of programming electronic digital computers; solution of scientific and engineering problems using symbolic and algebraic techniques on University computers.

GSc

440 MARINE GEOLOGY

SCHMALZ

Chemical and physical processes affecting topography and sediments of the sea floor.

GSe

456 INTRODUCTORY GEOCHEMISTRY

KE I TH

Element and isotope distribution and associations in earth, oceans, groundwater; crystal chemistry; geochemical processes, cycles, measurements, prospecting; biogeochemistry.

Graduate Courses:

AERO ENG

511 AERODYNAMICS OF A PERFECT FLUID

LUMLEY

Euler's dynamic equations, complex potential, conformal transformations, thin airfoils, Biot-Savart law; Prandt t three-dimensional airfoil theory.

AERO ENG 512 AEROOYNAMICS OF A VISCOUS FLUID

LUMLEY

Navier-Stokes equations, incompressible and compressible boundary layer theory, jet and wake problems, hydrodynamic stability, turbulence.

GEOL 540 CHEMICAL OCEANOGRAPHY

SCHMALZ

Chemical reactions in seawater and at the sea floor related to sedimentation and diagenesis.

GEOL

\section{GEOTECTONICS}

SCHOLTEN

Tectonics principals and elements: nature and development of geosynclines, island arcs, mountain structures, stable masses, cratons, mobile belts. 


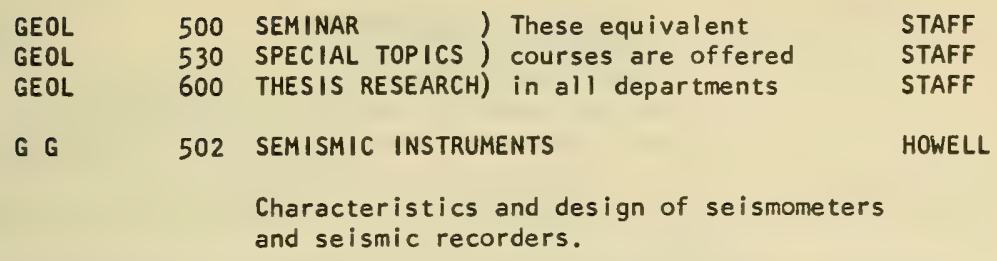

Seminar in the cause and nature of the principal deformations of the earth.

Principals and data from studies of phase equilibria, petrology and crystal structure as related to distribution of elements in minerals, rocks and the earth.

Geochemistry of radioactive elements and their daughters; age determination techniques and observations.

Theoretical basis and observations of isotope fractionation in nature; paleotemperature scale; temperatures of formation of ore deposits and other rocks.

Ionic and molecular equilibria related to stabilities and solubilities of minerals; Eh-pH, $\mathrm{P}_{02}-\mathrm{pH}$ relations applied to ground water, seawater, hydrothermal fluids.

Physical properties of seawater; heat balance of the oceans; theory and observations of ocean currents, waves, tides. 
METEO

METEO

MIN

MIN

MIN

MIN

\section{ATMOSPHERIC WAVE MOTION}

From classical and physical hydrodynamics to the numerical prediction of wave motion in a baroclinic atmosphere.

\section{ADVANCED ATMOSPHERIC DYNAMICS}

DUQUET

Numerical prediction models, general circulation, thermal and gravitational tides in a spherical shell, and empirical orthogonal functions of statistical forecasting.

\section{METHODS OF ANALYSIS OF SEDIMENTS}

GRIFFITHS

Principles and practices used in analyzing sedimentary rocks for size, shape and accessory (heavy) minerals.

524 INTRODUCTION TO SEDIMENTATION

KRYNINE

526 STATISTICAL PROBLEMS IN SEDIMENTARY GEOLOGY GRIFFITHS

Applications of experimental design, sampling procedures multiple regression and discriminant analysis in solving problems in sedimentary petrography.

530 STRUCTURE, PROPERTIES AND OCCURRENCE OF CLAY MINERALS

GRIFFITHS, BATES, BRINDLEY

Structure analysis and identification of clay minerals; mineral transformations and behavior; occurrence, genesis and petrography of finegrained sediments.

In addition to the above courses, the University offers a wide variety of courses in Geochemistry, Geology, Geophysics, Meteorology, Mineralogy, Petrology and Sedimentation which are directly applicable to the marine sciences.

For information contact:

Dr. Richard H. Jahns, Dean

College of Mineral Industries

University Park, Pennsylvania 


\author{
Pomona College \\ claremont, California
}

DEPARTMENT OF ZOOLOGY

Instructiona1 Staff:

YOST U. AMREIN, Ph.D., Professor of Zoology, Department Chairman

ANDREW TODD NEWBERRY, Doctoral Candidate, Stanford University, under Dr. Donald P. Abbott, Hopkins Marine Station, Pacific Grove, California

Degrees offered:

None.

Courses:

Courses offered are at the Kerckhoff Marine Laboratory, Corona del Mar during the five summer weeks Pomona College contracts with California Institute of Technology for use of the laboratory.

S130. MARINE INVERTEBRATES

NEWBERRY

A study of invertebrates residing in the sea: their phylogenetic relationship, their morphology, and their physiology. Laboratory devoted principally to Pacific Coast types.

S150. MARINE ECOLOGY NEWBERRY

A study of marine invertebrates as they exist in the field. Discussion of the distribution of each species observed and the factors which may account for these distributional patterns.

For Information Contact:

Yost U. Amrein, Ph.D.

Department of Zoology

Seaver Laboratory

Pomona College

Claremont, California 


\section{University of Puerto Rico

Mayaguez, Puerto Rico

\section{INSTITUTE OF MARINE BIOLOGY}

Instructional Staff:

CARLOS AGUAYO, Ph.D., Research Associate

LUIS R. ALMODOVAR, Ph.D., Associate Investigator MANUEL DIAZ-PIFERRER, M.S., Associate Investigator PETER W. GLYNN, M.S., Associate Investigator JUAN GERARDO GONZALEZ, M.S., Assoclate Investigator FRANK G. LOWMAN, Ph.D., Research Associate JOHN E. RANDALL, Ph.D., Director of Research JUAN A. RIVERO, Ph.D., Director

GERMAINE L. WARMKE, M.S., Curator of Mollusks

Degrees Offered (in the Blology Department):

Master of Science in Blology

Courses offered (upper division and graduate):

417. MARINE INVERTEBRATE ZOOLOGY

GLYNN

452. ICHTHYOLOGY

RANDALL

453. FISHERY BIOLOGY

RANDALL

461. MARINE BOTANY

ALMODOVAR

470. SPECIAL PROBLEMS IN ZOOLOGY

STAFF

495. MARINE ECOLOGY

GLYNN

515. PRINCIPLES OF SYSTEMATIC ZOOLOGY

AGUAYO

590. SEMINAR

STAFT

593. ANIMAL BEHAVIOR

RIVERO

* nuclear techiniQues in oceanography

LOWMAN

* PLANKTOLOGY

GONZALEZ

* Course number not yet assigned. 


\section{Rensselaer Polytechnic Institute}

Troy, New York

\section{DEPARTMENT OF GEOLOGX}

Instructional Staff:

SAMUEL KATZ, Ph.D., Professor of Geophysics

Degrees offered:

None in Marine Sclence; the listed course may be applied towards a B.S., M.S., or Ph.D. In Geology, Geophysics, or Geochemistry.

\section{Course:}

T10.60 PHYSICAL OCEANOGRAPHY

KATZ

Ocean basins; sea water and ice; heat budget and thermal processes; currents, tides, and waves; sea-air boundary effects; transmission of acoustic and electromagnetic radiation; instruments and measurements. 


\section{University of Rhode Island \\ Kingston, Rhode Island}

\section{GRADUATE SCHOOL OF OCEANOGRAPHY}

The Graduate School of Oceanography, in addition to the usual classroom facilities, has a modern, fully-equipped oceanographic laboratory which was completed in 1960. The School also has the use of the TRIDENT, a 180 foot research vessel owned by the University.

Research programs in progress involve a wide range of topics in physical, chemical, geological and biological oceanography, including ocean currents, sea water radioactivity as related to circulation studies, dynamics of sedimentation, origin of the sea floor, plankton production and distribution, underwater sound of biological origin, productivity of estuaries and coastal ponds, fishery biology and information retrieval, ecology of marine bacteria and algal antimetabolites.

\section{Instruction Staff:}

JOHN A. KNAUSS, Ph.D., Dean and Professor

CHARLES J. FISH, Ph.D., Professor

NELSON MARSHALL, Ph.D., Professor

DAVID M. PRATT, Ph.D., Professor

ROBERT L. McMASTER, Ph.D., Associate Professor

SAUL B. SAILA, Ph.D., Assoclate Professor

JOHN MCN. SIEBURTH, Ph.D., Associate Professor

JOHN T. CONOVER, Ph.D., Assistant Professor

HARRY P. JEFFRIES, Ph.D., Assistant Professor

DALE C. KRAUSE, Ph.D., Assistant Professor

DAVID R. SCHINK, Ph.D., Assistant Professor

THEODORE J. SMAYDA, M.S., Assistant Professor

Degrees Conferred:

Master of Science in Oceanography

Doctor of Philosophy in Oceanography

(Both degrees are given with options in physical, chemical, geological, and biological oceanography.)

Undergraduate Courses:

1. GENERAL OCEANOGRAPHY

STAFF

Introduction to the study of the sea: nature of sea water and its movements, ocean floor and its sediments and characteristic plant and animal comunities that have evolved in this enviroment. 
Graduate courses to which qualifled upperclassmen are admitted:

201. PHYSICAL OCEANOGRAPHY

KNAUSS

Basic course covering all aspects of physical oceanography. Physical properties of sea water, heat budget, distribution of variables, dynamics, water masses and general circulation. Waves, tides, history and interrelationships with other marine sciences.

221. CHEMICAL OCEANOGRAPHY

SCHINK

A study of the processes regulating the composition of sea water, and the distribution of chemical species. The interaction of marine chemistry with the ocean floor, atmosphere, and marine organisms.

241. GEOLOGICAL OCEANOGRAPHY

McMASTER

Brief survey of marine geology and its relationships to other marine sciences. Growth and destruction of beaches, physical characteristics of continental terraces and theories as to their origin, major features of the vast ocean basins, such as coral reefs, ridges and deeps, and influence of these features on currents and life and sources and distribution of marine sediments.

242. PETROGRAPHY OF MARINE SEDIMENTS

MCMASTER

Principles of sedimentary petrology applied to study of recent marine sediments. Major emphasis on methods of analysis and presentation of analytical data. Processes that lead to deposition of these sediments and environmental forces acting on them once deposited.

243. SEMINAR IN DEEP-SEA GEOLOGY

KRAUSE

Class discussion of selected topics in deep-sea geology based on extensive reading in the scientific literature. A research paper by each student and lectures will supplement the discussions.

261. BIOLOGICAL OCEANOGRAPHY

PRATT AND FISH

Nature of life in the sea; adaptations, patterns of distribution, and production of plankton, nekton and benthos, their interrelationships and interaction with the environment. 
262. BENTHOS

MARSHALL

Bottom enviroments ranging from the deep ocean to freshwater lakes will be considered. Attention will be directed to the organization of biotic communities and their interrelationships, to trophic dynamics and to critical physical and chemical parameters and exchange processes involving the benthic biota.

264. PHYTOPLANKTON

SMAYDA

The systematics, ecology and methods of investigation of the pelagic microscopic plants are considered, including their morphology, adaptations, physlology, succession, production, distribution and reglonal dynamics as influenced by environmental factors.

266. ZOOPLANKTON

A study of the blology of marine zooplankton, dealing with morphology, adaptation, distribution, physiology, production and interrelationships with other members of the marine blota.

267. MARINE BACTERIOLOGY

SIEBURTH

Present concepts of the distribution, nature, and functions of bacteria and related microorganisms in the marine environment. Methodology will include sampling, culture, taxonomy and study in regard to their physical and physiological ecology.

268. FISHERY BIOLOGY

SAILA

Blology of fish populations and methods of fishery research, including Influence of environmental factors on morphology, physiology, abundance and distribution of fishes, estimation of stocks, growth, aging, mortality, measurement of fish production and theory of fishery regulation.

291, INDIVIDUAL STUDY

STAFT

292.

Individual study of assigned topics or special problems, Involving literature search and/or original investigation, under one or more members of the staff. 
Courses for graduate students only:

341. RECENT SEDTMENTARY ENVIRONMENTS

MCMASTER

Concentrated study of the estuarine, littoral and neritic sedimentary enviroments with primary emphasis on the relationships between the sediment properties of each environment and its environmental conditions.

361. ECOLOGICAL CONCEPTS IN MARINE RESEARCH

JEFFRIES

Advanced course in ecology with emphasis on marine environment. Ecological theory pertaining to population dynamics, energy in ecological systems and the application of quantitative biology in oceanography. Application of experimental methods in ecological research.

391. SEMINAR IN OCEANOGRAPHY

Seminar reports on problems and current research in various areas of oceanography by students.

For Information Contact:

John A. Knauss, Dean

Graduate School of Oceanography

University of Rhode Island

KIngston, Rhode Island 


\section{San Diego State College San Diego, California}

\section{DIVISION OF LIFE SCIENCES}

Instructional Staff:

ERIC G. BARHAM, Ph.D., Assistant Professor of Zoology RONALD W. CRAWFORD, Ph.D., Associate Professor of Zoology DAVID A. FARRIS, Ph.D., Assistant Professor of Zoology WILLIAM McBLAIR, Ph.D., Assistant Professor of Oceanography GORDON H. TUCKER, Ph.D., Professor of Zoology

Degrees Offered:

None - a minor in Oceanography and Aquatic Blology is being developed.

\section{Courses:}

\section{Oceanography}

100. THE OCEANS

MCBLAIR

Blological and physical aspects of the oceans and their significance to man; problems of modern oceanography.

\section{Blology}

111. AQUATIC BIOLOGY

\section{CRAWFORD}

Biological, chemical and physical considerations of inland waters.

112. FISHERY BIOLOGY

\section{FARRIS}

Theory and practices of fishery management. Life historles and biology of important game and food fishes.

113. BIOLOGICAL OCEANOGRAPHY

BARHAM

A study of benthic and pelagic marine organisms and their environmental parameters.

Zoology

112. MARINE INVERTEBRATES

TUCKER

Identification and study of behavior and Ife histories of invertebrates of the San Dlego region. Frequent collecting trips to the beaches required. 
115. ICHTHYOLOGY

CRAWFORD

Evolution, interrelationships, structure, identification, habits and ecology of fishes. 


\section{Scripps Institution of Oceanography Lesolla, California}

\section{DEPARTMEANT OF MARINE BIOLOGY}

\section{Instructional Staff:}

ANDREW A. BENSON, Ph.D., Professor of Biology DENIS L. FOX, Ph.D., Professor of Marine Blochemistry CARL L. HUBBS, Ph.D., Professor of Biology PER F. SCHOLANDER, M.D., Ph.D., Professor of Physiology BENUJAMINE E. VOLCANI, Ph.D., Professor of Microbiology CLAUDE E. ZOBELL, Professor of Marine Microbiology FRANCIS T. HAXO, Ph.D., Associate Professor of Biology (Chairman of the Department)

RALPH A. LEWIN, Ph.D., Associate Professor of Biology

GAIEWN E. JONES, Ph.D., Assistant Research Microbiologist MARTIN W. JOFNSON, Ph.D., Professor Emeritus

EDWARD W. FAGER, Ph.D., D. Phil,, Associate Professor of B10logy

\section{Degrees Offered:}

Master of Science in Marine Blology

Doctor of Philosophy in Marine Biolology

Upper Division Courses:

114. MARTNE VERTEBRATTES

HUBBS

121. MARINE MICROBIOLOGY

ZOBELU, JONES

Methods of studying bacteria and allied microorganisms, with particular reference to their importance as biochemical and geological agents in the sea.

125B. LABORATORY IN ALGAL PHYSIOIOGY

HAXO

125C. PHYSIOLOGY OF MARINE ALGAE

\section{HAXO}

Comparative physiology and biochemistry of algae with emphasis on marine problems. 
199. SPECIAL STUDIES

STAFF

Graduate Courses:

222. BIOCHROMES

FOX, HAXO

Physical and chemical foundations of color marifestation; the chemistry, distribution, metabolism, and significance of pigments occuring in the living world.

226. MARINE AND COMPARATIVE BIOCHEMISTRY FOX

Chemistry of living matter; osmotic adaptations, marine colloids; comparative biochemical and physiological activities of marine organisms; biochemical cycles in the sea; animal pigments.

227. EVOLUTION IN THE MARINE WORLD HUBBS

Origin and evolution of sea and its organisms. Migration from and to the sea. Adaptation and speciation in various habitats. Experimental studies on evolution of marine forms.

252. SEMINAR IN EXPERIMENTAL AND COMPARATIVE BIOLOGY VOLCANI, STAFF

260. SEMINAR IN ADVANCED ICHTHYOLOGY HUBBS

285. ILABORATORY IN PHYSIOLOGY SCHOLANDER

Research techniques and problems in selected areas of environmental physiology.

299. RESEARCH

STAFF

Research in such biological fields as: phycology, biophysics, genetics, evolution, microbiology, vertebrate and invertebrate zoology, comparative biochemistry or physiology of marine plants and animals. Students must present evidence of satisfactory preparation for the work proposed.

For Information Contact:

Dr. Francis T. Haxo

Chairman, Department of Biology

Scripps Institution of Oceanography

Lajolla, Califormia 


\section{DEPARTMENT OF OCEANOGRAPHY}

\section{Instructional Staff:}

JOHN D. ISAACS, B.S., Professor of Oceanography

FRED B. PHLEGER, Ph.D., Professor of Oceanography and Director of Foraminifera Laboratory

NORRIS W. RAKESTRAW, Ph.D., Professor of Chemistry

ROGER REVELLE, Ph.D., D. Sc., Professor of Oceanography and Director of the Scripps Institution of Oceanography

MILNER B. SCHAEFER, Ph.D., Professor of Oceanography and Director of the Institute of Marine Resourses

FRANCIS P. SHEPARD, Ph.D., Professor of Submarine Geology

FRED N. SPIESS, Ph.D., Professor of Oceanography and Director of the Marine Physical Laboratory

WARREN S. WOOSTER, Ph.D., Professor of Oceanography

ROBERT S. ARTHUR, Ph.D., Associate Professor of Oceanography CHARLES S. COX, Ph.D., Associate Professor of Oceanography EDWARD W. FAGER, Ph.D., D. Phil., Associate Professor of Blology (Chairman of the Department)

DOUGLAS L. INMAN, Ph.D., Associate Professor of Geology

KIAUS L. HASSELMANN, Ph.D., Assistant Professor of Oceanography JOHN A. McGOWAN, Ph.D., Assistant Professor of Oceanography MELVIN N. A. PETERSON, Ph.D., Assistant Professor of Oceanography PHILIP RUDNICK, Ph.D., Research Physicist, and Lecturer

GIFFORD C. EWING, Ph.D., Associate Research Oceanographer and Lecturer

JEFFERY D. FRAUTSCHY, B.S., Associate Research Engineer, Lecturer and Assistant Director of the Scripps Institution of Oceanography

TJEERD H. VAN ANDEL, Ph.D., Associate Research Geologist, and Lecturer

JOSEPH R. CURRAY, Ph.D., Assistant Research Geologist, and Lecturer WILLIAM R. RIEDEL, M.S., Assistant Research Geologist and Lecturer EDWIN L. HAMILTON, Ph.D., Research Associate and Lecturer

$$
\star * \star * *
$$

MILTON N. BRAMLETTE, Ph.D., Professor Emeritus

EDWARD D. GOLDBERG, Ph.D., Professor of Chemistry

CARL H. ECKART, Ph.D., Professor of Geophysics

CARL L. HUBBS, Ph.D., Professor of Biology

MARTIN W. JOHNSON, Ph.D., Professor Emeritus

WALTER H. MUNK, Ph.D., Professor of Geophysics

FRANCIS T. HAXO, Ph.D., Associate Professor of Blology 


\section{Degrees Offered:}

Master's Degree in Oceanography

Because of Iimited facilities, the Department does not at the present time encourage students who wish to proceed only to the master's degree. Special arrangements can, however, be made if circumstances warrant 1 .

\section{Doctor of Philosophy in Oceanography}

Upper Division Courses:

\section{INIRODUCTION TO PHYSICAL OCEANOGRAPHY ARTHUR}

Physical description of the sea; physical properties of sea water; boundary processes including interaction between sea and atmosphere; principles of dynamics applied to motion and distribution of variables; methods of measurement with demonstration at sea.

IIOC. INIRODUCIION TO DYNAMICAL OCEANOGRAPHY ARTHUR, COX

Mechanics of fluids on a rotating earth; Napier-Stokes equations, boundary layer phenomena, turbulent flows, and wave motion with oceanographic applications.

\section{SUBMARTIE GEOLOGY SHEPARD, INMAN}

The topography and sediments of the ocean floor, and their recent history; sedimentary processes as they affect the shore, continental shelf, and ocean floor; comparison between recent sediments and sedimentary rocks; the development of coral reefs.

IIIC. ANALYSIS OF SEDIMEANTS

CURRAY

Lectures and laboratory study of methods of analysis and interpretation of sediments, especially grain-size distributions and composition of the sand-size fraction.

112. BIOLOGY OF THE SEA

An integrated survey course dealing with fundamental aspects of the biological economy of the sea; the explanation of biologically associated marine phenomens; and the interrelation of biological, chemical, and physical processes in the environment.

112C. MARINE ORGANISMS

MCGOWAN

Laboratory and discussion of the phylogeny, comparative morphology, life historles and taxonomy of maxine organisms. Emphasis will be placed on plantonlc groups. 
113. CHEMISTTRY OF SEA WATER

RAKESTRAW, GOLDBERG

Chemical compositon of sea water; physical properties of sea water; biochemical activity in the oceans; marine sedimentation; thermodynamic considerations; history of the oceans; models of oceans from chemical considerations; problems of measuring composition.

118. STATISTICS

FAGER

Methods of statistical analysis; sampling and design of experiments applicable to marine studies.

118C. COMPUTER PROGRAMMING

PERRY

The logic of computer programing for statistics applications using automatic coding systems; median, mean, range, variancecoveriance, regression, distributions. Especially designed for students in marine geology and biological oceanography.

119. TIME SERIES

RUDNICK

Correlation functions; linear filtering; applications to geophysical time series.

123. INTRODUCTION TO MECHANICS OF MARTNE SEDIMENTATION INMAN

Marine sedimentary processes, including waves, currents and tides, and their effect on sediment transport and the formation of beaches and other sedimentary structures.

199. SPECIAL STUDIES

STAFF

Graduate Courses:

210. PHYSICAL OCEANOGRAPHY, GENERAL

ARTHUR

Dynamics of ocean currents; turbulence; wind currents; atmospheric boundary layer; water masses and circulation of the ocean.

271. WAVES

$\operatorname{cox}$

Generation and propagation of surface and internal waves; wind waves, swell and surf; wave action on beaches; methods of observation; field work. 
217. HYDRODYNAMICS

ECKART

Application of hydrodynamics to the motion of stratified fluids, such as the atmosphere and oceans. Internal waves, steady currents, and related phenomena.

219A. MARINE MICROPALEONTOLOGY

BRAMLETIE, PHIEGER, RIEDEL

Introductory lectures and laboratory study of the principal groups of marine microfossils, with special emphasis on the applications to problems of oceanography, and paleoceanography.

219B. MARINE MICROPAIIEONTOLOGY

BRAMIETIE,

PHLEGER, RIEDES

Advanced study of specific groups of microfossils in the marine environments, emphasizing their ecology and stratigraphic applications.

220. SPECIAL TOPICS IN OCEANOGRAPHY STAFT

Within the next few years the following subjects will be given:

PRINCIPLES OF OCEANOGRAPHIC RESEARCH SYSTEMS

SOUND AND LIGHT OF THE SEA

POPULATION DYMAMICS

ZOOGEOGRAPHY OF THE SEA

ADVANCED METHODS OF FISHERIES RESEARCH

NUMERICAL ANALYSIS

STUDIES OF TURBULENCE AND WAVES

223. IITTORAL PROCESSES

INMAN

Study of the physical processes in the nearshore environment, including waves and currents and their effect on the transportation of sediments and the formation of sedimentary features.

224. PETROGRAPHY OF SEDIMENTS

VAN ANDEL, BRAMLETPE

Lectures and laboratory. Principles of sedimentary petrology; techniques of sediment analysis; microscopic mineralogy, thin section analysis, laboratory analysis; graphical and statistical data processing. 


\section{MARINE ECOLOGY}

Behavior, single-species population dynamics, interspecific relationships and environmental factors as they relate to the distribution and abundance of marine organisms.

226. ADVANCED INVERTEBRATE ZOOLOGY

NEWMAN

This course will cover the natural history, zoogeography, taxonomy and phylogeny of selected invertebrate groups. Entuphasis will be on the broader aspects of current research. Two special problems w1ll be undertaken during the semester, orlginal problems will be encouraged.

229. MARINE SEDIMENTS

VAN ANDEL

Advanced treatment of special topics in sedimentology; selected examples of sediment research; trends of sediment research and their influence on geological thinking; application of sediment studies to stratigraphy and paleogeography.

250. SEMINAR IN OCEANOGRAPHY

STAFF

251. PROBLEMS IN GENERAL AND PHYSICAL OCEANOGRAPHY STAFT

Presentation of reports, review of literature, and discussion of current research in general oceanography and physical oceanography.

253. PROBLENSS IN BIOLOGICAL OCEANOGRAPHY

STAFF

Presentation of reports, review of literature, and discussion of current research in biological oceanography.

255. PROBLFMS IN MARINE GEOLOGY

STAFF

Orlgin and structure of ocean basins and continental margins, and their physiographic features. Origin, distribution, interpretation, and methods of study of marine sediments.

299. RESEARCH

STAFF

Research in one or more of the oceanographic sciences.

\section{For Information Contact:}

Dr. Edward W. Fager

Chairman, Department of Oceanography

Scripps Institution of Oceanography

LaJolla, California 


\section{The University of Southern California \\ Los Angeles 7, California}

In addition to the usual research laboratory facilities, the University of Southern California students have access to the outstanding library and marine biological collections of the Allan Hancock Foundation. Much of the work in marine sciences is made possible through the use of the Hancock Foundation's 110-foot vessel, VELERO IV.

Blological research includes ecologic, systematic and blogeographic studies of marine animals and plants. Field investigations are in progress off the southern California coast, and in the Arctic and Antarctic Oceans.

Geological research is concentrated in the shallow waters and on sediments of the continental margins with emphasis on quantitative studies of chemical, physical and biological parameters.

DEPARTMENT OF BIOLOGICAL SCIENCES

\section{Instructional Staff:}

PAUL R. SAUNDERS, Ph.D., Professor and Head

LESLIE A. CHAMBERS, Ph.D., Professor, Director of Allan Hancock Foundation

E. YALE DAWSON, Ph.D., Professor

JOHN L. MOHR, Ph.D., Professor

RICHARD TIBBY, Ph.D., Professor

JOHN GARTH, Ph.D., Associate Professor

OLGA HARTMAN, Ph.D., Assoclate Professor

JAY M. SAVAGE, Ph.D., Assoclate Professor

GERALD J. BAKUS, Ph.D., Ass1stant Professor

RUSSEL L. ZIMMER, M.S., Instructor

The following persons do not hold appointments in the Department of Biological Sclences but are Research Associates of the Allan Hancock Foundation and are engaged in marine blological research:

JOHN D. SOULE, Ph.D.

FRED C. ZIESENHENNE, M.S.

Degrees offered:

Master of Science in Biology with specialization in Marine Blology Doctor of Philosophy in Blology with specialization in Marine Biology

Graduate Courses:

506ab. SEMINAR

STAFF

Review of current biological literature; assignments in the fields of special interest or research. 
509abL. INVERTEBRATE ZOOLOGY

ZIMMER

Living animals, particularly marine invertebrates; their habitats, lncluding mud flats, sandy beaches, rocky shores.

510abL. SPECIAL PROBLEMS IN BIOLOGY

STAFF

Library or laboratory investigation of research problems in a selected fleld of biology.

530ab. SEMINAR IN MARINE INVERTEBRATE ZOOLOGY STAFF

542L. ICHTHYOLOGY. SAVAGE

Evolution, systematics, ecology, behavior, life history, and distribution of living fishes, including the basic principles of fisheries biology.

546L. CRUSTACEAN BIOLOGY

GARTH

Systematics, morphology, physiology, ecology, life history, distribution, behavior, and experimental use of living crustacea.

550L. BIOLOGICAL OCEANOGRAPHY

TIBBY

Marine enviroments with reference to the distribution and dynamics of biotic commities.

552L. DEEP-SEA BIOLOGY

The fauna of the deep-sea below 2000 meters in relation to the various characteristics of the environment.

573L. MARINE ECOLOGY

BAKUS

Interrelationships between marine populations and communities and their enviroments.

580L. MARINE BOTANY

DAWSON

Morphology, anatomy, ecology, physiology, life histories, evolution and distribution of marine plants.

790ab. RESEARCH

STAFF

For Information Contact:

Dr. Paul R. Saunders, Head

Department of Blological Sciences

University of Southern California

University Park

Los Angeles 7, California 


\section{DEPARTMENT OF GEOLOGY}

Instructional Staff:

ORVILIE L. BANDY, Ph.D., Professor

THOMAS CLEMENTS, Ph.D., Professor Emeritus

GREGORY A. DAVIS, Ph.D., Assistant Professor

DONN S. GORSLTNE, Ph.D., Associate Professor

JACK GREEN, Ph.D., Adjunct Professor

Degrees Offered:

Master of Arts in Geology with specialization in Oceanography

Doctor of Philosophy in Geology with specialization in Oceanography.

Upper Division Courses:

460L. DESCRIPTIVE GEOCHEMISTRY

GREEN

Geochemical structure of the earth; distribution and geochemical behavior of elements in the lithosphere and other geochemical spheres. Iecture and Lrboratory.

478I. MICROPALEONTOLOGY

BANDY

Microscopic fossils; Foraminifera; ostracods, conodonts; classification, common genera, morphology, evolutionary trends; laboratory and field techniques.

Greduate Courses:

500. PALEOECOLOGY

BANDY

Classification of marine habitats; criteria for recognizing paleoecologic conditions; study of changing environments based on fossil assemblages.

510. SEDIMENTARY PROCESSES

GORSLINE

Origin, trensportation, deposition of sediments; conditions modifying sedimentary processes; environments of sedimentation; interpretation of former climatic and physiographic conditions. 
511. SEDIMENTARY TECHNIQUES

GORSIINE

Collection of samples; analyses for grain size, gross fractionation methods; description and interpretation of sediments.

512. OCEANOGRAPHY

GORSIINE

Chemical and physical properties of sea water; movement of water masses; relation of water characteristics to meteorological factors; relation of marine organisms to water composition.

514. MARINE GEOLOGY

GORSLINE

Origin of ocean basins, characteristics of rock underlying the ocean floor; development of island arcs, continental shelves, continental slopes, submarine canyons, coral reefs.

519L. SEDIMENTARY PETROGRAPHY

CLEMMENTS

Application of the microscope to the study of sediments.

550ab. SPECIAL PROBLFMS

STAFF

Intensive study in one or more of the fields of geology.

560. ADVANCED GEOCHEMISTRY SEMINAR GREEN

Selected research problems in elemental abundances and distribution in the geochemical spheres.

578L. ADVANCED MICROPALEONTOLOGY

BANDY

Microfaunal correlations; stratigraphic sequence of microfaunas; phylogenesis of foraminifera; paleoecology; applied micropaleontology; reports on microfaunas from local and foreign strata.

790ab. RESEARCH

STAFF

An intensive study of specific problems under the direction of a member of committee of the staff in Geology.

For Information Contact:

Dr. Donn S. Gorsline

Department of Geology

University of Southern California

Ios Angeles 7, California 


\section{Stanford University}

Stanford, California

HOPKINS MARINE STATION, Pacific Grove, California

Instructional Staff:

DONALD P. ABBOTT, Ph.D., Associate Professor of Biology

ISABELLA A. ABBOTT, Ph.D., Research Biologist

LAWRENCE R. BLINKS, Ph.D., Professor of Blology, and Director

ROLF L. BOLIN, Ph.D., Professor of Marine Biology and Oceanography, and Assistant Director

CHARLES A. GIESE, Ph.D., Professor of Biology

CORNELIS B. VAN NIEL, D.Sc., Herzstein Professor of Blology

JOHN H. PHILlIPS, Ph.D., Assistant Professor of Blology

Degrees Offered:

Master of Science in Marine Blology

Doctor of Philosophy in Marine Biology

Courses (Autumn, winter and spring quarters):

Although formal courses will not be offered, the staff will welcome the opportunity to direct work of graduate and undergraduate students in the flelds indicated. The tides and weather permit collecting throughout the year, in some cases even more successfully than in the sumer.

199h. SPECIAL PROBLEMS

STAFF

Properly qualified undergraduate students may undertake individual work in the fields indicated under Course $300 \mathrm{~h}$. Such studies are intended to introduce the serious student to methods of research. Arrangements must be made by consultation or correspondence.

$300 \mathrm{~h}$. RESEARCH

Graduate study involving original work may be undertaken with members of the staff in the fields indicated.

\section{MARINE ZOOLOGY}

ABBOTT

Problems connected with the anatomy, taxonomy, development, and ecology of marine invertebrates. 
Problems of general and cellular physiology, especially of marine plants. Permeability, photosynthesis, and bioelectric phenomena are especially under study.

MARINE FISHES, ECOLOGY BOLIN

Morphology, taxonomy, embryology and ecology of marine fishes. Oceanic biology.

PHYSIOLOGY

GIESE

Problems on the physiology of invertebrate animals; photoblology, especially the effects of ultraviolet light.

MICROBIOLOGY

VAN NIEL

Morphology, taxonomy, and biochemistry of the various groups of micro-organisms.

BIOCHFMISTRY AND IMMUNOLOGY

PHIITIPS

Comparative biochemistry and immunology of narlne organisms. SUMMER QUARTER

Evening Iectures and Seminars

These are given by visiting scientists as occasion offers.

100h. MARINE ALGAE

HOLLENBERG

Lectures, laboratory, and field work on the various classes of algae. Particular attention will be given to the marine algae of the Pacific Coast.

101h. NATURAL HISTORY OF MARINE ANIMALS

HADERLTE

This course provides an opportunity for the student to visit several different types of marine habitats, to become acquainted with about 400 named species of living animals representing most of the known phyla and classes, and to examine more carefully about 50 living forms. Stress is placed upon the adaptations which fit the animals for life in their particular habitats. 
11Ih. MARINE INVERTEBRATES

ABBOTT

Survey of the lower marine invertebrates, echinoderms, and protochordates. Erphasis is placed on basic body plan, functional anatomy, pattern of development, higher classification, and phylogenetic relationships, rather than on detailed morphology and species identification.

153h. GENERAL MICROBIOLOGY

VAN NIEL

This course will be concerned mainly with the methods of culture, the morphology, general physiology and ecology of representative types of micro-organisms.

169h. ECOLOGICAL PHYSIOLOGY

GIESE

Physiological responses of animals to variations in environmental factors and to organisms. Most of the work will deal wil marine invertebrates.

199h. SPECIAL PROBLEMS (see above, autum, winter, and spring quarters)

300h. RBSEARCH (see also above, autum, winter, and spring quarters)

Candidates for advanced degrees may work on thesis problems with staff members, in either half of the quarter or during the full quarter.

\section{SECOND HALF}

112h. MARINE INVERGEBRATES (continued)

ABBOTT

Contimuation of Course $11 \mathrm{~h}$, covering the molluscs, annelids, arthropods, and allied lesser phyla. While the two courses form a continuous sequence, either half may be taken separately when space permits.

136h. GENERAL ICHTHYOLOGY

COHENT

An introduction to the study of Iishes, including the elements of morphology, taxonomy, embryology, natural history, and principles and techniques of conservation. Commercially important, very common, or spectacularly modified groups of North American fishes are stressed, and local material collected by the class if used in the laboratory. 
154h. GENERAL MICROBIOLOGY (Continued) VAN NIEL

In the second half-quarter, the material of Course $153 \mathrm{~h}$ will be expanded, and special emphasis will be placed on the biochemical properties of micro-organisms, from which the fundamentals of "oomparative biochemistry" will be derived. Some general methods for the study of biochemical phenomena will be presented.

164h. PHYSIOLOGY OF ALGAE

BLTNKS

Lectures and experiments on the physiology of fresh-water epiphytic, marine and brine algae. Osmotic and salt effects, permeability, respiration, pigments, photosynthesis and tropisms are among the topics studied.

199h. SPECIAI PROBLEMS (see under First Half)

300h. RESEARCH (see under First Half) 


\author{
University of Texas
}

Austin, Texas

INSTITUTE OF MARINE SCIENCE, Port Aransas, Texas

The Institute of Marine Science at Port Aransas, Texas is a division of The Main University of Texas at Austin. The permanent staff is primarily concerned with basic research and graduate instruction with an integrated teaching program in Marine Science made up of the course offerings of the Institute and related departments of science and engineering on the main campus. The resident faculty research programs are Ecology, Ichthyology, Microbiology, Geology, and Chemistry. The Institute serves as an outlet to the sea for higher education in the southwestern region through its service program for classes, visiting investigators, and summer students. Also conducted are studies which are basic to the development of the Marine Resources of Texas.

Instructional Staff:

H. T. ODUM, Ph.D., Director, Lecturer in Zoology, Biological Oceanography Limnology, Ecosystems.

E. W. BEHRENS, Ph.D., Lecturer in Geology. Marine Geology, Sedimentation

R. J. BEYERS, Ph.D., Comparative Ecology, Microcosms.

J. C. BRIGGS, Ph.D., Lecturer in Zoology, Ichthyology, Marine Zoogeography

B. J. COPELAND, M.S., Limnology, Pollution Ecology,

LLOYD HAMPTON, M.A., Lecturer in Physics, Defense Research Laboratory, Marine Acoustics.

C. VAN BAALEN, Ph.D., Lecturer in Botany, Marine Microbiology, Algal Physiology.

Degrees offered:

The Master of Science and Doctor of Philosophy degrees are offered in marine sciences in cooperation with main campus Departments of Geology, Microbiology, Zoology, Chemistry, Botany, Physics, and Environmental Health Engineering.

Summer Courses:

(The Institute of Marine Science is primarily a research organization and offers extensive course work only in the summer.)

\title{
382.1 MARINE INVERTEBRATES
}

A Advanced consideration of classification, morphology, development, and natural history of marine invertebrates. 
382.2. MARINE' MICROBIOLOGY

VAN BAALEN

Isolation and physiology of marine microorganisms and consideration of their role in marine processes.

382.3. MARINE GEOLOGY

BEHRENS

Geological processes and methods for exploring the sea floor. Special emphasis on sedimentation in gulf and bay environments.

382.4. MARINE BOTANY

Biology of marine plants with special reference to those of the Gulf of Mexico.

382.5. MARINE ICHTHYOLOGY

BRIGGS

The systematics of fishes, including their major classification, comparative anatomy, embryology, and general distribution.

382.6. MARINE CHEMISTRY

Chemical processes in the sea.

481. BIOLOGICAL OCEANOGRAPHY AND MARINE ECOLOGY ODUM

Study of communities, populations, and biological processes in marine environments. Consideration of environmental influences, productivity, biochemical cycles, and conservation. May count as zoology. Lectures, laboratory, field work, and introduction to periodical literature.

680. RESEARCH

680.1. BIOLOGICAL OCEANOGRAPHY, MARINE ECOLOGY, LIMNOLOGY

680.2. MARINE MICROBIOLOGY

680.3. MARINE GEOLOGY

680.4. MARINE BOTANY

680.5. MARINE ICHTHYOLOGY 
680.6. MARINE CHEMISTRY

690. GENERAL MARINE SCIENCE

ODUM, HAMPTON,

An introduction to the science of the sea. Lectures, laboratory, and field work.

For information contact:

Dr. H. T. Odum

Director, Institute of Marine Science

Port Aransas, Texas 


\title{
Virginia Institute of Marine Science Gloucester point, Virginia
}

In affiliation with: College of William and Mary Williamsburg, Virginia

\author{
University of Virginia \\ Charlottesville, Virginia
}

The Institute, a major research and teaching center in marine science, is located on deep water 30 miles from the mouth of Chesapeake Bay. Facilities include modern permanent laboratory buildings, a research fleet with regular cruises over the continental shelf and an all year round research program.

All classwork and graduate study is directed by working scientists in the environment of an active marine research program. Modern laboratory and field instruments are available.

Research is being carried on in marine ecology, pollution problems, microbiology, radiobiology, diseases of shellfish, fish life histories, fishery biology, geology, physical oceanography and parasitology.

Instructional Staff:

WILLIAM J. HARGIS, JR,, Ph.D., Dean and Professor of Marine Sciences

JAY DONALD ANDREWS, Ph.D., Professor of Marine Science MORRIS LEROY BREHMER, Ph.D., Professor of Marine Science EDWIN BIBB JOSEPH, Ph.D., Professor of Marine Science WILlARD ABRAHAM VAN ENGEL, Ph.B., Ph.M., Professor of Marine Science

JOHN LANGILLE WOOD, Ph.D., Professor of Marine Science ROBERT E. LEE BLACK, Ph.D., Associate Professor of Marine Science and Biology

PHILIP WYMAN HARRISON, Ph.D., Associate Professor of Marine Science

DEXTER STEARNS HAVEN, M.S., Associate Professor of Marine Science

GEORGE MOSKOVITS, Ph.D., Associate Professor of Marine Science MAYNARD M. NICHOLS, Ph.D., Associate Professor of Marine Science

JOHN JUDSON NORCROSS, M.S., Associate Professor of Marine Science

BERNARD ClARENCE PATTEN, Ph.D., Associate Professor of Marine Science

MARVIN LEROY WASS, Ph.D., Associate Professor of Marine Science LANGLEY HARRISS WOOD, A.M., Assistant Professor of Marine Science

EVELYN CLARE WELLS, M.S., Marine Science Librarian 
Associate Instructional Staff:

ALFRED R. ARMSTRONG, Ph.D., Professor of Chemistry

MITCHELL A, BYRD, Ph.D., Professor of Biology

ROBERT L. ELLISON, Ph.D., Professor of Geology, University of Virginia

BRUCE W. NELSON, Ph.D., Professor of Geology, V.P.I. WILLIAM W. SCOTT, Ph.D., Professor of Botany, V.P.I.

Degrees Offered:

Master of Arts in Marine Science from the College of William and Mary

Doctor of Philosophy in Marine Science from the University of Virginia

Majors in: Biological Oceanography, General Oceanography and Fishery Biology

Advanced Undergraduate and Graduate Courses:

401. INTRODUCTORY PHYSICAL OCEANOGRAPHY

NICHOLS

Physical paroperties of sea water, interaction with the atmosphere, movement of water masses, and dynamics of currents, waves and tides. Special emphasis in the laboratory will be devoted to techniques and instruments employed in biological, chemical, geological, and physical oceanography.

402. GENERAL MARINE ECOLOGY

STAFF

Studies of the interactions of biological, chemical and physical variables of the marine environment at the individual, population and community levels; distribition of marine organisms; development of the concept of the marine ecosystem as a generalized open system.

403. PROBLEMS IN MARINE SCIENCE

STAFF

Supervised projects selected to suit the needs of the advanced undergraduate student. Projects to be chosen in consultation with the hand of the student's major department, the supervising professor and the Dean of the School of Marine Science. Acceptable topic outlines and terminal project reports are required. 
Detailed, advanced study of special groups of marine organisms such as Mollusca or Crustacea, which are within the special interests and training of particular staff members. Emphasis on organisms of economic importance such as Balanus, Callinectes, Crassostrea.

405. SYSTEMATICS AND PHYLOGENY

HARGIS

General consideration of the principles and theories of systematics and phylogeny. Techniques of taxonomy, studies of the historical development of species and higher biological units.

406. MARINE BIOLOGY

STAFF

A general introduction to marine science including biological, chemical, geological and physical oceanography.

407. BIOMETRY I.

NORCROSS

Application of biometrical techniques to analysis of biological data. Enumeration statistics, measures of central tendency and dispersion. Analysis of variance and regression analysis.

408. ICHTHYOLOGY

JOSEPH

A detailed treatment of the biology of fishes including phylogeny and classification, functional morphology, speciation, respiration and reproduction.

409. CYBERNETICS

PATTFN

Elements of cybernetics, with special emphasis on application to biological systems: Nature of systems, change, the determinate machine, coupling and feedback, stability, black box problems, constraint, athe Markovian machine, automatic control, topics from information, game and decision theories.

410. MARINE AND FRESHWATER INVERTEBRATES

STAFF

Classification and identification, adaptation, ecology, life histories. Local marine, estuarine and freshwater forms emphasized. 
$\begin{array}{ll}\text { 411. MARINE GEOLOGY NICHOLS, } & \text { HARRISON }\end{array}$

Topography and structure of the sea floor, origin of the ocean basins, coral reefs, continental shelves, submarine canyons, depositional environments and sedimentary processes.

412. MARINE BOTANY

STAFF

A general introduction to the ecology and systematics of algae and spermatophytes encountered in the marine environment.

413. BIOGEOGRAPHY

WASS

A survey of biogeographic regions, their geological origin and the paleo- and neo-distribution of representative groups of organisms. Emphasis on marine environments.

415. BIOLOGICAL CHEMISTRY

STAFF

A consideration of the chemistry of biological systems.

417. BEHAVIOR OF MARINE ORGANISMS WOOD

A survey of physiological and ecological correlates of behavior, with emphasis on marine organisms and their environment; a critical review of behavioral theory: electrophysiological demonstrations of the interaction of sensory processes and environmental stimuli.

Graduate Courses:

501. MARINE SCIENCE SEMINAR

STAFF

The organization and presentation of scientific data. Oral discussion and written outlines and critiques of selected seminar topics are required of all students in the department.

502. BIOMETRY II. VAN ENGEL, STAFF

Correlation, covariance analysis, multiple regression, and curvilinear regression. 
503. ADVANCED PROBLEMS IN MARINE SCIENCE

STAFF

Supervised research projects selected to suit the needs of the graduate student. Projects to be chosen in eonsultation with the student's major professor and the Dean of the School. Acceptable research outlines and project reports are required. Training in specific areas such as marine parasitology, epidemiology and pathology of marine organisms, marine productivity, physiology of algae, experimental design, and other subjects which staff members are qualified to teach is also offered.

504. EMBRYOLOGY AND ANATOMY OF MARINE INVERTE- BLACK BRATES

The comparative embryology and adult anatomy of local representatives of all major phyla will be considered. Emphasis will be placed on the evolutionary relationships between groups. Experiments to illustrate possible mechanisms of fertilization, cleavage and organ differentiation will be performed.

505. RADIOBIOLOGY

BREHMER

A study of the principles of tracer techniques, procedures for radio-assay, limitations of tracer methodology, hazards, safe handling procedures with particular emphasis on the use of isotopes in marine research.

506. BIOLOGY OF PLANKTON

STAFF

The structure and dynamics of estuarine plankton communities, with emphasis on the local biota; classification, morphology and ecology of major constituents; planktological methods.

507. MARINE MICROBIOLOGY WOOD, STAFF

Morphology, physiology, ecology, taxonomy, methods of isolation, cultivation and identification of aquatic microoganisms with emphasis on those from the marine environment.

508. PHYSIOLOGY OF MARINE ORGANISMS

BLACK

Major physiological processes will be considered. Special attention will be given to those processes in which evolutionary trends are apparent. 
509. CHEMICAL OCEANOGRAPHY

STAFF

Introductory study of chemical processes in marine waters including composition of sea water, nutrients, carbon dioxide systems.

510. POLLUTION BIOLOGY

BREHMER

Study of the various types of pollutants, domestic and industrial wastes, soils, insecticides, herbicides and radioactive materials and their effects on the marine environment.

512. BIOENERGETICS

PATTEN

The biological processes of energy transformation: Elementary thermodynamics, photosynthesis, chemosynthesis, metabolish, respiration and trophodynamics.

514. LITTORAL PROCESSES

NICHOLS, HARRISON

Physical and chemical processes in the nearshore environments including littoral waves, tides, currents, transportation of sediments and the formation of sedimentary features.

516. ADVANCED PHYSICAL OCEANOGRAPHY

STAFF

Dynamics of ocean currents, turbulence, wind currents, waves, water masses and circulation of the ocean.

518. MARINE FISHERY SCIENCE

STAFF

Principles and techniques; including the theory of fishing, age and growth, methods of defining stocks, catch statistics, description of world fisheries, and life histories of selected species.

560. THESIS

Original research in Marine Science or Fisheries Biology. Project to be chosen in consultation with the student's major professor and the Dean of the School.

For information contact:

Dr. William J, Hargis, Jr.

Director

Virginia Institute of Marine Science

Gloucester Point, Virginia 
Walla Walla College

Co llege Place, Kashington

\section{WALLA WALLA COLLEGE BIOLOGICAL STATION}

\section{Instructional Staff:}

DONALD F. BLAKE, Ph.D., Instructor in Biology

HAROLD G. COFFIN, Ph.D., Professor of Biology, Director of the Biological Station, Head of the Department of Biological Sciences

BEATRICE T. EMERY; M.S., Assistant Professor of Biology

DONALD W. RIGBY, M.S., Assistant Professor of Biology

JOHN F. STOUT, Ph.D., Instructor in Biology

Degrees offered:

None

Courses: (summer only)

181. INVERTEBRATE ZOOLOGY

RIGBY

A study of the invertebrate animals of Puget Sound with emphasis on systematics and natural history.

182. ICHTHYOLOGY

STOUT

A systematic study of the fishes found in Puget Sound with a survey of the fishes of other waters.

183. MARINE BOTANY

EMERY

A systematic study of plants found in Puget Sound, with a survey of marine plants from other areas. Field trips by boat among the islands and dredging trips to collect sea weed specimens comprise most of the field work.

187. BIOLOGICAL OCEANOGRAPHY

COFFIN

A study of the geology, geography, and biology of the ocean.

169. LIMNOLOGY

BLAKE

A study of the factors responsible for the presence and distribution of animals and plants in fresh waters.

For information contact:

Dr. Earl Lathrop

Department of Biology

Walla Walla College

College Place, Washington 


\section{University of Washington}

Seattle 5, Washington

\section{DEPARTMENT OF OCEANOGRAPHY}

Instruction Staff:

KARL BANSE, Ph.D., (equivalent European degree), Assistant Professor of Oceanography

CLIFFORD A. BARNES, Ph.D., Professor of Oceanography

LAWRENCE COACHMAN, Ph.D., Assistant Professor of Oceanography JOE S. CREAGER, Ph.D., Assistant Professor of Oceanography THOMAS S. ENGLISH, Ph.D., Assistant Professor of Oceanography RICHARD H. FLEMING, Ph.D., Professor of Oceanography, Chairman of the Department

MEREDITH A. GROSS, Ph.D., Assistant Professor of Oceanography STANLEY R. MURPHY, Ph.D., Lecturer in Oceanography; Senior Physicist, Applied Physics Laboratory

ERLING J. ORDAL, Ph.D., Professor of Microbiology

MARICE RATTRAY, JR., Ph.D., Associate Professor of Oceanography FRANCIS A. RICHARDS, Ph.D., Associate Professor of Oceanography

Degrees offered:

Bachelor of Arts, Bachelor of Science, Master of Science, and Doctor of Philosophy in Oceanography

Undergraduate Courses:

101. SURVEY OF OCEANOGRAPHY

CREAGER, ENGLISH

Origin and extent of the oceans; nature of the sea bottom; causes and effects of currents and tides; animal and plant life in the sea. Recommended for nonmajors.

$110,111,112$. LECTURES IN OCEANOGRAPHY FLEMING

Weekly lectures, demonstrations, and tours to familiarize students with the subject matter and opportunities in oceanography. To be taken in the first or second year by students majoring in oceanography. May be entered any quarter. 
A description of the oceans and their relation to man; physical, chemical, biological, and geological aspects of the sea; areal distribution and seasonal cycles of properties; currents; factors affecting populations. Demonstrations and some classes abroad ship and in laboratories.

360. METHODS AND INSTRUMENTS IN OCEANOGRAPHY

VAN HAAGEN

Theory and practice of instrumental measurement and sampling in oceanography; shipboard equipment, position finding, selected information on equipment design and properties of materials, calibration and observation of the behavior of typical instruments.

390. GENERAL OCEANOGRAPHY BARNES, RICHARDS

Physical, chemical, biological, and geological aspects of the oceans. Introductory to all courses in 400 series.

401. GENERAL PHYSICAL OCEANOGRAPHY

BARNES

Physical properties and processes, interaction with atmosphere, theories and methods involved in ocean currents, waves, and tides. Not open to students who have taken 410 .

403. BIOLOGICAL OCEANOGRAPHY BARNES, ENGLISH

Marine organisms; biological aspects of life om tje sea' omf;iemce of the environment; principal habitats.

405. GEOLOGICAL OCEANOGRAPHY

\section{CREAGER}

Methods of marine geological exploration; physiography and structure of the ocean basins; processes of sedimentation; sediments in the marine environment.

410. PHYSICAL OCEANOGRAPHY

BARNES

Physical properties, processes, and the theory of the distribution of variables in the sea; mass and energy budgets.

411. OCEAN TIDES AND WAVES

RATTRAY

Cause, nature, measurement, analysis, and prediction of tides and tidal currents and surface waves. 
Characteristics of currents and of forces that establish and modify them; methods of direct measurement and computation, use of indirect techniques; associated distribution of mass and properties.

415. FUNDAMENTALS OF UNDERWATER ACOUSTICS

MURPHY

Wave equation in liquids and solids; propagation in inhomogeneous media; exact and approximate solutions related to actual properties of the ocean medium.

416. APPLICATIONS OF UNDERWATER ACOUSTICS

MURPHY

Characteristics of practical systems utilized in acoustic studies in the ocean, including sound sources and sound detectors. Physical limitations of actual systems.

421,422 . CIIEMICAL OCEANOGRAPHY

RICHARDS

Physical and chemical properties of sea water and marine products; methods of quantitative analysis.

423, 424. CHEMICAL OCEANOGRAPHY LABORATORY

RICHARDS

Laboratory problems in the analytical and physical chemistry of sea water and marine materials.

$440,441,442$. UNDERGRADUATE SEMINAR

FLEMING

Reviews of history and literature; description of local waters and applications of oceanography. Required of all majors.

452. SEDIMENTARY PROCESSES

GROSS

Origin, transportation and deposition of sediments; environments of sedimentation; interpretation of past climatic and physiographic conditions.

453. SEDIMENTARY TECHNIQUES

GROSS

Laboratory study and statistical analysis of physical properties of sediments; size analysis, texture, composition, porosity, permeability and mass properties; description and interpretation of sediments. 
460. FIELD EXPERIENCE IN OCEANOGRAPHY

COLLINS

Practical work on shipboard and ashore by participation in regular oceanographic operations on the "Brown Boat" and other vessels; chemical, physical, biological, and geological analyses; preparation of reports. (Offered Summer Quarter only.)

461. APPLICATIONS OF OCEANOGRAPHY

FLEMING

Analysis of special cases involving application of oceanography to practical problems.

499. UNDERGRADUATE RESEARCH

Research on assigned topics which may involve laboratory work, field work, or literature surveys. Open to qualified seniors.

Graduate Courses:

$511,512,513$. MARINE HYDRODYNAMICS

RATTRAY

Methods for solving problems in physical oceanography.

514. FIELD WORK IN MARINE HYDRODYNAMICS

RATTRAY

Application of marine hydrodynamics principles to field measurements. (Offered Summer Quarter when demand is sufficient.)

515. WAVES

RATTRAY

Application of marine hydrodynamics principles to wave motion in oceans.

516. OCEAN CIRCULATION

RATTRAY

Hydrodynamic theories concerning origin and characteristics of major ocean currents.

517. OCEANOGRAPHY OF INSHORE WATERS BARNES, RATTRAY

Theories and techniques of investigation and interpretation of conditions existing in inshore waters with particular reference to mixing and flushing and to areas adjacent to the state of Washington; use of dynamic models.

518. SEMINAR IN PHYSICAL OCEANOGRAPHY BARNES, RATTRAY

Lectures, discussions, and field and laboratory work on selected problems of current interest. 
519. INTERACTION OF THE SEA AND ATMSOPHERE

Interchange of heat, water, and energy; study of budgets and of mechanisms of exchange.

520. SEMINAR

521. SEMINAR IN CHEMICAL OCEANOGRAPHY

RICHARDS

Lectures, discussions, and field and laboratory work on selected problems of current interest.

523. ADVANCED PROBLEMS IN CHEMICAL OCEANOGRAPHY

RICHARDS

Field and laboratory work on selected problems of current interest.

531. SEMINAR IN BIOLOGICAL OCEANOGRAPHY

BANSE

Lectures, discussions, and field and laboratory work on selected problems of current interest.

532. MARINE MICROBIOLOGY

ORDAL

Ecology and biochemistry of marine bacteria.

533. ZOOPLANKTON ECOLOGY

STAFF

Adaptation, modifications, and life histories of animals in the plankton. Evaluation of methods and techniques used in field and laboratory studies. (Offered Summer Quarter only in alternate years beginning 1962, at Friday Harbor, Washington.)

534. PHYTOPLANKTON ECOLOGY

STAFF

Contemporary problems in marine phytoplankton investigation.

Evaluation of methods used in field and laboratory studies. (Offered Summer Quarter only in alternate years, beginning 1962, at Friday Harbor, Washington.)

535. ADVANCED PLANKTON ECOLOGY

BANSE

Factors controlling the distribution, abundance, and production of plankton organisms, with a consideration of recent methods of sampling and analysis.

536. BENTHOS ECOLOGY

BANSE

Quantitative consideration of the population of the sea-bed. Discussion of modern methods of sampling and analysis. Factors affecting production. 
551. SEMINAR IN GEOLOGICAL OCEANOGRAPHY

CREAGER

Lectures, discussions, and field and laboratory work on selected problems of current interest.

552. RESEARCH TECHNIQUES IN MARINE GEOCHEMISTRY

GROSS

Introduction to and evaluation of analytical techniques and instruments applicable to problems of marine geochemistry.

553. RESEARCH TECHNIQUES IN MARINE GEOLOGY

CREAGER

Planning field programs; selection of equipment and survey procedures; collection, analysis, compilation, and presentation of bathymetric and sediment data; evaluation of techniques and results.

555. MARINE GEOCHEMISTRY

GROSS

Geochemistry of the oceans and marine sediments.

556. ADVANCED MARINE GEOLOGY

CREAGER

Contemporary problems in marine geology; concepts supporting or at variance with accepted hypotheses; discussion of recent advances.

600. RESEARCH

700. THESIS

Special Courses:

X101. SURVEY OF OCEANOGRAPHY

STAFF

An evening class offered Autumn and Winter Quarters and also a day course during Summer Session, covering the same topics as the regular course.

385. THE WORLD OF WATER

FLEMING, SPECIAL STAFF

Oceanography and related earth sciences for junior and senior high school teachers; a summer institute for 30 selected teachers sponsored by the National Science Foundation. 
X380. DESCRIPTIVE OCEANOGRAPHY, THEORIES

FLEMING, STAFF AND METHODS

A survey of oceanography emphasizing coastal waters and the techniques used in the collection, analysis and presentation of data. For hydrographic surveyors. A contract course with the U.S. Coast and Geodetic Survey. 


\section{University of Wisconsin}

A graduate training program in oceanography and limology now exists at the University of Wisconsin. There is not now a separate department of oceanography or marine sclence. Instead, the training program will extend across department and college lines so as to take advantage of the courses and talent already avallable. The courses listed represent selected offerings in oceanography or closely related subjects. Specialization in a particular basic disclpline will be possible and expected of candidates in the program. Experience at sea or its equivalent is required of all candidates.

Research activity includes work on aerial sensing of sea surface phenomena; migration of fishes; marine sediments, both old and new; marine seismolOgy; geophysics of the Arctic basin; marine climatology; experimental hydrodynamics; and physical Iimnology of the Great Lakes.

A new Laboratory of Iimnology has been completed and is avallable for experimental work on oceanogrephic and limological problems. Two light aircraft are operated for aerial sensing of radiation over land and water surfaces, and a capability for instmmenting larger aircraft for over-ocean measurements of surface parameters and magnetic field has been developed.

Degrees Offered:

PH.D. In Oceanography and Limology

Minor in Oceanography for $\mathrm{Ph} . \mathrm{D}$. In other fields

DEPARTMENT OF AGRONOMY

Instructional Staff:

JAMES H. TORRIE, Ph.D., Professor

Courses:

139. BIOMETRY

TORRIE

DEPARTMENT OF CIVIL ENGINEERING

Instructional Staff:

ARNO T. LENZ, Ph.D., Professor, Chatrman

GERARD A. ROHLICH, Ph.D., Professor

JAMES R. VILLEMONTE, Ph.D., Professor

G. FRED LEE, Ph.D., Assistent Professor - water chemistry

PEIER I. MONKMEYER, Ph.D., Assistant Professor

Courses:

177. HYDRODYNAMICS

MONKMEYER

276. FREE SURFACE FLOW

MONKMEYER 
Water Chemistry Program

193. WATER ANALYSIS TLEE

205. WATER CHEMISTRY SEMINAR IEE

280. PRINCIPLES OF WATER CHEMISTRY LEE

280. ADVANCED TECHNIQUES OF WATER ANALYSIS IEE

DEPARTMENI OF BACTERIOLOGY

Instructional staff:

WILIIAM B. SARLES, Ph.D., Professor, Chairman

OSCAR M. ALIEEN, Ph.D., Professor

PERRY W. WILSON, Ph.D., Professor

STANLEY G. KNIGHT, Ph.D., Professor

HARIYN O. HALVORSON, Ph.D., Professor of Bacteriology and Botany

ELIZABEIH McCOY, Ph.D., Professor

Courses:

120. ADVANCED GENERAL MICROBIOLOGY

SARLES, ATUEN

123. SOIL MICROBIOLOGY

AIIEN

126. PHYSIOLOGY OF BACTERIA

WILSON, KNIGHR, HALVORSON

134. MOLDS, YEASTS AND ACTINOMYCETES

RAPER

230. TAXONOMY AND NOMENCLAUTTRE OF BACTERIA

McCOY

DFPARTMENT OF BOTANY

Instructional Staff:

GRANT COTTAM, Ph.D., Professor

RICHARD I. EVANS, Ph.D., Associate Professor

JOENATHHAN D. SAUER, Ph.D., Associate Professor

Courses:

103. ALGAE

EVANS

164. PLANT ECOLOGY

COTTAM 
DEPARTMENI OF GEOLOGY

Instructional Staff:

LEWIS M. CLINE, Ph.D., Professor, Chairman

JAMES DORMAN, Ph.D., Visiting Professor

ROBERT T. BLACK, Ph.D., Professor

ROBERT H. DOTT, Ph.D., Associate Professor

ROBERT P. MEYTR, Ph.D., Assistant Professor

Courses:

109. GEOMORPHOLOGY

BLACK

133. SEDIMENTATION

TYLER, DOTT

134. MARINE GEOLOGY

DOIT, STAFF

170. MARINE GEOPHYSICS

DORMAN

161. GRAVITY AND MAGNEIICS

STAFF

164. ELEMENPIARY SEISMOLOGY

STAFF

DEPARTMENT OF METEOROLOGY

Instructional Staff:

HEINZ H. IEITAU, Ph.D., Pyofessor, Chairman

REID A. BRYSON, Ph.D, Professor

ROBERT A. RAGOTZKIE, Associate Professor

WERNER SCHWERDTFEGER, Ph.D., Professor

Courses:

101. GENERAL METEOROLOGY

SCHWERDTFEGER

103. MICROMETEOROLOGY

IEITAU

140. DYNAMIC CLTMATOLOGY

BRYSON

144. INIRODUCTORY OCEANOGRAPHY

RAGOTZKIE

271.* PROGRAMS IN VISCOUS FLOW

IETPAU

272.* PROBLEMS OF TURBULENTI FLOW

LEITAU

*Jointly listed in Civil Engineering and Meteorology Departments. 


\section{DEPARTMENI OF ZOOLOGY}

Instructional Staff:

LFMUEL A. FRASER, Ph.D., Professor ARTHUR D. HASLER, Ph.D., Professor JOHN T. EMLEN, Ph.D., Professor JOHN C. NEESS, Ph.D., Professor LOWEIL E. NOLAND, Ph.D., Professor WILJIAM G. REEDER, Ph.D., Professor JOSEPH J. HICKEY, Ph.D., Professor of Wilalife

G. E. FOGG, Ph.D., Visiting Professor

C. H. MORTIMERR, Ph.D., Visiting Professor

D. H. CUSHING, Ph.D., Visiting Professor FERRIS NEAVE, Ph.D., Visiting Professor

Courses :

124. IIMNOLOGY

125. ECOLOGY OF FISHES

141. INVERTEBRATE ZOOLOGY

138. BIOLOGY OF VERTEBRATES

108. PROTOZOOLOGY

126. FIELD ZOOLOGY

170. BIOLOGY OF THE PLANKTION

231. BIOMEIRIC TECHNIQUES
HASLER

HASLER

FRASER

EMLEN, NEESS, REEDER

NOLAND

REEDER

FOGG, CUSHIRG, MORTIMER

HICKEY, NEESS

All Departments offer course number 200 for research credit.

For Further Information Contact:

Robert A. Regotzkle

Department of Meteorology

University of Wisconsin

Madison, Wisconsin 
Yale University

New Haven 11, Connecticut

\section{BINGHAM OCEANOGRAPHIC LABORATORY}

Instructional Staff:

ALYN C. DUXBURY, M.S., Research Associate and Lecturer in Mechanical Engineering

ALFRED W. EBELING, Ph.D., Research Assistant, Assistant Curator of Ichthyology, Instructor in Zoology

DANIEL MERRIMAN, Ph.D., Director, Associate Professor of Zoology

GRACE E. PICKFORD, Ph.D., Research Associate, Associate Professor of Zoology

GORDON A. RILEY, Ph.D., Associate Director, Professor of Oceanography (Zoology)

PETER J. WANGERSKY, Ph.D., Research Associate

Degrees Offered:

None

\section{Courses:}

Bingham Laboratory is primarily a research institution. However, the following two courses are offered in marine science:

134. ICHTHYOLOGY

A year's course involving classification, life histories, and the principles of fisheries biology.

135. OCEANOGRAPHY

A year's course, consisting of an intensive general survey of the history and principles of biology and chemical and physical oceanography. 


\section{ALPHABETICAL FACULTY LIST}

Donald P. Abbott, Stanford

Isabe11a A. Abbott, Stanford

Carl W. Adams, U of Hawaii

Richard M. Adams, Texas A\&M

Carlos Aguayo, U of Puerto Rico

George H. Allen, Humboldt State College

Oscar M. Allen, $U$ of Wisconsid

Luis R. Almodovar, $U$ of Puerto Rico

Yost U. Amrein, Pomona College

Jay Donald Andrews, Virginia Institure

Ernest E. Angino, Texas A\&M

Albert Arking, NYU

Alfred R. Amstrong, Virginia Institute

Samuel A. Arny, USDA Graduate School

Robert S. Arthur, Scripps Institution

John C. Ayers, U of Michigan

J. R. Bailey, Duke

W. Robert A. Bailey, U of Delaware

Gerald J. Bakus, U of Southern California

Orville L. Bandy; U of Southern California

Albert H. Banner, $U$ of Hawaii

Karl Banse, $U$ of Washington

Eric G. Barham, SanDiego State College

Richard A. Barkley, $U$ of Hawail

John P. Barlow, Cornell

Clifford A. Barnes, $U$ of Washington

H. L. Barnes, Pennsylvania State

T. F. Bates, Pennsylvania State

Paul S. Bauer, American U

E. W. Behrens, $U$ of Texas

Andrew A. Benson, Scripps Institution

Joseph W. Berg, Jr., Oregon State

Robert A. Berner, $U$ of Chicago

R. J. Beyers, $U$ of Texas

Charles A. Biese, Stanford

Francis Birch, Harvard

Robert E. Lee Black, Virginia Institute

Robert T. Black, $U$ of Wisconsin

Donald F. Blake, Walla Walla College

Harvey Blatt, U of Houston

Lawrence R. Blinks, Stanford

Edward G. Bottinger, U of Connecticut
C. G. Bookhout, Duke

Rolf L. Bolin, Stanford

Milton N. Bramlette, Scripps Institution

Morris Leroy Brehmer, Virginia Institute

Vernon E. Briard, $U$ of houston

J. C. Briggs, U of Texas

G. W. Brindley, Pennsylvania State

Wallace Broecker, Columbia

Andrew F. Bunker, NYU

M. D. Burkhardt, USDA Graduate School

Wayne V. Burt, Oregon State

Mitchell A. Byrd, Virginia Institute

John V. Byrne, Oregon State

Andrew G. Carey, Oregon State

James H. Carpenter, Johns Hopkins

George F. Carrier, Harvard

Dayton E. Carritt, MIT

Theodore Chamberlain, $U$ of Hawaii

Leslie A. Chambers $U$ of Southern California

D. C. Chandler, U of Michigan

Valentine J. Chapman, Oregon Inst, of Marine Biology

Jule G. Charney, MIT

A. F. Chestnut, $U$ of North Carolina

George W. Chu, $U$ of Hawait

Arnold M. Clark, $U$ of Delaware

George L. Clarke, Harvard

William H. Clayton, Texas AGM

Thomas Clements, $U$ of Southern California

Robert C. Cleverdon, $U$ of Connecticut

Lewis $M . C l i n e, U$ of Wisconsin

Johr D. Cochrane, Texas A\&M

Harold G. Coffin, Walla Walla College

Eugene E. Collins, $U$ of Washington

John T. Conover, $U$ of Rhode Island

B. 3. Copeland, U of Texas

Eugene F. Corcoran, $U$ of Miami

Milton J. Cormier, $U$ of Georgia

D. P. Costello, U of North Carolina

J. D. Costlow, Duke

Grant Cottam, $U$ of Wisconsin

Charles S. Cox, Scripps Institution 
Doak C. Cox, U of Hawail

Ronald W. Crawford, San Diego State College

Joe S. Creager, $U$ of Washington

Herbert Curl, Jr., Oregon State

Joseph R. Curray, Scripps Institution

D. H. Cushing, $U$ of Wisconsin

Franklin C. Daiber, U of Delaware

William Dwight Dather, Naval Postgraduate School

Benjamin Davidson, NYU

Gregory A. Davis, $U$ of Southern California

E. Yale Dawson, U of Southern California

David Dean, $\mathrm{U}$ of Connecticut

Meir H. Degani, SUNY Maritime College

Peter Dehlinger, Oregon State

William H. Dennen, MIT

John W. DeWitt, Humboldt State College

Manuel Diaz-Plferrer, $U$ of Puerto Rico

James Dorman, $U$ of Wisconsin

Robert H. Dott, U of Wisconsin

M. S. Doty, U of Hawaii

Charles L. Drake, Columbia

R. T. Duquet, Pennsylvania State

Leon S. Dure, U of Georgia

Alyn C. Duxbury, Yale

Robert G. Eagon, $U$ of Georgia

Alfred W. Ebeling, Yale

Carl H. Eckart, Scripps Institution

Ian E. Efford, Oregon Inst. of Marine Biology

Alfred W. Eipper, Cornell

Robert Elder, USDA Graduate School

Robert L. Ellison, Virginia Institute

Sayed Z. El-Sayed, Texas AGM

Beatrice T. Emery, Walla Walla College

Cesare Emiliani, U of Miami

John T. Emlen, U of Wisconsin

Thomas S. English, U of Washington

Richard I. Evans, $U$ of Wisconsin

Gifford C. Ewing, Scripps Institution

W. Maurice Ewing, Columbia

Edward W. Fager, Scripps Institution

W. E. Fahy, U of North Carolina
Paul H. Fan, U of Houston

David A. Farris, San Diego State College

Howard M. Feder, Oregon Inst, of Marine Biology

Charles J. Fish, U of Rhode Island

Richard $\mathrm{H}$. Fleming, $U$ of Washington

G. E. Fogg, U of Wisconsin

Gerald A. Fowler, Oregon State

Denis L. Fox, Scripps Institutióp

Guy A. Franceschini, Texas AGM

Peter W. Frank, Oregon Inst, of FMarine Biology

Dirk Frankenberg, $U$ of Georgia

Lemuel A. Fraser, $U$ of Wisconsin

Jeffery D. Frautschy, Scripps Institution

Hubert $W$. Frings, U of Hawail

Harry K. Fritchman, Oregon Inst, of Marine Biology

Herbert F. Frolander, Oregon State

Dave Fultz, U of Chicago

John Garth, $U$ of Southern California

James A. Gast, Humboldt State College

Peter W. Glynn, U of Puerto Rico

Edward D. Goldberg, Scripps Institution

Juan Gerardo Gonzalez, U of Puerto Rico

Richard M. Goody, Harvard

Bernard L. Gordon, Northeastern

Donn S. Gorsline, U of Southern California

William A. Gosline, $U$ of Hawail

W. P. Graebel, U of Michigan

I. E. Gray, Duke

Jack Green, U of Southern California

Leonard Greenfield, U of Miami

Robert Greenwood, $U$ of Houston

J. C. Griffiths, Pennsylvania State

Meredith A. Gross, $U$ of Washington

Harlyn 0. Halvorson, $U$ of Wisconsin

Edwin L. Hamilton, Scripps Institution

Lloyd Hampton, $U$ of Texas

William J. Hargis, Virginia Institute

Philip Wyman Harrison, Virginia Institute

Olga Hartman, $U$ of Southern California

Arthur D. Hasler, $U$ of Wisconsin

Klaus L. Hasselmann, Scripps Institution 
Dexter Stearns Haven, Virginia Institute Francis T. Haxo, Scripps Institution Joel $W$. Hedgpeth, U of the Pacific, U of Chicago

Bruce Heezen, Columbia

Philip Helfrich, U of Hawaii

Vernon J. Henry, U of Georgia

L. F. Herzog, Pennsylvania State

E. W. Hewson, U of Michigan

Joseph J. Hickey, $U$ of Wisconsin

Homer W. Hiser, U of Miami

M. H. Hommersand, U of North Carolina

Donald $W$. Hood, Texas A\&M

Warren J. Houck, Humboldt State College

J. L. Hough, U of Michigan

Henry G. Houghton, MIT

B. F. Howe11, Jr., Pennsylvania State

John J. Hoyt, $U$ of Georgia

Sidney C. Hsiao, U of Hawaii

Carl L. Hubbs, Scripps Institution

George L. Huebner, Texas A\&M

Gilbert C. Hughes, III, U of the Pacific

H. J. Humm, Duke

Frederick V. Hunt, Harvard

Russe11 P. Hunter, Duke

Wanda S. Hunter, Duke

Edward R. Ibert, Texas A\&M

Takashi Ichiye, Florida State

Clarence P. Idy11, U of Miami

Roy L. Ingram, $U$ of North Carolina

Douglas L. Inman, Scripps Institution

John D. Isaacs, Scripps Institution

Columbus O!D. Iselin, Harvard, MIT

Edwin S. Iversen, $\mathrm{U}$ of Miami

Dr. Richard H. Jahns, Pennsylvania State

Harry P. Jeffries, $U$ of Rhode Is 1 and

C. E. Jenner, U of North Carolina

Martin W. Johnson, Scripps Institution

Ralph G. Johnson, $U$ of the Pacific, $U$ of Chicago

T. W. Johnson, Duke

Albert C. Jones, U of Miami

Galen E. Jones, Scripps Institution

Edwin Bibb Joseph, Virginia Institute

Glenn Harold Jung, Naval Postgraduate School

James C. Kakvas, U of Delaware

Fred I. Kamemto, U of Hawaii

John W. Kanwisher, MIT

Samuel Katz, Rensselaer Poly

Delbar P. Keily, MIT
M. L. Keith, Pennsylvania State

Gene Ross Kellough, U of Houston

George C. Kent, Cornell

Bostwick H, Ketchum, Harvard

C. Albert Kind, $U$ of Connecticut

John M. Kingsbury, Cornell

Blair Kinsman, Johns Hopkins

John A. Knauss, U of Rhode Island

Stanley G. Knight, U of Wisconsin

Fritz F. Koczy, U of Miami

Eva Konrad, $U$ of Delaware

Louis S. Kornicker, Texas A\&M

Eugene N. Kozloff, $U$ of the Pacific

Dale C. Krause, $U$ of Rhode Island

James B. Krause, $U$ of Delaware

P. D. Krynine, Pennsylvania State

J. Laurence Kulp, Columbia

Taivo Laevastu, $U$ of Hawail

Charles E. Lane, $U$ of Miami

William M. Lanphere, Humboldt State College

Earl Lathrop, Walla Walla College

Dr. George H. Lauff, $U$ of Georgia

G. Fred Lee, $U$ of Wisconsin

Dale F. Leipper, Texas A\&M

Arno $T$. Lenz, $U$ of Wisconsin

Ralph A. Lewin, Scripps Institution

D. A. Livingstone, Duke

Frank G. Lowman, U of Puerto Rico

J. L. Lumley, Pennsylvania State

William A. Lund, $U$ of North Carolina

John C. Marr, U of Hawaii

Nelson Marshall, $U$ of Rhode Island

Donald C. Matthews, $U$ of Hawaii

W. Bruce McAlister, Oregon State

William McBlair, San Diego State College

James E. McCauley, Oregon State

Elizabeth McCoy, $U$ of Wisconsin

John A. MeGowan, Scripps Institution

Hugh J. McLellan, Texss A\&M

Robert L. McMasters, $U$ of Rhode Island

Giles W. Mead, Harvard

E1y Mencher, MIT

R. W. Menzel, Florida State

Daniel Merriman, Yale

Charles B. Metz, Florida State

Robert P. Meyer, $U$ of Wisconsin

Samuel P. Meyers, U of Miami

F. C. Michelson, $U$ of Michigan

James E. Miller NYU

Robert L. Miller, $U$ of Chicago

Ralph M. Moberly, $U$ of Hawaii 
John L. Mohr, U of Southern California Peter L. Monkmeyer, U of Wisconsin Raymond B. Montgomery, Johns Hopkins Hilary B. Moore, U of Miami J. Robert Moore, $U$ of Houston Richard Y. Morita, Oregon State C. H. Mortimer, $U$ of Wisconsin George Moskovits, Virginia Institute Barry S. Muir, U of Hawaii

Walter H. Munk, Scripps Institution Stanley R. Murphy, U of Washington John E. Nafe, Columbia

Ferris Neave, $U$ of Wisconsin

John C. Neess, U of Wisconsin

Bruce W. Nelson, Virginia Institute

Gerhard Neumann, NYU

William A. Newman, Scripps Institution

Maynard.M. Nicholos, Virginia Institute

Lowell E. Noland, U of Wisconsin

John Judson Norcross, Virginia Institute

Matthew F. Norton, American U

Worth D. Nowlin, Texas A\&M

Richard A. Nystrom, U of Delaware

Eugene P. Odum, $U$ of Georgia

H. T. Odum, U of Texas

Jack E. Oliver, Columbia

Katsuyuki noyama, NYU

Carl H. Oppenheimer, $U$ of Miami

Erling $\mathrm{J}$ : Orda1, $\mathrm{U}$ of Washington

Charles Osterberg, Oregon State

J. Rosson Overcash, Northeastern

Ray D. Owen, Cal. Tech.

Harding Owre, U of Miami

H. A. Panofsky, Pennsylvania State

Kilho Park, Oregon State

Bernard Clarence Patten, Virginia Institute

June G. Pattu110, Oregon State

William J. Payne, U of Georgia

William G. Pearcy, Oregon State

Willis E. Pequegnat, Texas A\&M

Melvin N...A. Peterson, Scripps Institution

Sverre Potterssen, U of Chicago

Norman A. Phillips, MIT
John H. Phillips, Stanford

Fred B. Phleger, Scripss Institution

Grace E. Pickford, Yale

Willard J. Peirson, Jr.., NYU

Orrin Pilkey, U of Georgia

George W. Platzman, U of Chicago

Lawrence R. Pomeroy, $U$ of Georgia

H. J. Porter, U of North Carolina

C. F. Powers, U of Michigan

David M. Pratt, $U$ of Rhode Island

Donald W. Pritchard, Johns Hopkins

K. M. Rae, U of Alaska

Robert A. Ragotzkie, $U$ of Wisconsin

E. H. Rainwater, $U$ of Houston

Norris W. Rakestraw, Scripps Institution

John E. Randa11, U of Puerto Rico

Edward C. Raney, Cornell

John S. Rankin, Jr., U of Connecticut

Maurice Rattray, $U$ of Washington

Susan S. Raup, Johns Hopkins

Sammy M. Ray, Texas AGM

Robert 0 . Reid, Texas A\&M

William G. Reeder, $U$ of Wisconsin

Emst S. Reese, $U$ of Hawail

Arthony Reso, $U$ of Houston

Roger Revelle, Scripps Institution

Francis A, Richards, $U$ of Washington

Richard L. Ridenhour, Humboldt State College

William R. Riedel, Scripps Institution

Donald W. Rigby, Walla Walla College

Wilbur A. Rinehart, Oregon State

Gordon A. Riley, Yale

Juan A. Rivero, U of Puerto Rico

C. Richard Robins, $U$ of Miami

Alan R. Robinson, Harvard

Gerald A, Rohlich, U of Wisconsin

Raphael R. Ronkin, $U$ of Delaware

Philip Rudnick, Scripps Institution

George R. Rumney, U of Connecticut

Gene A. Rusnat, $U$ of Miami

William Sackett, Columbia

Saul B. Saila, $U$ of Rhode Island

Emest 0. Salo, Humboldt State College

Muriel I. Sandeen, Duke

William B. Sarles, U of Wisconsin

Johnathan D. Sauer, U of Wisconsin 
Paul R. Saunders, U of Southern

$$
\text { California }
$$

Jay M. Savage, $U$ of Southern California Horace J. Sawin, U of Delaware

Milner B. Schaefer, Scripps Institution David R. Schink, U of Rhode Island

Per F. Scholander, Scripps Institution

Richard M. Schotland, NYU

R. F. Schmalz, Pennsylvania State

John J. Schule, USDA Graduate School

Morris Schulkin, USDA Graduate School

Donald C. Scott, U of Georgia

William W. Scott, Virginia Institute

Gunter Seckel, U of Hawaii

Richard W. Shafer, Oregon State

Francis P. Shepard, Scripps Institution

Robert R. Shrock, MIT

Carl N. Shuster, U of Delaware

John MeN. Sieburth, U of Rhode Island

Raymond Siever, Harvard

Silvio Simplicio, NYU

Donald M. Skauen, U of Connecticut

Lawrence F. Small, Oregon State

Theodore J. Smayda, $U$ of Rhode Island

F. G. Walton Smith, Oregon State

G. Fred Somers, U of Delaware

John D. Soule, U of Southern California Jerome Spar, NYU

Fred N. Spiess, Scripps Institution

Shirley Sparling, Oregon Inst. of Marine Biology

Victor P. Starr, MIT

Henry Stevens, USDA Graduate School

A. E. Stiven, U of North Carolina Joseph St. Jean, U of North Carolina Henry M. Stomme1, Harvard

John F. Stout, Walla Walla College

Elizabeth Strong, Oregon State

E. Dixon Stroup, Johns Hopkins

George Sutton, Columbia

Gustav A. Swanson, Cornell

Michio Takata, U of Hawaii

Walter Rowland Taylor, Johns Hopkins

Fred Telonicher, Humboldt State College

Albert L. Tester, U of Hawaii

Adam Thomas, $U$ of Houston
Warren Charles Thompson, Naval Postgraduate School

Charles Thor, SUNY Maritime College

Richard Tibby, $U$ of Southern California

James $H$. Torrie, $U$ of Wisconsin

Joshua I. Tracey, USDA Graduate School

Francis R. Trainor, $U$ of Connecticut

Marenes R. Tripp, $U$ of Delaware

Gordon H. Tucker, San Diego State College

John S. Tucker, $U$ of the Pacific

Sidney J. Twonsley, U of Hawaii

Tjeerd $\mathrm{H}$. Van Andel, Scripps Institution

C. Van Baalen, $U$ of Texas

Willard Abraham Van Engel, Virginia Institute

Richard H. Van Haagen, $U$ of Washington

Comelis B. Van Niel, Stanford

DeWitt C. Van Siclen, $U$ of Houston

Pieter Van Weel, $U$ of Hawail

F. J. Vernberg, Duke

George Veronis, MIT

James R. Villemonte, $U$ of wisconsin

William C. Vinyard, Humboldt State College

Benjamin E. Volcani, Scripps Institution

William S. Von Arx, MIT

Gilbert L. Voss, U of Miami

Peter 3. Wangersky, Yale

Germaine L. Warnke, $U$ of Puerto Rico

Marvin Leroy Wass, Virginia Institute

Kenneth L. Webb, U of Georgia

J. N. Weber, Pennsylvania State

Dwight A. Webster, Cornel1

Evelyn Clare Wells, Virginia Institute

Ralph M. Wetzel, $U$ of Connecticut

Peter K. Weyl, Oregon State

Jacob Bertram Wickham, Naval Postgraduate School

A. B. Williams, U of North Carolina

Robert H. Williams, $U$ of Miani

E. Bright Wilson, Jr., Harvard

J. T. Wilson, $U$ of Michigan

Perry W. Wilson, $U$ of Wisconsin

John W. Winchester, MIT

Warren Wisby, U of Miami

John Langille Wood, Virginia Institute 


\author{
Langley Harriss Wood, Virginia \\ Institute \\ Philip S..Woods, U of Delaware \\ Willian Joseph Woods, U of North \\ Carolina \\ George P. Woollard, $U$ of Hawaii \\ Warren S. Wooster, Scripps Institution \\ J. Lamar Worzel, Columbia \\ Georg Wust, Columbia
}

Bruce Wyatt, Oregon State

Ellis Yochelson, American U

John Zeigler, $U$ of Chicago

Harry Zeitlin, $U$ of Hawaii

Fred C. Ziesenhenne, $U$ of Southern California

Russel L. Zimmer, $U$ of Southern California

Claude E. Zobel1, Scripps Institution 


\section{APPENDIX 4}

AQUATIC SCIENCES IN THE GREAT LAKES AREA, SUBMITTED BY HON. JAMES H. WAKELIN, JR., ASSISTANT SECRETARY OF THE NAYY AND PREPARED BY ROBERT B. ABEL, EXECUTIVE SECRETARY, INTERAGENCY COMMITTEE ON OCEANOGRAPHY, INCLUDING OTHER DOCUMENTS ON SAME TOPIC 

A Q U A T I C S C I E N C E S

\section{N T H E}

GREAT LAKES A R E

Prepared by :

Robert B. Abel, Executive Secretary, Interagency Committee on Oceanography

June 1963

The Great liakes comprise the largest body of fresh water in the world. They are vitally important to health, recreation, economic growth, and cultural enhancement to the poples of the surrounding territories in the Inited itatos and Canada.

The increasine national. and rogional intercust in the Great l,akes as one of our great natural resources has brought to the attention of federal, state, and local authorities the urgent need tor a significant upgrading in research programs pertinent to the area.

It is the purpose of this report to tabulate studies in aquatic sciences being prosecuted under federal sponsorship or participation in this area. It should be noted, however, that extensive work is also being accomplished in projects supported independently by state governments and industry.

Subjects covered include all forns of aquatic science such as oceanography (in a laboratory sense); limnology; fresh water, marine, aud fisheries biology; and hydrosjhere-atmosphere programs. 
In recognition of the need for scientific research and productive development, the governments of the United States and Canada have joined in forming the International Joint Commission, whose objective is the safeguarding of the quality of the waters bounding Michigan; the Province of Ontario, and New York. Co-chairmen of this commission are Mr. Tino Roncalio for the United States and Mr. A. G. L. McNaughton for Canada. The work of this commission is but one evidence of the extremely advanced state of cooperation between federal, state, and county governments, colleges, and industrial concerns in prosecuting privately and federally sponsored programs.

In 1909 the United States and Canada signed the Boundary Waters Treaty. The International Joint Commission was created by that treaty. The treaty recognized the importance of the Great Lakes to both countries for:

(1) domestic and sanitary purposes;

(2) navigation including the services of canals;

(3) power and irrigation.

Since the treaty was signed, needs for industry, recreation, and conservation of fish and wildlifo have also come into prominence.

Approximately 4,600,000 people residing in about 90 neighboring communities obtain water from the Great Lakes and tributary rivers. Domestic water requirements are presently in excess of 888 million gallons per day. The size of the filtration and chemical treatment problems incident to this usage is obvious. A considerable amount of research and planning have gone into the establishment of the 39 major domestic water intakes. In many Instances chemical treatment involves special measures for removal of highly toxic compounds resulting from industrial waste.

Depredation by the lamprey and, other obrioxious living sources of infestation and destruction has almost totally halted all commercial fishing in the Great Lakes areas. However, there is considerable sport fishing in Lake Superior, Lake Huron, and Jake Trie. The Joint Commission is working closoly with federal and state fish and eame departmente to frotect those fisherfes and to plan for eventual expansion and recovery of commerefal. fishing. Numbers of areas contiguous to the waters are known as excellent hunting grounds, both public and private. These are primarily habitats for waterfowl. Here again the commission is active in supervising methods for control and conservation.

A number of public and private bathing beaches exist for recreational use in the Great Lakes area. The largest accommodates 40,000 people. Other forms of water recreation include pleasure boating and skin diving. Although the exact number is not known it is possible that there are 
nearlv 100,000 pleasure craft of a.1 sizes operating in these waters. The commission has becn actj.ve in combatting pollution, the worst obstacle to develolment of a large number of otherwise splendid potential resort areas.

It has heen repurted that, durine the last, ravinat jor season, which spans about eight ice free months, commerce passing through the Great Lakes area exceeded the combined tonnage transiting both the Panama and Suez Canals, in an entire year. It is interesting to note that about $85 \%$ of all of the iron ore produced in the United States is transported vis the Great Lakes. During the last decade Montreal was believed to be the second largest port in the entire North American Continent in terms of total tonnage handlea. This alone gives some indication of the enormous use being made of the Great Lakes for navigational purposes and of the interest of the Joint Commission representing the two governments in giving all possible encouragement and support to development of navigational aids, harbor and channel dredging programs, and ice forecasting projects.

The Commission works very clnsely with a large number of industrial interests including automotive, steam power, oil refining, pulp and paper, and chomjca] ard strnel. industries of all. kinds. Considerable aquatio research

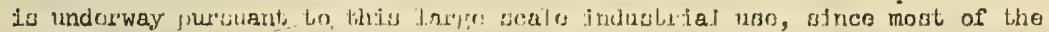
water is returned directily to the lakes as waste.

By far the must important function of the Commission is the overview of sanitation programs. Objectives in pollution contrel include tre creation of maintenance of clean and healtihy surroundings (including development of resort areas) the axpans:-or of industry, and tise furnishing of resources for agriculture, navigation, and power. In pursuance of these aims the Commission is concentrating its effort on:

(1) construction of treatment facilities;

(2) measurement of chemical constituentis of waste dischargos; and

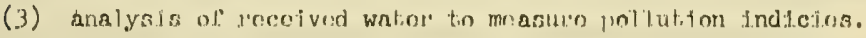

As evidence of the interest of the United istatics, louticularly in poilution studies, the I'ublic llealth Service supports more scientific prograns in the Great Lakes area than any other federal agency.

The Commission works very closely with the U.S. Public Health Service, Michigan Water Resources Commission, the Michigan State Department of Health, the Water Pollution Control Board of New York, the New York State Department of Health, the Department at National Health and Welfare of Carada and the Ontario Department of Health (Canada). The method of operatinn used by the Commission is usually to appoint, advisory boards of technical experts who plan, direct, and control fleld investigations and report their findings. The Comission then recomiends appropriate measures to the two governments. 
The Great Lakes Research Institute was established at the University of Michigan by act of the Board of Regents on May 16, 1965. The charter of the Institute included the "encouragement and integration of studies of the physical, chemical, biological, and other aspects of the Great Lakes and related areas." The Institute was reorganized as a division of the Institute of Science and Technology of the University of Michigan on April 1, 1960.

The division now states its objectives as follows:

(1) "to contribute by every means at its disposal to increase understanding of all aspects of the Great Lakes Region.

(2) To cooperate with other organizations on the campus (of the University of Michigan) within the state, and outside the state in the condurt. of mutually beneficial research on the Great Lakes and their tributary waters.

(3) To make available the results of Great Jakes investigations zad to make special efforts to place them in the hands of those concerned with practical operations.

(4) To serve in general as a center for Great Lakes information and research for the university, the state, and the Gre:at Lakes rrejion. of Michigan."

(5) To implement the teaching and research program of the Iniversit:

The primary finction of the divisjion it the r, rocesention of ressuares

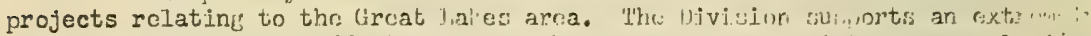
large and competent staff of oceanographurs, narine biolopistis, metcor'oin, ists, hydrologists, and a number of practitinnors of disciplines subordinate to trese.

The Division sponsors an annual conference on Great Lakes.research, normaliy held at the university at ann Arbor. Scientists from all of the active Great Lakes research organizations are invited to present papers at these conferences. At the same time each includes information on the objectives, organization, functions, and accomplishments of the research unit to which he belongs. This enables up-to-date compilations of the nature and activities of all of the organizations carrying out scientific programs of importance to the Great Lakes area. The last portion of each of these conferences is normally devoted to comprehensive panel discussions wherein the participant, summarize their impressions of' the current status of Great Lakes research. The final period of the conference is usual ty occupies in freneral disfinssion of ways and moans of improvin; the resfarch prograin.

A sccund activity of the Division is that of actinf, as a special. clearing house for compilation and distribution of deasrarch data related tor the area. The Division cooperates with the Great Lakes Comission in insuitu periodic research check lists of this area. 
The Sixth Conference on Great Lakes Research has just been completed (June 13-15, 1963). It was conducted in conjunction with the 26th annual meeting of the American Society of Limnolegy and Oceanography. The program theme was the Aquatic Environment. The entire period was divided into sessions covering:

(1) Physical characteristzs,

(2) Chemical characteristics,

(3) Geological and meteorological characteristics,

(4) Biological integrators, and

(5) Biology and water resources. 
Projects will be tabulated under sponsoring agency and project title and described by:
a. Principal investigator
b. Purpose of project
c. Nature of Iroject
d. Funding, if known

Items marked with an asterisk are projects of general interest, not exclusively concerned with the Great Lakes.

\section{A. Public Health Service}

The 1961 Appropriations Act included $\$ 500$ thousand for the Public Health Service to commence development of a comprehensive water pollution control program for the Great Lakes. During the first three years particular effort was devoted to the IIInois Waterway at the Southern end of Lake Michigan. The most important project with in the overall program concerns a series of 11 current measuring stations forming the first part of a 52 station network. These form a Ereat, pattern covering the entire area of Lalie Michigan. Sonsitive automatic recording devices masure winds, curronts, temprature, and related environmental conditions; the information is storod for several months on photographic film. The l'ublic Health Wervice has opened $a^{\circ}$ ficld $^{\prime}$ basin. According to the plan, investigations are to proceed to Lake Huron, Lake Ontario, and Lake Superior in that order. They are scheduled over a seven year period and are considered to be approximately $40 \%$ complete to date. Health Service.

The following projects are contractually supported by the Public

\section{Isolation and taxonomy of yeast in lakes and sewage.}

a. Dr. Leslie R. Hedrick, Chairman of the Biology Department, IIIinois Institute of Technology.

b. To increase knowledge of the ecological distribution of yeast in trosh water lakes and atreams.

c. Yeasta aro isolated from their habitat by means of enrichment proceedures or membrane filters. The yeasto are studied for their identification and classification. 
2. Ecology-quality changes in Lakes Michigan and Erie.

Michigan.

a. Dr. C. F. Powers, Department of Zoology, University of

b. To study the chemical constituency and biological population in the waters in these lakes as an aid to pollution procedures.

c. Quantities of water are sampled throughout these lakes and are subjected to chemical analysis and biological identification.
d. $\$ 51,326$

3. Diatoms of the west end of Ilake Erie.

a. Dr. C. E. Taft, Department of Botany, Ohio State University.

b. To identify plankton in Lake Erie.

c. Samples of water are subjected to biological identification.

c. $\$ 9,085$

4. Vitamin B-12 in the Great Lakes and its ecological significance.

a. Dr. A. D. Hasler, University of Wisconsin.

b. To determine certain chemical functions of the environment and its effects on the population.

c. The waters in the Great Iakes are analyzed for their vitamin B-12 content; a number of organisms are subjected to varied proportions of this ingredient to determine their life processes as a measure of its concentration.

5. A study of fundamental productivity in a stream. Michigan State University.

a. Dr. Robert C. Ball, Department of Fisheries and Wildlife,

b. To evaluate productivity of a stream and describe results of solar energy input.

c. B10Iorf.cal. rroductivity studies havo bron carricd out and evaluated in terms of physical and chemical properties of the water.

6. Serum stress patterns as related to stream ecology.

a. Dr. Robert C. Ba.11, Professor of Iimnology, Department of Fisheries, Michigan State Universitj. 
b. Ho explore the possibility that stresses on local organisms are indicative of clanges in the marine environment in the Great Lakes.

c. Electrophoresis and chromatographic techniques are utilized in analyzing serum protein of vertebrates and invertebrates.

d. $\$ 14,116$ (present fiscal year)

7. Uptake of organic compounds by marine invertebrates.

of Minnesota.

a. Dr. G. C. Stevens, Asspociate Professor of Zoology, University among aquatic animals.

b. To study the capacity to absorb selected organic molecules

c. Radioactive tracers are used to study changes in distribution of radioactivity between solutions and the experimental animal to determine the nature of the selective uptake of the material.

8. Microbiology of dilute enrichment.

Illinois.

a. Dr. R. S. Wolfe, Professor of Microbiology, University of

b. To study Great Lakes organisms of potential nuisance अalue.

c. The ecology, nutrition, and physiology of these orgarisms is studied in the laboratory under conditions of continuous supplies of dilute nutrients.

9. Growth and physiology of Alage.

a. Dr. Olf-Hasen, University of Wisconsin.

b.. To study the growth of various types of Great Lakes alage (green and blue-green) and fungi with respect to the uptake of nutrients.

c. Growth patterns of these algae are examined under varied concentrations of vitamin B-12 and carbon 14-labeled bicarbonate and organic substrates.

10. Biological factors in the management of lak flies.

a. Dr. William L. Hilsenoff and others, University of Wisconsin.

b. Netermination of conditions necossary for optimum frowth

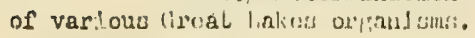


c. Laboratory tests are run on a number of these organisms. Samples are collected from a number of lakes to determine changes in bottom fauna. Chemical and physical measurements are made at the same time.

11. Tho jdentjficatjon and Determination of organic substances, particularly posticides and vils, in fish and surface waters.

a. Charles S. Myers, Division of Sanitary Engineering, Pennsylvania Department of Health.

fish.

b. Determine deleterious effects of pesticides and oils upon

c. A number of organic compounds have been isolated from Pennsylvania streams feeding the Great Iakes. These are being studied, with special attention being given to pesticides and odor producing substances. Oils and gasolines found on the surface and underground waters are also being identified. The effects of the toxic effects of many of these compounds are being studied on fish.

13. Effect of paper-fibre waste on fish eggs and juvenile fiches.

a. Dr. Lloyd L. Smith, Department of Entomology, Fisheries and Wildife, University of Minnesota and others.

areas.

b. To study fish egg mortality rates in contaminated stream

c. Influence of varying wood-fibre loads on minnows and walleye pike at different levels of temperature and oxygen content is being studied through measurement of blood characteristics and mortality rates. Influence of gas toxins evolved from sludge mats is being determined on fish and invertebrates.

14. Investigation of biological control of snails.

a. Dr. Clifford 0. Berg, Professor of Limnology, New York State College of Agriculture at Cornell University.

b. To gain understanding of the natural history and morphology of snail flies in the Great Lakes area.

c. Laboratory and field testing is being carried out to find species for introduction to problem areas. Biotic potentials are being evaluated of these species and their chances of survival and multiplication in Great Lakes environmental conditions. 
organisms.

15. The nature of cellular response in various Great Lakes

a. Dr. Dominic L. Degiusti, Professor of Parasitology and Biology; Wayne State Iniversity.

b. To study the ecology of parasitism in a small stable stream environment.

c. the morpholory and iffe cycle: of a number of (ireat lakes organisms are being studied on various lith coacts.

16. The sexual hormones of achlya bisexualism. Botanical Garden.

a. Alma W: Barksdale, Sendigr Research Associate, New York mold in the Great Lakes area.

b. To study sexual reproduction in certain species of water

c. Repisoduction is initiated and regulated by a series of substances secreted by the sexualiy reactive thal]i. The nutritional and environmental conditions necessary for maximum production of hormones are determined; this hormone is extracted, wurifind and studtag with resiect to sexual reproduction.

*17. Chronic effects of stable organic substances on sunfish. Academy of Natural Sciences.

b. To study chronic effects of subweakened ancentrations of stable complex organic compounds upon the blue gil. sunfish.

c. Oxygen uptake, whising speed, fatigue, and tissue changes in the gills are examined relative to the effect of various compounds upon the glue gill sunfish.

*18. Factors influencing free living nematodes in water supplies. University of Milinois.

a. Mr. R. S. Engelbrecht, Professor of Sanitary Engineering,

b. To study the fundamental factors surrounding the presence of free living nematodes in water supplies.

c. The ecology of these worms is studied both in raw water and under laboratory conditions. Environmental control measures are evaliated as are present day water treatment methods for removal of these creatures from water supplies. Food and feeding habits of the worms are also investicated. 
*19. Biological extraction and accumulation in streams.

a. Dr. C. J. Veiz, Chairman, Department of Environmental Health, University of Michigan and others.

b. To determine the basic environment condition giving rise to formations of growths in streams.

c. To determine biological actions governing the rates of extraction of oxygen and to 1nvestigate the means of controling or eliminating such formations.

d. Varlous atroams which react differently with respoct to gross formation of blological Erowtho, concentration of oxygen will be studied over perlods of time and geographlcaliy. Basic Invest1gations will be conducted In laboratories and in the natural streams.

\section{B. The National Sclence Foundation.}

The National Science Foundation sponsors a number of projects in the Great Lakes area. Sponsorsinip is primarily centered in the Division of Blological and Medical Sclences and the Division of Mathematical, Physical and Engineering Sciences.

1. Relation of population density to growth and competition. University of Michigan.

a. Dr. Frederick E. Smith, Associate Professor of Zoology, In the Great Lakes.

b. To describe the growth rolations of certain populations

c. Numerous species in the family daphnidae are belng studied to relate the population growth to the population density and food density. Iffe table techniques are being used with mass cultures. All possible twospecies systems are being followed to determine competitire relationships.

*2. Functional analysis of certain plant communities.

Garden.

a. Mr. Pler Dansereau, Assistant Director, New York Botanical

b. To test and Improve methods for analysis of various types of plants and to apply a large body of data for functional grading of phytosoclological units in the Gaspé Peninsula.

c. The principal communities are being sampled geographlcally; ecosystems under study include the mesophytic forest, riparlan forest, open shrubby grass land, salt marshes, rocky cliffs, and barren flelds. 
invertebrates.

*3. $\Lambda$ study of hatching and of the ocololsy of egC masses of aquatic

University.

a. Charles C. Davis, Mepartment of Blologry, Western lieservo

b. To study the hatching prazess of aquatic invertebrates.

c. Quantitative studies of Yauna and flora are being carried out in connection with egg cases and egg masses including investigations of invasions of egg masses by various organisms. Numerous collections of animals are being observed during hatchings as well as their responses to environmental conditions.

*4. North American ichthyology.

University .

a. Dr. lidward C. Raney, Conservation Jepartment, Cornell

b. 'I'coljoct and study blood scrum and hemogolobin: to investigate the systematics of scvoral species of darter; to study the systematics of redhorse sckers; to study a number of other Great Lakes organisms.

c. A series of comrehensjy biologica? jnvestigations of a number of organisms of the Great Lakes area is being carried out relative to the chemical and biological characteristics of the Great Lakes environment, primarily off lake Ontario.

*5. Ecological and taxonomic studies on aquatic coleoptera.

of Indiana.

a. Dr. Frank N. Yound, Assocjate l'rofessor of kioology . Iniviriti.

b. In classify North American water beetles and to prepare a manual of the species. Five genera of water beetles are being studied biologically and chemicaliy.

6. Interspecific relationships in natural and laboratory populations of paramectum.

a. Dr. Nelson G. Hairston, Associate Professor of Zoology, University of Michigan.

b. To examine competitive relationships. among four varieties of paramecium in the vicinity of the lakes surrounding Ann Arbor.

c. Fleld examinations in Jaboratory tests are carried out among varieties of ṕramecitan. 
7. Dynamics of fresh water stream invertebrate populations.

a. T. F. Waters, Associate Professor, Department of Fisheries and Wildilfe, University of Minnesota.

b. T'o study major population dynamics of fresh water stream invertebrate populations.

c. Down stream drift of invertebrates is studied, involving relationships among production rate, rate of change in population density, and removal rate. Production rate is estimated and related to drift.

8. Dynamics and ecology of Castor danadensis.

University.

a. D. L. Allen, Professor of Wildlife Management, Purdue

b. To determine the number and relationships of the beaver In a biotic community dominated by the timber wolf and in which the principal prey species is the moose.

c. This study of an insular bcaver population in upper Lake Superior involves an analysis of the trends of beaver numbers and their food supply.

*9. Viral diseases of fresh-water fish.

of diseases.

a. R. G. Malsberger, Lehigh University.

b. To isolate and characterize the virus causing a number

c. Tissue culture methods are used in addition to examination of various fresh-water fishes for lichens from which viruses might be isolated.

*10, Systematic and ecological survey of North American Desmidiaceae.

University.

a. G. W. Prescott, Professor of Botany, Michigan State

b. To synopsize North American Desmidiaceae and to provide a reference work.

c. All available records and drawings of this group of western hemisphere algae are being compiled together with substantiated records of other workers on North American Desmids. The resulting publication gives a brief description of each species and variety together with distribution data, habitat notes, and a summary of what is known about the ecology (with 11lustrations). 
*11. Morphogenesis in aquatic fungi.

a. J. S. Livett, Assistant Professor, Department of Biological Sciences, Purdue University.

b. To investigate the basis of growth, differentiation, and reproduction in simple and aquatic fungi.

c. Nutrition and sexual reproduction of certain species are studied; the conditions necessary for reproducible synchronous germination and growth are analyzed; the biochemistry and phytology of the earliest stages during zoospore germination aro analyzed.

12. An Investifation of ecolorical succession in sand spit ponds:

a. E. J. Kormandy, Assistant Professor Zoology, Oberlin College.

b. To study the ecological attributes of succession in ponds of comparable origin th Lake Erie.

c. Physical, chemical and biological characteristics are measured on Presque Isle on Lake Erie. Measurements include temperature, water level fluctuation, turbidity, morphometry and exposure. Dissolved axygen, carbon dioxide, pH, alkalinity, phosphate, nitrogen, and iron are also measured.

13. Larval and adult Hydracarine and their insect pests.

UnIversity.

a. R. M. Crowell, Associate Professor of Biology, St. Lawrence

hosts.

b. To correlate water mites with their adult forms and Insect

c. Field collections of free living stages of mites are made with subsequence observations of developmental stages in the laboratory. Emersonifa.

*I4. Continued studies of the water fungi, Blastocladiella and

University.

a. E. C. Konteno, Professor of Botany, Michigan State

b. To relate differentiation of resistant cells and rise and fall enzyme activities.

c. The aquatic phycomycete, blastocladiella emersonila, are studied with respect to differentiation and enzyme activities induced by the bicarbonate concentration in the environment. 
15. Limnological interaction in lake Mendota.

of Wisconsin.

a. A. D. Hasler, Professor of Zoology, and others, University

environment in Lake Mendota.

b. To study comprehensively all of the interactions in the

c. The environmental factors upon the life history of the white bass are investigated including the causes of variations in the reproductive success and the mechanism by which the fish recognize an ecological barrier. The possible relationship between oscillation of internal waves in the lakes and activity of the fauna in these regions is also under investigation.

16. Fnergy budget of Copepoda of liake Winnedal;o Wisconsin.

Collogto.

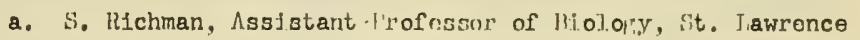

b. To determine the energy budget of the predominant Cladoceran and Copepod species of the primary consumerate level in Lake Winnebago.

c. The algae are labeled with radioactive carbon-14 to determine energy input. The expended energy is calculated by converting oxygen consumed to calories used. Food organisms and herbivores are analyzed for energy content by means of a miniature bomb calorimeter. Life histories are studied to determine growth and reproduction rates.

17. Natural radiocarbon determination of absolute sedimentation rates and pollen stratigraphic analysis of environments of deposition.

Wesleyan University.

a. J. Gordon Ogden III, Associate Professor of Botany, Ohio"

b. To determine sedimentation rates in the Great Lakes areq.

c. Carbon content is determined, followed by radiocarbon

determination. Samples are cored in selected lakes in the Great Lakes area. Between 20 and 40 radiocarbon determinations are made on each core.

18. Fossil plant pigments as indices to productivity in acquatic and semi-acquatic habitats.

University of Minnesota.

a. E. Gorham, Associate Professor, Botany Department,

b. To test the value of productivity indices such as fossil plant pigments over a wide range of environments. 
c. A number of studies are carried out on lakes, bogs, and swamps, mostly in the Minnesota area. Stratigraphic sediment sare analyzed to elucidate lake evolution.

\section{Office of Naval Research}

The Office of Naval lesearch sponsors a wide variety of Great Lakes research in most of the "big ten" schools in that area. These projects are sponsored in the geophysics, biology, and geography branches of ONR. Although these projects are classified properly as basic research, ultimate application. can be seen in most cases, and oceanography is also generaliy emhanced by this "laboratory" study of lakes as test tubes for oceanic application.

1. Determination of currents in the Great Lakes.

of Michigan.

a. J. C. Ayers, Great Lakes Research Division, University

b. To evolve a mathomatical method for determination of currents in deep lakes.

c. Computatjons of dynamic hejphts have been evolved in manner very similar to those used in the donp occans. 'lhese have been simplified in turn by independent determination of explansive effects of temperature and compressive effects of pressure. Also, new tables have been prepared,directly readable to $0.1^{\circ}$ centigrade. The method has been applied in Lake Huron.

2. Aerial sensing of environmental conditions on the ground.

a. R. A. Bryson, University of Wisconsin

b. To improve capabilities of determining environmental conditions on the ground by rapid aerial survey methods.

c. A wide variety of air-borne sensors is being used to survey an area extending from Wisconsin and the Great Lakes to the Arctic, emphasizing the thermal and ice regimes of lakes and vegetation as major indicators of environmental conditions. Relationships are determined between environmental factors especially on a seasonal basjs in order to sense some conditions from other conditions.

d. $\$ 90,000$

*3. Map transformation studies.

a. W. R. Tobler, University of Michigan.

b. To investigate map distortions of lines, angles and areas. 
c. Digital computer techniques are applied to investigations and correction of these distortions. The projection areas are evaluated to determine overall probable error envolved in a particular map; projection distortion is corrected in connections with problems of changing map scales.

d. $\$ 17,000$

4. Compilation of freezing and thawing dates for the Great Lakes and surroundine arcas.

a. I. A. Ragotzkie, University of Wisconsin.

b. To study the freezing and thawing of lake ice as events in the annual heat cycle of a lake. To determine dates useful as climatic indicators.

c. All available information is compiled and combined with field studies to determine the exact dates of freeze-ups and break-ups of lake 1ce in Wisconsin, Minnesota, Michigan, and Canada. This compilation is published in a report to the Office of Naval Research.

5. Studies on orientation and of migration of fishes.

Wisconsin.

a. A. D. Hasler, Professor of Zoolory, University of

b. 'To study scnsory mechanisms to which fish respond in the Great Lakes environment.

c. The role and importance of chemical sensors in the lives of flshes are investigated, primarily in the laboratory. The ability of fishes to respond to various fresh-water and marine odors is studied as are sound production and perception in fish. Concentrations of fishes are mapped in the Great Lakes area using echo sounding instruments.

*6. Metabolism of insect pests.

a. W. H. McShan, Professor of Zoology, University of Wisconsin.

b. To study RNA (ribonucleic acid) content of several species of fresh water zooplankton, in order to relate this factor to trophic level and primary productivity.

c. The electron microscope is used to study insect thoracic or flight muscle. Intact tissue and particulates are studied. Chemical composition and enzymatic properties of the particles are evaluated. 
7. Lake Erie geological studies.

University.

a. H. J. Pincus, Department of Natural Resources, Ohio State

Lake Erie.

b. To study the short erosion and sediment transport in

c. A number of Ohio municipal agencies have combined with Ohio State UnIversity on a vast geological research program in Lake Erie to study erosion and sediment transport with a view to corrective actions.

8. Great Lakes Limnology.

Michigan.

a. D. C. Chandler, Professor of Zoology, University of

Lakes.

b. To investigate all phases of the environment in the Great

c. A wide variety of observational and research programs are carried on in the Great Lakes exploring the life cycles of the populations with respect to the environment.

\section{Bureau of Commercial Fisheries}

The Bureau of Commercial Fisheries has programmed $\$ 49,000$ for limnological research. The major phases of effort include the study of physical and environmental conditions in Lake Erie, the ecology of Great Lakes estuaries, and the chemical characteristics at index stations on Lake Superior, Michigan, and Erie.

Thj.s work is carrind out as an in-house prolpram; almost no effort Is contracted out by this liurcali. llowever, the ICF is involved in a creat number of cooperative programi with state, local, and unjversity agencies, and laboratories. Most of the work of the liureau of Commercial Fisheries is centered in their biological laboratory at Ann Arbor,Michigan. The environmental research program report of that laboratory is attached. It is one of the most comprehensive discussions of Great lakes research and development programs extant.

\section{E. The Atomic Energy Commission}

The Atomic Energy Commission has been fairly active in sponsoring a few worth while projects in the Great Lakes area, normally those utilizing radioisotopes. Most of the AEC research in the Great Lakes area is sponsored by their Division of Biology and Medicine. 
1. Movement of radioisotopes through lake ecological systems.

a. A. D. Hasler, University of Wisconsin.

b. To study the ecology of the Great Lakes area:

c. Radioisotopes are used to trace biological activity and a number of organisms in the Great Lakes.

d. $\$ 17,700$

2. Study of productivity in a stream ecosystem using radioactive

tracers.

a. R. C. Ball, Michigan State University.

b. To Investigate the ecology productivity in the Great

Lakes.

c. Radioactive tracers are used to study productivity rates In a number of orcanisms in tho stroame foedinf, tho (irriat liakrio.

d. $\$ 29,600$

3. Fate and effects of radioisotopes in an aquatic food chain.

a. Chandler and Marshall, University of Michigan.

b. To study certain biological populations which feed on

other populations.

c. Radioisotopes are used to trace the fate of organisms which are digested by other organisms, etc. in the biological food chain.

d. $\$ 44,800$

The projects which are sponsored by the AEC are centered geographically in areas contiguous to the Great lakes, involving mostiy the feeder streams to the lakes themselves. They relate primarily efther to movement of material through the geographical environment or to passage of the constitumts in the biological chain process, relating to factors such as growth etc.

4. Radioisotopes exchange studies in lakes.

of Wisconsin.

a. A. D. Hasler, Professor of Zoology and others, University

applicable to marine situations.

b. To use small lakes as pilot models for experiments 
c. Radioisotopes are used as tracers in studies of permanently stratified lakes. Ionic movement and biological transport of certain elements in these lakes are observed during various seasons of the year, utilizing radiological techniques. from fallout.

5. Pathologic effects in fishes exposed to radioactive iodine
a. A. Gorbman, Professor of Zoology, Columbia University.
b. To study the effects on fish from fallout.
c. Radioactive jodine is introduced into certain environments In the Great Lakes area to study the pathologic effects on members of the marine population. of animals.

6. Radiation and other factors in influencing the distribution

a. W. J. Breckenridge, Director, Museum of Natural History and others, University of Minnesota.

b. To analyze the factors responsible for the peculiar distribution of toads in the Great Lakes (Minnesota) area. The differential tolerances of eggs and tadpoles in water have been studied under varying concentrations of sulfate, chlorides, carbonates, and hydrogen ions. The normal behavior and survival. of toads while underground is beinf, studied in the Great Lakes in the field, and in the laboratory under simulated natural conditions of soll temerature and moisture.

7. Situdies on the productivity of vascular hydrophytes in acquatic ecosystoms.

a. R. T. Hartman, Associate Professor of Botany, and others, UnIversity of Pittsburith.

b. To study productivity rate of various organisms under varying conditinns of the environment.

c. Radioisotopes are used to study mineral uptake by the root and shoot system of the vascular hydrophytes. The loss of absorbed elements to surrounding water is studied as woll as the rate of return of elements through organs. Compensation points, relative photosynthetic rates, and annual production values are determined for several species of these plants. Changes in the composition of their internal atmosphere are determined. 
8. Radionuclides and fresh-water clams.

College.

a. I. George l'ahl, Assocjate Professor of Bjology, St Mary's

b. To observe the reaction of fresh water clams under radioactive environments.

c. A number of species of clams are studied with radionuclides to observe their productivity and fate.

\section{F. Geological Survey}

The U. S. Geological Survey is rather active in the Great Lakes aroa. Its effort is conducted on an in-house basis, cooperatively with city and state geological surveys and engineering staffs in local municipalities. A program which is supported half from the states and half from the federal government is concerned with the monitoring of the water inflow and outflow of the Great Lakes. Urban area water supplies and resources are studied. In particular a system study of thr Maumer li.iver js brint carried out to dotermine the salitis, scdiments, and yollution beim; capried into Jake frie.

A project of areal radiological measurements is being carried out by means of these surveys in the Minnesota, Wisconsin, and Chicago areas. Geologists of the survey fly over and monitor ground patterns covering $10,000 \mathrm{sq}$. miles or more. Magnetometer surveys are being conducted in the area around Lake Superior to complete an aeromagnetic map of that general area. Another project concerns the study of sedimentary rocks adjacent to the Great Lakes. This entire program is being funded at a rate of about $\$ 1.5$ Milion.

The Geological Survey is carrying out a special project in Burnt Lake, Michigan in connection with which they are developing special bottom sensors. These sensors will be towed hehind ships to determine bulk density and radioactjuit,y ol' andimentis.

The oljective of the n'oject entitled 'Lhermal Characteristics of the Iakes, headcd by John Picke, is to study lake tomperatures and their relation to hydrometeorologic conditions, the energy required to maintain isothermal conditions, methods of eliminating temperature stratification, and changes in water quality, biota, and evaporation due to elimination of the thermocline.

\section{G. Weather Bureau}

The Weather Bureau oceanography research in the Great Iakes region is motivated primarily by the desire to investigate several problems of general oceanic interest in a region in which they could be more or less isolated from other phenomena and incidentally provide some assistance to our public forecast program. Two projects, initiated with respect to the 
Great Lakes are now being extended to open coast regions. They are:

1. The numerical solution of the equations governing the effect of meteorological disturbances on sea level. This project was started in 1957 at the University of Chicago. The university project will be consolidated with a similar project at the Central Office early in FY64:

2. The development of empirical equations, along theoretical Iines, relating the water-level disturbances to earlier observed winds at land stations. Most of this has been carried out at the Central Office.

Other projects initiated in FY63 are:

3. A study of the exchange of mechanical energy, heat and moisture: between the atmosphere and the water by means of micrometeorological tower located in Lake Michigan. The tower and some of the instrumentation is being provided by the Lake Surtey, U.S. Army Corps of Engineers. The University of Michigan is designing and assembling: most of the instrumentation system under a research contract with the ffeather Bureau, but is providing some instrumentation with funds from other sources. The university, the Weather Bureau and the Lake Survey will cooperate in the operation of the observing system and the analysis of the data.

4. Projects to improve the ice forecasts for the Great Lakes and the estimation of rainfall intensities over the dakes are now underway in the Weather Bureau office in Dotroit. These are being carried out on a time avallable basis by personnel axigned to the office for other duties with the cooperation of the Jake Survey and groups doing similar work in Canada.

5. The Weather Bureau is also providing technical support and consultation service on meteorological and some oceanological problems to the Public Health Service Great Lakes IIlionis River Basins Project under a reimbursable funds agreement.

An approximate cost breakdown follows:

\section{PROJECT}

1
2
3
4
5

FYY 1963

20,000

10,000

50,000

13,000
FY 1964 (Estimated)

$$
\begin{array}{r}
5,000 \\
3,000 \\
60,000 \\
\hline 18,000
\end{array}
$$




\section{H. Department of Agriculture}

The United States Department of Agriculture sponsors a few projects in the Great Lakes area through its Cooperative State Experiment Station Service. These projects are not all carried out in the lakes themselves but pertain to the Great lakes area generally. As might be expected, the Department of Agriculture generally evades programs in the aquatic sciences leaving these to departments or bureaus with more closely aligned missions.

\section{Farm fish pond management}

State University.

a. R. C. Ball, Department of Fish and Wildlife, Michigan

b. To estimate production of plants and animals per unit area or volume of water in the farm type ponds and natural ponds. Determine to what extent fertilization of ponds will increase production of fish food and fish. Devise practical management of programs for farm ponds including the number of fish to plant and harvest. To detect and measure possible detrimental affects of use of fertilizcrs in fish ponds.

c. The release of stored nutrients in subaqueous soils is measured by adding chelating materials to the waters by chemical methods. The paths of nutrients added to the waters are evaluated and traced through tagging with radioactive tracers. The carbon-14 light and dark bottle technique is used to measure the rates of fixation of nutrients and accumulation of organic material.

\section{Physiologic response of aquatic organisms to pollutants.}

State University.

a. P.0. Fromm, Department of Meteranary Medicine, Michigan

b. 'To determine the rihysjological cause of death in those aquatic animals most susceptible to jollutants and establish the sympotoms of sublethal amounts of those pol.lutants.

c. The kinetics of surface binding of chromium cells are studied as are the metalolic response of intact fish to chromium containing waters. Permeability of fish skin is also studied.

3. Mechanisms of biological production in streams.

Minnesota.

a. T. F. Waters, Department of Entomology, University of

b. To identify the plant community serving as the primary producer of organic matter in streams and the relation betwoon organic production and such environmental factors as nutrient content, ljght, and temperature. 
c. Tentakive methods of estimating the production rate of stream bottom organisms are evaluated. Drift rates are being measured between pools and riffles over \& 24 hour period monthly.

\section{Coast Guard}

In its role as a menace to navjegation j.ce in the Great Lakes is naturally of considerable interest tothe Coast Guard. This Service has carried out ice observations in the lakes for a number of years. Research has concerned transportation, ship structures, and considerations of the heat budget. The Coast Guard collaborates in this program with Northwestern University and the Great Lakes Research Division,which in turn is sponsored by the National Science Foundation. The Coast Guard funds this project at the approximate rate of $\$ 30,000$ per year.

\section{J. Office of Saline Water}

The Office of Saline Water has no directly sponsored projects in the Great Lakes area as such; however, they are sponsoring two firms, W. L. Badger Associated in Ann Arbor, Michigan and Chicago Brick and Iron (who have gained considerable experience in the Great lakes area) in operating experimental fresh water plants in North Carolina and New Mexico respectively:

\section{K. U. S. Air Force}

The United States Air Force is leading a large scale cooperative project know as the Great Lakes Seismic Experiment. The Geological Survey, ARPA, the Office of Naval Research, and the Coast Guard are cooperating with the Air Force to carry out a seismic survey in Lake Superior. The Coast Guard cutter WOODRUSH is being used as the experimental platform from which seismic shots are conducted and listened for by inland stations, in connection with the U. S, program for the Upper Mantle Project. Institutions participating under sponsorship of the named agencies include the Carnegie Institute (coordinating agency), Oregon State University, Princeton University, Southwest Research Center, Southern Methodist, Pennsylvania State University, University of Wisconsin, University of Minnesota, and University of Michigan. 


\author{
CORPS OP EIGLULS, U. S. ARIT

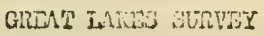

\title{
HISTORY
}

The U.S. Lake Survey was crented as the result of the Congressional Act of 3 March 1841 which authorized a "Hydrographical Survey of the Northerm and Northwestern Lakes." The hydrographic surveys led the Lake Survey into a number of related scientific fields: e.g.; into hydraulics and hydrology, because the lake levels vary and the variations are pertinent to complation of the surveys and use of the resulting navigation charts; into meteorology, prior to the establishment of the U.S. Weather Bureau, because of the impact of weather on the conduct of the hydrographic surveys; into geolocy through the smpling of lake and river bottom materials, to provide information on anchorages and the composition of shoals and reefs, and through study of movement of the earth's crust to determine the inopact of this phenomenon on chart datums and navigable depths.

Since 1898, the Lake Survey has been assigned a two-fold mission which, simply stated, consists of (a) the publication of navigation charts of the Great Lales (later expanded to cover contiguous waters) and (b) the study of all matters affectine the hydraulics and hydroloey of the Great Lakes. Under the hydraulics and hydrology portion of its miscion the Luke Survey activitios are sumarized bilefly in the followinc paragraphs.

During the period prior to 1898 , stations were maintained where precipitation, temperature, wind direction and velocity were observed, and 


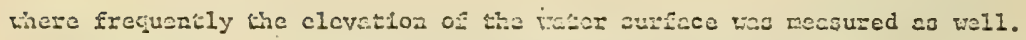

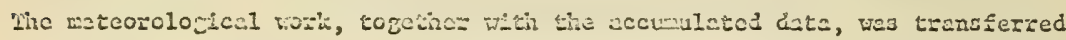
to the U. S. Wastier Durcau after fte orcaniation. Delisble and systematic records of the lalse Ievelg have becn mantained by the Lake Survey since 1060.

The Congressional sundry Civil A.ct, appoved 4 June 1867, provided Eor "completing 1wprovement of chanai connecting tutcis of the Great Lakes between Chicago, Duluth, and Iuffalo, inciuding neccsacis observations and investigations. In conncction with the preservacion of such channel depths." The first measuremente of lalie outrlows through the St. Marys and the St. Clair Rivers twe mude by the Lake Sutvey during the 1867 field

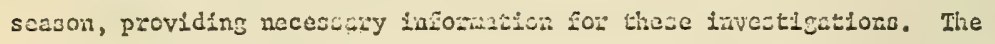

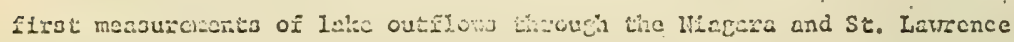
Rlvers were also mide by the Line survey fin 1867.

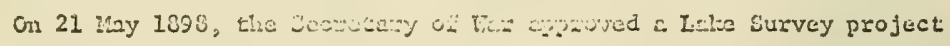

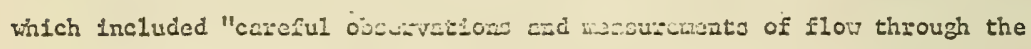

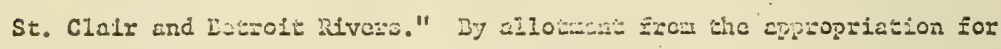

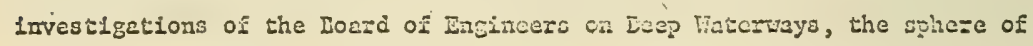
the 1898 discharge observations by tire Lnic survoy ".... extencied to include

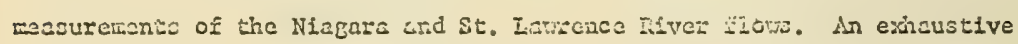

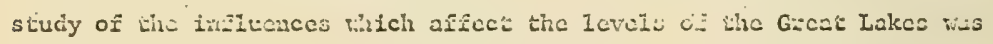

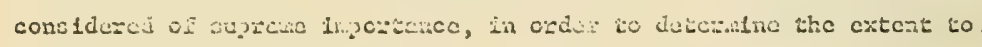

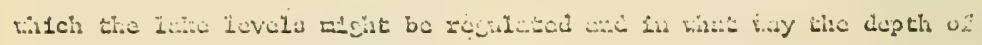

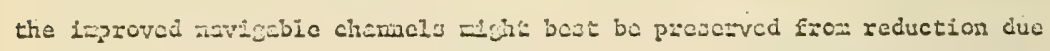

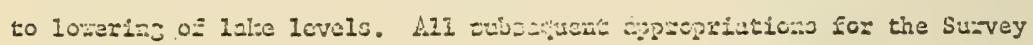


of Northern and Northweatern Lakes have Ineluded as part of their stated purpose the Investigation of lake levols.

Since 1898, extensive serles of measurements have been made by the Lake Survey in the natural lake outlet rivers and formulae have been determined for computing the lake outflows from the observed water levels. The Lake Survey publishes outflow data covering the perlod from 1860 to date.

The Lake Survey furnishes technical advice to the Division Englneer, NCD, pertaining to the Division Engineer's International Board activities, includIng those of the International Lake Superior Board of Control, the International Nlagara Board of Control, the International Nlagara Cormittec, and the International St. Lawence River Board of Control. The Lake Survey has developed, or participated in international development of; various plans for regulation of the Great Lakes.

In 1959, the Lake Survey was assigned a civil works Investigation project CW-181 t1tled, Lake Hydrology Studies. The profect is for the purpose of sunmarlafig avallable Information pertaining to Great Lakcs hydrology and 1mprovIng present methods of estlouting and foreccsting Great Lakes vater supply and hydrologic effects.

The recognized miosion of the Lake Survey todey is to collect, correlate, analyze, and make avallable in usable form to all interested agencles physical data relating to the vater resources of the Great Lakes. Examples of phycical data assembled in usable form by the Islic Survey Distrlet include: water Ievels and depths, current velocltier, river flows, vater supplieg to the Great Laikes, teaperatures, topography, hydrography, crubtal movenent, Ifttoral drift, shoalIng ard sedivantation, geodetic positions, wind velocities, and ice formation and related phenomera. 


\section{RESEARCH OBJECTIVES}

The Lake Survey research program has been described in terms of the nine flelds or areas outined below. For each fleld, there are lucluded a general deacription of the program, a general statement of the objectives or purposes of the work, and a bricf outline of specific projecta contcoplated. The rescarch flelds are:

\author{
1. Currents and Tlows \\ 2. Lake Lavelo \\ 3. Ice Formation \\ 4. Have Action \\ 5. Forecasting of Supply
}

6. Hater Quality

7. Crustal hoverent

8. Ground Water

9. Shoreline Conservation

\section{CURREITIS AND FLOHS.}

General Descrintion and Oblectives of the Promenrs: Lale and rfver currents and river flows affect shore processes, ice fortation and covarant, distribution of suspended and dissolved foreign meterials, sedimentation rates ard other phenomena as vell as the riparian, navigution, and potver interests. The Lake Survey has masured rlver currents for use in the design of navigation channels and for colnguting diccharged from the laled necessary to the formulation of plans of remulation. The purpose of this program is to complete a study. of the cause and effects of liske and river currents and the inter-relation of currents with other phenosiena throughout the cntire Great L:1eus Basin; to Improve tcchniques and fnstrument use in measuring currents and flow; to develop techniques of forecasting currents; to determine the effects of currents on the distribution. and behavior of water-borne forelgn tinterial; to apply knouledge of the currents to the design of harbors, channela and various protective works.

\section{Profects:}

Observe currents in three selected harboris on each lake, first on Lake Michigan, and relate those observed currencs to those recorded upon the lake.

Operate extensive watcr level gage network on each lalke, first on Lake Michigan, to determine the effects of the forces generating currents.

Investigate the effects of currents in the diotribution and behavior of waterborne forcign materials, in volution and fri euspension.

Measure outflows fron Lakos Iuron and Ex1e under unuoual water level fluctuathons caused by suryes and aciches und derive more preclae methods of corputing the effecto of surges and setches.

Datermine the retarding effects of lce and warine growth on flows of the

St. Clair, Datroit and Nlagara Riverd.

Derive lake current parterns and velocities and the relationship to the causal forces, and recultant mass movements of water.

Develop methods of forecasting lake currents and publish forecasts as needed. 


\section{IANE LEVELS}

Genurn l Lescrintion and Objectives of the Proman: LonE tern lai:e leve? - fluctuations arc a function of tre net supply to the laic basin. Siort tarm. riuctuations olso occur anc are the result of surzes, seiches and barcmetric iressure variations. Sucli fluctuations bear in varyin cearecs uron riporian

- intcrests, navigation and power. The elso cause variations in river flow, tho sirore rocesses, currents and the rate and cirection of rrounduater flo\%. The

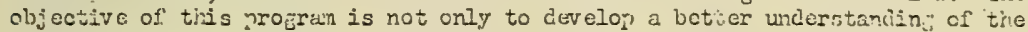
factors csusine lake level variations, but also to improve the utilizaten of

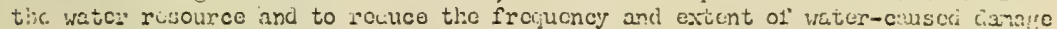

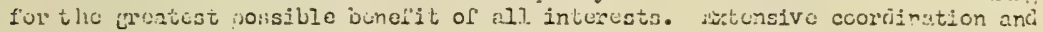

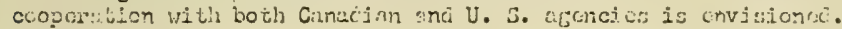

\section{injojecin:}

Irmprove gago patterns, installstions unc operation so s: to ji aile to cetermino, wjicly and accuratoly, the instant mean lcvel of the Inje.

Investigate the factors and derive their eficcts relative to lake Ievels, inclucing such as runoff, nrecinitation on lake surface, river anci auluifor inflow anci outrlow, evaioration loss, frounciwater inflow and outilow, and jiversions from anu juto likes.

Investiteate the ecoromics of lakc levels and. the hazards to life and property lol atca thereto for use in lake regulation and construction planring. outrloirs. Develop and/or refine plans for the repulation of lake levels and

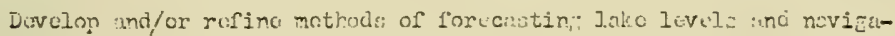

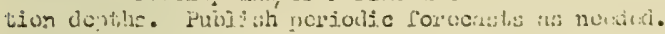

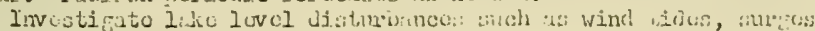

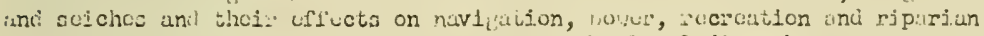
interests. Dovelon mothods of forccistin. Iidso levol disturbances.

\section{ICE FORMATION}

Genoral Descrijution of the Promen: Knovleclice of the ice rhonumenon on the Great Likes is extremely limited. Its presencc affucts navigetion ama power, veter lcvels, ejver discilugcs, and lake evaporstion rates, jte nove-

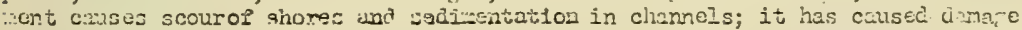
to structures an proiective works in nevifable waters as well as flloods and tre

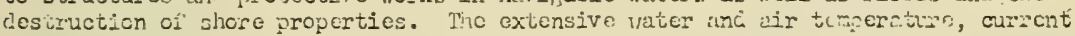

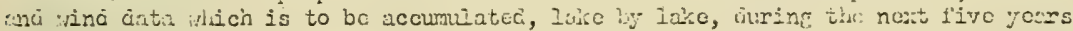
:211, wien couplod with periodic obscrvitions of "co lormition and novercht,

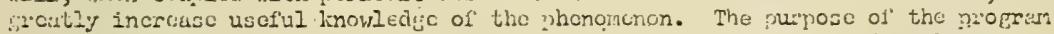

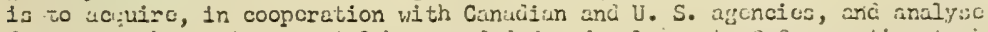

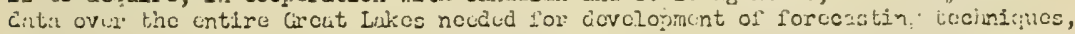

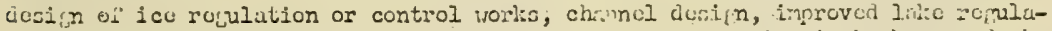
tion plans, devulopment of tochniques to rotirti ice formition in hobors and channels and lo reduce or elininate floodin due to jarmini: Undor the actis of the Canadian Comiuteo on Cccanorrephy, agencies of the Canudian Govornment have begun the studies of ice in Canadian waters of the Great lakes. 


\section{projectis:}

iccord from gorial observetions tho formition, extont, isernont, ind broik-up $0_{\text {: }}$ ice in the Uritec States sicie of all lilies and in U. S. hiv'bors lindic detailed observitions from air, land and shipboard of ice and velated fictors successively covorine each lake, its hwbors and outflow river, unci recorc formation, extent, thickness, euality, movument anci lrcali-lip. Investiggte the effects of ice on river flows, iower plant operations, siructures, channel banks anò lake shores.

Prepare and disseminate synopt1c ice charts as necded.

Determine the relationship betweon ice and the crusative factors.

Devise methocis of forecasting the formition and brak-up of ice, $2 n c$. pulish ihe forecrsts as needed.

Incerporite in lalie repulation rlans tho measures to reciuce adverse clifects u.t. icc.

Investigate mothods to raciuce or eliminate ice in ncvijation chnnnol.s ancl hiubors such as by introciucina air in decp watcr, by circulation of water, by instollini: booms ind by use of ice bruakers.

4. WAVE ACTION.

Gencral Descrintjon of the Program: Naves affoct navidution, shore processes, structures, protective irorks and the formation of ice covers adverscly. irccint in a gross sense, little is known of the formation, decay und eficcts of irives in ihe creat lekes environment. The necd tor wave lnowledige for use in the solution of practical, economically important problems is "rent. The oijjectives of this program are to determine the causes of vave formation, prouth and decay in lales, loivers and harbors; to determine the effects of waves urion nevigation (vesacls, channols ancl harburs), upon ice formation ani movement, unon the ihore processcs, and ujon structures und protective works; ind, hrou. h the? analysis ol' it.c dota, to f'umish information fon the improverient of cizmncl anci harbor dosi,ns, to cevclop wavo forecasting tochniques, to cieter'lne saijing courses less subject to severe storm wave interferenco, and to provice information necded in the desing of protective works enci for the reprulation of vessel spcecis in restrictud wators.

\section{Projects:}

Record decowater waves successively in each laik for one yenr by

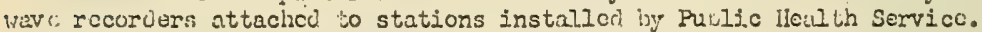
(Dther muthocis of vave obsorvation such as aerial photozrephy will be ovaluated anci u'jlizeci il desirable anc economically feasible.) vlioto: "?aphy.

Riccord waves in three selected hirbors by wave recoiciers and aeria'

Compile anai make statisticel analysis of watve records.

Determine the relationship of wave Frouth and amplitude to ind spoet, dirccition, curation, fetch, and, water and air tornperutures. study the wavo action in harbors and relato to lako waves snd to harbor ilimensions.

f'or tyoical storms.

Proparo and publjah charts showling weve characteristics by roiluns

Derive mothods of forccasting' waves in spocif1o areas for rocroation, navigaicion and shoro interosts, and in cooporation with U. S. Veathor iureau cij.ssominate these forecasts as needed. 


\section{FORECASTING OF SUPPLY}

General Descrintion of the Program: The economic and recreational vencfits derived from the rater resoure: of the creat Lakes basin dencni upon the waten. sumiy. Water su.p.y $1 \mathrm{~s}$ also a factor in shore pronerty damage and in the state of he:lth of peovle living around the steres and workins on whe

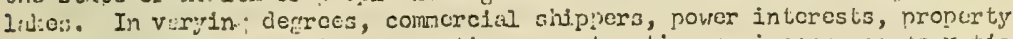
o:mers, nurverors of water recrcation, construclion encincirs, condervitionists, aus runy other interests dejend uyon or muko use of vater surply informition 0: forncasts. In cecent yonrs, rather inexnct mothoc's o." estimai.in. future suprilies have beon ceveloped and utilized f'or rnviration anci in the operation of Laje Ropulation Flans. Tivis program, which islil be accomplished in cooperation ivitin Canadian a fencies, has as its pulmose the cevelvipent ol imroved methods of forcostin: suplies utilizinr bata becrinon water surply acruirod under the lake levels and the roundiater flow prorrans. Fefincmonis in who forccasting techniues rilj. be translated irto increased benefits for most in erests tirou improved refulation plans anci more yrcciss water supply information.

\section{Projicats:}

Tor use in forccastin:: future supplics, cicvilon vater suryig incicses for the wator equivalent of snow cover, lake water temperatives,

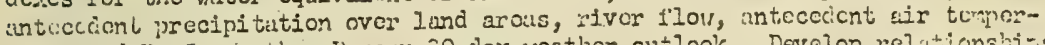
ature and $U$. S. . We Lher Iureau 30-day venther outlook. Develoo relatienshi-s betwecr these incexes and actual supplios for each lal:o basin.

Levelos method: of for ucastine supplies and publish forceuste es

needeci.

Investigate water sunply cycles durine che rerlod of rocord ind in texms of colo:ic time and doternine the relitionships to othor ihenomuna.

\section{WATER QUALITY}

Goncisl Deccuintion of the Propram: Water quality consiriers the physical,

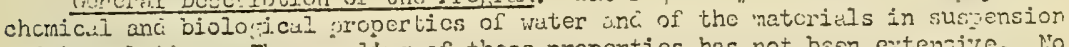
and in solution. The senjiln of these properties has rot bsen cxtensire. No com chensive stuly ct the canse and of ceci of these propertics, their cistuibution, their inceraction snd their relutionshin th other jhenomena has becr. accomplichos. The accuicition and analysis of these data vill serve mesy ruposes. Icr cximple, turiporaturo distribution affects biolofical ":ocesses, is al In

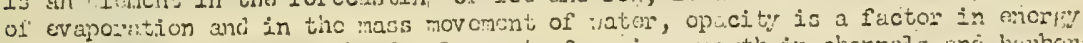

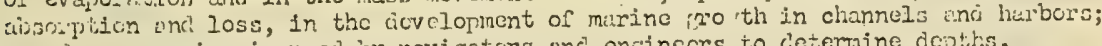
sounc rropulion is used by navizators and cngincors to letermine doptis. Curtain physicel and chemical properties may serve as a link with tlic past wi a clue io he future in climatolojicul siuclies. The pupose of this program will bo to ietermine the physicul and chemical poperties of water and waterbcino forci:m materials, heir distribution, the rcasons for viriations 'ith time anc?

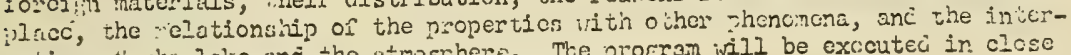
action ot he late and the atmosphere. The profram ivill be exccutec in close coorcination with other interosted agencios. 


\section{Hojeres:}

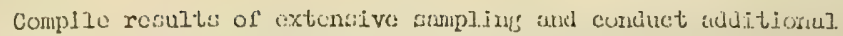
sampling, as necessary, of each lake, succcssively, and of its tributary and outflow rivers to determine the properties of the water and the foreign material in transport. Compile concurrent observations of the related factors.

Select indicator sampling stations for each lake basin and initiate a continuous sampling program to determine vater quality at these stations.

Derive the relationships between quality determinations made at the indicator stations and quality conditions throughout the lake basin, thereafter derive variations in water quality from the indicator stations.

Prepare and publish charts showing normal seasonal distribution of various factors comprising water quality in the lakes.

Develop methods to determine the dispersion and deposition of waterborne foreign materials.

Investigatc the practicability of forecasting those properties of water which bear on quality.

Conduct sound propagation testa, annlyze and publish the results.

\section{CRUSTAI MOVEMENT.}

General Description of the Program: During the last glacial period, the Great Lakes region was depressed. At the present tine the crust is rebounding. The rate of rise is not uniform throughout the region and is so slow as to be difficult to measure when considering short periods of time. Its long=range effects on depths in harbors and navigation channels and upon outflow rates from the lalkes is very important. This phenomenon can be studied from the geological history of the region and from water level records. Both methods. must be used to verify or revise the theories now widely held. Extensive field investigations may be required. The kmowledge gained from this program will provide information for harbor and channel design and for refinement of lake regulation plans.

\section{Projortin:}

Investigate past glacia]. lake levels from beach traces and derlve crustal movement rates therefrom.

\section{level records.}

Re-evaluate crustal movernent rates derived from existing lake

Compile charts showing underwater topography extended up to shorelines of highest lake levels in the past glacial period for use in crustal movement studies.

Prepare outlook of future crustal movement and determine effects on harbors, navigation channels and lake outflows.

\section{CROUND JIATER.}

General. Descrintion of the Prourum: Groundwater is a stcady Eourcc of water to the Great Inakes. Since croundwater flowi clange slowly, finowledge of its behavior is very importunt in forceasting the watcr supplicis to tho lakes. A related phenomenon, possible deep subterrancan flows betwcen Jinkes and into or out of the regional basin awaits determination. Iittle is known 
of this latter phenomenon althourh some evidence exists to indicate that lakes are losing or gaining water through this type of flow. In order to determine the existence and magnitude of these ground flows, extensive gcologic investigations will be required. Accordingly, this program will be coordinated in detail with the U. S. Ceologic Survey as well as with interested Canadian egencies.

\section{Projects: .}

Derive the amount of water entering the lakes from groundwater flow and the amount of lake water stored in the ground.

Detemine the relationship of groundwater levels to lake levels.

Investigate the deep subterranean flows from and to the lakes.

Incorporate the knowledge of groundwater and deep subterranean flow in methods of forecasting water supply and lake levels.

\section{SHORELINE CONSERVATION}

Genem 7 Description of the Program: Knowledge of the shore processes in lakes and rivers of the basin is sketchy. In order to understand the processes, the shoreline effects of wave action, of surees, of seiches, of currents, of water levels, of vessel wake, of ice scour and the like rnquire determination, upon which may then be based the designs for correction or control. The knowledge will serve a host of interests such as recreation (beaches), private and commercial riparian interests, engineering (designs of channels, harbors and control works). The program will be initiated concurrently with the beginning of data collection by the Public Health Service on Iake Michigan in FY 64 . It is contemplated that the detailed project plan and its execution will be coordinated with the Beach Erosion Board.

\section{Projects:}

From available data and additional field investigations determine relationship between causative forces and quantitative along-shore material transport.

Investigate the lateral inovement of material (shore to off-shore and reverse) and determine the forces and conditions under which this action occurs.

Evaluate effects of typical waves (including storm waves) on shore and near-shore topography.

Evaluate the effects of lake levels on the shore and near-shore processes.

Study the shoreline effects of inshore structures. Devise methods of predicting these effects and of designing compensating or control works. Develop methods of estimating the maximum predicted wave and derive its action against various structures. caused forces.

Determine means of conserving shoreline against natural and man- 


\section{NEAR TERM RESEARCH. PROJECTS}

Described herein is the research work being accomplished in FY 1963 and planned for FY 1964.

LAKE LEVELS. In this field there are two active projects, determination of over-water precipitation and determination of evaporation from large water areas.

Actual precipitation over the lakes will be measured by placing precipitation recorders on six small islands in Lake Michigan and on two islands in Lake Erie. Later a determination of differentials between over-land and over-water precipitation rates will be investigated and their effects on the water supply established. The Lake Erie island stations will serve also for calibration of over-water precipitation images on radar screens. For this investigation, the U. S. Weather Bureau will operate two radar stations, at Detroit and at Buffalo. During the fall months of 1963 , the storage-type precipitation gages which have been in operation for 10 years in Lake Michigan will be replaced by still-experimental long-range recording devices. In Lake Erie, the stations will be newly established. The Lake Erie Project is being conducted with the Weather Bureau as a joint effort.

Evaporation causes large water losses from the Great Lakes. Although it is impossible to change the evaporation from the Great Lakes, the krowledg': 
of the magnitude, seasonal variations and causative factors will contribute to science and to practical use in forecasting water supplies. The evaporation can be evaluated by indirect methods such as accounting for all incoming and outgoing water, the difference being the losses caused by evaporation. A similar mothod is by measuring incoming and outgoing heat energy, the difference being the energy required to calse evaporation. During the summer of 1963, instruments will be placed on South Manitou Island in Lake Michigan and on a tower erected in Lake Michigan one mile from shore in the vicinity of Muskegon, Michigan. These instruments will measure the incoming and outgoing heat energy and many other factors. The project, started this year, will continue through 1965 and is a joint effort among Weather Bureau, the University of Michigan, the Public Health Service and the Lake Survey. The tower is owned by the Corps.

ICE FORMATION AND RELATED PHENOMENA. Two projects closely related are in operation or being planned in this field. One is the conduct of aerial ice observations and the other is the accomplishment of detailed ice surveys.

Aerial ice observations were initiated by Canadian Department of Transport two years ago. The Lake Survey project started carly this year with a pilot study, principally of Lake Michigan, and will be expanded to regular observations of the U. S. waters of all lakes next winter. Two trained ice observers from the District are to be flown by the Civil Air Patrol over the 
lakes and will prepare charts of ice cover and ice characteristics as far as this is possible to establish from the air. It is planned to test experimental infrared sensing devices to determine if they may be used for ice thickness measurement. The utility of high altitude Air Force aerial photos and also the satelite pictures are under study.

Detailed ice surveys are planned for the coming winter. Selected, rather small, ice fields will be surveyed for ice thickness, quality, color, strength, and foreign materials. Concurrent observations will be made of water and air temperatures, wind, and incoming and reflected radiant energy. Projects will be coordinated with Canadian Department of Transport, University of Michigan and to smaller extent with Public Health Service and Weather Bureau, as appropriate.

WATER QUALITY. Activities in this extremely broad field will be coordinated with the Public Health Service and other agencies. Lake Survey efforts at this time are quite limited. A network of water temperature recorders is being established this year. Ten highly sensitive recorders will be installed on U. S. shore of the Great Lakes. A similar project under the Canadian Department of Transport will cover the' Canadian waters.

CURRENTS AND FLOWS. In the field of currents and flows, two projects are in operation; one, the currents in harbors and the other, surges and seiches. Three harbors in Iake Michigan were selected for the surveys of currents. A field party will trace the current moxomants and recording instruments will 
measure currents, waves, wind and water and air temperatures. The data collected by Public Health Service on the currents in Lake Michigan will be utilized for establishing the relationships between lake and harbor currents. Placement of instruments is underway.

Lake Michigan surges and seiches will be recorded by sensitive water level recorders placed on shore and on islands. Twenty-one temporary recorders are being installed to augment the existing permanent network of gages. Data from this project will be used also to correlate the current movement in the lake, measured by Public Health Service, with the wind and water level changes, thus establishing indexes for water movement in the lake to be used when the current measurement in the lake will be discontinued.

WAVE ACTION AND RELATED PHENOMENA. Formal projects in this field are still under development. However, wave recorders will be placed in connection with the other projects. Three magnetic-type wave recorders will be placed near harbor entrances for investigation of the effect of waves on harbor currents. Two recorders will be in places where accurate measurements of the wind and other factors will be made, one on the Lake Michigyan tower and the other on South Manitou Island.

SHORELINE CONSERVATION. Projects in this field are in planing stage. Lack of skilled manpower prevented any project from being started this summer.

DATA PROCESSING. Plans are being developed for the storage of data covering the Great Lakes. Such data must have random access and be adaptable 
to machine processing. Initially a card puncher and a rented electronic digital computer will be employed. At first the currently collected data will be stored on punch cards and magnetic tape with the expansion aiming at the storage and proper publication of all available data.

At the same time the Lake Survey technical library will be expanded to serve the research program.

LAKE ERIE STUDY GROUP. This group was organized for coordination of research effort's in Lake Erie of all American and Canadian agencies. This year, the main research effort is in Lake Michigan; however, in the future more emphasis will be placed on Lake Erie. Lake Survey was selected as the data storage and processing agency for the data collected by the Group. As mentioned previously, Lake Survey also will investigate precipitation over Iuake Lrio and supply data for calibration of radar obuervations.

MANPOWER. The expanded research program requires personnel with skills high in demand at the present time. Solution of this problem is basic and will have the deciding effect on the rate of expansion.

The following efforts are being made to assembile the needed manpower.

a. Shifting of Lake Survey personnel from engineering to research and providing necessary training. Two persons were trained by Navy Oceanographic Office, one in oceanography, the other in aerial ice observations.

b. Hiring personnel educated and experienced in oceanographic research. A recruiting program is underway. 
c. Hiring young graduates with advanced degrees and training them on the job. Two Ph.D. candidates were hired, one oceanographer and one mathematician. 


\author{
UNITEC STATES \\ DEPARTMTIT OF THE INTERIOR \\ BUREAU OF OUTDOOR RECREATION \\ WASHINGTON 25, D.C.
}

Nis. Robert B. Abel itli- io 1060

Executive Secretary

Interacency Corsittice on Occanoarephy

Execut1ve Office Building

Washington 25, D. C.

Dear Me. Abel:

We are submitting the following lufcrintion on the Eureau of Outdoor Recreation activities in the Great Ioles area in reply to your telephone request:

\title{
River Basin Studies
}

1. Studies are underway of outäoor recreation resources, regas, and potentials in connection uith comprohensive vatcr quility ranererent study of the Great Laires-IIIInols River Rasin by U.S. Public Jealth Service. The Bureau of Outioor Ricicctica is excected to participate for Ilve years with an cstirficd 195,000 ol funds allocaticd by the Public Hcalth Service.

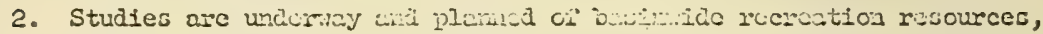
needs and potcntials and evaluation oi revivolr sitce in the obio River Basin in conjunction vith Corps oI Daginoers with win estimated $\$ 156,000$ allocated by the Corps Por four years. A similiar study of the Wabash River Easin will be carricd out with the Corps supplyine an estimated $\$ 110,000$ for five years.

\section{Proposed Areas}

The Bureau is evaluating the National Recrection Arca qualificutions of the Iollowing areas: Picturcd Rocles, Nichican; SIcepius Pear Dunes, Michigan; Indiang Dunes, Indiana.

\section{lationwide and Stato Plsuning}

The Bureau is undertaking the propurticin ois a netionilde nlan for outdoor recreat1on, which w1II inclulit condourtion of the recreation resources, needs, and potentials in thi cicat Inlios region.

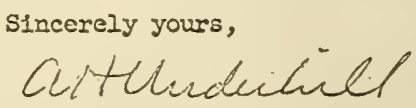


Dear Senator:

I am pleased to forward the attached study which you requested of Federallysupported aquatic investigations relevant to the Great Lakes area. Listed are both projects applying directly to the Great Lakes and those of more general application in which scientists working in the Great Lakes area are engaged.

As a matter of possible interest, the 6th Conference on Great Lakes Research, held in conjunction with the 26th Annual Meeting of the American Society of Iimnology and Oceanography, has just been concluded. A copy of the program is enclosed. I have also enclosed a number of reports describing in detail some of the major projects underway in the Great Lakes area in the hope that they will prove interesting and useful to you.

As I explained in my letter of June 6th, research in lakes and rivers, by definition, does not fall within the cognizance of the Federal Council's Interagency Committee on Oceanography, so that none of these programs is included in the National Oceanographic Program, previously furnished. I should mention, however, that this Government-wide compilation of Great Lakes aquatic research was carried out by the ICO's Executive Secretary, thus effectively utilizing this interagency mechanism.

A considerable portion of this matcrial has bocn provided by riarticipating agencies with the understanding that details will not be relcased for publication or public reference, except with permission from the principal investigators concerned.

Again, may I express appreciation for your interest in marine research.

Sincerely,

S/Jerome B. Wiesner

Encls

$$
\text { a/s }
$$

Honorable Philip $A$. Hart

U.S. Senate

Washington $25, \mathrm{D} . \mathrm{C}$.

bcc: Mr. Robert Abel, ICO 
Finvironmental Research Program

Biolocical Laboratory

Bureau of Comercial Fisheries

Ann'Arbor, Michigan

The need for limological research on the Great Lakes has been recognized by the Ann Arbor Laboratory for many years. We think of the Great Lakes as an environment for fish; consequently, we are interested in the physics, chemistry, and blology of the lakes as well as meteorological and other external influences on the aquatic environment.

The large size of the lakes has Iimited exploration of many aspects of their limnology. Considerable information is avallable, however, on certain facets, especially those related to navigation and power production. In other disciplines very little is known. For example, a list of the more common species in the plankton of Lake Huron would be an original contribution. Vessels and sultable equipment have not been available for exteneive basic research on the creat Lakes until fairly recently. Consequently, much of the Iimnolocicnl. 11terature deals with limited data collected in shallow areas near shore. Lately, various 1deas, as well as equipment have been borrowed from the oceanographer. Bathythermographs, reversing thermometers, Nansen bottles, Clarke-Bumpus plankton samplers, sonic fathometers, and coring devices are now as commonplace on our research vessels as on oceanographic vessels. As a consequence of the special. problems, the lakes offer a common meeting ground between limology and oceanography.

Our Environmental Research Program was set up as a separate unit in 1957 and now emphasized three approaches: general surveys; long-term studies, and unit studies.

General surveys of the lakes were made flrst. Basic knowledge of the chemsatry, physics, and biolory of the lakes was needed to plan speciflc stuales. General fishery and limnological surveys were made by the $M / V$ C1sco in Lake Michigan in 1951, 1952, 1954, 1955, 1960, and 1961; Lake Huron In 1952 and 1956; Lake Superior In 1952, 1953, and 1959; and In Lake Er1e In 1957 and 1958. Limnoloplcal data were collected also by the Bureau's research vessels (Musky II and Slocowet) nasiened to Laker ErLe and Superlor. These data were turned over to us for nnalyais. The results are now avallable to the flshery research programs in the lakes.

Bureau research vessels have obtained over 8,000 bathythermograph tracings and several thousand reversing thermometer temperatures. Approximately 30,000 individual determinations have been made on water samples. Drift bottle studies of surface currents have been completed in Lakes Erie, Huron, Michigan, and Superior. Extensive sampling of planktonic and benthic organisms also have been done. 
Some degree of thermal stratification occurs in all of the lakes during the warmer months. They are almost homothcrmous throughout most of the winter and spring. The effect of deep mixing is apparent in lake Superior where homothermous water arourd $2^{\circ} \mathrm{C}$. occurs to depths of 100 fathoms. The lakes differ chiefly in the rate at which they exchange heat and in the stablity of thermal stratification. The deep waters of all the lakes probably remain close to $4^{\circ} \mathrm{C}$. throughout the year. Well defined and persistent thermal stratification is usually established in Lake Erie by mid-June and Lakes Huron, Michigan, and Ontario by the end of June. The epilimnion extends to about 8 fathoms in Lakes Huron, Michigan, and Ontario, and to 11 fathoms in Lake Erie during the period of maximum stratification in August. Lake Superior usually does not exhibit any well lefined stratification until mid-July. The lower limit of the epilimnion is around 8 fathoms. Thermal stratification is not uniform from area to area and may be transitory. The metalimnion is usually poorly developed. Solid ice sheets in winter are generally limited to sheltered areas, embayments, channels and along shore. Off-shore ice usually occurs as floes. Jakes Erie, Ontario, and Superior may have 80 to 95 percent of their surfaces ice covered in severe winters. Lakes Huron and Michigan normally remain open though shore ice may extend lakeward 8-10 miles. In particularly severe winters all of the lakes may be fully ice covered $(1962-63)$.

The Great Iakes consist of vicurbonate wuters. Total alkilinity ranges from 46 parts per milizion (ppm $\mathrm{CaCO}_{3}$ ) in Lake Siperior to $113 \mathrm{ppm}$ in Lake Michigan. 'The pH ranges from 8.0 to 8.5 for most of the watcrs, except Lake Superior ( $\mathrm{pH}$ 7.4). Sulfate concentrations are sreater than chlorides in the lakes above Lake Exie and they are almost equal in Lakes Erie and Ontario. The proportions of calcium, mannesium, and sodium in the upper lakes are about 10:3:1. Potassium usually averages around 1 ppm in all the lakes. Silica fluctuates around 2-3 ppm, although only trace amounts occur at times in the highly productive waters of Lake Erie. Concentrations of total phosphorus range from less than 5 parts per billion in Lake Superior to $13 \mathrm{ppb}$ in the other lakes except Erie. The phosphorus content in the latter is about six times greater. The dissolved-oxygen content of most of the lake waters is near saturation, even at the createst depths, and supersaturation is common. Dissolved-oxycen concentrations of less than 1 ppm have been found in Lake File. These low valueg have been detected in the bottom waters in an arou of more than 1,000 square miles of the central basin.

Our knowledge of the currents of the lakes have increased considerably within the past few years. . Nevertheless, current pattern determination remains fragmentary. Most studies describe surface currents but none of them have extended over Iong enough periods to support conclusions regarding seasonal patterns.

Several methods have been developed to study currents and water masses of the lakes. Drift missiles have been used for many years, 
especially in areas where the shores are highly populated. More than 80 percent of the drift bottles from a single release, made by the Bureau in Little Bay de Noc (Lake Michigan), have been returned in a short time. Synoptic surveys have been made by the Bureau and other interested groups, usually on a cooperative basis. The distribution of temperatures, transparency, various chemical constituents of the water as determined by these surveys, and current measurements made with dye and large floats, have been useful in identifying water masses and their movements. The Bureau's study in Sarinaw Bay (Lake Huron) has demonstrated that oceanographic methods for estlmating flushinf, rates, seaward transport of river waters, and exchange of sea and river water's in mine catuaries, can be used to cvaluate the circulation of this large freshwater bay.

Present evidence indicates that the currents in most of the lakes are variable and respond rather quickly to wind changes. The synoptic surveys of Lakes Huron and Michigan describe some large eddies in these lakes and some stability in flow patterns that are generated by the flow-through in Lake Huron and the outflow of Lake Michigan. The results of our drift bottle studies in 1956 indicated no single characteristic current system in Lake Huron, although a highly variable west-to-east drift was usually present. Surface currents were variable in all of Lake Michigan. A stable pattern was not detocterl during studies in 1954 or 1955. A north-bound current was observed several times along the eastern shore.

The General circulation pattern in all areas of Lake Superior has not been stindied. Pronent dntil show, however, that certain currents per-

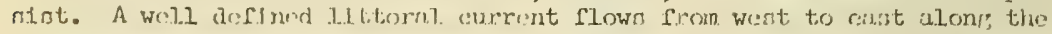
nouth shore. This littoral. current may be part of a monernl courterclockwise irculation of the entire lake.

The current svstem of Lake Erie is dominated by the outflow of the Detroit River--approximately $180,000 \mathrm{cfs}$. Circulation in the shallow western basin, that recelves the flow of the river, is similar in several aspects to that of an estuary. River water extends almost to the south shore, moves counterclockwise into Pigeon Bay, and flows into the central basin through Pelee Passage. A general west to east drift, with at least two large eddies, consisting of river water moves along the north shore. The main flow apparently is deflected onto the south shore of the eastern basin by Long Point.

Diatoms are the most fimportant conotitucnts of the Great Lakes plnnkton. Zooplankton mey occrslonully equal the dintomi in biomnsis, but not; in numbers. Blue-creen and reen nl crae are especially abundant at tines in Lake Erie and probably also in lake Ontario: Even in Lake Erie, however,

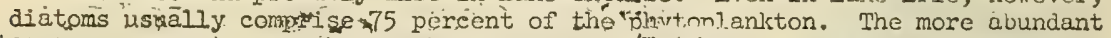
diatom gęnera are Astérionella, Cyclotella Frájilaria, Melosira, Synedra, and Tabellaria. Copepods make up the bulk if the zooplankton, but protozoans are more numerous. Cladocerans are very abundant in the summer, and rotifers, especiaily Keratella, are usually plentiful. Cyclops bicuspidatus, 
Diaptomus minutus, D. sicilis, D. ashlandi, and D. oregonensis are especially plentifuI. 1n Lake Erie and in the upper strata of the other lakes. The coldwater copepods Limnocalanus macrurus and Senecella calanoides are taken in the deep waters.

Little is knows of the abundance of plankton in the lakes. Most studies have been made on Lake Erie. Generally spealsing, peak plankton abundance occurs in the spring and again in the fall. The spring pulse consists almost entirely of diatoms. Populations of blue-green and green algae build up during August and September and contribute to the fall pulse, although diatoms are still dominant.

Large zooplankters of Lake Erle are abundant in summer and the smaller oncs In spriner and fall. Most of the Crustacen in Lialse Michilem reach only one population peak a year. Cladoccrans and the copopods Mesocyclops cdax and Epischura lacustris probably overwinter as escs. Cyclops bicusplatus, which is a winter and early spring form in Lake Erie, seems to be plentifuz throughout the entire year in the colder environment of Lake Michigan.

The vertical distribution of eight species of cladocerans, nine species of copepods, and the two benthic malacostracans, Pontoporeia affinis and Mysis relicta was studied by the Bureau in Lake Michigan. All species migrated toward and attained their greatest numbers at the surface late in the day; apparently in response to diurnal changes in light intensity. The number of individuals at the surface decreased toward midnight and limited evidence indicated an increase for some spectes at the surface argin slichtIy before dawn. A more detailed study of the misratory behavior of $M$. relicta indicated that lifht "trifrors" and controls thoir micrutions, while thermal conditions interact with und modify the influcnce of lifht. I"ollowlng the summer solstice the mysids ascended prosressively earlier each evening and descended later each morninfs. Moonlight and fog influenced the time as well as the amplitude of the vertical migration. The mysids frequently migrated through the thermocline when first ascending, but later in the night the majority occurred in or immediately below this layer.

Attempts to obtain estimates of the productivity of Great Lakes phytoplankton populations have met with certain problems. The low plankton populations in Lake Superior make it necessary to concentrate samples for productivity measurements. Estimates of productivity made at a few stations are obviously not representative of conditions in an entire lake or even in the larger bays. Consequently, methods are belng developed that will apply to large lakes.

The deep-water bottom fauna of the Great Lakes is dominated by the

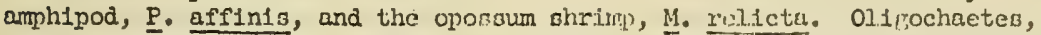
especially Imnodrilus, and the Sphoeridildac, listilim and Sphrerium, are also numerous. Mage larvae of the renus Sraniotoma, are found at depths greater than 30 fathoms. The shallow-water faund has many of the species common in the smaller inland lakes. Himdir a and various Tendipedids are 
II].entiful at depths less than 40 fathoms. Various castropods-Lymnca, Valvata, Amnicola, Goniobasis--are important in shallow areas. Trichoptera larvae and especialiy the ephemeropteran, Hexagenia, are abundant in some areas.

A major weakness in Great Iakes research has been the lack of longterm studies. Our solution to this lack is to take information from general surveys and specific studies, such as the synoptic surveys of western Lake Erie, and attempt to divide the Great Lakes into ecological zones. Once we have established an "ecological zone," we establish one or more "index stations." Intensive sampling of most aspects of the environment is done at these stations at least three times each year. Present sampling includes: net and nannoplankton, bottom fauna, temperatures, analyses for $\mathrm{Ca}, \mathrm{K}, \mathrm{MG}$, $\mathrm{Na}, \mathrm{Cl}, \mathrm{SO}_{4}, \mathrm{SiO}_{2}$, dissolved oxycen, alkalinity, pll, and $\mathrm{P}$, water movements,

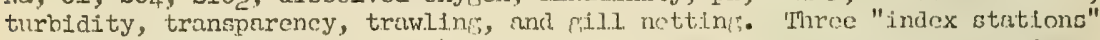
have been established in the Apostle Islands repion of Lake Supcrior and seven in western Lake Erie.

Comparison of data compiled during the past 60 years with those from more recent studies demonstrates that major changes have occurred in some of the lakes, particularly in the benthic and fish faunas of Lake Erie. Mayfly nymphs are 10 percent or less of their former abundance, while a marked increase has occurred in the numbers of oligochaetes and midge larvae. Blue pike and cisco, which formerly dominated the commercial catch, have almost disappeared from the fishery.

The bacterial load in the western basin of Lalie Erie increased threefold between 1913 and 1948. Concentrations of various major ions have increased since 1907. Recent analyses show incrcases of from 1 to 10 ppm in calcium, magnesium, sodium plus potassilin, snd sulfrte over carlicr valucs. The averaye chloride concentration was around 10 ppin or loss in 1930 . 'loday the averare chloride concentiation is around 25 pum. Present mean annual water temperatures are approximately $2^{\circ} \mathrm{F}$. warmer than those for the 1918 1928 period. Very low dissolved oxyscon concentrations have been observed in Lake Erie in recent years, although low concentrations have been reported several times since 1930. Nevertheless, the severity of oxygen depletion is greater at present. Synoptic surveys made of dissolved oxygen concentrations in 1959 and 1960, showed that bottom waters over an area of 1,400 square miles had concentrations less than 1 ppm. The nitrogen and phosphorus content of the water has shown a marked increase. The exact degree of increase is uncertain, since data from previous years are conflicting.

Iast year, laboratory and field measurements were made of the oxygen demand of the water and sediments, and of the organic content of the sediments in Lake Erie. A very rapid uptake of dissolved oxycen occurs in less. than 5 minutes, when a small amount of botton sediment is mixed with oxysenated water. This immediate demand is probably chemical whereas a subsequent, continued gradual uptake of oxygen is probably biolorical. The biological oxyen demand of the hypolimnetic waters was not great enourh to account for the low dissolved oxyisn concentrations observed in the lake. 
Sediments with the highest immediate oxygen demand had the greatest orranic content. Laboratory studies on Lake Erie sediments showed that large amounts of iron and phosphorus are released into the water from the sediments when the oxycen content of the water dropped below 1 ppm.

The sampling efficiencies of the Petersen, orance-peel, and SmithMcIntyre dredges in relation to water depth and bottom type in Lake Michigan have been compared. Three samples were taken with each dredge at depths of $3,10,20,30$, and 40 fathoms along each of four transects. Data from this undertaking have not been analyzed fully. However, a comparison made in 1960 of the Petersen and Smith-McIntyre dredges showed that both collected about the same number of organisms from bottoms shallower than 15 fathoms. The Petersen dredge collected fewer organisms at each subsequent 5 -fathom increase in depth whereas the Smith-McIntyre collected about the same numbers at all depths from 15 to 30 fathoms. These results cast doubt on the validity of much of the data on abundance of benthic organisms in the deeper waters of the Great Lakes.

We have started to investigate the nature and concentrations of organic nutrients in Great Lalse: vaters. Nlthour developments of sampline procedures and methods for identifyiu; orranic compounds are of immediate concern, nevertheless, we are usini activated charcoal filters to adsorb and concentrate the organies in water. A filter unit is in operation at llammond Bay, Lake Huron, and a similar unit was installed aboard the $\mathrm{M} / \mathrm{V}$ Cisco during 1961. Spectrophotometric (ultraviolet, infrared), polarographic, and radiographic methods are being investigated for identifying the organics. Standard methods for detecting alkyl-benzene-sulfonants (detergents), tanin, and Iignin will be employed to study the interrelationships betreen these major organic groups. An adsorption column assembly has been constructed to study several. physical variables such as column size and flow rate.

The organic compounds are extracted from the activated charcoal with chloroform and alcohol. Amounts of choloroform and alcohol extractables appear to be useful for indlcating relative water qualities. Chloroform extractables are assumed to represent less polar compounds of industrial origin (pollution) and alcohol cxtractahles the more polar varieties from humic acid (natural organics), ctc. These critcril indicate that the watere of northern Lake Michigan and in the victnity of Ilounond. Joy, Lake lluxon, are "clean" waters. The IImnetic watcrs of Lale Michigan had a particularly high ratio of alcohol to chloroform extractables. This ratio indicates a seasonal fluctuation when monthly samples are compared. 
$\mathrm{V}$

\section{CONCLUSION}

The foregoing charter domonstrates the groat interest beine shown In the Great Lakes area by the two eovernments, the states and provinces, local municipalities, and colleges.

The first examination may lead one to conclude that at least the sponsoring agencies are unduly emphasizing the biological sciences. It must be realized that the major applications of this work concern health and sanitation which are very important considerations in the Hational welfare. However, the scientific attack is being conducted on a broad front including the physical and chemical sciences, geology, and meteorology.

In particular, the Big Ten universities in the area are devoting a large amount of talent and facilities to technological development of the area.

This interest cannot fail to pay off in better health, better recreation, more effective exploitation of the natural resources, and better understanding of aquatic processes of the Great Lakes. 


$$
\text { Program of tho }
$$

IWENTY-SIXTH ANNUAL MELIINC;

$$
\text { AMERICAN SOCIETY OT }
$$

LIMNOLOGY AND OCEANOGRAPIIY, INC,

$$
\text { in conjunction with }
$$

SIXT'H CONFERLNCL ON GREAT LAKES RESEARCII

$$
* * *
$$

The University of Michigans.

Aun Arbor, Michigan

June 13-15, 1968

$$
\text { *** }
$$

OPHSCER OP ASLO

\section{Parent Society}

President.

Vice-President.

R. W. Pennak

G. L. Pickard

Secretary. ..G. H. Lauft

Treasurer.oss...n....nos.s....A. M. Beeton

\section{Pacific Section}

President..................P. A. Richards Vice.President.............M. Waldichuk Secretary. Treaurer ....M. Blackburn

\section{$*+*$ \\ Host! GREAT LAKES RESEARCH DIVISION \\ The University of Michigan \\ Oeneral Chairmans David C. Chandler}


FIELD TRxp: June 12. Trip to nort of Grand Haven. Michisan, to insned re. seitrch verisels nperating! on the Great latkes. Bus will depart from side entrance of Michiggan Union at $1: 00 \mathrm{p} . \mathrm{m}$.

REGISTRATION: Beginning 8:00 a.m. June 13, Angell Fall Concrurse at Audi. torium A. (All scesions will be held in Angell Hall, Auditoriums $A, C$, or D.)

\section{Program}

\section{Theme: The Aquatic Environment}

\section{THURSDAY MORNING', JUNE 13}

Angell Hall, Auditorium A

8:30-Welcone. HARLAN HATCHLR, President of The University of Michigan.

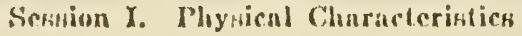

Inviecd l'ajuers:

Angrell Mall, Auditorium A. ROBBRT W. PlBNNAK presiding.

9:00-IJIKARD, G. L. University of British Columbia. Marine physical envirum. mist.

9:30-MOR'TIMLR, C. H. Scottikh Marine Biological Station, l'ronticrs in physj. cal limnelogy.

Constributed Papers:

Section A. Ansell Hall, Auditorium C. GEORGH? L. PICKARJ) presiding.

10:15-OLSON, F. C. W. and T. ICHIYE. AMS, RCA Lahoriturics, Elfect wi stratification on the period of inertial motion.

10:30-MEE, THOMAS R., JR. Cornell Acronautical Lab. Measurements of cirhisil velocitics in water waves,

10:45-VERBER, JAMES L. U.S. Public Health Service, Chicago. Initial current studic: in Lake Michigan.

11:D0-DLAKKAN, BRUCE D. University of Michigan. A fershwater gemmagnetic clectrokinctograph.

11:15-MARSHALL, NELSON, University of Rhode Island. Circulation adjacent (n) the hetton as related to the enibenthic covironment.

11:30--JOIINSON, R1JS'sER, L. Michipan Department of Healch, Escamaha. Tides and sciches in Grent Bay.

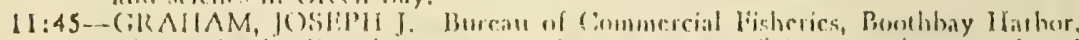

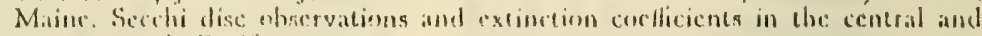
satern moth bacific:

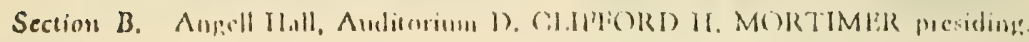

10:15-SIIONTINC, I)AVII) II. U.S. Naval Underwater ()ednance Station, New.

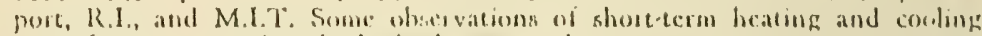
in surface waters using the bithyelicrmograph.

10:30-MCFADIDEN, J. D. and R. A. RAGOTYKIE. University of Wiscunsin. Acrial mapping of surface temprinture pattern of Lake Michigan.

10:45-ANIDERSON, D. V. and G. K. RODCERS. Ontario Department of Lands and Forests, and Great Lakes Institute, University of Toronto. The thermal structure of Lake Ontario.

11:00-WINTERFELD, THOMAS. National Occanographic Data Center. Sumc aspects of the use of sea surface reference temperatures in bathythermograph processing.

11:15-FARRELL, JOYCE and CARL MOREY. U.S. Naval Underwater Ordnance Station, R.I. Automatic interpolation of occanographic station data at isen. tropic levels using the IBM 1620 data processing system.

11:30-RODGERS, G. K. Great Lakes Institute, University of Toronto. Lake Eric: recent observations on some of its physical and chemical properties: Part II.

11:45-ANDERSON, D. V. and G. K. RODGERS. Ontario Department of Lands and l'oresta, and Greal Lakes Inatitute, University of Toronto. $\Lambda$ symoutic survey of Ianke Suprerior. 


\title{
'TIUURSDAY AF"IELNOON, JUNE 13
}

\author{
Session II. Chemical Characteristics
}

Invited Papers:

Angell Hall, Auditorium A. GORDON A. RILEY presiding.

1:30-HOOD, DONALD W. A. \& M. College of Texas, Chemical characteristics of the marine environment.

2:00-HAYES, F. RONALD. Dalhousie University. Chemical characteristics of fresh watcr.

\section{Contributed Papers:}

Scction A. Angell Hall, Auditorium C. DONALD W. HOOD presiding.

2:45-ANGINO, E.E., K. B. ARMITAGE, and J. C. TASH. A. E M. (inllepe of Texas and University of Kansas. Compartive chemistry of threc saline lakes, Victurin Land, Antarctica

3:00-JOHNSON, R. $\mathrm{I}^{2}$. University of Miami. The source of carbonate in mollus. can shell formation.

3:15-C.ARR, J. F., A. M. BEIETON, and H. ALT.EN. U.S. Burcau of Commereial Pisheries, Ans Albor. Hactors associated with low dissolved oxygen enecne trations in Iake Iiric.

3:30-SIE(BLL, AIVIN. Wouds Ifole Oceanographic Institution, Equilibrum binde

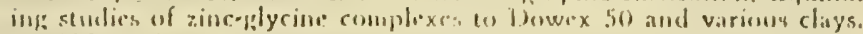

3:45-BRAVOS, MRS. L. and R. M. IN(BIL, Helorida State Beard of Conserva. tion Marine Lab. Problems of vitamin B-12 assay in sca water.

4:00-BENOIT, R. J. and T. E. ADAMSON. General Dynamics, Groton, Conn. Synthetic urganic chemicals and ground water pollution in Connecticut.

4:15-RILEY, GORDON A. Bingham Oceanographic Lah, Yalc University. Or. ganic aggregates in sea water and the dynamics of their fornation and utilization.

4:30-CALLAWAY, R. J. U.S. Public Health Scrvice, Portland, Orc. Diffusion of sulfite waste liquor from a submarine outfall.

Scetion B. Angell Hall, Auditorium D. F. RONALD HAYES presiding.

2:45-EBERLY, WM. R. Manchester College, Indiana. Metalimnctic oxyfen maxi$\mathrm{ma}$ in some Wisconsin lakes.

3:00-DOLLAR, A. M. and R. L. BURGNER. University of Washington. A comparative study of the distrihution of trace mincrals between witer and particulate matter from fifteen Alaskan red salmon nuiscry lakes.

3:15-DANIELS, S., L. L. KEMPE, E. S. GRAHAM, and A. M. BEETON. U.S. Burcau of Commercial Fisheries and University of Michigan. Quantitation of miernorganic compounds in water of the Great Lakes by adsorption on activated cartion.

3:30-THIOMAS, NIBSON A. U.S. Public Ilath Sicrvice, Cincinmati. Oxypen deficit rates for the centhal hasin of latke Pase.

3:45-MLGRLGIAN, S., 1'. D. IUII,BR, and C. RISI.I:Y, IR. U.S. Puhlic llealeh Service, Chicago. Chemical Characteristice of Lake Michigan; a preliminary report.

4:00-RISLEY, CLIFFORD, JR. U.S. Public Health Service, Chicago. Radio. activity levels in Lake Michigan; a preliminary report.

4:15-SHAPIRO, JOSEPH. The Johns Hopkins University. Phosphorus and pro. ductivity.

8:00 P.M.-Sinoker.

\section{FRIDAY MORNING, JUNE 14}

\section{Session III. Geological and Meteorological Characteristics}

Inviced Papers:

Angell Hall, Auditorium A. GEORGE B. LANGFORD presiding.

8:30-HOUGH, JACK L. University of Illinois. Geological and sedinentary char. acteristics of the freshwater environment.

9:00-BRUCE., J. P. Canada Department of Traneport. Metcorological factors and their influence on the freshwater environment. 
Cuntributed Papers:

Section A. Angell Hall, Auditorium C. JACK L. HOUGH presiding.

9:45-NICHOLS, M. M. Virginia Institute of Marine Science. Organic production and scdimentation of arid coustal liggoons.

10:00-L.OY, WM. G. University of Minnesota. The cvolution of bay.head bars in westem Lake Supcrior.

10:15-ZUMBERGE, J.H. and W. R. PARRAND. Grand Vallcy Collegc, Mithigan, and Columbia University. Lake Superior corcs and bottom topngraphy.

10:30-MAcLEAN, WM. F. University of Michigan. Modern pscudoupwarping around Lake Eric.

10:45-TLRASMAE, J. and R. J. MOTT. Gcological Survey of Canada. Problems of dating abancioned shorelines in the Lake Huron basin.

11:00-DrCOOKE, B. G. U.S. Lake Survey, Detroit. Rescarch aspects of Lake Ontario regulation.

11:15-MUSHAM. H. A. Chicago. Loss of level on Lakes Michigan and Huron occasioned by improvemente for navipation.

11:30-IC:NATIUS, IX. G. Geologrical Survey, l'inland, and Univerkity of Illíinois. Studice of the Baltic oca floor.

Section B. Angell IYall, Auditorium D. J. P. BRUCE presiding.

9:45-NOBLE, VINCENT. University of Michigan. Shipboard auturnatic dighital meteorological data system.

10:00-BAJORUNAS, L. U.S. Lake Survey, Detroit. Natural regulation of the Gicat Lakes.

10:15-WILLIAMS, GEORGE C. State University of New York. A lake snow mechanism contributing to areas of snowfall tending to parallel the lake shore.

10:30-BRUNK, IVAN W. U.S. Weather Burcau, Chicago. Additional evidence of lowering of Lake Michigan-Huron levels.

10:45-RICHARDS, T. L. Canada Department of Transport. Metcorological fac. tors affecting icc on the Great Lakes.

11:00-HEAP, JOHN A. University of Michigan. Some characteristies of the winter ice enver of I.ake Micluigan 1962.63.

11:15-PLATZMAN, G. W. and D. B. RAO. University of Chicago. The 14thour period of Lake Eric.

11:30-BELLAIRE, F. R. University of Michigan. Relation of lake winds to alonge shore currentö in lower Lake Michiģan.

\section{FLIDAY AFTERNOON, JUNE 14}

\section{Sension IV. The Biolopical Inteyratore}

Liwited Papers:

Angell Hall, Amberium A. JOIIN C: AYYlus preriding.

1:30-KEICHIM characteristics of the inarine environincut.

2:00-SAUNDERS, G. W. Wayne State University, Detroit. The biological char. acteristics of the freshwater environment.

Contributed Papers:

Section A. Antell Hall, Auditorium C. B. H. KETCHUM presiding.

2:45-ROBERTSON, ANDREW. Scottish Marine Biologienl Station. Distribution of the marine Cladocera in the North Atlantic.

3:00-BISHOP, J. W. and J. P. Barlow. Cornell University. The significance of body size in cstimating the metabolism of zooplankton populations.

3:10-TAUB, FRIEDA B. and A. M. DOLIAR. University of Washington. A Chlorella-Daphnia food chain study: the design of a compatible chemically defined culture medium.

3:20-NISKIN, SIYALF, and J. I. JONBS. Institute of Marine Science, Miami. $\mathrm{Ncw}$ collecting and recording devices for limnological and occanographic rescarch.

3:3.5-WHEELER, B. A. and NELSON MARSHALL. University of Rhode Is. land. The primary food of an estuarine flats environment as related to off shore and river contributions.

3:45-BOUSI'IRLD, E. L. National Muscum, Ottawa, Preliminary resulte of investigations on the littoral marine clustaceans of the Atlantic coast of Hloridit and Georgia. 
Section B. Angell Hall, Auditoriun D. GBORGE W. SAUNDERS presiding.

2:45-MARSHALL, J. S. and A. M. BELTON. University of Michigan and U.S. Burcau of Commercial Fisherics. Infuence of mincral composition of natural waters on strontium accumulation and discrimination by freshwater phyto. plankton.

3:00-EICHELBERGER, H. F. The Potamological Institute, University of Louis. ville. An ccological investigation of the periphyton community in the Ohio River at Louisville, Kentucky.

3:15-SEILHEIMER, J. A. Southern Colorado State College. The dynamics of potamopiankton populations in the Ohio River at Louisville, Kentucky, 1961.1962.

3:30-COOK, GROVER W. U.S. Public Health Service, Chicago. The plankton and henthic fauna of Lake Michigan's southern basin.

3:45-SCARCE, LEROY E. U.S. Public Health Service, Chicngo. A limnological study in the distribution of the bacterial flora of Lake Michigan.

4:00-Anumal Business Meeting of ASLO. Auditorium A, Angell Hall.

\section{SATURDAY MORNING, JUNE 15}

\section{Session V. Biologsy (cont.) nnd Water Resourcess}

Invited Papers:

Section A. Angell Hall, Auditorium C. I.YLE R. CRAINE presiding.

9:00-RENN, CHARLES E. The Johne Iopkina University. Biologists as organization men in water resources.

9:30-LACKEY, JAMES B. University of Florida. The seientist and marine water resources.

10:00-BERGER, BERNARD B. U.S. Public Health Service, Washington, D.C. Scientists and water quality rescarch.

10:30-OEMING, LORING F. Michigan Water Resources Commission. Water resources management-the scicntist's contribution.

11:00-POSTON, H. W., W. Q. KEHR and C. R. OWNBEY, U.S. Public Health Service, Chicago. Scientific rescarch and water quality management.

Contributed Papers, Biology (continued):

Section B. Angell Hall, Auditoriun D. GEORGE H. LAUPF presiding.

9:00-DAVIS, CHARLES C. Western Reserve University. Hatching mechanism in the cegs of aquatic invertebrates.

9:15-PARKER, RICHARD A. Washington State Univeristy. Some effects of photoneriod and temperature on daphnid reproduction.

9:30-ANIDERSON, W. H. L. and W. I. I.'LSPIERANCE. University of Michifan. An conesmetric model of the market for yellow perch.

2:45-FABIER, DANILL J. Univertity of Wiscossin. Larval fish taken with tow. nets in the open water of a small northern Wisconsin lake.

10:00-CHANDI.ER, DAVID C. University of Michigan. Burrowing maytly nymphs in western Lake Eric previous to 1947.

10:15-WOOD, KENNETH G. Thiel College, Greenville, Pa. The bottom fauna of western L,ake Eric, 19.51.52.

10:30-BRITT, N. WILSON. Ohio State University. Some changes in the bottom fauna of the island area of western Lake Erie in the decade 1953.1963, with speciai reference to the aquatic insects.

11:00-CARR, JOHN F. and J. K. HILTUNEN. U.S. Burcau of Commercial Fisheries, Ann Arbor. Changes in the bottom fauna of Lake Eric, west of the islands, $1930 \cdot 1961$.

11:15-DENDY, J. S. Auburn University, Alabama. Observations on ecology of bryozoans in farm ponds.

11:30-DORRIS, TROY C. and B. J. COPELAND. Oklahoma State University. Chlorophyll in oil refincry effluent-holding ponds.

11:45-COLE, GERALD A. and JOHN G. WEISE. Arizona State University. Calanoid copepods from autumnal temporary ponds in Arizona. 



\section{APPENDIX 5}

OCEANOGRAPHY-THE TEN YEARS AHEAD, SUBMITTED BY HON. JAMES H. WAKELIN, JR., ASSISTAN'T SECRETARY

OF THE NAVY, INCLUDING LETTER OF TRANSMITTAL TO SPEAKER MCCORMACK, DATED JULY 26, 1963, AND SIGNED BY DR. JEROME B. WIESNER 



\section{OCEANOGRAPHY \\ The Ten Years Ahead}

\section{A LONG RANGE \\ NATIONAL OCEANOGRAPHIC PLAN 1963 - 1972}

INTERAGENCY COMMITTEE ON OCEANOGRAPHY

of the

FEDERAL COUNCIL FOR SCIENCE AND TECHNOLOGY

United States of America

ICO PAMPHLET NO. 10

JUNE 1963

427 


\section{FEDERAL COUNCIL FOR SCIENCE AND TECHNOLOGY \\ JEROME B. WIESNER, Chairman \\ Director, OFFICE OF SCIENCE AND TECHNOLOGY}

\author{
Harold Brown \\ Director of Defense Rescarch \\ and Engineering \\ DEPARTMENT OF DEFENSE
}

J. Herbert Hollomon

Assistant Secretary for Science

and Technology

DEPARTMENT OF COMMERCE

\section{BoIsfeuillet JONES}

Special Assistant to the Secretary

for Health and Medical Affairs

DEPARTMENT OF HEALTH, EDUCATION, AND WELFARE

John C. Calhoun, JR.

Science Adviser to the Sectetary

DEPARTMENT OF INTERIOR

RAgnaR Rollefson - (Obsetver)

Director, Office of International

Scientific Affairs

DEPARTMENT OF STATE
Glenn T. Seaborg

Chairman

ATOMIC ENERGY COMMISSION

Alan T. WATERMAN

Director

NATIONAL SCIENCE FOUNDATION

JAMES E. WEBB

Administrator

NATIONAL AERONAUTICS AND

SPACE ADMINISTRATION

Willard Cochrane

Director, Agricultural Economics

DEPARTMENT OF AGRICULTURE

Elmer B. StaAts - (Observer)

Depruty Ditectot

BUREAU OF THE BUDGET

N. E. HALABY - (Observer)

Administrator

FEDERAL AVIATION AGENCY

EDWARD WENK, JR. (Executive Secretany)

Techrical Assistant to the Director

OFFICE OF SCIENCE AND TECHNOLOGY

\section{INTERAGENCY COMMITTEE ON OCEANOGRAPHY}

James H. WAKelin, JR., Chaiman

Assistant Secretary of the Novy (Research and Development)

DEPARTMENT OF DEFENSE

RADM H. ARNOLD KaRo

Director, US. Coost and Geodetic Surve DEPARTMENT OF COMMERCE

Donald L. MCKernan

Director, Bureau of Commercial Fisheries DEPARTMENT OF THE INTERIOR

RADM R. D. SCHMidTMAN

Chief, Office of Operations

U.S. Coast Guard Headquarters

DEPARTMENT OF THE TREASURY

Harve J. Carison

Assistant Director for Biological and Medical Sciences NATIONAL SCIENCE FOUNDATION

\section{Harry G. Hanson}

Associate Chief, Bureau of State Services

Public Health Service

DEPARTMENT OF HEALTH,

EDUCATION, AND WELFARE
JOHN N. WOLFE

Chief, Environmental Sciences Branch

Division of Biology and Medicine

ATOMIC ENERGY COMMISSION

\author{
I. E. WALLEN \\ Assistant Director for Oceanography \\ Museum of Natural History
}

SMITHSONIAN INSTITUTION

Observers:

RAGNaR Rollerson

Director, Offuce of International Scientific Affairs, DEPARTMENT OF STATE

Athelstan Spilhaus

Chairman, Committee on Oceanography NATIONAL ACADEMY OF SCIENCES

E. L. Dillon

Budget Examinet

BUREAU OF THE BUDGET

EDWARD WENK, JR.

Technical Assistant to the Director

OFFICE OF SCIENCE AND TECHNOLOGY

Robert B. Abel (Secretary)

Assislant Research Coordinator

Office of Naval Research

DEPARTMENT OF THE NAVY 


\section{CONTENTS}

Foreword

Frontispiece

Summary

\section{Chapter I - INTRODUCTION}

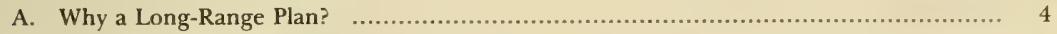

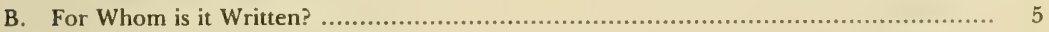

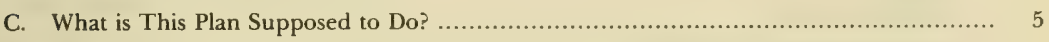

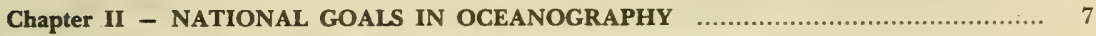

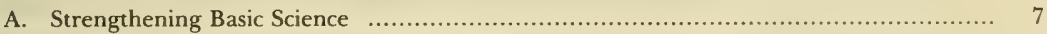

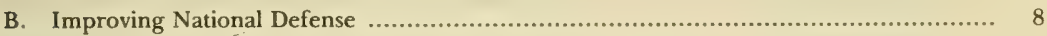

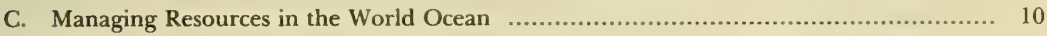

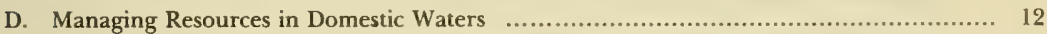

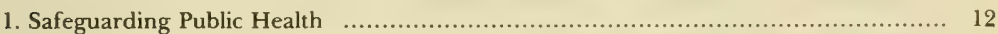

2. Conservation of Resources Held in Common ........................................ 12

E. Protecting Life and Property Ashore; Insuring the Safety of Operations at Sea ......... 13

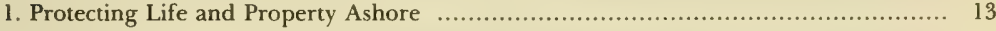

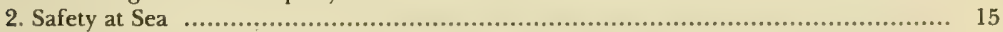

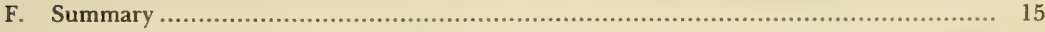

Chapter III - SPECIAL GROUPS CONCERNED WITH OCEANOGRAPHY $\ldots \ldots \ldots \ldots \ldots . . \ldots$

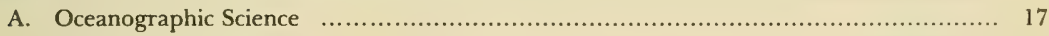

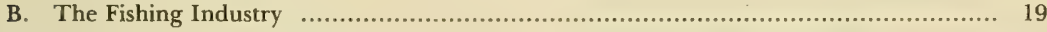

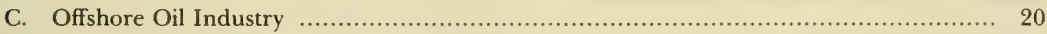

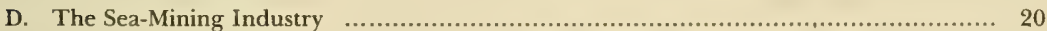

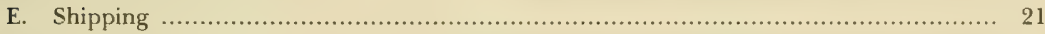

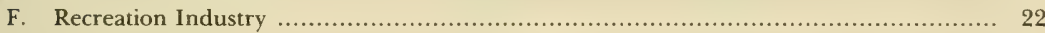

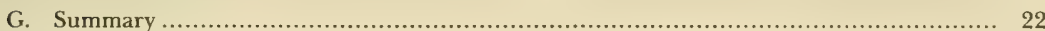




\section{CONTENTS (Continued)}

\section{Chapter IV - CAPABIUITIES AND SYSTEMS TO SUPPORT}

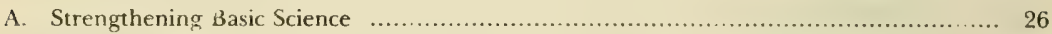

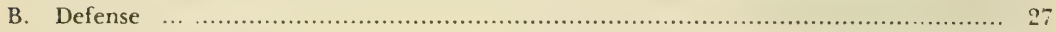

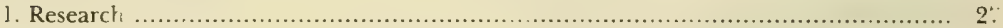

2. Ships $\ldots . . . \ldots \ldots \ldots \ldots \ldots \ldots . . . .27$

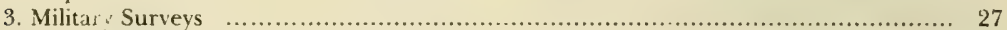

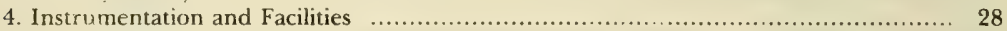

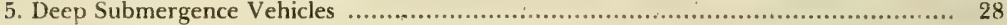

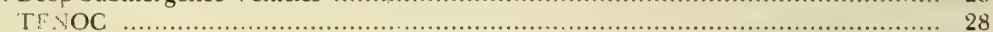

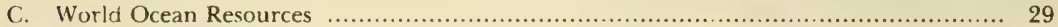

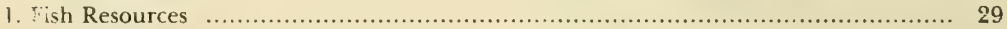

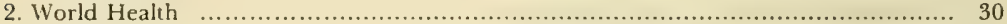

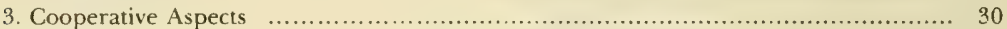

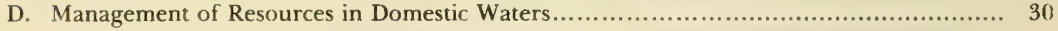

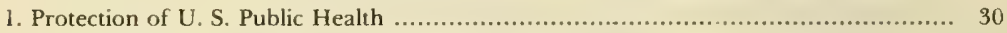

2. Management of U. S. Resources Held in Common ................................... 31

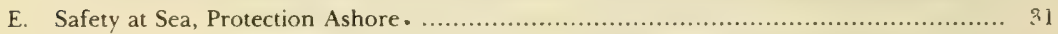

1. Protecting Life and Property Along the Coastlines .................................... 32

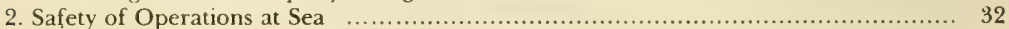

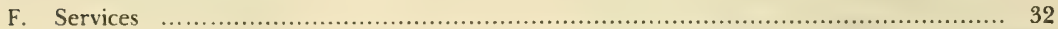

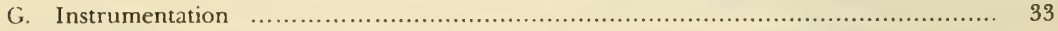

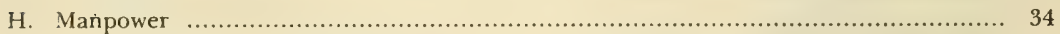

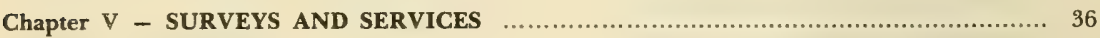

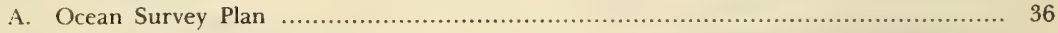

B. The National Oceanographic Data Center .............................................. 37

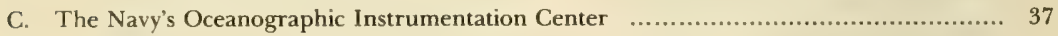

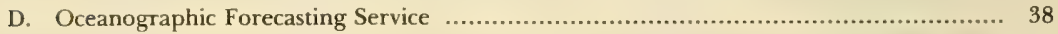

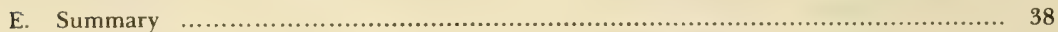


CONTENTS (Continued)

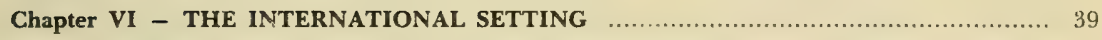

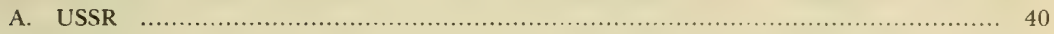

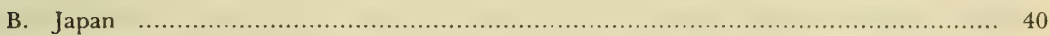

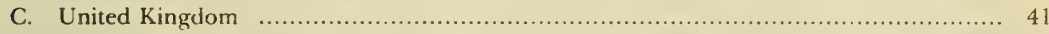

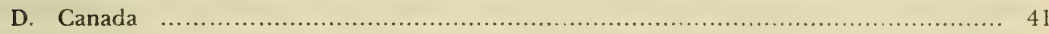

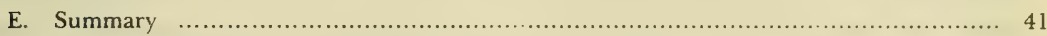

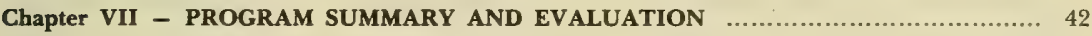

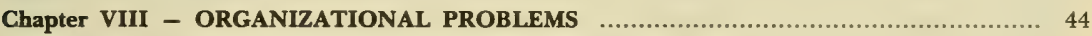

Appendix A - RECENT BUDGET SUMMARIES -

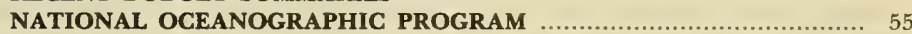




\section{FOREWORD}

The Interagency Committee on Oceanography of the Federal Council for Science and Technology has since 1959 been coordinating the annual plans and programs of the federal agencies in the marine sciences. During this time the need to view agency plans and their implications on a more extended time scale has greatly increased, especially considering the continued growth of federal support for science and the consequent sharpening of the competition for such resources as skilled manpower and funds. This long-range plan is designed to meet this need.

Until very recently the pressure of this competition has kept oceanography in a comparatively primitive state with respect to resources, activity, and accomplishment. With the completion of studies both inside and outside of government, a widespread conviction developed that the national interest demanded more rapid growth. Sharply accelerated support during the last three years has now brought oceanography to a level from which our planning for the next ten years can be projected in balance with all of science and technology supported by the government, which shows signs of doubling over the next ten years.

To be effective these expenditures require comprehensive and farsighted plans, taking account not only of the relationship between scientific discovery and application, but also a desired balance of effort among the various scientific disciplines and among institutions in universities, industry, and government who perform this research. And as these relationships become increasingly well understood, it will become ever more important for those working in one field to become aware of plans being made for others. In this way they will be able to participate more effectively in the pursuit of broadly shared objectives.

This Long-Range National Oceanographic Plan has therefore been drafted within the framework of a statement of national goals. This and the long time scale on which the effort is discussed should facilitate the appraisal of the shorter term steps to be taken along the way. The rapidity with which the oceanographic program has grown and the large number of federal agencies involved makes such appraisal both difficult and necessary, to determine its consistency with other indices of the national interest such as congressional resolutions, aims enunicated by the President, and goals established by the Federal Council for Science and Technology. It should be emphasized that although the benefits of our program are intended to accrue to the Nation at large, the effort described herein is limited to that sponsored by the Federal Government itself. That is, this plan represents a federal effort to further national goals.

This federal funding not only supports oceanographic activity in federal agencies but even more extensive programs in private institutions as well. The Interagency Committee on Oceanography has endeavored to express in this document the means through which federal, academic, and industrial members of the oceanographic community can look ahead together.

Finally, it should be noted that this plan is a statement of our needs and aspirations. It is in no way fixed or irrevocable. It must be expected to change year by year as new scientific results and new technological opportunities become available, and new requirements or priorities develop. A measure of its success will be the extent to which it fosters progress toward the solution of many of the problems of seeming importance today, while providing an enhanced capability to meet shifts in priorities and the opening of new paths toward our national goals which may take place tomorrow. 
BREAKDOWN BY GOALS

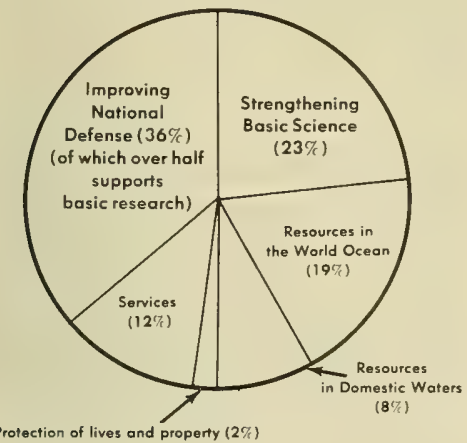

BREAKDOWN BY ICO FUNCTIONAL AREAS
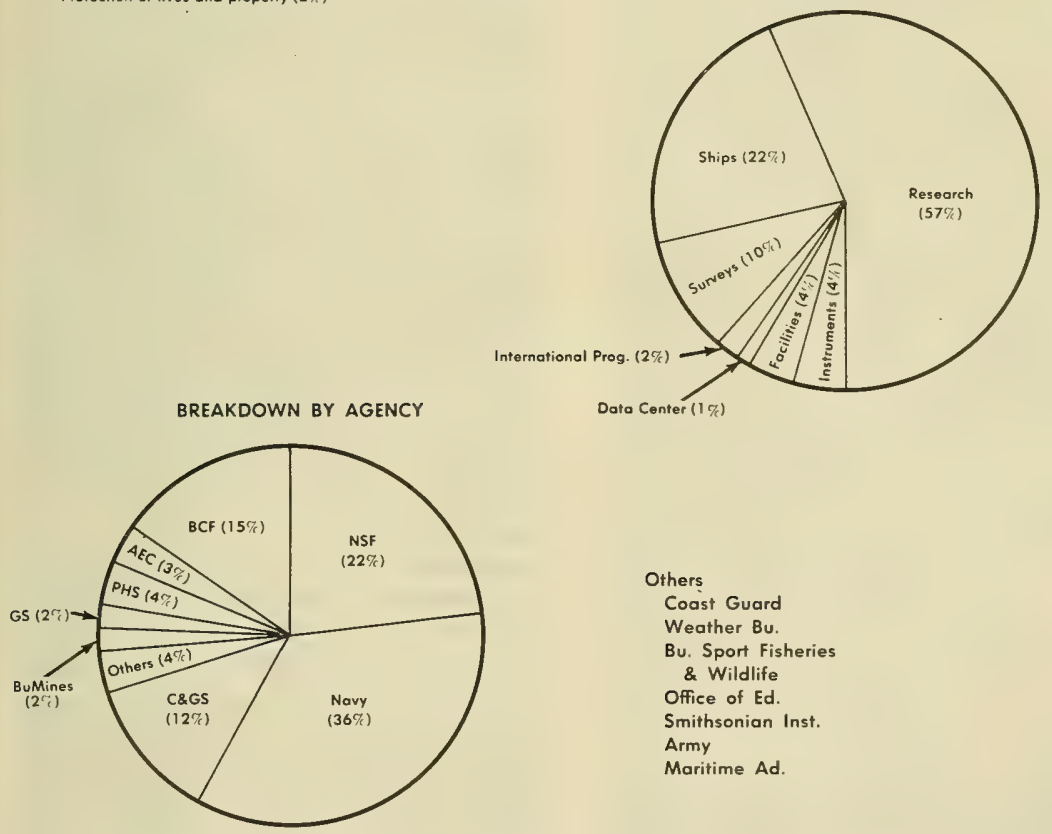

Others

Coast Guard

Weather Bu.

Bu. Sport Fisheries

\& Wildlife

Office of Ed.

Smithsonian Inst.

Army

Maritime Ad.

Frontispiece - National Oceanographic Budget for the Ten-Year Period $-\$ 2.323$ Billion 


\author{
A LONG RANGE \\ NATIONAL OCEANOGRAPHIC PLAN \\ $1963-1972$
}

\begin{abstract}
This Nation's destiny and the sea have been significantly linked together since the day this country was discovered by seafaring men. During this Nation's early growth, the sea provided both a natural barrier to aggression, and a highway for world-wide exchange of goods and of culture. Later on, the Nation's interest in and dependence on the sea waxed and waned. During World War II, it was stimulated by the offensive and defensive manifestations of undersea warfare, and attention was focused even more sharply on submarine warfare when nuclear power suddenly cast the entire ocean, from bottom to surface, as the arena for warfare. The POLARIS system was a natural evolution of this new technique as a new, virtually undetectable, form of deterrent.
\end{abstract}

SUMMARY

Simultaneously, late in the decade of the fifties, came a new appreciation of the potential of the ocean's abundant fish stocks to feed undernowrished peoples of the world. Also, the new era of scientific exploration revealed oceanography lagging significantly by comparison to rapid growth in sister fields. But to achieve these objectives for security or for peaceful exploitation of the ocean greatly increased knowledge was required of the sea itself, its contents, its boundaries, and its interaction with the atmosphere. Federal agencies having oceanographyrelated missions requested the National Academy of Sciences to undertake a comprehensive study of the opportunities of science to contribute to man's understanding of the unseen 72 percent of the planet. With the 1958-59 publication of the NAS reports, both the Executive and the Congress recognized "inner space" to be a challenge deserving of enhanced support.

Federal budgets have grown from $\$ 24$ million in FY 1958 to $\$ 124$ million in FY 1963. Equally significant, oceanographic research, which is a concern of some 20 separate agencies, began in 1959 to be planned on a Government-wide basis. Scope and effectiveness of joint planning and conduct of research have kept pace with growth in research, and since FY 1961, these plans have been published as "National Programs" annually developed through the Interagency Committee on Oceanography.

As valuable as have been these yearly programs in guiding developments by constituent ICO agencies and in providing a coherence to activities of the scientific community that conducts much of this research, there has been a growing need for a perspective in which the oceanographic programs of various federal agencies over the next decade can be more clearly seen in relation to each other, and especially in relation to the national goals which they support.

This plan is now complete-neither as a rigid blue print to be followed slavishly, nor as a single master document. Rather, it is a restatement of national objectives that depend on oceanography, an assignment of relative priorities expressed in terms of levels of activity associated with these different goals, a projection of the growth necessary to achieve these goals, expressed in terms of required research resources-funds, manpower, and facilities. These requirements are expressed in contemporary terms, but with intention of flexibility that reflects an accommodation, even an integration, of new technologies of instrumentation, deep diving vehicles and data collection systems that will make the conduct of oceanography of the seventies far different from that of the sixties.

Finally, the plan establishes the different roles of federal agencies who participate in these programs, with changes in their programs that are more than a simple linear expansion of present activity.

This report, incidentally, anticipates the preparation of additional "satellite" reports-projecting in more detail plans for specific scientific objectives, plans for individual agencies and research institutions, but all presumably related to a common goal: The national goal in oceanography: To comprehend the world ocean, its boundaries, its properties, and its processes, and to exploit this comprehension in the public interest, in enhancement of our security, our culture, international posture, and our economic growth. 
These projections required certain basic assumptions in planning - first, that annual growth in manpower over the next decade will average 9 - 10 percent compared to about 7 - 8 percent in all fields of science and technology as a whole. Oceanographic budgets will grow about $10-11$ percent annually on the average. For oceanography, the growth is expected to be about in pace with the national average for all of science and technology, faster during the next five years than in the subsequent five years, with annual expenditures rising to $\$ 350$ million in FY 1972.

The greatest rate of increase in funding must occur during the early part of the period when the need to replace obsolete and inadequate oceanographic ships is greatest. The net growth in the size of the fleet is kept proportional to the growth in manpower while facilities are expected to grow primarily in size rather than in numbers.

Some major changes in emphasis within the overall program are projected. The proportion of the total effort which is devoted to research should be markedly increased, as should that directed to exploiting and managing oceanic resources and controlling pollution and threats to health. The fraction devoted to defense and to routine surveys and services, while remaining = major effort, is expected to decrease although the absolute amounts will rise. Efforts on behalf of protecting life and property along seacoasts and in promoting the safety of operations at sea should remain relatively unchanged.

The greater emphasis on research reflects a general consensus that applied work demands a firmer footing on theory and empirical observation and broad understanding than now exists to permit even narrow questions of practical importance to be answered properly. Moreover, research conducted within the context of any single goal or agency mission by its nature contributes to the general pool of knowledge and inevitably finds application to other problems in other agencies. The Navy will continue to devote its oceanographic budget to research in areas of immediate and potential importance to defense, but much of this research has nonmilitary implication; the Bureau of Commercial Fisheries will devote almost two-thirds of its growing program to basic studies, and the National Science Foundation is expected to increase its program almost fourfold. All told, about 56 percent of the projected effort over the decade will be basic research, with broad though incalculable implications for the applied work of all agencies in support of every national goal. The program in support of basic oceanography is divided as follows:

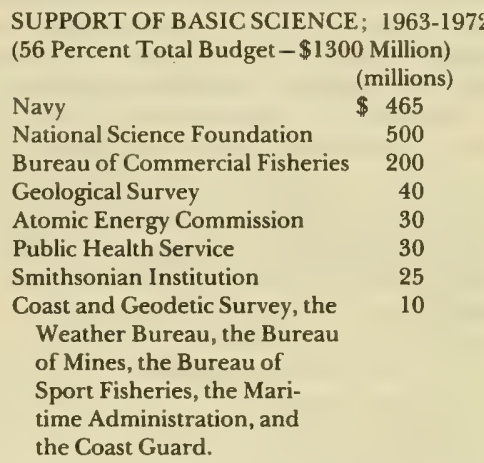

About 32 percent of the total budget consists of programs with direct application to other national goals. It is divided as follows:

\section{SUPPORT OF APPLIED OCEANOGRAPHY}

(32 Percent Total Budget $-\$ 750$ Million)

(millions)

The direct support of defense $\$ 370$ projects

Problems of resource management and the control of health threats in the world ocean

Exploiting resources on and under the continental shelf

The protection of the U.S. public from local pollution and unfit seafood

Protecting life and property along the coasts and enhancing the safety of operations at sea.

The remaining 12 percent ( $\$ 280$ million) of the budget supports routine surveys and services of general utility to the entire oceanographic community.

Most of this effort is also highly beneficial to private groups with a special interest in the sea. Much of it is considered essential to the fishing industry, helpful to the shipping and recreation 
industries, desirable for the mining industry, and indispensable to the oceanographic scientists themselves. The oil industry has traditionally supplied its own oceanography.

The new capabilities and systems to be purchased during this decade include 85 to 97 new research and survey ships (about 52 will be additions to the fleet, and the remainder replacements for vessels now in operation) six to eight submersibles for the exploration of depths from a few to 18,000 feet, and one designed for 36,000 feet; approximately 12 new major government oceanographic laboratories or facilities, plus underwater experimental installations for mining on the continental shelves.

Possibilities which may be added to these include:

An operational oceanographic forecasting system for general use;

Automatic recording and telemetering buoys for ocean surveys;

Additional meso- and bathyscaphs;

Operational fish farms; and

Radically new fishing vessel designs and equipment.

Based on the current manpower projection, the ten-year comparison in capabilities and systems is planned to appear as follows:

$\begin{array}{lrrr} & 1963 & 1972 \\ \text { Ships } & 76 & 128 \\ \text { Major Laboratories } & \text { over } 50 & \text { over } & 70 \\ \text { Professional Manpower } & 2700 & \text { over } 6000\end{array}$

The extensive ocean survey program on which the United States has embarked can be enhanced by international cooperation. The Intergovernmental Oceanographic Commission (IOC) of UNESCO is undertaking to organize this cooperation, as it has the International Indian Ocean Expedition and the Tropical Atlantic Investigations, both of which the United States supports. Even the five largest oceanographic nations-the U.S., the USSR, Japan, the United Kingdom, and Canada-cannot support individual efforts capable of meeting all their own needs and will find it advantageous to pool their efforts with each other and the 39 smaller members of the IOC for many desirable programs.

The United States organization for coordinating federal efforts in oceanography, the Interagency Committee on Oceanography of the Federal Council for Science and Technology, needs strengthening to meet its growing obligations. It should add a small full-time analytical staff to its present Secretariat, and funds should be provided for studies, where necessary, to draw on competence outside the Federal Government. Otherwise, many of the approximations and value judgments which, with time and effort, might have been made more exact and objective in this plan will remain to hamper future planning, and the consequences for the planned program of unexpected setbacks and unforeseen opportunities which will inevitably occur in the future may not be seen quickly and clearly enough to permit an optimal accommodation. 


\section{Chapter I INTRODUCTION}

Three questions have been examined at the outset before proceeding to the plan itself. They are:

Why is this plan needed?

For whom is it written?

What is it supposed to do?

\section{A. Why a Long-Range Plan?}

This plan is needed for two reasons. The first is to provide a perspective, both over the field of oceanography as a whole and over the time period ahead, within which the relationship of the highly varied and diverse activities to each other and to the overall effort can be seen. The second reason is to assure that this overall effort is responsive to the national interest.

Perspective is needed because oceanography, always a complex of pure and applied programs in a variety of disciplines involving numerous institutions, has grown so rapidly during the past five years that it is increasingly difficult for people concerned with one aspect of the field to be wellinformed about work being carried on elsewhere without a plan and without the coordination afforded by a plan. The danger is that inadvertent duplication and waste of effort will occur on the one hand and, far more likely, that opportunities for joint large-scale efforts which could tackle problems beyond the scope of individual agencies or laboratories will be overlooked on the other. Furthermore, though primary support for oceanography now comes from the Federal Government it is applied through some 20 separate offices and bureaus, each charged with a t.fferent basic mission. Oceanography, though still small compared to many other programs, has now become large enough to have to face up to one of the requirements associated with size, diversity, and a common source of support-the requirement for centralized planning.

Such planning is all the more important in terms of making most effective use of research resources when considering that oceanography is small with respect to some indices of its practical importance. The burgeoning world population, particularly in the underdeveloped areas, makes the oceans with their huge and inefficiently exploited food resources of inevitable and in- creasing value to humanity as a whole. Questions of how to manage this resource wisely and well can only be answered in the international arena, since the fish of the sea acknowledge no national boundaries. Oceanographic knowledge and understanding is essential if valid purpose is to enter our approach to such management.

Other indices of the strategic importance of the oceans are becoming ever more clearly recognized. The cloak of concealment provided by a medium which is virtually opaque to all forms of energy except sound is of immense military significance. For example, it permits us to deploy the Polaris submarine system, a component of our deterrent forces which is virtually nonpreemptable, and thus to reduce the temptation a would-be agressor might otherwise feel to launch a surprise attack on our complex of retaliatory weapons systems. Further understanding and exploitation of both the defensive and offensive potentialities of underwater sound transmission and related ocean phenomena is then a clear military necessity.

Other aspects of the oceans affecting all or large numbers of us in common include the health hazard posed by pollution from industrial wastes such as oil, chemicals, sewage, etc. and from radioactive substances; danger to life and property from waves and flooding; risk to shipping from floating ice, storms and navigational hazards; and threats to resources such as the recreational value of the seas which should be common property. Again, our programs in these areas must reckon with the policies and actions of other nations and be motivated by a concern for the public good.

There are, of course, many special groups within the Nation that are concerned with oceanography in their own behalf, without explicitly equating their interest to that of the Nation as a whole. Fostering their healthy development, subject to normal political, social, and economic constraints; is almost a definition of the national interest. The fishing industry, the shipping industry, mining and oil industries, and in a sense the scientific community, are among the groups in our society for whom the oceans have a special significance. Though the benefits accruing to these segments of the Nation through federally supported programs in oceanography cannot be 
measured in precisely the same terms as the benefits accruing to the Nation as a whole, these benefits are obviously related and overlapping. This is clearly the case with the scientific community whether in private or government employ. The scientist by satisfying his curiosity and desire to understand provides at the same time the knowledge by means of which strategic, military, economic, and commercial goals related to the sea can be achieved. And by satisfying their more special goals, the military, economic, and commercial sea-going activities support each other with tools of various kinds, engineering developments, facilities, and platforms and together make possible the furthering of scientific as well as national goals. Nevertheless, the national goals are not merely the sum of the special interest goals. They are rather those goals like the preservation of peace, the extension of the rule of law and justice, the maintenance of a strong economy, and the safeguarding of health, property, and resources held in common which must be achieved to permit the full realization of the goals held by individuals and special groups which constitute our society.

A centralized plan is therefore needed because of the size, complexity, and importance of the field and the fact that its growth, by being so sensitive to decisions made at the federal level, introduces considerations of the national interest.

\section{B. For Whom is it Written?}

This plan is written for the information of all those interested in the nature, scope, and growth of oceanography in the United States. Most particularly, it is hoped that this information will be of interest and assistance to those people working so actively in one aspect of the field that they have difficulty seeing their work in relation to that of others.

It is written for the Congress. The appropriations required for the execution of the plan developed here come from the Legislative Branch, and it is of basic importance that a clear explanation be made of the objectives and projected means for their achievement for which support is solicited. It is hoped that this document fulfills this important purpose.

Finally, it is written for those in the Executive Branch who must make decisions within their own spheres of responsibility regarding the implementation of the plan outlined here. It should be emphasized that this plan is not a decision in itself; it is a basis for decision. It presents from the national viewpoint the goals and the capabilities required to achieve these goals, indicates the nature of the systems, forces and relationships required to provide these capabilities, and points out the direction which must be taken by research and development to remedy deficiencies or exploit as yet unrealized but exciting potentialities in these systems and forces. It does so, however, only as a first approximation and acknowledges numerous alternatives and contingencies. Much of the information needed to resolve the many uncertainties contained herein lies either concealed in the future or inaccessible at the time of writing.

\section{What is this Plan Supposed to Do?}

Many of the decisions made in oceanography not only have long lead-times before their results are apparent, but also have consequences and implied commitments which, when once felt, extend over very long periods. For example, it takes as much as four years from planning to completion to build a major oceanographic research or survey ship, and perhaps 20 or 30 more to wear it out. Expeditions take many, many months to organize, several years to carry out, and their findings may change the world for all time. The real worth of such decisions cannot be seen except from the long-range viewpoint, and one of the functions of this plan is to portray as clearly as possible the consequences of present and contemplated commitments of this sort. Further, this type of planning must be accomplished with particular care, since expeditions are expensive and research manpower in scarce supply. Each decision therefore involves consideration and abandonment of many alternative opportunities.

A second function which can be served by a long-range plan, in contrast to a short-range plan, is to influence the magnitude of the resources available to oceanography, and effectiveness of their utilization. Short-range plans, being basically extrapolations from the present, must deal primarily with the allocation of a given effort and fixed resources. On a short time scale, the overall resources to work with are already largely determined by past decisions and only minor modification is possible. Over the long run, however, decisions still to be made could very greatly affect the overall effectiveness of the effort 
and lead to the development of new resources. For example, a decision to investigate the oceanic circulation directly through current measurements rather than indirectly through density determinations would have profound consequences in terms of productivity for a given budget. A reinvestment of some fraction of research funds for training and education of oceanographers expands the future capability. Some of the options which would become available to oceanography through future budgets are thus appropriate to consider in a long-range plan. Conversely, some of the presently planned opportunities which would be lost in the event of restricted growth in support can also be examined. Exploration of alternatives and their potential value can minimize undertaking or perpetuating those with less promise and undesirably high deferred costs.

A long-range plan can also take explicit account of uncertainty. Uncertainty in planning is of two kinds. The first is uncertainty which can be eliminated by one's own efforts. For example, in the question of current meter versus density investigations of the oceanic circulation there seems to be considerable uncertainty about the reliability of the buoyed meters. Also, not enough is known about the effects of other physical processes on variations in the current velocity to determine what kind of a network of observing points and intervals would be required to filter out unwanted variations and reveal those due to the process under study. What is known suggests that the velocity network would have to be much tighter than a density determination network yielding the same amount of information. Yet the density technique, although dealing with a less "noisy" spectrum than the velocity measurement technique, has the drawback that is difficult to establish absolute rather than merely relative current motion. The limitations in the usefulness of the present technique on the one hand and uncertainties about the technical and economic feasibility of the proposed technique on the other suggest that a choice between the two be postponed pending the results of an effort to remove this uncertainty. It is the function of a long-range plan to call attention to the desirability of such efforts.

The second kind of uncertainty is inherent not so much in the state-of-the-art as in the nature of the future. The outcome of the effort to establish the feasibility of direct current measurements by fixed buoys throughout the ocean cannot be predicted. Yet some of the consequence, if the effort is successful, can be foreseen. Agreements must be reached with regard to legal responsibilities and rights of the sponsoring nation; frequency allocations must be made so that radio beacons and lights do not interfere with operations of ships at sea, etc. Dealing with this kind of uncertainty requires maintaining programs which will enable uncertain or even unexpected developments to be exploited if they materialize. Similarly, if the buoyed meter technique remains either technically or logistically infeasible, such other developments as constant density floats should be supported as insurance against the failure of alternatives. Insurance is perhaps the key word in programs to be designed in the face of this type of uncertainty, insurance against both success and failure.

The goals, capabilities, and programs developed in this plan can advance the cause of other federal committees and study groups concerned with related problems. The Council's Water Research Committee, for example, is one; its Interdepartmental Committee for Atmospheric Sciences is another. The plan attempts to point out where this is the case and also acknowledges where the converse is true. Similarly, international organizations such as the Intergovernmental Oceanographic Commission and the International Hydrographic Bureau provide a framework for mutually valuable coordinated activity.

In this regard it must be realized that we are not the only nation engaged in oceanography, although we may be carrying out as much as a quarter of the total world program. This plan should therefore provide comparisons with the programs of others as a basis for estimating relative rates of progress and obtaining insights into national objectives in oceanography elsewhere.

Revisions in this plan must be contemplated as time and effort reveal the answers to matters which are now assumptions or opinions. Therefore, those with executive authority should regard it as a guide, not a blueprint, for action. They should anticipate that their decisions as well as unforeseen happenings will of necessity modify the future anticipated here, and that the new knowledge which results will provide the basis for a new plan to exploit the new opportunities to be revealed by the passage of time.

Finally, this plan calls attention to its own inadequacies and proposes measures for removing present organizational obstacles to better planning in the future. 


\section{Chapter II \\ NATIONAL GOALS IN OCEANOGRAPHY}

The National Goal in Oceanography: To comprehend the world ocean, its boundaries, its properties, and its processes, and to exploit this comprehension in the public interest, in enhancment of our security, our culture, our international posture, and our economic growth.

To show that the long-range plan in oceanography derives logically from considerations of the national interest as expressed by the abovementioned national goal is desirable, but not easy. Each of us perceives the national interest in his own way, relating it-quite properly-to his own interest. In a democracy the national interest is in fact a collective expression of regional, sectional, local, institutional, and individual interests, and as these evolve, change, and interact with each other and our environment so the national interest appears in a variable and shifting light. Nevertheless, something abides to which we all respond; the recent growth in oceanography from a ten-million-dollar enterprise involving only a few hundred professional workers in 1953 to one thirteenfold greater in 1963 pursued by a few thousand demonstrates how greatly the seas have begun to evoke this response from present-day Americans. Even if the more conservative projections. of this plan apply, at least a further doubling in annual financial effort can be expected before the end of the next decade, and if some of the possibilities which are promising but as yet uncertain come to pass the amount could be far greater still.

Such figures, like the statements of public offcials that oceanography is of vital importance to the Nation,* the declared intention of Congress that the United States capability in this field be second to none, and the vigorous efforts of numerous representatives of the oceanographic community such as the National Academy of Sciences Committee on Oceanography† to promote a public awareness of oceanography's scientific and social significance, are indices-though not explanations-of the extent to which oceanography is

*See, for example, the President's Budget Message to Congress, March 1961.
Subordinate Goals: Strengthening Basic Science Improving National Defense

Managing Resources in the World Ocean

Managing Resources in Domestic Waters

Protecting Life and Property; Insuring the Safety of Operations at Sea

related to the national interest. For an explanation we must turn to more specific and concrete matters, the goals and responsibilities of the Federal Government.

Government is the principal agent for furthering the national interest. For this purpose it is possible to identify certain continuing goals. As stated in a recent publication by a distinguished nonpartisan group of leaders in modern American thought, $\neq$ "The paramount goal of the United States was set long ago. It is to guard the rights of the individual, to ensure his development, and to enhance his opportunity." It may be considered that oceanography supports the maritime aspects of this goal.

In pursuit of this goal, the Federal Government has assumed a number of specific responsibilities. Those relating to defense and the general welfare for which a knowledge of the oceans is particularly pertinent are shared by some 16 agencies and bureaus within almost all the major departments of the Executive. To see why oceanography has moved nearer the center of the stage represented by the diverse activities of these departments, it is instructive to examine the missions and roles with which these agencies are collectively charged.

\section{A. Strengthening Basic Science}

The Federal Government has in recent years financed an ever-increasing share of the Naticn's research and development activity. During the current fiscal year, this share is estimated at about

†NASCO's 1959 report "Oceanography 1960-1970" is generally considered responsible for stimulating much of the growth and interest the field is experiencing today.

"Goals for Americans," The Report of the President's Commission on National Goals, 1960, by the American Assembly, Columbia University. 
two-thirds, where ten years ago it was less than one-half. Expenditures amount to about $\$ 12.4$ billion. Ten years ago, they were less than $\$ 3$ billion.

The reason for this is well understood. Science and technology have become great, if not our greatest, national resources. The discoveries of science and their applications in technology have become so woven into the fabric of modern life that "our economy, our defense, our material welfare and comfort, and our physical wellbeing"** would soon disintegrate and vanish without them.

Federal support for basic research has also grown-to well over $\$ 1-1 / 2$ billion this year, roughly 70 percent of the Nation's total.

Much has been written about the need to maintain a vigorous and growing base of fundamental research, adequate to meet the suction for knowledge imposed upon it by the applied and developmental activities. Such a capability that ostensibly is free of concern for immediate use does not flourish without some measure of federal interest-and in fact, it has become a fact of history that governments become patrons of the sciences, as well as of the arts. But in contemporary terms this is not sheer altruism. We know from experience in war, in tough economic competition, and in man's fight for a life free of poverty and disability that research pays. It is the Federal Government that, in oceanography as in other fields, has strengthened basic research to provide the reservoir of intelligence needed to satisfy specific practical objectives. It must thus assume some responsibility for training and educating highly skilled manpower that it consumes, including the sponsorship of basic research undertaken by graduate students and their faculty advisors.

The scientific goals in oceanography whose pursuit is most likely to produce worthwhile scientific advances are described in the next chapter. At the federal level, the National Science Foundation and the Office of Naval Research have formal commitments to see that basic work directed primarily towards the goals of the oceanographic scientists themselves is adequately supported. Large programs in the universities and various private laboratories and institutions, including

* A Great Age for Science," by Warren Weaver, in Goals for Americans, The American Assembly, Columbia Univ, 1960 those of industry, are supported by these agencies. But in addition, other agencies have found it necessary to support some basic research as well as applied in their own agencies or laboratories. The funds from all federal agencies which are directly applicable to the conduct of basic oceanographic science in 1963 amount to about 43 percent of the entire budget, making this goal of approximately equal importance to that of defense. During the next ten years, this figure is expected to rise to 57 percent. ${ }^{\dagger}$

\section{B. Improving National Defense}

It has become widely accepted that we, like the other major nations of the world, have a heavy stake in the preservation of peace. In the current world situation, military strength is a necessary element in our way of life. This must be a national capability so strong that the fact of its availability to the Free World is a deterrent to major infractions of the peace of the cold war.

Within our defense team the Navy's domain is the world ocean, from its deepest depths through the air-sea interface and into skies above. During peacetime one of its most important missions is maintaining the freedom of the seas so that we and the other nations of the world may enjoy the advantages of water-borne commerce and transportation so vital to our growing economy. During wartime it must, in addition, deny this freedom to the enemy.

Freedom of the seas is a phrase and a concept which, through long usage, has been taken for granted and has, for many, come to have the inevitability of a law of nature. It should be remembered that it is instead a term for a situation which in the last analysis depends on the willingness and ability of those nations dedicated to it to resist the encroachments of those who would deny it to them. The United States Navy is the major Free World force upon which this freedom now depends. Since we are without question being faced by a serious challenge to our mastery of the oceans, the Navy is energetically pursuing a multitude of significant research and development programs to maintain our dominant posture at sea.

† Funds for conduct of basic research include costs for ship operations, instruments, and expendable supplies. 
In oceanography the major objective, of course, is the greater understanding of the environment to enhance our capabilities in all forms of warfare. One example, and perhaps the one which most directly benefits from oceanography, is Anti-Submarine Warfare. Here, the sophistication and effectiveness of major improvements which have been made in weapons systems have been due not only to increased knowledge of the environment, but largely to advances in other areas of science and technology. Signal processing is a good example. The effective utilization of these systems, however, requires a broader and more detailed understanding of the environment, its properties and processes. Such understanding will, in addition, lead to new concepts of operations as well as new systems. It is for this main purpose that the Navy has undertaken a major oceanographic effort.

Let us briefly examine some of the properties of the environment and manner in which they influence naval planning. Sound is the only form of energy which propagates to any distance in the sea so that this work centers on audibility problems. A submarine's audibility to underwater listening gear in various operating areas during the different seasons of the year depends not only on sound transmission conditions, which are affected by the temperature, salinity structure, depth, and reflectivity characteristics of the bottom, but also by the screening effect of noise created by breaking waves at the surface, the engines of other marine traffic, and the creaks, groans, snappings, and whistles emitted by a variety of sea creatures.

This is as true, of course, for enemy submarines as it is for our own. Everything we learn about how to hide our Polaris boats from enemy detection contributes, therefore, to our knowledge of how best to go about finding his.

When it is realized that sound not only travels five times as fast in water as it does in air but for a given source intensity produces pressures which are some 60 times as great, it is not surprising that such ordinary sounds as the singing of rotating propellers and the swish of bubbles and eddies in the passage of a hull through the sea, all of which seem of comparatively short range to a listener on land, suddenly assume tremendous significance when the sound source is in water and the listener has "underwater ears."
Furthermore, the ocean is layered to an extent seldom realized in the atmosphere and the transmission of sound by "channels" in a fashion somewhat like the production of mirages in the air is a common occurrence in the sea. Submarines tens and even hundreds of miles away can sometimes be heard by listening equipment exploiting these sound conduits. Some layers, the most persistent, are very deep and can be utilized only by hydrophone arrays lowered down the sloping edges of islands or on the edges of the continental shelves to catch the deep sound transmission. Certain frequencies in the sound spectrum are more favored than others under some conditions. In general, the high frequencies are more easily attenuated and it is the very low frequencies which travel farthest. Since the size of the underwater ear must match the size of the wavelength being listened to, there is a complex design problem involved in fitting equipment to specific operational missions. That is, there is an important difference in systems optimally suited to an acoustic environment where treble notes with wavelengths of a few inches dominate as compared to systems best suited to one where the bass notes which have wavelengths of many feet are most important.

The essential point is that increasing the range of detection of hostile submarines and the accuracy of target classification depends critically on oceanographic research. The Navy's Oceanographic Office, the Bureau of Ships, and the Office of Naval Research conduct or support research on various aspects of this problem, including the prediction of the key features of the "anti-submarine warfare environment" and how to exploit it operationally.

Almost every other Navy mission depends on similarly complex and critical relations between operations, technology, and environment. One reason aircraft carriers must be so large, for example, is to be sufficiently stable in a seaway that high-performance aircraft need not be exposed to dangerously large excursions of the flight deck as they approach the stern for a landing. Even high-speed destroyers and frigates have to slow down if waves are too high, and faster transits to distant operating areas can often be made by taking "the long way around" and avoiding the worst sea conditions enroute. Where timely arrival on the scene is important, such routing could spell the difference between failure and success. Weapons technology is also pressing against 
environmental constraints as torpedoes, missiles, and bombs have to push their way long distances at high speeds through the water or penetrate the interface between the sea and air without undue interference from waves, to find their optimal depth for detonation.

"Habitability" in the deep sea environment into which future submarines are expected to penetrate must be studied before the various compromises between size, structural strength, performance, and expense can be made intelligently. The ability of divers to work underwater with varying degrees of mechanical assistance is also of interest. The Bureau of Weapons and the Bureau of Medicine have important oceanographic programs in these areas.

The Navy's concern with these and many other facets of the ocean environment is reflected within its oceanographic budget. In Fiscal Year 1963, the Navy effort accounts for about 44 percent of the federal funding $-\$ 57$ million of a total of $\$ 123$ million. In addition to this work, the results of which may be applicable to many nonmilitary problems, the Navy allocates a substantial additional amount ( $\$ 26$ million in FY 1963) to projects which are classified or which are of a more direct and unique military nature. These latter projects are not included within the scope of the program embraced by this report but are detailed in TENOC-the Navy's comprehensive Ten-Year Plan in Oceanography.

Over the ten-year (1963-1972) period of this long-range plan, the Navy total is expected to be about $\$ 835$ million, about 36 percent of the whole. Military oceanography not included in the plan amounts to $\$ 480$ million additional.

These fiscal requirements would be greater still if interagency cooperation did not exist to make available to the Navy, information about planning of research on biological phenomenon by the Bureau of Commercial Fisheries and the Smithsonian Institution, and on the characteristics of the ocean bottom of importance to ASW, Mine, and Amphibious Warfare, by the Coast and Geodetic Survey and the Geological Survey. The Army Corps of Engineers also contributes much information on harbor and channel regions in support of navigation and Mine Warfare operations, and the Atomic Energy Commission cooperates with all three services in atomic tests where underwater sound propagation, wave propaga- tion, shock effects, contaminant dispersal, and cratering can all be studied.

It is implicit that while various agencies contribute to defense oceanography the converse also occurs. As we have already seen, this is particularly true of programs sponsored by the Office of Naval Research. It is also true of the work of the Oceanographic Office. Nearly one-third of the Navy's oceanographic budget is devoted to supporting research in universities and private laboratories. Thus, the Navy's support of basic and applied research, amounting to about 22 percent of the entire national oceanographic budget in 1963 and nearly 20 percent over the coming decade, does a very important double duty. It supports the national defense effort, but simultaneously it strengthens basic science upon which progress in oceanography so greatly depends.

Earlier, it was noted that the Navy's primary motivation for oceanography was related to its position as a member of the defense team of our Nation, and within this team, to maintain the freedom of the seas. As the remainder of the National Plan and its goals are described, it would be well to remember that the pursuit of oceanography toward each of these other goals is dependent on this freedom of the seas which the Navy provides, and which the Navy's oceanographic program sustains.

\section{Managing Resources in the World Ocean}

The tyranny of nature is still the tyranny of most consequence to people throughout much of the world, and for these people the freedom of greatest immediate interest is the freedom from want. The two aspects of freedom, freedom from the tyranny of nature and freedom from the tyranny of thoughtless or malevolent men, meet in the world's oceans where the largely unregulated activities of men promise increasingly to create problems of world health, of the safety of operations, and of the ownership and use of important resources one of which, food, could relieve the cruel grip of hunger now confronting so many of the world's people.

Estimates of this potential are easy to arrive at but difficult to justify. The present world fish catch is estimated at about $\mathbf{4 0}$ million metric tons, or a bit over 88 billion pounds. World protein consumption now totals something like 400 million metric tons, so that if everyone's diet were the 
same the present fish catch would supply 10 percent of the protein needs of the world's population. In fact, it may supply more, being more highly favored by those with lower standards of living whose per capita protein intake is less than average. An estimate generally accepted as conservative puts the annual catch which could be sustained indefinitely without depleting the stock at something like 200 million metric tons of fish a year, or about five times the present take. More optimistic estimates range to many times this value. All agree, however, that vastly more information must be obtained on the ecology of fish populations and their distribution than is now available and that much more efficient management techniques must be developed and international agreements reached if even the lowest of these estimates of the potential food harvest of the oceans is to be realized.

The motive for making the necessary effort soon gains much of its strength from two considerations. One is that many of the fish presently most valued are already showing signs of overfishing, and the other is that the major alternative, intensified agriculture, seems promising mainly in land areas of rich nations while many starving nations border the seas which, in principle at least, are accessible to all.

The United States is a member of eight active international fisheries commissions in which a total of 20 other countries also participate. These commissions and their dates of establishment are: Pacific halibut, 1924; Pacific salmon, 1937; international whaling, 1948; inter-american tropical tuna, 1949; Northwest Atlantic fisheries, 1949; international North Pacific fisheries, 1952; Great Lake fisheries, 1955; North Pacific fur seal, 1957. As world fishing develops, the catch seems to be doubling every 12 years. More fisheries are becoming mature and require close supervision. Under consideration for control are the yellowfin tuna of the eastern tropical Pacific and certain other fishery stocks. Both for the economic benefit of the fishermen who see their livelihoods at risk and for the benefit of the populations who need what the seas can offer, learning how to find and exploit alternate species as well as how to increase the safe yield from present species is of vital importance.

The Bureau of Commercial Fisheries is tentatively planning to spend approximately $\$ 173$ million over the next 10 years on programs which will contribute directly to better management of fish resources in the sea. Although approximately $\$ 69$ million of this is to be devoted to the study of species which are now entirely or predominantly the province of the American fisherman, even those are bound up in the broad ecology of the oceans of which man is becoming the chief predator and for which he must be prepared to be accountable as competition for the food resources in the world ocean stiffens. Another $\$ 185$ million will go to basic research, strengthening oceanographic science while laying a much needed foundation for more effective applied work on fish resources management. This is in acknowledgment of the importance of knowledge of ocean circulation and vertical transport to prediction of the distribution of fish populations and general oceanic ecology.

The Smithsonian Institution plans to spend about $\$ 25$ million over the decade in describing organisms-their abundance, their life cycles, and their distribution in the ocean. The Smithsonian effort will contribute significantly to our understanding of both beneficial and harmful biological processes in the ocean. Although the Smithsonian may charter vessels for brief periods of time for work in remote areas, most of its collecting will be performed on ocean-going vessels of other agencies.

The health of the fish and other life which inhabit the ocean may be affected by poisons introduced by man in various ways; man himself may then be affected when he consumes contaminated seafood. He may also be affected by these poisons directly. Since the testing of nuclear weapons began after the war, the people of the already uneasy world have become increasingly concerned about the radioactive contamination of their environment. Disposal of low-level radioactive wastes by AEC in both the Atlantic and the Pacific Oceans since 1946, and by the British in the Irish Sea, has made it necessary to study ultimate consequences as the packages in which they are contained corrode through over the years and even the sluggish circulation in the ocean abysses eventually disperses them widely over the world. Nuclear reactors power a large number of submarines and an increasing number of surface ships, and are being developed to provide both electric power and propulsion for satellites and space vehicles. Appraisal of operational and accidental hazards that these devices represent 
requires similar study to reinforce public confidence in the safety of such operations.

The Atomic Energy Commission plans not only to expand its already extensive monitoring efforts at test sites, in the vicinity of stationary reactor sites on land, and at the places where wastes are disposed of at sea, but also plans greatly to expand its research effort on the effect of nuclides in ocean water in general. It expects to spend about $\$ 68$ million over the decade and will be assisted by the Navy, the Coast Guard, the Bureau of Commercial Fisheries, and the Public Health Service in one or another aspect of its work. Nearly half of these funds will go to support basic research. During the period of this report, our efforts at inventorying and understanding the biological wealth of the world ocean will account for 19 percent of the total budget; over half of this will be spent for basic research. A portion of this work has implications primarily for the U.S. public, as discussed in the next section.

\section{Managing Resources in Domestic Waters}

\section{SAFEGUARDING PUBLIC HEALTH}

The streams and rivers into which man pours his industrial waste and sewage in increasing concentrations as they flow through the countryside eventually reach the broad estuaries where they slowly mix with the sea. Although water, both fresh and salt, contains numerous chemicals and organisms capable of reducing noxious substances to harmless ones, and although dilution itself is of tremendous value, local concentrations of dangerous toxicity have always been a potential hazard, the vagaries of currents and flow being what they are. The ability of some organisms used for food by man to tolerate and store poisons at levels of concentration serious or even lethal to man is wellknown. Shellfish are particularly important, being susceptible as well to toxic substances not produced by man. Oceanographic studies concerned with the effects on estuarine and inshore waters from the disposal of municipal and industrial wastes have been conducted for years by the Public Health Service and the Bureau of Commercial Fisheries, and where they concern inshore marine foods this work is done in close cooperation with the states.

These traditional programs have recently assumed much greater importance due to the vast increase of population, and the consequent rising concentrations of "normal" wastes in our streams and estuaries, and to the appearance of new and highly resistant chemical wastes produced by modern technology. Radioactive wastes discharged by atomic plants are the first of the new longlived poisons which come to mind, but many other less familiar chemical products may be even more hazardous. Among these are alkylbenzene sulfonates (ABS), DDT, Aldrin, Parathion, Lindane, and a variety of nitrogen compounds. As a consequence, not only has the Atomic Energy Commission undertaken an increasing program in oceanographic research but the programs of the agencies traditionally concerned with oceanography have also expanded their research in marine pollution.

In 1963, the goal of safeguarding health in relation to seaside pollution accounted for about four percent of our oceanographic budget. Over the decade ahead it is likely to remain about the same, totaling about $\$ 95$ million.

\section{CONSERVATION OF RESOURCES HEID IN COMMON}

In 1947, the Supreme Court decided that the Federal Government and not the State of California had title to the submerged lands off the coasts of the United States. This decision and the two that quickly followed against Louisiana and Texas ended the uncertainty over rights which had hampered the oil industry in its efforts to exploit these areas.

Since then the oil companies have invested approximately $\$ 3.5$ billion in exploratory drillings along the continental shelves. Oil reserves offshore are far from being estimated. Their studies have largely been confined to areas of probable oil occurrence.

The mineral resources of the sea come next to mind. Although the sea contains dissolved minerals in nearly astronomical quantities, their dilution is so extreme that extraction is both dificult and expensive. Furthermore, most can be found in adequate amounts and with sufficient ease on land. Consequently, with the exception of a few minerals such as bromine and magnesium, neither industry nor the Federal Government has taken much interest in developing oceanic sources. Now, however, the picture is beginning to change. Large deposits of nodules rich in manganese, nickel, and cobalt, which were stumbled across 
on the ocean bottom many years ago, and some minerals extractable from sea water have assumed more importance.

The Bureau of Mines now intends to initiate both a comprehensive research program on the extraction of dissolved chemicals and a program to develop and explore sources on and beneath the ocean floor. This program of exploration, to begin most logically with the continental shelves (and the Great Lakes) where the water is only a few hundred feet deep and the geology similar to that of the continents, summons up thoughts of such past expeditions into the unknown, or only partly known, as the Lewis and Clark Expedition. Although much can be done by sampling and surveying from specially equipped surface vessels, when the few tens of miles of the shallow continental shelves are left behind for the vast abyssal plains where the water is two or three miles deep and the geology is unlike that ever before seen, efficient exploration will necessitate man's actually getting down and looking around. The Bureau of Mines is, therefore, considering the development of a manned deep submersible to supplement its other exploratory techniques. This submersible is to be shared with the Bureau of Commercial Fisheries and possibly other agencies. The landscapes seen for the first time by these underwater explorers can hardly help but produce strange and perhaps awesome experiences.

The Geological Survey will also participate in developing information on and maps of mineral resources.

Another resource which will always be held in common is the recreational value of the sea. Sport fishing and boating have been the traditional forms of recreation at sea just as the beach areas have been for swimming. To these traditional forms of ocean or oceanside recreation, SCUBA diving and underwater exploration in small submersibles and motorized underwater scooters have recently been added or are in prospect. As yet, it is not clear what needs to be done not already in hand by the various federal agencies long active on behalf of seagoing or seaside recreation. As is well-known, the Bureau of Sport Fisheries and Wildlife is engaged in game fish research; the Geological Survey, the Beach Erosion Board, and the Coast and Geodetic Survey provide data and studies for the use of oceanside recreation industries; and the National Park Service, which has lately become interested in underwater parks and nature trails for skindivers, maintains and operates public beaches and recreation areas while the Coast Guard and the Weather Bureau provide storm warning and rescue services.

Cultural patterns in the U.S. will continue to change with the rapid growth expected in the recreational industry. Private developments will be watched for indications of the need for future government activities on their behalf and on behalf of the conservation of resources themselves.

In 1963, about two percent of the oceanographic budget was considered to support this goal. This factor should double in the decade ahead.

\section{E. Protecting Life and Property Ashore; Insuring the Safety of Operations at Sea}

\section{PROTECTING LIFE AND PROPERTY ASHORE}

Those living near a seacoast are all too well aware of the hazard to life and property represented by a storm at sea. Hurricanes are most likely in late summer and early fall, but extratropical storms may strike our Atlantic and Gulf Coasts at any season, sometimes with immense damage. Although the high winds associated with these storms can sometimes do great and freakish damage, it is the water which is the greatest threat. Tides sometimes run many feet higher than normal as so-called "storm surges" associated with the storm' moving along the coast. Huge waves whipped up by the wind slam into shore, imposing forces measured in the thousands of tons against beaches, piers, and breakwaters with all the impact of a sequence of freight trains.

Both prediction and protection are important for dealing with these hazards. The Army Corps of Engineers through its Beach Erosion Board, conducts studies on the numerous factors which influence the way and amount waves and currents affect the coasts, including the modification of these effects by protective installations. The Weather Bureau not only attempts constandy to improve its ability to locate and predict the movement of such storms but also to predict more accurately the seas that they generate. That this last problem is difficult and only partially solved can be appreciated when it is realized that windgenerated waves run constantly away from the 
areas of generation at rates sometimes faster than the wind speeds by which they are produced, and much faster than the rate of progress of the storm centers that cause them. Also, the effectiveness of the wind in producing waves depends on what it has to work with; that is, over what reach, and how high the sea is already. The consequence is that the sea at any particular point in time and space is the joint product of many, many storms, some of them hundreds or perhaps thousands of miles distant, some interacting with others in the regions of wave generation and all being felt to some extent at the point of observation. Finally, as the bottom shoals toward land, its contours and their orientation modify the waves which roll in from the open sea, often augmenting their already formidable aspect.

The importance of the atmosphere-ocean interaction to prediction problems such as the genesis and life history of tropical storms is widely recognized. To increase the accuracy of short-range and long-range weather predictions oceanographic parameters are being considered and feed-back processes taken into account. Part of the energy which drives ocean currents and generates the waves at the sea surface is derived from the winds; another part of the energy is transmitted to the ocean by radiational processes which are modified by atmospheric conditions. But the winds and atmospheric conditions themselves depend on the distribution of physical properties in the ocean. Therefore, oceanic circulation and atmospheric circulation are closely linked and are being studied by the Weather Bureau to provide ultimately a better service to the public.

Research programs of the Army's Beach Erosion Board and the Weather Bureau for prediction and protection in relation to coastal areas are expected to total about $\$ 16$ million and $\$ 1$ million respectively over the decade.

Another deadly threat to life and property along the same seacoast, because it strikes without noticeable warning, is the seismic sea wave or tsunami, long an object of study and concern to the Japanese who have given it its name. Earth shocks, resulting in sea bottom movement, particularly frequent in the volcano-ringed Pacific, start water waves traveling out from a point at the surface above the center of the disturbance with speeds of 400 or 500 miles per hour. Ocean wave speeds are partly determined by wave length. Tsunami wave lengths, due to the method by which they receive their initial energy, are many hundreds of times greater than those produced by even the most violent wind. These very long waves "feel the bottom" even over the deep ocean abyss in much the same way the shorter wind-created waves start to feel the bottom as they reach shoal water along a beach, and the effect produced is the same, though magnified immensely by the proportionately greater change in depth. The upper portions of the wave begin to override the lower parts, and what would be an almost unnoticeable rise of a foot or two in the open ocean becomes a rise of perhaps 50 feet against a coastline across its path. And since these waves carry thousands of miles from the point of origin, they arrive unaccompanied by any other phenomenon which might announce the impending disaster.

The series of waves which struck the Hawaiian Islands on April I, 1946, destroyed 173 lives and $\$ 25$ million worth of property. It led to the establishment of the Seismic Sea Warning System by the Coast and Geodetic Survey, which already had a network of tide gauges in strategic locations around much of the source region. By extending the network, tying it into the network of seismological stations, and adding accurate time devices and instant communications, the Coast and Geodetic Survey is now able to predict with high accuracy the time of arrival of such waves at Hawaii and elsewhere in the Pacific and to issue warnings well in advance.

That the system is not perfect, however, is witnessed by the most recent tsunami which hit the city of Hilo in May 1960, destroying 61 lives and about $\$ 23.5$ million in property. A major defect in the system is its inability to predict the amplitude of the wave, and many apparent false alarms result when the tsunami is so small that it arrives unnoticed by the residents. By the same token, it is impossible for a resident to distinguish a warning which may be followed by an unusually dangerous wave. The same tsunami, produced by an earthquake off the coast of Chile, showed another major defect of the system. It presently provides warning for only a few other areas of the Pacific which may be as badly threatened as Hawaii. The shores of California, Alaska, Japan, and, many other areas were all greatly affected and widespread loss of life and property occurred. Much more research on the phenomenon is needed, and the warning system improved and extended. 
Since the problem is international, it is necessary that the solution to it will be also.

Less spectacular but nevertheless of importance are the ravages of marine organisms on manmade structures. For example, it is estimated that about $\$ 250$ million is spent annually for maintenance and repair of damage caused by marine organisms. Oceanographic work sponsored or conducted by the Navy's Bureau of Yards and Docks, the Office of Naval Research, the Maritime Administration, and the Atomic Energy Commission all has a bearing on this problem.

\section{SAFETY AT SEA}

Closely related to protecting life and property along the coasts is the responsibility to help assure the safety of operations at sea. It is shared by the Coast Guard, the Navy, the Coast and Geodetic Survey, and the Weather Bureau. For example, the annual spring "calving" of glaciers into hazardous floating icebergs and cakes of many sizes is monitored and warnings to shipping issued by the Coast Guard's conduct of the International Ice Patrol. Theoretical studies to support better prediction of likely courses taken by sea-ice and how long it can be expected to take to melt are also important. Weather Bureau and Navy weather predictions at sea are invaluable to shipping, and Coast and Geodetic Survey and Navy Oceanographic Office charts of navigational hazards and aids are being constantly improved and updated from survey work. As submarines go deeper, detailed bottom mapping will assume even greater importance as will determining the location of sea mounts and underwater mountain ranges rising toward the surface.

With the advent of meteorological satellites, their potential in oceanography must be explored. There are already indications that they will be useful in surveys of sea-surface temperatures and radiation (heat budget of the ocean), ice reconnaissance and sea-state observations. Such information will help greatly in oceanographic forecasts. It is expected that at the end of the ten-year period the Weather Bureau will be making a substantial effort in helping to solve these problems.

Most of the protective effort against natural hazards is operational or engineering, so that the small funding for oceanography under this goal (about two percent of the ten-year oceanographic budget) is only a small part of the story.

\section{F. Summary}

To comprehend the world ocean, its boundaries, its properties, and its processes, and to exploit this comprehension in the public interest, in enhancement of our security, our culture, our international posture, and our economic growth involves:

Strengthening Basic Science

Improving National Defense

Managing Resources in the World Ocean Managing Resources in Domestic Waters Protecting Life and Property; Insuring the Safety of Operations at Sea

These are the national goals toward which the federally supported oceanographic program is directed. They are more easily separated in concept than in practice. Each leans on one or more of the others for its own fulfillment and work done with the intent of furthering one may in the end more materially benefit another. Nevertheless, they are useful concepts, and particularly so when a framework is needed for organizing a plan such as this, a framework in which emphasis and balance can be more clearly seen.

The budget required for oceanographic programs, ships, instruments, and facilities to meet the aggregate national goals, taking into account availability of skilled manpower, should grow an average of 10 percent to 11 percent a year from a level of $\$ 124$ million in FY 1963 to $\$ 350$ million in FY 1972, for a total of about $\$ 2.3$ billion over the decade. Over 44 percent of the federal budget will go to private laboratories as compared to 37 percent in 1963. The total ten year budget is allocated among the various goals as follows (Further delineation is provided by Table 1):

1. About 57 percent will support basic research and serve to strengthen basic science; 33 of this 57 percent will contribute simultaneously to scientific development for other national goals as shown below. In 1963 this figure was nearer 43 percent.

2. About 35 percent will support defense as compared to 44 percent in 1963 . Some 20 percent supports Navy basic research already included in (1) above and 15 percent supports applied programs. 
3. Some 19 percent of the effort will go to improve our ability to manage resources and control threats to health in the "world ocean" (11 percent basic included in (1) above, and 8 percent applied): Only 15 percent of the 1963 budget can be considered to serve this purpose.

4. About 8 percent will go to discover and exploit resources on and under the continental shelves and to protect the health of the U.S. public from coastal pollution and other poisons (two percent basic included in (1) above and six percent applied). In 1963 this figure is about six percent.

5. Less than two percent will be applied to protection of lives and property ashore and safety at sea.
6. About 12 percent will provide oceanographic services such as nonmilitary ocean surveys, data processing and archiving, and instrumentation calibration and standardization which benefit all members of the oceanographic community. This is a drop from the 20 percent figure in 1963. Although much can happen to modify these projections, as is explained in Chapter IV, these represent the desired balance of effort weighing need against manpower available and against opportunities as viewed by the federal oceanographic community at the present time. In brief, emphasis in this National Plan is to be placed on private laboratories and universities, and on basic research, with exploitation for peaceful uses becoming increasingly a more prominent objective. 


\section{Chapter III \\ SPECIAL GROUPS CONCERNED WITH OCEANOGRAPHY}

One of the fundamental goals of the Federal Government is "to ensure the development (of the individual) and to enhance his opportunity." There are several private seagoing groups whose development and opportunity can be considerably enhanced by oceanographic knowledge. Among these are the fishing industry, the shipping industry, the oil and mining industries, the oceanrelated sport industries, and the community of oceanographic scientists itself. To the extent that it is compatible with broader national goals, the Federal Government should conduct its oceanographic program so that it supports the goals of these special groups as well. To see how this can best be done, let us next examine these individual goals as they involve oceanography.

\section{A. Oceanographic Science}

It has already been argued that there is an identity between the federal goal of strengthening oceanographic science and the scientist's goals in pursuing oceanographic knowledge for its own sake. Of course, it must be added that this identity is one of kind and not of degree. Some reasonable portion of the scientist's time and effort must be directed toward the numerous other and more practical goals of the government which is sponsoring his work. As an oceanographic scientist, however, what is it that interests him?

In oceanography, the National Academy of Sciences, through its Committee on Oceanography (NASCO), speaks for the scientific community as much as any committee can speak for people who are traditionally accustomed to speaking for themselves. The particular front-lines in oceanography as they existed four years ago which were singled out for special mention in NASCO's report of that year* are typified by a few of the questions posed in Volume II of this report, "Basic Research in Oceanography during the Next Ten Years." These fall into five main areas:

*Oceanography 1960-1970, a Report of the National Academy of Sciences Committee on Oceanography, 1959.

\section{THE HISTORY OF THE OCEANS}

"Why is the layer of unconsolidated sediments in the deep sea so thin, on the average only about 300 meters in thickness?. . . Why do we find fossils of Tertiary or Cretaceous age but none older? (That is, under about 100 million years.)

"In most cores taken in the Pacific and Atlantic there seems to be a sudden increase in radium content at an age level of about 200,000 years. What is the cause of this increase?...

"What is the history of the deep, narrow, almost sediment-free trenches that ring the Pacific Basin? ... Why are these border features ... apparently the loci of very low heat flow from the earth's interior?

"Existing abyssal plains are all adjusted to re. cent topography. Where are the ancient abyssal plains?...

"How have the broad swelling ridges that bisect the Atlantic and the South Pacific been formed? How old are they? Why are they the loci of very high heat flow from the earth's interior?

"Faults around the margins of the Pacific Basin appear to be right lateral as though the basin were rotating counterclockwise. Does submarine topography support this hypothesis? Are fracture zones the spokes of the wheel?

"Is the base of the crust a phase transition, or is there a real difference in chemical composition between crust and mantle?

"Are there pools or sheets of molten rock deep beneath the earth's crust associated with inland arcs, trenches and fracture zones? .. .

"What are the reasons for the large scale, remarkably regular magnetic topography of the deep sea floor off the west coast of North America? . .

"What is the history of sea water?...

"How did the pattern of the major ocean currents during past times compare with that of today?..."

\section{THE WAYS OF LIFE IN THE SEA}

"The fauna and bacterial flora of the great deeps provide unique opportunities for the general biologist. Nowhere else can he find organisms adapted 
to such high pressures and perpetual low temperatures. It also offers him intriguing questions:

"What are the enzyme systems that operate in these conditions?..

"What is the meaning-the function and history-of those strange structures, 'fishing rods' and 'lanterns', that characterize known inhabitants of the deeps?...

"Did an original ancient fauna adapt to and survive the severe drop from $12^{\circ}$ to $2^{\circ} \mathrm{C}$; or did this change bring widespread extinction and replacement?

"Recent years have brought discoveries of extremely ancient organisms;

"Under what conditions have these 'living fossils' survived? How can we account for the radically different evolutionary rates that we find in the sea?...

"The plankton is formed typically of small essentially floating creatures that we might expect to be uniformly dispersed, hence evenly distributed...

"How does the plankton, apparently helpless in the face of water movement, maintain discrete distributions?...

"What factors limit the distribution of communities, regulate their abundance and determine their internal structure?"

\section{THE MOTION OF THE WATERS}

"Direct current measurements during the past year have shown that the east-west transport of water in the eastern tropical Pacific is probably at least three times that previously estimated. We may ask:

"How good are some of the other estimates of water transport? Just what, how big, and how complex is the circulation pattern of the oceans? This question leads in turn to others. What are the 'time constants' of the oceans? Why are some water masses but not others homogeneous over hundreds of thousands of square miles? Why is there the vast oxygen minimum beneath the thermocline in the tropical eastern Pacific and eastern Pacific and eastern Atlantic? What is the rate of mass exchange across the thermocline? Even more fundamentally, how are thermoclines formed and why do they persist?

"That the questions listed above remain unanswered reflects not only the lack of quantitative measurements of the motions of the ocean waters, but also the inadequacy of our thermodynamic and hydrodynamic models of the sea and the air. The two great earth fluids can be thought of as interlinked heat engines, and both theory and experiment need to be concentrated on the boundary between them...

"How are the waves formed, and how do they grow and decay? What is the partition of energy and momentum, transmitted by the wind to the sea, between waves, currents and turbulent motion?

"Waves beneath the sea surface, called internal waves, are far more mysterious than the waves at the surface.

"How are internal waves generated? Do they break near shore? Are they effective in mixing nearshore water? What is the role of internal waves of tidal period in tidal friction?"

\section{OCEAN-ATMOSPHERE RELATIONSHIPS}

"So intimately connected are the oceans and the atmosphere that basic research in one field must necessarily involve the other...Studies of these relationships may be highly fruitful in long-range weather forecasting.

"Less well-known and little understood are the long-term effects on climate caused by the ultimate stirring up of the deep ocean waters.

"Does the supply and coldness of the deep water vary at its source around Antarctica from year to year, or decade to decade? And if such variations occur, how long after and by what mechanism do they affect climate?

"In the deep waters of the sea, with their slow transport, we have a natural built-in lag which is a most promising beginning for the understanding and ultimate prediction of long-term climatic fluctuations."

\section{ESTUARIES AND COASTAL WATERS}

"Men have lived since time immemorial near the seashore and have benefited from the natural resources of inshore waters. Yet little is known about basic processes at the margins of the sea. Consequently, coastal and estuarine waters are now claiming an increased share of attention from oceanographers.

"Some of the questions are:

"What are the mechanisms of sediment erosion, transportation, and deposition on the shelf and in the surf zone?... 
"How are turbidity currents generated? Are they the primary means of transporting terrestrial material to deep water? At what speeds do they flow?...

"What is the flux of sediment from land to deep ocean?...

"What is the nature of the stress exerted by waves and currents on the bottom?...

"What world-wide changes in sea level have occurred in the past? What changes are in progress now, or are to be expected in the near future?"

In general, the same questions challenge oceanographic scientists today at just the time that technology and engineering have put the answers to many of them tantalizingly near his reach. The assessment of the National Academy of Sciences four years ago was "that both the quantity and quality of basic research in the marine sciences can and should be increased substantially during the years ahead." The challenge and promise are even greater now.

\section{B. The Fishing Industry}

The remaining groups to be discussed, such as the fishing industry, are primarily consumers of oceanographic information, though some of them, like the government, may be producers or at least patrons of it also. The questions they ask of oceanography are highly practical and the motive is largely economic. To see their oceanographic needs, we must therefore view them in an econom ic setting.

Commercial fishing has been an important industry on this continent for nearly three and a half centuries. Today it supplies over a million tons of food each year for our population, which consumes an average of nearly 11 pounds a year per person. More than half a million people depend on it for their livelihood.

1962 was both favorable and unfavorable to the American fishing industry. On the favorable side, the year was one of the most prosperous in American fishing history. Catches of salmon and shrimp were sharply up from 1961, and the tuna industry, although short of its all-time high, had another successful year. Even the New England groundfish industry, beset by competition from foreign imports, did reasonably well. Only the oyster industry fared badly, but research already well advanced is expected to brighten its future also.
The most unfavorable aspect is the increasing competition from the fisheries of other nations. This competition takes two forms: cheaper imports from countries with labor costs lower than ours, and the invasion of traditionally American and Canadian fishing grounds by foreign fleets, most notably those of the USSR and Japan.

Technological problems arise from the advanced age of many of our fishing vessels, lagging progress in seafood processing, and from the adverse effects on some seafood stocks of pollution and engineering projects as well as from environmental changes due to natural causes. Technological progress is being made, however, in some quarters. Among these are the use of power blocks and synthetic fiber nets in the salmon and tuna fisheries and the widespread adoption of automatic peeling and shucking machines in the shrimp and crab industry. The industry has also recognized the advantage of voluntary quality inspection of many fishery products.

There is a strong feeling that one of the most promising avenues for the future is further development of fish protein concentrate. This material, a flour-like substance, can be made cheaply from fish wastes and from species either not being caught at present or now being discarded as trash. It is stable, easily transported and stored, and has a very high protein content. These characteristics make it particularly promising for use by countries with poor distribution and transportation systems, among which are many with diets seriously protein deficient.

A necessary condition for successful competition with foreign fleets is superior knowledge of the sea and its inhabitants. With some important exceptions, the industry is largely dependent on the Bureau of Commercial Fisheries for this knowledge. Since many areas of potential interest are remote from U.S. shores, international cooperation is frequently essential. The two largescale international enterprises in which this country is now participating, the International Indian Ocean Expedition and the International Cooperative Investigations of the Tropical Atlantic, represent important steps toward a better understanding of these two areas of potential interest to American fishermen.

The industry feels that knowledge is not enough, however. It needs more capable ocean-going fishing vessels, and more modern and efficient techniques for locating and capturing the fish. 
It will probably need federal assistance in developing, building, and operating such improved gear. It especially needs intervention by the Federal Government in developing international agreements on fisheries management. For as the inevitable increase in take occurs, whether or not Americans help produce it, the problems of rational exploitation discussed in the previous chapter will become critical. The scientific knowledge needed to further this national goal by effective participation in international regulatory bodies is critical for the fisheries whose livelihood is at stake.

\section{Offshore Oil Industry}

Offshore oil production in the United States began in the Gulf of Mexico from the Creole field adjacent to the Louisiana shoreline in 1938. It was followed by somewhat slower development off the California and Texas coasts.

Today there are also oil and gas fields producing in many inland bodies of water throughout the world, such as in Lake Erie. The largest offshore oilfield in marine waters is in the Persian Gulf, off the coasts of Saudi Arabia and the nearby Neutral Zone. Other producing fields are in the Gulf of Suez, off the shores of Venezuela, Japan, Mexico, Trinidad, and Peru. Operations are expected to be extended both geographically and in depth.

The magnitude of the offshore operations is illustrated by figures for the Louisiana marine area. Total investment at the end of 1962 exceeded $\$ 3$ billion, with a forecast of $\$ 2.6$ billion to be invested in the next five years. From 1938 to July 1 , 1962 , a total of 4325 wells had been drilled. Liquid hydrocarbon proved reserves exceed 2 billion barrels, plus 12 trillion cubic feet of natural gas reserves. In the essentially unexplored water depths of 100 to 600 feet, some 250 new oil and gas fields are expected to be found eventually. As many more fields may be found in shallower waters in the Louisiana area.

Oil production in this area, beyond the threemile limit, has increased steadily from 3 million barrels in 1954, to 11 million in 1956,36 million in 1959, and almost 88 million barrels in 1962. Offshore natural gas production has had a similar growth, with cumulative sales for all offshore Louisiana now 2 trillion cubic feet.
Project Mohole (not fiscally included in the National Oceanographic Program), a plan to drill through the earth's crust into the mantle, has demonstrated in the first phase of operations that drilling can be done in water as deep as 12,000 feet, and subsequent phases should enhance offshore drilling technology. An industry drilling vessel is now operating in 277 feet of water 40 miles from the Louisiana shore. This equipment is designed for use in waters 600 feet deep.

Cost is the major problem of the oil and gas industry in offshore operations. Equipment investment costs obviously are much greater than for onshore exploration, drilling, and production. Drilling and operating costs for a 10,000-foot well are about 50 percent more offshore than onshore. However, offshore drilling to date has been more productive (about 4 to 1 ) in terms of reserves found.

The oil industry has been relatively self-reliant in its oceanography and underwater geology. Information in its files on the topography and structure of many areas along the continental shelf probably exceeds that available elsewhere in both scientific quality and quantity. The beneficial effect of permanent structures and islands at sea on fishing is well-known. These structures attract fish and provide a desirable environment for them. This in turn attracts fishermen. Underwater television cameras used by the industry already have photographed forms of sea life not known before. Technically, many of the innovations developed in the search for oil under the seas have been immediately useful to other industries and other scientific pursuits. Much geological data, now unavailable for proprietary reasons, would also be of great general value if the oil industry finds itself in a position to release it in the future. Exploration of marine areas by the oil industry has been largely confined to areas of considerable economic potential, as for example, along the Gulf Coast and the coast of California where producing fields and geologic conditions of promise extend seaward. As on land, the industry looks to government for exploration in areas of unknown or marginal oil and gas potential.

\section{The Sea-Mining Industry}

Diamonds are recovered along the coast of South Africa, tin is dredged from shallow waters off the 
Indonesian archipelago, Japan mines iron from its coastal waters, and heavy minerals are taken from beaches and near beach areas of the United States, Australia, and India. Sulfur is recovered from beneath the Gulf of Mexico. Coal has been mined from tunnels extending from land to points under the seas in Canada and England, and bromine, magnesium, iodine, and common salt are recovered commercially from sea water.

However, all present marine mining is in relatively shallow waters less than $400 \mathrm{feet}$ in depth, and the equipment employed is generally the conventional hydraulic or bucket dredge. Normal evaporation, chemical precipitation, and ionexcharge procedures are applied to the removal of compounds and elements from salt water. Thus, there is no true deep-sea mining industry today.

The major deterrent to further extension of even the shallow-water mining, to say nothing of deep-sea mining, is cost. But there is also lack of a clear picture of where and what the resources are. The problems of investigation are formidable. At present, the industry lacks efficient methods and equipment either for prospecting or mining the sea bottom, it lacks knowledgeable marine scientists and engineers, and it lacks incentive since present sources are adequate to satisfy present markets.

It has heard the reports of manganese, phosphorus, gold, platinum, tin, and a host of other minerals found on the continental shelf or the deep sea floor; but looking at the cost-benefit relationships, the mining industry is apparently obliged to wait until there has been a large-scale, long-range comprehensive program of exploration before venturing very far into this difficult region. In the national interest, the initial exploration may be the role of government.

\section{E. Shipping}

In January 1963, the active U.S. Flag Fleet consisted of 904 ships of 1000 gross tons or over with a total capacity of $13,575,000$ deadweight tons. It included 21 combination passenger cargo ships, 601 freighters, and 282 tankers. 529 of these were employed in foreign trade, one in foreign-toforeign trade, 346 in domestic trade, and 36 in other U.S. agency operations. Another 52 were temporarily laid up for repairs or awaiting cargo.

Since the Merchant Marine is subsidized, its precise value as a factor in the economy is difficult to estimate. However, it provides employment for approximately 200,000 people in seafaring, shore side, shipbuilding, and repair activities and contributes more than $\$ 5$ billion annually to the domestic economy. It is estimated that it would take $\$ 10$ billion to replace it with new construction.

The primary reason for subsidization is the strategic value of the Merchant Marine to national defense. It is indispensable for the emergency supply of military field activities, defense manufacturing, and essential civilian needs.

Although its numbers are slowly decreasing, the average tonnage per ship and ship speed are both increasing so that there is a slow net improvement in overall capability. Replacement policies and steps toward ship automation are intended to further this improvement.

Two oceanographic activities contribute to more efficient operations: ship routing to avoid unfavorable wave conditions, and optimizing ship hull designs to meet the specific wave and weather conditions on routes where they would be used. Both these possibilities are in the experimental or development stage but appear promising.

For example, all Military Sea Transport Service ships use forecasts of wave conditions en route developed by the Naval Oceanographic Office and issued by either the Fleet Weather Facility in Norfolk, Virginia or the comparable facility in Alameda, California. Based on an extension by Richard James (of the Naval Oceanographic Office) of basic research conducted at New York University by Neumann and Pierson in the 1950's, wave forecasting is estimated by the MŞTS to save these ships an average of 18 - 20 hours per crossing, averaged over both oceans and all seasons. Over the year's total of about 1000 crossings, savings amount to about $\$ 2$ million.

A similar service is available to commercial interests through several private forecasting companies. Most United States shipping companies fail to use it, however, exceptions being the States Marine Corporation and the Pacific Fruit Company, but it is patronized by European shipping concerns who do not have such a service at home but apparently like what they get here.

Extensive research on the effects of sea conditions on ship hulls, carried on for many years by the David Taylor Model Basin, the Bureau of Ships, Stevens Institute, MIT, and the Maritime Administration, has now progressed to the point where it appears that ships can be designed specifically for weather conditions along specified 
routes, with improvements both in comfort and economy. It is likely to be many years before the quality of the fleet as a whole is much affected.

In this context, proposals regularly appear for consideration of a submarine tanker, or even a submarine cargo ship. It is true that, in principle, the absence of wave-making resistance would permit very large submarines to attain speeds sufficiently high to cut crossing times to the point where the high initial costs might be more quickly amortized than is the case in surface ships. But the payoff is uncertain and the date for this development is not felt to be near.

Finally, research continues on techniques to minimize the fouling of ship hulls by barnacles and marine organisms, and the associated hull roughness that reduces ship speed and increases propulsion costs.

\section{F. Recreation Industry}

Seagoing and seaside recreation has also within the last few years become a major industry. Swimming and bathing have traditionally been the most popular recreational uses of the sea, and in terms of the number of people who patronize our beaches and shore areas they still are. In terms of dollars spent in sports, however, they are far outclassed by the pleasure craft lovers. Something over 37 million Americans spent about $\$ 2.5$ billion last year on boats and boating. The size of the pleasure fleet is now approximately 7-1/2 million pleasure boats, on inland and coastal waters - an increase of 500 percent over 1958; sport fishing in offshore waters has passed the half billion dollar a year mark.

The states and Federal Government are hard pressed to acquire or even preserve beach and shoreline recreation areas to meet the increasing demands. Commercial and private interests are fast acquiring choice areas and erosion is affecting many others. In recognition of the urgency of the situation, the 87th Congress authorized the establishment of three national seashores, one on Cape Cod, one at Point Reyes in California, and one on Padre Island in Texas, together totaling 127,000 acres.

Two underwater nature trails have been developed in the Virgin Islands by the National Park Service to meet the growing demand for this type of facility, and a large area called the Key Largo Coral Reef Preserve has been set aside adjacent to Florida's Pennecamp State Park.
The Bureau of Sport Fisheries and Wildlife spends nearly $\$ 15$ million annually on behalf of sport fishermen, though only a small portion of this (less than 2 percent in 1963) is in oceanography.

The rising traffic of inexperienced pleasure boaters is creating a hazard to themselves and others, raising questions about how to help assure their safety. For example, there were over 3000 recreational boating accidents reported in 1961 in which over $\$ 4$ million in damage was done, 1100 lives were lost, and over 1000 persons injured. Nearly 300 of the fatalities resulted from capsizings in which weather or high seas was presumably a factor, so that improved wave and storm warnings might be of some help. Marine biological research would also foster understanding of "red tides," swarms of biological organisms that kill fish and inundate and make a seashore temporarily unusable.

It is clear that the growing size of the recreation industry is a measure of the rising value of seaside and ocean-going recreation to the general public and of the increased federal responsibility to conserve it for the benefit of all.

\section{G. Summary}

Oceanographic scientists and people in the fishing, shipping, oil, mining, and recreation industries constitute groups each benefiting in some special way from oceanographic knowledge. One of these groups, the scientists, is almost wholly dependent on government support of oceanography for its livelihood. A second, fishing, cannot expect to compete in the modern world without the benefit of government supported oceanography. The oil industry owes a great deal of its recent expansion to marine geology but has obtained much of it privately. Shipping, a subsidized industry, may in the future benefit marginally if it takes advantage of certain oceanographic services such as wave forecasting. Mining is deterred from expanding into the sea by high risks and costs and, being satisfied with terrestrial resources, looks to government to underwrite the risk of marine exploration. The recreation industry is flourishing but the greatly increased recreation-seeking public is endangering its own recreation resources by overcrowding. Its full enjoyment of the sea can probably be assured only by government action to conserve this valuable resource. 


\section{Chapter IV \\ CAPABILITIES AND SYSTEMS TO SUPPORT OCEANOGRAPHIC GOALS}

The size and scope of the overall program is based on an estimated growth in funding which averages about 10 percent per year, but which tapers from about 20 percent, from FY 1963 to FY 1964, to only about 7 percent in FY 1972. Expenditures corresponding to this expansion thus would increase from $\$ 123$ million in FY 1963 to about $\$ 350$ million in FY 1972, with a total over the decade of $\$ 2.3$ billion. It should be emphasized, incidentally, that this plan does not represent growth over and above that which would be projected by the individual agencies in its absence. Rather, it is a simple statement of superposed needs, goals, and programs for their achievement, modulated by the act of agencies planning together.

This rate of growth, incidentally, is slightly greater than that estimated for expansion in federal support over the next decade of all scientific fields and disciplines. The annual expenditures for FY 1963 of about $\$ 12.4$ billion- are projected to grow to about $\$ 28$ billion in FY 1972 , by a factor of about 2.2. Expenditures in oceanography are estimated to grow by a factor of 2.5 .

Whatever the assumed growth rate, it is essential to evaluate the compatibility between projected funds, facilities, and manpower. For planning purposes, it has been assumed that manpower in oceanographic research will increase at a rate of 9 percent per year, from a present work force of 2700 scientists to over 6000 in 1972. This figure is to be compared with an annual increase across the board in all disciplines (from education, training, field switching, etc.) that will average about 7 percent annually, for the decade. Thus, the plan anticipates a growth rate of participants in this field somewhat faster than the average for all fields; this is considered reasonable in light of the small base from which growth extends-oceanography now employs only 0.6 percent of all scientists and engineers engaged in research and development. The main problem in satisfying manpower requirements will arise out of the fact that the field should grow fastest during the first part of the next decade, whereas the production from universities will be greatest toward the end of the decade. Some temporary imbalances are bound to arise, perhaps to be met with the transition to greater emphasis on automation.

To take account both of inflation and the more sophisticated and expensive instrumentation and operations expected of the future, an annual increase of about 15 percent in the direct dollar cost of supporting each scientist has been assumed. (Since 1940, the cost per technical man year in all sciences has increased at an annual rate of about 11 percent.) Thus, research, instrumentation, and ship operations cost about $\$ 65$ million in 1963 . The comparable figure for 1972 is about $\$ 230$ million. The number of ships in the oceanographic fleet is arbitrarily planned to increase in the same proportion as the number of scientists; that is, by a factor somewhat in excess of two. But whether in fact the capability is augmented solely by ships, or by such devices as unmanned buoys remains to be determined by research itself. The amount to be invested in facilities is similarly related to the augmentation required in the current plant to accommodate the increased work force and their activities and assumes greater increase in size of individual laboratories than in their numbers.

It is not possible to justify the allocation of this overall program among the goals and agencies by a similarly quantitative argument. The situation is more complex, depending as it must on where each agency starts as well as where it wishes to go, and most particularly on the nature of the programs which it is conducting.

To see why judgment must supplement analysis in determining the allocation of effort among agencies and programs, it should be kept in mind that many of the programs in oceanography are in essence largely determined by the questions posed for them to answer.

Such programs, and there are many, cannot be confidently assigned to the support of any particular goal nor even prorated among them. For this reason much of the accounting in this chapter, and through the entire report, has been necessarily vague. Furthermore, in the interests of brevity as well as clarity, a discussion of details has generally been omitted. What remains, though approximate, is believed sufficiently accurate to show major features, general relationships, and matters of balance 
on the basis of which supplemental plans can be formulated in special fields by individual agencies and institutions. This is in keeping with the purpose of a long-range plan and the discussion in Chapter I.

In addition, such programs as the Ocean Survey Plan, the National Oceanographic Data Center, Oceanographic Forecasting System, the Navy's Oceanographic Instrumentation Center, and the like do not serve specific goals but support the entire oceanographic community. They are essentially oceanographic services of very wide and general utility, which facilitate the simultaneous attainment of national and special goals by the various agencies and the scientific community. They are therefore discussed in that context in a later chapter.

Before discussing the programs themselves, it is useful to review the overall balance of effort which they support. The way the approximately $\$ 2.3$ billion tentatively planned for oceanography in the decade ahead is apportioned among the various goals was summarized at the end of Chapter II, and is further delineated in Table 1. Figure
1 shows the same information as well as indicating how the budget is divided among the agencies. Table 2 outlines this by functional areas as categorized by the ICO. The relative amounts, in the order in which the programs to support the national goals will be discussed in the following pages are: Strengthening basic science ( 56 percent of which only 23 percent is not included also in the goals following), defense (36 percent), managing resources and health hazards in the world ocean (19 percent), protecting U.S. public health (4 percent), managing resources accessible to U.S. alone (4 percent), contributing to the protection of lives and property ashore and safety of operations at sea ( 2 percent), and, finally, surveys and services to oceanography (12 percent).

It should be noted that the total oceanographic progran has not heretofore been categorized by goals. Rather in the annual presentation of a national program, the effort has been classified according to function (research, instrumentation, ship construction, surveys, facilities, data center, and Indian Ocean Expedition) and by sponsoring agencies (Defense, Commerce, Interior, NSF,

Table 1

National Oceanographic Program 1963-1972

Fiscal Breakdown by Goals

(in percent of total)

\begin{tabular}{|c|c|c|c|c|}
\hline & $\begin{array}{c}\text { Basic } \\
\text { Science }\end{array}$ & $\begin{array}{l}\text { Applied } \\
\text { Programs }\end{array}$ & Services & Totals \\
\hline Basic Science (NSF) & 23 & & & 23 \\
\hline Defense & 20 & 16 & & 36 \\
\hline World Ocean Resources & 11 & 8 & & 19 \\
\hline Health & (3) & (1) & & (4) \\
\hline Resources & (8) & (7) & & (15) \\
\hline Resources in Domestic Waters & 2 & 6 & & 8 \\
\hline Health & (1) & (3) & & (4) \\
\hline Resources & (1) & (3) & & (4) \\
\hline Protection of Safety and Property & & 2 & & 2 \\
\hline Ashore & (0) & (1) & & (1) \\
\hline At Sea & (0) & (1) & & (1) \\
\hline Services & & & 12 & 12 \\
\hline Totals & 56 & 32 & 12 & 100 \\
\hline
\end{tabular}




\begin{tabular}{|c|c|c|c|c|c|c|c|c|c|c|c|c|c|c|c|}
\hline & $\overline{\bar{J}}$ & & $\underset{\infty}{\infty}$ & & 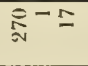 & & $\begin{array}{l}\infty \\
m \\
m\end{array}$ & 言 & 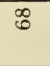 & & $\infty-$ & & $\stackrel{\infty}{\sim}$ & ลี. & $\begin{array}{l}\text { जै } \\
\text { w } \\
\text { Ni }\end{array}$ \\
\hline & ठ & & 0 & & N & & o & a & & & & & & & $\cong$ \\
\hline & 吾 & & $\sigma$ & & & & - & : & & & & & & & in \\
\hline & 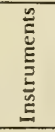 & & 8 & & $\infty \quad \infty$ & & $\infty$ in $\theta$ & & & & & & N & & $\stackrel{20}{g}$ \\
\hline \& & 氖 & & 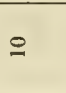 & & $m$ & & $\stackrel{-2}{=}$ & in & & & $\infty$ & & & & है \\
\hline & 产 & & ลื & & is & & $\mathscr{H}$ ov & F & & & & & $\sigma$ & & 蒿 \\
\hline 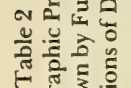 & 齐 & & $\stackrel{\circ}{-1}$ & & \& & & $\varrho$ & & & & & & a & & ๙ิ \\
\hline 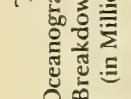 & 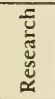 & & $\underset{\infty}{\stackrel{0}{0}}$ & & $\varrho-\sigma$ & & 온ำ & $\begin{array}{l}\infty \\
\text { 心్ }\end{array}$ & $\stackrel{\infty}{0}$ & & $\otimes^{-}$ & & $\cong$ & ล2 & $\stackrel{\infty}{=}$ \\
\hline 跣 & & 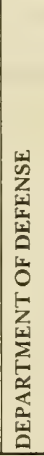 & 拿言 & 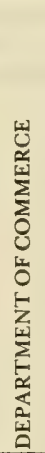 & 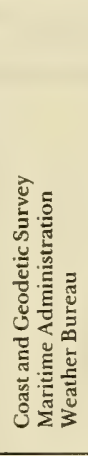 & 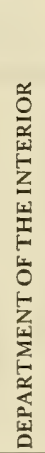 & 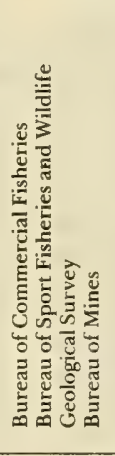 & 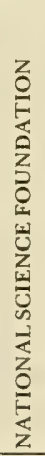 & 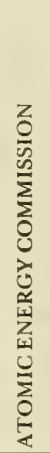 & 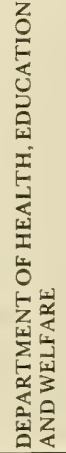 & 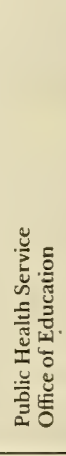 & 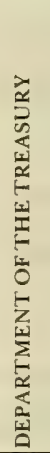 & 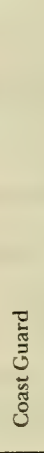 & 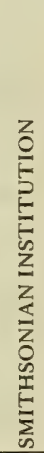 & E \\
\hline
\end{tabular}


AEC, HEW, Treasury, Smithsonian Institution). It is also possible, of course, to classify the program in yet a fourth way-by major scientific discipline involved.

It is probably apparent to the reader that, whereas the effort when sliced according to any of these four systems will always total 100 percent, there is considerable difficulty in developing a detailed compatibility along all four coordinated systems that is internally consistent. In the annual program, this is only accomplished by functional area and by agency. An effort is made in this LongRange Plan, however, to relate these two breakdowns also to the breakdown by goals.

In so doing, the reader is reminded that oceanographic effort associated with any goal includes the totality of research time, ship construction and operating costs, instrumentation, etc., that in the aggregate must be allocated to achievement of that particular goal.

Finally, what has been categorized as a goal of "strengthening basic science" should not be misinterpreted as equivalent to the conduct of "research" in the functional breakdown. The science goal sector includes an appropriate fraction of ship construction and operating costs, instrumentation, etc., , but no applied research. The functional research category, on the other hand, includes both basic and applied research, and ship operating costs associated therewith, but does not include ship construction costs, facilities or major instrumentations that are catalogued separately.

\section{A. Strengthening Basic Science (56 percent 1963-72 Effort)}

If the present plans are carried out, the goal of strengthening oceanograph; as a science will receive a greatly increased fraction of federal support during the next ten years. Not only does the National Science Foundation intend to expand its present program almost fourfold during the decade, but the Office of Naval Research will approximately double its basic research support; the Bureau of Commercial Fisheries intends to expand its support materially in areas related to marine biology. The Smithsonian plans to spend about $\$ 25$ million in basic science over the decade, and other agencies such as the Coast and Geodetic Survey and the Geological Survey will also contribute. Altogether, approximately $\$ 1.35$ bil- lion is planned to be spent during the next ten years, an expansion of more than threefold by FY 1972.

Figure 2 shows how this support is divided among the agencies. Three-quarters is administered almost equally by the Navy and the National Science Foundation, with the Bureau of Commercial Fisheries contributing another 15 percent. The remaining 11 percent is shared by the AEC, the Public Health Service, the Geological Survey, the Smithsonian, the Coast and Geodetic Survey, and the Weather Bureau.

It should be pointed out that Project Mohole is not being included in the oceanographic budget, although many of its results will be as applicable to geological oceanography and to oceanographic engineering as to geology as a whole. It is expected that other geological drillings into ocean sediments will be undertaken in water of moderate depth. None of these programs are currently included in this oceanography inventory, but future planning may suggest their addition rather than their classification of "earth sciences." While all aspects of oceanographic science will be supported, physical and biological oceanography will receive the major share.

Special international programs are included in this category of goals. The International Indian Ocean Expedition, a 32-nation, 40-ship effort begun in 1961 and expected to last until 1966 to which the U.S. is contributing 11 ships and about $\$ 24$ million, and the International Cooperative Investigations of the Tropical Atlantic are examples. Basic research will be conducted principally in 35 private laboratories.

A considerable number of small laboratories and university departments also conduct basic oceanographic research, and many of these, such as the one at the Massachusetts Institute of Technology, are growing and new ones are expected to come into being. There were, in addition, approximately 12 large government laboratories and more than 20 small ones in 1963. Overall, the growth in the next decade is expected to be primarily in the number of large laboratories employing 30 or more scientists.

Private laboratories now operate a fleet of over 15 seagoing research ships and about 20 will be added to it by NSF and Navy funds in the next decade. The bathyscaph, TRIESTE, presently the only operational deep research vehicle, is operated by 
the Navy. However, the Navy is sponsoring development of the ALVIN, a two-man submersible, capable of diving to 6000 feet, to be operated by the Woods Hole Oceanographic Institution. The ALUMINAUT, a three-man submersible, capable of 80 -mile cruises at 15,000 to 18,000 -foot depths developed and constructed with private funds, is being considered by the Navy for use in its research programs.

\section{B. Defense (36 percent 1963-1972 Effort; 20 percent Basic, 16 percent Applied)}

The oceanographic program of the Navy within the Plan in support of the national defense goal will total some $\$ 835$ million over the ten-year period.

\section{RESEARCH}

Included in this effort are the basic and applied research programs supported by ONR, BuShips, and BuWeps. These programs not only serve to advance the frontiers of oceanographic knowledge, but also serve to advance concepts in weapons development, detection devices, and naval armament systems in general by the consideration of favorable and limiting effects of environment. These research programs have applications to proand anti-submarine warfare, surface strike warfare, amphibious operations, Arctic operations, mine warfare, and in the general area of logistics support, including maintenance of hulls and submerged installations and transportation of men and material. A few highlighted research areas follow:

\section{(a) USW Research}

As has been stated previously, the Navy's primary concern in oceanography relates to undersea warfare. At least six Navy laboratories currently participate in an intensive campaign of oceanographic research that includes investigations of the shape and nature of the sea floor, description of the activity and constituency of the sea itself, and the quantification of the interactions between the ocean and atmosphere related to underwater acoustics and the parameters of temperature, salinity, sea surface phenomena, etc.

\section{(b) Other Physical Properties}

Many other physical properties and phenomena, such as surface and internal waves, tides, currents and turbulence, infrared and electromagnetic properties, radioactivity, optical properties, and many individual bottom properties, have technical and design implications. Practically every bureau laboratory active in Navy oceanography participates in one or another aspect of this program which is coordinated by the Office of Naval Research.

\section{(c) Marine Biology}

Marine creatures interfere with underwater acoustic systems, influence mines and mine coun. termeasures, damage structures, luminesce, are poisonous, venomous or toxic, and provide clues about the presence of underwater targets. Again the Office of Naval Research coordinates this research program which includes participation of five Navy laboratories.

\section{SHIPS}

The second major category of Navy funding concerns construction of oceanographic ships. It is divided nearly evenly between the direct support of Navy projects and the support of interagency or privately initiated projects from which the Navy is expected to benefit in common with other participants. The quarter-billion dollars projected for ship construction is tentatively allocated as shown in Table 3.

\section{MILITARY SURVEYS}

The Naval Oceanographic Office carries out a program of military surveys. In contrast to the national Ocean Survey Program (described in the next chapter) which has as its objective a general strengthening of knowledge of the oceans, the military survey program is focused specifically on the Navy's operational requirements. These surveys are designed either as mapping and charting expeditions for strategic areas or to provide environmental information requisite to design installation and operation of anti-submarine warfare systems. A fleet of eight ships and a current annual budget of about $\$ 11$ million supports this program.

During the coming decade 13 ships (of which seven will replace existing hulls) will be added. 
TABLE 3

Navy TENOC Shipbuilding Program (1963 through 1972)

\begin{tabular}{|l|c|c|c|c|}
\hline \multicolumn{1}{|c|}{ Type } & Replacements & Non-replacement & Total & Total Cost \\
\hline \hline Basic Research (1) & 7 & 5 & 12 & 57.9 \\
Applied Research (2) & & 5 & 5 & 24.1 \\
Ocean Surveys (3) & 1 & 5 & 6 & 48.0 \\
Coastal and Special Surveys (4) & 6 & 6 & 12 & 92.5 \\
\hline & 14 & 21 & 35 & 222.5 \\
\hline
\end{tabular}

(1) Assigned to privace labs under ONR contract

(2) Assigned to Navy labs and NavOceano

(3) Assigned to NavOceano

(4) Assigned to NavOceano

Although data are collected for classified military operations, a very large fraction resulting from those surveys is publicly available through the National Oceanographic Data Center.

\section{INSTRUMENTATION AND FACILITIES}

Seven percent of the Navy's projected budget (\$60 million) is allocated to development and procurement of oceanographic instrumentation. Featured in development programs will be sensingrecording-processing systems for rapid and accurate data acquisition and treatment. Part of the Oceanographic Office instrumentation budget supports the developmental effort at the Navy's Oceanographic Instrumentation Center. The remaining one percent of the budget will go toward the building of new facilities, both privately operated and military.

\section{DEEP SUBMERGENCE VEHICLES}

While recognizing the sea, from surface to ocean floor, is the available arena for naval warfare, most activities have been carried out at or near the surface. Combat submarines are being designed for deeper operation, but by and large the only manned-vehicle for full vertical access to the ocean has been the TRIESTE. However, it has only a two-mile horizontal range. A far more ambitious study of Navy requirements is now being undertaken in relation to deep operations, including salvage.
The Navy is considering three types of vehicles, but no explicit funding is provided in this plan. The first type, designed for cruising along the continental shelf and work on bottomed equipment along the continental slope, is intended to dive to approximately 5000 feet, and cruise at slow speeds for $8-10$ hours. Four of these are considered required early in the decade with six more later.

A second type is intended to operate to 15,000 20,000 feet and consequently to be able to reach bottom across 90 percent of the ocean floor. It should be able to cruise at slow speeds for as much as a day. Two of these are to be required for research prior to 1970 with two more thereafter.

The third type is intended for deep trench investigations and should go to 36,000 feet. It will probably have a limited ability to cruise at depth. A total of two of these is desired, one prior to 1970 .

\section{TENOC}

The Navy first developed a long-range plan in oceanography in 1959, referred to as TENOC ("Ten Years in Oceanography"). Periodically updated, TENOC reflects advances in both science and operational requirements, with a balanced program organized in ten areas of effort. These areas and their relative emphasis projected over the next ten years are shown in Figure 3. However, of the Navy's total oceanographic budget of $\$ 1315$ million, only $\$ 835$ million, or about two-thirds, is included within the National Oceanographic 
Program as categorized by the ICO. Some additional $\$ 480$ million is devoted to applied research and development of a more direct military character.

The research to be accomplished by the more immediately defense-oriented portion of this plan is in four major subject areas including acoustics, magnetics and gravity, Arctic operations, and environmental forecasting.

\section{(a) Acoustics Research}

The Bureau of Ships coordinates the acoustics program, which is directed toward understanding, predicting, and exploiting acoustic propagation phenomena. This is concentrated in nine Navy laboratories supplemented by ONR-supported work in eight private and university laboratories. Many industrial organizations under contract to the Navy for sonar, torpedo, and other ASW/USW equipment also do work in oceanographic acoustics in connection with their development programs.

\section{(b) Magnetics and Gravity Research}

Programs to examine and exploit geomagnetic and gravimetric phenomena are coordinated by the Bureau of Naval Weapons. Four naval laboratories and four private oceanographic laboratories participate in this program related to submarine navigation, missile guidance and ballistics, submarine detection, and mine countermeasures operations.

\section{(c) Arctic Research}

Operations in the Arctic now require knowledge of under-ice as well as ice-edge phenomena. The Office of Naval Research coordinates work done principally in four Navy laboratories and the Arctic Research Laboratory of the University of Alaska on the Arctic oceanic environment.

\section{(d) Environmental Forecasting}

The oceanographic forecasting program, though planned to absorb only one percent of the Navy's oceanographic budget during the next decade, deserves special mention. This figure includes only the research and development aspects of programs, most of whose cost is to be borne by fleet operating and maintenance budgets. They are intended to improve the capability to forecast the ASW environment, as well as to predict the consequences of harbor flushing and disposal of nuclear products, etc.

Many of these forecasting programs will emerge from the research or experimental stage and enter the operational stage in the coming decade. The ASWEPS, for example, is expected to become operational in 1965. When it does, it will be funded by the Navy under its fleet operations budget and will not appear within the TENOC projection.

\section{World Ocean Resources (19 Percent of the 1963-1972 Effort;}

11 Percent Basic, 8 Percent Applied)

The two agencies primarily concerned with this goal of developing while conserving ocean resources are the Bureau of Commercial Fisheries and the Atomic Energy Commission, although the Bureau of Mines has a responsibility to study oil pollution at sea.

\section{FISH RESOURCES}

The Bureau of Commercial Fisheries intends considerable expansion in its basic research program during the coming decade. By 1972 about 65 percent of its total research should be basic research as compared with only about 30 percent today.

As might be expected, the distribution and nature of the various fundamental oceanographic variables and properties which define, often within rather narrow limits, the habitat of various fish will receive considerable attention. So will studies of marine communities with their patterns of dominant species, of food webs which interconnect the inhabitants of these communities, and of rates of energy and food transfer throughout these webs. Ecological balances must be thoroughly understood before the consequences of man's intrusion on them can be predicted.

Studies of particular species already or potentially useful to man will be continued, and a major program of technological and engineering research will be undertaken to improve present methods of locating, catching, preserving, and preparing fish for the table. In this connection a program of economic, legal, and social studies will be undertaken as basic to the management and mar- 
keting problem. That this last is not trivial is illustrated by the availability of some wholesome fish foods in considerable quantities which are presently wasted due to local conventions or legal restrictions. Finally and of much interest to both marginal fish industries and underdeveloped nations bordering on the sea, a program devoted to increasing the yield of the sea itself is planned. Introducing new species into at present unoccupied food niches in the marine community, modifying the environment to favor food fish over predators, placing fish shelters on areas with barren bottoms, and the addition of trace elements and nutrients to fertilize the oceans, at least locally, are all under study.

To carry out this program, the Bureau of Commercial Fisheries estimates it requires 25 new ships in addition to the 20 now operating in oceanography and seven new laboratories. By the end of the decade, they should have a total of 41 ships, considering retirements, and 27 laboratories. In addition, they expect to have a medium-depth underwater research vehicle, a mesoscaphe, which they will share with the Bureau of Mines. Their proposed expenditures over the ten-year interval would run somewhat over $\$ 350$ million.

\section{WORLD HEALTH}

The Atomic Energy Commission has monitored radioactive contamination produced by detonation of nuclear devices, wastes from reactors, and effects from nuclear-powered ships since 1944 when the first materials were introduced into the environment. Since then the disposal of packaged wastes in both the Atlantic and Pacific by several nations has occurred in amounts sufficient to warrant continued close routine monitoring and the refinement of limits on maximum permissible concentration. Future hazards from accidents involving nuclear propulsion systems, both waterborne and missile-connected, are under study, as is the prediction of the consequences from nuclear detonations of all kinds. The research program concerns the appearance and distribution of radioactivity in marine organisms, in the sea itself, and in the sediments and rocks under the sea, through chemical as well as physical and biological processes. It is of necessity mainly basic rather than applied and is expected to run about $\$ 68$ million over the next ten years. The AEC plans to build no ships of its own but will continue to use those of other agencies.

\section{COOPERATIVE ASPECTS}

Although increasing competition and conflict are possible in man's increasing use of the world ocean for its fish and to dispose of his wastes, the possibilities of cooperation for mutual benefit and the support of underdeveloped nations are also great. The past history of regulation of the whaling, halibut fishing and fur sealing industries augurs well for future accommodations among the competitive nations. The potentialities of surveys and studies in direct support of the fisheries of such underdeveloped nations as the Ivory Coast and Nigeria have only partially been realized. In addition to improving the material well-being of such nations, a cooperative program enlisting nationals of such countries as participants could serve to introduce them into at least one aspect of modern science and perhaps pave the way for further scientific progress in other fields. The International Indian Ocean and the Tropical Atlantic expeditions currently dominate the international oceanographic picture, although other international programs are in various stages of development.

\section{Management of Resources in Domestic Waters}

\section{PROTECTION OF U.S. PUBLIC HEALTH (4 Percent 1963-1972 Effort; 1 Percent Basic, 3 Percent Applied)}

Closely allied to the preceding goal is the direct protection of the health of the U.S. public from industrial or radioactive wastes and other forms of pollution. The AEC program, particularly that concerned with monitoring and studying the effects of reactor wastes carried to sea by rivers, makes a contribution to this goal, but it is the Public Health Service which carries the main effort.

The Public Health Service oceanographic activities are an integral part of a continuing program of research on health hazards and of the environment taken as a whole. The oceanographic aspects center on water pollution surveys and shellfish sanitation and are carried out in close connection with state programs. During the next ten years, the Public Health Service will focus 
studies in particular locations on the Columbia River, Delaware River, Susquehanna River, and Chesapeake Bay, with new studies beginning after 1965 of the Southeast Drainage Basins and the Alaska Drainage Basins.

The program should total about $\$ 88$ million in the next ten years. Three new facilities will be added to the present nine conducting oceanographic projects. No ships are required.

\section{MANAGEMENT OF U.S. RESOURCES HELD IN COMMON}

(4 Percent 1963-1972 Effort, l Percent Basic 3 Percent Applied)

Although a comparatively modest effort, the funds for investigating and managing the resources along the shore and on and under the continental shelf represent such an increase from the small amount being spent on this area today (less than 1 percent) that a considerable change in the picture of what these resources are should develop by 1972. The Geological Survey and the Bureau of Mines plan a systematic exploration of this potentially valuable area for mineral deposits. The Bureau of Commercial Fisheries will continue to study such local food resources as clams, oysters, lobsters, and the like, and the Office of Saline Water is prepared to participate or advise as needed. The Bureau of Sport Fisheries and Wildlife, the Bureau of Outdoor Recreation, and the National Park Service expect to concern themselves with recreational values.

The Geological Survey plans to establish two „ew major oceanographic research centers closely tied to its Washington (D. C.) and Menlo Park (Calif.) geological research centers. From these centers, it will study the composition, structure, geologic and hydrologic processes, and resources of the ocean floor, in cooperation with other government agencies and private institutions. The studies will permit offshore extension of geological and geophysical knowledge of land areas and will provide a better understanding of sedimentary rocks and resources that were formed beneath the oceans and subsequently raised above sea level to form lands. Current emphasis is being placed on estuaries, bays, continental shelves and other nearshore areas of the United States, its possessions and trust territories. As knowledge of these areas becomes available, the emphasis will be extended seaward to the deep oceans.
The Bureau of Mines proposes the construction of a marine research center at an as yet unspecified shoreside location with provisions for process laboratories for sea water extraction and mineral separation studies, core libraries for specimen storage, analytical facilities for sample determinations, and docking space for research vessels, instrument shops, and the like. In addition to the mesoscaphe which it will share with the Bureau of Commercial Fisheries, the Bureau of Mines will require a number of specialized surface and underwater craft or devices for drilling, dredging, and taking piston cores. Both the Geological Survey and the Bureau of Mines will need extensive new instrumentation. By the end of the decade the Bureau of Mines expects to have various underwater mining demonstration laboratories. The preparation of an ocean floor mine shaft will be investigated with initial drifts, a mine shaft collar to the ocean surface, an elevator, and various underwater shelters at the mine opening. Under study are floating underwater laboratories for seagoing research operations and on-the-spot analysis and testing. Bureau of Mines and Geological Survey programs should run in the vicinity of $\$ 100$ million for the tenyear period.

With regard to the resource represented by the recreational value of the seas and shores, the Bureau of Sport Fisheries and Wildlife expects to add one research center on the Gulf of Mexico to the two it now operates and to provide research vessels for each to take the place of the chartered ships now in use. Its program emphasizes the inventory of game fish populations, determining particularly suitable locations for game fishing, and the development of sea water systems at each of its three research laboratories for holding game fish and rearing their young.

The oceanographic effort on behalf of recreation is expected to run about $\$ 15$ million over the decade.

\section{E. Safety at Sea, Protection Ashore}

\section{PROTECTING LIFE AND PROPERTY ALONG THE COASTLINES (LESS THAN 1 PERCENT OF THE 1963-1972 EFFORT)}

The Army's Corps of Engineers (with the Beach Erosion Board as one of its research agencies) plays the major role in protecting beaches and 
harbor areas from wave-attack, and in providing navigation channels and harbors in the coastal area, while the Weather Bureau issues warnings of the occurrence of dangerous conditions from storms. Both will continue their research programs at about present levels throughout the decade. This is expected to amount to about $\$ 16$ million for the Corps of Engineers and to be slightly under $\$ 3$ million for the Weather Bureau.

In the Pacific, the tsunami warning service of the Coast and Geodetic Survey will be improved and expanded as part of an international program to extend the greatly needed warning to other areas of the Pacific: Further research will also be undertaken in an attempt to learn to forecast the wave heights as well as times of arrival. The Coast and Geodetic Survey plans to allocate about $\$ 1$ million to this effort in the coming decade in a cooperative venture with other nations.

\section{SAFETY OF OPERATIONS AT SEA (1.2 Percent 1963-1972 Effort)}

The traditional responsibility of the Coast Guard for maritime safety and the maintenance of navigational aids at sea has always led to activities of great use and value to oceanography. While conducting the International Ice Patrol and such regulation enforcement operations as the Bering Sea Patrol, and while conducting icebreaking operations in the Arctic, its ships have usually accommodated scientists from other agencies and laboratories and carried oceanographic and meteorological instruments of various sorts. It was especially fitting that in the Fall of 1961 the Coast Guard's charter was formally amended to authorize the conduct of oceanographic research within the agency itself, in relation to its mission. During the coming decade, its program will support work in connection with such diverse goals as ocean survey program, inshore surveys, studies of ocean waves and swells, ice in the sea; oceanographic forecasting, radioactivity in the oceans, and oil pollution of navigable waters. Two new oceanographic ships and much new instrumentation represent major requirements for their expanded role. Their oceanographic budget is expected to run about $\$ 28$ million over the ten years.

As to promoting safety at sea, the chart and map service of the Naval Oceanographic Office and the Coast and Geodetic Survey are of vital importance. Additionally, they serve as the necesary base maps for other scientific investigations. These products, and the surveys to provide the data on which they are based will be continually improved and updated throughout the period.

\section{F. Services (12 Percent 1963-1972 Effort)}

These will be described in more detail in the next chapter. They are mentioned here as important activities in support of the entire oceanographic community from which all benefit in common. Although a smaller fraction of effort during the next decade than at present, they do in fact represent an expansion over the present program. Much of this expansion is in the Ocean Survey Program conducted by the Coast and Geodetic Survey primarily in association with the Navy but with participation of the Coast Guard, the Bureau of Commercial Fisheries, the Geological Survey, and the Weather Bureau. The Coast and Geodetic Survey will require eight new ships and the Navy four for this operation. Buoys, also under development for the ocean survey program, could add greatly both to the effectiveness (and probably to the cost) of the program if they are successfully developed and optimally employed.

An oceanographic forecasting service for nonmilitary use may come into the program during this period. Its costs and requirements cannot yet be estimated. It would presumably benefit from-and probably resemble-the Navy's ASWEPS program.

The National Oceanographic Data Center, already an integral part of the national community, will continue at a slightly expanded rate, and a new facility, the Naval Oceanographic Office Instrumentation Center, recently established by the Navy, will function to some extent in support of the entire community. In advancement of the concept of coordinated effort, the oceanographic units of a number of federal agencies have moved, or are in process of moving to a three-acre area in the Washington, D. C. Navy Yard Annex.

The Interagency Committee on Oceanography feels that there may be a need for one or more interagency marine centers where interdisciplinary programs beyond the capacity of single agencies could be carried on. No firm plans for such centers exist as yet, however. 


\section{G. Instrumentation}

The instrumentation requirements for the programs just described are generally similar-and formidable. At the same time, technology and engineering promise at last to provide much that has long been lacking. They are, therefore, discussed together, although the funds planned for them have been included in the agency budget figures already given.

It has been difficult to keep oceanographic instrumentation in step with technological advances in other areas for two major reasons. One is that the need for high precision while being used in a very harsh environment places extreme demands on a designer's skill. Temperatures must be correct to the nearest .01 degree Celsius and salinity to the nearest two parts in a hundred thousand over pressure ranges from one to perhaps 1000 atmospheres if density determinations made from them are to be correct to the nearest part in a million, as is required for the study of some physical processes. Other instruments, such as thermal probes to measure heat flow through the sediments at the bottom, depth recorders, sonic probes, plankton collectors, and audiovisual devices for fish observations and surveys and the like, have similar extreme demands on their quality.

The second reason for the archaic state of oceanographic instrumentation is that this demand for high quality is coupled with little demand for quantity. As a consequence, there has been little incentive for heavy investment in their development by those industries most competent to advance the state-of-the-art. As a result, most instruments were originally designed, built, and even manufactured in such quantity as needed by versatile oceanographers themselves. The numerous Nansen devices, still in use after 50 years, the bathythermograph, and the Ekman current meter, are all examples, excellent of their kind yet hardly to be compared in engineering sophistication with recent products of the space industry. Telemetering, data processing, communications, and other back-up systems could all be improved, as could almost every device now in use.

Development during these next ten years is expected to emphasize increased speed and efficiency of standard measurements rather than the creation of devices for obtaining new types of information. In addition to automating many of the shipboard procedures now carried out tediously by hand, the Navy, Coast and Geodetic Survey, Bureau of Commercial Fisheries, Coast Guard, and the Weather Bureau are seeking automated fixed stations for sensing and transmitting oceanographic data remotely on a routine basis.

Instrumentation for marine biology has lagged even farther behind than that for other aspects of marine science, and particular effort will be made to develop more satisfactory plankton recorders, sampling gear, and underwater camera and television equipment. A so-called "parameter follower" is being sought by several agencies. This device, intended to be towed or self-propelled, would sense a given concentration of one parameter and remain within it while recording variations in others. It is expected to be particularly helpful in fish migration studies, simulating some of the important behavior patterns of migrating fish.

Moored buoys with strings of current meters for obtaining extended records at a given point have been in use for several years. The present models require retrieval in order to obtain the data, and this has proved both time consuming and unreliable. Developing moored buoy systems to accommodate a variety of instruments and telemeter data first to the surface and then to shore stations, aircraft, or satellites has therefore been an attractive possibility. The Office of Naval Research has been conducting a systems study program for the last two years on various configurations and alternatives.

These studies have determined an optimum size and configuration for a system capable of telemetering data at the rate of 300 bits per minute on an intermittent schedule with high reliability over a distance of 2500 miles while remaining unattended for up to a year. Prototypes are under construction together with a shore command station, mooring techniques are being developed, and oceanographic sensors are being designed. A complete buoy system should be available at the end of about two more years. The program is being guided by an advisory committee of the ICO consisting of research oceanographers as well as experts in buoy technology and representing private institutions as well as the Navy. This development program is estimated at about $\$ 3$ million.

Other smaller buoys for specialized purposes have been developed with ONR support at both 
Scripps Institution of Oceanography and the Woods Hole Oceanographic Institution for a number of years and this work will continue.

Many agencies are contemplating plans based on the use of anchored buoy stations in rather large networks within the next few years. Before these plans are executed, three important interim steps should be taken. First, the development program should be carried to the point where sensors are reliably capable of long unattended operation and the buoy can be counted on to hold its moorings and transmit significant amounts of information over the required distances. No buoys have these characteristics at present and much more expensive development is required. Second, once such buoys are available, none should be installed until the time space data sampling requirements are thoroughly worked out. These requirements depend on the scientific question being asked, the process to be studied, and the scale characteristics of other processes also capable of producing sensor responses appearing as "noise" in the data record. The noise must not obscure the signal. Finally, efforts under way at the international level to establish legal and operational conventions must be completed.

Figure 4 shows the relative effort contributed to the instrumentation program by the various agencies. The Navy expects to carry three-fifths of the planned total of $\$ 103$ million, reflecting a massive effort to expedite solutions of problems of packaging sensing-recording-processing systems, to perfect deep diving exploration vehicles, and to overcome sound attenuation. The remaining twofifths will be fairly evenly divided among the Bureau of Commercial Fisheries, Geological Survey, Bureau of Mines, Coast Guard, Weather Bureau, and the Coast and Geodetic Survey. Particular efforts are therefore being made to assure thorough exchange of information among the agencies concerned by the establishment of a central file of instrumentation data at the National Oceanographic Data Center, the publication of an encyclopedia of oceanographic instruments, and the joint agency use of the Navy's Oceanographic Instrumentation Center at the Navy Yard Annex in Washington, D.C.

\section{H. Manpower}

A final capability on which all else depends is an adequate corps of trained, imaginative, and skillful scientists. No other problem in basic oceanography currently warrants greater attention than the manpower problem, and this in spite of the fact that the ranks of oceanographers are expected to continue to grow at a rate moderately in excess of the national average for scientists as a whole. This projected growth in oceanography of about ten percent where the national increase in all types of scientists has averaged about seven percent is the basis for the programs now planned in pursuit of the national goals in oceanography. Meeting these requirements is expected to result from the continued transfer of scientists from other basic fields such as physics, geology, chemistry, biology, mathematics, and engineering since fewer than 100 degrees in oceanography are granted each year. The greatest educational shortages are projected to lie in the areas of physical and meteorological oceanography, although systematic biologists, marine geophysicists, and geochemists are also scarce. Other types of marine biologists and geologists are currently being trained at an adequate rate. Two attacks on the problem currently being mounted involve motivation at lower academic levels and increased application of training grants.

In one respect, the large number of transfers from other fields is desirable. It provides a crossfertilization of ideas which is particularly valuable in oceanography where many of the processes of greatest interest are best dealt with from a multidisciplinary point of view. As oceanographic frontiers are pushed back, more and more specialized knowledge in an increasing variety of technologies and fields of knowledge is required to help solve the novel problems which keep turning up, and to devise new "tactics" to surmount unprecedented difficulties.

On the other hand, the "strategic" approach to oceanographic knowledge to assure its advance over a broad front can hardly be certain without the creative activity of a large number of people broadly trained and widely experienced in oceanography itself.

In the light of this situation, the direct support provided by the National Science Foundation, and the Departments of Interior and HEW for fellowships and training grants in oceanography might seem small, especially since the ten-year projection shows little increase over the period. However, the problem is strongly cyclic and self-limiting. Uni- 
versity departments have more than their share of trouble attracting oceanographers already in short supply anyway and temperamentally more interested in research, particularly seagoing research, than they are in teaching. They tend to go to the great oceanographic institutions such as Woods Hole and Scripps where research receives major emphasis. It is a rare university which can combine both types of facilities. They might produce still more if they retained more of their graduates in teaching positions rather than losing them to research, but this would produce an even greater deficit of research oceanographers during the interim. The best way to prime the educational pump in oceanography is one of the subjects greatly in need of study during the coming years and is a high priority item for one of the panels of the Interagency Committee on Oceanography. 


\section{Chapter V \\ SURVEYS AND SERVICES}

Some programs and activities in oceanography are undertaken to meet needs felt more or less strongly by each group within the oceanographic community but which are beyond the capacity of each to meet separately or of any to provide for all. Among these are broad area surveys, the maintenance of a complete library of oceanographic data, the testing and calibration of a variety of instruments, including novel ones, and forecasting oceanic conditions of both research and operational interest.

The first two of these are present realities as are ice and wave forecasting. The Ocean Survey Program, described in ICO Pamphlet No. 7, ultimately may be a part of an international effort as described in the next chapter. It has already begun in a small way with the closely controlled underway lines and the network of oceanographic stations conducted ir. the North Pacific by the Coast and Geodetic Survey's PIONEER in 1961.

The second service type activity is the National Oceanographic Data Center (NODC) which was established two years ago to assemble, process, archive, and disseminate to interested users all oceanographic data collected anywhere. Both these programs were endorsed and implemented through the Interagency Committee on Oceanography.

The Navy has just established its own Oceanographic Instrumentation Center and steps are being taken to make this available to users on a national basis. The Navy's ASWEPS (Anti-Submarine Warfare Environmental Prediction System) is expected to become operational around 1965. It may also provide some nonmilitary applications.

\section{A. The Ocean Survey Plan}

Both the scientific community, through the National Academy of Sciences Committee on Oceanography, and the various federal agencies have expressed the need for systematic mapping of the major properties of the oceans, the basins which contain them, the sediments which lie under them, the forces such as gravity and magnetism which permeate them, and the life which they contain. Such mapping can, of course, serve a variety of goals, providing tools for use in military and economic welfare, as well as in scientific oceanography. The measurements of interest to each federal agency, the areas for early investigation (limited for some time by the availability of Loran C precision navigational aids), and the 1964 ship assignments are presented in ICO Pamphlet No. 12, May 1963. Detailed discussion is presented in the ICO "Ocean Survey Plan," ICO Pamphlet No. 7, May 1963.

The ship requirements for an ocean survey program cannot be exactly determined, since the desired rate of progress cannot be established except on subjective and intuitive grounds. Furthermore, the actual rate of progress which various survey ships will demonstrate, once assigned, cannot be precisely estimated. Presumably much can be done to make present operations more efficient if the ship is designed and equipped for participation in a coordinated program than would be the case if its survey work were done in isolation. Finally, the value of information collected from survey lines taken at close intervals, say ten miles apart, as compared to that which would result from lines 20 or even more miles apart must be weighed against the differences in cost or time associated with each. It is possible that buoy developments may proceed rapidly enough to replace some ship survey effort late in the time period. The economic and effectiveness considerations involved here have not yet been analyzed.

Both the need and the magnitude of the job will never be greater than at present, however, and it is the present intention to proceed with an orderly survey program as rapidly as funds and personnel will allow. The Coast and Geodetic Survey, acting as agent for the ICO, has awarded a contract for a major planning study of optimal survey systems and their deployment. As estimated now but subject to reconfirmation as plans mature, the next decade should see 24 new survey ships -16 built by the Navy to serve both in the ocean survey program (5) and for special military surveys (11) and eight by the Coast and Geodetic Survey (primarily for the ocean survey program). These plans will be responsive to new developments in instruments, particularly in buoys which may multiply the unit effectiveness and permit much more rapid prog- 
ress, and to progress in cooperative plans with other nations. The present estimate is that the ultimate share of the United States in the world ocean survey will be approximately 30 percent (to be prosecuted mainly by the Naval Oceanographic Office and Coast and |Geodetic/Survey with assistance from other agencies).

The program planned here is expected to run about $\$ 260$ million over the decade.

\section{B. The National Oceanographic Data Center}

The need for a centralized repository for the Nation's oceanographic data has been recognized for many years. Action began about four years ago to establish such a facility and the 86th Congress originated, but failed to pass, a bill establishing a National Oceanographic Data Center. At the same time, the federal agencies through the Interagency Committee on Oceanography recommended a jointly sponsored center to the Federal Council for Science and Technology and this was approved in June of 1960 . In November, the NODC was established as an administrative component of the Navy's Hydrographic (now Oceanographic) Office, and began work under the policy guidance of an interagency Advisory Board representing the six supporting agencies* and the National Academy of Sciences. Steps are being taken to assure close communication with ICO by having the NODC Advisory Board Chairman report the activities of the Center to the Chairman of the ICO.

NODC functions as a service activity for all segments of the Nation's scientific community with respect to marine environmental data and information requirements. It also makes these data accessible to the general public free of charge or provides copies at cost.

In performing this function NODC must, of course, receive, compile, process, and preserve oceanographic data in a form permitting rapid retrieval. It thus establishes procedures for insuring that the accuracy and general quality of the data meet the criteria established by an Advisory Board. Finally, it prepares data summaries, tab-

*Navy, Coast and Geodetic Survey, Bureau of Commercial Fisheries, the National Science Foundation, the Atomic Energy Commission, and the Weather Bureau. ulations, and atlases showing annual, seasonal, and monthly oceanographic conditions. The technical problems in carrying out these functions adequately are formidable, and all the resources of modern data handling technology as well as an informed understanding of the oceanographic community's needs are being brought to bear.

Housed in downtown Washington in the former Naval Weapons Plant, the National Oceanographic Data Center has a staff of approximately 80 . Its budget during the next ten years is expected to total approximately $\$ 15$ million. About half of this is presently borne by the Navy, and most of the remaining half is evenly divided among the Cosst and Geodetic Survey, the National Science Foundation, and the Bureau of Commercial Fisheries. The Weather Bureau, the Atomic Energy Commission, the Coast Guard, the Geological Survey, and the Department of Health, Education, and Welfare each contribute about two percent.

\section{The Navy's Oceanographic Instrumentation Center}

Although the Oceanographic Instrumentation Center is a Navy activity, it cooperates with other government agencies, private industry, and the academic community to bring about improvements and refinements in instrumentation, serving their needs to the extent possible. It is an attempt on the part of the largest user of oceanographic instruments to assure that the data it obtains about the oceans is precise and accurate.

After a slow evolution in the 1950's, the Navy's Oceanographic Office Instrumentation Division blossomed into the present Center in November 1962. It has a staff of about 100 engineers, scientists, technicians, and supporting personnel. It contains engineering facilities for laboratory and contractual development, test, and evaluation, and the maintenance of instruments. It is developing such new instrumentation as improved electronic bathythermographs, shipboard wave recorders, a shipboard survey system, submerged buoy systems, and sound velocimeters.

Its test equipment is extensive and modern, including pressure test vessels, shock and vibration test equipment, tensile test facilities, pressure and temperature tanks, reversing thermometer calibration equipment, a 60 -foot clear-water instrument test tower, and a,small craft for environ- 
ment testing in local waters. It intends to provide engineering advice and assistance to agencies and activities on oceanographic instrumentation matters, and to serve as a clearing house for information on the oceanographic instrumentation development program.

Its budget, which is borne by the Navy, is expected to total approximately $\$ 30$ million over a ten-year period.

\section{Oceanographic Forecasting Service}

The Navy has two environment and wave forecasting programs which could conceivably lead to developments of interest to nonmilitary users. They are instrumented to handle on a fully automatic basis incoming bathythermograph and sea surface temperature observations and to issue charts of the depth of the upper isothermal layer and the surface temperature variation. The major limitation is the crudeness of the present data inputs so that its outputs are relatively unsophisticated, but improvements are continuing and they provide valuable supplements to the ASWEPS program, scheduled to become fully operational sometime after 1965. Standing for Anti-Submarine Warfare Environmental Prediction System, ASWEPS is intended to provide forecasts of a a large variety of oceanographic variables of particular significance to the operating forces. These variables will describe in considerable detail the ocean environment in at least the upper layers. It is hoped that enough information about the sensors, installations, prediction techniques, data processing know-how, and various automa- tion methods can be made available for the development of a parallel nonmilitary system, or that the Navy system can also serve some nonmilitary users on a not-to-interfere basis.

Very approximate estimates of the cost of developing a world-wide ASWEPS system run about $\$ 3$ million " annually for the R\&D phase, totaling $\$ 20$ million. Operating costs will run very nearly another $\$ 3$ million a year thereafter.*

\section{E. Summary}

The oceanographic service of greatest magnitude planned for the next decade is the Ocean Survey Program. It should contribute to the goals of all the agencies, the scientific community, and other special groups such as the fishing and mining industries. Of international importance, as is noted subsequently, it is expected to reflect about one-third of a planned international effort. Costs amount to approximately $\$ 240$ million including the construction of 12 new ships.

Other services whose growing importance is out of all proportion to their comparative small costs are the National Oceanographic Data Center and the Navy's Oceanographic Instrumentation Center.

The Navy's ASWEPS will provide an important capability to forecast oceanographic conditions for military purposes. The possibility of providing some nonmilitary services or of establishing a nonmilitary counterpart is under consideration.

*Not included fiscally in the National Oceanographic Program 


\section{Chapter VI \\ THE INTERNATIONAL SETTING}

Many of the considerations which have led the United States to its recently intensified interest in the sea have similarly motivated other nations as well, and in many cases for much longer. As each has sought to learn more about the sea, it has quickly come to realize that the sea is very large and its own unaided efforts very small. As far back as 1899 , a conviction that effective exploration of the sea based on sound scientific principles demanded international cooperation led to the formation of the International Council for the Exploration of the Sea (ICES). Established by eight nations* to conduct a joint exploration of the North Atlantic, the North Sea, the Baltic Sea, and the adjacent waters, the ICES raised and tentatively settled such important issues as the standardizing of techniques and instruments and the exchange of data.

The International Geophysical Year is the most recent major manifestation of the tradition of international cooperation in scientific exploration of the oceans. It was boih the result and the cause of a great number of international organizations for scientific cooperation, both governmental and private. UNESCO, which had sponsored the development of many intergovernmental associations, established the Intergovernmental Oceanographic Commission (IOC), in 1960, with a membership list of 40 countries, including the United States. The IOC held its First Session in October 1961, with attendees from most member countries and from many of the 26 international scientific organizations which showed an interest in oceanographic problems. Two other United Nations bodies, the Food and Agric"sture Organization (FAO) and the World Meteorological Organization (WMO), and one nongovernmental organization, the Scientific Committee on Oceanographic Research (SCOR) of the International Council of Scientific Unions, were the three most closely identified with the IOC's purpose and have maintained close working relationships with it ever since.

The IOC's Second Session in September 1962 added four more nations to its membership list

*Denmark, Finland, Germany, Great Britain, Netherlands, Norway, Russia, and Sweden. and extended its already long list of proposed projects for international cooperation. It assumed coordinating responsibility for the International Indian Ocean Expedition, originally organized and coordinated by SCOR, with SCOR continuing to act in an advisory capacity. It agreed to undertake the International Cooperative Investigations of the Tropical Atlantic Ocean, as suggested by the United States, and is actively making plans to start two closely related projects, both suggested by the USSR. These are a standard section program to' study time changes in characteristics of the oceans and a North Atlantic expedition for studying fields of currents by dynamic techniques. In addition, it concerns itself with the perennial questions of standardization, intercalibration, and the exchange of data as well as some of the more particularly modern problems such as the legal status of fixed buoys, frequency allocation for telemetering and other communications, and the availability of new aids to navigation such as Loran $\mathrm{C}$ and the Transit satellite system under development by the United States.

Not the least important aspect of such activities is the opportunity they provide for scientists and technicians from nations without research ships and facilities of their own to participate and to further their own training while contributing to the collection of knowledge which is itself of mutual benefit.

The United States, with 11 ships already committed to the Indian Ocean Expedition and five more to the Tropical Atlantic Expedition, plans to put somewhere between $\$ 70$ million and $\$ 90$ million into such cooperative programs during the coming decade. The Interagency Committee on Oceanography, at the request of the State Department, is the United States point of contact for activities related to the IOC. United States participation in these programs is based on requirements which we would otherwise have to pursue alone. By joining our efforts with those of other nations with similar needs, we not only foster friendships and common interests among the collaborators, but greatly increase the scientific benefit which we, like the other participants, realize for the effort which each has expended.

It is not possible to determine with any great accuracy the present size and scope of specific 
foreign oceanographic programs. Like ours they are changing in both respects. Up-to-date figures are not always available even when free access to official information is granted, and in the case of the USSR, the program of perhaps greatest size and interest, this access is not free. Also, definitions are not uniform. For example, foreign programs show about three technicians for every scientist where the U.S. shows only one. Perhaps a third or more of the foreign technicians might be classed equally well as scientists, effectively doubling the numbers given in the sections which follow. What is known, however, indicates that the United States, the USSR, Japan, the United Kingdom, and Canada, lead the other nations of the world in the exten: and quality of their programs.

It has been the declared intention of the President and the Congress that the U.S. should maintain world leadership in this field of science. The following discussion should help illuminate this country's present position in terms of size, scope, and quality. In a field where so much opportunity exists for new discoveries, there is never room for complacency.

\section{A. USSR}

The USSR is reputed to have more than 60 - 70 ships available for oceanographic research though undoubtedly many of these do double duty as mother ships for fishing fleets or act as icebreakers and as naval escorts or supply ships. Their fishing fleet of over 3000 vessels, deployed to fishing grounds all over the world, presumably contributes to the collection of oceanographic data also. It is also likely that many of their merchant fleet, now consisting of something over 1000 ships and growing rapidly, take observations of near-surface oceanographic conditions as well as reporting meteorological conditions into the world synoptic weather net.

Their best known research ships are the MIKHAIL LOMONOSOV, built in 1957 of about 5960 displacement tons with some 16 oceanographic laboratories and space for about 75 scientists on board; the VITIAZ, similar in size though built in 1939; the SVERYANKA, a research submarine; and the 12,000-ton OB, built in 1953 . In addition to these floating laboratories, two other large ships of about 4600 tons, the PETR LEBEDEV and the SERGEY VAVILOV, were re- fitted in 1960 while the SEVASTOPOL, a 2500 tonner, has been in the research fleet since 1951. The ZARYA, a small sailing ship, is the world's only nonmagnetic research vessel. The exact size of their professional oceanographic scientific staff is not known but is estimated at about $500-700$ scientists and about 1600 technicians, thus considerably smaller than that of the U.S. Their work is of broad scope and generally high quality. It is of interest to note that the Soviet Interdepartmental Coordination Scientific Council on the study of the oceans and seas is somewhat similar in concept to the ICO.

\section{B. Japan}

The Japanese effort in oceanography is now estimated to have passed that of Great Britain and to rank behind only those of the U. S. and the USSR. It has traditionally been concerned with the problems of fisheries, shipping, and protection against marine catastrophes such as tsunamis, storm surges, and typhoons. These preoccupations, natural to an island nation with a dense population, little arable land, and modest mineral resources, have resulted in a strong emphasis on applied research and a program conducted almost entirely within the governmental meteorological, fisheries, and hydrographic agencies. Though some 16 or so universities have facilities for oceanographic and fisheries studies, their role in Japanese oceanography has been primarily educational. In addition to excellent fisheries research, Japanese oceanography has long been considered to excel in air-sea interaction studies, tsunami prediction, sea water chemistry, and problems of the Kuroshio current dynamics.

Recent developments indicate a trend towards more basic research and broader scope. A new Oceanographic Institute devoted to basic research is planned for Tokyo University, and two research vessels of about 300 tons are to be built for its use. Greater emphasis on physical, chemical, and geological oceanography can be expected in the future.

This broadening interest is already manifest in the recently initiated program of "Japanese Expeditions to the Deep Sea," a continuing series, four of which have already taken place.

Japan's traditional willingness to participate in international surveys and expeditions, as well as 
her growing interest in deep sea oceanography, is shown by the assignment of five out of her approximately 24 survey and fisheries research vessels to the International Indian Ocean Expedition. This fleet is comparatively new, threequarters of it being less than 12 years old. It is also very capable, with six of the ships exceeding 1000 tons and only two under 200 tons in size.

The Oceanographic Society of Japan includes more than 500 members, and the work force is estimated at $200-225$ professionals with about 600 technicians. Some $30-35$ students graduate with bachelor's degrees in oceanography each year but only four or five doctorates are conferred. The annual oceanographic budget is estimated at about $\$ 10$ - $\$ 12$ million.

\section{United Kingdom}

It was the British "Challenger" Expedition in 1873-1876 which first opened the oceans of the world to modern science, and the British have maintained a leading place in world oceanography ever since.

British oceanography centers in the work of the National Institute of Oceanography, generally considered one of the outstanding oceanographic institutions in the world. It was founded in 1949 , in Surrey, to centralize the work of three older establishments-the Discovery Committee, the Oceanographic Branch of the Admiralty, and the Underwater Sound Establishment at Teddington.

The work at NIO emphasizes physical oceanography, including wave studies and current measurements, but its program also includes some marine chemistry, sea-floor geology, geophysics, and marine biology. Its staff is led by some 20 senior scientists, and its major oceanographic vessel is the new DISCOVERY. Its operating budget ha: risen from about $\$ 3 / 4$ million in the middle of the last decade to about $\$ 1.8$ million today.

The Ministry of Agriculture and Fisheries conducts a program of applied oceanography at its laboratory in Lowestoft, operating the research vessel ERNEST HOLT. The Fisheries Biology for Scotland has a laboratory in Aberdeen, and the Marine Biological Association has a laboratory in Plymouth.

Education and research in physical oceanography is conducted at the Department of Oceanography at Liverpool where the University also maintains the famous Tidal Observatory. The Department of Geodesy and Geophysics at Cambridge conducts ocean-floor studies, and some eight additional universities have recently initiated programs also in marine geology. The British Museum and the British Petroleum Company also have programs in geological oceanography.

Large-scale hydrographic survey work is conducted on a world-wide basis by the Admiralty with a survey fleet of about ten.

There are about 300 professional oceanographers in the United Kingdom supported by about 900 technicians. Some 40 - 45 bachelor's degrees in oceanography are granted each year, but only 5 - 6 doctorates. The ocean-going research fleet includes about 16 vessels and the annual budget is estimated at about $\$ 8-\$ 10$ million.

\section{Canada}

Canada conducts a large, well-rounded program in all phases of oceanography but with special application to the Arctic and sub-Arctic. A central Canadian Committee on Oceanography, representing both universities and government agencies, establishes basic policy and coordinates the research program through four working groups, each concerned with a different geographical area.

There are approximately 170 professional oceanographers and 500 technicians working in a total of about 14 laboratories. The Canadian research fleet consists of 17 vessels including several refitted icebreakers, and ships normally operated for the Fisheries Research Board. The annual budget is estimated at about $\$ 58$ million.

\section{E. Summary}

The international apparatus for cooperative oceanographic enterprises is large, active, and highly effective. The member nations with the greatest capabilities are the United States, the USSR, Japan, the United Kingdom, and Canada, but there are 39 others represented as well. It is estimated that more than 250 oceanographic research ships exist capable of open ocean operations and that there are numerous smaller enterprises as well as the Ocean-Wide Survey Plan that can best be executed through international cooperation. 


\section{Chapter VII \\ PROGRAM SUMMARY AND EVALUATION}

The national plan in oceanography for the next decade is in its gross features an extension of the trend established during the last five. Yet in many ways, it also represents something new.

What is new is hard to measure since it is precisely what is most uncertain. It includes continuously recording instruments which will permit survey ships to make measurements under way, new submersibles for exploring the ocean at all depths, new buoy systems for quasi-permanent installation over great areas and new satellites for interrogating them and relaying their stored up data to shore stations for analysis, new forecasting systems for the major oceanic variables of interest to fisheries and to shipping as well as to scientists, new ways of mining the ocean floor, new ways of hunting, herding, achievement of an underwater pest control (through interference with the food chain), and even cultivating fish, and perhaps even a new habitat for workers in underwater laboratories and communities. These are new tools on the one hand and new applications on the other. What is new, in other words, is the coming technology. What this plan attempts to provide, therefore, is an oceanographic establishment of men, ships, and facilities and a program of research and development which is ready and able to capitalize on whatever may materialize out of the coming technology and to apply it to the furthering of our national goals.

The establishment which is being planned can best be seen in graphical form. Figure 5 shows the budget trend which is continued over the next ten years. The national budget of under $\$ 10$ million in 1953 represents the relatively small effort devoted to the field until very recently. In 1958, it had increased only $\$ 20$ million. The increase from that point on has been at a rate of nearly $\$ 100$ million in five years and projecting this into the future brings the overall-annual figure to about $\$ 350$ million by 1972 .

Some changes in the way the budget is allocated, however, are expected to take place during the decade. Figure 6 shows the 1963 allocation, both by goal and by agency, and Figure 7 shows the projection for 1972. Most evident is the great expansion in the portion of the effort which supports basic science. It rises from some 43 percent of the budget today to about 57 percent in 1972. The support for defense has decreased in percentage from 44 percent to 32 percent while the effort put into resource and health management in the world ocean has increased from 15 percent to 24 percent.

The oceanographic fleet is expected to change as is shown in Figure 8 . There are 76 ships in it today. If the projections of this plan materialize, there should be over 120 by 1972 . In addition, there may be a fleet of six to eight submersibles capable of exploring all depths of the oceans.

The major marine laboratories, of which there are now 63 , should have grown to some 85 by 1972 as shown in Figure 9. The 26 which are operated privately today should have been joined by another 10 to total 36 by this time while government laboratories are expected to increase in number from 37 to 49.

With these tools we should be able to make major advances in our basic understanding of the oceans, and the next decade is expected to see a great improvement in our ability to forecast and use oceanographic conditions for military advantage and to increase the yield of fish which the sea contains. With international cooperation a good start should have been made in surveying the oceans and their basins and in mapping the distribution of major properties. Most of the mineral resources on and under the continental shelves should have been located and assayed.

At least, that is the plan. How can the plan itself be evaluated? The terms for such an evaluation were suggested in Chapter 1 . They can be summarized in the following questions:

Has the plan been able to avoid duplication and waste,

overlooking opportunities for new joint enterprises made possible by centralized planning, and

inconsistency between goals, programs, and resources?

Does the plan -

justify the balance of effort among the various goals,

show the long lead-time items in perspective, both as to requirements and worth,

indicate major possibilities as yet uncertain but worth working for, 
point out prerequisites for success likely to be overlooked as well as important alternatives which should be supported as insurance against failure of major efforts,

provide a comparison with like efforts abroad, and

criticize its own shortcomings and indicate the remedy for future revisions?

Does it provide a sufficiently clear basis for action (or reaction) in its support by -

the public,

the scientific community,

the Congress, and

the Executive Branch?

The answers to these questions ought to be "yes." But candor compels that it be at best, "well, partly." Duplication and waste do not seem to be evident on the interagency scale this plan is concerned with, but it has been impossible to confirm this at levels of greater detail. The work of an individual agency often contributes to several goals, and most goals require the support of several agencies, but coordination at the interagency level is felt to be generally effective in minimizing duplication and waste. Thorough documentation is not possible.

Mention has been made of ICO hopes for joint marine centers where enterprises of an interdisciplinary and interagency nature might be undertaken. Since the need or utility of such centers has not been thoroughly documented as yet, nor is it being formally studied, it is not yet clear whether this may be an opportunity made possible by centralized planning which is in danger of being overlooked.

One possible inconsistency between goals and programs has been revealed. Unless the program for training new manpower for oceanography is more successful than seems likely at present, one or more of the federal goals will suffer through dilution of the quality of the work force. The most vulnerable is the goal of strengthening basic science and the most likely encroachment is from defense. Unfortunately the manpower problem is only partly solvable at the federal level, being strongly dependent on actions by universities and by individuals now outside the field. The present federal program should be carefully reviewed, however, to see whether more is possible.

Ships and facilities, the longest lead-time items, seem roughly in balance with the goals they are to support, the rest of the programs of which they are a part, and with each other. The net gain of about 50 ships which is planned over the decade together with the approximately $\$ 104$ million in new facilities to be built averages overall to somewhat more than the ratio of $\$ 1.5$ million in facilities for every new ship in the fleet which was recommended by the National Academy of Sciences Committee on Oceanography. Whether this will work out to be a proper balance in the way each is deployed is impossible to estimate at the moment.

The comparison with oceanographic programs abroad was made to the extent the limited information allowed. It was limited to the present, rather than projecting into the future, and was less than adequate in the case of the USSR. With the possible exception of the USSR, the United States effort appears to exceed considerably that of the other world leaders in oceanography-Japan, the United Kingdom, and Canada. All are sufficiently small, however, in comparison with their objectives to make international cooperation highly beneficial to each.

The major deficiencies in this plan appear to be those which can be remedied by more extensive and systematic analysis of alternatives, choices, and their consequences. The ICO is not at present in a position to remedy this defect without some strengthening, and how this might be done will be discussed in the next chapter. Finally, whether what has been presented here is of value to the scientific community, to Congress, and to the general public, only they can determine. The hope that this will prove to be the case, however, has strongly motivated the effort which this document represents. 


\section{Chapter VII \\ ORGANIZATIONAL PROBLEMS}

The President, with advice and assistance of the new Office of Science and Technology, is responsible for government-wide program planning and coordination. In oceanography, the Director of OST, who serves as Chairman of the Federal Council for Science and Technology, looks to the Interagency Committee on Oceanography to carry out this activity. The present Chairman of the ICO is the Assistant Secretary of the Navy (Research and Development), and ICO membership includes eight federal bureau chiefs. It carries out its functions through special panels on Research, Surveys, Instrumentation and Facilities, Manpower and Training, International Programs, and Ship Construction. It is an organization which is built on the skills and competence found in the departments and which provides a means for the expression of many points of view. It is considered more workable and responsive to the diverse and complex requirements of the broad spectrum of oceanographic management problems than would any single executive department vested with the same responsibility, an alternative which is sometimes suggested.

Its panel structure is highly effective in identifying technical needs in various research categories, devising programs and measures to meet these needs, identifying desirable allocations of technical effort among the agencies and suggesting assignment of technical leadership, and facilitating interagency communication at management levels.

The ICO itself reviews these panel findings and recommendations, assures an appropriate division of technical effort, examines the balance of effort among the different research categories and the adequacy of the overall program, makes findings concerning the technical manpower base for the program, and recommends management policies to improve the quality and vigor of the effort.

Government-wide plans and programs, budgets and organizational recommendations are reviewed and approved by the ICO's parent body, the Federal Council for Science and Technology, based on analyses developed by staff and consultants of the Office of Science and Technology.
The ICO depends on the individual agencies to evaluate the scientific worth of projects within their own programs.

Including as it does technical, operating, administrative, and scientific people on the committee and its panels, and functioning as it does within the framework of the Federal Council for Science and Technology, it has been able to avoid both paralysis on the one hand and superficial and hasty action on the other, the two fates on which most committees founder. Nevertheless, deficiencies and difficulties exist. Two in particular seem worth noting.

Although it has been highly successful in establishing effective communications at the management level, the ICO needs to do more to improve communications among the scientists, engineers, and others at the working level. It has published numerous pamphlets and bulletins on the results of panel work of general interest: an annual interagency plan, yearly ship operating schedules, college curricula, Ocean Survey Plan, etc. This series is intended to continue and to be extended. It also intends to publish an encyclopedia of oceanographic instrumentation. Being considered, but not yet at the planning stage, are interagency marine centers in which interdisciplinary programs of large scope could be carried on more efficiently with pooled facilities than they could on a single agency or laboratory basis. Finally, there is a possibility that something of value might result from ICO-sponsored interdisciplinary conferences organized perhaps around particular goals in oceanography, such as the federal goals discussed in this plan or those of special seagoing groups such as fishing, shipping, and mining. The ICO, through its present panel structure, is probably already capable of this extension of its activities if it should undertake this effort.

Second, to improve its own effectiveness in decision-making and in planning, the ICO should have the support of a small full-time analytical staff in addition to its Secretariat. The staff should, in effect, work for and be responsible to the Chairman of the Committee. It should be responsible for systematic analysis which will aid in planning, 
on both a short-term and long-term scale, and assisting in the development and application of criteria for evaluating of research and development projects and programs. Funds should also be provided for studies, where necessary, to draw on competence outside the Federal Government.

Both communication and staffing problems will become more severe as the program of growth described in this plan materializes, and their solution is therefore a matter of some urgency.

Finally, a word should be said on leadership of the program presented here. The ability of federal agencies and their boards and committees to make wise decisions for implementing the plan depends critically on the quality of the scientist-administrators who hold posts of leadership. Their own scientific experience and ability should be sufficient to understand clearly the scientific impact of their decisions, and their judgment should be clear enough to realize at the same time that the basis for their decisions in cases of conflict is pragmatic, not scientific, that the goals that guide them are national or agency goals, not scientific ones. It is therefore of utmost importance that the Federal Government attract scientist-administrators of this type into agency service, 

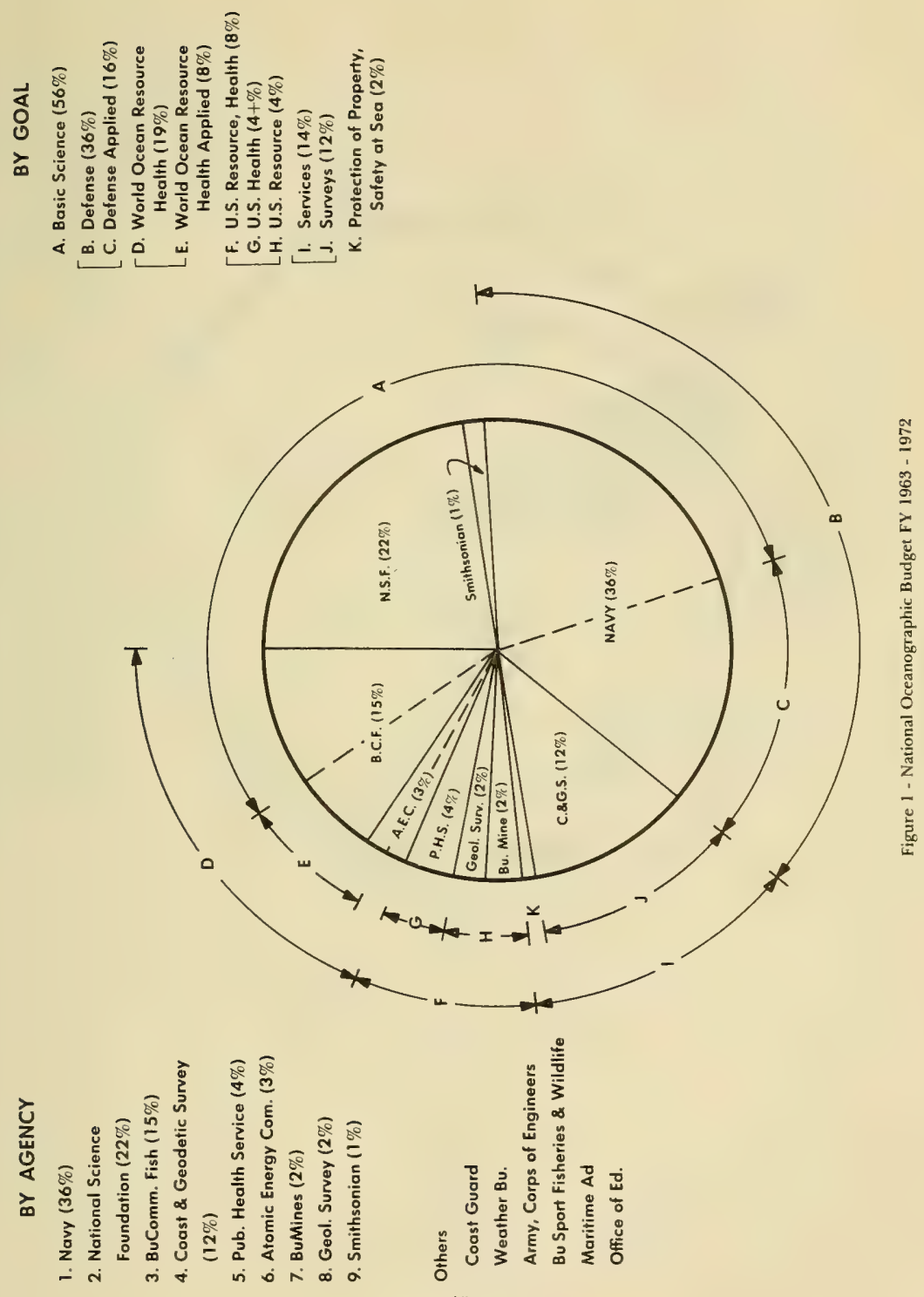


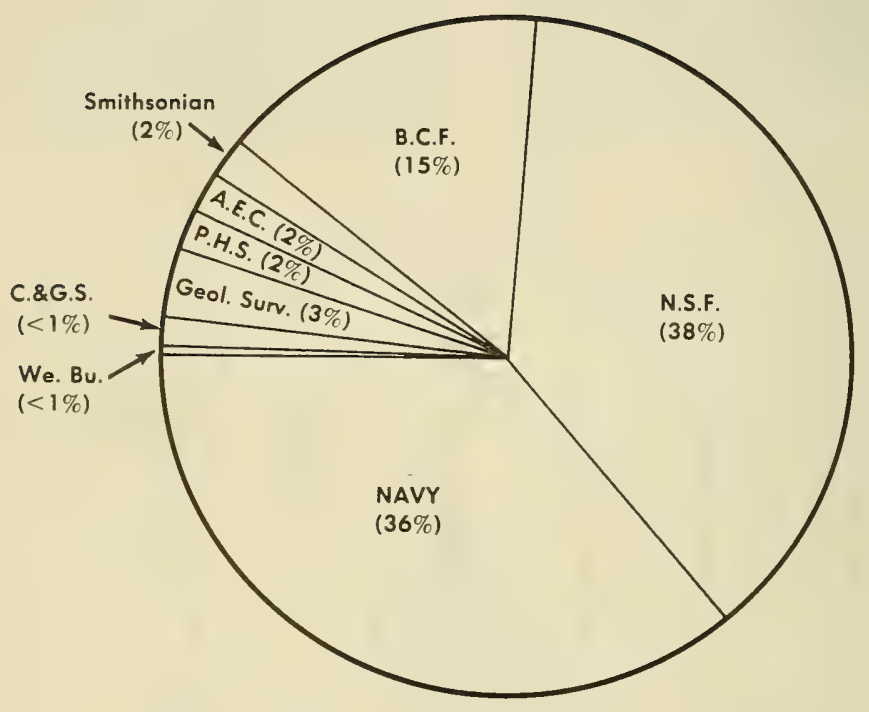

Figure 2 - Federal Support of Research 


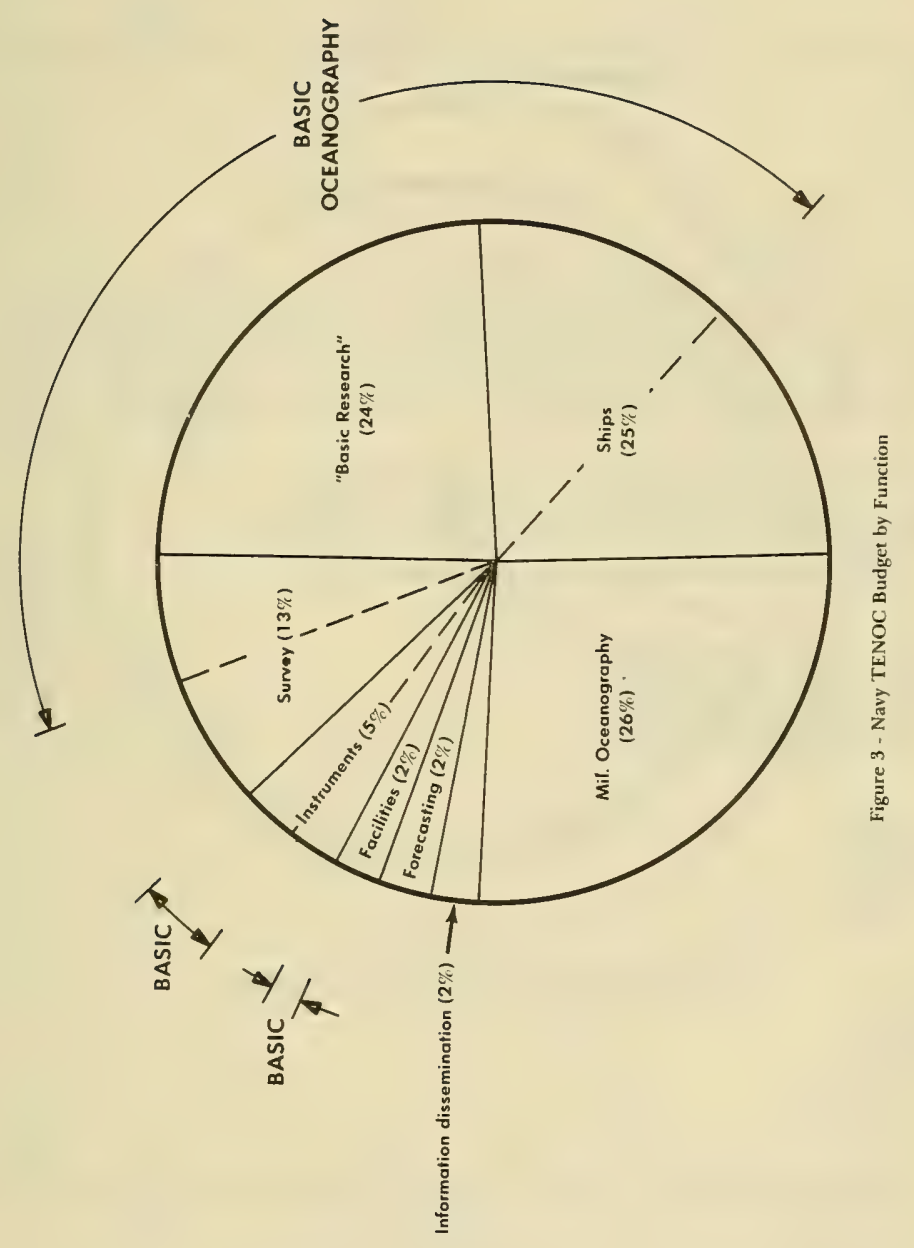




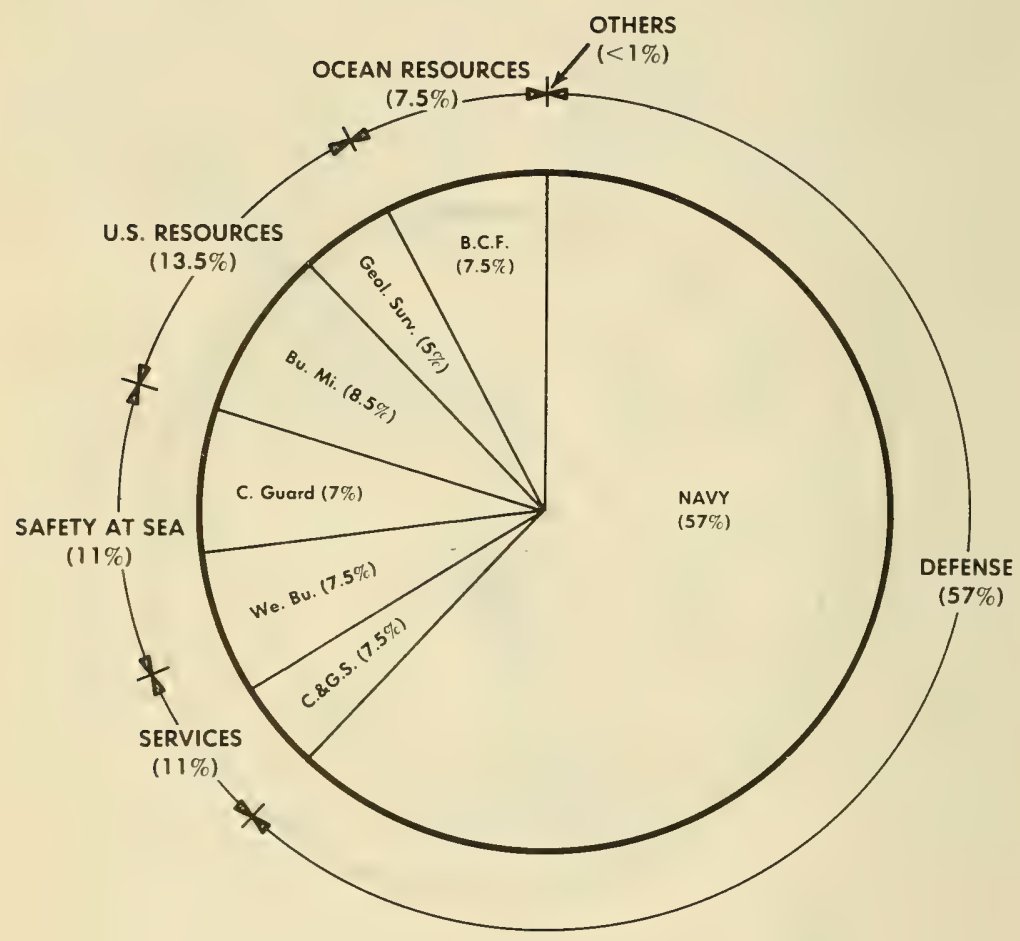

Figure 4 - National Instrumentation Budget, Comparative Years 


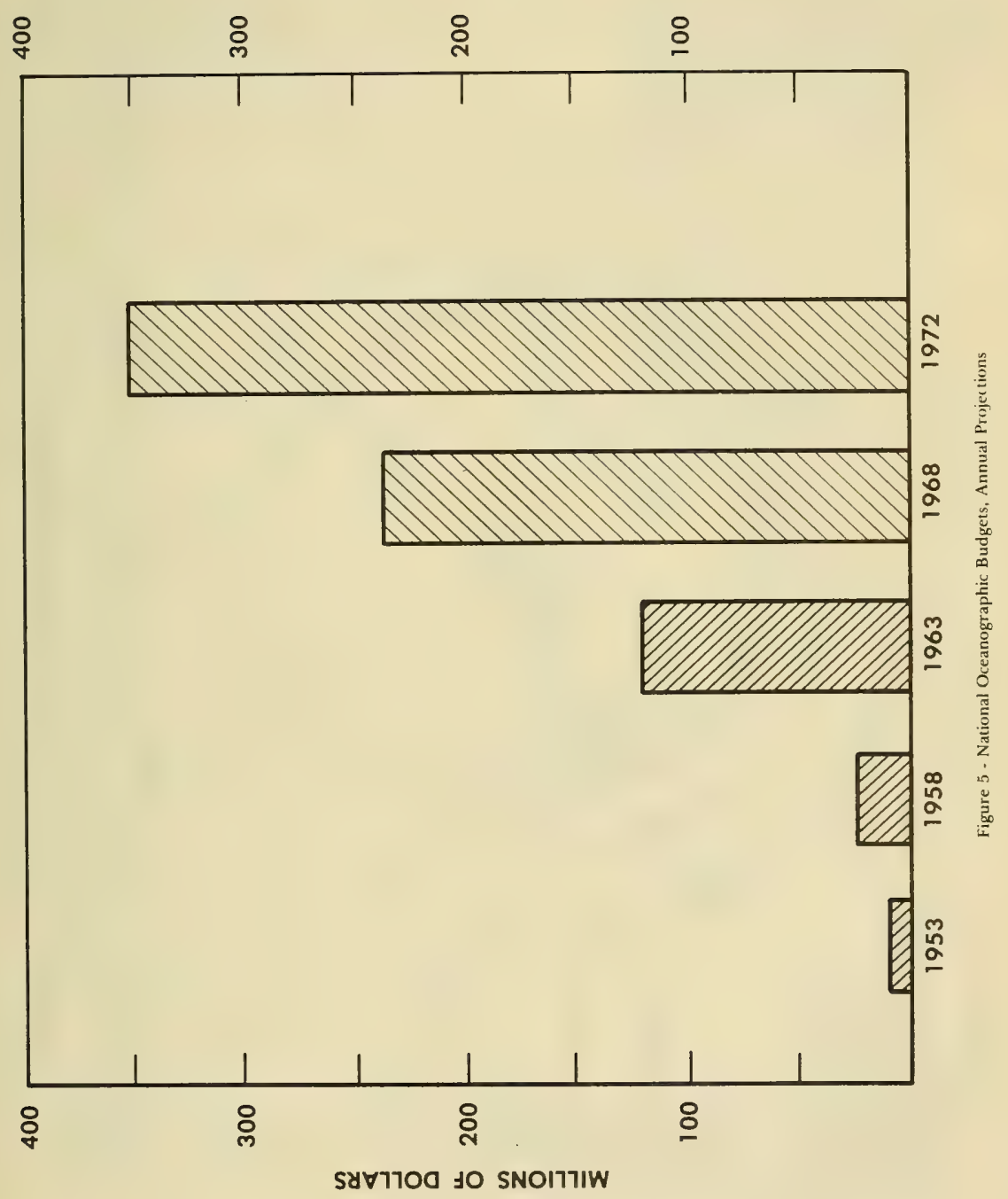




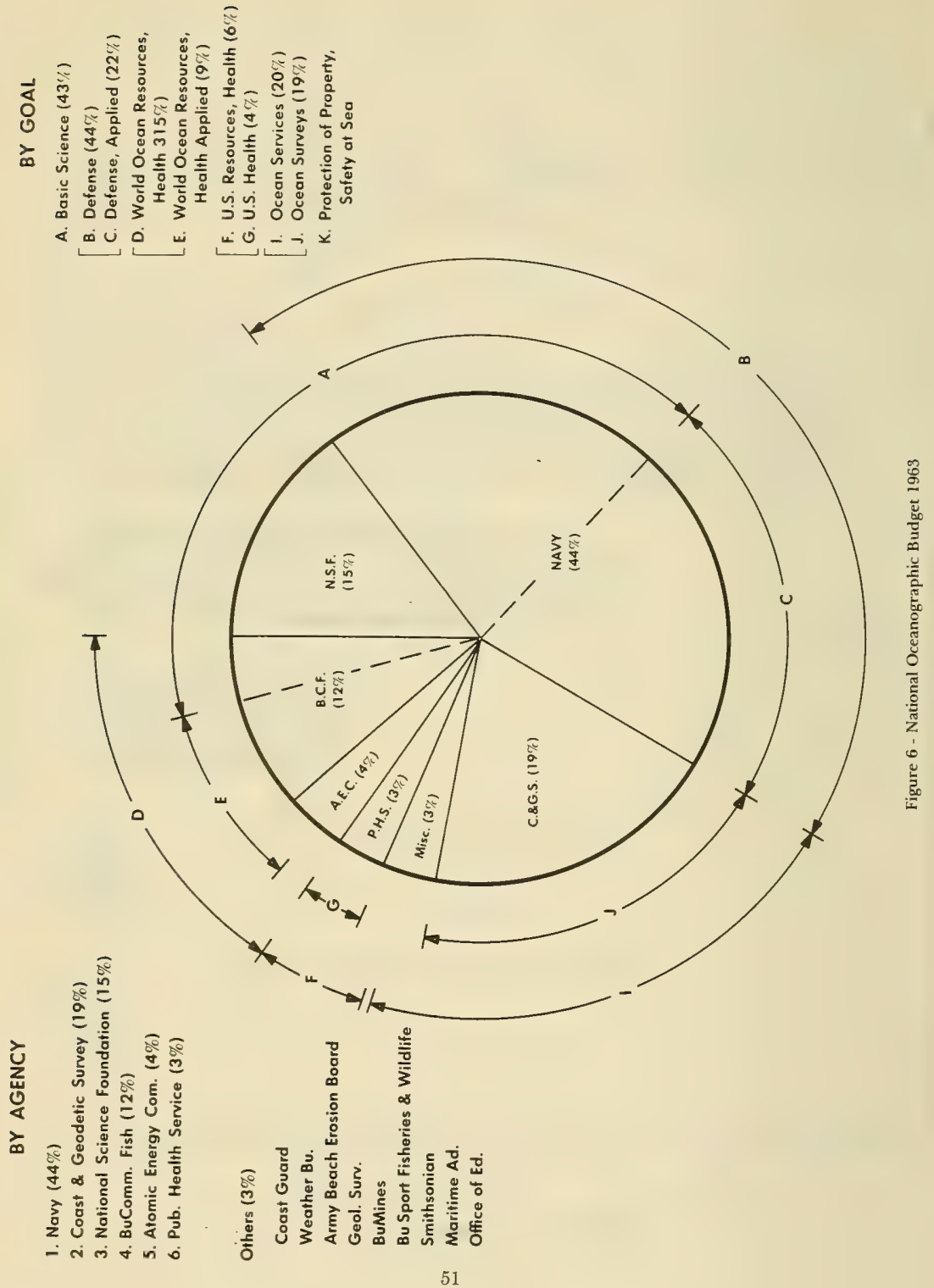




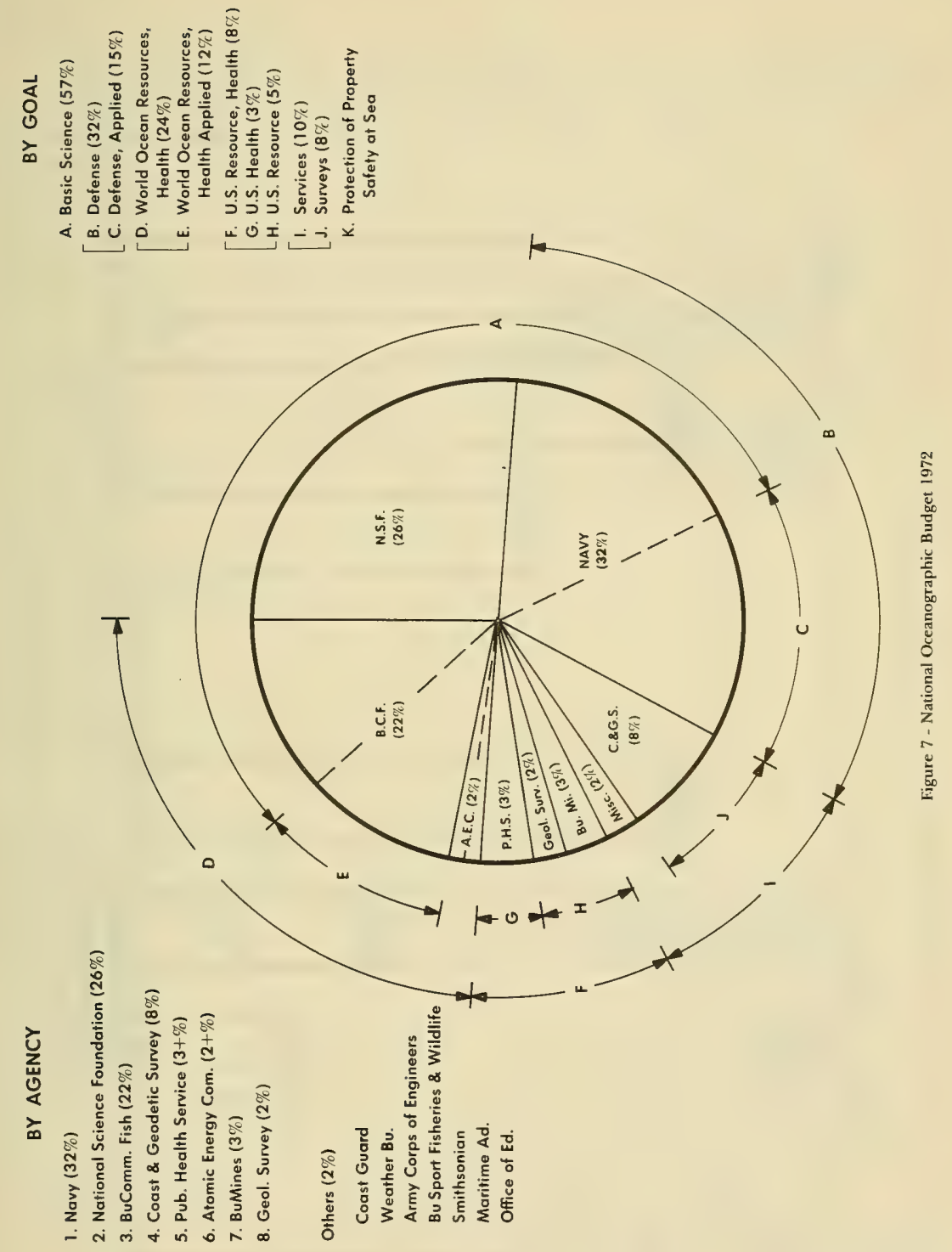




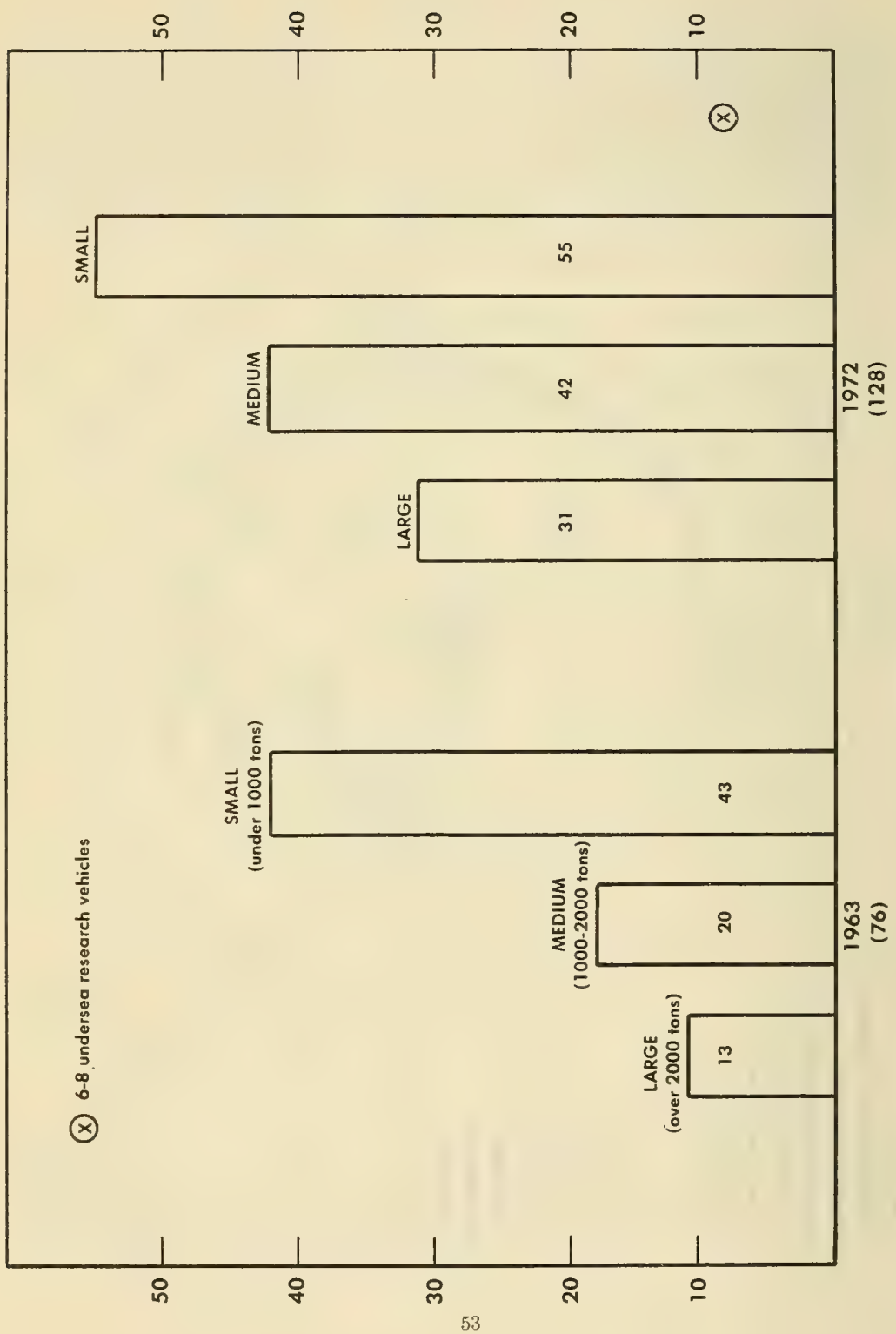




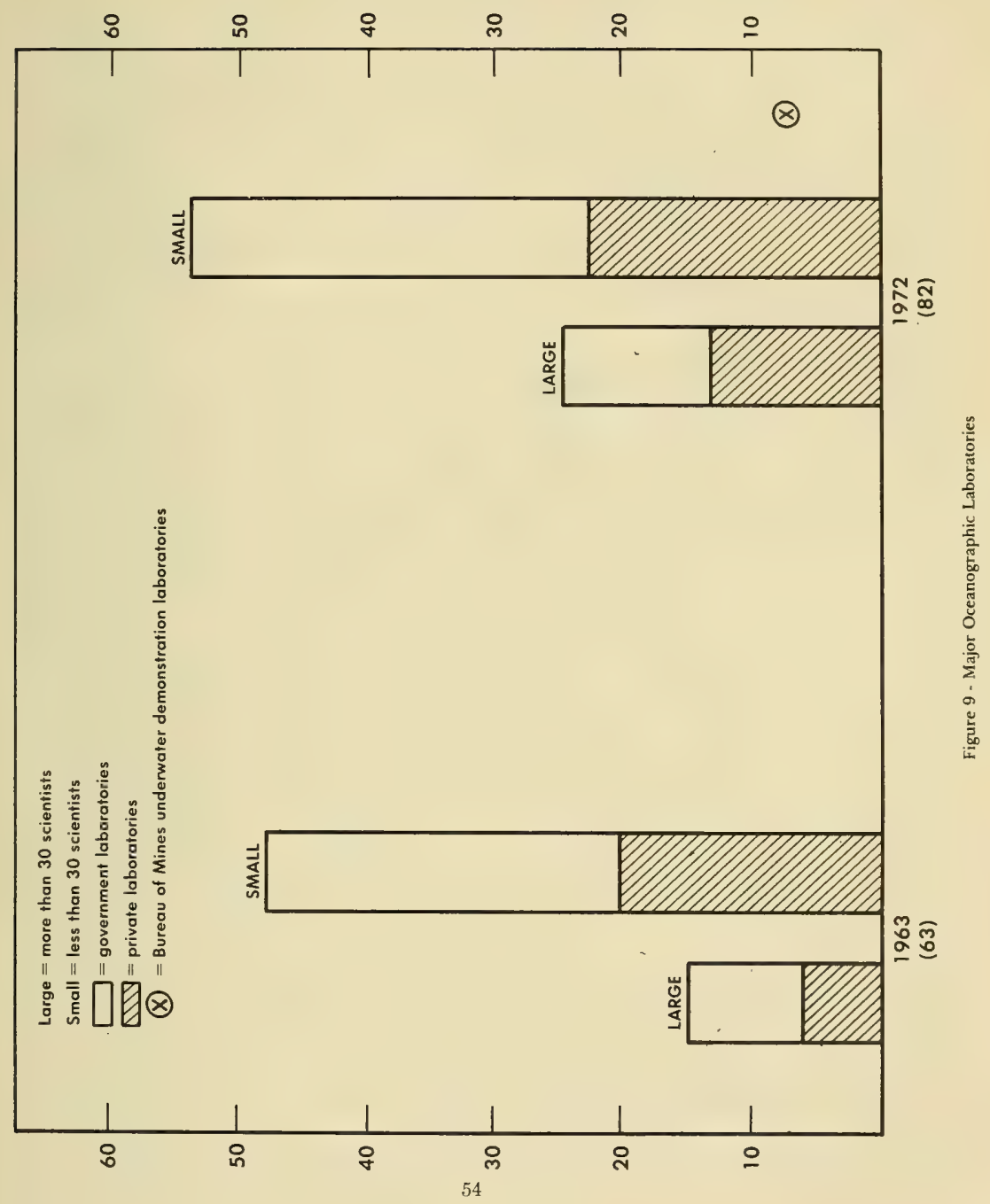



Appendix A

RECENT BUDGET SUMMARIES

NATIONAL OCEANOGRAPHIC PROGRAM 


\section{NATIONAL OCEANOGRAPHIC PROGRAM BUDGET}

(thousands)

FY 1960 FY 1961 $\quad$ FY $1962 \quad$ FY $1963 \quad \begin{gathered}\text { President's } \\ \text { Budget } \\ \text { FY 1964 }\end{gathered}$

A. BY AGENCIES

Defense

Commerce

Interior

National Science Foundation

Atomic Energy Commission

Health, Education, and Welfare

Treasury

Smithsonian Institution

$\begin{array}{rr}\$ 32,048 & \$ 31,615 \\ 6,202 & 11,400 \\ 6,703 & 8,658 \\ 7,833 & 7,883 \\ 1,708 & 1,691 \\ 340 & 694 \\ 134 & 133\end{array}$

$\$ 54,968$

$\$ 62,074$

$\$ 104,787$

$\$ 124,010$

$\$ 156,352$

B. BY FUNCTIONAL AREAS

$\begin{array}{lrrrrr}\text { Research } & \$ 26,577 & \$ 30,860 & \$ 39,023 & \$ 46,955 & \$ 62,565 \\ \text { Instrumentation } & * & 850 & 3,000 & 6,630 & 8,878 \\ \text { Ships } & 13,533 & 13,998 & 34,010 & 38,103 & 47,665 \\ \text { Surveys } & 13,368 & 14,900 & 17,366 & 18,487 & 20,228 \\ \text { IIOE } & & 760 & 1,974 & 4,002 & 5,854 \\ \text { Facilities } & 1,350 & 430 & 8,904 & 9,223 & 10,257 \\ \text { Data Center } & 140 & 276 & 510 & 610 & 905 \\ & & & & & \$ 156,352\end{array}$


INDIVIDUAL AGENCY BUDGETS

\begin{tabular}{|c|c|c|c|c|c|}
\hline Agency - Function & FY 1960 & FY 1961 & FY 1962 & FY 1963 & $\begin{array}{c}\text { President' } \\
\text { Budget } \\
\text { FY } 1964\end{array}$ \\
\hline DEFENSE - TOTAL & $\$ 32,048$ & $\$ 31,615$ & $\$ 42,081$ & $\$ 55,246$ & $\$ 74,966$ \\
\hline Navy - Total & 31,492 & 31,077 & 41,593 & 54,621 & 73,892 \\
\hline $\begin{array}{l}\text { Research } \\
\text { Instrumentation }\end{array}$ & 13,752 & 16,618 & $\begin{array}{r}15,692 \\
2,150\end{array}$ & $\begin{array}{r}19,559 \\
5,370\end{array}$ & $\begin{array}{r}25,295 \\
6,128\end{array}$ \\
\hline Ships Construction & 8,400 & 4,200 & 13,600 & 18,153 & 28,000 \\
\hline Surveys & 9,200 & 9,311 & 9,321 & 9,889 & 11,195 \\
\hline $11 O E$ & & 760 & 580 & 1,300 & 2,500 \\
\hline Facilities & & & & & 250 \\
\hline Data Center & 140 & 188 & 250 & 350 & 424 \\
\hline Army - Total & 454 & 435 & 488 & 625 & 1,074 \\
\hline Research & 454 & 435 & 488 & 625 & 1,074 \\
\hline COMMERCE - TOTAL -- & $\$ 6,202$ & $\$ 11,400$ & $\$ 23,567$ & $\$ 24,024$ & $\$ 24,792$ \\
\hline Coast \& Geodetic Survey - Total & 6,079 & 11,267 & 23,384 & 23,791 & 24,559 \\
\hline Research & 12 & 11 & 196 & 482 & 1,012 \\
\hline Instrumentation & & 850 & 850 & 890 & 1,190 \\
\hline Ship Construction & 2,033 & 4,700 & 14,185 & 14,400 & 13,000 \\
\hline Surveys & 4,034 & 5,446 & 7,911 & 7,667 & 7,980 \\
\hline IIOE & & & & & 200 \\
\hline Facilities & & 250 & 162 & 272 & 1,036 \\
\hline Data Center & & 10 & 80 & 80 & 141 \\
\hline Weather Bureau - Total & 123 & 133 & 133 & 183 & 183 \\
\hline Research & 123 & 123 & 123 & 173 & 173 \\
\hline Data Center & & 10 & 10 & 10 & 10 \\
\hline Maritime Administration - Total & & & 50 & 50 & 50 \\
\hline Research & & & 50 & 50 & 50 \\
\hline INTERIOR - TOTAL & $\$ 6,703$ & $\$ 8,658$ & $\$ 14,252$ & $\$ 16,102$ & $\$ 18,960$ \\
\hline BCF - Total & 6,303 & 8,069 & 13,619 & 15,320 & 16,900 \\
\hline $\begin{array}{l}\text { Research } \\
\text { Instrumentation }\end{array}$ & 6,003 & 5,874 & 7,409 & $\begin{array}{r}9,747 \\
70\end{array}$ & $\begin{array}{r}11,902 \\
223\end{array}$ \\
\hline Ship Construction & 100 & & 53,225 & 2,650 & 3,065 \\
\hline Surveys & & & & 20 & 125 \\
\hline IIOE & & & & 102 & 154 \\
\hline Facilities & 200 & 180 & 2,905 & 2,651 & 1,290 \\
\hline Data Center & & 10 & 80 & 80 & 141 \\
\hline Geological Survey - Total & $\$ 400$ & $\$ 425$ & $\$ 425$ & $\$ 494$ & $\$ 1,304$ \\
\hline Research & 400 & 425 & 425 & 474 & 520 \\
\hline Instrumentation & & & & 20 & 480 \\
\hline Surveys & & & & & 15 \\
\hline Facilities & & & & & 279 \\
\hline Data Center & & 57 & & & 10 \\
\hline
\end{tabular}


INDIVIDUAL AGENCY BUDGETS - (Contd)

\begin{tabular}{|c|c|c|c|c|c|}
\hline Agency - Function & FY 1960 & FY 1961 & FY 1962 & FY 1963 & $\begin{array}{l}\text { President's } \\
\text { Budget } \\
\text { FY } 1964\end{array}$ \\
\hline \multicolumn{6}{|c|}{ INTERIOR - TOTAL - (Contd) } \\
\hline BSF \& $\&$ - Total & & 154 & 158 & 238 & 344 \\
\hline Research & & 154 & 158 & 238 & 292 \\
\hline Facilities & & & & & 52 \\
\hline BuMines - Total & & 10 & 50 & 50 & 412 \\
\hline Research & & & 50 & 50 & 224 \\
\hline Instrumentation & & & & & 88 \\
\hline Ship Construction & & & & & 100 \\
\hline Surveys & & 10 & & & \\
\hline \multicolumn{6}{|l|}{ NATIONAL SCIENCE } \\
\hline FOUNDATION - TOTAL & $\$ 7,833$ & $\$ 7,883$ & $\$ 17,321$ & $\$ 18,160$ & $\$ 25,801$ \\
\hline Research & 3,683 & 4,742 & 7,010 & 8,080 & 11,860 \\
\hline Ship Construction & 3,000 & 3,093 & 3,000 & 2,900 & 3,500 \\
\hline IIOE & & & 1,394 & 2,600 & 3,000 \\
\hline Facilities & 1,150 & & 5,837 & 4,500 & 7,300 \\
\hline Data Center & & 48 & 80 & 80 & 141 \\
\hline \multicolumn{6}{|c|}{ ATOMIC ENERGY COMMISSION } \\
\hline TOTAL & $\$ 1,708$ & $\$ 1,691$ & $\$ 4,106$ & $\$ 5,428$ & $\$ 5,390$ \\
\hline Research & 1,708 & 1,681 & 4,096 & 5,418 & 5,312 \\
\hline Data Center & & 10 & 10 & 10 & 18 \\
\hline \multicolumn{6}{|l|}{ HEALTH EDUCATION \& } \\
\hline WELFARE - TOTAL & $\$ 340$ & $\$ 694$ & $\$ 3,109$ & $\$ 4,108$ & $\$ 4,820$ \\
\hline PHS - Total & 340 & 660 & 3,000 & 4,058 & 4,770 \\
\hline Research & 340 & 660 & 3,000 & 1,558 & 4,170 \\
\hline Surveys & & & & 700 & 600 \\
\hline Facilities & & & & 1,800 & \\
\hline Office of Education - Total & & 34 & 109 & 50 & 50 \\
\hline Research & & 34 & 109 & 50 & 50 \\
\hline TREASURY - TOTAL & $\$ 134$ & $\$ 133$ & $\$ 134$ & $\$ 511$. & $\$ 1,152$ \\
\hline Surveys & 134 & 133 & 134 & 211 & 313 \\
\hline Instrumentation & & & & 300 & 769 , \\
\hline Facilities & & & & & 50 \\
\hline Data Center & & & & & 20 \\
\hline SMITHSONIAN - TOTAL & & & $\$ 217$ & $\$ 431$ & 531 \\
\hline Research & & & 217 & 431 & 531 \\
\hline
\end{tabular}




\section{OFFICE OF SCIENCE AND TECHNOLOGY EXICUTIVE OFFICE BUILDING WASHINGTON, D. C. 20506}

July 26, 1963

Dear Mr. Speaker:

Recognizing the strong interest by the Congress in advaning this Nation's program in oceancgraphy, I am pleased to forward a new report of the Federal Council for Suience and Technology that provides a broad and Iong-range perspective for the development of an effective and expanding scientific study of the sea.

The report - "Oceanography: The Ten Years Anead" - embodies for the first time the coordinated plans for the decads 1963-1972 of the 20 Federal agencles whilh conduzt and sponsor oseanographis resear:h, included are a statements of research objectives, and projections of the funds, facilities and manpower needed for their aciomplishment. This plan thus reflects this Administration's dedication to a comprehensive program to understand the world ocean, its boundarles, its properties, and 1 ts processes - and to exploit this understanding in the publ1: interest for enhan:ement of our national defense; for improved protection and development of marine mineral and flsherles resources; for pollution control; for more accurate. prediction of storms and tides likely to endanger property or lives; and for extending silentific knowledge generally.

I should like also to call attention to the Government-wide sharacter of this program, by which responsibility for the achievement of these various national goals is reflected in existing statutory authority vested in a number of separate agencles. Through the Council's Interagenay Committee on Deanography that prepared this report, activities of some 20 agencles are planned ahead and planned together. Coordination is thus instituted to minimize gaps and unwiting duplication; to assure adequate depth, breadth and selected emphasis between different seators of the program, to permit sharing of ships and research failities, to foster cooperative training of oceanographic scientists; and to enhance comunication between Government and the non-Government scientists who fointly share the responsibilities for the conduct of this important program. 
This ten year plan represents the best judgment of the Federal Council as to size and priorities of programs consistent with national requirements. It also takes into account the compatlbility between funds, manpower and facilities. It has been aarefully reviewed by a number of outside consultants serving the Office of Sclence and Technology. But rather than an unalterable blueprint, this plan is more an outline - a statement of requirements in which context annual plans san be prepared. It will be supplemented by additional reports on special topies suin as manpower and instrumentation needs. The most recent annual report, "National Oeeanographic Program for FY 1964," and the first in a serles of special reports, "National Plan for Ocean Surveys," accompany this document.

Very little precedent exists for the preparation of long-range projections of sclentiflc programs, especially those which simultaneously cross numerous scientific disciplines as well as departmental lines. Elements of this program are contained in budgets of the separate agencies concerued, and are accordingly reviewed by separate Congressional appropriations subcommittees having jurlsdistion. Accordingly, those documents may prove valuable in meeting needs of the Congress in 1 ts evaluation of the President's oceanographic proposals for Fiscal Year 1964. These proposals may now be viewed as part of a long-range, unifled program, a program which in its sound growth w11l assure continued world leadership of the United States in oceanographic research.

\section{Sincerely,}

Jerome B. Wiesner

Encls

a. $/ 8$

Honorable John W. McCormack

Speaker of the House of Representatives

Washington, D. C. 


\section{APPENDIX 6}

NATIONAL OCEANOGRAPHIC PROGRAM-FISCAL YEAR 1964, SUBMITTED BY HON. JAMES H. WAKELIN, JR., ASSISTANT SECRETARY OF THE NAVY 



\title{
NATIONAL
}

OCEANOGRAPHIC PROGRAM

\section{FISCAL YEAR \\ 1964}

\author{
INTERAGENCY COMMITTEE ON OCEANOGRAPHY \\ of the
}

FEDERAL COUNCIL FOR SCIENCE AND TECHNOLOGY United States of America 
FEDERAL COUNCIL FOR SCIENCE AND TECHNOLOGY

JEROME B. WIESNER, Chairman OFFICE OF SCIENCE AND TECHNOLOGY

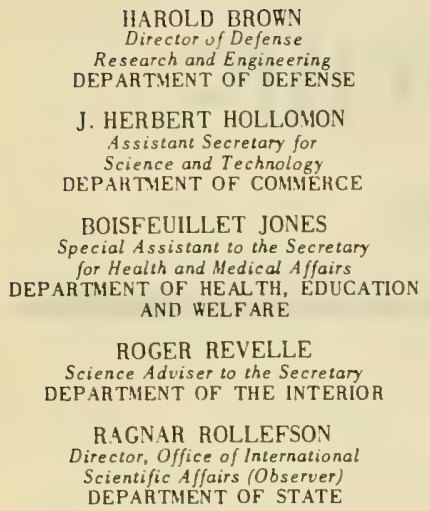

\author{
GLENN T. SEABORG \\ Chairman
ATOMIC ENERGY COMMISSION \\ ALAN T. WATERMAN \\ NATIONAL SCIENCE FOUNDATION \\ JAMES E. WEBB \\ Administrator \\ NATIONAL AERONAUTICS AND \\ SPACE ADMINISTRATION \\ WILLARD COCHRANE \\ Director, Agricultural Economics \\ DEPARTMENT OF AGRICULTURE \\ ELMER B. STAATS \\ Deputy Director \\ BUREAU OF THE BUDGET (Observer) \\ N. E. HALABY \\ Administrator \\ FEDERAL AVIATION AGENCY (Observer)
}

EDWARD WENK, JR.

Technical Assistant to the Director

OFFICE OF SCIENCE AND TECHNOLOGY

(Executive Secretary)

INTERAGENCY COMMITTEE ON OCEANOGRAPHY

JAMES H. WAKELIN, JR., Chairman

Assistant Secretary of the Navy

RADM. H. ARNOLD KARO

U.S. Coast and Geodetic Survey DEPARTMENT OF COMMERCE

DONALD L. McKERNAN

Bureau of Commercial Fisheries DEPARTMENT OF INTERIOR RADM. R. D. SCHMIDTMAN
U.S. Coast Guard DEPARTMENT OF THE TREASURY

\section{RAGNAR ROLLEFSON}

Office of International Scientific Affairs DEPARTMENT OF STATE
HARVE J. CARLSON NATIONAL SCIENCE FOUNDATION

$$
\begin{gathered}
\text { HARRY G. HANSON } \\
\text { Public Health Service } \\
\text { DEPARTMENT OF HEALTH, } \\
\text { EDUCATION AND WELFARE } \\
\text { JOHN N. WOLFE } \\
\text { ATOMIC ENERGY COMMISSION } \\
\text { I. E. WALLEN } \\
\text { Museum of Natural History } \\
\text { SMTHSONIAN INSTITUTION }
\end{gathered}
$$

\author{
ROBERT B. ABEL \\ Office of Naval Research \\ DEPARTMENT OF THE NAVY \\ (Secretary)
}




\section{FOREWORD}

The Federal Council for Science and Technology has given the Interagency Committee on Oceanography the assignment of planning and coordinating programs in the science of oceanography sponsored by government agencies. The principal assignment of the Committee is the annual preparation of the National Oceanographic Program. This document is a coordinated plan for the accomplishment of national goals while pursuing individual agency missions.

The National Oceanographic Program for fiscal year 1964 incorporates the Committee's best judgement as to balance and emphasis with respect to both long-term and short-term scientific requirements. The program is designed as a step in a series of annual plans beginning in 1960 and continuing into the future, through which the ultimate questions of marine investigation may be answered.

Copies of this document may be obtained from the Interagency Committee on Oceanography, Building T-3, 17th and Constitution Avenue, N. W., Washington 25, D. C. 
TABLE OF CONTENTS

$\underline{\text { Page }}$

I. INTRODUCTION 1

II. SUMMARY OF 1963 PROGRAM ACTIVITIES 1

III. NATIONAL OCEANOGRAPHIC PROGRAM, FISCAL YEAR 1964

A. Research 6

B. Instrumentation $\quad 12$

$\begin{array}{ll}\text { C. Ship Construction } & 15\end{array}$

$\begin{array}{ll}\text { D. Surveys } & 20\end{array}$

E. Manpower and Training 23

F. International Programs 24

G. Facilities 25

H. National Oceanographic Data Center 25

IV. CONCLUSION 27

V. BUDGET SUMMARIES 28

A. Summary of National Oceanographic Program Budget, by Federal Agency

B. Summary of National Oceanographic Program Budget, by Functional Area

C. Agency Program Summaries

APPENDICES

A. International Cooperative Investigation of the Tropical Atlantic

B. International Indian Ocean Expedition 


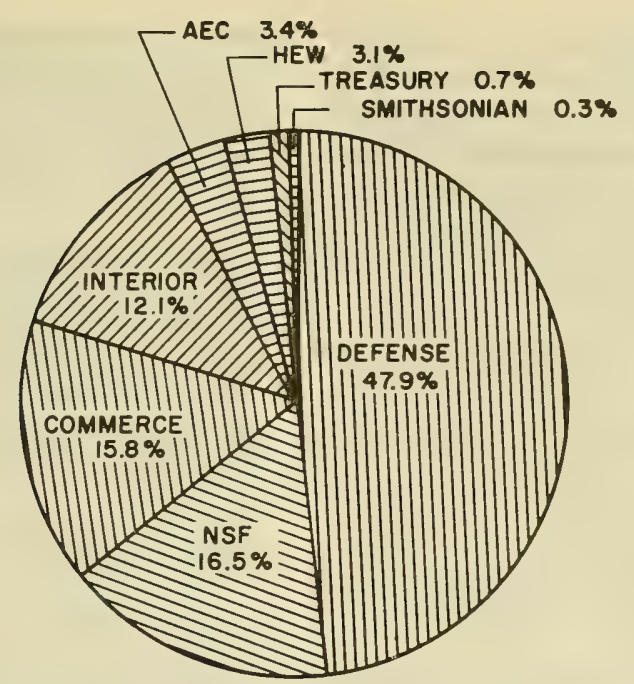

NATIONAL OCEANOGRAPHIC PROGRAM BUDGET PERCENTAGES BY AGENCY

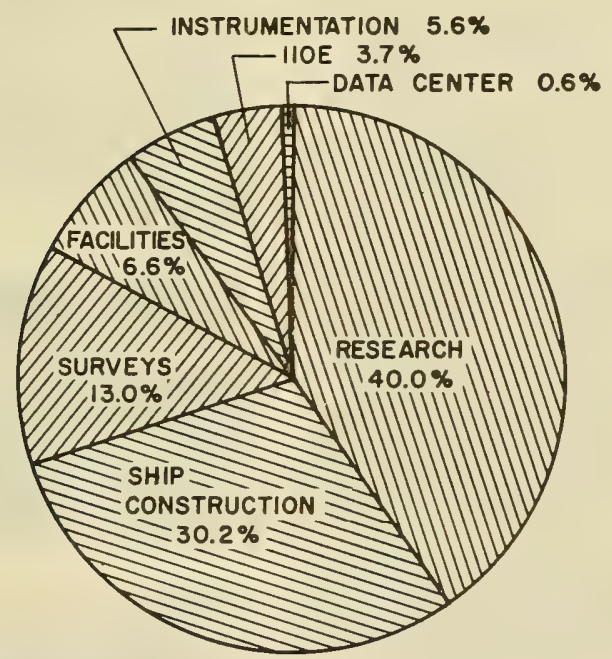

NATIONAL OCEANOGRAPHIC PROGRAM BUDGET PERCENTAGES BY FUNCTION 


\section{INTRODUCTION}

Executive order 10807 , promulgated by President Eisenhower in 1959, established the Federal Council for Science and Technology (FCST) to coordinate Federal support of science in the United States. The committee on Oceanography, originally a temporary subcommittee of the FCST standing committee, was made permanent in 1960, and in 1961 the FCST Chairman, Dr. Jerome B. Wiesner, affirmed the continuance of the ICO with the following mission:

To develop annually a national oceanographic program incorporating its judgement as to balance and emphasis in terms of both long range scientific needs and requirements of government agencies through the following mechanism:

a. Reviewing current activities and planned programs of individual agencies in the context of the government's overall long range effort.

b. Engaging in coordinated budget planning so as to recommend level of funding required for each fiscal year.

c. Considering special problems that may arise in implementing the National program, and recommended solutions therefore.

The FY 1964 National Oceanographic Program continues the necessary growth in this Nation's scientific activities related to the oceans. It is a growth' which has been stimulated by the President and by Congress through a number of pronouncements indicating that oceanography is an area of science which must be vigorously pursued in the national interest and for the benefit of all mankind.

The recommended program for FY 1964 amounts to $\$ 156$ million, an increase of 25.9 per cent over the $\$ 124$ million budgeted for FY 1963. The apportionment of funds by agency and functional area is depicted on the opposite page and detailed in the tables in part $V$ of this report. Significant expansion in all areas has been programmed, with the largest increments in research and ship construction. Although each of the functional areas is described in detail in the pages that follow, certain features of the program deserve mention here.

The shortage in scientific manpower needed to conduct an expanding program in oceanography effectively has been a matter of concern for several years. Results from the ICO Manpower Study now underway indicate a need for substantially greater numbers of physical oceanographers. There is evidence, however, that scientists trained in other disciplines are turning to oceanography in numbers which will permit the growth of the marine sciences to the level planned for FY 1964. This does not suggest that the increasing numbers of scientists and technicians required for future oceanographic research will be supplied without intelligent plānning and vigorous support.

Very significant logistics elements have been incorporated into the FY 1964 National Oceanographic Program. In the area of research the agencies have increased training programs, both for their own personnel and for full time graduate students. The program in facilities will not only contribute to increased performance and training within agency boundaries, but will provide for university and institutional research facilities beyond the minimum recommendations made by the National Academy of Sciences Committee on Oceanography (NASCO) in its report to the President's Science Advisor in August 1961.

Also of significance in FY 1964, is the growing participation of the United States in international marine science programs. As a major participant in the Intergovernmental Oceanographic Commission (IOC), this Nation must maintain the necessary leadership to insure an effective coordinated international effort. The FY 1963 program described our contributions to the International Indian Ocean Expedition (IIOE). This effort continues in FY 1964. The IOC-Sponsored International Cooperative Investigations of the Tropical Atlantic, conceived, planned, and coordinated by the U.S., is well under way. The vastness of the oceans and their prospective resources clearly indicates the necessity for such international cooperation.

\section{SUMMARY OF FISCAL 1963 PROGRAM ACTIVITIES}

During the fiscal year 1963, the National Oceanographic Program is being implemented over a broad front. Notable are the extent and variety of cooperative national and international research and survey cruises, the launching of new research vessels, and the establishment of a center for calibrating and testing instrumentation by the Naval Oceanographic Office.

\section{Research}

Among the research cruises undertaken by member agencies are investigations of the Marianas Trench complex, the Drake Passage 
area, the Argentine Basin, the Labrador Sea, the Atlantic and Pacific Equatorial undercurrents, the Mediterranean circulation, the Oyashio current, and many other open ocean and coastal features. These studies embrace the physical, chemical, and biological characteristics of these water masses in addition to bottom topography and geology.

New fishery resources have been identified in several areas. Commercial quantities of fish and shellfish have been found to occur at depths of at least 600 fathoms off the Columbia River. This is about three times the depth at which present commercial operations are carried out. Immense scallop beds discovered off the East Coast of Florida are considered to have great commercial potential. Exploitation of new fisheries off the Alaskan Coast was begun during the year.

The application of blood typing to fisheries research revealed important information about the stocks from which certain Pacific fishes are derived. Studies showed that stocks of Northern Pacific albacore are genetically isolated from those of the Southern Hemisphere. Sardines in the Gulf of Baja California were found to be genetically distinct from those off the Coast of Southern California. During the next few years blood typing may pave the way for significant advancement of our knowledge of fish derivations and behavior.

Experiments conducted with skipjack tuna in experimental ponds showed that they recognize and respond to underwater sound. A specific olfactory response was also demonstrated in tuna.

\section{Instrumentation}

One of the highlights of 1963 was the opening of the Naval Oceanographic Office's new Instrumentation Test and Calibration Center at the Navy Yard Annex in Washington. The latest electronic and mechanical equipment has been assembled in excellent laboratory accommodations which, when fully staffed and equipped, will provide the finest developmental, testing, evaluation, and standardized calibration capabilities available. Extensive shop facilities for model building, modification, and repair have also been provided.

The Oceanographic Office has staffed the center with experts in all fields of instrumentation and plans to contribute to research and development of new instrumentation in addition to the center's other missions. The ICO is studying the operation of the new Center as a model for the proposed National Instrumentation Test and Calibration Centers to be established on the East and West coasts of the United States.

Contracts for the development of packaged oceanographic instrumentation systems have been awarded by the Naval Oceanographic Office in cooperation with other ICO agencies. These systems will provide automatic measurement and recording of a wide variety of oceanographic data in a single easily installed and serviced unit. Small systems for placement on merchant vessels and other ships of opportunity will be included in this program.

The testing of buoy systems was continued by member agencies during calendar year 1962 . planning for an oceanographic satellite to monitor buoy stations and make direct oceanographic measurements was begun during the year.

The Bureau of Commercial Fisheries has established an oceanographic instrumentation shop to conduct its new instrumentation program and to coordinate with the Oceanographic Office Instrumentation Center. A general purpose automatic fish counter is being completed and a contract has been given the University of Washington for work on a semi-automatic fish scale reader. The perfected instruments will be directly applicable to projects under sponsorship of the Bureau of Sport Fisheries, Atomic Energy Commission, Office of Naval Research, and National Science Foundation.

The Geological Survey developed a sediment fractionator providing continuous graphical data readout for direct computer analysis. The Survey has also contracted for development of a transistorized probe for measuring $\mathrm{pH}$, dissolved oxygen, temperature, turbidity, and other parameters. The contractor has successfully completed initial testing and the final tests are underway. This development is being reviewed with interest by at least fifteen agencies as integral to oceanographic field work of all kinds.

Instruments on which development has been carried out during the year by the coast and Geodetic Survey include: a hydrographic digital recording system, a narrow-beam stabilized transducer for deep ocean echo sounding, precision navigation equipment, an oceanographic multisensor system, a deep sea underwater stabilized platform for magnetics, and improvements in the existing tsunami warning system. Successful accomplishment of development of any of these will materially reinforce programs underway in Defense, Interior, $\mathrm{AEC}, \mathrm{HEW}$, and NSF. 
The Coast Guard began instrumenting its first ocean station vessel in a program which will eventually provide all ocean stations with an oceanographic capability, which will be used to provide field assistance to government agencies, university laboratories, and industrial programs.

\section{Facilities}

Last year funds were approved for construction of a new $\$ 2-1 / 4$ million oceanographic laboratory in Seattle for the Bureau of Commerical Fisheries. The Bureau's Beaufort, North Carolina, facility was expanded by construction of a Radiobiological laboratory.

The Coast and Geodetic Survey accomplished the third step in its five year program for improving and expanding its Norfolk Ship Base, and construction of an oceanographic laboratory, research facility, and ships' base at Seattle has commenced. Through the support of the National Science Foundation, the University of Washington, Oregon State University, Johns Hopkins University, and the Woods Hole Oceanographic Institution have commenced construction of laboratories which will greatly enhance their training and research capabilities.

\section{Manpower and Training}

The Manpower and Training Panel of the Interagency Committee on Oceanography is completing its report to the ICO on the present status of training and the availability of scientific manpower. This report will be submitted by the ICO to the FCST as part of the ICO series and will include recommendations for means of expanding training in categories in which shortages exist or are anticipated.

\section{International Programs}

The United States formally participated as a full member in several activities of the Intergovernmental Oceanographic Commission during calendar year 1962. Included were representation at the Bureau meeting of the Commission in April, 1962 and the meeting of the full Commission in September. In addition, the United States was host to two International Oceanographic Commission Working Group meetings at the National Oceanographic Data Center, Washington, D. C. One meeting concerned the International Cooperative Investigations of the Tropical Atlantic, a program which was formally proposed to the Commission by the U. S. at the April Bureau meeting. The other was a meeting of the Working Group on Data Exchange. The U. S. also sent representatives to working group meetings in Paris on Fixed Oceanographic Stations and Communications.

At the Intergovernmental Oceanographic Commission meeting in Paris, a number of resolutions of significance for international programs in oceanography were adopted. The Commission passed a resolution requesting its advisory bodies to draw up a general scientific framework for conducting a comprehensive study of the world ocean. Such a study would include programs similar to the International Indian Ocean Expedition, International Cooperative Investigations of the Tropical Atlantic, and the Dynamic Study of the Northern Oceans. Both the IIOE and ICITA were made official programs of the Commission at this meeting. The Commission suggested that the Soviet proposal for the Dynamic Study of the Northern Oceans be implemented in a series of stages such as those proposed in the Tropical Atlantic studies. Resolutions were passed concerning fixed oceanographic stations, the legal status of buoys, and the problem of alloting radio frequencies for oceanographic communications.

The Commission also requested its advisory bodies to arrange for national and international intercalibration of instruments and standardization of techniques, and to arrange for symposia on the results. In addition, the Commission explored the possibility of holding a Second International Oceanographic Congress at an early date, perhaps during 1964 or 1965. Dr. William Cameron of Canada was reelected Chairman of the Commission, with Vice Admiral Tchekourov of the USSR and Captain Capurro of Argentina as Vice Chairmen.

A meeting on Inter-American cooperation in oceanography, jointly sponsored by the $\mathrm{Na}$ tional Academy of Sciences and the Office of Naval Research, was held in November 1962 in Miami. This meeting explored possible cooperation on programs which are too extensive to be accomplished by a single nation. The problem that appeared to be common to most countries was the need for stimulating the education and training of new oceanographers. Several cooperative programs for achieving this end were proposed and will probably be initiated in the near future.

United States participation in the International Cooperative Investigation of the Tropical Atlantic and in the International Indian Ocean Expedition during 1963 is described in appendices $\mathrm{A}$ and $\mathrm{B}$ to this report. 


\section{Ship Construction}

During the past year construction was completed on five new research vessels. These ships represent the first specially designed research craft added to the nation's oceanographic fleet since construction of the R/V Atlantis in 1931 . The gain in efficiency, capacity, habitability, and productivity from use of such ships, rather than converting older vessels for research, will greatly augment our research capability.

Three of the new ships, the CONRAD, GILLIS, and DAVIS, are AGOR's, constructed with Navy funds according to specifications and design developed by the Navy's Bureau of Ships. The CONRAD will be operated by the Lamont Geophysical Observatory in pursuance of its research activities. The GILLIS and DAVIS will be operated by Navy research laboratories on a cooperative basis.

The new ALBATROSS IV is a 1000 ton biological research vessel with capability for both fishery research and general oceanography. It will be employed by the Bureau of Commercial Fisheries' Woods Hole Laboratory in studies of the distribution and abundance of ground fishes in the western North Atlantic in relation to environmental factors, and to determine the effects of domestic and foreign fishing on fish stocks.

The Woods Hole Oceanographic Institution received the new research vessel, ATLANTIS II, to replace the famous sailing vessel it has had in service for the past 31 years. ATLANTIS II is a 2100 ton ship with spacious laboratory and living accommodations.

The addition to the research vessels, two new survey ships, the PEIRCE AND WHITING, were delivered to the Coast and Geodetic Survey. These 760 ton ships are designed for both hydrographic and oceanographic surveys, and replace two obsolete vessels.

All the new vessels are equipped with the latest and best equipment for their assigned tasks. In addition to the conventional instrucmentation, winches, etc., they incorporate such features as underwater viewing ports, center wells, underwater television equipment, bow thrusters, and other significant improvements over previous designs.

Surveys

Survey activity was again marked by extension of the degree of coordination among the agencies with survey interests.

\section{Naval Oceanographic Office \\ (unclassified surveys)}

During FY-1963, hydrographic surveys were conducted in the Gulf of Siam (USS MAURY), Equatorial Pacific (USS REHOBOTH), NE Providence Channel (USS SHELDRAKE), and a joint US-Icelandic survey of FaxaFloi. A survey in the vicinity of Key West will be accomolished this year (USS TANNER). Oceanographic survey. were conducted in the Arctic aboard U. S. Navy and U. S. Coast Guard icebreakers. Oceanographic, hydrographic, and geophysical data were collected. In addition, the Office now is participating in the I.I.O.E. aboard the USS SERRANO (AGS-24). On this survey, most of the effort will be devoted to collecting oceanographic information, including bathymetric data which will be taken concurrently. Aeromagnetic surveys have provided or will provide complete vector magnetic data along approximately 160,000 nautical miles of survey track throughout the world. Surface ship surveys have produced approximately 40,000 line miles of total magnetic intensity data. Geodetic observations included eight 1st-order Astro stations in the SW Pacific; positions of satellite tracking stations in the Philippines, Samoa, Japan, and Brazil; and location of monitoring sites for the East Coast Loran-C network.

\section{Coast and Geodetic Survey}

Fourteen USC\&GS ships conducted hydrographic surveys in the Chukchi Sea, Southeastern Alaska, Gulf of Mexico, Puerto Rico, Straits of Florida, in the mid-AtIantic States coastal areas (special resurveys following large scale coastal damage from a severe storm in March 1962), and in the Gulf of Maine. Intensive oceanographic surveys were conducted from three ships in the North Pacific, and tropical Atlantic. The PIONEER in the first half of FY-1963, and the PIONEER and SURVEYOR in the last half devoted all their time at sea to the Ocean Survey Program.

Survey facilities and technology were markedly advanced through expansion of shipboard laboratory facilities, installation of deepsea anchor winch systems on two major ships, and procurement or development of numerous new survey instruments. Among these were the development of an acoustic probe for continuous sub-bottom profiles, a gas chromotography system for dissolved oxygen analysis, new improved shipboard salinometers, and underway current measuring equipment. 
Two N-S sections from the Hawaiian to Aleutian Islands were conducted synoptically in late Fiscal Year 1963, continuing a time series of deep oceanographic stations across this key oceanic basin fróm 1961 and 1962. Visiting scientists from U. S. Geological Survey, U. S. Weather Bureau, University of Hawaii, Institute fur Meereskunde (Kiel), and New York University, actively participated in the survey program.

\section{Coast Guard}

Continuing the International Ice Patrol surveys, the Coast Guard, using the USCGC EVERGREEN, conducted four surveys of the Grand Banks and Labrador Sea and one postseason survey of Davis Strait. A total of 438 oceanographic stations were occupied. During the course of the Coast Guard's annual Bering Sea Patrol, USGGC NORTHWIND conducted surveys in the western and northern Bering, Chukchi, and East Siberian Seas. A total of 247 oceanographic stations were occupied.

In fulfillment of its FY-63 commitment, the Coast Guard commenced oceanographic observations from U. S. Ocean Stations with the outfitting of USCGC CASCO with an oceanographic winch and laboratory. CASCO is serving as a pilot installation and is making regular timeseries as a regular part of cruises to stations ECHO and DELTA.

\section{Bureau of Commercial Fisheries}

The principal survey activities of the Bureau of Commercial Fisheries in FY 1963 were in the planning of the International Cooperative Investigations of the Tropical Atlantic (ICITA). A Working Group Meeting, sponsored by the IOC, was held in Washington, D. C., in June 1962 to coordinate and develop detailed plans for the Investigations. Nomination of Mr. V. E. Brock of the Bureau of Commercial Fisheries as International Coordinator for ICITA was approved by the Secretariat of the IOC. The plans for ICITA, as developed at the Working Group Meeting, are given in the appendix to this report. Considerable effort and funds were expended by the Bureau in the conversion of the GERONIMO (760 tons) for use in the Tropical Atlantic Investigations. Preliminary planning continued on a detailed study of the oceanography of the Trade Wind Zone of the central Pacific.

\section{Weather Bureau}

The Weather Bureau's survey operations consisted of having meteorological technicians making observations from seven ships in all three oceans. The ships, areas of operation, and observational programs are tabulated below:

Ship

Region Programs

PIONEER

North

ELTANIN

Antarctica

(1), (2), (4)

EXPLORER

Tropical

(1), (2), (5)

CHAIN

Tropical

GERONIMO

Tropical Atlantic

CONRAD

Indian Ocean

(1), (2), (3), (6)

ANTON BRUUN Indian Ocean (1), (2), (3), (6)

(1) Surface observations, (2) Upper-air observations, (3) Surface wind stress; (4) Surface ozone concentration, (5) Infra-red surface radiation observations, (6) Rainfall.

\section{NATIONAL OCEANOGRAPHIC PRO- GRAM, FISCAL YEAR 1964}

The National Oceanographic Program budget recommended for Fiscal Year 1964 is $\$ 156,352,000$, an increase of $\$ 32$ million over that of the present fiscal year. The program budgets are described in detail within each functional area (sections a through $\mathrm{h}$ ), and summarized in the tables in section $\mathrm{V}$.

Although considerable increases have been effected in ship construction and research support, a significant portion of the increase in research funds will be required to support the operations of new research ships coming down the line. The Long Range National Oceanographic Plan, now nearing completion, brings into focus the ever increasing demand upon research funds created by the conversion and new construction of oceanographic research vessels.

The major accomplishment of the Long Range Plan will be the setting forth of national long range goals in oceanography toward the attainment of which each succeeding annual program can be developed in a logical manner.

In the area of manpower, a new edition of the extremely successful catalog, College 
Curricula in Oceanography, and a comprehensive Bibliography of Oceanographic Publications will be issued and should contribute materially toward motivation and indoctrination of young students.

The following sections present in some detail the further effort by the ICO to coordinate the National Oceanographic Program.

\section{A. RESEARCH}

Oceanographic research programs, in general, are of a continuing nature requiring many years to solve satisfactorily the problems involved. The publication, Oceanographic Research in the Federal Government, prepared by the Interagency Committee on Oceanography (ICO pamphlet \#5) for FY 1963, presented a detailed report of agency research efforts. The report which follows describes how the FY 1963 efforts will be modified by the FY 1964 program in light of the expected scientific and technological advances. In order that each year's research programs may be compared conveniently, the program will be presented in terms of five research objectives. In addition to identifying the research to be emphasized during this period, finding information is provided in terms of the increase in agency budgets between FY 1963 and FY 1964. These budget differences are general guidelines in the magnitude of the new programs in relation to the continuing efforts.

In FY 1964 the Research Program will increase by $\$ 15.5$ million to a total of $\$ 62.6$ million. Much of this increase has been programmed to provide for the tools and other support required to conduct research. During this period, the Navy will have in its program for the first time four new applied research vessels, and the Bureau of Commercial Fisheries will be operating two. This type of increase is expected to continue during the next several years as the oceanographic fleet is expanded.

In reviewing the research budget it will be noted that one of the largest increases in funds has been programmed for objective three, the exploitation of the living resources of the sea. The results of research in this area of oceanography represent the most readily apparent application of research efforts in support of national and international programs for the benefit of mankind. Among the many contributing projects, emphasis will be placed on synoptic oceanography and productivity studies in high seas areas to determine fishery potentials, basic work in experimental marine biology and taxonomy, and instrument development programs to improve apparatus for sampling and studying marine organisms.

OBJECTIVE ONE - TO describe the distribution of physical and chemical properties of the oceans and to understand the dynamic processes which affect this distribution.

\section{DEPARTMENT OF DEFENSE}

\section{Department of the Navy}

Office of Naval Research. A large part of the increase in the Office of Naval Research (ONR) oceanographic budget will be focused upon this objective. ONR will sponsor work in the tropical Atlantic to be undertaken by the Woods Hole Oceanographic Institutions, University of Rhode Island, New York University, Johns Hopkins University, Agricultural \& Mechanical College of Texas, and the University of Miami. At three of these laboratories there will be new or newly converted research ships for which increased funding will be required. These are the ATLANTIS II at Woods Hole and the two converted FS'S at the University of Rhode Island and Texas A\&M.

A concerted effort will be undertaken to understand the scale of water movement in the North Atlantic and its variations over a period of time both from the analytical and experimental standpoints. The experimental work will be performed primarily through use of a system of anchored buoys which measure ocean currents and other pertinent parameters.

Similar observations of currents, in particular the equatorial circulation, will be carried out in programs supporting the International Indian Ocean Expedition. A somewhat increased effort over that of FY 1963 is anticipated in this region, which will include an $\mathrm{R} 5 \mathrm{D}$ aircraft to work with meteorologists and oceanographers, enabling them to correlate conditions in the atmosphere with investigations of the ocean. An increased effort in the investigation of the physical and chemical properties of limited areas of the ocean, with emphasis on environmental effects in anti-submarine warfare operations, will also be undertaken.

Naval Oceanographic Office. The Oceanographic Office will accelerate its programs for investigating the physical and chemical properties of the sea. These programs will be oriented toward greater understanding of the dynamics of 
the ocean, especially turbulence, in order to enhance the office's forecasting capability.

Bureau of Ships. The Bureau of Ships program at the Navy Electronics Laboratory (NEL), investigating the effects of physical and chemical properties of the ocean on sound transmission, will be markedly increased. This will, in part, result from the fact that NEL will have the new research vessel, DAVIS, to assist in their program. The combination of a broadened program and the operating costs of the new ship will account for a large part of the increase in the Bureau of Ships oceanographic research budget.

\section{Department of the Army}

Beach Erosion Board, Corps of Engineers. The Beach Erosion Board plans to increase its studies of tidal flow. This will include laboratory studies on the tidal prism, the effect of waves on tides, and other problems of the dynamics of confined bodies of water. The results of laboratory and analytical studies will be tested on successively larger models, and will include field work in small, medium, and large bodies of water. The Indian River Inlet, in Delaware, will be one of the areas selected for intensive investigation. A complementary study of the flushing of estuaries will be made in connection with the above investigations.

\section{DEPARTMENT OF COMMERCE}

Coast and Geodetic Survey. The Coast and Geodetic Survey will triple its effort in the following areas which contribute to Objective One:

a. Increased tsunami research to take advantage of technological and theoretical advances.

b. An assualt on the basic problem of measuring water motion.

c. The development of techniques for handling and processing data aboard ship.

d. Initiation of a program for providing a network of buoys encircling the continent.

Weather Bureau. Studies of coastal flooding related to storm conditions will be continued.

\section{DEPARTMENT OF THE INTERIOR}

Bureau of Commerical Fisheries. Major increases in the Bureau of Commercial
Fisheries FY 1964 program will be devoted to participation in the International Cooperative Investigations of the Tropical Atlantic and to synoptic studies of the trade wind zone of the central Pacific. Lesser amounts are being requested to start planning and preparation for participation in a cooperative research program in the eastern Pacific (EASTROPAC), and to expand Bureau activities in the International Indian Ocean Expedition.

Geological Survey. During FY 1964, the Geological Survey will initiate studies on the influence of fresh-water discharge from the continent into tidal bays, estuaries, and on the Continental Shelf.

\section{NATIONAL SCIENCE FOUNDATION}

Investigations of the dynamic properties of the ocean will be accelerated through support from the National Science Foundation. These will include expanded efforts in the International Indian Ocean Expedition and in the joint East Coast laboratories program to study the circulation and turbulence of the North Atlantic. A continuing and expanding program of Antarctic oceanography will be conducted aboard the USNS ELTANIN.

OBJECTIVE TWO - To increase knowledge of interactions between sea and atmosphere.

\section{DEPARTMENT OF DEFENSE}

\section{Department of the Navy}

Office of Naval Research. The program of moored buoy and tower observations of wave properties in the Gulf of Mexico supported by ONR will be expanded moderately. This will involve additional automated data gathering and handling equipment utilized cooperatively by several Gulf Coast laboratories.

Naval Oceanographic Office. Within the Oceanographic Office and through contracts, considerable emphasis will be placed upon ocean-atmosphere studies. These programs will be directed towards understanding the fundamental processes occurring at the ocean-air interface in order to increase the accuracy of predicting oceanographic conditions affecting fleet operations. Considerable emphasis will be given to the study of surface and internal waves.

Bureau of Ships. The Navy Electronics Laboratory and the Underwater Sound Laboratory 
programs in ice physics and Arctic oceanography will be increased. These programs will be closely related to submarine operational programs in the Arctic Ocean.

\section{DEPARTMENT OF COMMERCE}

Weather Bureau. The Weather Bureau will continued programs carried out in FY 1963 at about the same level of effort.

Maritime Administration. The Maritime Administration's program in the study of wave spectra at sea and the effect of waves on ship design will be continued in FY 1964 at the same level as in the previous year.

\section{DEPARTMENT OF INTERIOR}

Bureau of Commercial Fisheries. The Bureau will continue basic studies at its Stanford Laboratory on the interrelations of long-term atmospheric and oceanic conditions and their effects on the abundance and distribution of fish stocks.

\section{NATIONAL SCIENCE FOUNDATION}

Although support for no major new program is envisaged by the National Science Foundation under this objective at this time, it is anticipated that many of the existing programs will be expanded over their FY 1963 levels.

OBJECTIVE THREE - To determine the kinds, distribution, adaptations and productivity of the living population of the sea and to understand the interrelation of the marine organisms to each other and to the physical and chemical properties of the sea.

\section{DEPARTMENT OF DEFENSE}

\section{Department of the Navy}

Office of Naval Research. In addition to a general expansion of programs in marine biology, ONR will place new emphasis on the biology of the deep oceans and the relation of deep water organisms to those in surface layers. The contributions of submicroscopic nannoplankton forms to the economy of the marine environment will be analyzed. The chemical basis of marine deterioration will be intensively examined as will the pharmacological and chemical character of biologically active substances produced by marine organisms.

Systematic research, the study of the developmental relations among biological organisms, will be increased and the use of computers as aids in this area will be examined.

Bureau of Ships. The Navy Electronics Laboratory's program for the classification and analysis of noises originating from marine organisms and its program for study of the vertical distribution of marine life correlated with the physical and chemical properties of the water, using the bathyscaph TRIESTE; will be accelerated in FY 1964. The TRIESTE is currently undergoing complete overhaul.

\section{DEPARTMENT OF INTERIOR}

Bureau of Commercial Fisheries. In working towards optimum use of the living resources of the sea, the Bureau of Commercial Fisheries will expand its research program in radiobiology along with laboratory and field studies on the physiology and behavior of tuna, sardines, and other important marine species. With the aid of a new vessel, studies will be augmented on the ecology and population dynamies of groundfishes in the western North Atlantic. In addition, the Bureau will cooperate with other agencies in balanced biological, chemical, and physical oceanographic programs in the tropical Atlantic, eastern tropical Pacific, and central Pacific areas. Fellowships in the marine sciences will be granted to qualified students in the hope that some of these students will choose careers in the marine sciences. Exploratory fishing efforts will be greatly expanded in the Caribbean and western tropical Atlantic together with the development and testing of new fish sampling gear and techniques. Particular attention will be devoted to development of new techniques for catching fish in commercial quantities. These new techniques will be used on exploratory cruises to delinate areas of fish abundance.

Bureau of Sport Fisheries and Wildlife The Bureau will intensify its studies, on both the Atlantic and Pacific Coasts, of the life histories, physiology, growth, and behavior of marine game fish; environmental studies will be expanded.

\section{NATIONAL SCIENCE FOUNDATION}

The National Science Foundation's Division of Biological and Medical Sciences will expand 
support of a wide variety of studies of life and living processes in the sea. In FY 1964 an orderly growth in the amount of support for research in systematic biogeographic and analogical relations of marine animals and plants and their interactions with the marine environment is contemplated. Increased support will also be provided for ship time in biological oceanography, and for the expansion and improvement of marine laboratories and their graduate training programs. Two ocean-going vessels, one in the Pacific and one in the Atlantic, will be used cooperatively by scientists from many universities throughout the country. These vessels will be designed and operated to emphasize basic research and graduate training in marine biology. A large portion of the increase in funds for FY 1964 will go to the support of research and training on these ships. In addition, the major costs of the U.S. biological program for the International Indian Ocean Expedition will be provided during FY 1964. This program will encompass the efforts of 150 biologists representing approximately 100 different universities.

\section{SMITHSONIAN INSTITUTION}

In FY 1964 there will be a modest increase in the Smithsonian's taxonomic program. Although taxonomy is basic to the study of marine biological processes, the shortage of taxonomists is such that growth in this area will be slow in relation to the need. Tremendous quantities of bulk specimens will be obtained in the oceanographic programs planned. The Museum of Natural History has established a National Sorting Center to increase the efficiency of the collection of specimens as well as their scientific processing. This activity and the research staff will be increased.

OBJECTIVE FOUR - TO describe and understand the geological, geochemical, and geophysical nature of the sea floor, including its relation to the adjoining land masses.

\section{DEPARTMENT OF DEFENSE}

\section{Department of the Navy}

Office of Naval Research. One of the most active segments of ONR's oceanographic program is marine geophysics. The rapid development of new and more precise techniques for measuring the geothermal, magnetic, seismic, and gravimetric properties of the earth while at sea will allow for a vigorous and expanding research program in these areas. In addition to localized investigations aimed at understanding the detailed structure and dynamic processes in specific areas beneath the sea, there will also be an expanded program of exploratory geophysics to obtain gross properties over large areas. An example of one such program will be the geophysical investigations carried out as part of the International Indian Ocean Expedition.

The Office of Naval Research and National Science Foundation will jointly support a program for obtaining sediment cores of much greater length than has heretofore been possible. These cores will be examined to determine their physical and chemical properties, geochronology, paleotemperatures, and fossil contents.

Naval Oceanographic Office. During FY 1964, the Oceanographic Office will give increased emphasis to study of the acoustic properties of the ocean bottom, the exploration of the microstructure of the geomagnetic field, and the correlation of magnetic anomalies with crustal structure.

Bureau of Ships. The bathyscaph TRIESTE will be used to investigate the physical properties of the ocean bottom, including the static and dynamic properties of sediment and their relation to its acoustical properties. In addition, sound transmission and reflection characteristics of sediments will be carried out aboard the DAVIS.

\section{Department of the Army}

Beach Erosion Board, Corps of Engineers. The tidal and wave studies, described under Objective One, will be directed also toward understanding the movements of sand and other sediments. Particular attention will be paid to erosion of beaches caused by waves generated by large storms.

\section{DEPARTMENT OF COMMERCE}

Coast and Geodetic Survey. In FY 1964, C\&GS will undertake the development of a sophisticated technique for analysis of bottom sediments from echo sounder records. Further, an intensive geological-geophysical survey will be made of the Pacific mid-ocean area explored during the 1962-63 Ocean Survey Program. This study will be directed towards advancing the knowledge of mid-ocean geomorphology. Research will continue on the geophysical and bathymetric results of the Ocean Survey Program in the Pacific and of the Atlantic Continental Shelf program. 


\section{DEPARTMENT OF INTERIOR}

Geological Survey. The Geological Survey's expanded effort in oceanography will be directed partly toward investigations of the mineral resources on and beneath the U. S. Continental Shelf. To carry out this program, the Survey will staff, equip, and support a West Coast laboratory of marine geology near San Francisco Bay from which research will be conducted on estuarine processes and Continental Shelf geology. On the East Coast, the Survey's program of Continental Shelf investigation, carried out jointly with the Woods Hole Oceanographic Institution, will be augmented by the purchase of major items of scientific equipment to extend the scope of the program. In the Gulf Coast area, the Survey will expand its effort in the collection and interpretation of existing commercial geological and biological data on the Gulf Coast Continental Shelf and will prepare this material for publication.

Studies of bottom samples and geophysical data collected by the Coast and Geodetic Survey near Hawaii and elsewhere in the North Pacific Ocean will continue.

Bureau of Mines. In FY 1964, the Bureau will markedly increase its program to determine the economic significance, methods of recovery, and utilization of marine mineral resources. The extent and grade of oceanic deposits will be investigated and research will be initiated on techniques and procedures for mining and processing material found in the sea. Feasibility studies will be made of a submersible research vessel for drilling and surveying in the deep ocean. Other unusual vehicles for investigations on the conservation and development of marine resources will be considered for eventual use in the Bureau of Mines oceanographic program. New and more efficient instruments for studying conditions on and under the sea floor will be developed and installed on a Bureau of Mines survey vessel. Emphasis will be placed on conceptual design, engineering, and testing of prototype marine research equipment developed in Bureau of Mines facilities, which will benefit not only the Bureau's oceanographic program but those of other government agencies, private institutions, and industry as well.

\section{NATIONAL SCIENCE FOUNDATION}

The National Science Foundation will provide funds in FY 1964, as in past years, for the support of marine geophysics, geology, and geochemistry programs at various oceanographic institutions. The FY 1964 program will highlight an expansion of effort in bathymetric investigations; age determination of marine sedimentary deposits; paleotemperature studies; sediment distribution and drilling operations; organic and inorganic geochemistry; sediment transport techniques, both in the ocean and on the shore; and seismic, gravity, and geothermal investigations. In addition, it is expected that coring operations penetrating to greater depths than have hitherto been attainable by conventional coring techniques will be conducted in the deep oceans.

\section{OBJECTIVE FIVE - To determine the modifi- cation of the ocean resulting from man's activities.}

\section{DEPARTMENT OF DEFENSE}

\section{Department of the Navy}

Naval Oceanographic Office. Theoretical and field studies of turbulence and diffusion will be expanded in both near-shore and deep oceanic waters. These studies will provide basic information for application to pollution problems.

\section{DEPARTMENT OF INTERIOR}

Bureau of Commercial Fisheries. Studies will be intensified of the effect of radioactive substances on marine organisms, and how these may be concentrated by plants and animals and transmitted to man.

Geological Survey. The Geological Survey will expand its investigations of the distribution of radioactive materials within the estuaries and near-shore waters of the United States.

Bureau of Mines. In FY 1964 the Bureau will accelerate its coordinated study of the disposal of oil at sea and in coastal waters, and will explore means for preventing or reducing pollution caused by this disposal, and possible means for alleviating the harmful effects of necessary waste oil discharges.

\section{DEPARTMENT OF HEALTH, EDUCATION, AND WELFARE}

Public Health Service. Principal emphasis in the FY 1964 Public Health Service direct research program will be in the elucidation of phenomena associated with the disposal of waste in marine environments. Twenty-three coastal states depend heavily on estuarine and nearshore waters for disposal of domestic and 
industrial wastes. Fundamental information on dispersion and diffusion phenomena, and on biological and chemical interactions with the marine environment is seriously lacking. A principal portion of the increased expenditures in FY 1964 will go toward staffing a marine water-quality standards research laboratory. The Service will also support a significant increase in grants to academic and other non-profit institutions to per form research and for training marine scientists.

The Public Health Service will initiate a direct research effort on the fate of radioactivity in the marine environment. The cost of staffing new shellfish research centers at Kingston, Rhode Island, and Dauphin Island, Alabama, will account for a major part of the increase in PHS's research program. Principal elements of this research will include work on the chemical and microbiological characteristics of shellfish growing areas, on the survival of microorganisms - especially viruses in estuarine environments - and on biologically active systems such as paralytic shellfish poisoning.

\section{ATOMIC ENERGY COMMISSION}

The Atomic Energy Commission's program in oceanography will attain a planned optimal level of operation in FY 1964. This research program will provide information required to predict and explain the diffusion and concentration resulting from the deposit of radioactive materials in the ocean, to determine residence time in estuaries and coastal waters of long lived radioisotopes from nuclear vessels, production and research reactors, and to determine the distribution by and biological effects on marine organisms of radioactivy in the ocean.

The trend in the FY 1964 program is to emphasize the food webs, biological inventories, and ecological relationships. In addition, studies will be initiated on those radioactive materials associated with auxiliary nuclear power sources and nuclear propulsion systems being used or proposed for use in aerospace systems and which may be introduced into the oceans.

TABLE 1

FY 1964 BUDGET FOR RESEARCH

(Thousands)

\section{Agency}

\section{Department of Defense}

Department of the Navy

Department of the Army

\section{Department of Commerce}

Weather Bureau

Coast and Geodetic Survey

Maritime Administration

Department of Interior

Bureau of Commercial Fisheries

Bureau of Sport Fisheries and Wildlife

Geological Survey

Bureau of Mines

Department of Health, Education, and Welfare

Public Health Service

Office of Education

FY 1964

National Science Foundation

Atomic Energy Commission 
TABLE 2

(Thousands)

\section{Objective}

1. Physical and Chemical Properties; Dynamic Processes.

2. Ocean-Atmosphere Interrelations.

3. Biological Properties.

13,000

4. Sea Floor Studies.

10,500

5. Modification From Man's Activities.

$\$ 46,955 \quad \$ 62,565$

\section{B. INSTRUMENTATION}

The recommended expenditure in instrument development and procurement in FY 1964 is $\$ 8.88$ million, an increase of 28.9 per cent over FY 1963.

An important segment of these funds will be expended in development and procurement of unmanned buoys. Research on oceanographic buoys is presently being sponsored by the Navy, Bureau of Commercial Fisheries, Weather Bureau, Coast Guard, Coast and Geodetic Survey, and Public Health Service. Important development effort is underway at the Scripps Institution of Oceanography, and the Woods Hole Oceanographic Institution. These programs are considered of extreme importance by the ICO, and coordinated programs will be developed to the maximum extent possible. Effort is being concentrated on increasing the accuracy and precision of sensing elements, devising means of anchoring buoys in deep water, and improving telemetering. No other aspect of the instrumentation program holds greater promise for the future of oceanography than buoy systems.

An integral part of the planning for Ocean Surveys is the work being done by the Naval Oceanographic Office on the development of shipboard instrument systems for survey vessels, and of more compact and portable systems for installation on "Ships of opportunity." A substantial bonus to the National Oceanographic Program instrumentation effort will be derived from this Office's extensive development in the Anti-Submarine Warfare Environmental Prediction System (ASWEPS).
The Bureau of Commercial Fisheries is giving much-needed attention to the development of biological sampling devices, particularly large nets, mid-water trawls, and other gear for measuring the abundance of fish and other marine organisms. An instrumentation group is being established within the Bureau for the following purposes:

(1) To provide instrumentation services for BCF biological laboratories and exploratory fishing bases.

(2) To develop special instrumentation required by fisheries scientists.

(3) To coordinate instrument development being carried out by other Bureau units.

(4) To coordinate instrumentation activities with those of other bureaus.

The Bureau of Mines is conducting engineering research and development on devices for deep and shallow sampling of sediments and hard rock below the ocean floor. Recovery of long, undisturbed cores of representative mineral matter from deep holes, not heretofore considered practical, is a major goal. Development of new instruments or conversion of existing instruments for shipboard evaluation of ocean floor resources is another feature of the Bureau of Mines program.

The Geological Survey is developing a variety of new geophysical instruments for studying the bottom of the ocean, whereas the Weather Bureau is continuing its efforts in the measurement of the air-sea interface.

Improvements in the instrumentation of its Ocean Station Vessels, lightships, and patrol vessels by the Coast Guard will greatly increase their output of time series data of great value to all agencies with interests in the ocean.

The ICO will continue to study the Naval Oceanographic Office's newly established Instrumentation Test and Calibration Center as a prototype of the proposed national centers. Development and testing at the new Center will contribute to the programs of all ICO member agencies.

Perhaps none of the programs listed here are more timely than those of the Coast and Geodetic Survey and the Oceanographic Office on the machine processing of oceanographic data and the improvement of capabilities for the conversion, analysis, presentation, and transmission of oceanographic information.

The FY 1964 budget for equipment and instrumentation is outlined in Table 3. 


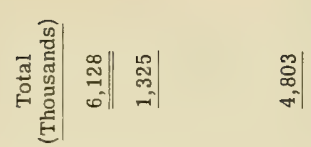

పี๊ స్|

$\underset{\substack{\infty \\+}}{ }$

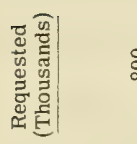

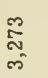

오

움
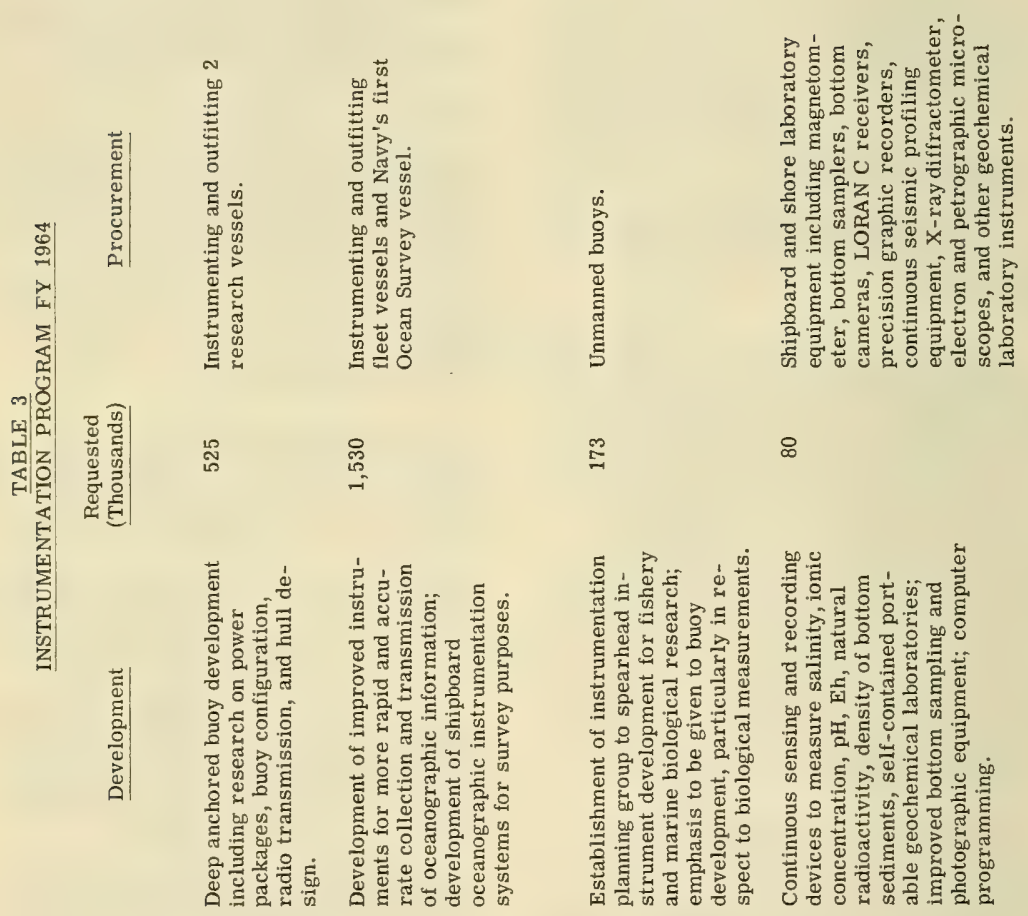

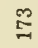

\&

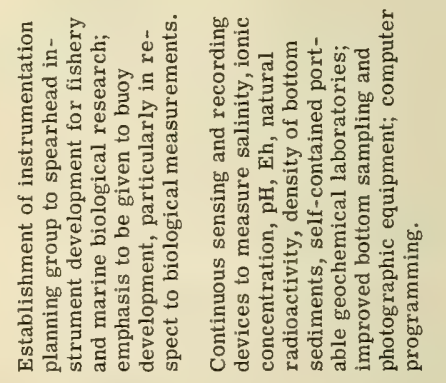

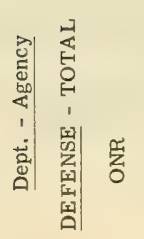

눈

$\stackrel{8}{z}$

영 몸

엉 
$\infty \mid$

8

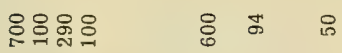
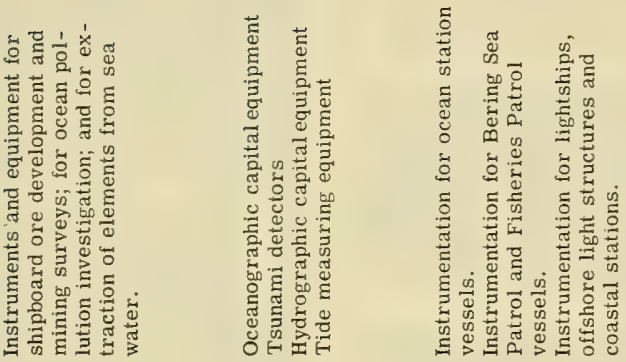

$\stackrel{\infty}{N}$

ผึ
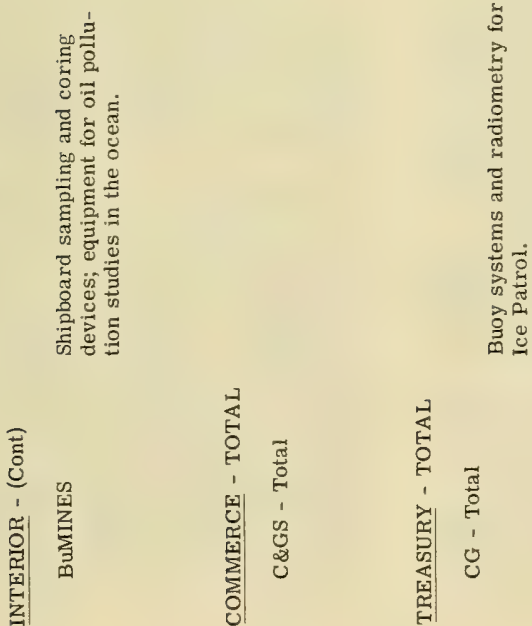

 


\section{SHIP CONSTRUCTION}

At the beginning of Fiscal Year 1964, the government will be supporting the operations of 76 oceanographic vessels. During the fiscal year, three more will be completed. The FY 1964 Shipbuilding Program will provide funds for 12 ships at a total cost of $\$ 47.7$ million, an increase of about $\$ 9.6$ million over the FY 1963 program. This increase will help to correct the lag in the oceanographic program caused by lack of ships. Table 4 depicts agency shipbuilding plans for FY 1963 and FY 1964. Table 5 shows the schedule of construction of ships programmed for prior years as well as those recommended herein.

As a result of the activities of the Interagency Committee on Oceanography, agencies have increased their shipbuilding efforts at a satisfactory rate. The first influx of new ships to the program is just now beginning. Lead time from budget submission to actual delivery of the ship is about 3 years. Therefore, ships included in the FY 1964 program will not be delivered before the Spring of 1966.

In an attempt to cut down on this long lead time, agencies have traditionally resorted to the expediency of converting older ships for oceanographic purposes. The use of such conversions is admittedly a short term solution suitable only for special purposes such as work in the Antarctic, inshore research, or for certain types of biological work. Detailed studies by the Coast and Geodetic Survey, Navy, and Ships Panel of the ICO leave no doubt that conversions are a poor substitute for specially designed vessels. Conversions are more expensive to operate and maintain, are less efficient in carrying out modern research experiments, and are much less habitable with respect to air conditioning for tropical work, space arrangement, and recreational facilities. The average conversion has a life expectancy of only 10 years, compared with 30 years for new construction, and is 50 to 100 per cent more expensive to operate. Thus, in the long run, use of converted vessels is considerably more expensive than constructing new ones; even considering the much higher first cost.

The most important objection to conversions (and the reason why it is so necessary to replace our older ships as soon as possible) is their inability to carry out the wide variety of research and survey activities involved in modern-day programs. Old ships designed for wartime use are too noisy for modern acoustic and seismic experiments, and are too broken up with watertight bulkheads to permit efficient laboratory arrangements.

Our modern research ships contain the most modern technical equipment available: roll stabilization tanks, quiet gas turbines, portable instrumentation vans, retractable bow propulsion units, and electronic recorder rooms to accommodate data processing equipment and other instruments of the future. The initial inventory of equipment for such vessels will include gravity meters, magnetometers, electronic computers, towed thermistor chains, several types of oceanographic winches, Swallow arrays for tracking subsurface currents, deep echo sounders, hull mounted hydrophone arrays for tracking remote controlled vehicles, salinometers, sound velocity meters, advanced navigation equipment, and special equipment for meteorological, biological, and seismic work at sea.

To an ever-increasing extent, our new ships will record data in digital form and process them with electronic computers aboard ship. The combination of improved instrumentation and rapid data processing gives new vessels an order of magnitude greater efficiency than older ships. Further, as a result of design for quiet operations, they will be able to undertake work not possible with older vessels and conversions.

The proposed shipbuilding program for FY 1964 will provide five ships to replace older ones which will be from 20 to 35 years old when the new ships are delivered. Although these new ships will have tremendously increased capabilities over the ships being replaced, the requirement to maintain and expand geographical coverage requires a one-for-one replacement.

In addition to the five replacements, seven new ships will be funded: one for Ocean Survey, a small and large vessel for fishery research, two small craft for wire drag work, a vessel will be converted for mining research, and the committee estimates that one new ship will be constructed with NSF funds. The Ocean Survey ships will provide the Nation with a new capability to survey all of the oceans, recording all types of oceanographic data. They will also be made available for international expeditions, giving increased flexibility to all U. S. cooperative expeditions with other countries. In addition to the ICO program of ship construction, several research vessels under $1,000 \mathrm{~T}$ have been provided by the Office of Naval Research as a part of its research contracts in order to 


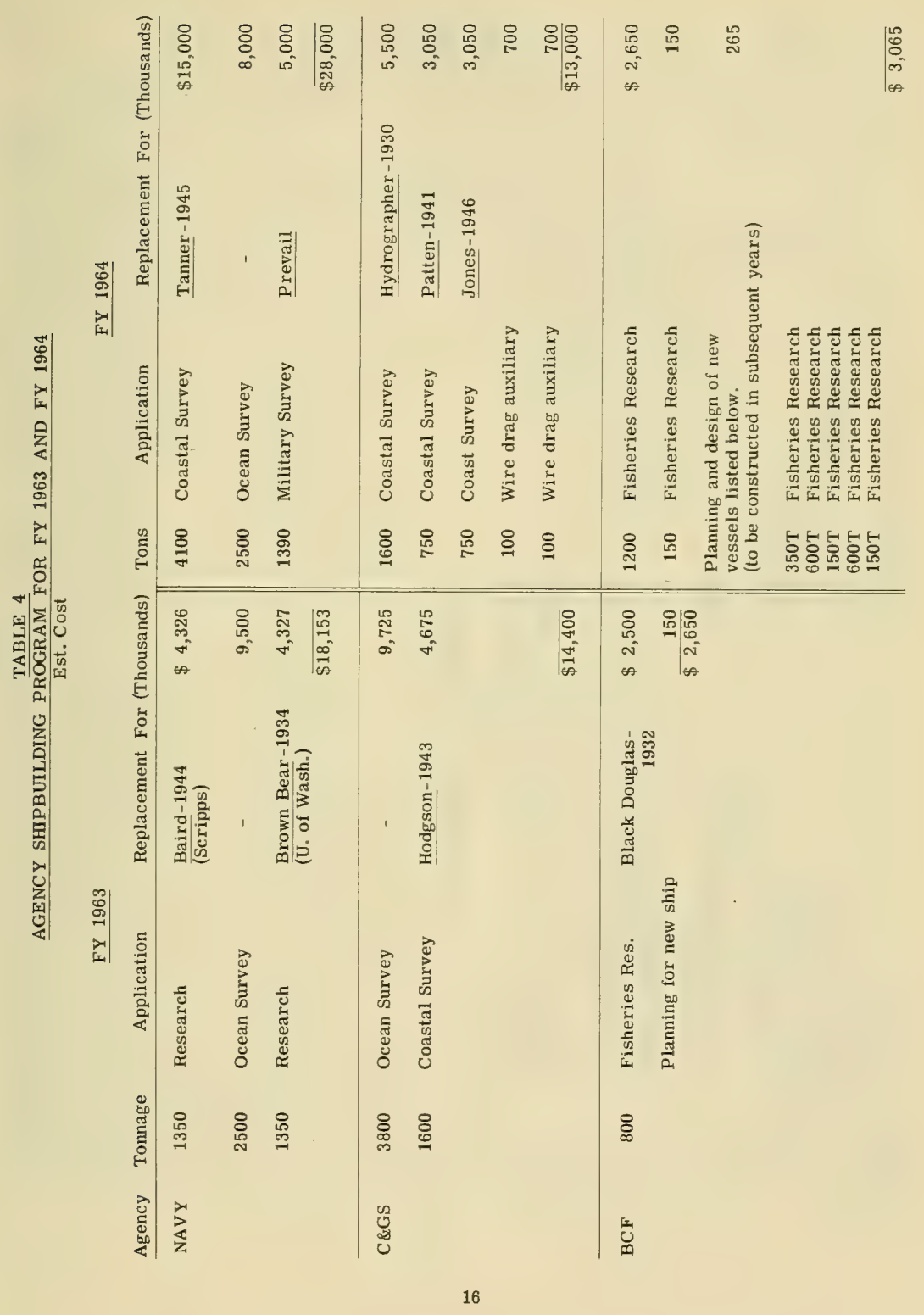




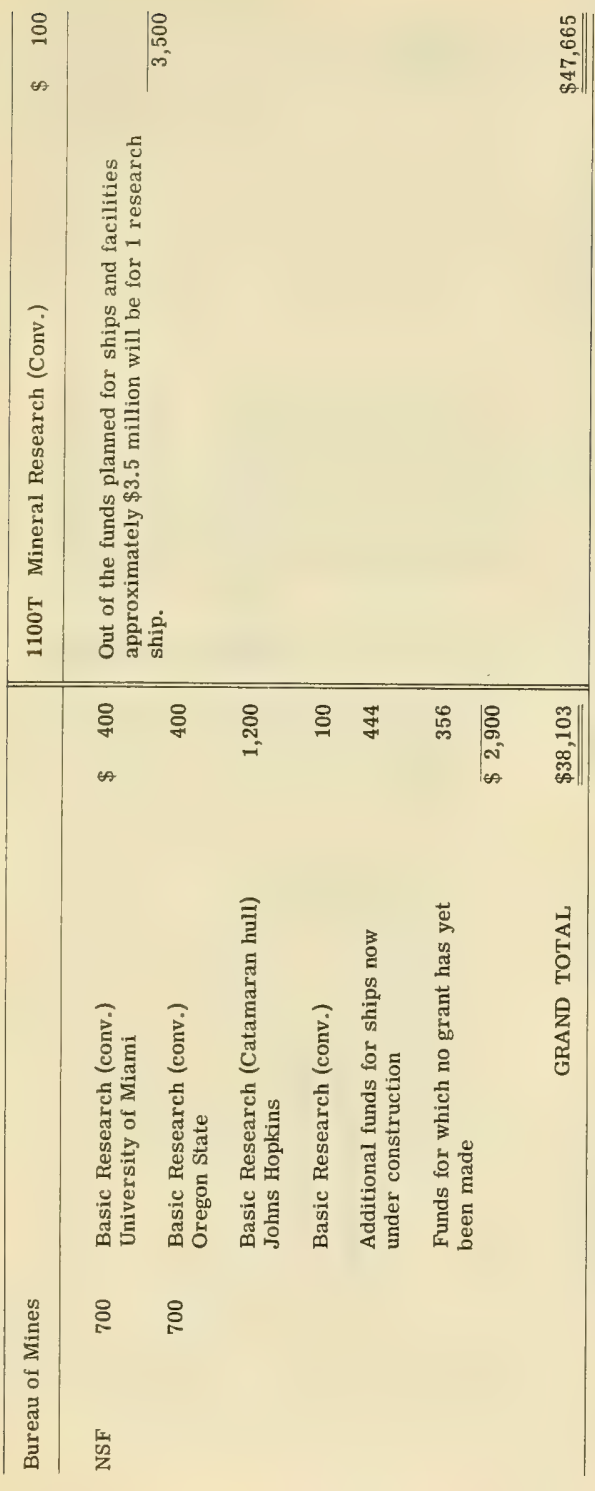


TABLE 5

ARRIVAL OF NEW SHIPS

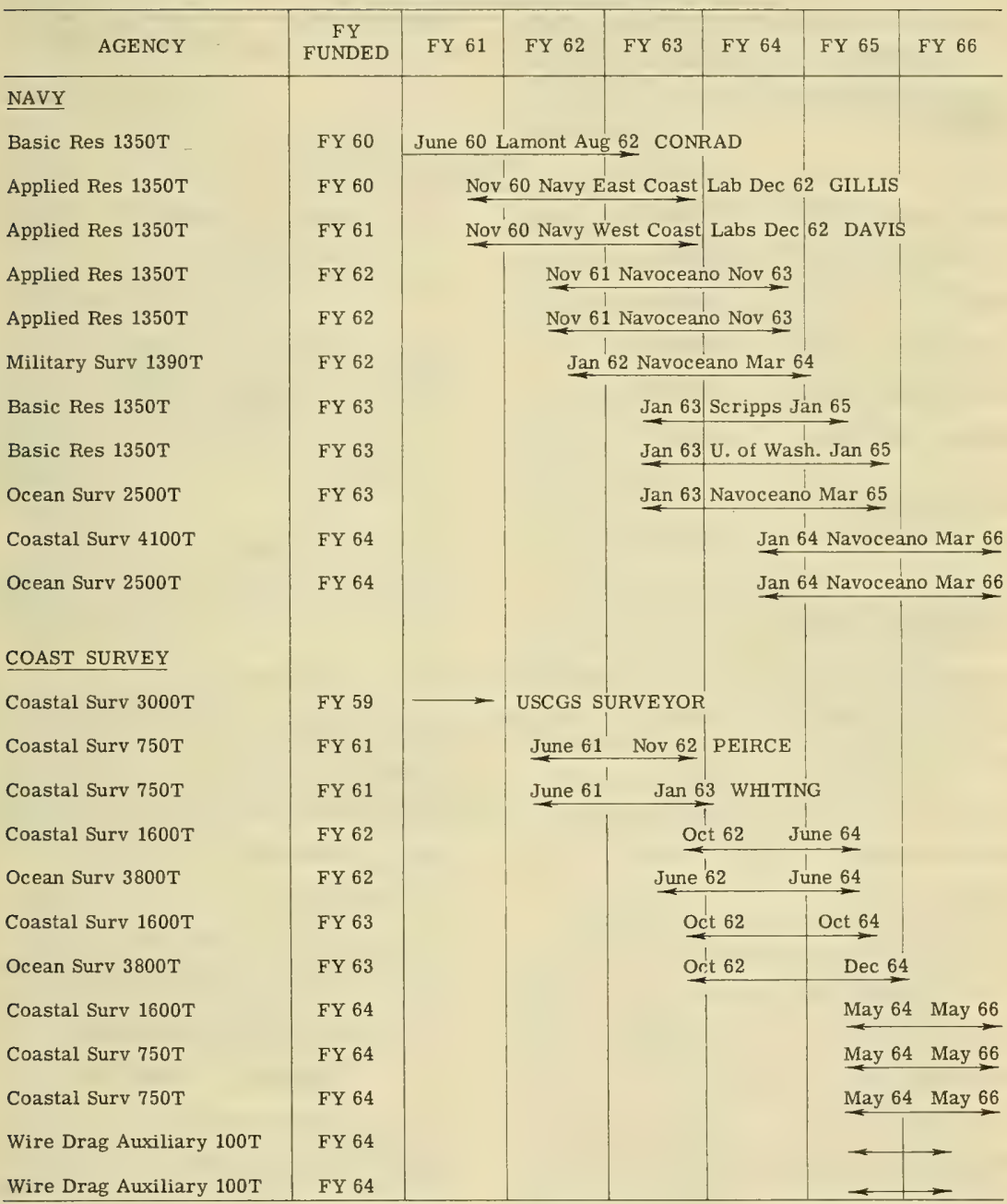


TABLE 5

ARRIVAL OF NEW SHIPS-Continued

\begin{tabular}{|c|c|c|c|c|c|c|c|}
\hline AGENEY & $\underset{\text { FUNDED }}{\text { FY }}$ & FY 61 & FY 62 & FY 63 & FY 64 & FY 65 & FY 66 \\
\hline \multicolumn{8}{|l|}{$\begin{array}{l}\text { BUREAU OF COMM. } \\
\text { FISHERIES }\end{array}$} \\
\hline Fisheries Res. 1,000T & FY 61 & & May 61 & Nov 62 & ALBATR & ROSS IV & \\
\hline Fisheries Res. $650 \mathrm{~T}$ & FY 62 & & & & $\operatorname{Mar} 63 \mathrm{~J}$ & June 64 & \\
\hline Fisheries Res. $700 \mathrm{~T}$ & FY 62 & & & Dec & 62 Dec & & \\
\hline Fisheries Res. $150 \mathrm{~T}$ & FY 62 & & & & & ec 63 Dec & c 64 \\
\hline Fisheries Res. $800 \mathrm{~T}$ & FY 63 & & & & June 63 & June 64 & \\
\hline Fisheries Res. 1,200T & FY 63 & & & & Sep 63 & $3 \quad \operatorname{Mar} 65$ & \\
\hline Fisheries Res. $150 \mathrm{~T}$ & FY 63 & & & & $\leftarrow$ & $\rightarrow$ & \\
\hline \multicolumn{8}{|l|}{ BUREAU OF MINES } \\
\hline $\begin{array}{l}\text { Mineral Res. } 1,000 \mathrm{~T} \\
\text { NATIONAL SCIENCE } \\
\text { FOUNDATION }\end{array}$ & FY 64 & & & & $\leftarrow$ & $\rightarrow$ & \\
\hline Basic Res. $2100 \mathrm{~T}$ & FY 60 & Woods Hc & ole Jan 63 & $-{ }^{A}$ & TLANTIS & II & \\
\hline Antarctic Res. $4600 \mathrm{~T}$ & FY 61 & Nov & 60 Nov 61 & (Conv) U & JSNS ELTA & ANIN & \\
\hline Basic Res. $400 \mathrm{~T}$ & FY 61 & & Duke Ur & niversity & & & \\
\hline Basic Res. 336T & FY 61 & & Stanforo & d Universi & ity (Conv) & TE VEGA & \\
\hline Basic Res. 25T & FY 62 & & $\mathrm{U} . \mathrm{Mic}$ & ch. INLA & ND SEAS & & \\
\hline Basic Res. $425 \mathrm{~T}$ & FY 62 & & & $\stackrel{\text { of Mich. }}{\longrightarrow}$ & (Conv) & & \\
\hline Basic Res. $735 \mathrm{~T}$ & FY 62 & & & exas A\&M & (Conv) AI & LAMINOS & \\
\hline Basic Res. $1780 \mathrm{~T}$ & FY 62 & & & & - (Conv) Al & NTON BRU & UUN \\
\hline Basic Res. $735 \mathrm{~T}$ & FY 63 & & & $\stackrel{\text { Mian }}{\longleftarrow}$ & $\underset{-}{\operatorname{mi}}$ (Conv) & PILLSBU & URY \\
\hline Basic Res. 735T & FY 63 & & & & regon State & e (Conv) & \\
\hline Basic Res. 100T & FY 63 & & & & hons Hopkin & & \\
\hline Basic Res. & FY 63 & & & & $\longrightarrow-\mathrm{C}_{0}$ & onv) & \\
\hline Basic Res. & FY 64 & & & & $\leftarrow$ & - & $\rightarrow$ \\
\hline
\end{tabular}


meet the needs and capabilities of the institutions contracting to perform ONR research. These vessels are listed below.

\begin{tabular}{|c|c|c|c|}
\hline $\begin{array}{l}\text { ACONA } \\
\text { FY } 1959\end{array}$ & $\begin{array}{l}\text { Oregon State } \\
\text { University }\end{array}$ & $154 \mathrm{~T}$ & (new) \\
\hline $\begin{array}{l}\text { HOH } \\
\text { FY } 1962\end{array}$ & $\begin{array}{c}\text { University of } \\
\text { Washington }\end{array}$ & $90 \mathrm{~T}$ & (conv) \\
\hline $\begin{array}{l}\text { KYMA } \\
\text { FY } 1962\end{array}$ & $\begin{array}{l}\text { New York Uni- } \\
\text { versity }\end{array}$ & $90 \mathrm{~T}$ & (conv) \\
\hline $\begin{array}{r}\text { TRIDENT } \\
\text { FY } 1962\end{array}$ & $\begin{array}{l}\text { University of } \\
\text { Rhode Island }\end{array}$ & $820 \mathrm{~T}$ & (conv) \\
\hline $\begin{array}{l}\text { AGASSIZ } \\
\text { FY } 1962\end{array}$ & $\begin{array}{c}\text { Scripps Institution } \\
\text { of Oceanography }\end{array}$ & $400 \mathrm{~T}$ & (conv) \\
\hline
\end{tabular}

With these added to the ICO construction program, it is evident that not only is the category of basic research receiving much-needed attention, but that, where appropriate, steps have been taken to meet promptly the immediate needs of growing establishments by making available smaller craft through the medium of conversions.

Present planning anticipates that ship construction will reach a peak in the next few years followed by a gradual decrease, as the present backlog is overcome, to a level which will sustain normal growth.

Although the shipbuilding program is expensive and accounts for a large part of the total national program, the U.S. cannot expand its oceanographic activities until we have sufficient modern ships to meet the demands of research and technology. An adequate shipbuilding program is of major importance to the National Oceanographic program.

\section{SURVEYS}

The Survey Program of the Federal Government for FY 1964 is budgeted at $\$ 20.23 \mathrm{mil}$ lion. This represents an increase of $\$ 1.74 \mathrm{mil}$ lion over FY 1963. The largest portion of this represents increased deep ocean work of the Naval Oceanøgraphic Office brought about primarily by the delivery of a new ship.

Surveys for FY 1964 are, for the purposes of this report, separated into two categories: Ocean Surveys, and those oceanographic (including hydrographic) surveys which are related to other missions of the various agencies but do not fall within the rather narrow definition of "ocean-wide surveys" originally proposed by
NASCO. Ocean Surveys are the first attempt of any country to undertake the systematic survey of the entire deep ocean. The surveys are accurately controlled navigationally, and include mapping the shape of the sea floor; the magnetic and gravity properties of the deep sea; the phys ical, chemical, and biological characteristics of the water; geological characteristics of bottom sediments; and the meteorology of the overlying atmosphere.

After a slow start in FY 1964, and a modest increase to a total of $\$ 1.78$ million in FY 1963, this program undergoes more than a three-fold increase in FY 1964 to a total of $\$ 6.04$ million. This is due to several factors. The first of these is the assignment of the additional C\&GS Ships SURVEYOR and PEIRCE to full-season operations within the Ocean Surveys concept. The second is that both that agency and the Naval Oceanographic Office are increasing their participation in the Ocean Survey Program by planning more time of other large ships for this program. The third factor is the increased effort of the Bureau of Commercial Fisheries in placing biologists aboard survey ships, and the beginning of the Geological Survey's participation in this program.

It is particularly noteworthy that, while the FY 1964 support for Ocean Surveys has increased by $\$ 4.26$ million, there has actually been a decrease of nearly $\$ 2$ million in total funds for other mission-oriented surveys. This indicates that the total survey effort is expanding toward Ocean Surveys rather than existing mission-oriented work. The major expansion in the Nation's Ocean Survey Plan will occur in FY 1965. During that year, the Navy's first vessel specifically designed and constructed for this purpose will begin operations, as will the two such vessels of the Coast and Geodetic Survey.

The International Cooperative Investigations of the Tropical Atlantic are described in Annex A to this report. As an indication of the level of effort for FY 1964, it is estimated that the Bureau of Commercial Fisheries will support the Investigations from its research funds at a level of about $\$ 1.1$ million. ONR is planning to support private oceanographic institutions in this expedition at about $\$ 0.2$ million, the C\&GS has one ship participating in FY 1963, and the Coast Guard will have a ship in the FY 1964 phase. The Oceanographic Office, though not participating with ships, is providing services in assisting the planning. The total cost of the U. S. portion of this program in FY 1964 is estimated at less than $\$ 2$ million. 


\section{Department of Defense}

U. S. Navy. Oceanographic surveys are carried out for the Department of Defense by the Naval Oceanographic Office. The major portion of its effort is directed toward military surveys, but for FY 1964 considerably more ef fort will be devoted to the Ocean Survey effort. The TANNER and REQUISITE will be engaged part-time in coastal hydrographic surveys in the Atlantic, with major emphasis in the general areas of the Windward Passage and the North Atlantic. A portion of the time of each of these vessels will be spent on ocean surveys within the framework of the term as defined by the Ocean Surveys Advisory Panel of the $\mathrm{ICO}$. The effectiveness of these two ships will be increased by their working as a team throughout most of the field season. Similarly, the MAURY and SERRANO will be involved in comparable surveys in the Pacific. The two major oceanographic survey ships of the Naval Oceanographic Office, the SAN PABLO and the REHOBOTH, will be carrying out military project surveys in the Atlantic and the Pacific respectively. It is possible that these two ships will also be able to contribute to the Ocean Survey Program during the working season, but this will be determined by the rate at which the required military surveys progress. The remaining three ships, the PREVAIL, SHELDRAKE, and LITTLEHALES, will be engaged in military project survey in the Atlantic.

Survey funds planned for the Navy in FY 1964 total just over $\$ 11$ million as follows:

TABLE 6

Costs of Operation and Technical Manning of the Survey Ships (Thousands)

TANNER

MAURY

SAN PABLO

REHOBOTH

SERRANO

PREVAIL

REQUISITE

SHE LDRAKE

LITTLEHALES

New Vessel (AGS 214)

\$ 1,914

1,914

1,260

1,260

758

712

672

672

320

840

Total

$\$ 10,322$

Support for analysis, interpretation, and related activies for ocean surveys.

Total for surveys
Data from the above activities will be made available to the scientific community through the National Oceanographic Data Center. It is not possible at this time to ascertain exactly the amount of time that these ships will be engaged in Ocean Survey work as compared with coastal hydrography and other missions. It is estimated, however, that the TANNER, MAURY, REQUISITE, and SERRANO will devote 20 per cent of their time to the Ocean Survey Program, and the REHOBOTH 10 per cent. For the purposes of this report, the ocean survey funding for the Oceanographic Office is $\$ .873$ million for data processing and other costs related to this program and $\$ 1.178$ million for ship time for a total of $\$ 2.051$ million out of a total survey item of $\$ 11.195$ million.

Prior high priority commitments prevent the Oceanographic Office from participating directly in the International Cooperative Investigations of the Tropical Atlantic, but as in FY 1963 this agency will contribute to this effort through special compilation and printing activities for which funds are not earmarked specifically.

The Office of Naval Research will support some of the activities of the private oceanographic institutions taking part in the International Cooperative Investigations of the Tropical Atlantic. An estimated $\$ 200$ thousand will be spent on this research effort by the private institutions in FY 1964.

\section{Department of Interior}

Bureau of Commercial Fisheries. The Bureau of Commercial Fisheries plans an increase of $\$ 105$ thousand over the $\$ 20$ thousand budgeted in FY 1963 for its part in the Ocean Survey Program. These funds will cover the cost of placing biologists and special equipment items aboard the ships of other agencies engaged in such surveys. Although BCF does not have ships to carry out Ocean Surveys of its own, the degree of cooperation with the Oceanographic Office, the Coast and Geodetic Survey and the Coast Guard has been high, and biologists are routinely placed aboard the ships of these agencies.

Geological Survey. The Geological Survey budgeted no funds in FY 1963 under the heading of surveys. For FY 1964, this agency has included $\$ 15$ thousand under this category. By FY 1964 it is expected that the Ocean Survey Program will have progressed sufficiently that additional equipment will be needed for special 
studies being planned by the Geological Survey. The $\$ 15$ thousand will provide for the equipment to be used aboard ships of the Naval Oceanographic Office and the Coast and Geodetic Survey.

\section{Department of Commerce}

Coast and Geodetic Survey. The Coast and Geodetic Survey will receive a modest increase of $\$ 313$ thousand in survey funding for FY 1964. Two new Class III ships, the PEIRCE and WHITING, are scheduled for delivery late in FY 1963 as replacements for existing hydrographic survey ships. These ships will be equipped to carry out both charting and oceanographic operations. After shake-down cruises in the Gulf of Mexico, both will be assigned to the East Coast with one of them operating fulltime on oceanographic-hydrographic surveys of the continental shelf, while the other will be engaged primarily in coastal charting activities with some supplementary oceanographic work. The first Class I ocean survey ship, the OCEANOGRAPHER, will be delivered in FY 1964. It is planned to start operations with this ship on Ocean Surveys in the North Pacific, continuing the work of the PIONEER while that ship goes to the Indian Ocean. The sum of $\$ 200$ thousand has been budgeted specifically for the additional costs to be incurred in the latter half of FY-1964 in operating the PIONEER in the International Indian Ocean Expedition.

During the first half of FY 1964 the PIONEER will continue its ocean survey operations in the North Pacific between Hawaii and the Aleutians. In addition to the underway operations, a study of the current structure in the boundary area between the sub-arctic and central Pacific water masses is planned. Bottom photography, sediment studies and cooperative projects will be carried out with several other agencies and private institutions. The SURVEYOR will perform similar underway operations to the west between Midway and the Aleutians and will run a line of synoptic stations with the PIONEER. She will operate in areas of particular interest to the Navy.

In both FY 1963 and FY 1964, increasing amounts of oceanographic survey work are being added to the planned operations of the other major ships. The EXPLORER, in FY 1964, will carry out combined oceanographic and hydrographic surveys in the Cape Hatteras area, working within the general framework of the study of the Continental Shelf of the East Coast in which the Geological Survey and the Woods Hole Oceanographic Institution are cooperating.
The Duke University Marine Laboratory will cooperate in these studies. The PATHFINDER will conduct primarily hydrographic surveys in the Hawaiian Islands area and in the Gulf of Alaska. The HYDROGRAPHER in FY 1964 will be carrying out combined oceanographic and hydrographic operations in the Flordia Straits.

The survey activities of the Coast and Geodetic Survey, in FY 1964, reflect the continuing trend of adding more oceanographic survey work to the charting activities of the major ships, and of increasing the amount of ship time devoted to the ocean survey program.

\section{Department of Health Education and Welfare}

Public Health Service - Water Supply Pollution Program. Surveys undertaken in conjunction with water pollution represent marine studies requested in federal enforcement actions underway in Puget Sound and Raritan Bay, and in the development of comprehensive water pollution control programs for the drainage basins of the Delaware River, Columbia River, Susquehanna River, Chesapeake Bay, and the tri-state metropolitan area (New Jersey, New York, and Connecticut). A special project will be initiated to develop fundamental physical, chemical, and biological data on the interactions of pollutants and the marine environment, and the effects of water movements, marine geology, and similar factors on the dispersion and fate of pollutants in estuarine and near-shore waters.

Radiological Health Program. Public Health Service plans to continue its surveillance activities in estuaries in relation to the discharge of radioactive materials from nuclear energy facilities. The purpose of these studies is to determine in marine waters and in seafood the levels of radioactivity resulting from nuclear weapons testing and other sources in order to arrive at a better understanding of the fate of radionuclides in the marine environment. Results of these studies may disclose indicator organisms useful in detecting radioactive pollutants, as well as being useful in developing mechanisms for the removal of radioactive nuclides from the acquatic environment.

Shellfish Program. In cooperation with coastal states, surveys of shellfish-growing areas will be conducted in FY 1964.

Total funds for surveys to be conducted by the Public Health Service in FY 1964 amount to $\$ 600$ thousand. 


\section{Department of the Treasury}

Coast Guard. The Coast Guard plans to spend $\$ 313$ thousand for survey operations in FY 1964; an increase of $\$ 102$ thousand over FY 1963. This includes operations of the International Ice Patrol, the Bering Sea Patrol, Polar Operations, Ocean Surveys Patrols, and the Oceanographic Unit at Washington, D. C. Other Coast Guard activities which contribute to the national survey effort are the Ocean Station Vessels, the Fishery Patrols, lightships, and offshore stations.

The operations of this agency are closely coordinated with those of the Naval Oceanographic Office and of the Coast and Geodetic Survey, and space aboard Coast Guard vessels will again be made available to scientists from other government agencies and the private institutions.

\section{Smithsonian Institution}

Through the activities of the National Sorting Center, the Smithsonian Institution will obtain and process biological collections from many ships engaged in the Ocean Surveys Program.

TABLE 7

Summary of Proposed Support for Oceanographic Surveys FY 1964

(Thousands)

\begin{tabular}{|c|c|c|c|}
\hline & $\begin{array}{l}\text { Ocean } \\
\text { Sur - } \\
\text { veys }\end{array}$ & $\begin{array}{c}\text { Other } \\
\text { Mission- } \\
\text { Oriented } \\
\text { Surveys }\end{array}$ & Total \\
\hline $\begin{array}{l}\text { Naval Oceano- } \\
\text { graphic Office }\end{array}$ & $\$ 2,051$ & $\$ 9,144$ & $\$ 11,195$ \\
\hline $\begin{array}{l}\text { Coast and Geodetic } \\
\text { Survey }\end{array}$ & 3,849 & 4,131 & 7,980 \\
\hline $\begin{array}{l}\text { Bureau of Com- } \\
\text { mercial Fisheries }\end{array}$ & 125 & --- & 125 \\
\hline Geological Survey & 15 & $\ldots$ & 15 \\
\hline Coast Guard & --- & 313 & 313 \\
\hline \multicolumn{4}{|l|}{ Public Health } \\
\hline & $\overline{\$ 6,040}$ & $\overline{\$ 14,188}$ & $\$ 20,228$ \\
\hline
\end{tabular}

\section{E. MANPOWER AND TRAINING}

During the past year, the ICO Panel on Manpower and Training has been conducting an extensive study of the implications of an expanding National Oceanographic Program on the availability and employment of professionals trained in oceanography. In the same context, there was also some examination of the supply of professionals trained in sciences directly related to oceanography such as marine biology, meteorology, and geophysics. The general situation in oceanographic manpower, however, appears reasonably clear.

While opinions differ as to the extent of available manpower in different fields of oceanography, the study has verified the existence of a shortage of scientists trained in the two areas given intensive study, physical oceanography and marine taxonomy. Of course the latter field is much smaller in terms of manpower requirements.

If the numbers of graduate degrees currently awarded in these fields may be considered as an index of the number of scientists being trained, one may conclude that a much greater training effort will be necessary to meet the requirements of the research programs proposed for the close of the decade of the 1960's. The two specific fields cited should be considered illustrative only. Continued study may reveal shortages in other areas as well.

The research programs currently proposed by the ICO represent, in terms of expenditures, an increase of two thirds from the FY 1962 base to FY 1964 . While scientific manpower requirements engendered by these programs are not expected to increase in exact proportion, they are expected to expand by perhaps 50 per cent over the 1962 level.

Graduate schools awarded six doctorates and nine masters degrees in oceanography in academic year 1960-61, the most recent year for which national data have been reported by the Office of Education. Additional degrees were awarded in related sciences to students who can be expected to be strongly attracted to oceanographic research. This number cannot be judged with any precision with the information at hand, but the total number of doctorates awarded in related fields not requiring substantial additional training for application to oceanography probably would not exceed 20 in any recent year. A similar figure for masters degrees might be 40 . 
It seems clear that academic output at these levels will not by itself meet the additional requirements for professionally qualified personnel of the FY 1964 program. Continued expansion of in-service training programs will alleviate some of this shortage. Some improvement may also be achieved by increasing the ratio of technicians to scientists in order to free scientists for more direct application of their talents to research. For future years the research and facilities programs of the National Oceanographic Program, if properly implemented with this aim in mind, could provide a good part of the seeds for the augmentation of manpower specifically trained in oceanography. For FY 1964, and for the next few years of the program, the necessary personnel to maintain effective expansion of our efforts must come in part from related science fields. There is already some evidence that this mechanism is currently proving effective; it probably will have to be more widely exploited if the program as currently planned is to be adequately staffed during the next two or three years.

In summary, shortages of qualified personnel now exist in some areas of oceanography. It is almost certain that for the next several years the number of personnel completing graduate training in oceanography and related fields will not satisfy the need for research personnel. In order to prevent the personnel situation from jeopardizing this program, major efforts must be made in training programs for agency personnel, in the support of graduate students, in construction of training facilities, in the more effective utilization of present staffs, and, particularly for the immediate situation, in the recruitment of larger numbers of individuals from other scientific fields.

\section{F. INTERNATIONAL PROGRAMS}

Two principal international programs in oceanography will officially be part of the FY 1964 U. S. National Oceanographic Program: the International Indian Ocean Expedition (IIOE) and the International Cooperative Investigations of the Tropical Atlantic (ICITA). Both will be continuations of efforts undertaken during FY 1963.

The ICITA program will concentrate on the study of the dynamic properties of the ocean and atmosphere and the relation of these properties to the fishing potential in the tropical equatorial belt between the east coast of South America and the west coast of Africa. Included in the program are synoptic oceanographic stations to be made by all ships taking part. These will all initiate at the same time from the northern part of the area working south, thus giving as nearly as possible a synoptic picture of the entire tropical Atlantic. Population and productivity studies will be made concurrently with physical and chemical investigations. Between synoptic surveys, the U. S. and U.S.S.R. will occupy selected buoy stations to make current measurements. The meteorological program will include satellite observations. The Bureau of Commercial Fisheries, Coast \& Geodetic Survey, and several private institutions supported with federal funds will represent the United States. The National Oceanographic Data Center will be the focal point for the collation of the results of these investigations.

The Interagency Committee on Oceanography has designated the Bureau of Commercial Fisheries as the coordinating agency for this effort. A report describing the preliminary planning may be found in Appendix A.

The International Indian Ocean Expedition, initially organized under the auspices of the Scientific Committee on Oceanic Research (SCOR), is now being coordinated primarily through the Intergovernmental Oceanographic Commission. All aspects of oceanography are being undertaken in this endeavor, with emphasis on the effect of shifting monsoon conditions on the oceanic circulation and biological productivity of the area. Four general programs are being pursued. These are: (1) interaction of the sea and atmosphere, (2) description of the physical and chemical properties of the water, (3) investigation of the living population and, (4) a study of the geology and geophysics of the Indian Ocean Basin.

It is expected that six U. S. ships and one R5D aircraft will participate in the IIOE during FY 1964. Five of the ships and the aircraft will be from civilian research institutions supported for the most part by funds from the National Science Foundation and the Office of Naval Research. The sixth ship will be from the Coast \& Geodetic Survey.

Several international working group meetings will be held during this period to organize an effective mechanism for processing, analyzing, and interpreting the great quantity of data obtained and for making them available to all participants. The U. S. participation in the IIOF is being coordinated by the National Science Foundation. A detailed report of the program will be found in Appendix B. 
Numerous smaller international programs will be undertaken cooperatively between the U. S. and several Latin American countries. In general, these will be regional studies involving neighboring countries wishing to concentrate on problems too large for the capability of any individual country. Examples of this type of program are: (1) General Circulation of the Southwest Atlantic, (2) Investigation of the Brazil Current, (3) El Niño Study, and (4) Catalog of marine plankton in the Mediterranean.

\section{G. FACILITIES}

The construction and improvement of shore facilities to support oceanography is being continued in FY 1964 at a level of about 12.2 per cent over that of the previous year. The recommended expenditure for Government and nonGovernment activities is $\$ 10.3$ million. Although the total increase is small, the facilities budget includes $\$ 7.3$ million to support research facility construction for universities and other private institutions to increase their capabilities for training of oceanographers. The balance of $\$ 3.05$ million will be used for the expansion and improvement of existing federal facilities and for a modest program of new laboratory construction.

In FY 1964 the Bureau of Commercial Fisheries plans to begin constructing, or will have under construction, four new research laboratories. In the spring of 1963 construction will start on a new Biological Laboratory at La Jolla, California, for research on tuna, sardines, anchovies, other related species, and oceanography of the California Current and eastern tropical Pacific. In the summer of 1963 work will start on a new biological laboratory at Seattle, Washington, which will be concerned with the ocean-phase of salmon life history and other fishery problems of the eastern North Pacific. About the same time, construction of a biological laboratory at Milford, Connecticut, for specialized studies on large-scale artificial culture of shellfish and other marine organisms will commence. Construction will also get underway on a Radiobiology Laboratory at Beaufort, North Carolina, where the effects of radioactive isotopes on marine life will be studied.

The Geological Survey will establish a laboratory on the West Coast for research in marine geology and geophysics. The Bureau of

Mines will house its marine resources and engineering staff in temporary West Coast facilities during fiscal year 1964 . Plans will be formulated for the design and construction of a permanent Bureau oceanographic center at a convenient location at a later date.

The Coast and Geodetic Survey will improve its ship base at Norfolk, and will transfer its Seattle operations to a newly leased ship base. This latter installation is especially critical to the Coast and Geodetic Survey program. As its vessels for Ocean Surveys become available, this facility will provide the necessary logistic support for Pacific operations.

The National Science Foundation has programmed $\$ 7.3$ million in FY 1964 in grants for new and expanded oceanographic facilities in universities and private research institutions.

The FY 1964 budget for facilities construction and improvement, as outlined in Table 8, will help to relieve crowded working conditions in many locations and will provide housing for entirely new research groups and for training of new oceanographers. It will also allow growth in physical plants for research in step with planned expansion in research, surveys, and ships.

\section{H. NATIONAL OCEANOGRAPHIC DATA CENTER}

Manpower and Training. During FY 1962 , the National Oceanographic Data Center (NODC) provided personnel from its staff in support of survey operations and for reciprocal training; i.e., training of survey personnel in data processing procedures (primarily from the standpoint of quality control) and the training of NODC personnel in the many phases of survey operations. In addition, the NODC has trained visiting scientists and survey personnel in data processing procedures for short term periods. During FY 1964, the NODC will increase this effort within the limits of available funds. The NODC plans to recruit sufficient personnel by FY 1964 to handle the "data out" phase of its work in keeping with its policy of providing support service to the oceanographic community.

International Program. In its short period of existence, the NODC has assumed responsibilities connected with two international programs - complete responsibility for continuing the function of World Data Center A-Oceanography (WDC-A) and data processing responsibilities for the International Indian Ocean Expedition (IIOE). It has been suggested that, in addition to its data processing responsibilities to the IOE, the NODC undertake the preparation of an atlas for the Expedition under the guidance of an international board of editors composed of 
$\frac{\text { FACILITIES PROGRAM }}{\frac{\text { TABLE } 8}{\text { PRO } 1964}}$

Dept. - Agency

DEFENSE - Total

Navy - Total

INTERIOR - Total

BCF - Total

GS - Total

BSF\&W - Total

COMMERCE - Total

C\&GS - Total

NATIONAL SCIENCE

FOUNDATION - Total

TREASURY - Total

CG - Total
Purpose

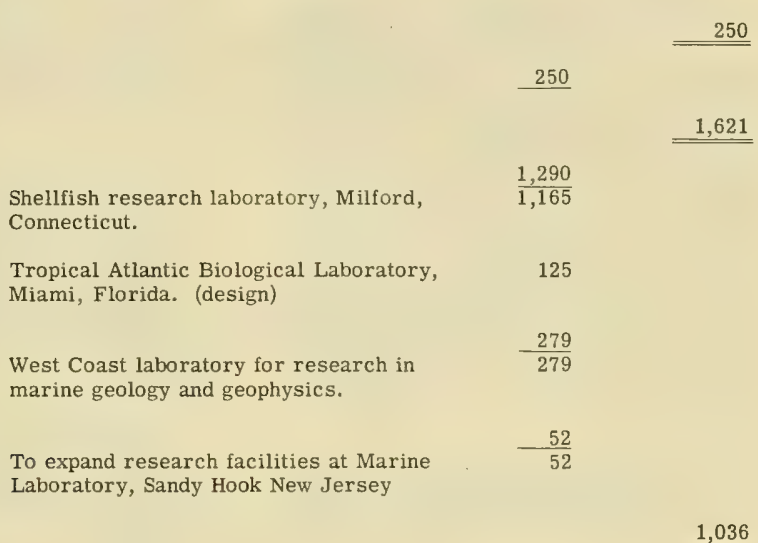

Construction of new ship base at Norfolk and acquisition of leased base in Seattle, Washington

Construction of facilities for physical and biological oceanographic research and education.

\section{$\underline{7,300}$}

For oceanographic units at Woods Hole.

For oceanographic facilities on two offshore structures. 
network for receipt of oceanographic data from Arctic areas. It has been suggested that the University of Alaska might be the logical place to initiate this service.

Ocean Surveys. With the acceleration of oceanographic survey programs in the next ten years, rapid communication of oceanographic data will be essential to the success of a national program in oceanography. A transmitting and receiving capability to be established at NODC and aboard ships will eliminate routine processing of raw data aboard ships. Raw data can be transmitted to the NODC and by the use of computers it will be possible to transmit fully processed data back to the ships for analysis and planning future operations. Scientists aboard ships will no longer be in doubt as to whether they have obtained valid data, whether their sampling has been sufficient, and whether additional sampling will be required in the area. With present techniques aboard ships, it is virtually impossible to have raw data reduced to meaningful information before leaving the station or area.

As in the past, the NODC will assist in presurvey planning through data analyses, data summaries for particular areas, the production of atlases, etc.

Instrumentation. The NODC will evaluate the data output of existing instruments to provide advice on new instrumentation, and to assist in choosing instrumentation to be purchased, through evaluating the precision of a given instrument, quality of data obtained from the instrument, and the requirements to be placed on the data. The NODC also will advise on, and develop methods for, recording, reducing, and storing data from present and future instrumentation to obtain maximum use of the output from new instruments.

New Data Areas. In FY 1964, the NODC plans to develop a capability for processing radiation and ice data from space satellites. The processing of oceanographic data from satellites will be done with the cooperation of both the National Aeronautics and Space Agency and the Weather Bureau.

At the present time, both the Naval Oceanographic Office and the Coast and Geodetic Survey have amassed a considerable backlog of bathymetric data. With retrieval systems currently under development the NODC will have acquired a capability for handling these data by the end of FY 1964. At that time, the reduction of this backlog may be initiated by contract with industry.

\section{CONCLUSION}

The National Oceanographic Program for Fiscal Year 1964 provides for the further advancement of the Nation's effort in the marine sciences. The experience of the past two years has been heavily drawn upon for guidance in the most productive use of the funding outlined herein.

The ICO is nearing publication of its Long Range National Program, and the FY 1964 program has been prepared within the framework of this long range planning, as will future annual programs.

Within the functional areas of interest, the ICO will have completed its study of the shortage of oceanographic manpower and will have outlined the problem and commenced the steps to be taken in its solution. The 1963 edition of the successful "College Curricula in Oceanography" is also expected to prove helpful in this regard.

Surveys will receive special attention with promulgation of the "Ocean Survey Plan." The ICO is hopeful that dissemination of these types of information will aid communications in the marine sciences and provide better guidance for planning and conduct of projects. It is in this manner that we believe we can be most helpful in achieving the understanding of the oceans so necessary for enhancement of the national welfare. 


\section{NATIONAL OCEANOGRAPHIC PROGRAM BUDGET}

\section{(Thousands)}

\section{Actual}

FY 1962

A. BY AGENCIES

Defense

Commerce

Interior

National Science Foundation

Atomic Energy Commission

Health, Education, and Welfare

Treasury

Smithsonian Institution

$$
\begin{array}{r}
\$ 42,081 \\
23,567 \\
14,252 \\
17,321 \\
4,106 \\
3,109 \\
134 \\
217 \\
\hline \$ 104,787
\end{array}
$$

B. BY FUNCTIONAL AREAS

$\begin{array}{lr}\text { Research } & \$ 39,023 \\ \text { Instrumentation } & 3,000 \\ \text { Ships } & 34,010 \\ \text { Surveys } & 17,366 \\ \text { IIOE } & 1,974 \\ \text { Facilities } & 8,904 \\ \text { Data Center } & 510 \\ & \frac{\$ 104,787}{}\end{array}$

\section{Estimated} FY 1963

President's Budget FY 1964

$\$ 74,966$

24,792

18,960

25,801

5,330

4,820

1,152

531

$\$ 156,352$ 


\section{INDIVIDUAL AGENCY BUDGETS}

\section{Agency - Function \\ DEFENSE - TOTAL}

Navy - Total

Research

Instrumentation

Ships Construction

Surveys

IIOE

Facilities

Data Center

Army - Total

Research

\section{COMMERCE - TOTAL}

Coast \& Geodetic Survey - Total

Research

Instrumentation

Ship Construction

Surveys

IIOE

Facilities

Data Center

Weather Bureau - Total

Research

Data Center

Maritime Administration - Total

Research

INTERIOR - TOTAL

BCF - Total

Research

Instrumentation

Ship Construction

Surveys

IIOE

Facilities

Data Center

\begin{tabular}{|c|c|}
\hline $\begin{array}{c}\text { Actual } \\
\text { FY } 1962 \\
\end{array}$ & $\begin{array}{c}\text { Estimated } \\
\text { FY } 1963 \\
\end{array}$ \\
\hline$\$ 42,081$ & $\$ 55,246$ \\
\hline 41,593 & 54,621 \\
\hline $\begin{array}{r}15,692 \\
2,150\end{array}$ & $\begin{array}{r}19,559 \\
5,370\end{array}$ \\
\hline 13,600 & 18,153 \\
\hline 9,321 & 9,889 \\
\hline 580 & 1,300 \\
\hline-- & --- \\
\hline 250 & 350 \\
\hline 488 & 625 \\
\hline 488 & 625 \\
\hline
\end{tabular}

President's

Budget FY 1964

$\$ 74,966$

73,892

25,395

6,128

28,000

11,195

2,500

250

424

1,074

1,074

$\$ 23,567$

$\$ 24,024$

$\$ 24,792$

23,384

23,791

482

890

14,400

7,667

---

80

183

173

10

50

50

50

$\$ 14,252$

$\$ 16,102$

$\$ 18,960$

13,619

15,320

16,900

7,409

3,225

...

2,905

80

9,747
70
2,650
20
102
2,651
80

11,902

223

3,065

125

154

1,290 


\section{INDIVIDUAL AGENCY BUDGETS - (Contd)}

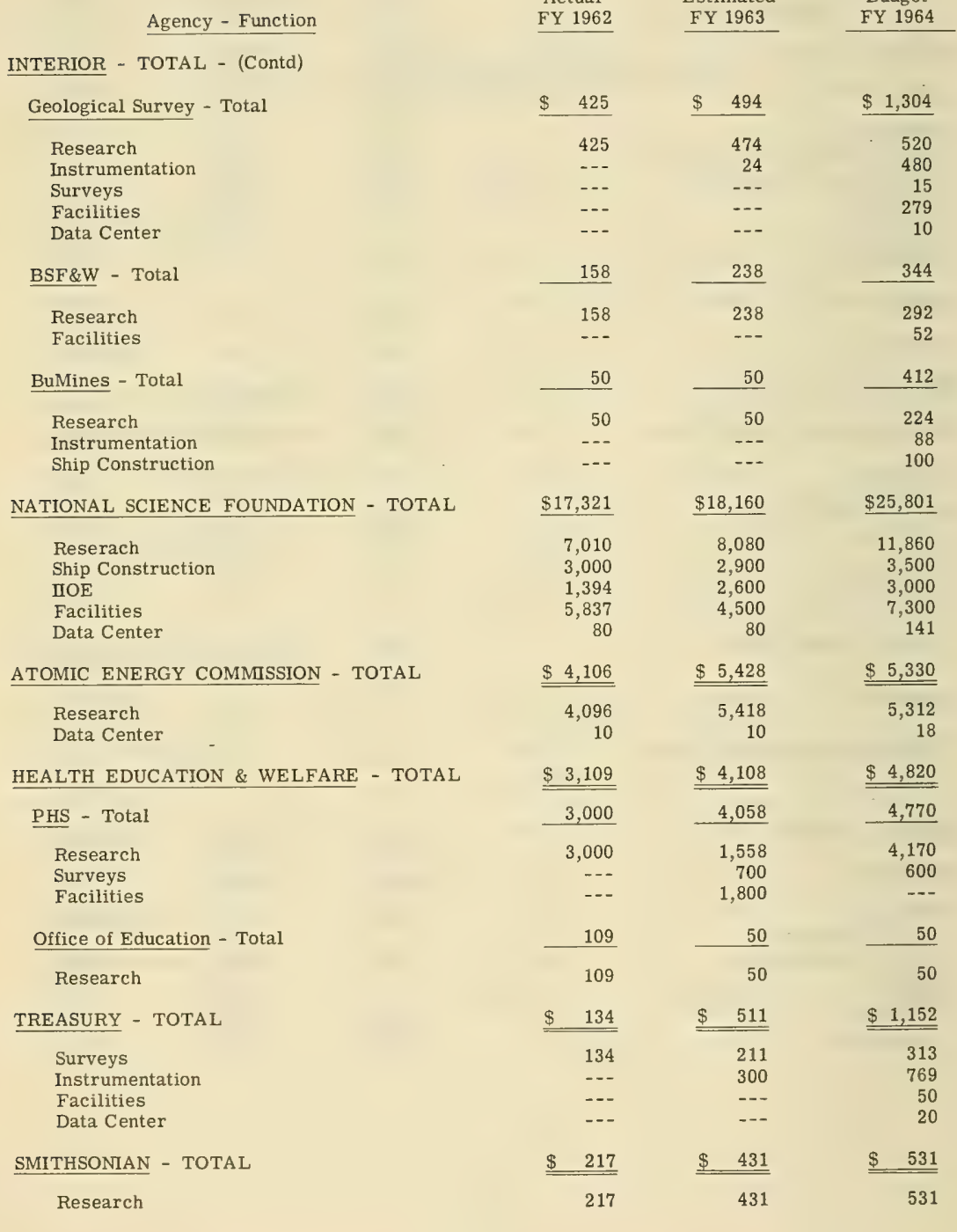




\title{
APPENDIX A \\ THE INTERNATIONAL COOPERATIVE INVESTIGATION OF THE TROPICAL ATLANTIC
}

\author{
Prepared by Vernon E. Brock, International Coordinator, ICITA
}

\section{BACKGROUND}

In early 1961, two programs were proposed for oceanographic and fishery studies in the Gulf of Guinea:

1. A study of the demersal fisheries off the west coast of Africa, by the Commission for Technical Cooperation in Africa, South of the Sahara (CCTA).

2. An investigation of the pelagic fishes of the Gulf of Guinea by the Bureau of Commercial Fisheries (BCF).

Each proposal included plans for supporting physical, chemical and marine biological studies. When a request for support to the Agency for International Development (AID) by CCTA brought its program to the attention of the Bureau of Commercial Fisheries, it was proposed that the CCTA and BCF investigations be carried out cooperatively. - In late 1961, at a meeting in Lagos, Nigeria, the details of cooperation between these programs were formulated.

The Bureau's proposed program was presented to and accepted by the Inter-Agency Committee on Oceanography and approved by the National Academy of Sciences Committee on Oceanography.

In February, 1962, the BCF held a meeting of oceanographers from the eastern United States to determine their interest in a cooperative investigation of the waters of the Tropical Atlantic. At this meeting a high level of interest was apparent, augmented plans for research were developed, and it was proposed that these be submitted to the Intergovernmental Oceanographic Commission (IOC) for consideration as an international effort.

The plans were presented to the Bureau of the IOC in April, 1962, and at the suggestion of this Bureau the U.S. Department of State issued an invitation to interested Member Nations and activities of the IOC to send representatives to a Working Group Meeting in Washington, D. C.
The representatives met in June, 1962, and developed plans for the International Cooperative Investigations of the Tropical Atlantic (ICITA) which were adopted at the Second Session of the IOC in Paris in September, 1962. Nomination of Mr. V. E. Brock of the Bureau of Commercial Fisheries as International Coordinator by members of the International Coordination Group for the ICITA was approved by the Secretariat of the IOC.

The ICITA plans developed at the Working Group Meeting in June, 1962, and adopted by the IOC involves mid-winter and mid-summer, multiple vessel, synoptic surveys of the Tropical Atlantic, from Africa to South America and from $18^{\circ} \mathrm{N}$ to $18^{\circ} \mathrm{S}$ latitude. The first of these two surveys, designated as EQUALANT I, was scheduled to start on February 15, 1963; the second, EQUALANT II, on August 1, 1963.

EQUALANT I involves two 15-day synoptic surveys; separated by a 15-day period. EQUALANT II will involve one 15-day, multiple vessel, synoptic survey.

Fourteen vessels from seven nations are scheduled to participate in EQUALANT I. These include five from the United States (CHAIN, CRAWFORD, EXPLORER, GERONIMO and OREGON), three from the Soviet Union (LOMONOSOV, ZVEZDA and OLONEZ), two from Brazil (BAEPENDI and BERTIOGA) and one each from Argentina (A.R.A. COMODORO LASERRE), Republic of Ivory Coast (REINE POKOU), Nigeria (KIARA), and Republic of Congo, Brazzaville (OMBANGO). See Figure 1 for vessel tracks, EQUALANT I.

It is anticipated that 16 vessels from 10 nations will participate in EQUALANT II. These include five from the United States (ALAMINOS, GERONIMO, PILLSBURY and possibly the HORIZON and one U. S. Coast Guard vessel, three from the USSR, one each from Republic of Ivory Coast, Nigeria, Republic of Congo (Brazzaville) and possibly one each from Brazil, Argentina, Spain, Japan and Poland.

In brief; the plans for the programs common to all vessels call for oceanographic stations to 
2000 meters, with observations to the bottom at 120 mile intervals. Standard observations from all of the 14 participating vessels during the 15-day periods include:

1. Temperature, salinity, oxygen and phosphate at each depth sampled at each station;

2. Measurement of the rate of primary productivity using the Carbon 14 isotope technique and measurement of the standing crop of zooplankton at least once each day; and

3. Surface meteorological observations (upper air observations from selected vessels).

In addition to the observations common to each vessel, a number of oceanographic, biological, and geophysical programs will be carried out by scientists from activities operating the vessels or by scientists from other United States and foreign oceanographic laboratories who will be working aboard the vessels.

\section{UNITED STATES PARTICIPATION IN THE ICITA}

\section{Research Vessel Commitments}

\section{EQUALANT I (February 15 to March 18, 1963)}

Five United States vessels are scheduled to participate in EQUALANT I; the CHAIN and CRAWFORD (Woods Hole Oceanographic Institution), GERONIMO and OREGON (Bureau of Commercial Fisheries) and the EXPLORER (U.S. Coast and Geodetic Survey). As may be seen from Figure 1, the GERONIMO will work in the Gulf of Guinea, the EXPLORER in the central area, the CHAIN and CRAWFORD in the western sector and the OREGON in the waters off the northeast Coast of Brazil.

Special requirements imposed by various research programs aboard these vessels and logistical considerations will result in some deviations by individual ships from the schedules and plans as proposed by participants in the IOC Working Group Meeting.

\section{EQUALANT II (August 1 to August 15, 1963)}

Three U.S. vessels, GERONIMO (Bureau of Commercial Fisheries), ALAMINOS (Texas A \& M) and PILLSBURY (University of Miami) are firmly committed to participate in EQUALANT II; two others are tentatively committed, the HORIZON (Scripps Institution of Oceanography) and an as yet undesignated vessel operated by the U.S. Coast Guard. Various U.S. Government and University activities, other than those directly concerned with vessel operations, will participate in the ICITA.

\section{CONTRIBUTIONS OF PARTICIPATING ORGANIZATIONS}

\section{U. S. WEATHER BUREAU (USWB)}

\section{Marine Unit}

Surface Observations - Surface meteorological observations will be assembled from each vessel (standard six-hour observations forwarded through Radio Central) and from other sources in the ICITA area (merchant vessels and shore stations) for preparation of daily forecasts. These forecasts will be transmitted to participants each day by the USWB. Where necessary, instruments will be provided, vessel personnel instructed, and $\log$ sheets and instruction manuals forwarded to each vessel. Weather Bureau observers will be assigned to the EXPLORER, GERONIMO and CHAIN. Subsequent to the ICITA field operations, the USWB will prepare daily summary charts of selected parameters for publication in the ICITA Atlas.

Upper Air Observations - The upper air observing program includes NWSC supported pibal installations of the GERONIMO and CHAIN and ONSF supported radio-sonde observations from the EXPLORER. The Weather Bureau observer aboard each of these three vessels will be assisted by a member of the scientific party.

\section{National Weather Satellite Center}

Special Cloud Observations - Observations of clouds, including a simple sketch of high, middle and low cloud layers and related data, are to be made daily from each vessel. During daylight hours these observations will be made at time of TIROS satellite transits over the ICITA area. Supplemental cloud photographs will be taken by the USWB observers for correlation with aircraft and satellite photographs.

Sea Surface Radiation Measurements - Six vessels will be provided with Suomi-Kuhn. radiometers to measure long wave radiation from the sea surface.

Airplane Overflights - Overflights of the ICITA area by fully instrumented USWB 
hurricane reconnaissance airplanes are scheduled during the first synoptic period of EQUALANT I (provided that a TIROS satellite is in operation). Two DC-6 type planes will fly parallel tracks 300 miles apart from Recife to Dakar and return the following day. If TIROS operations permit, an extra flight may be made from Dakar over the ICITA area prior to the return to Recife.

\section{BUREAU OF COMMERCIAL FISHERIES (BCF)}

\section{Vessel Operation: EQUALANT I - GERONIMO and OREGON}

\section{EQUALANT II - GERONIMO}

In an effort to standardize biological data, the Bureau of Commercial Fisheries provided each participating vessel with all necessary equipment and supplies for the determination of primary productivity and measurements of the standing crop of the zooplankton. Arrangements are being made for performing the essential Beta counting services for the primary productivity measurements and for determination of . the displacement volume of each zooplankton sample.

Mr. Vernon E. Brock, Director, Bureau of Commercial Fisheries Biological Laboratory, Washington, D.C., was approved by the IOC Secretariat as the International Coordinator for the ICITA. His duties, as defined in a resolution adopted by the IOC, include, in part, "coordinating and advising concerning schedules and programs of observations... keeping all participants of the ICITA and interested organizations informed....assisting, where practicable', in procurement, loan and exchange of equipment... convening meetings of the International Coordination Group and implementing the assembly and preparation of the data resulting from the ICITA for publication and preparation and publication of the Atlases."

\section{U. S. COAST AND GEODETIC SURVEY (USC\&GS)}

\section{Vessel Operation: EQUALANT I - EXPLORER}

Bathymetry - Plotting sheets and instructions for their use were prepared by the USC\&GS for use aboard each participating vessel, both U.S. and foreign. It is anticipated that following the field surveys these plotting sheets will be assembled by the NODC and copies provided to $\mathrm{WDC} / \mathrm{A}$ and $\mathrm{WDC} / \mathrm{B}$.

Drift Cards - Several thousand drift cards were prepared by the USC\&GS for release from the ICITA vessels. Each card, laminated in plastic, carries instructions printed in English, French, Portuguese, Spanish and Russian.

Tidal Data - The Tide Section of the USC\&GS will assemble all tide data from stations in the ICITA survey area for the period of the investigations. These data will be prepared for publication, as applicable, in both the Data Reports and the Atlas.

Radio Central - The EXPLORER will serve as radio central during EQUALANT I. The communication capabilities aboard the vessel were considerably augmented by the USC\&GS for the purpose. Instructions for transmitting the encoded surface weather and upper air observations, as prepared through coordinated effort of the USWB, USC\&GS, USCG, USAF, and NODC, were distributed to each vessel. The daily forecasts for the survey area, prepared by the USWB, will be received from NSS Washington and re-broadcast from the EXPLORER.

\section{NATIONAL OCEANOGRAPHIC DATA CENTER (NODC)}

The NODC, at the request of the International Coordinator, assumed responsibility for assembly and shipment of various encoding forms for oceanographic data, coding manuals, BT log sheets and instructions, meteorological reporting forms and manuals, plotting sheets for navigational purposes, and instructions for selected standardized observations. (Translated into French, Spanish and Russian by the Department of State.) Sets of each of the above were furnished to each participating vessel.

In cooperation with the USC\&GS, the NODC arranged the communication plan and schedules for use during EQUALANT I. In addition to the arrangements for communications among radio central (EXPLORER) and the other vessels, arrangements were made with Captain L. Capurro of the Argentine Hydrographic Office for transmission to the NODC of the data from at least one complete oceanographic station each day. Vertical sections of temperature, salinity, density and oxygen will be maintained as these data are received via teletype through the Potomac River Naval Command.

It was proposed by the participants in the June Working Group Meeting that the NODC 
assemble, exchange and publish the data from both EQUALANT I and II, and prepare and arrange for publication of the ICITA Atlas. A proposal for review by the International Coordination Group (the "Editorial Board") is in preparation.

\section{U. S. NATIONAL MUSEUM (USNM)}

A scientist from the USNM, working from the GERONIMO, will collect and preserve fishes (shipboard trawl hauls, night lighting, and shore collections) for return to the National Sorting Center. All zooplankton samples collected during the 15-day synoptic periods are to be shipped to the Bureau of Commercial Fisheries, Biological Laboratory, Washington, D. C. After determination of displacement volumes, these samples will be sent to the National Sorting Center, USNM, for sorting, identification of organisms, and preparation of lists of such identifications.

\section{AGENCY FOR INTERNATIONAL DEVELOPMENT (AID)}

Funds were provided by AID for support of the CCTA Trawling Campaign and for purchase of oceanographic equipment for use aboard the REINE POKOU (Republic of the Ivory Coast) and the KLARA (Nigeria).

\section{U. S. NAVY OCEANOGRAPHIC OFFICE (USNOO)}

The USNOO assisted in preparation of the salinity samples for use in intercalibrating the data from analyses made aboard the participating vessels, provided bathymetric charts for use aboard the vessels and prepared and printed a compilation of charts depicting the distribution of various oceanographic properties in the ICITA area.

\section{U. S. COAST GUARD}

Vessel Operation: undesignated vessel in EQUALANT II (commitment not firm).

\section{DEPARTMENT OF STATE}

The United States State Department arranged clearance for U.S. vessels to operate in territorial waters of foreign nations, expedited. through arrangements with American Embassies, the shipment and delivery of equipment to the participating foreign laboratories and vessels, and translated instructions for various types of observations and sampling techniques, common to each vessel, into French, Spanish and Russian.

\section{NON-GOVERNMENTAL ORGANIZATIONS}

\section{Vessel Operation:}

Woods Hole Oceanographic Institution CHAIN and CRAWFORD in EQUALANT I

Texas A \& M - ALAMINOS in EQUALANT II

\section{University of Miami - PILLSBURY in EQUALANT II}

Scripps Institution of Oceanography - HORIZON in EQUALANT II (commitment not firm).

U.S. scientists from Bingham Oceanographic Laboratory, Yale University, Institute of Marine Sciences of the University of Miami, New York University, Scripps Institution of Oceanography, and Johns Hopkins University will undertake various oceanographic, marine biological, geological, and geophysical programs aboard the U.S. vessels. Oceanographers from Texas A \& M will participate aboard the Argentine vessel A.R.A. COMODORO LASERRE.

The details of programs summarized above relate primarily to EQUALANT I (February March, 1963): Preliminary plans for EQUALANT II (August 1963) were prepared by participants in the June IOC Working Group Meeting. Preliminary plans and schedules are now in preparation; some final details must await consideration of results from EQUALANT I. 


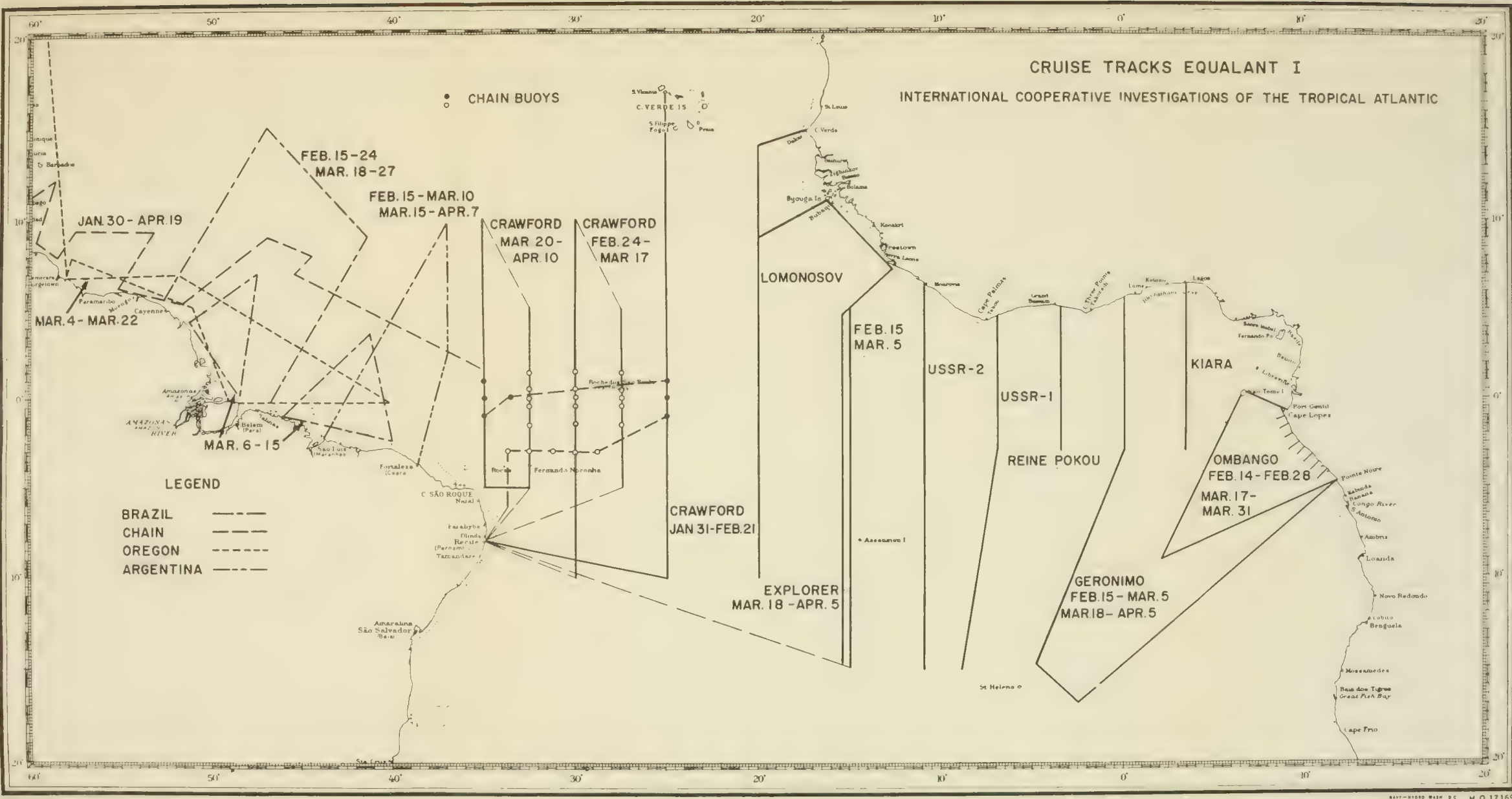




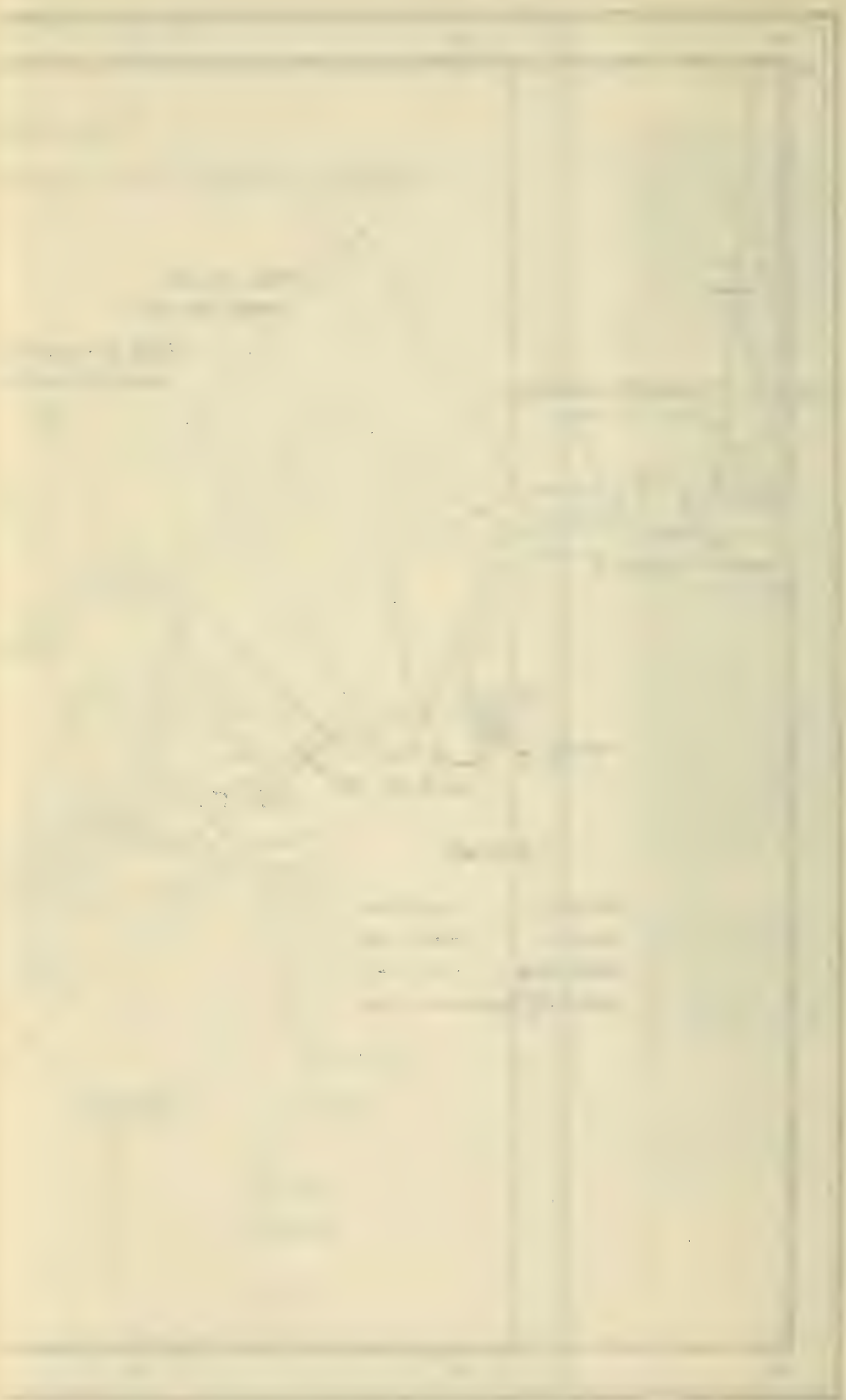




\title{
APPENDIX B
}

\section{UNITED STATES PARTICIPATION}

\author{
IN THE
}

\section{INTERNATIONAL INDIAN OCEAN EXPEDITION}

\author{
Prepared by John Lyman, Indian Ocean Coordinator, National Science Foundation
}

\section{ORGANIZATION AND HISTORY}

The International Indian Ocean Expedition (IIOE) was conceived at the first meeting of the Special Committee of Oceanic Research (SCOR) of the International Council of Scientific Unions (ICSU) in September 1958. United States participation was initially planned by the Committee on Oceanography of the National Academy of Sciences (NASCO). The preliminary plan was presented to the Federal Council of Science and Technology in May 1960, and approval for United States participation was announced by the White House on June 13,1960. Scientific responsibility for the United States participation was assigned to the National Academy of Sciences National Research Council, and the National Science Foundation was directed to plan and coordinate Federal support for United States participation in the program.

At the request of the Director of the $\mathrm{Na}$ tional Science Foundation, other Federal agencies with potential interest in the $\Pi O E$ appointed representatives to serve as single points of contact and facilitate communication among the agencies. As a result of meetings of these representatives held during the summer of 1960 , it was determined that the preliminary plans were inadequate to carry out the stated aims of the IIOE, particularly in the areas of biological oceanography and of air-sea interaction, and following international meetings held by SCOR at Copenhagen and Helsinki in July 1960, NASCO enlarged its Indian Ocean Expedition Panel, set up five Working Groups (Biology; Geology, Geophysics, and Bathymetry; Meteorology; Physical and Chemical Oceanography; and Expedition Data, respectively), and drew up an enlarged program for U. S. participation.

During the spring of 1962 it was agreed between SCOR and the new International Oceanographic Commission (IOC) that henceforth the Secretary of the IOC would have responsibility for coordination of the IIOE. Simultaneously NASCO, as the United States adhering body to SCOR, has felt it inappropriate for it to continue to coordinate the United States participation in the IIOE, and full responsibility for the United States program thus has been assumed by the National Science Foundation.

\section{FINANCIAL SUPPORT}

The original Presidential directive in June, 1960 , provided that United States participation in the חIOE would be funded by normal budgetary process. Accordingly, the United States Navy, historically the chief Federal sponsor of basic research in oceanography through its Office of Naval Research, agreed to permit vessels whose operations it finances through research contracts at Scripps Institution of Oceanography, Woods Hole Oceanographic Institution, and Lamont Geological Observatory to undertake cruises to the Indian Ocean. Likewise the dataprocessing facilities at the Navy Oceanographic Office were put at the disposal of the U.S. participants, and survey vessels in the Indian Ocean were assigned to make oceanographic observations in support of the IIOE.

The National Science Foundation, which supports research through grants made as the result of applications proposing specific research projects, encouraged United States research institutions to submit proposals for research connected with the חOE, and took steps to augment its available research funds by the inclusion of a special item for the IIOE, commencing with its Fiscal Year 1962 budget.

Other Federal agencies have been less successful in obtaining the additional funding required to permit them to operate themselves in the Indian Ocean or to support research there in fields related to their specific missions, and in some cases the National Science Foundation has transferred funds to enable these agencies to carry out urgent programs related to the IIOE.

The following tabulation, extracted from the 1963 National Oceanographic Program, 
prepared by the Interagency Committee on Oceanography of the Federal Council of Science and Technology (with the addition of information from the U. S. Weather Bureau) summarizes planned Federal support of the U. S. participation in the IIOE through Fiscal Year 1963:

\section{THOUSANDS OF DOLLARS}

\begin{tabular}{lccr}
\multicolumn{1}{c}{ Fiscal Year } & $\underline{1961}$ & $\underline{1962}$ & $\underline{1963}$ \\
USN & 760 & 580 & 1,300 \\
NSF & - & 1,500 & 4,000 \\
Bur. Com. Fish. & - & - & 70 \\
Weather Bureau & - & - & 792
\end{tabular}

\section{SCIENTIFIC PROGRAM BY DISCIPLINES}

The United States program for the IOE, in accordance with the original stated aims of the expedition, is devoted to the scientific examination of four great areas of interest in the Indian Ocean. The first of these concerns itself with the problems of why there is an ocean basin in the first place; what are the forces that have shaped and are continuing to shape the basin; what are the resemblances between this piece of the earth's crust and any other; and how is the basin of the Indian Ocean dissimilar from other ocean basins? The technicues used in attempting to answer these questions are primarily geophysical and geological, and they have been or will be employed on expeditions sent out by Scripps Institution of Oceanography, Lamont Geological Observatory, Stanford University, and Woods Hole Oceanographic Institution.

The second broad area of investigation involves the chemical and physical description of the waters of the Indian Ocean, and the study of their motions. The techniques used involve sampling of the waters in predetermined patterns, with respect both to horizontal distribution and to vertical spacing of the samples; concurrent precise measurements of water temperature; subsequent $\mathrm{ch}=\mathrm{mical}$ and isotopic analyses of the water samples; and determination of current flow at various depths by all possible means. All United States ships participating in the IIOE will be equipped for such water sampling, and the direct measurement of current flow is the particular object of a University of Rhode Island expedition embarked in the Scripps Institution vessel ARGO (Knauss, 1961).
The third major field of interest is the living populations, plant and animal, of the Indian Ocean. All United States ships will be equipped to sample plankton and to observe surface biological phenomena, and some will measure primary productivity. The research vessel ANTON BRUUN will have biological oceanography as her primary mission, and the Stanford University vessel TE VEGA will concentrate on biological and physiological studies of island groups and other shallow water areas.

The fourth main area of research is concerned with the interaction between the ocean and the atmosphere. Several of the U. S. research vessels that will work in the Indian Ocean will be equipped to make upper-air meteorological observations, but the United States will have the greater part of its meteorological effort based ashore. Observations from meteorological aircraft of the U. S. Weather Bureau and of Woods Hole Oceanographic Institution, working in connection with the International Meteorological Center that has been established with the assistance of the Government of India and the United Nations Special Fund; from meteorological satellites; and from meteorological buoys (to be planted in the Bay of Bengal and Arabian Sea with the help of the Indian Navy), will be utilized in the program (Ramage, 1962).

\section{SCIENTIFIC PROGRAMS OF INSTITUTIONS}

As indicated in the preceding paragraphs, research programs of all United States vessels participating in the חOE will contribute to at least two of the four fundamental areas of interest; many will contribute to three; and some to all four. For this reason, it is more practical to describe the programs in detail by setting forth the past, present, and planned cruises of each institution.

\section{SCRIPPS INSTITUTION OF OCEANOGRAPHY}

The Scripps Institution of Oceanography of the University of California at San Diego plans to undertake three major cruises to the Indian Ocean under the overall direction of Dr. Robert L. Fisher. The first of these, called MONSOON, was carried out by the research vessel ARGO according to the following itinerary: 
1960

19 October

23 October

13 November

14 November

18 November

7 December

10 December
Schedule

ARGO left Darwin

Joined by $M / V$ MALITA

MALITA detached

ARGO arrived Jakarta

ARGO left Jakarta

Arrived Mauritius

Left Mauritius

\section{Program}

Geological-geophysical exploration, under Dr. R. L. Fisher. Emphasis on two-ship seismic refraction work between Darwin and Jakarta.

Same program, except for seismic refraction. Emphasis on heat flow, large-volume water-sampling; topography.

Same

Arrived Fremantle
Left Fremantle
Arrived Hobart
Left Hobart
Arrived Wellington

Arrived Fremantle

Left Hobart

Arrived Wellington

The following observations were made between Darwin and Wellington:

\section{Underway Observations}

Precision depth recordings

Gravimeter recordings

Towed proton precession magnetometer recordings

Insect collection, nets on superstructure

Bathythermograms

Surface Water Samples (for radio caesium).

\section{Station Operations}

$\begin{array}{lc}\text { Seismic refraction stations } & 16 \\ \text { Gravity cores } & 48 \\ \text { Piston cores } & 6 \\ \text { Heat flow measurements by temperature probe } & 33 \\ \text { Hydrographic casts to bottom } & 18 \\ \text { Special 2-liter water samples } & 13 \text { stations } \\ \text { Midwater trawl hauls } & 13 \\ \text { One-meter standard plankton tows } & 18 \\ \text { 17-cm vertical microplankton hauls } & 49 \\ \text { Bottom samples (biological) } & 7 \\ \text { Rock dredges } & 6 \\ \text { Large-volume water samples (C } & 14 \text { and trace elements) } \\ \text { Bottom photography } & 18 \text { stations } \\ \end{array}$

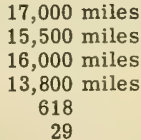

29

In addition, some seismic reflection shooting was carried out, occasional air samples were taken, gravity was measured in ports of call; rocks and biological specimens were collected in ports of call; and large organisms were dip-netted at light lures on most night stations.

The second Scripps cruise, called LUSIAD, is also being carried out by the R/V ARGO, according to the following itinerary:

$\underline{1962}$

\section{June}

24 July

27 July

25 August

28 August

25 September
Schedule

Leave Singapore Arrive Mombasa

Leave Mombasa

Arrive Colombo

Leave Colombo

Arrive Cochin

\section{Program}

Studies of equatorial circulation during one monsoon season, under Dr. John Knauss. Hydrographic casts and direct current observations with the aid of anchored buoys. 


\section{2}

1 October

26 October

28 October

29 November

2 December

23 December

27 December

\section{Schedule}

Leave Cochin

Arrive Port Louis, Mau.

Leave Port Louis

Arrive Fremantle

Leave Fremantle

Arrive Port Darwin

Leave Port Darwin

\section{Program}

In company $\mathrm{R} / \mathrm{V}$ HORIZON: two-ship seismic refraction work under Drs. George G. Shor, R. W. Raitt, and R. L. Fisher. Bottom-sampling; hydrographic casts; heat-flow measurements. $\mathrm{C}^{14}$ collections under Dr. N. W. Rakestraw. Topography, magnetism, gravity, underway measurements; under Dr. R. L. Fisher

\section{3}

15 January

18 January

14 February

17 February

15 May

18 May

7 June
Arrive Jakarta
Leave Jakarta
Arrive Visakhapatnam
Leave Visakhapatnam
Arrive Mombasa
Leave Mombasa
Arrive Cape Town

Repeat equatorial circulation during second monsoon, under Dr. Knauss. Geological-geochemical-geophysical observations under Drs. George Bien, John Belshé, and Charles Keeling.

The itinerary of the R/V HORIZON during LUSIAD is scheduled as follows:

\section{2}

16 September

17 September

27 September

1 October

26 October

28 October

29 November

2 December

23 December

\section{Schedule}

Leave Suez

Arrive Aden

Leave Aden

Arrive Cochin

Leave Cochin

Arrive Port Louis, Mau.

Leave Port Louis

Arrive Fremantle

Leave Fremantle

Arrive Port Darwin

Besides serving as consort to the $\mathrm{R} / \mathrm{V}$ ARGO between Cochin and Port Darwin, the HORIZON will carry out hydrographic studies between Suez and Cochin and from Port Darwin she will return to San Diego via the Pacific. Figure 1 shows the track of MONSOON and Figure 2 that of LUSIAD.

The third planned Scripps cruise will be carried out by the R/V SPENCER F. BAIRD between February and May 1964 under W. R. Riedel. Emphasis will be on detailed stratigraphic, geochemical, and heat flow development in the central and eastern Indian Ocean where earlier cruises have indicated areas of especial interest. Continuous underway magnetometer recordings will also be made.

\section{LAMONT GEOLOGICAL OBSERVATORY}

Three cruises of the $\mathrm{R} / \mathrm{V}$ VEMA have been planned as part of the IIOE.

\section{Program}

Conduct underway reflection profiling of Red and Arabian Seas.

In company $\mathrm{R} / \mathrm{V}$ ARGO; two-ship seismic refraction work under Drs. George G. Shor, R. W. Raitt, and R. L. Fisher. Bottom-sampling, hydrographic casts, heat-flow measurements.

\section{VEMA 16 Itinerary Figures 3 and 4}

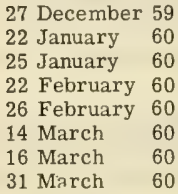

Left Cape Town Arrive Mauritius Left Mauritius Arrive Fremantle Left Fremantle Arrive Adelaide Left Adelaide Arrive Wellington

Under the direction of C. Fray, as Chief Scientist, VEMA made the passage from Cape Town to Mauritius and from Mauritius to Fremantle. More than 8300 miles of topographic track was recorded with a precision depth recorder in the southern Indian Ocean. The existence of a mid-ocean ridge and associated rift valley was verified by six crossings of this topographic feature. A towed magnetometer produced a continuous plot of the totai intensity of the earth's magnetic field along the ship's 


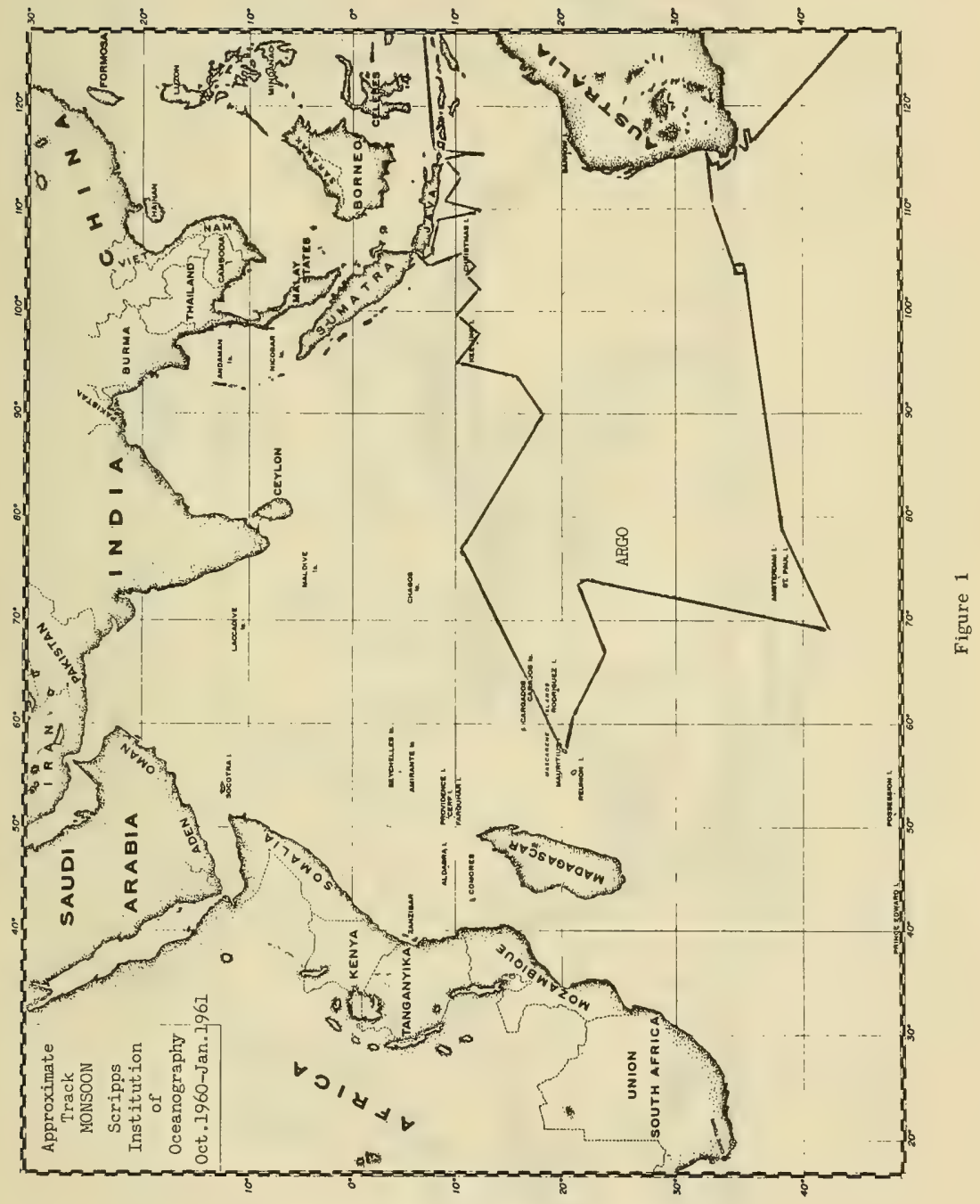




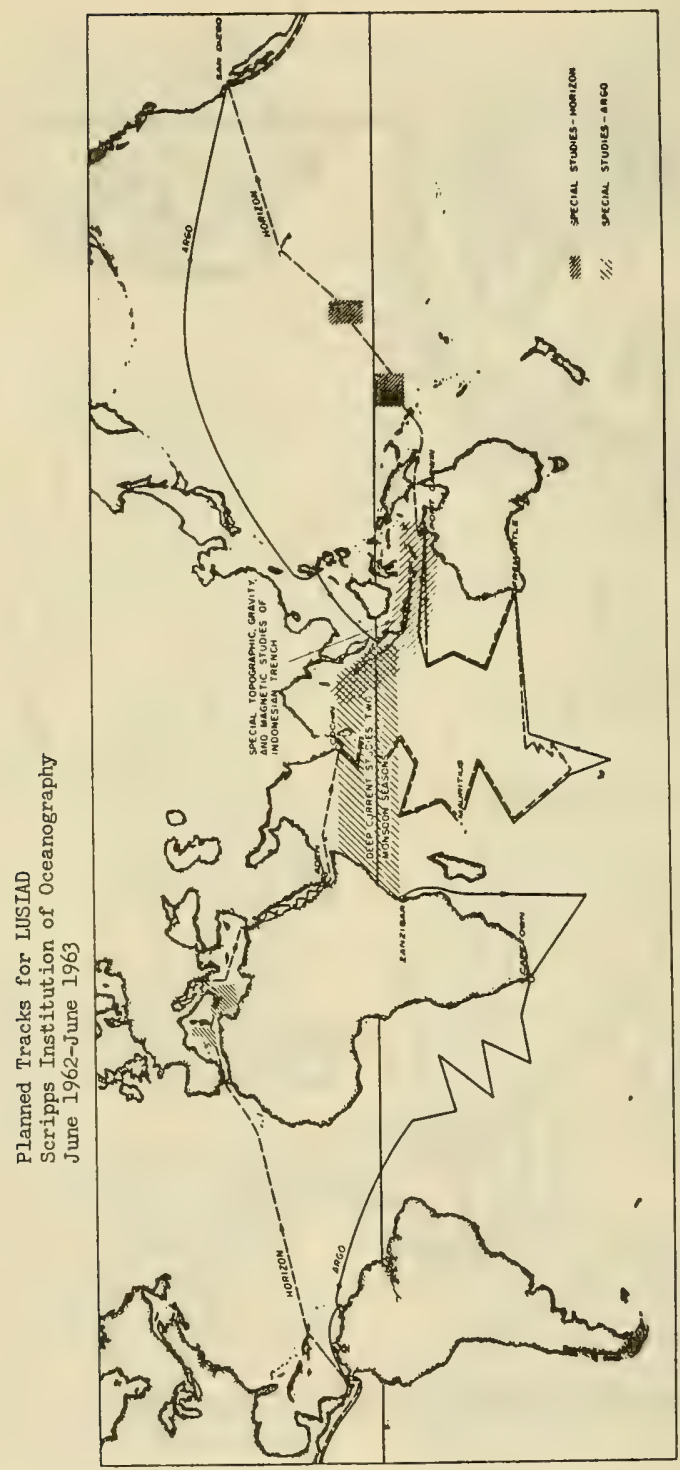

N 


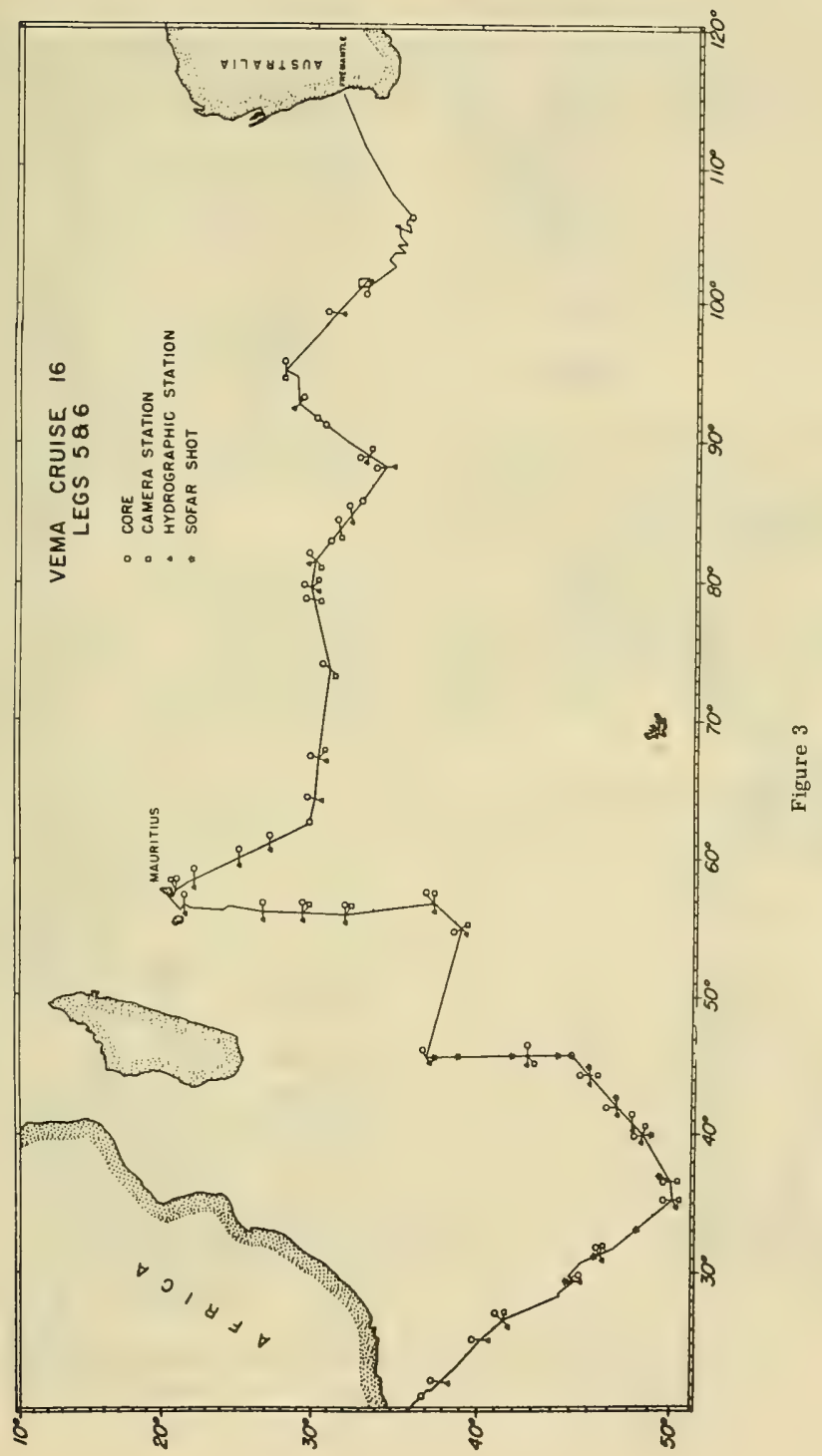




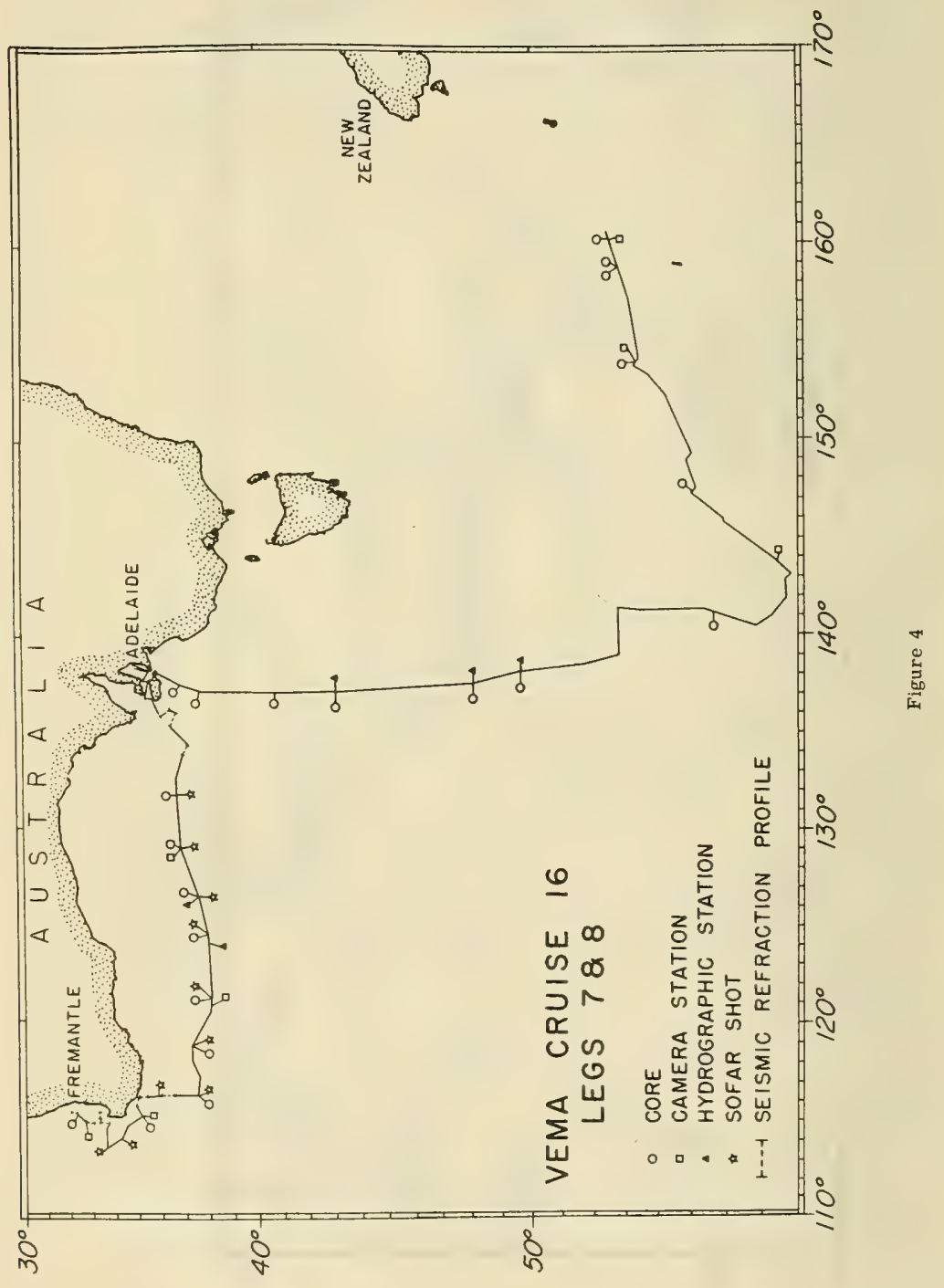


track. Forty-seven piston cores of the bottom sediment were obtained. Multiple photographs of the bottom were taken at 23 stations. Thirty hydrographic stations were occupied and consisted of serial observations of temperature, salinity, and oxygen. Sixteen large volume water samples, representative of all of the water masses, were collected for C-14 age determination. Biological collections included 11 bottom trawls and 80 plankton samples. Additional observations included measurements of the heat flow through the ocean floor, and propagation of sound through the SOFAR channel.

Under the direction of John E. Nafe, as Chief Scientist, VEMA made passages from Fremantle to Adelaide and from Adelaide to Wellington. During the early part of this program seismic refraction measurements were undertaken in cooperation with HMAS DIAMANTINA. During the remainder of the passage the program of observations underway and at stations was closely similar to that of the Cape Town to Fremantle traverse.

\section{VEMA 18 Itinerary Figure 5}

$\begin{array}{lr}3 \text { June } & 62 \\ 20 \text { June } & 62 \\ \text { 22 June } & 62 \\ \text { 12 July } & 62 \\ \text { 14 July } & 62 \\ 1 \text { August } & 62\end{array}$

Leave Cape Town Arrive Mauritius Leave Mauritius Arrive Fremantle Leave Fremantle Arrive Wellington
Manik Talwani, as Chief Scientist, directed the work of VEMA from Cape Town to Mauritius. Marcus Langseth was in charge from Mauritius to Wellington. The underway program included continuous magnetic, topographic, gravity, and seismic reflection measurements. At the Stations cores and Camera Stations were the most common combinations, with more emphasis than usual being placed on plankton sampling. In the area south of Australia a number of bottom trawl stations have been occupied. The passage from Bass to Wellington was begun about July 25th. Particular emphasis is placed on comparison of total sediment thickness with that found in the Atlantic Ocean.

\section{VEMA 19 (1963)}

VEMA 19 (1963) is being planned to enter the Indian Ocean via either Suez or Cape Town, proceeding to Kerguelen and thence to Fremantle. The new R/V CONRAD, to be operated by Lamont Geological Observatory, will also spend three months in the Indian Ocean in 1963.

During all VEMA cruises, the following program is being carried out under the supervision of the investigators named. Dr. Maurice Ewing is the principal investigator on all VEMA cruises.

Underway Observations

Precision depth recordings

Gravimeter recordings

Magnetometer total field intensity recordings

Bathythermograms

Seismic reflection

Surface water temperature

\section{Station Operations}

Seismic refraction profiles

\section{Gravity cores}

Hydrographic casts

Large-volume samples for $\mathrm{C}^{14}, \mathrm{H}^{3}, \mathrm{Sr}, \mathrm{Cs}$

Microbiological sampling

Plankton sampling

Bottom trawling for biological specimens

Sound velocity and transmission measurements

Bottom temperatures and temperature gradients

Bottom dredging for rocks

Bottom photography
Bruce Heezen

J. L. Worzel

J. R. Heirtzler

R. Gerard

J. I. Ewing

M. Ewing

Charles Drake

J. E. Nafe

J. I. Ewing

C. Fray

R. Gerard

W. Broecker

P. R. Burkholder

Alan Bé

Alan Bé

J. I. Ewing

M. Langseth

C. Fray

M. Ewing

\section{In Port Observations}

Rock collections

C. L. Drake 


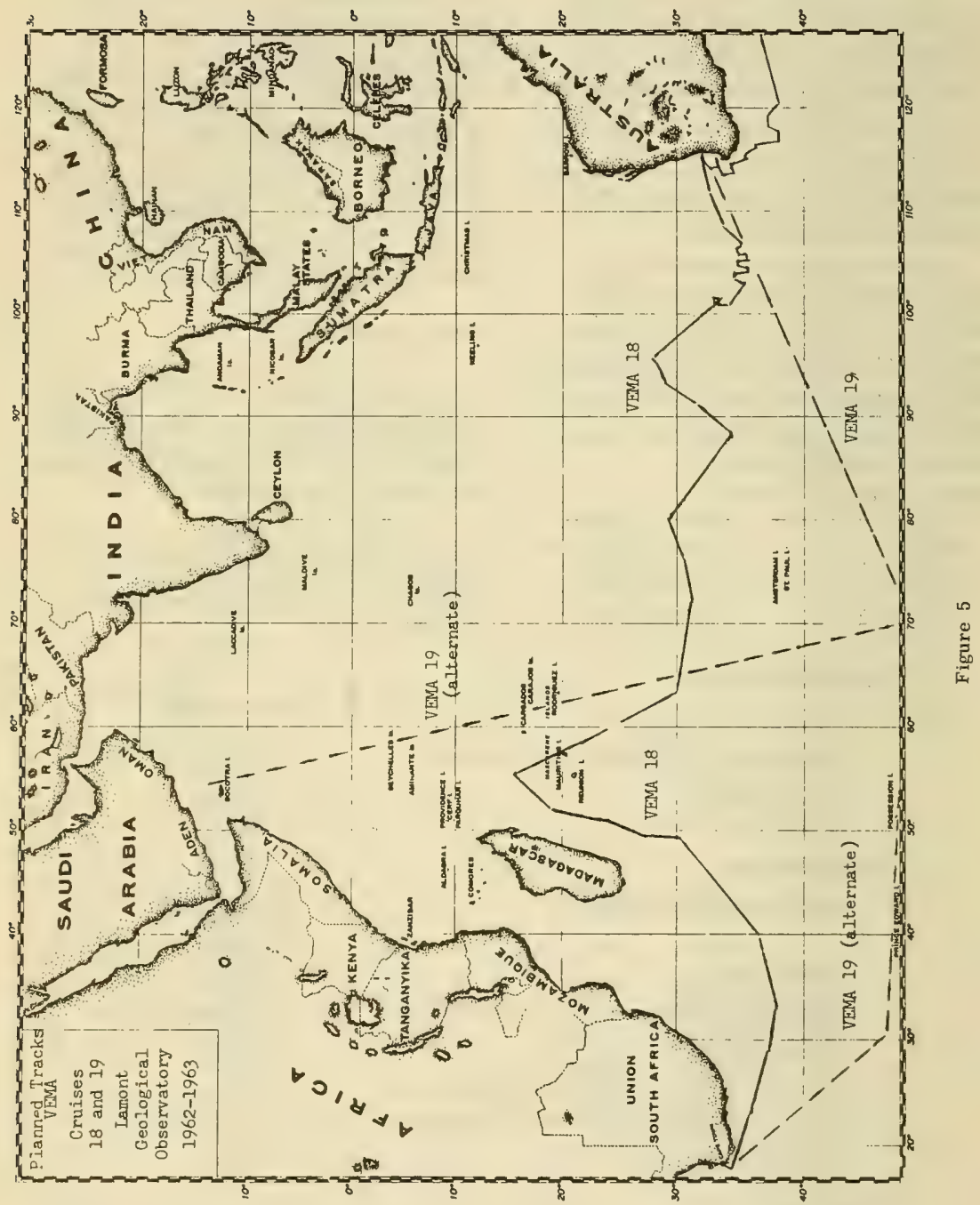




\section{UNIVERSTTY OF RHODE ISLAND}

Under Dr. John A. Knauss, the Narragansett Marine Laboratory of the University of Rhode Island is carrying out two three-month studies of the equatorial current circulation in the Indian Ocean aboard the R/V ARGO, whose cruise itinerary has been given above. Planned locations of the sections are shown in Figure 6.

\section{WOODS HOLE OCEANOGRAPHIC INSTITUTION}

The Woods Hole Oceanographic Institution, under the direction of Dr. Paul Fye, is planning the following cruises to the Indian Ocean:

\begin{tabular}{|c|c|c|c|}
\hline 1963 & June - Nov. & ATLANTIS II & $\begin{array}{l}\text { Physical and chemical studies in Red and Arabian Seas } \\
\text { and Agulhas Current (Figure 8) }\end{array}$ \\
\hline 964 & Sept. - March & CHAIN & $\begin{array}{l}\text { Geophysics and submarine geology between Socotra a } \\
\text { Cape Agulhas (Figure 7) }\end{array}$ \\
\hline 65 & Sept. - March & CHAIN & $\begin{array}{l}\text { Geophysics and submarine geology, Cape Agulhas to } \\
\text { Laccadives, Chagos to India, India to Suez (Figure 7) }\end{array}$ \\
\hline 65 & Feb. - July & ATLANTIS II & $\begin{array}{l}\text { Physical and chemical studies in Red and Arabian Se } \\
\text { and Agulhas Current (Figure 8) }\end{array}$ \\
\hline
\end{tabular}

The programs indicated for the CHAIN and ATLANTIS II respectively are the primary ones. The CHAIN cruises will also include physical and chemical oceanography and the ATLANTIS II cruises geophysics and submarine geology. Key scientists involved in the above program are Earl E. Hays, J. B. Hersey, C. O'D. Iselin and A. R. Miller.

In addition, the Woods Hole Oceanographic Institution will also have scientific responsibility for the operation of the R/V ANTON BRUUN, which will be devoted primarily to biological work. Under the direction of Dr. John H. Ryther, assisted by Dr. Edward Chin, the following schedule has been established:

$$
\text { Arrive }{ }_{1963} \text { Sail }
$$

\begin{tabular}{|c|c|c|c|}
\hline \multirow[t]{6}{*}{ Cruise 1} & (Feb. 8) & Feb. 18 & Bombay \\
\hline & Feb. 26 & Feb. 28 & Puket, Thailand \\
\hline & Mar. 13 & Mar. 16 & Rangoon \\
\hline & Apr. 15 & Apr. 18 & Vizagapatam \\
\hline & Apr. 29 & May 2 & Madras \\
\hline & May 7 & - & Bombay \\
\hline \multirow[t]{4}{*}{ Cruise 2} & - & May 17 & Bombay \\
\hline & May 19 & May 22 & Ceylon \\
\hline & Jun. 27 & Jul. 2 & Port Louis, Mau. \\
\hline & Jul. 22 & - & Bombay \\
\hline \multirow[t]{3}{*}{ Cruise 3} & - & Aug. 1 & Bombay \\
\hline & Aug. 21 & Aug. 25 & Port Louis \\
\hline & Sep. 16 & - & Tamatave \\
\hline \multirow[t]{4}{*}{ Cruise 4} & - & Sep. 27 & Tamatave \\
\hline & Oct. 11 & Oct. 15 & Aden \\
\hline & Nov. 5 & Nov. 10 & Karachi \\
\hline & Dec. 1 & - & Bombay \\
\hline
\end{tabular}

Dredging and bottom trawling on continental shelf additional (Figure 9).

Midwater and/or surface collecting additional (Figure 10).

Midwater and/or surface collecting additional (Figure 9).

Dredging and bottom trawling on continental shelf additional (Figure 11). 


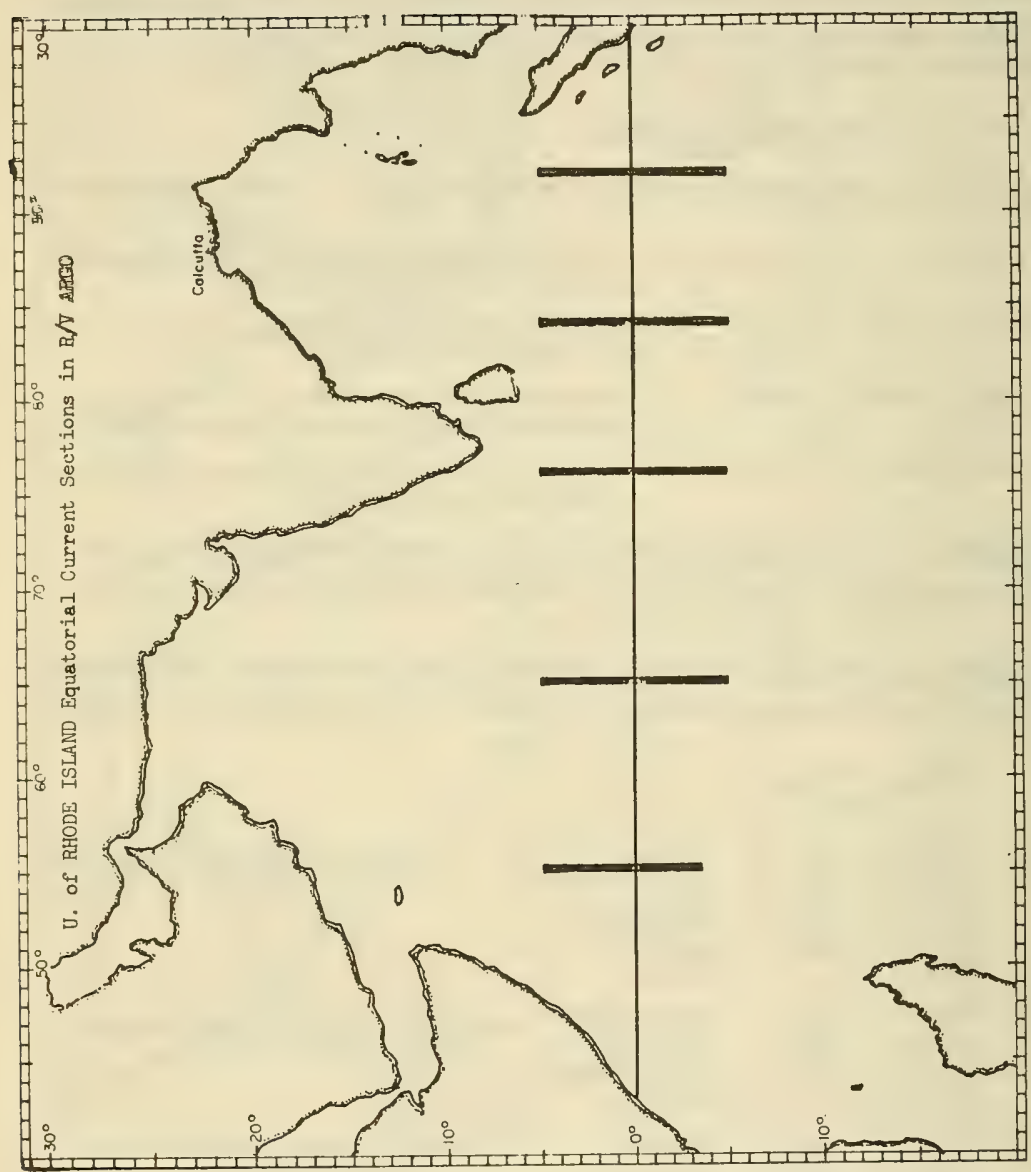

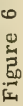




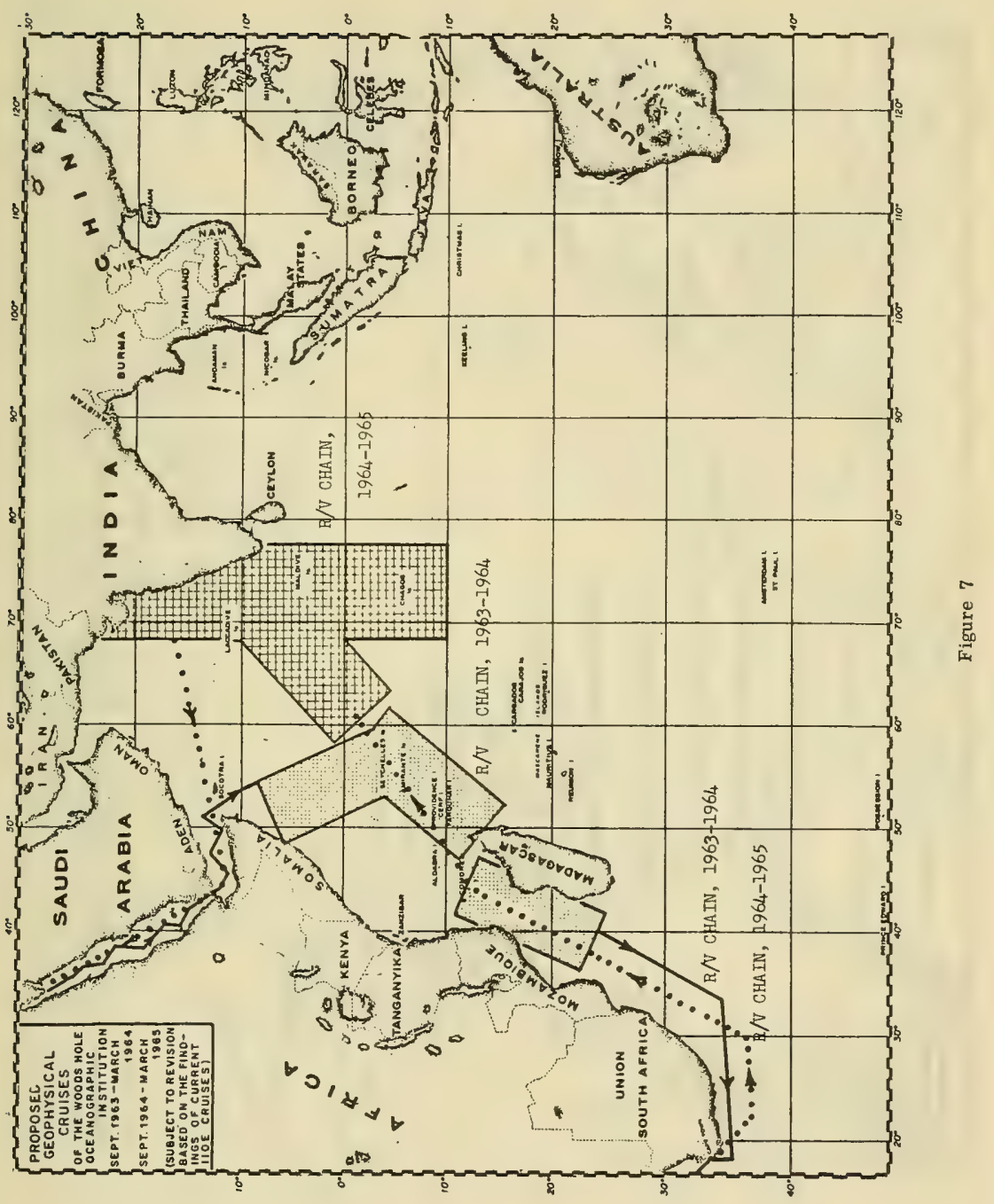




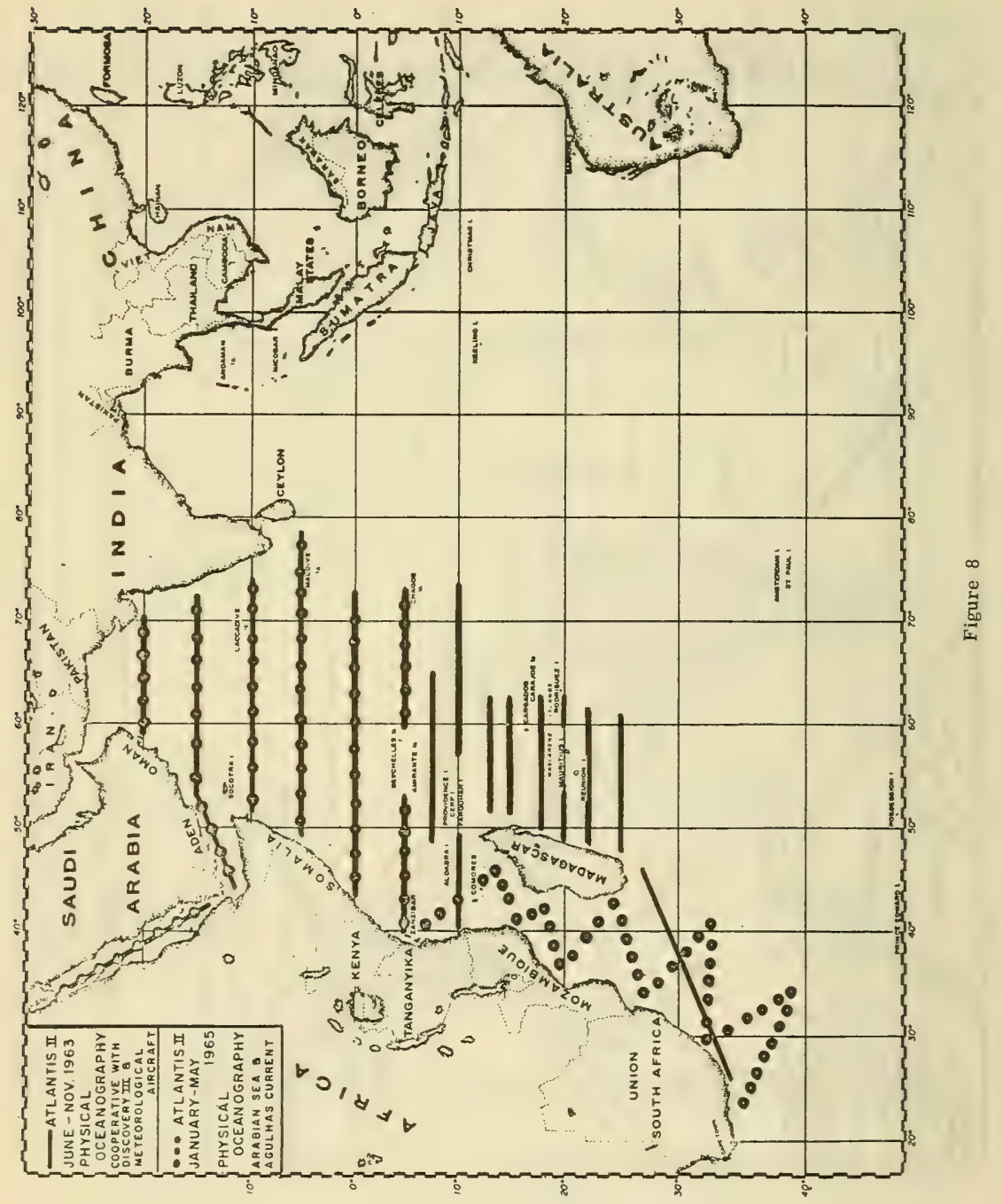




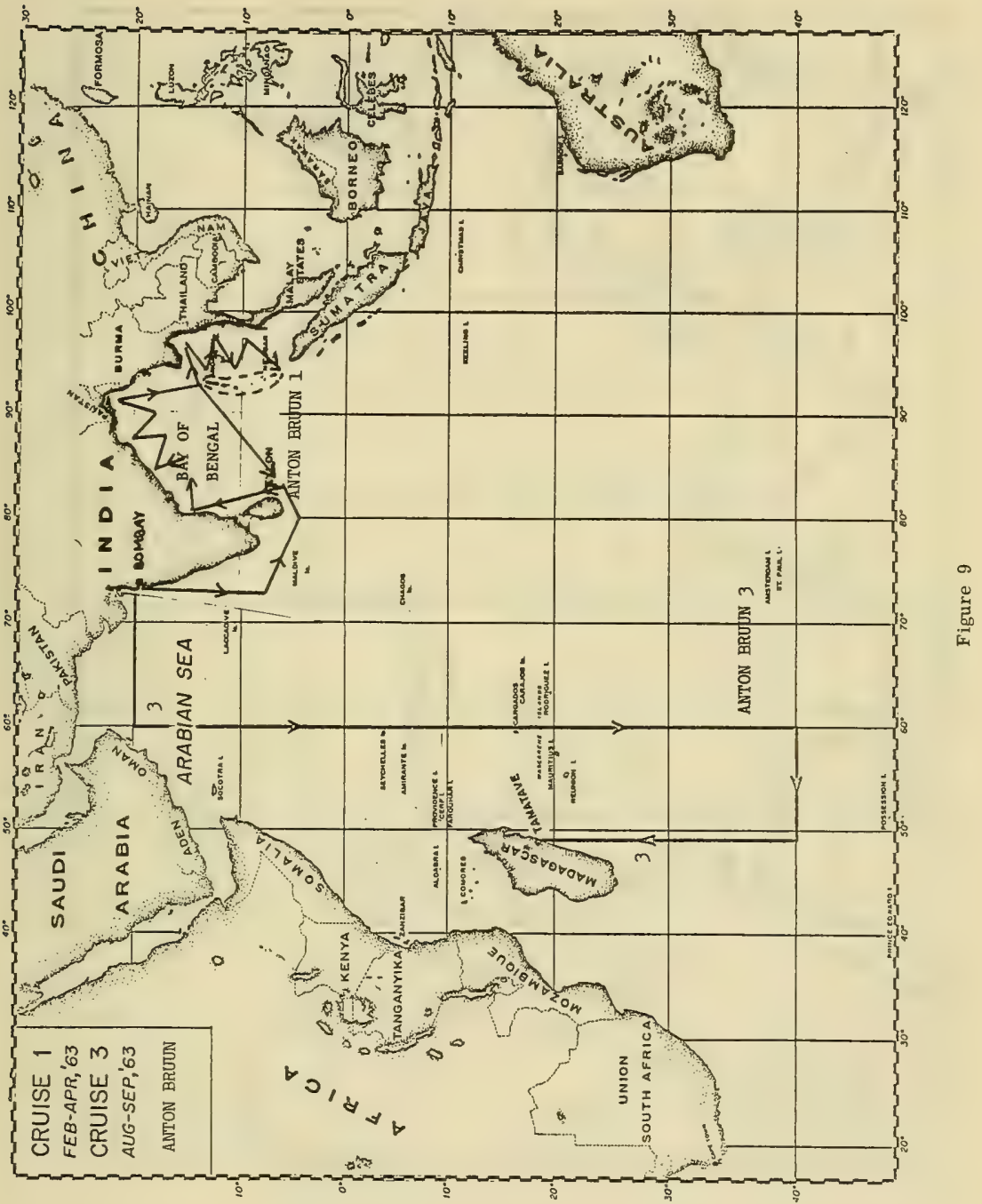




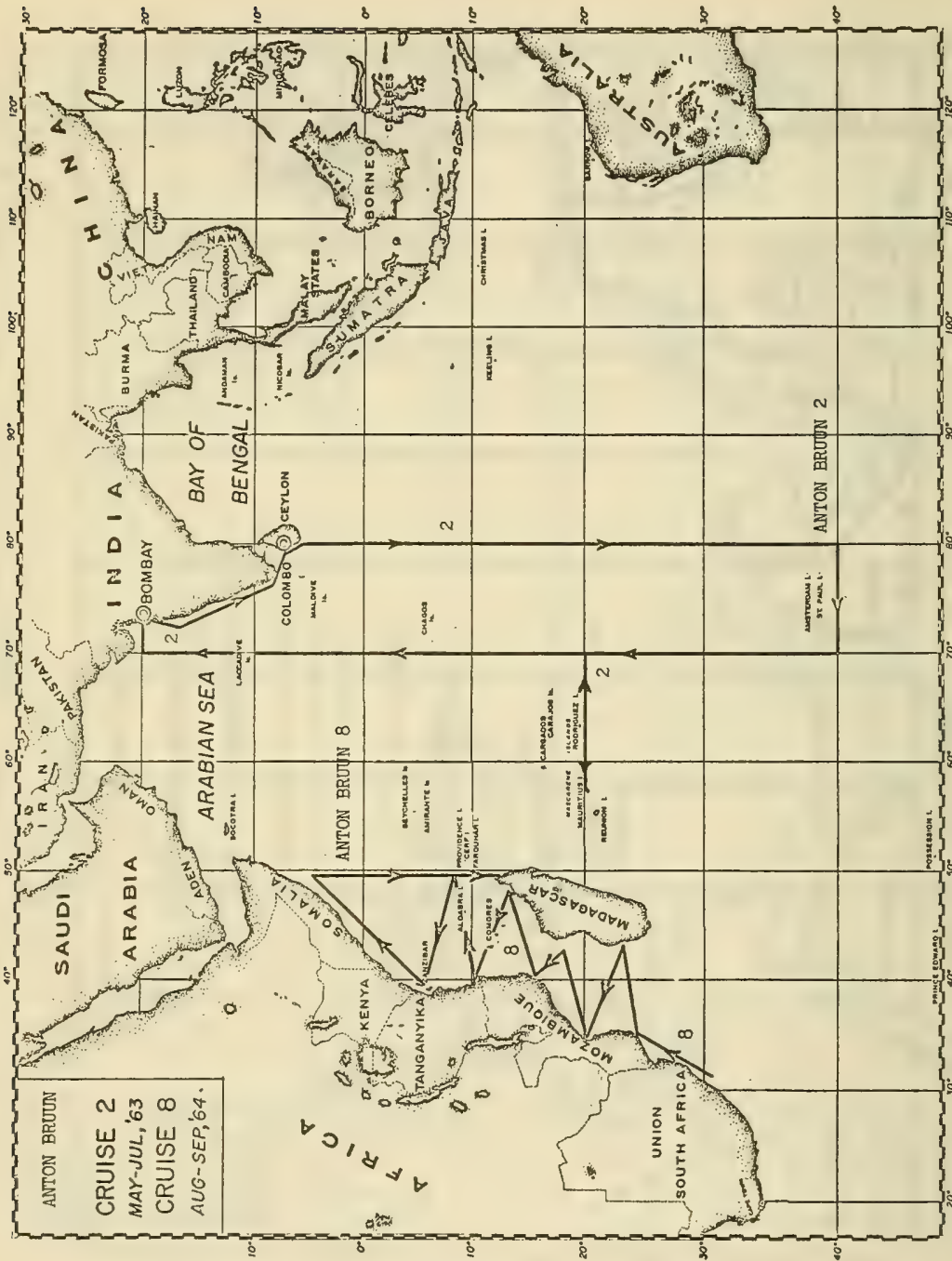

음 


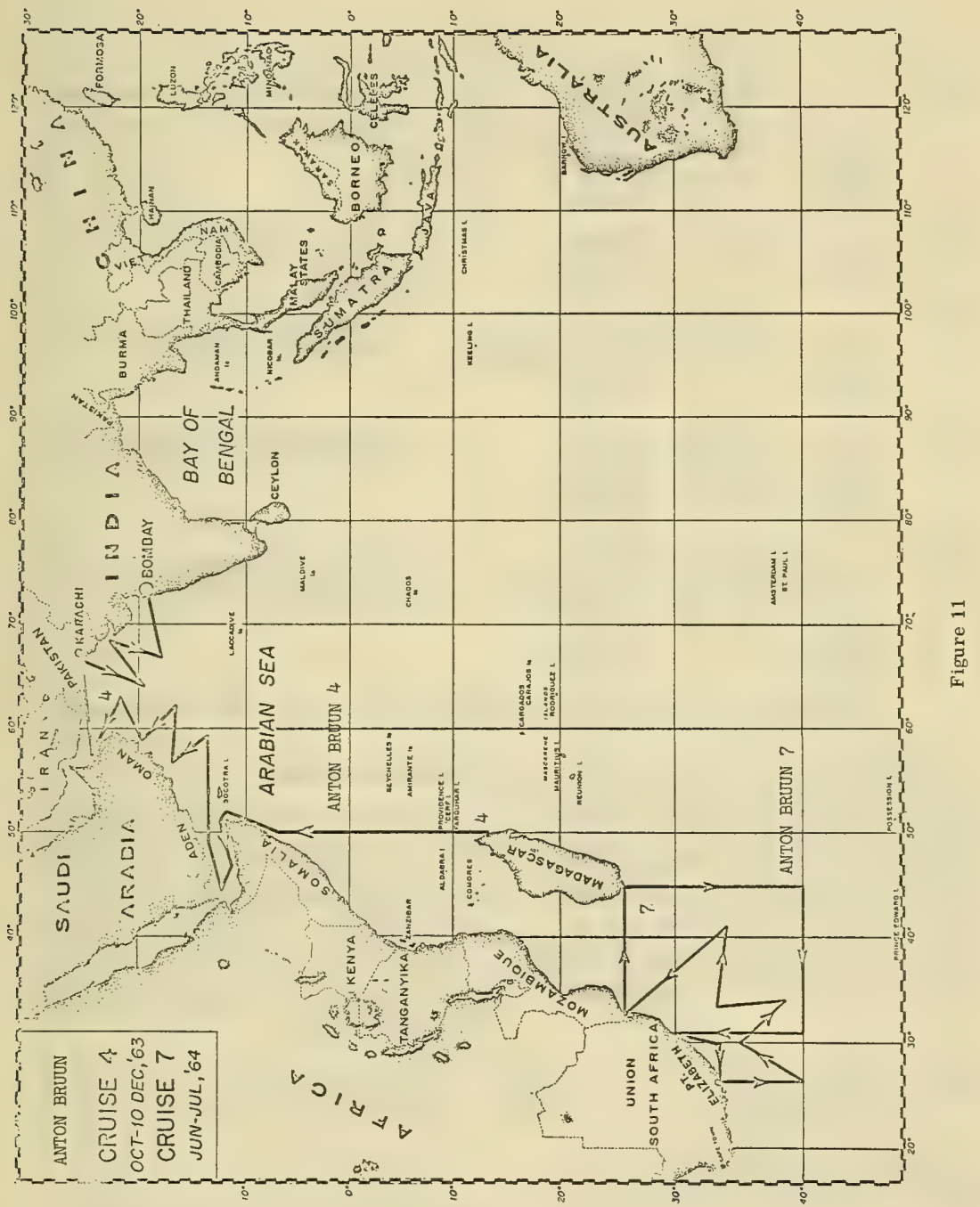


Arrive 1964

\begin{tabular}{|c|c|c|c|}
\hline \multirow[t]{6}{*}{ Cruise 5} & - & Jan. 13 & Bombay \\
\hline & Jan. 24 & Jan. 28 & Victoria, Seychelles \\
\hline & Feb. 5 & Feb. 9 & Port Louis \\
\hline & Mar. 13 & Mar. 17 & Diego Garcia, Chagos \\
\hline & Mar. 23 & Mar. 26 & Cochin \\
\hline & Mar. 28 & - & Bombay \\
\hline \multirow[t]{3}{*}{ Cruise 6} & - & Apr. & Bombay \\
\hline & Apr. 30 & May 4 & Port Louis \\
\hline & Jun. 1 & - & Durban \\
\hline \multirow[t]{4}{*}{ Cruise 7} & - & Jun. 12 & Durban \\
\hline & Jun. 23 & Jun. 27 & Lourenco Marques \\
\hline & Jul. & Jul. 13 & Tulear, Madagascar \\
\hline & Jul. 26 & - & Durban \\
\hline \multirow[t]{5}{*}{ Cruise 8} & - & Aug. 6 & Durban \\
\hline & Aug. 19 & Aug. 22 & Beira \\
\hline & Aug. 27 & Aug. 30 & Mozambique \\
\hline & Sep. 9 & Sep. 13 & Zanzibar \\
\hline & Sep. 25 & - & Tamatave \\
\hline \multirow[t]{5}{*}{ Cruise 9} & - & Oct. & Tamatave \\
\hline & Oct. & Oct. 12 & $\begin{array}{l}\text { Port des Galetes } \\
\text { (Reunion) }\end{array}$ \\
\hline & Oct. 19 & Oct. 30 & Victoria \\
\hline & Nov. 6 & Nov. 17 & Diego Garcia \\
\hline & Nov. 25 & - & Bombay \\
\hline
\end{tabular}

Midwater and/or surface collecting additional (Figure 12).

Midwater and/or surface collecting additional (Figure 13).

Dredging and bottom trawling on continental shelf additional (Figure 11).

Dredging and bottom trawling on continental shelf additional (Figure 10).

Dredging and bottom trawling on continental shelf and island groups additional (Figure 13).

A full listing of the scientific personnel scheduled to participate in the ANTON BRUUN cruises is given in the Appendix.

Under the direction of Professor Andrew F. Bunker, Woods Hole Oceanographic Institution will also operate a four-engined meteorological aircraft over the Indian Ocean during 1962,1963 , and 1964. The plane will be instrumented for the large-scale determination of turbulent transport and the various terms in the heat budget. Four six-week trips are planned. The ATLANTIS II will be equipped with meteorological instruments and will make observations in assistance of the program.

$$
\begin{aligned}
& \text { October - December } \\
& \text { February - April } \\
& \text { June - September }
\end{aligned}
$$

On Cruise $\mathrm{C}$ a party of physiologists will be embarked, and emphasis will be placed on obtaining live Latimeria for physiological study.

\section{STANFORD UNIVERSTTY}

The Research Vessel TE VEGA will undertake three cruises for biological and geological collection and observation in and around island groups and shallow water areas, landing shore parties on atolls for intensive two- to threemonth studies. Extensive investigations of each region by auxiliary vessel. Small boats, dark room, some laboratory space, diving equipment and dredging and experimental trawling to 100 fathoms. The following schedule has been established (Figure 14):

\author{
A Singapore - Nicobars - Andamans - Colombo \\ B Colombo - Laccadives - Maldives - Chagos - Mauritius \\ C Mauritius - Seychelles - Comores - Zanzibar
}

\section{U. S. COAST GUARD}

During May 1961, the U. S. Coast Guard Icebreaker EAST WIND, returning from a trip 


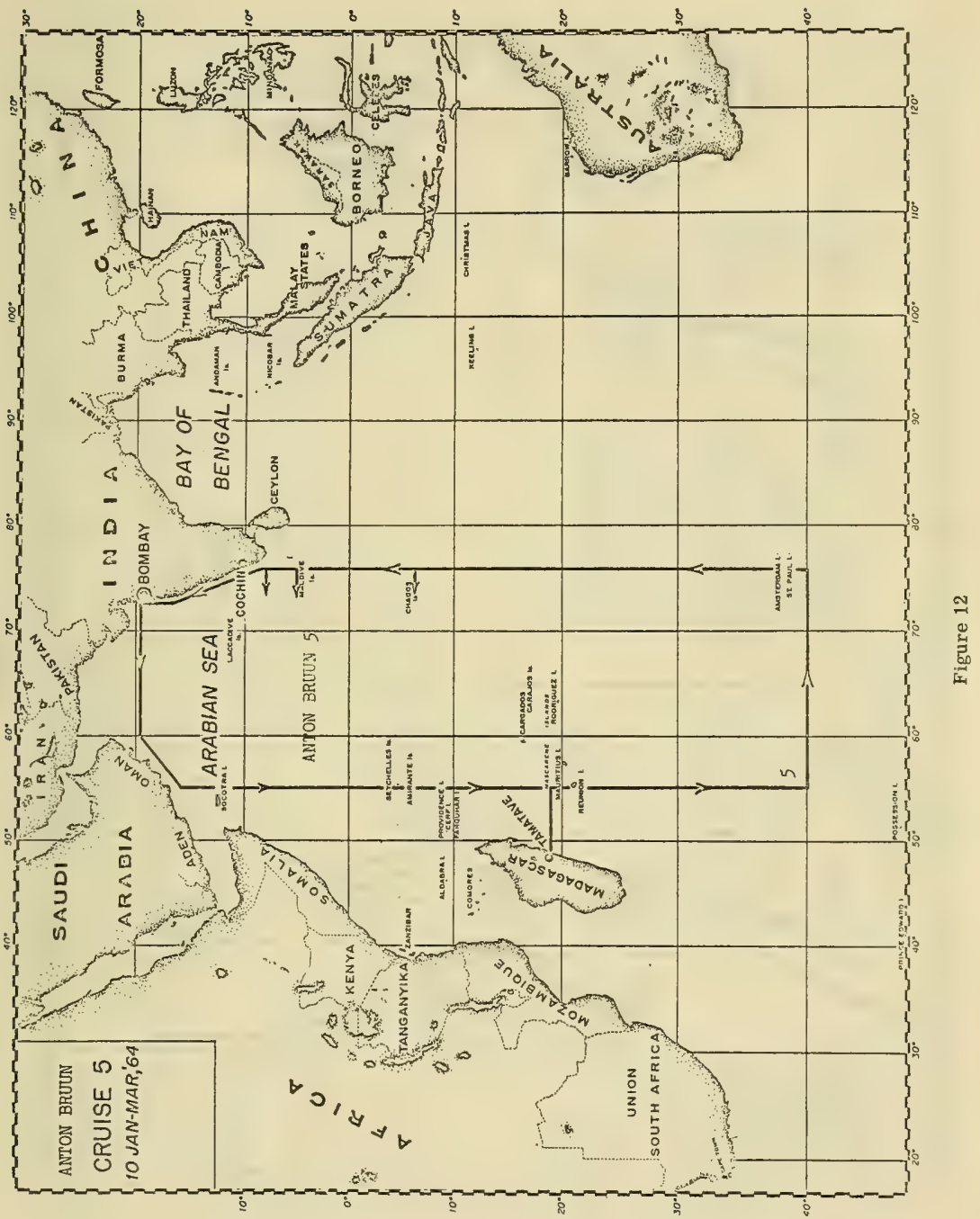




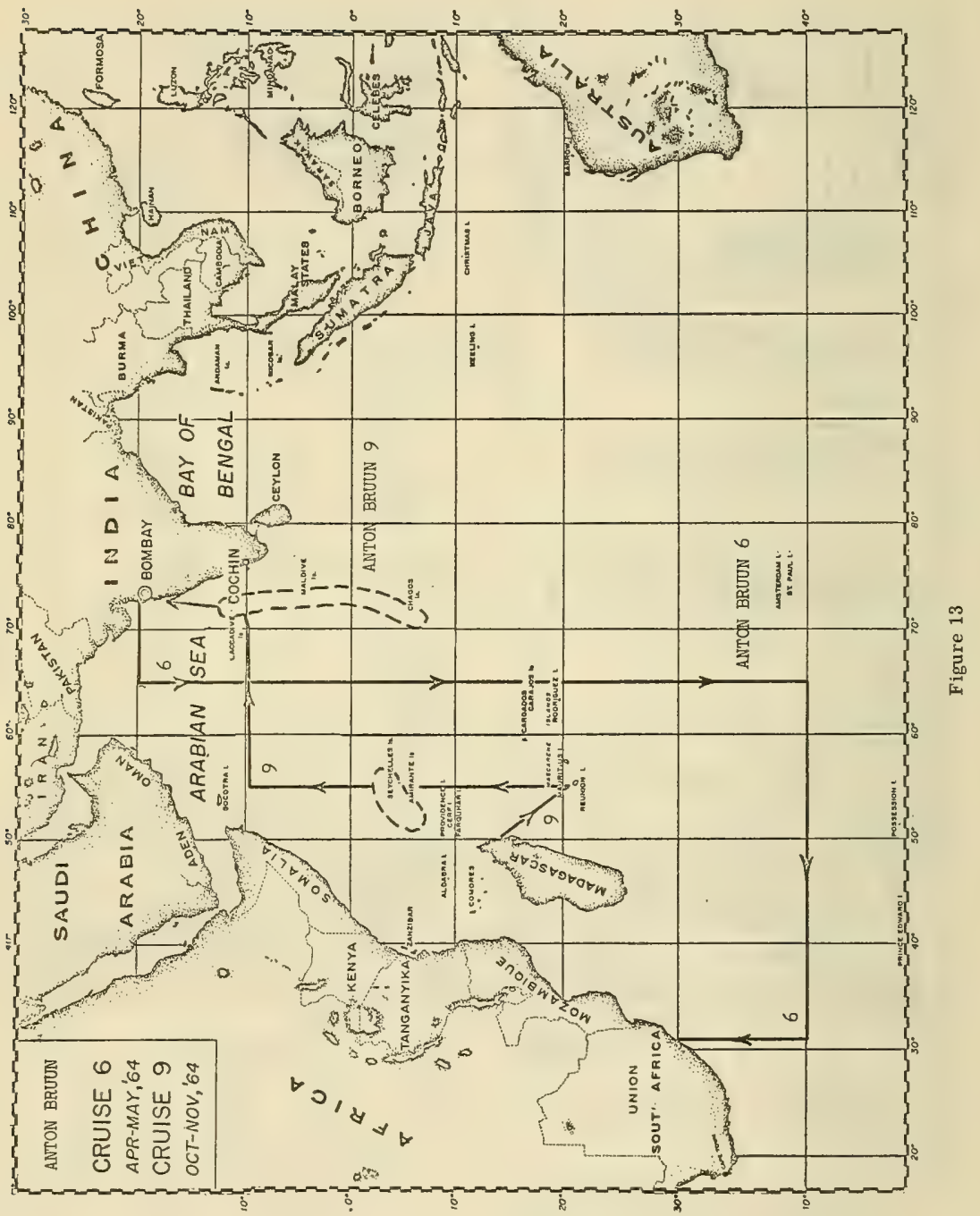




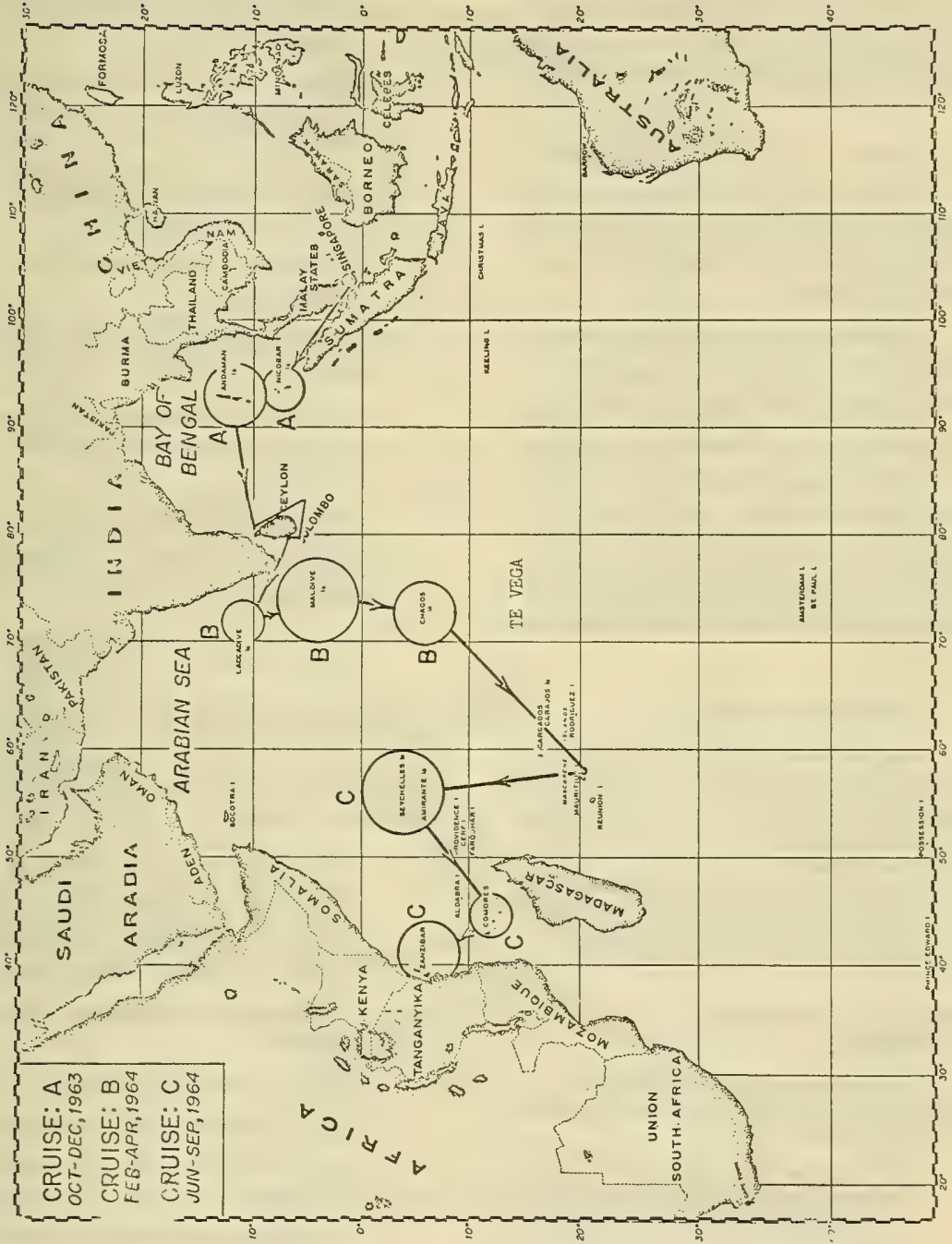


to the Antarctic with oceanographic observers from the Hydrographic Office aboard, occupied a line of hydrographic stations from Fremantle west to $78^{\circ} \mathrm{E}$, and then north to $4^{\circ} \mathrm{N}$. Her track is shown in Figure 15.

\section{U. S. NAVY}

Survey vessels of the U. S. Navy have occupied hydrographic stations in the Persian Gulf and Andamm Sea, as shown in Figure 15. Swinnerton and Sullivan (1962) have reported some of the results.

The research vessels CHAIN of Woods Hole Oceanographic Institution, ARGO of Scripps Institution of Oceanography, and CONRAD of Lamont Geological Observatory are owned by the U. S. Navy, and their operations are supported by the Office of Naval Research. The Office of Naval Research also supports part of the operations of the VEMA and HORIZON. The Navy is also providing one R5D aircraft for use in the Woods Hole Oceanographic Institution meteorological program and is supplying a NOMAD weather station. Support has been given to the National Oceanographic Data Center for research on data processing for the NOMAD buoy observations.

\section{U. S. WEATHER BUREAU}

Four planes of the Weather Bureau Research Flight, normally based in Miami, Florida, in hurricane observation, will operate in India from May to July 1963 and again in January and February 1964. The Weather Bureau is also assigning two professional meteorologists to the International Meteorological Center at Bombay. Radiosonde equipment is being loaned by the Weather Bureau for installation on the ANTON BRUUN and ATLANTIS II.

\section{BUREAU OF COMMERCIAL FISHERIES}

The research program of the Bureau of Commercial Fisheries in the Indian Ocean has the following objectives:

1. To study the distribution and abundance of adult tunas in relation to the circulation during the two monsoon seasons.

2. To study the relation of the apex predators (tunas, marlins, sharks, etc.) to the food-chain, standing crops and productivity. a. Organisms eaten (qualitative and quantitative analyses of stomach contents).

b. Standing crop of nekton (qualitative and quantitative analyses of midwater trawl collections).

c. Standing crop of zooplankton (qualitative and quantitative analyses of zooplankton collections).

d. Phytoplankton productivity ( $\mathrm{C}^{14}$ uptake).

3. Investigate subpopulations (serology of apex predators: tunas, billfish, and sharks).

4. Distribution and abundance of larval and juvenile fish (plankton and night-light collections).

5. Zoogeography of zooplankton and zooplankton forms as biological indicators (distribution and abundance of selected zooplankters such as copepods of the genus Candacia).

6. Taxonomy, occurrence, and distribution of demersal fishes and invertebrates.

This program will be carried out by personnel of the Bureau's Biological Laboratory, Honolulu, aboard the ANTON BRUUN. On cruises 2 and 5 , a party of 8 fishermen and 3 scientists will be embarked to engage in longline fishing as follows:

a. On each cruise, fish 60 baskets of gear at each station. Occupy 16 stations along each of two meridian; 13 of the stations to be at $5^{\circ}$ latitude intervals and remaining 3 stations to be occupied in areas of high abundance.

b. Data and biological samples to be collected.

(1) Catch (by species) and effort.

(2) Length and/or weight of each fish.

(3) Sex and general state of maturation.

(4) Preserve stomachs in 10 percent formalin.

(5) Preserve ovaries in 10 percent formalin. 


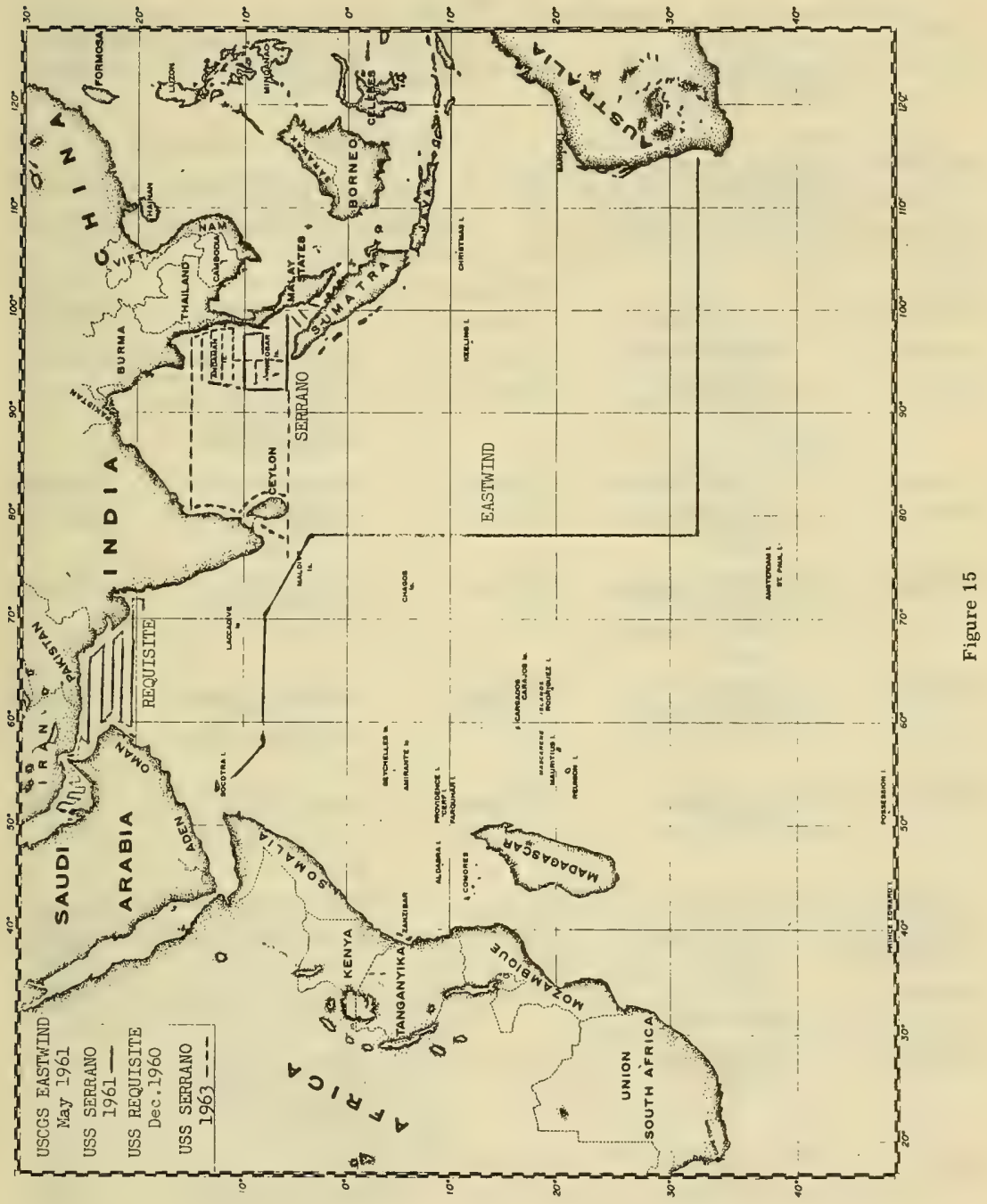


(6) Preserve blood samples for serological studies.

(7) Preserve selected whole specimens for taxonomic studies.

Bottom trawling to study the distribution and relative abundance of demersal species in relation to the topography and nature of the bottom, will be conducted on Cruises 1 and 4 , using a single-warp shrimp trawl. Catches will be assessed quantitatively at $s \in a$, given a preliminary sorting, and sent to the U. S. National Museum for final distribution to qualified taxonomists for systematic studies of the fishes and invertebrates collected.

\section{NATIONAL SCIENCE FOUNDATION}

Support of the United States program for the חOE by the National Science Foundation is epitomized by the following tabulation of grants made since 1960:

\section{NSF Grant No.}

G-11800

G-16570

G16570A1

G-17182

G-19289

G-20952

C-282

Amendment \#1

G-21960

G-22223

G-22255

Amendment \#1

G-22260
Institution

National Academy of Sciences -

National Research

Council

National Academy of Sciences -

National Research Council

National Academy of Sciences -

National Research Council

Woods Hole

Oceanographic Institution

University of

Hawaii

Woods Hole

Oceanographic

Institution

\section{University of}

Rhode Island

Office of Naval

Research

University of

California

Columbia Univ.
Principal

Investigator

R. C. Vetter

Title

Support to the Special

Committee on Oceanic

Research of the Inter-

national Council of

Scientific Unions

G. D. Meid

Support of Coordinator, Indian Ocean Expedition

L. Hoover

Support of Coordinator, Indian Ocean Expedition

J. H. Ryther

Planning of a program in biology for the Indian Ocean Expedition

Support of U. S. Meteorology Program of the Indian Ocean Expedition

U. S. Program in biology for the I.I.O.E.

450,000

500,000

425,000

Equatorial Circulation $\quad 100,000$ of the Indian Ocean

NOMAD weather station for the International Indian Ocean Expedition

Participation in the International Indian Ocean Expedition

150,000

$6,80,300$

Participation in the International Indian Ocean Expedition 


\begin{tabular}{|c|c|c|c|c|}
\hline NSF Grant No. & Institution & $\begin{array}{c}\text { Principal } \\
\text { Investigator }\end{array}$ & Title & Amount \\
\hline G-22388 & $\begin{array}{l}\text { University of } \\
\text { Michigan }\end{array}$ & D. J. Portman & $\begin{array}{l}\text { Heat and water vapor } \\
\text { exchange for the Inter- } \\
\text { national Indian Ocean } \\
\text { Expedition }\end{array}$ & $\$ 231,900$ \\
\hline G-22389 & $\begin{array}{l}\text { Woods Hole } \\
\text { Oceanographic } \\
\text { Institution }\end{array}$ & A. F. Bunker & $\begin{array}{l}\text { Air-Sea Interaction } \\
\text { for the International } \\
\text { Indian Ocean Expedi- } \\
\text { tion }\end{array}$ & 97,000 \\
\hline $\begin{array}{l}\text { G-22413 } \\
\text { Amendment \#1 }\end{array}$ & $\begin{array}{l}\text { University of } \\
\text { Hawaii }\end{array}$ & C. S. Ramage & $\begin{array}{l}\text { Atmospheric Circula- } \\
\text { tion Project for the } \\
\text { International Indian } \\
\text { Ocean Expedition }\end{array}$ & $\begin{array}{l}146,600 \\
181,800\end{array}$ \\
\hline G-25115 & $\begin{array}{l}\text { Woods Hole } \\
\text { Oceanographic } \\
\text { Institution }\end{array}$ & A. F. Bunker & $\begin{array}{l}\text { Research Aircraft } \\
\text { for meteorological } \\
\text { program of the Inter- } \\
\text { national Indian Ocean } \\
\text { Expedition }\end{array}$ & 100,000 \\
\hline GP-465 & U. S. Air Force & E. J. Timberlake & $\begin{array}{l}\text { Research meteorolo- } \\
\text { gists for the I.I.O.E. }\end{array}$ & 60,000 \\
\hline GP-571 & $\begin{array}{l}\text { University of } \\
\text { Washington }\end{array}$ & R. G. Fleagle & $\begin{array}{l}\text { Comprehensive study } \\
\text { of energy transfer } \\
\text { near the earth's sur- } \\
\text { face }\end{array}$ & 140,000 \\
\hline GP-576 & $\begin{array}{l}\text { U. S. Weather } \\
\text { Bureau }\end{array}$ & $\begin{array}{l}\text { F. W. Reiche1- } \\
\text { derfer }\end{array}$ & $\begin{array}{l}\text { Meteorological re- } \\
\text { search utilizing U. S. } \\
\text { Weather Bureau air- } \\
\text { craft }\end{array}$ & 490,980 \\
\hline GP-599 & ditto & ditto & $\begin{array}{l}\text { I.I.O.E. meteorological } \\
\text { program aboard } \\
\text { oceanographic vessels }\end{array}$ & 330,000 \\
\hline
\end{tabular}

\section{U. S. COAST AND GEODETIC SURVEY}

The USC\&GS Ship PIONEER will sail in mid-February of 1964 from San Francisco to take part in the International Indian Ocean Expedition, returning to San Francisco the following September. In addition to underway observations, en route to and from the Indian Ocean, the PIONEER will concentrate on gravity, magnetic, and hydrographic operations in the Andaman Sea and the eastern Bay of Bengal. Space will be made available aboard the vessel for two meteorologists and one or two biologists. Three north-south profiles of oceanographic stations are planned from $5^{\circ} \mathrm{N}$ to $5^{\circ} \mathrm{S}$ across the Equator south of the Bay of Bengal.

These are only tentative plans covering work on specific Coast and Geodetic Survey projects. It is anticipated that they will be modified and added to as the information from other participants becomes available and as other organizations develop cooperative programs with the PIONEER.

These plans are predicated on the assumption that TRANSIT navigation will be available for determining ship positions throughout the expedition.

\section{Leg I - San Francisco to Singapore}

Leg II - Singapore - Trincomalee (Figure 16)

From Singapore, the track will be northwest through the Malacca Straits into the 


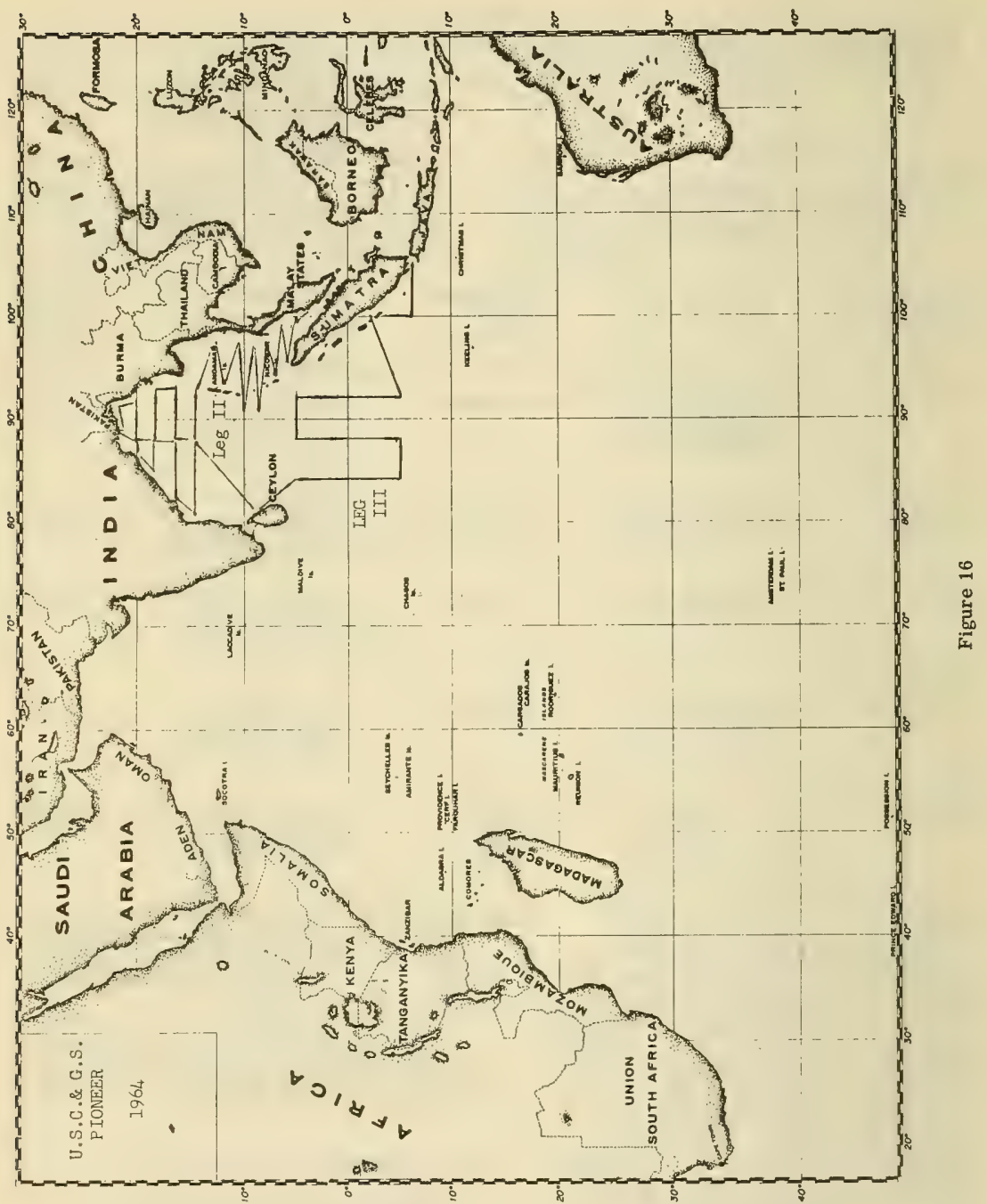


Andaman Sea. The actual tracklines in the Andaman Sea will depend in part on the results of the work of the ARGO which returns from this area in the early summer of 1963 . In general, however, there will be a series of sawtooth crossings of the Andaman Sea carrying out all of the standard underway observations with special attention paid to the bathymetry and the gravity work. Sediment cores and bottom photographs will be taken in the Andaman Sea along these lines. Rock dredgings will be attempted at places where the topography suggests that rock outcrops might be present. Planned tracklines in this area will be modified in the field as dictated by the bottom topography and gravity anomalies encountered. The pattern will include at least two crossings of the Andaman-Nicobar Ridge into depths of at least 3000 meters "-'est of the ridge. These could conceivably be through Ten Degree Channel and Duncan Pass. At the northern end of the Andaman Sea, special lines shall be run to determine if submarine channelling extends seaward of the mouths of the Irrawaddi River.

From the Andaman Sea, the ship will pass into the Bay of Bengal where the underway operations, cores (or dredgings), and bottom photography will continue along a series of East-West lines at approximately two-degree spacing from the coast of Burma out to approximately $88^{\circ} \mathrm{E}$. Topographic, gravimetric, or magnetic anomalies found along these lines will be developed more fully. Special care will be taken along the more northerly of these lines to look for any southerly extension of the Ganges Canyon. This has been surveyed in some detail by the Pakistan Navy as far as the edge of the continental shelf. The GALATHEA'S lines showed that it extends south into the Bay of Bengal beyond the shelf, but its extent is not known. It is possible that the valley found by the ALBATROSS east of Ceylon may be the extension of this Ganges Canyon. After a stop at Calcutta, the PIONEER will carry out a detailed survey of the Ganges Submarine Canyon seaward of the continental shelf. The canyon will be traced as far seaward as is possible. Cores will be obtained from the canyon floor where possible and attempts will be made to dredge the canyon walls. Bottom photographs will be obtained where camera lowerings appear feasible. If the canyon terminates well north of the latitude of Ceylon, the east-west lines previously run in the eastern Bay of Bengal shall be continued westward from $88^{\circ}$ to the coast of India. If the canyon continues south to or beyond Ceylon, it shall be followed to its termination with cross sections run at frequent intervals.

On the termination of this project, the ship will proceed to Trincomalee, Ceylon.

\section{Leg III - Trincomalee to Djakarta}

HO Charts 2523 and 3689 show hard ridges through which has been cut a submarine canyon that heads in Trincomalee and Goddiyar Bays on the northeast coast of Ceylon. The canyon has apparently been cut in quartzite and other hard Pre-Cambrian rocks. The canyon extends seaward to depths of at least 800 fathoms where the soundings terminate. As the ship leaves Trincomalee, this canyon will be traced seaward with a set of profiles, and an attempt will be made to dredge the steep walls. Sediment cores and bottom photographs will be obtained where possible.

Upon the completion of the canyon survey, three north-south sections of oceanographic stations will be occupied from $5^{\circ} \mathrm{N}$ to $5^{\circ} \mathrm{S}$ along $84^{\circ} \mathrm{E}, 88^{\circ} \mathrm{E}$, and $92^{\circ} \mathrm{E}$. Stations will be at $5^{\circ}$, $4^{\circ}$, and $3^{\circ}$, and at $1 / 2$-degree intervals to the Equator for a total of 17 stations along each profile. The stations at $5^{\circ}, 3^{\circ}$ and $1^{\circ} \mathrm{N}$ and $\mathrm{S}$ will be deep stations to the bottom, the others will be to 2000 meters. Standard bottle spacing will be used, except that depth of stations and bottle spacing may be modified in the light of other results obtained before the PIONEER sails.

From the southern end of the easternmost line $\left(5^{\circ} \mathrm{S}, 92^{\circ} \mathrm{E}\right)$, the track to Djakarta is tentatively planned to accomplish two crossings of the northwestward extension of the trend of the Java Trench. These would be underway observations as described above. The first line would approach the Sumatra coast near Padang and then turn southwest continuing to the latitude of the Sunda Strait, thence due east through the Sunda Strait to Djakarta. The tracklines between the end of the oceanographic stations and Djakarta are only tentative and will be changed to supplement the work of the ARGO currently operating in this area. 


\section{SCIENTIFIC PERSONNEL SCHEDULED TO WORK ABOARD R/V ANTON BRUUN}

\section{CRUISE 1}

R. T. Abbott

J. E. Bohlke

Hans Brattstrom

E. Brinton

D. M. Cohén

W. J. Hargis

T. S. Hida

K. Isarankura

E. C. LaFond

K. LaFond

R. Norris

A. T. Pruter

S. Sudara

\section{CRUISE 4}

R. J. Barsdate Robert Bieri

M. A. Byrd

L. S. Cieresko

R. C. Dugdale

R. Foster

F. Fraga

T. S. Hida

J. K. Kunnenkeri

R. Norris

A. T. Pruter

M. Watson

S. Watson

L. P. Woods

\section{CRUISE 7}
O. L. Bandy
M. A. Byrd
M. R. Carriker
E. Cutler
B. C. Heezen
R. J. Menzies
R. Norris
V. Orr
D. F. Squires
W. Wieser.

\section{CRUISE 2}

M. A. Byrd

R. C. Dugdale

S. McDowell

J. A. McGowan

R. Norris

R. Shomura

S. J. Townsley

\section{CRUISE 5}

M. B. Allen

W. J. Hargis

S. Kite

E. J. Kuenzler

-M. M. Mullin

R. Norris

R. Shomura

M. Vannucci

\section{CRUISE 8}

K. J. Boss
M. A. Byrd
B. B. Collette
N. Della Croce
S. Frontier
R. M. Johnson
M. Menaché
R. Norris
J. M. Peres
F. D. Por
S. Springer
M. L. Wass

CRUISE 3

\author{
A. W. H. Bé \\ Robert Bieri \\ T. Chen \\ G. L. Clarke \\ R. C. Dugdale \\ A. W. Ebeling \\ J. W. Fell \\ R. H. Gibbs \\ W. J. Hargis \\ D. McGill \\ R. Norris \\ S. J. Townsley
}

\section{CRUISE 6}

R. H. Backus

D. M. Cohen

G. D. Grice

W. J. Hargis

G. W. Mead

D. McGill

R. Norris

P. J. S. Raj

\section{CRUISE 9}

F. G. Carey

W. J. Hargis

E. Kirstauer

R. Norris

E. L. Pierce

R. H. Rosenblatt

J. M. Teal

M. Watson

S. Watson 


\section{BIBLIOGRAPHY}

1961

KNAUSS, John A., The International Indian Ocean Expedition, Science, 134: 1674-1676.

1962

RAMAGE, C. S., The United States meteorology program for the International Indian Ocean Expedition, Bull. Am. Met. Soc., 43: 57-61.

SWINNERTON, J. W., and J. P. SULLIVAN, Shipboard determination of dissolved gases in sea water by gas chromatography, NRL Report 5806,13 pp., U. S. Naval Research Lab. 



\section{APPENDIX 7}

NATIONAL OCEANOGRAPHIC PROGRAM-FISCAL YEAR 1965, SUBMITTED BY HON. JAMES H. WAKELIN, JR., ASSISTANT SECRETARY OF THE NAVY, INCLUDING LETTER OF TRANSMITTAL, DATED MARCH 19, 1964, ADDRESSED TO SPEAKER

MCCORMACK AND SIGNED BY PRESIDENT JOHNSON 



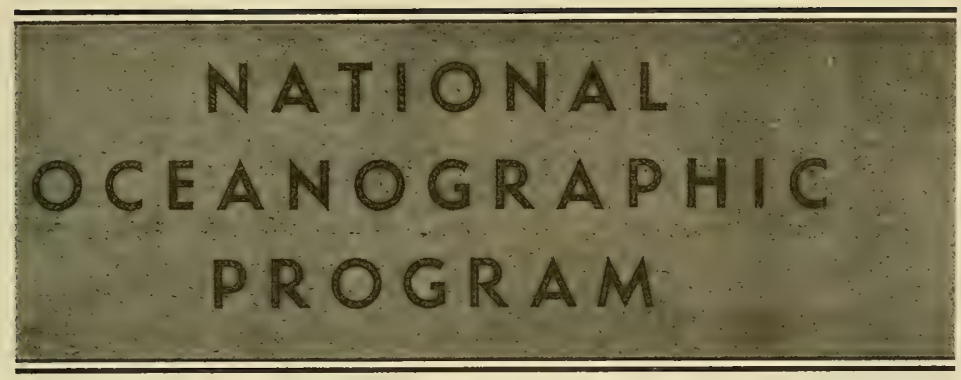

FISCAL YEAR

1965

INTERAGENCY COMMITTEE ON OCEANOGRAPHY

of the

FEDERAL COUNCIL FOR SCIENCE AND TECHNOLOGY

United States of America

ICO Pamphlet No. 15

March 1964 


\section{FEDERAL COUNCIL FOR SCIENCE AND TECHNOLOGY}

DONALD F. HoRniG, Chairman

Director, OFFICE OF SCIENCE AND TECHNOLOGY

NyLE C. BRAdY

Director, Science and Education DEPARTMENT OF AGRICULTURE

Harold Brown

Director of Defense

Research and Engineering

DEPARTMENT OF DEFENSE

John C. Calhoun, JR.

Science Adviser to the Secretary DEPARTMENT OF THE INTERIOR

LELAND J. Haworth

Director

NATIONAL SCIENCE FOUNDATION

J. Herbert hollomon

Assistant Secretary for

Science and Technology

DEPARTMENT OF COMMERCE
GLENN T. SEABORG

Chairman

ATOMIC ENERGY COMMISSION

JAMEs E. WebB

Administrator

NATIONAL AERONAUTICS AND

SPACE ADMINISTRATION

\section{N. E, HaLABY}

Administrator FEDERAL AVIATION AGENCY (Observer)

RAGNar Roliefson

Director, Office of International

Scientific Affairs (Observer)

DEPARTMENT OF STATE

ELMER B. StaAts

Deputy Director

BUREAU OF THE BUDGET (Observer)

BoISFEuILLeT Jones

Special Assistant to the Secretary

for Health and Medical Afjairs

DEPARTMENT OF HEALTH, EDUCATION

AND WELFARE

EDWARD WENK, JR.

Technical Assistant to the Director

OFFICE OF SCIENCE AND TECHNOLOGY

(Execulive Secretary)

\section{INTERAGENCX COMMITTEE ON OCEANOGRAPHY}

JAMES H. WAKELIN, JR., Chairman

Assistant Secretary of the Navy

(Research and Development)

Radm. H. ARnold Karo

U.S. Coast and Geodetic Survey

DEPARTMENT OF COMMERCE

DONALD L. MCKERNAN

Bureau of Commercial Fisheries

DEPARTMENT OF INTERIOR

RADM. R, D. SchmidTMAN

US. Coast Guard

DEPARTMENT OF THE TREASURY

RAGNAR ROLLEFSON

Office of International Scientific Affairs DEPARTMENT OF STATE

\section{HaRVE J. CARLSON}

NATIONAL SCIENCE FOUNDATION

HARRY G. HANSON

Public Health Service

DEPARTMENT OF HEALTH,

EDUCATION AND WELFARE
JOHN N. WOLFE

ATOMIC ENERGY COMMISSION

I. E. WALLEN

Museum of Natural History SMITHSONIAN INSTITUTION

EDWARd WENK, JR. (Obsetver) OFFICE OF SCIENCE AND TECHNOLOGY

Robert Fleagle (Obsetuet) OFFICE OF SCIENCE AND TECHNOLOGY

ENoch L. Drulon (Observer) BUREAU OF THE BUDGET

Atthelstan SpILhaus (Observer) NATIONAL ACADEMY OF SCIENCES COMMITTEE ON OCEANOGRAPHY 


\title{
NATIONAL OCEANOGRAPHIC PROGRAM
}

\author{
PART 1: SUMMARY \\ FISCAL YEAR 1965 \\ Interagency Committee on Oceanography \\ Federal Council for Science and Technology
}

MARCH 1964 
TABLE OF CONTENTS

Part I

Foreword

1 Introduction

II Oceanic Research to Meet National Goals

A. Improve National Defense

B. Manage Resources in the World Ocean

C. Facilitate Intelligent Legislation and Regulation

D. Safeguard Public Health

E. Protect Life and Property Ashore

F. Strengthen Basic Science

G. Conserve Resources Held in Common

H. Recognition of Foreign Policy Implications

III FY 1965 Plans and Budgets 4

IV Interpretation of the FY 1965 Oceanography Budget

A. Balance Between Research, Surveys, and Facilities …….................................. 7

B. Areas Selected for Special Emphasis 7

V Relationship with Other Federal Research and Training Programs 7

VI Program Management _...

A. Planning and Coordination _ . 8

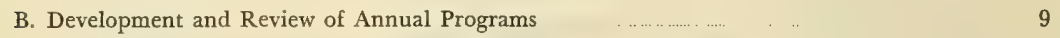

C. Gap Filling $\quad 9$

D. Long Term Investments in Manpower Training . 9

E. Data Control ....

VII Our Present Posture in Oceanography $\quad \ldots \ldots \ldots \ldots \ldots$

VIII Problems and Emerging Issues 10 


\title{
NATIONAL OCEANOGRAPHIC PROGRAM
}

\author{
PART 1: SUMMARY \\ FISCAL YEAR 1965
}

\author{
Interagency Committee on Oceanography \\ Federal Council for Science and Technology
}

MARCH 1964

\section{FOREWORD}

This summary of the National Oceanographic Program for FY 1965 has been prepared particularly for the U.S. Congress, as a background for their consideration of the President's budget transmitted to the Congress January 21, 1964. An account is given of the diverse ways in which the oceans contribute to the Nation's security and welfare, and an outline is presented of specific plans and the associated funding required to advance our understanding of the sea and to exploit this understanding. Also, details are provided of the steps being taken under Federal leadership to strengthen and coordinate this program with due regard for thrift in the use of both manpower and appropriations.

The National Oceanographic Program involves participation of scientists, engineers, technicians, and administrative officers from numerous universities, government agencies, and industry. But it is the Federal Government that has had to assume leadership and responsibility for funding a program which both the Executive and Legislative Branches have specifically endorsed to meet our national needs.

From FY 1958 to FY 1964, Federal support has grown from around $\$ 35$ million to $\$ 124$ million. Support for the FY 1965 program, now before the Congress, is projected to come to $\$ 138$ million. These funds are contained in the budgets of eight major departments and independent agencies, a distribution which illustrates the diverse ways in which knowledge of the sea underpins accomplishment of a variety of important statutory missions. Yet, these components are fundamentally linked together because all agencies must draw on the same pool of scientific results. We have learned that research conducted for one purpose will often simultaneously serve for other practical ends; in order to provide for coordination and for mutual use of the results of research, there is an increasing use of the "delegated agent" concept by which one agency with specialized interests and competence undertakes responsibility to support a critical element of the program on which all other agencies depend. Accomplishment of the government-wide objectives thus depends significantly on support for all parts of the program.

The President, in implementing this articulated program, has sought to coordinate its varied parts through the Office of Science and Technology (OST) and the Federal Council for Science and Technology (FCST). The Council's Interagency Committee on Oceanography (ICO) is called upon to identify collective goals, to coordinate plans for their achievement, and to make recommendations for government-wide programs.

Carefully reviewed by the Council and OST, these recommendations are then employed as guidelines by the participating agencies and the Executive Office of the President when making choices as to priorities out of the entire spectrum of competing needs for all fields of science and for all functions of government. The product of this process for FY 1965 has been integrated in the President's Budget for FY 1965 and is abstracted in Special Analysis $\mathrm{H}$.

Further details as to objectives, plans, and coordination, together with an outline of emerging issues that may influence the future development of a vigorous program in oceanography are set. forth in this report. 


\section{INTRODUCTION}

This Nation's destiny has been vitally influenced by the sea since the days of the early discoverers and explorers. In their role as an immense defensive moat, the oceans have permitted the growth of our remarkable economy and the development of our free institutions. The oceans have also served as open highways for peaceful commerce.

In the modern world, while these influences which mutually fostered development of this $\mathrm{Na}$ tion as a world power remain important, there are additional reasons for seeking a more thorough understanding of the sea. Oceanic resources offer an untapped potential for nutrition, for minerals, for recreation, and for understanding the planet on which we live. Storms tidal waves, and ice present threats to life, to coastal beaches, to ships, and property; damage from water and waves runs annually to hundreds of millions of dollars. Thoughtless contamination and pollution of the sea by man can be disastrous.

The oceans are the last great frontier of our planet. Apart from seeking to describe the geography of this $71 \%$ of the earth's surface, scientists have looked to the sea for solutions to broader questions concerning the origin of the universe and the mysteries of life.

Despite these compelling reasons to understand the sea, national awareness of its importance, and interest in its exploration, have been uncertain and variable.

In 1958, this country was spending less than $\$ 35$ million annually for studies in the oceans, out of a national basic research budget of well over $\$ 1$ billion. Concerned that this feeble effort seriously thwarted fulfillment of their statutory missions, a number of Federal Agencies requested the National Academy of Sciences (NAS) to identify the national requirements for oceanographic research and to propose a ten-year program for their accomplishment.

The Academy's report catalyzed action by both the Executive and the Congress and provided an eloquent source of awakened public understanding of man's relationship to the sea. Almost immediately after release of the report, the 86 th Congress took the initiative to examine its implications. In March 1959, Representative George P. Miller began a series of extensive hearings under the House Merchant Marine and Fisheries Committee. In April 1959, Representative Overton
Brooks introduced H.R. 6298, the first of a series of bills extending through the 88th Congress, which are concerned with strengthening the Nation's oceanic research. In June 1959, Senator Warren G. Magnuson introduced Senate Resolution $136 \mathrm{ex}$ pressing Congressional intent to stimulate oceanography as a matter of national policy. This Resolution passed unanimously. In July 1960, the House Science and Astronautics Committee released a comprehensive report (number 2078) concurring with the goals enunciated by the NAS and indicating that the Committee was "open to persuasion" that annual Federal support should grow to levels of about $\$ 160$ million by 1970 , rather than the $\$ 80$ million projected by the Academy. Acts of Congress passed in 1960, 1961, and 1962 expanded the research functions of the Coast and Geodetic Survey ${ }^{1}$, Coast Guard ${ }^{2}$, and Geological Survey ${ }^{3}$. H.R. 6997, which would formalize the Executive planning process, is pending.

The Executive Branch also acted on the basis of the Academy recommendation. In 1959 the Federal Council for Science and Technology, then a newly formed "science cabinet," undertook appointment of the Interagency Committee on Oceanography to lay plans to correct the serious deficiencies in the program. Increased funding was begun in the FY 1960 budget. On 29 March 1961, shortly after his inauguration, President Kennedy, in a special message to the Congress, took note of the comparatively primitive state of oceanography in relation to its potential for the Nation, and urged a step increase in funding for FY 1962 that should bring this field into better balance with other scientific and technical fields.

This was a conspicuous policy decision of the President to make sure that this Nation would not again lapse in its quest for knowledge of the sea. Although the short-term practical needs for oceanic research were recognized, the intent of this program was first to strengthen and expand the tiny nucleus of oceanic scientists interested and capable of doing fruitful research in the oceans, and to provide modern tools for such researchships, instruments, and shore-based laboratories. Strengthening these resources was a critical prerequisite to meeting the aggregate and competing future requirements for these limited capabilities.

\footnotetext{
${ }^{1}$ Public Law 86-409, April 5, 1960 (74 Stat. 16).

? Public Law 87-396, Oct. 5, 1961 (75 Stat. 61)

s Public Law 87-626, Sept. 5, 1962 (76 Stat. 427).
} 
In 1963, the Federal Council approved the ICO's Long Range National Oceanographic Plan (19631972) (ICO Pamphlet No. 10) which sets forth in systematic form the objectives of the program, substantive plans, requirements for funds, manpower, ships, and facilities, and roles of partici- pating agencies for its development over the coming decade. The President approved and forwarded this plan to Congress through the Council Chairman. The FY 1965 budget is the first of the annual ICO budgets which has been prepared within the context of the Long Range Plan.

\section{OCEANIC RESEARCH TO MEET NATIONAL GOALS}

The Long Range Plan states that the national goal is "To comprehend the world ocean, its boundaries, its properties, and its processes, and to exploit this comprehension in the public interest, in enhancement of our security, our culture, our international posture, and our economic growth."

It is important to note that this statement and its elaboration express the harmony of views of the National Academy representing the scientific community, the Federal Council representing the President and Executive Departments, and the Congress representing the nation as a whole.

Specific objectives or applications of our oceanographic research program reflected in this broad statement of goals arise from the following six national needs to:
A. Improve National Defense
B. Manage Resources in the World Ocean
C. Facilitate Intelligent Legislation and Regula- tion
D. Safeguard Public Health
E. Protect Life and Property Ashore
F. Strengthen Basic Science
G. Conserve Resources Held in Common
H. Recognition of Foreign Policy Implications

\section{A. Improve National Defense}

This Nation is dedicated to preserving world peace. As a matter of policy we maintain military capabilities necessary to meet challenges to the peace. As a matter of policy, we maintain military -the Polaris deterrent, antisubmarine and mine counter-measure forces, carrier attack and amphibious forces-all depend for safe, effective operation on accurate knowledge of the ocean environment. Development of nuclear propelled submarines makes submerged operation for very long periods possible, and this creates in the under-sea region an arena for extensive naval operations, one that must become familiar to us. It is essential that we observe and study the sea from the surface to the ocean floor, the topography of the bottom, the peculiarities of sound transmission through the sea, the many complex effects of ocean turbulence, currents, fish and plankton concentrations on naval operations, especially on the detection and tracking of underwater vehicles. This information is essential if we are to use the sea for concealment, and if we are to anticipate the concealment which our competitors may attempt.

\section{B. Manage Resources in the World Ocean}

Fish are a potent source of protein for the diets of many underfed peoples of the world. But we know very little of growth patterns and habits of particular fish, reasons for their migration, or of means to increase stocks and catches.

Ocean water and especially the ocean bed may be the source of minerals that the world must exploit when ores and fossil fuels now found on land are depleted. These resources are now unknown in richness and distribution. Extensive, sophisticated surveys may be required to inventory this potential.

\section{Facilitate Intelligent Legislation and Regulation}

The "law of the sea" has historically been more conscientiously accepted as a code of international behavior than any other. Yet changes in prevailing rights of sovereignty, transit, and conservation in. creasingly depend on technological facts and scientific understanding. State as well as Federal legislators and policy makers must increasingly depend on oceanic science. When the interests of recreation, commercial fishing, sport fishing, oil exploration, and waste disposal compete for use of the same coastal resources, wise decisions that extend beyond preservation of the status quo can only be based on the fullest knowledge of the properties of the sea and its coastal areas. International disputes on defense aspects and fishing rights, which now occur with greater frequency, and matters of ownership of undersea mineral re- 
sources, sovereignty of straits or restricted waters or of strategically located sea mounts are a potential source of tension, and must be subject to agreements based on better data than now available.

\section{Safeguard Public Health}

Because of its size, the ocean has often been - regarded as an unlimited reservoir for waste disposal. Yet, as we have learned about pollution in an apparently unlimited expanse of fresh air, the ocean must similarly be protected against unwitting disposal of oily and industrial waste, sewage, and radioactive materials. Data are required concerning the potential dilution of waste by ocean currents and concerning the food chain which may involve transfer of substances or bacteriological organisms harmful to man. Such inquiries have become urgent in an increasingly urbanized society wherein effluents may be concentrated in estuarine and in-shore waters that are simultaneously sites for recreation and the habitat of attractive sea food.

\section{E. Protect Life and Property Ashore}

Improve weather prediction. Weather and climate on land are critically influenced by the sea. Droughts, floods, blizzards, and tornadoes a thousand miles from the sea coast are generated as part of a complex process, driven by moisture evaporated from the oceans. Without collection of essential oceanic data related to meteorology and the interaction of wind and water, accurate weather forecasting will always be limited to short time intervals.

Protect lives and property. The violence of the sea in storm-propelled or tidal waves and hazards from ice pose threats to life and property. Warnings of tsunamis and hurricanes and of icebergs are often of life-and-death importance. Also important is an understanding of the phenomena of beach building and erosion, of countermeasures by man which will contribute to the protection of life and of private property.

\section{F. Strengthen Basic Science}

Past experience has demonstrated that our national welfare is critically related to the quality, scope, and vigor of our scientific base. As the demands of national security, of economic development, and of related technical fields become stronger, it becomes more and more important that we provide a reservoir of intelligence-of knowledge and of skilled talent-to meet specific requirements and also to serve as a long range investment to meet the unforeseen. Basic research is important for its possible application. But it also provides answers to important questions regarding the world around us, the origin of the planet itself, the processes by which the continents are formed, the evolution of life itself. Those who pursue such knowledge for its own sake and share it with humanity as a whole satisfy man's basic curiosity and need to understand the world in which he lives. In the past these men have helped modify man's ways of thought in complex and far reaching ways. The Federal Government has made it a matter of de facto policy to maintain the strength of the U.S. scientific enterprise, and to broaden its geographic distribution around potential centers of excellence. Expanding the manpower base in oceanography is a specific objective of this program.

\section{G. Conserve Resources Held in Common}

Strengthen the fishing and shipping industries. In the face of severe foreign competition, the Congress has provided direct protection and subsidy for the fishing and shipping industries. Such support may become more effective if oceanographic information is fully and aggressively applied. With a better understanding of fish behavior and deployment of modern equipment, the fish catch can be enhanced. Also, using data on surface wave spectra, and improving sea state forecasting ships can be more efficiently designed and routed for fast freight delivery and reliable passenger service.

Assist off-shore oil and mineral industries, and recreational development. Although there are numerous indications of rich mineral and oil deposits that one day will claim commercial interests, their exploitation does not provide immediate incentives to private investment. Because geologic maps of the continental shelves and of the deep ocean are non-existent, the possible economic benefits from the mining of common substances or of trace elements that have been concentrated by the sea are unknown. Such mapping, and study of prototype techniques for exploitation, which is beyond the present capability of private interests, can be considered a logical extension of mineral surveys and pilot plant operation on land. These activities are of increasing 
importance to our national economy as worldwide demands for resources increase. In regard to our rapidly growing demand for recreational opportunities, oceanic research will aid protection and even extension of beaches, sport fishing development, safety for boating, swimming, surfing, and skindiving.

\section{H. Recognition of Foreign Policy Implications}

In addition to six explicit factors motivating oceanic research, there is another concerned with implementing foreign policy. Maintaining a strong military capability is the necessary first step toward world peace. But hunger and malnutrition con- tinue to debilitate many newly emerging nations and threaten their desire for self-determination. We are committed to helping other nations find their rightful destiny and to employ science and technology where it may lessen world tensions and meet economic and social needs. We thus seek information about the sea that may help those nations which suffer from indigenous protein deficiency to use contiguous living resources of the sea more effectively. In addition, because the oceanic phenomena affect all nations and are too extensive for any one to explore alone, cooperative international expeditions offer fruitful avenues for discourse, planning, and use of scientific results to mutual advantage.

\section{FY 1965 PLANS AND BUDGETS}

The national program in oceanography represents the consolidation of plans of various agencies whose statutory missions encompass achievement of these previously described goals: the Navy primarily has responsibility for defense; Interior's Bureau of Commercial Fisheries, Bureau of Sport Fisheries and Wildlife, Gelogical Survey and Bureau of Mines for resources development; the Coast and Geodetic Survey, the Coast Guard, and Army's Corps of Engineers are concerned with protection of life and property; Maritime Administration with improved sea transport; the National Science Foundation, Office of Education, and Smithsonian, for developing our national research and manpower resources, and to maintain the strength of the U.S. scientific enterprise; the Atomic Energy Com.

mission for verifying safety of low-level radioactive waste disposal; and the Public Health Service for protecting the health of our citizens.

The trend in the aggregate obligations by these agencies for oceanography is shown in Table 1:

Table 1.

Federal Obligations for Oceanographic Research, Surveys and Facilities

$\begin{array}{lr}\text { FY } 1960 & \$ 55 \text { million } \\ \text { FY } 1961 & 62 \\ \text { FY } 1962 & 104 \\ \text { FY } 1963 \text { FY } 1964 \text { (estimated) } & 124 \\ \text { FY } 1965 \text { (proposed) } & 124 \\ & \end{array}$

Table 2

FY 1965 Obligations for the National Oceanographic Program, by Agency

\begin{tabular}{|c|c|c|c|}
\hline & $\begin{array}{l}\text { Actual } \\
\text { FY } 1963\end{array}$ & $\begin{array}{c}\text { Estimated } \\
\text { FY } 1964\end{array}$ & $\begin{array}{l}\text { Proposed } \\
\text { FY } 1965\end{array}$ \\
\hline Defense & $\$ 55,475$ & $\$ 54,631$ & $\$ 66,619$ \\
\hline Commerce & 23,645 & 23,752 & 20,486 \\
\hline Interior & 16,104 & 16,509 & 19,652 \\
\hline National Science Foundation & 19,700 & 20,200 & 20,600 \\
\hline Atomic Energy Commission & 3,516 & 4,167 & 4,730 \\
\hline Health, Education and Welfare & 4,108 & 2,855 & 3,280 \\
\hline Treasury & 511 & 1,152 & 1,822 \\
\hline \multirow[t]{2}{*}{ Smithsonian Institution } & 607 & 605 & 881 \\
\hline & $\$ 123,666$ & $\$ 123,871$ & $\$ 138,070$ \\
\hline
\end{tabular}


Table 3

FY 1965 Obligations for the National Oceanographic Program, by Function

\section{Research}

Instrumentation

Ships

Surveys

International Indian Ocean Expedition (IIOE)

Facilities

Data Center

(II)

Ship construction

Surveys and data collection in support of research and agency missions

Research, Instrumentation, IIOE and Facilities (Navy)

Research, Instrumentation, IIOE and Facilities (Civil)

These budgets represent the collective plans of Federal Agencies, coordinated in planning and execution by the Federal Council's ICO to meet the collective goals outlined in the preceding section and simultaneously to strengthen the base of research and training resources required for the future.

A summary of budgets is given in Volume 2, with a breakdown by agency, year, and functional area.

The FY 1965 budget for oceanography achieves the goal, enunciated by President Johnson in his budget message of January 21, 1964 to meet national needs while keeping costs under tight control. The oceanographic component has also been developed from careful planning in relation to other needs and requirements which compete for Federal support. Finally, the research budget was developed taking into consideration the rate at which this field can grow so as not to outdistance

\begin{tabular}{|c|c|c|}
\hline $\begin{array}{l}\text { Actual } \\
\text { FY } 1963\end{array}$ & $\begin{array}{c}\text { Estimated } \\
\text { FY } 1964\end{array}$ & $\begin{array}{l}\text { Proposed } \\
\text { FY } 1965\end{array}$ \\
\hline$\$ 46,410$ & $\$ 58,722$ & $\$ 69,143$ \\
\hline 6,658 & 6,386 & 9,110 \\
\hline 37,250 & 27,387 & 21,350 \\
\hline 18,036 & 21,916 & 25,014 \\
\hline 5,802 & 5,582 & 3,979 \\
\hline 8,875 & 2,937 & 8,420 \\
\hline 635 & 941 & 1,054 \\
\hline$\$ 123,666$ & $\$ 123,871$ & $\$ 138,070$ \\
\hline Actual & Estimated & Proposed \\
\hline FY 1963 & FY 1964 & FY 1965 \\
\hline$\$ 37,250$ & $\$ 27,387$ & $\$ 21,350$ \\
\hline 18,671 & 22,857 & 26,134 \\
\hline 26,700 & 31,917 & 41,177 \\
\hline 41,045 & 41,710 & 49,409 \\
\hline$\overline{\$ 123,666}$ & $\$ 123,871$ & $\$ 138,070$ \\
\hline
\end{tabular}

the specialized science skills upon which it depends.

It should be recognized that this national program in oceanography is a multi-disciplinary enterprise that embraces both basic and applied research in classical disciplines of biology, physics, chemistry, as well as engineering applications related to the sea. Moreover, expansion of knowledge about the sea entails a dual activity of (a) stating and solving problems using methods of mathematics and the basic sciences, and (b) observing the gross features of the ocean. Historically the first endeavor was characterized as "oceanology," the charting and mapping being designated as "oceanography." These two mutually supporting activities are in this budget termed "research" and "surveys."

Research has been classified by five problem areas, shown in Table 4: 
Table 4.

FY 1965 Obligations for Oceanographic Research, by problem area

\section{Objective}

1. Physical properties and motion of the sea

2. Ocean-atmosphere interrelationship

3. Biological properties

4. Structure and history of the ocean floor

5. Modification of the sea

Totals *

$\begin{array}{r}\text { FY } 63 \\ \hline 11,812 \\ 4,000 \\ 15,000 \\ 12,500 \\ 8,900 \\ \hline 52,212\end{array}$

Approximate

FY 64

$\begin{array}{r}15,000 \\ 5,500 \\ 18,500 \\ 15,000 \\ 10,000 \\ \hline 64,000\end{array}$

Proposed.

$\frac{\text { FY } 65}{20,524 * *}$

5,890

18,611

$19,235 * *$

8,862

- These figures include support for research performed within the International Indian Ocean Expedition Program. They equate to the sum of the Research and IIOE functional areas in the budget tables. By prior arrangement, the meteorology program carried out within IIOE is reported by the Interdepartmental Committee on Atmospheric Sciences; this tends to depress the apparent support given to objective II.

- Some areas of research have received increased emphasis because of new development or urgent needs in these areas. Marine biology has been a field set aside for special emphasis.

Table 5.

FY 1965 Operating Areas of Survey Ships

\section{Atlantic}

Western Atlantic

Southeast Coast of USA

North Atlantic

4 large 1 small

1 large 4 small

These categories of research problems, while mutually exclusive, are necessarily arbitrary. Ship operating costs, small laboratory equipment, and expendable supplies are included with research. The International Indian Ocean Expedition has been separately listed in Table 3 because of the very extensive nature of U.S. commitments but, by class of activity, it is considered research.

Again, further details are set forth in Volume II.

It should be understood that a substantial fraction of the research is conducted in private and university laboratories and that grants and contracts are awarded by the National Science Foundation, Office of Naval Research, and other agencies on the basis of merit and available funds.

Surveys can be characterized best by the following table showing the number of ships by geographical areas in which survey operations are scheduled during FY 1965.
Gulf of Mexico

Western Tropical Atlantic

1 large

1 large -

2 large -

Pacific

Western Pacific (mostly

Japan-Philippines area) 4 large 1 small

Eastern Pacific

North Pacific

Indian Ocean

1 large

4 large

I large

Unassigned (on shakedown)

3 large

These surveys include measurement of water depth, water temperature, salinity, magnetic field, gravity, samples of bottom sediment, and biota.

Capital plant expansion in the form of new ships, new instrumentation, and new shore facilities, are also detailed in Volume II.

Funding for the National Oceanographic Data Center, a Navy-administered but jointly funded data bank, is also separately described. 


\title{
IV. INTERPRETATION OF THE FY 1965 OCEANOGRAPHY BUDGET
}

\author{
A. Balance between Research, Surveys, and Facilities
}

The $\$ 138$ million proposed for FY 1965 represents $11 \%$ growth over Congressional appropriations for FY 1964. Considerably below Presidential requests, FY 1964 appropriations just equalled FY 1963 levels. To maintain the effective cutting edge of research and training, the new budget has been carefully tailored to foster growth in the conduct of research. Levels are proposed of $\$ 73$ million, up from $\$ 64$ million in FY 1964 and $\$ 52$ million in FY 1963. Sustaining this momentum has been accomplished by slowing down ship construction. In the long run, the program may benefit by this decision because of the opportunity deliberately taken to evaluate performance of new ships already in operation or funded, before proceeding with construction of duplicates. Opportunity will also thus be afforded to explore the emerging potential of such unconventional data gathering tools as unmanned buoys, submarines, and FLIP-type platforms. Growth in research funding is not a direct yardstick of growth in program scope, however, because unit costs of doing research continue to increase annually, and because ship operating expenditures are now reflecting important additions to the oceanographic fleet.

Another consideration in preparing the FY 1965 budget was an assessment and confirmation of the balance between funds, number of ships, and number of available qualified oceanographers.

\section{B. Areas Selected for Special Emphasis}

Relative emphasis as between goals is best understood by reference to the budget breakdown by agency. As revealed in Table 2, roughly half of the budget is supported by the Defense Dept. and associated with national security. This is consistent with the $46 \%$ of the total Federal R \& D budget funded by the Department of Defense.
New growth in the National Oceanographic program is primarily in the Navy's component, reflecting heightened interest in environmental factors which influence naval performance.

Considered by problem area, a sharp growth in physical oceanography and geophysics, problem areas I and IV has resulted.

Two special substantive areas have been identified and earmarked for special emphasis. These are the air-sea interaction, problem area II, and research in the deep oceans (parts of all five problem areas). In both cases, an expansion in research effort is being encouraged because of the increasing opportunities to solve old problems with new tools for research-buoys, deep diving submarines, telemetering, etc. Inasmuch as program planning must precede funding, the attention being directed to these areas will not be reflected in later budgets. However, special studies are being made that will be published as separate reports by the ICO later this year.

Geographical areas receiving special attention in Fiscal Year 1965 include:

a. Indian Ocean: The International Indian Ocean Expedition, involving significant support from twelve nations, will continue. As field operations phase out in FY 1965, attention will center on data analysis and dissemination.

b. Tropical Atlantic: Field operations in the International Cooperative Investigation of the Tropical Atlantic, involving ten nations, will terminate. Effort will be mainly devoted to data analysis and publication of atlases.

c. U.S./Japan Investigations of the Pacific: Pursuant to a bilateral agreement between the two nations, a number of individual cooperative projects in Pacific oceanography will be prosecuted.

\section{RELATIONSHIP WITH OTHER FEDERAL RESEARCH AND TRAINING PROGRAMS}

To facilitate understanding of the oceanographic program, it is important to recall that other programs sponsored by the Federal Government contribute to knowledge of the ocean, although they are not catalogued under this definition. For example, basic research in classical disciplines such as biology, geophysics, mechanics, and even mathe- matics and now in engineering contribute important fragments of answers to questions about the sea.

Expenditures for basic research as a whole, including oceanography, are expected to grow as follows. 
Table 6

Expenditures for conduct of Basic Research (in millions of dollars) ${ }^{1}$

$\begin{array}{lccc}\text { All agencies } & \text { FY 1963 } & \text { FY 1964 } & \text { FY 1965 } \\ \begin{array}{c}\text { NASA (including } \\ \text { booster costs) }\end{array} & 1,350 & 1,657 & 1,809 \\ \begin{array}{c}\text { All Agencies } \\ \text { except NASA }\end{array} & 525 & 727 & 790 \\ { }^{2} \text { Source: The Budget FY } & 825 & 930, \text { Special analysis H; Page } 409 .\end{array}$

On the more applied side of the program, the Navy is funding programs in ASW and in ship hydrodyn-mics. In response to the THRESHER disaster and a subsequent special study of deep submergence vehicles, the Navy is expected to expand its capabilities for search, rescue, and salvage.* These separate new programs should contribute engineering knowledge concerning ships, structures, vehicles, and equipment to operate in and under the sea, results that should provide better tools for basic research, and also lay ground- work for engineering application of oceanographic research. Basic research and civilian engineering stands to gain greatly from a program of Navy development, and special steps are being taken to assure a rapid flow of new engineering information.

Accelerated physiological studies on manned free diving under Navy sponsorship, should lay a durable base for a more concerted attack on the sea.

Coordination is also being effected with other government-wide programs, developed under the Federal Council, such as for air-sea interface research of mutual interest to the Interdepartment Committee for Atmospheric Sciences and the Interagency Committee on Oceanography.

Finally, in the areas of manpower, education, and training, numerous programs funded by NSF, National Institutes of Health, and the Office of Education provide fellowships, matching funds for research facilities, etc., that may concurrently serve needs in oceanography, although not so delineated. Such support was recently expanded for graduate education in engineering, through a new training grant program in NSF.

\section{PROGRAM MANAGEMENT}

\section{A. Planning and Coordination}

The national goals expressed in the Long Range Plan and restated in Section II are reflected in existing statutory requirements of some 20 Federal Agencies. Yet, the program as a whole is not the specified responsibility of any single one. When stimulation of this field was deemed necessary, it was necessary to choose between strengthening existing programs, or excising jurisdiction for oceanography from the many agencies now involved and recombining these interests in a new Federal Oceanographic Agency. Because of the relevance of research in the oceans to broader missions: to defense, to the protection of public health, to improve weather forecasting, etc., the first alternative was chosen. Coordination thus became essential to the healthy growth of this program, to minimize both unwitting duplication and to minimize gaps. The role of the Federal Council for Science and Technology, and of its Interagency Committee on Oceanography in coordination and in program and budget planning has already been described.

In addition to these continuing responsibilities,

- Report of Deep Submergence Systems Review Group March, 1964 the ICO has taken the initiative in the following matters. Oceanographic data collected by separate agencies are now centrally standardized, deposited, and made available for distribution. Ships schedules of all agencies and laboratories are published in advance to permit the efficient sharing and utilization of facilities by others. Government-wide manpower requirements are coordinated. To foster interest on the part of young students, a report cataloguing oceanography curricula of all U.S. universities has been published. A special study has been undertaken to determine the demand, the sources of supply and the mobility of oceanographic manpower, as a guide to the investment of future training funds and as a model for understanding manpower dynamics generally. Under ICO direction, with Coast and Geodetic Survey acting as a delegated agent, an operations analysis is being conducted to optimize planning for effective, economical surveys using modern techniques of data gathering, and to meet a variety of needs for data. Finally, in concert with the State Department, the ICO develops plans and U.S. position for international coopera- 
tive efforts, especially for the Intergovernmental Oceanographic Commission (IOC). Such interchange is in our national interest because it fosters the collection of data beyond the capacity of a single nation. Cooperative research also provides an additional avenue for world understanding.

\section{B. Development and Review of Annual Programs}

This is the fourth annual development of a government-wide program in oceanography transmitted to the Congress. By no means a rigid blueprint, the plans developed by ICO are intended as guidelines to individual agencies and the Executive Office of the President when making final budget determinations.

The planning process comprises three steps:

1. Preparation of programs and budgets on a functional basis by ICO Panels, their screening, refinement, and consolidation by the parent committee;

2. Evaluation of that program by an independent panel of consultants, convened by the Director, Office of Science and Technology, and by the OST staff; and

3. Consideration of these proposals, recommendations, and criticisms by the Council, with endorsement that represents a single coherent planning guide for all participating agencies to use in budget preparation.

The quality of research is sustained in each agency by the normal processes of proposal evaluation, contract, or grant administration, and by justification processes at various levels in the agency. In addition, as noted in the planning sequence, the collective plans and programs of agencies are subject to further review by consultants from industry and universities convened by the Office of Science and Technology. These consultants evaluate the proposals by the ICO for scope and balance, and test them against the needs and opportunities as set forth by the National Academy of Sciences Committee on Oceanography (NASCO), supplemented by more recent contributions from the scientific and engineering community.

\section{Gap Filling}

Insuring that important research problems or possibilities for development are not overlooked is the most important administrative function relating to the oceanographic program. Gaps in the program may occur through (a) the emergence of new fields lying between the missions of existing agencies, and (b) through delay in recognition of new possibilities.

Each of these possibilities is monitored continually by the ICO through its research panel, by OS I through its staff and consultants, and by the $\mathrm{Na}$ tional Academy of Sciencies through its Committee on Oceanography. Examples of problems and po. tentialities which have been identified in this way include marine biology, air-sea interaction, deep submergence vehicles, and ocean engineering.

\section{Long Term Investments in Manpower Training}

Federal stimulation of oceanographic research carries with it the responsibility to support the longer term training of the manpower needed to carry out the program in the future. A large number of well trained scientists and engineers will be required to carry out future programs, and the changing demands of a science which is rapidly becoming more and more sophisticated must be reflected in steadily improving quality of our university teaching programs. The Federal Government through its fellowship and training programs and through research grants and contracts, is supporting rapidly growing educational programs in oceanic sciences at universities scattered throughout our country. In many cases a trained scientist and a curious, energetic student may explore nature together on a campus remote from the sea, obtaining their original data or testing their hypotheses through cooperative arrangements with other institutions.

\section{E. Data Control}

To meet the need for a centralized repository, the National Oceanographic Data Center (NODC) has been established in Washington, D. C. Policy guidance is provided by an advisory board representing six supporting agencies and the National Academy of Sciences. The Naval Oceanographic Office furnishes administrative support.

In addition to its original functions of organizing data collection, archiving, and editing of inherited data, the NODC now devotes much of its effort to serving the research users of data. For example, $56 \%$ of the total dollar receipts for FY63 data services were for data evaluation and analysis.

By its charter, NODC is "responsible for acquiring by exchange, gift, or purchase, oceanographic data of scientific value from domestic or foreign sources." To this end, exchange relationships have been established with the new Canadian Oceanographic Data Center and similar arrangements are 
in process with upcoming centers in Australia, New Zealand, Japan, and the United Kingdom. The transfer of World Data Center A, Oceanography (WDCA), a repository for IGY results, to space in the data center has simplified these exchanges. International agreements have been made to facilitate exchanges between WDCA and its counterpart WDC-B, in Moscow. NODC also cooperates with the International Council for Exploration of the Sea (embracing 16 European nations) and 30 other foreign oceanographic organizations. NODC is processing the data from the International Indian Ocean Expedition and the International Cooperative Investigations of the Tropical Atlantic.

NODC is promoting and using modern techniques of data handling and retrieval. Under present development are systems for sorting and retrieving biological and geological-geophysical data, better data interpolation techniques, and field quality control methods.

\section{OUR PRESENT POSTURE IN OCEANOGRAPHY}

A great deal of progress has been made, and the FY 1965 budget proposals within overall budget guidelines are minimum to sustain the program. If the President's FY 1965 proposals are accepted, then during the past five years the Federal Government will have invested $\$ 134$ million in new ships expressly for oceanography. For the first time in this Nation's history, we have the beginnings of a fleet of efficient floating laboratories and are starting to replace the present inadequate facilities. With the addition of ships newly completed or funded, tonnage of ships for oceanographic and fisheries research will have increased more than $50 \%$. Also, during the past five years, the Federal Government will have invested $\$ 39$ million in new shore facilities. Most important, the annual support for conduct of research and associated instrumentation will have grown from approximately $\$ 27$ million in FY 1960 to $\$ 83$ million in FY 1965.

The number of scientists and engineers will have increased from 1600 estimated in 1960 to 3000 esti- mated in 1964 and industry has responded by developing its staff, facilities, and planning capabilities focused on research and development.

This current year is one of overall modest budget growth. It should also be one of careful analysis -by members of the scientific community engaged in research; by the Executive Branch charged with utilizing fruits of that research for accomplishment of assigned missions; by industry which contributes new engineering tools for the conduct of research and which serves as entrepreneur to transfer scientific discoveries to practical benefit; and by the public and its legislative representatives who give expression to the collective concerns through decisions on policy and appropriations.

Such analysis should be aimed at identifying those scientific areas that have ripened to a point where a more concerted attack would be productive, and those practical policy, security, economic or social needs which can be met only by selective emphasis on special areas.

\section{PROBLEMS AND EMERGING ISSUES}

Questions which the Executive Branch will be examining this year include:

1) Manpower-Is our supply of high talent growing rapidly enough to meet the needs and opportunities in this field? If not, what collective steps by universities and Government are necessary to accelerate education and training?

2) Private Investments-Are results of research being enunciated effectively to the private sector of our economy, so that as users of research results they may assess opportunities for investment in underwater engineering applied to fishing, mining, recreational developments? Are these opportunities of such value to the Nation to meet economic and social needs that additional incentives are needed?
3) Participation by industry-How may the engineering competence of American industry be more effectively blended with American science, for a concerted exploration on the sea frontier?

4) Policy-making-How may fruits of research be wisely introduced into Federal, State and International legislative and regulatory processes, so that policy and administrative rules may be responsive to new facts about the sea; and how may policy makers become partners in formulating questions about the sea requiring research?

In short how may the U.S. program be further advanced, developed and coordinated to satisfy the long range goals: to comprehend the sea, to explore it, and to exploit these resources? 



\section{NATIONAL OCEANOGRAPHIC PROGRAM}

FISCAL YEAR

1965

PART II: THE PROGRAM AND ITS COST

MARCH, 1964 


\section{TABLE OF CONTENTS}

\section{Part II}

Introduction

Chapter I-OCEANOGRAPHIC EFFORT

A. Fields of Research

1. Physical Properties and Motion of the Sea _ . ............................. . 17

2. Ocean-Atmosphere Inter-Relationships 19

3. Biological Properties $\ldots \ldots \ldots 21$

4. Structure and History of the Ocean Floor $\quad . \quad \ldots \quad$. . . . . . 24

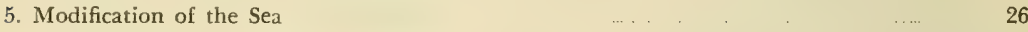

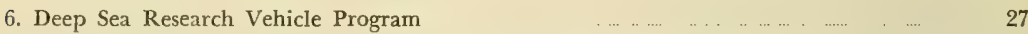

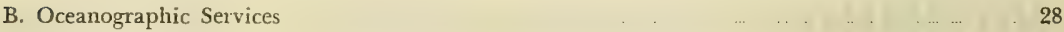

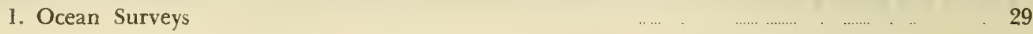

2. National Oceanographic Data Center

C. International Oceanographic Programs

1. International Indian Ocean Expedition (IIOE) _ . . _ . . . 31

2. International Cooperative Investigations of the Tropical Atlantic (ICITA)

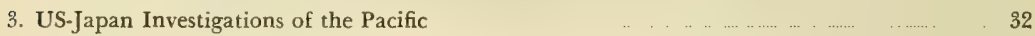

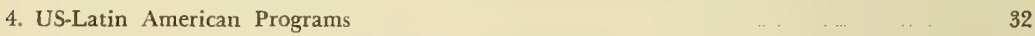

5. Cooperative Study of the Kuroshio . $\quad$.. $\quad$.. 32

6. Program for World Oceanographic Study $\quad \ldots . \ldots \ldots . . \quad 33$

Chapter II-OCEANOGRAPHIC RESOURCES

A. Ships $\quad \ldots \quad \ldots \quad$. . 35

B. Instrumentation $\quad 35$

C. Facilities

D. Manpower and Training $\quad 37$

Chapter III-NATIONAL OCEANOGRAPHIC PLAN BUDGET _ _ . . . ........... 39

A. By Agencies $\quad \ldots \ldots \ldots$. . . . . . 39

B. By Functional Areas . $\quad \ldots \quad \ldots \ldots \ldots \ldots \ldots$

C. Individual Agency Budgets ...... . . . ... . 40

Appendix-ICO Oceanographic Survey/Research Ships …_................. . . . . 43 


\section{INTRODUCTION}

Federal support for the National Oceanographic Program for Fiscal Year 1965 has been developed within the framework of the recently completed Long Range National Oceanographic Plan (19631972).* This plan sets forth the national goals and describes the contributions of the various federal agencies to these goals. The program is carried out in part by scientists and technicians in govern-

- Federal Council for Science and Technology, Oceanog. raphy, The Ten Years Ahead, A Long Range National Oceanographic Plan, 1963-1972 Interagency Committee on Oceanography Pamphlet No. 10, June 1963, 58 pp. ment laboratories, bureaus, and offices; and a most essential part is carried out by universities and research institutions with government support. In the following pages a concise account is given of the federal effort proposed in FY 1965 to maintain the momentum in oceanography developed in the last few years and to modify the direction and pace of the program in the light of new knowledge or of new perspective. The total budget proposed here is $\$ 138$ million, $\$ 14$ million more than was appropriated by the Congress in FY 1964. The relative emphasis of the five fields of research are portrayed in Table $I$ on page 2.

Table I*

National Oceanographic Program Research Budget, by Problem Area (thousands \$)

\begin{tabular}{|c|c|c|c|}
\hline \multirow[b]{2}{*}{ PROBLEM AREA } & \multicolumn{3}{|c|}{ FISCAL YEAR. } \\
\hline & $\begin{array}{c}\text { Esti- } \\
\text { mated } \\
1963\end{array}$ & $\begin{array}{c}\text { Approximate } \\
1964\end{array}$ & $\begin{array}{c}\text { President's } \\
\text { Budget } \\
1965\end{array}$ \\
\hline 1. Physical Properties and Motion of the Sea & $\$ 11,812$ & $\$ 15,000$ & $\$ 20,524$ \\
\hline 2. Ocean-Atmosphere Inter-Relationships & 4,000 & 5,500 & 5,890 \\
\hline 3. Biological Properties & 15,000 & 18,500 & 18,611 \\
\hline 4. Structure and History of the Ocean Floor & 12,500 & 15,000 & 19,235 \\
\hline 5. Modification of the Sea & 8,900 & 10,000 & 8,862 \\
\hline Total Research Budget & $\overline{\$ 52,212}$ & $\$ \$ 64,000$ & $\overline{\$ 73,122}$ \\
\hline
\end{tabular}

- These figures include support for research performed within the International Indian Ocean Expedition Program. They equate to the sum of the Research and IIOE functional areas in the budget tables. By prior arrangement, the meteorology program carried out within IIOE is reported by the Interdepartmental Committee on Atmospheric Sciences; this tends to depress the apparent support given to objective $\mathbf{I I}$. 
Chapter I

\section{OCEANOGRAPHIC EFFORT}

\section{A. Fields of Research}

\section{PHYSICAL PROPERTIES AND MOTION OF THE SEA: $\$ 20,524,000$}

Description and understanding of the distribution of temperature and salinity, of the velocity of ocean currents, and of the concentrations of various chemical elements and compounds is central to the total oceanographic program. Description is based on observations of many kinds taken at sea, and understanding develops through the application of the methods and principles of mathematics, physics, and chemistry to ocean data. Thus, a wide range of research contributes to an understanding of the physical properties of the sea, and the results are applied to the investigation of such diverse problems as biological productivity of the sea, ship design, and weather forecasting.

\section{DEPARTMENT OF DEFENSE}

\section{UNITED STATES NAVY}

\section{Office of Naval Research: $\$ 8,682,000$}

ONR supports research through contracts with universities, research institutes, other government agencies, and industry. An extensive program will be directed at obtaining time series measurements of physical quantities in the deep ocean. Long range telemetering buoys are being developed by the Convair Corporation. Together with the necessary shore command stations, and sensors, experimental buoys will be used by Texas A\&M, Scripps Institution of Oceanography, Lockheed Aircraft Corporation, University of Wisconsin, the Navy Electronics Laboratory, and other institutions. In addition to current studies other experiments will be undertaken to determine the energy spectra of internal waves both in the open ocean and in confined bodies of water.

Oceanographic institutions will intensify attempts to measure and understand oceanic currents and circulation. Direct measurements will be taken of the Yucatan and Florida currents in the Gulf of Mexico, the Gulf Stream and the equatorial currents in the Atlantic, the California and the equatorial currents in the Pacific, and the equatorial currents in the Indian Ocean. General circulation patterns will be studied by using temperature-salinity relationships, chemical isotope mea- surements, biological population distributions, and electronic computer analysis of improved theories.

Investigation of the Tropical Atlantic will continue through investigation in both the Woods Hole Oceanographic Institution, New York University, and Texas A\&M as part of the International Investigations of the Tropical Atlantic (ICITA), and investigation of the Indian Ocean will continue through the Scripps Institution of Oceanography, Lamont Geological Observatory, University of Rhode Island, and Woods Hole Oceanographic Institution as part of the International Indian Ocean Expedition (IIOE).

\section{Naval Oceanographic Office: $\$ 1,547,000$}

NAVOCEANO supports research through contract and also conducts in-house research, particularly that directed toward military planning and antisubmarine and mine warfare.

Investigations of oceanographic conditions in the Arctic Ocean north of Siberia and in the Greenland Sea will be continued and extended to other areas, in collaboration with Canadian oceanographers and those from the University of Washing ton. Newly developed buoy capability will be further exploited to study time variations of deep ocean currents, their temperature, and other environmental conditions. Measurements of background isotopic radiation, initiated in FY 1964, will continue. Full-scale studies of the use of isotopes in determining the three-dimensional circulation patterns of the oceans will be carried out. Research and development directed toward improvement of oceanographic instruments and measurement techniques will be continued.

\section{Bureau of Ships: $\$ 1,956,000$}

Using improved sensors mounted on oceanographic towers, surface ships, and the bathyscaph TRIESTE, studies of the distribution of sound velocity will be continued. In collaboration with the Office of Naval Research, BuShips will support the Navy Electronics Laboratory investigations. of wave generation and wave spectra. Increased emphasis will be placed on an analytical approach to accumulated data by combining statistics, oceanography, computer technology, and acoustics. The degree of stability of oceanographic variables. 
for large ocean areas will be assessed. Field programs on surveillance of sea ice will continue.

\section{Bureau of Naval Weapons: $\$ 2,330,000$}

In FY 1965 new oceanographic research ships will be used by Bureau laboratories to conduct experiments important to weapon system design, development, and predication of systems perform. ance. The University of Washington Applied Physics Laboratory, using a deep-sea unmanned vehicle will continue to study the horizontal variability of physical properties. The Naval Ordnance Test Station, China Lake, California will use a recently developed sound velocity-temperaturepressure measuring set to study the microstructure of physical and chemical properties.

\section{Bureau of Yards and Docks: $\$ 100,000$}

In order to allow more accurate and effective design of piles for shallow water structures the reduction and analysis of data collected on a three foot diameter pile, located in 100 feet of water in the Gulf of Mexico, will be continued. A time and spectral analysis of the data will be conducted to determine mass and drag coefficients.

\section{UNITED STATES ARMY}

Corps of Engineers Coastal Engineering Research Center: $\$ 290,000$

The Corps of Engineers plans to intensify its study, both in the laboratory and in the field, of tidal flow at inlets and in estuaries in order better to understand the processes of silting, shoaling, and beach erosion. The Corps hopes to simplify evaluations of estuary and lagoon flushing characteristics.

\section{DEPARTMENT OF COMMERCE}

\section{Coast and Geodetic Survey: $\$ 512,000$}

The ships of the C\&GS will operate in coastal waters and in the deep ocean. Data collected on cruises will be used for charts and atlases of ocean properties. C\&GS will also support the research efforts of other Federal Agencies and scientific institutions.

For FY 1965, plans include participation in the international study of Antarctic tidal phenomena, as well as research in deep-ocean tides, propagation of tide waves along U.S. coasts, long-period tides, and tsunamis.
Coastal currents will be studied, and work will continue on the development of a system for automatic measuring of currents and their variations with time.

Ocean survey data will continue to be utilized in research on general dynamics of the deep sea, with special emphasis on the study of oceanic fronts.

\section{Maritime Administration: $\$ 50,000$}

In order to promote safety and efficiency of ship operation a research program is supported through contract with the Massachusetts Institute of Technology. Experimental and theoretical studies of ocean wave spectra and their effect on ship motion will be continued.

\section{DEPARTMENT OF THE INTERIOR}

\section{Bureau of Commercial Fisheries: $\$ 2,740,000$}

Because of the intimate but obscure relations between the physical state of the sea and the productivity of the sea, BCF is committed to an expanding program of research on physical and chemical oceanography.

In FY 1965, field work will start on a synoptic study of the Eastern Tropical Pacific Ocean in which knowledge of the response of the ocean to the atmosphere will be an important objective. Also, this year, the Bureau will initiate a cooperative investigation of the oceanography of the trade wind zone in the Central Pacific.

Work will continue on a fishery-oceanography program in the Tropical Atlantic as part of ICITA. Environmental investigations in the western North Atlantic will be intensified.

The Bureau will increase its support of oceanographic buoy development; it will cooperate with other agencies in the use of buoys for collecting physical and chemical data and monitoring environmental changes.

In its continuous study to relate changes in the ocean climate to variations in fish occurrence and abundance, the Bureau proposes to support in every possible way the collection of more lengthy time series of oceanographic data.

\section{Geological Survey: $\$ 142,000$}

The USGS will intensify its efforts to determine the effects of fresh water and sediment discharge from land areas on the composition and physical properties of marine water within bays and estu- 
aries and on the Continental Shelves of the United States. The objective of these studies is to determine the quantities and composition of water and sediments carried to the ocean by rivers, and to determine the distribution and precipitation of sedimerits and associated wastes in marine waters. Studies of the dynamics of mixing fresh water and salt water and the loss of fresh water from aquifers that extend beneath the continental shelf will continue. Also to be studied will be chemical reactions taking place within sediments and rocks on the sea floor.

\section{National Science Foundation: $\$ 2,175,000$}

NSF grant and contract support will include, in addition to its usual support of research at universities and institutes, major efforts in the International Indian Ocean Expedition and a continuing program of Antarctic oceanography conducted aboard the USNS ELTANIN.

Theoretical investigations and model studies on general circulation and exchange rates are being conducted at Massachusetts Institute of Technology, New York University, Lamont Geological Observatory, Johns Hopkins University, and the University of Washington. Such work will advance our understanding of oceanic current development and of estuarine and coastal circulation.

Major field studies aimed at elucidating the character of both deep and shallow water circulation are being undertaken by Scripps Institution of Oceanography, Woods Hole Oceanographic Institution, Oregon State University, the University of Miami, University of Southern California, University of Connecticut, Yale University, University of Washington, Texas A\&M College, and the University of Rhode Island. These will be in close cooperation to similar work supported by ONR.

The chemistry of sea water is being investigated by various means. Amherst College, Scripps, Washington, Woods Hole, and Miami are active in this work.

\section{OCEAN-ATMOSPHERE INTER- RELATIONSHIPS: $\$ 5,890,000$}

The ocean and the atmosphere constitute an interacting mechanical and thermodynamic system. Thorough understanding of such problems as weather prediction, acoustic communication channels through the sea, the behavior of the Gulf Stream, or the upwelling of cold water, which may sustain a rich growth of biological material all depend in complex ways upon the interaction of air and water. The most critical research needs in this area may be grouped in the following way: (a) laboratory and field studies of the physical chemistry of the interface and its role in transfer through the surface, (b) development and testing of instruments and platforms to measure wind stress and vertical transfer of heat, water vapor, carbon dioxide, and other materials, (c) coordinated field programs comparing several independent methods for measuring vertical transfer, (d) development of observation, data collecting and processing systems covering large ocean areas, and (e) incorporation of effects of interaction in large scale dynamic problems (e.g., 30 day weather prediction). Planning in this area has been carried out initially by the National Academy of Sciences and by the Joint ICO-ICAS Committee on Air Sea Interaction.

The need for increased effort in this area and, especially, the need for centralized coordination of field programs has been recognized by the ICO and by the Interdepartmental Committee on Atmospheric Sciences (ICAS). As a result the Department of Commerce has recently been assigned the responsibility for leadership in coordination of activities which contribute to a coherent national program, in stimulation of interest and understanding of those parts of the program which need strengthening, and in administrative coordination of area studies in which universities, research institutions, and government agencies may participate. A small staff is being assembled for this purpose.

\section{DEPARTMENT OF DEFENSE UNITED STATES NAVY}

Office of Naval Research: $\$ 2,734,000$

Stereophotography of the sea surface will be used in a program sponsored jointly by ONR, NAVOCEANO, and the Applied Physics Laboratory of Johns Hopkins University. The program will involve stereophotography conducted from aboard ship by ONR, to determine capillary wave spectra. Measurements of radar backscatter to determine the spectra of larger wind waves will be taken by the Applied Physics Laboratory, concurrently with aircraft stereophotography conducted by NAVOCEANO.

A four-engine aircraft has been made available to Woods Hole Oceanographic Institution by the 
joint efforts of ONR and NSF, for operation in the Indian Ocean during FY 1964 and FY 1965. Observations made from this airplane will include dropsonde humidity and temperature, wind, solar and albedo radiation fluxes, turbulent transport of heat and water vapor, nuclei counts, cloud distribution, and radar observations of precipitation areas.

The Scripps Institution of Oceanography will establish a series of wave recorder stations across the Pacific Ocean, from New Zealand to the Aleutian Islands. The purpose of the program will be to measure the changes in surface wave spectra as the wave trains traverse the ocean and to determine the effects of the trade winds on these spectra. The program was initiated because earlier measurements indicated a discrepancy between theoretical and observed values.

\section{Naval Oceanographic Office: $\$ 865,000$}

Emphasis in FY 1965 will be placed on development of specialized sensors and observational techniques for accurate measuring of energy fluxes across the interface. In particular, simultaneous observations of the eddy fluxes of momentum and heat will be attempted at two elevations near the sea surface utilizing extremely sensitive and accurate cup anemometer and temperature probes now under development. Field studies will be continued on ARGUS ISLAND, an instrumented tower near Bermuda, and these will include joint data collections by ship and aircraft whenerer possible.

Investigation of time and space variations of the surface thermal structure will be continued by using airborne radiation thermometer, buoys, and survey ships. Particular attention will be paid to the installation of accurate and reliable sea surface temperature sensors on all ships of the synoptic net, to upgrade the reliability of oceanographic analyses. Studies of two-dimensional wave spectra will be made cooperatively with ONR by using stereophotogrammetric techniques augmented by joint surface-aircraft platforms. Continued investigations of the one-dimensional wave spectra within the limits of the linear theory are also planned.

Oceanographic similarities between different regions will be studied, to develop methods for predicting conditions in areas where little or no oceanographic information is presently available.

\section{Bureau of Ships: $\$ 500,000$}

Laboratory and field work will be conducted by the Navy Electronics Laboratory to gain a better understanding of the fundamental physics of ice formation and breakup. Field observations on temporary ice stations will be made in cooperation with ONR and NAVOCEANO.

At the Navy Electronics Laboratory, the effect of heat balance on energy transfer in ice (ocean cryology) will continue in studies of sea-ice physics. Computer programming and correlations between clata furnished by the Weather Bureau and data obtained in the field will be sought to predict heat radiation levels. Albedo, formation of surface pools, and brine processes will be actively investigated as factors affecting sea ice thickness and bearing strength. Relationships will be established among brine content, plane wave velocity, and flexural strength. Controlled experiments, including formation of under-ice brine cells, will continue in the laboratory pool.

\section{UNITED STATES ARMY}

\section{Corps of Engineers Coastal Enginecring Research Center: $\$ 200,000$}

Recent effort has been directed toward improving wave generation theory. Data to be collected by automatic reading stations in coastal waters will provide valuable data to support the research effort.

The Coastal Engineering Research Center, presently engaged in measuring the effect of fetch on wave generation, will intensify this effort next year. Additional basic data will be provided by installing five more wave gages in water of limited fetch.

\section{DEPARTMENT OF COMMERCE}

\section{IVeather Bureau: $\$ 208,000$}

In addition to carrying out its responsibility to the overall program in air/sea interaction which was described in the introduction to this section, the Weather Bureau plans to carry on the following program.

A study will be made with the U.S. Lake Survey and the University of Michigan of turbulent exchange processes near the water surface in Lake Michigan, as it contributes to our knowledge of similar processes in the ocean. Research will continue on the development of a numerical computation program for the prediction of storm surges 
and transient wind generated currents near the ocean shore. Empirical storm surge prediction methods will also be developed for critical areas of the sea coast. These two activities are a part of the basic severe storm (hurricane) research program of the Weather Bureau. The empirical storm surge program utilizes data from Coast \& Geodetic Survey supplemented by Army Corps of Engineers information. The present air/sea interaction program will be closely integrated with the oceanographic activities of the Coast and Geodetic Survey.

As a part of its studies of tropical meteorology and hurricane research, the Weather Bureau will obtain data and information on wind stress at the ocean surface by means of surface observations from ships or other platforms augmented by data obtained from aircraft. The Weather Bureau will carry out radiosonde and surface synoptic meteorological programs, aboard research vessels, in cooperation with the Coast and Geodetic Survey, National Science Foundation, Woods Hole Oceanographic Institution, and other agencies.

The Weather Bureau will continue developmental work on the "MAMOS" buoy and on portable infrared radiometers for use aboard merchant ships in obtaining sea-surface temperatures.

\section{Coast and Geodetic Survey: $\$ 25,000$}

Variations in sea level provide a sensitve indicator of the influence of the atmosphere on the sea.

As in the past cooperative efforts with the Weather Bureau will be continued in studies of sea level variations and increased research will be conductd to determine the cause of observed "wind tides." Cooperative developmental work on a buoy system for measuring interface features will also continue. The Coast \& Geodetic Survey and Weather Bureau expect to initiate a joint project on instrument evaluation. The two agencies will also cooperate in sponsoring a special symposium on air/sea interaction.

\section{DEPARTMENT OF THE INTERIOR}

\section{Bureau of Commercial Fisheries: $\$ 998,000$}

Research on the effect of the atmosphere on the ocean is concentrated in the central Pacific tradewind zone and in the eastern Pacific where air/sea interaction is thought to have a strong effect upon the distribution and abundance of commercially valuable fish, such as tuna. Bureau laboratories at Honolulu, San Diego, and Stanford have been active in this work for several years. Based on this work an expanded program of observation and analysis will be directed at understanding changes in ocean structure.

\section{National Science Foundation: $\$ 300,000$}

Major projects currently being supported by NSF include studies of energy interchange at the surface, conducted at the University of Washington, and studies of heat and water vapor exchange between ocean and atmosphere, conducted at the University of Michigan. Research support will continue to be given to these and similar projects, as proposed by competent scientists.

\section{DEPARTMENT OF TREASURY}

\section{Coast Guard: $\$ 60,000$}

In 1963 CGC CASCO was outfitted as a prototype installation for oceanographic observations from weather ships. By the end of FY 1965, twenty-four of the Coast Guard's 32 ships will have been similarly outfitted. By the end of FY 1965 four offshore towers along the Atlantic Coast will be equipped with wave gauges, tide gauges and other observational equipment for use in air/sea research. A research program dealing with the origin, drift, and attrition of ice hazards to navigation will be continued as part of the Coast Guard International Ice Patrol Operations. Research will also be conducted to improve search and rescue techniques.

\section{BIOLOGICAL PROPERTIES: $\$ 18,611,000$}

A comprehensive understanding of the distribution, ecology, physiology, the behavior, and the interrelationships of the many marine organisms is needed in order to plan wisely for use of the sea as a greater source of food and to anticipate the response of marine life to environmental changes. To achieve such understanding requires a large scale collection and identification program, and also includes related studies of the physical and chemical properties of the ocean in the ocean sediments. Thoughtful effort is needed to develop a view of marine life on the planetary scale. 


\section{DEPARTMENT OF DEFENSE}

\section{UNITED STATES NAVY}

\section{Office of Naval Research: $\$ 2,142,000$}

Contracts and grants will continue to support research concerned with fouling by marine organ isms, to protect swimmers and survivors of ship sinkings from attacks by poisonous or carnivorous marine animals, to understand effects of biological organisms on sound propagation, to predict and control bioluminescence, to understand the mechanics of fish propulsion, and to understand marine animal communication.

A new program on ship fouling involving other ICO bureaus and scientists from many foreign countries will be undertaken. Samples of test panels which have been subjected to fouling in different areas of the oceans are to be shipped to a single laboratory within the United States where the fouling organisms will be identified. The present studies which are confined primarily to fouling in shallow water will be extended to fouling in the deep oceans, with particular emphasis placed on sessile organisms and acoustically significant marine animals.

Further effort will be directed toward a better understanding of primary productivity and standing crops of marine organisms as these subjects are related to problems of interest to the Navy. Efforts will be made to develop computer programs for rapid taxonomic and ecological evaluation of marine organisms. Increased emphasis will also be given to the closely related biochemical taxonomy and the genetics of marine organisms.

\section{Burcau of Ships: $\$ 200,000$}

Research conducted by the Navy Electronics Laboratory is directed at scattering and attenuation of underwater sound by plankton and nekton and the noises originated by marine organisms. Both phenomena may interfere with sonar performance and complicate submarine detection. By using the bathyscaphe TRIESTE, scientists at NEL will investigate the biological populations of the sea and correlate the observed characteristics of marine life with physical and chemical properties of the water at various depths.

During past dives of the TRIESTE, locations of the scattering layers and their composition have been determined by a surface ship employing 12 kc echo sounders, while TRIESTE maneuvered up and down through the layers.
The deep scattering layers in the deep ocean will continue to be investigated during FY 1965. Bathyscaphe TRIESTE and surface ships will support this effort. Taxonomic studies will be continued in FY 1965 in areas of interest. Acoustic cross sections will be correlated with the species observed.

\section{Naval Oceanographic Office: $\$ 20,000$}

NavOceano has made detailed studies of the seasonal setting and growth rates of fouling organisms in coastal waters. Recently, such studies have been extended to include the deep water of the Tongue of the Ocean near the Bahamas and they will be extended to other areas including deep water locations. Results have shown a decrease in fouling organisms from the surface through the euphotic zone, with drifting forms below that depth and some boring organisms on the bottom. Collections of marine organisms will continue to be made on Antarctic oceanographic cruises and sent to various universities for study. Also, a study of the distribution and ecology of bioluminescent forms will continue.

\section{DEPARTMENT OF THE INTERIOR}

\section{Bureau of Commercial Fisheries: $\$ 9,050,000$}

Research is needed to achieve three major objectives vital to the mission of BCF: 1 . To obtain maximum sustained yields from the sea's living resources; 2 . To reduce the cost of locating and catching fish to a minimum; and 3. To improve basic knowledge of interrelations among the living resources and their environment in order to predict fluctuations in availability and distribution.

Explorations off the Columbia River have recently given evidence that commercial quantities of fish and shellfish may occur up to depths of at least 3600 feet. As a result of such exploratory fishing, commercial operations have started in a number of areas on what were unknown or underexploited resources.

The Bureau will continue to devote considerable research effort toward gaining a better understanding of the oceans and to develop reliable methods for predicting places and times of fish concentration. For example, since 1959, annual predictions based on changes in ocean circulation have been made for the catch of the Hawaiian skipjack fishery. These data are proving to be of considerable importance to the fishing industry. 
In conformity with international agreements research will continue on various marine animals.

BCF has pioneered the use of serology, or blood group analysis, in the identification and separation of races, or subpopulations, of marine fishes. Expansion of university support for taxonomic research is planned.

Bureau scientists have also made important contributions to the knowledge of the physiology and behavior of fishes and invertebrates and will strengthen their efforts in the field of taxonomy. Expansion of these studies at Woods Hole, La Jolla, and Honolulu is planned.

The Bureau participates in a number of international commissions concerned with the conservation and use of marine resources. Much of the Bureau's research effort will continue to concern salmon and fur seal in the North Pacific, tuna in the Eastern Tropical Pacific and groundfish in the shallower coastal waters.

Studies will be continued on the artificial culture of marine organisms, particularly shellfish in order to determine their response to changes.

Bureau of Sport Fisheries and Wildlife: $\$ 262,000$

The BSF\&IV research program consists of the following two objectives: 1. Life history studies of fish species, to fill gaps in knowledge about distribution in space and time, age, rates of growth, identity, sizes of populations, migratory habits, food habits, reproductive seasons, enemies, parasites, and diseases; and 2. Analysis of environments, to identify and measure factors affecting distribution, movements, abundance, and well-being of game-fish species.

Laboratory and field research will continue at the Bureau's Atlantic Laboratory on Sandy Hook, New Jersey, and its Pacific Laboratory at Tiburon, California.

Several broad-based programs are planned for FY 1965. The Bureau plans full participation in a coastwide cooperative effort to study the life history and environment of game species. Charter vessels will be used for inshore and continental shelf investigations.

Construction of a field laboratory has been planned on Narragansett Bay, Rhode Island, to study migration of fishes along the Atlantic coast.

Research will be conducted on the life history of such species as sea trout, bluefish, swordfish, and sharks, principally through support of graduate students in universities.
The environmental tolerances and behavior of marine fishes in seawater tanks will be studied.

\section{Geological Survey: $\$ 56,000$}

USGS will extend its research efforts on modern organisms and sedimentary environments to gain a better understanding of fossil marine fauma and ancient sedimentary rocks. This information is important in increasing the accuracy of correlations between land and sea areas in the exploration for oil and other resources. In cooperation with BCF, the USGS will continue environmental studies of sessile marine organisms contained on and in sediments of bays and the continental shelves.

\section{National Science Foundation: $\$ 5,925,000$}

NSF will continue to support a wide variety of studies of life and living processes in the sea. In FY 1965, an orderly continuation of growth is planned to support research in systematic biogeographic and analogical relations of marine animals and plants and their interactions with the marine environment. Increased support will also be provided for shiptime in biological oceanography and for the expansion and improvement of marine laboratories and their graduate training programs. Two oceangoing vessels, one in the Pacific and one in the Atlantic, will be used cooperatively by scientists from many universities throughout the country with emphasis on basic research and graduate training in marine biology.

\section{Smithsonian Institution: $\$ 881,000$}

Within the National Oceanograhic Program, the main responsibility of the Smithsonian Institution will continue to be the collection, preservation, and study of marine materials made by the Smithsonian Institution itself, by other Federal agencies, and by private organizations referring collections to the Institution. The Smithsonian Oceanographic Sorting Center will process specimens collected for the National Program as a service to the scientific community. During the past year, nearly 4000 lots comprising over 300,000 specimens were sorted for distribution to specialists in various groups for study. This modest beginning includes the first collections from the two large cooperative oceanographic efforts: the International Indian Ocean Expedition (IIOE) and the International Cooperative Investigations of the Tropical Atlantic (ICITA). 
The addition of taxonomists in FY 1965 to the marine sciences staff will increase the quantity of systematic research. The Smithsonian Institution will participate in expeditions of other governmental and private vessels, to gather information on the kinds and distribution of organisms in the sea.

The Smithsonian Oceanographic Sorting Center will expand its capabilities to embrace the areas of algology, sedimentology, and planktonology. Improved methods of sorting and the introduction of mechanical devices will be exploited to speed up sorting. The volume of collections processed is expected to increase tremendously.

\section{DEPARTMENT OF HEALTH, EDUCATION-AND WELFARE}

\section{Public Health Service: $\$ 75,000$}

PHS is concerned with water quality for all legitimate uses, purity of foods delivered from the sea, and the effects of marine organisms on the human body.

Another PHS objective is to determine the identity of medically or pharmacologically important substances which may be produced by marine organisms.

Earlier studies on marine organisms which produce toxins (such as paralytic shellfish poison) will be continued. Emphasis will be placed on the ecology of marine organisms producing neurotoxins which are endangering public health. PHS will also continue studies of marine substances which appear to inhibit the growth of certain human disease-producing viruses and bacteria. A research program will be undertaken in cooperation with the Bureau of Commercial Fisheries on the ecology and growth characteristics of the bacteria responsible for Type $\mathrm{E}$ botulism toxin in fishery products.

\section{STRUCTURE AND HISTORY}

OF THE OCEAN FLOOR: $\$ 19,235,000$

Very rapid strides have been made in the last decade in observing and understanding the structure of the $70 \%$ of the earth's crust which is covered by the sea and in reading the history of the earth as revealed in ocean sediments. New instruments and instrumental techniques of great precision and great power have been applied to these problems: precision depth recorders, acoustic refraction tech- niques, gravity meters, sensitive magnetometers, deep coring facilities, and ocean bottom photography. Understanding of the structure of the ocean floor and of the sediments will contribute very greatly to the larger understanding of the earth's structure and history, and it may have economic benefits in ocean mining of minerals and drilling for oil.

\section{DEPARTMENT OF DEFENSE}

\section{UNITED STATES NAVY}

\section{Office of Naral Research: $\$ 9,572,000$}

Using new seismic instruments and observational techniques, Lamont Geological Observatory, Scripps Institution of Oceanography, Texas A\&M University, and the Woods Hole Oceanographic Institution will continue comprehensive seismic investigation of the bottom structure of the Atlantic and Pacific basins and the Indian Ocean. In the same oceans, Woods Hole and Texas A\&M will make geomagnetic measurements. Lamont, UCLA, Oregon State, and the University of Hawaii will take gravity measurements. Continued effort will be applied in FY 65 to developing still better techniques for measuring the thickness of sediment.

In addition, a modest but comprehensive program will be undertaken to determine from manned ice islands the structure of the Arctic Ocean basin.

\section{Naval Oceanographic Office: $\$ 261,000$}

To improve the accuracy of gravity measurements from ships, gravity ranges are being established off the United States, in both the Atlantic and Pacific Oceans. A mathematical formulation to reduce the gravity field to different altitudes above sea level is being programmed for a computer.

Observations of variation in telluric currents and the relation of telluric currents to the geomagnetic field will be continued in FY 1965. Recently initiated studies of temporal variations and small-scale spatial variations in the geomagnetic field will continue. Improvements in automatic processing of marine geophysical data (gravity, geomagnetism, telluric currents) will also be made in FY 1965.

\section{Bureau of Ships: $\$ 1,125,000$}

Geological-geophysical research will be supported at the Navy Electronics Laboratory and at the La- 
mont Geological Observatory, with emphasis on problems of sound propagation applied to undersea warfare.

In FY 1965 studies will continue of geological structure, sedimentation processes, and mass physical properties of sediments, by using the TRIESTE and other vehicles. Research on deeper off-shore areas will be emphasized. Theoretical studies of properties, useful in determining stability of sediments when only partial information is available, will require emphasis on the interrelation of shear strength, density, porosity, and consolidation. Lamont Geological Observatory and NEL will continue their complementary investigations. Adclitional properties, including electrical resistivity, will be measured. Stereo-color photographic techniques for sea floor work will be improved. Observational and instrumental techniques for obtaining information on the processes of erosion, turbidity currents, and sediment transport will be developed. Improved acoustical techniques for probing and recording the bottom and sub-bottom characteristics will be emphasized.

\section{Bureau of Naval Weapons: $\$ 75,000$}

The Bureau's Naval Ordnance Laboratory will continue to investigate the earth's magnetic field and its sea-floor fluctuation. In the coming fiscal year, DEEP-DIP will be used in an expanded program of data collection and analyses.

\section{UNITED STATES ARMY}

Corps of Engineers Coastal Engineering

Research Center: $\$ 290,000$

Tide and wave studies will be intensified to relate quantitatively storm wave attacks and resulting shore erosion. Investigations will attempt to locate in 30 to 50 feet of water potential beach sand sources for beach re-supply off the Florida and Delaware coasts.

\section{DEPARTMENT OF COMMERCE}

\section{Coast and Geodetic Survey: $\$ 188,000$}

In-house research will continue in marine gravity, magnetism, estuarine and shelf structure, and sediment transport. For FX 1965, the projects planned include continuing study of heat flow through the sea floor, theories of the origin of ocean basins, submarine geomorphology of the western Aleutians and East Coast Shelf, sedimentation of estuaries and coastal regions, sub-bottom acoustic properties, and the nature of marine magnetics and gravity. Preliminary research in the area of marine seismology will be initiated. A cooperative program with the USGS is being planned to study the offshore geological properties along the Pacific Coast of the continental United States.

\section{DEPARTMENT OF INTERIOR}

\section{Geological Survey: $\$ 520,000$}

New maps of regional topography, marine sediment distribution, and underlying geologic structure are being prepared as part of the joint USGSWoods Hole Oceanographic Institution study of the marine geology and hydrology of the Atlantic continental shelf and slope. Similar studies of marine geology and hydrology of the continental shelf and slope along the West Coast will be initiated in FY 1965 in cooperation with the Coast \& Geodetic Survey. The Geological Survey will be responsible for operations on land, including processing and laboratory studies of samples collected at sea and will acquire and analyze existing geological and geophysical information needed to interpret the off-shore data. The C\&GS will be responsible for operations at sea. Scientists of the two organizations will collaborate in the collection of samples and data at sea and in the interpretation and publication of the results.

The USGS will continue to collect and interpret existing geological and biological data concerning the Gulf Coast and Alaska continental shelves. Operations on the Atlantic continental shelf will be augmented by the addition of bottom coring. Studies of bottom samples and geophysical data from the North Pacific Ocean and elsewhere, collected by the Coast \& Geodetic Survey and by other organizations, will continue.

\section{Bureau of Mines: $\$ 104,000$}

The small economic evaluation programs of ocean floor minerals, carried on with the cooperation of Oregon State University and Scripps Institution of Oceanography, has revealed the existence of possible valuable nearshore deposits of glauconite and has indicated surprising variability in the composition of deep sea manganese nodules. In order to extend these investigations, engineering studies of deep sea mining equipment will be initiated in FY 1965. Collection and analysis of 
minerals will be continued with the cooperation of universities and institutes.

Mining methods, cost research, and metallurgical work on manganese, phosphorite, and other commercially valuable sea minerals will be continued.

\section{National Science Foundation: $\$ 7,100,000$}

Geological, geochemical, and geophysical oceanographic investigations are supported at many universities and research institutes including: Miami, California, Delaware, Illinois, Washington, Michigan, Southern California, Georgia, Florida State, Columbia, Lehigh, California Institute of Technology, Oregon State University, Massachusetts Institute of Technology, Woods Hole Oceanographic Institution, Yale, and Rice.

The FY 1965 program will highlight continued expansion of effort in bathymetric investigations; age determination of marine sedimentary deposits; paleotemperature studies; sediment distribution studies and drilling operations; organic and inorganic geochemistry; sediment transport mechanisms; and seismic, gravity, and geothermal investigations.

\section{MODIFICATION OF THE SEA: $\$ 8,862,000$}

Undesirable and dangerous effects of pollution of coastal and estuarine waters on food resources and on recreational areas are already well known and are likely to increase unless checked by wise planning. The potential danger of release of radioactive material in the ocean also needs thorough and continuing study. In each of these cases research of various kinds is essential.

The ocean also can be deliberately modified in local areas in order to achieve certain desirable results: beach erosion can be controlled, surface waves minimized, evaporation reduced, etc. At present, achievements of this sort are minimal; but research directed toward increased useful modification of the sea is needed.

\section{DEPARTMENT OF DEFENSE \\ UNITED STATES NAVY}

Office of Naval Research: $\$ 400,000$

In 1965, Chesapeake Bay Institute will continue their investigations of dispersion using the recently developed rhodamine-B dye-tracer techniques.
Woods Hole Oceanographic Institution and Scripps Institution of Oceanography will study organisms concentrating certain radioactive isotopes to determine the rate of radioactivity introduced in the oceans by fallout from nuclear weapons tests.

The program of measuring carbon dioxide concentrations and the carbon- 14 ratios in the oceans and atmosphere will be continued at University of Rhode Island and Scripps Institution of Oceanography to determine whether man's activities are resulting in an increase of climatic temperatures.

\section{Naval Oceanographic Office: $\$ 19,000$}

Investigation of natural background isotopic radiation, which has been recently initiated, will be continued and extended.

\section{UNITED STATES ARMY}

\section{Corps of Engineers Coastal Engineering Research Center: $\$ 333,000$}

Studies of tidal changes resulting from man-made works in the tidewater areas will be investigated both in the laboratory and in the field, leading to a better understanding of flushing characteristic of bays and estuaries. Quantitative studies to relate-tidal flow to man-made changes in inlets will be initiated.

\section{DEPARTMENT OF THE INTERIOR}

\section{Bureau of Commercial Fisheries: $\$ 865,000$}

The Bureau will continue investigating the accumulation of radioactivity by marine species and its transmission to man. Research will also be directed toward understanding the effects of pesticides on commercial fish. Estuarine studies conducted to determine the effect upon commercial fish of proposed engineering changes in coastlines, waterways, marshes, and bays will continue.

Investigations will be undertaken in FY 1965 on marine and brackish-water pollution. Research on rapidly changing coastal and estuarine environments will be expanded to determine the extent to which engineering and industrial developments are altering the natural biological, physical, and chemical regimes and, consequently, the productivity of these areas.

In cooperation with the Atomic Energy Commission, research on the biological effects of radioactive materials will be continued and expanded, with more attention paid to the use of radioactive 
tracers in studies of feeding and nutrition of marine organisms.

Geological Survey: $\$ 60,000$

Studies of the distribution and disposal of radioactive materials and organic wastes within the marine environment will be included as part of general studies on marine geology, sedimentation, and hydrology referred to earlier in this report.

\section{DEPARTMENT OF HEALTH, EDUCATION AND WELFARE}

The HEW budget includes an estimated $\$ 50,000$ for fellowships granted by the Office of Education under the National Defense Education Act. These fellowships are described under the Manpower and Training section of this report.

\section{Public Health Service: $\$ 2,430,000$}

PHS has initiated studies on the effects of municipal and industrial waste discharges on water quality and aquatic life in the estuaries and in coastal areas. These studies will be conducted in Raritan Bay, the Chesapeake-Susquehanna River Estuary, Puget Sound, Columbia River Estuary, and the Delaware River Estuary. Further studies will be supported by PHS research grants concerned with the following: oceanographic factors affecting design of sewers (University of California); relationship of the environment to ocean pollution (University of Southern California); methods for sea water analysis (New York University); ocean outfall diffusers (Oregon State University); estuarial pollution factors (Oregon State University); insecticides in marine environment (Texas A \& $\mathrm{M}$ Research Foundation); metabolism of marine bays (University of Texas); effects of thermal effluents on marine organisms (Virginia Institute of Marine Science); feasibility of waste disposal in marine environment (University of Southern California) ; estuarine pollution problems (University of Florida).

PHS shellfish sanitation laboratory facilities at Kingston, Rhode Island; Dauphin Island, Alabama; and Purdy, Washington, will undertake research on the fate of pathogenic microorganisms (including viruses) in the marine waters and on the accumulation of suspended, colloidal, dissolved, and radioactive pollutants by shellfish. Additional research facilities under construction in Rhode Island will be used in investigating the effects of pollution on shellfish and other aquatic life, on recreational facilities, and other water use.

\section{Atomic Energy' Commission: $\$ 4,705,000$}

Scientists of BCF, supported by the AEC, will continue to study the distribution and abundance of fish, shellfish, and other biota in limited oceanic and coastal regions of particular concern to the AEC. Increasing emphasis will be placed on ecological studies of the marine food web, to demonstrate and measure the cycling of nutrients and trace elements.

A part of the AEC's marine sciences program will be devoted to measuring and defining the chemical and physical forms which radionuclides can take in sea water. Processes which dilute and those which concentrate radionuclides will continue to be studied using tracers such as rhodamine-B and short-half-life radioisotopes.

The AEC will support studies to define and to measure coastal circulation or to determine the possible influences of one estuary on another or of the open ocean on a particular estuary. On a large scale (ocean basin size), AEC will support studies to determine mixing times and circulation patterns. Techniques will include measurement of distribution of fallout nuclides, cosmogenically formed nuclides like carbon-14, and natural partitions of activities in the uranium and thorium decay series. Studies of oceanic sediments to determine mechanisms of formation and rate of deposition are among other objectives to be pursued.

\section{DEEP SEA RESEARCH VEHICLE PROGRAM}

The oceanographic community recognizes an urgent need for underseas vehicles to provide an additional degree of freedom to oceanographic research. A few federal agencies have enunciated their interest in DRV development, as embodied in various chapters of this report.

To meet the need for concerted attention to the development problem, the Interagency Committee on Oceanography has documented the scientific requirements of many branches of oceanography for deep submersibles and selected this area for special emphasis beginning in FY 1965. The requirements and the program proposed to satisfy them will be described in an ICO Pamphlet supplementary to this volume.

The primary objective of the proposed DRV re- 
search program is to apply the advantages offered by this unique tool to urgent research problems in oceanography. Deep sea research vehicles will enable a more "personal" type of research than has traditionally been the case in a science frustrated by the high pressure environment. The trained mind and eyes can be taken to the source of information, on a relatively stable working platform. Another advantage offered by a well equipped DRV concerns the instantaneous control over the experiment, by the observer on the spot. Delicate adjustments and revised programming of instrumentation can be executed to adjust to the requirements of the observer. The DRV platform aids in lowering the observational sensitivity threshold commensurate with the superiority of the eye over most instruments. As a test platform, it permits on-the-scene evaluation of new devices and instrumentation.

Potentially, the greatest value of the DRV lies in its own development process. Clearly, the United States must attain a deep ocean engineering capability if it is to exploit its surrounding waters more efficiently and completely.

An entirely new technology is needed to build in this environment the off-shore structures, moored buoys and bottom mounted arrays of instruments important to research and national defense. Deep sea research vehicles will enable the marine engineer to survey and study undersea areas where he plans to build. With a DRV, model structures and equipment prototypes may be located where their performance can be observed long enough to understand the limitations which are imposed by the sea environment.

These, then, are a few of the immediate, practical applications of the DRV to marine engineering. The ultimate exploitation of the ocean floor presents engineering problems of a new and different kind. DRVs will be needed to survey and explore mineral deposits. Then, to mine these resources man will have to go underwater-to work. Tools will have to be developed to dig, drill and manipulate safely at tremendous pressures. Experience obtained in DRV construction and operation is needed to design and to build these future engines of the deep.

Out of a broadly conceived program for research using underseas vehicles can come an understanding of search and rescue techniques that would help locate and recover lost vehicles, space capsules or other items on the bottom of the sea. This subject is being examined in cooperation with the Navy's Deep Submergence Systems Review Group.

Fiscal Year 1965 plans encompass operation of existing vehicles in various research projects and design and construction of new models.

The only vehicles which will be available to the oceanographic community in FY 65 are the bathyscaph TRIESTE, the ALVIN, and possibly the ALUMINAUT.

The Bureau of Ships will fund TRIESTE's investigations at the Naval Electronics Laboratory. These will include studies of: (a) wave generation and wave spectra; (b) the Deep Scattering Layer; (c) correlation of characteristics of biological populations with physical and chemical properties of the water; (d) fine-grain structure of the ocean bottom; and (e) sedimentation processes. These studies are planned for both near-shore and deep off-shore areas. TRIESTE has infinite depth capability, can carry 3 occupants, and can cruise at slightly more than a knot.

The Office of Naval Research will sponsor the evaluation of ALVIN's capabilities at the Woods Hole Oceanographic Institution. This study will be important in determining the future roles to be played by DRV's in oceanographic research. It is believed at this point that the ALVIN type of vehicle will have particular application to underwater acoustics, biological and geological investigations. The ALVIN will be designed to carry two operators at a speed of 2.4 knots at depths up to $6000 \mathrm{ft}$.

The Office of Naval Research plans to construct one DRV in FY 65. It will utilize the ALVIN's spare pressure sphere and thus will be similar in capability to that vehicle. Design and construction plans for FY 65 are still somewhat fluid; at least with respect to Navy's program they will depend to a great extent on the findings and recommendations of the Deep Submergence Systems Review Group.

The ALUMINAUT is being constructed by Electric Boat Company under contract to the Reynolds Metals Co. Completion is expected in 1965. It is being designed to carry three operators at cruising speeds of 4-6 knots, to depths up to 15,000 feet.

\section{B. Oceanographic Services}

Ocean surveys and operation of the oceanographic data center are services which the federal government carries out for the benefit of the entire 
oceanographic community, universities and research institutes as well as government agencies.

\section{OCEAN SURVEYS: $\$ 25,014,000$}

The survey program is aimed at the intelligent collection of accurate and meaningful data at sea, data required both by various specific missionoriented agencies and to serve the basic purpose of providing a framework of oceanic knowledge upon which future exploitation and research must depend.

The rationale, purpose, and objectives of the survey program have been spelled out in detail in the National Plan for Ocean Surveys (ICO Pub. No. 7, May 1963).

The survey program is responsive not only to the immediate demands of the Federal agencies for oceanographic data, but also provides the basic information which the research oceanographer needs to formulate the questions he must askquestions for which his own research work at sea will provide the answers.

Surveys are planned and carried out on a fieldseason basis. This runs generally from January or February to November and thus overlaps two fiscal years. As in previous ICO reports, the discussions that follow are for the 1964 field season and cover the latter half of FY 1964 and the first half of FY 1965.

The survey schedule, as presented here is drawn in general terms, still subject to change in specifics. The operations research study of ocean surveys funded by the Coast and Geodetic Survey will be completed during the first half of FY 1965. The survey program for subsequent years will reflect this detailed analysis of the government's ocean survey operations.

\section{*** \\ NAVY $-\$ 14,704,000$}

\section{Atlantic}

USS TANNER-Deep water hydrographic surveys in Western Atlantic, coastal surveys of Central America.

USS REQUISITE-Military oceanographic-hydrographic surveys (Oceanographic stations, acoustics, bottom reflectivity).

USNS GILLISS-Surveys in western Atlantic for Navy Laboratories (prediction of three-dimensional thermal structure, sound transmission and water characteristics, buoy arrays for heat and water exchange in deep water, "meso-scale" struc- ture near Gulf Stream, electromagnetic phenomena).

USNS SANDS-Scheduled to join fleet in 1965.

$A G S$-(Unnamed) 2250 tons. Shakedown in early FY 1965. Automated collection of temperature, speed of sound and ambient light data vs. depth. Also bathymetric, sea surface temperature, magnetic field, and gravity data.

\section{Pacific-Indian}

USS MAURY-Hydrographic surveys of Manila Bay and Subic Bay, shoal investigation.

USS SERRANO-Works with MAURY in Philippines. Upon completion will conduct oceanographic surveys in Western Pacific as schedule permits.

USS REHOBOTH-Oceanographic surveys of Point Arguello, California, currents by measurement and computation.

USNS DAVIS-Cooperative cruise of Oceanographic Office and west coast Navy laboratory, San DiegoPhilippines-Japan. Oceanographic and acoustics measurements with submarine BAYA. Experiments with underwater research vehicle and shipboard positioning system for vehicle.

USNS LYNCH-Will be completed during FY 1965. Will work with Davis and icebreakers in studies of polar water masses and their circulation. This information will be used in sea-ice predictions.

AIRCRAFT-WV-2 aircraft with side-looking radar will be used for all-weather ice studies.

COAST AND GEODETIC SURVEY $-\$ 9,101,000$

\section{Atlantic}

EXPLORER-Oceanographic/hydrographic surveys of Sonda de Vieques, P.R. Later in the year will shift to area of east coast of U.S. and continental shelf area of Cape Hatteras, doing magnetic surveys, oceanographic stations, deep-sea photography, coring operations, biological studies, and current studies. Duke University will cooperate.

HYDROGRAPHER-Hydrogtaphic surveys offshore north of Miami, then Sabine Pass in the Gulf of Mexico. Oceanographic stations and bottom samples.

WHITING-Hydrographic surveys off South Carolina and Florida. Whiting will also survey Nantucket Sound area if not used in cooperative Gulf Stream studies.

PIERCE-Same as WHITING, but with more extensive work in the hydrographic surveys. If Gulf Stream surveys are not carried out, magnetic, photographic, and bottom material studies will be done cooperating with Geological Survey. 
MARMER-Current studies in the Chesapeake Bay in cooperation with Virginia Institute of Marine Sciences and Chesapeake Bay Institute.

\section{Pacific-Indian}

PIONEER-Working in International Indian Ocean Expedition in Bay of Bengal, Andaman Sea and Indian Ocean, enroute measurements of gravity, magnetic field, bottom topography, temperature structure, surface temperature and salinity, surface and upper air meteorological observations, plankton hauls, productivity studies. Cooperating with Weather Bureau, USGS, NavOceano, BCF, Scripps Institution of Oceanography and University of Hawaii. Special surveys in Philippine, Yap and Mariana Trenches. Special intensive study of Palau Trench in cooperation with Geological Survey.

SURVEYOR-Profiles of gravity, magnetic field, bottom topography, and other oceanographic and meteorological observations between Hawaii and the Aleutians, east of $170^{\circ} \mathrm{W}$. Also, intensive study of a selected seamount in cooperation with University of Hawaii and USGS. Water circulation, and changes in geophysical properties near seamounts will be studied. Oregon State University is cooperating to supply gravity meter and geophysicists.

PATHFINDER-Hydrographic, magnetic and oceanographic surveys off Maui and inshore surveys in Cook Inlet, Alaska.

BOIVIE and HODGSON-Water circulation in Puget Sound, Washington.

LESTER JONES and PATTON-Hydrographic surveys in Clarence Strait and Carroll Inlet, Ketchikan, Alaska.

OCEANOGRAPHER-Shakedown trials, some oceanographic surveys depending on scheduled time available.

DISCOVERER-Same as OCEANOGRAPHER.

\section{U. S. COAST GUARD- $\$ 439,000$}

\section{Atlantic}

Ocean Station Vessels. Eighteen of the ships of this type will be equipped with oceanographic winches and laboratories developed from tests of different methods used on board CGC CASCO. Monthly observations of standard sections are planned. Plankton samples will be taken in cooperation with Lamont Geological Observatory. Underway plankton samplers are being used between stations " $B$ " (56-30 N, 51-00W) and " $D$ "
$(44 \mathrm{~N}, 41 \mathrm{~W})$ in cooperation with Edinburgh Marine Laboratory.

EI'ERGREEN-Survey Grand Banks-Labrador Current-Gulf Stream area from March through July for International Ice Patrol Operations. Will enter Labrador Sea and Davis Strait on a postseason cruise. Also will make thirtieth annual occupation of the oceanographic section between Labrador and Greenland.

AIRCRAFT-A ir b o r n e radiation thermometer flights between Cape Cod and Cape May, in cooperation with Bureau of Sport Fisheries and Wildlife.

\section{Pacific}

NORTHIVIND-Survey and research operations in Arctic Ocean. Cooperation with ONR, NavOceano, and non-government agencies.

OCEAN STATION VESSELS-"N" $\left(30^{\circ} \mathrm{N}-140^{\circ}\right.$ W) and " $V "\left(34^{\circ} \mathrm{N}-164^{\circ} \mathrm{E}\right)$ will receive instrumentation as noted under Atlantic above.

AIRCRAFT-Airborne radiation thermometer flights in cooperation with BCF.

\section{U. S. GEOLOGICAL SURVEY $-\$ 20,000$}

\section{Atlantic}

Research in cooperation with the Woods Hole Oceanographic Institution in Atlantic Continental Shelf Program. Ships of other agencies will provide working platforms on opportunity basis.

\section{Pacific}

Palau Trench work in cooperation with C\&GS, cooperating with Hawaiian Volcano Observatory and C\&GS with dredge and photographic methods in study of submarine lavas of the Pacific. Joint C\&GS survey from U.S. Pacific Coast westward.

\section{BUREAU OF COMMERCIAL FISHERIES- $\$ 10,000$}

Atlantic

The BCF plans to continue to place biologists and biological sampling equipment aboard the survey vessels of other agencies working in the Atlantic. They will also participate in the final phases of the International Cooperative Investigations of the Tropical Atlantic and conduct investigations on the distribution of bottom fauna in the northwest Atlantic in relation to geological factors.

\section{Pacific}

The BCF will continue to place biologists and sampling equipment aboard the survey vessels of 
other agencies working in the Pacific. During FY 1965 they will conduct preliminary cruises in the central Pacific to develop methods and test equipment in preparation for the Trade Wind Zone Oceanography Program which will get under way with full-scale field operations early in FY 1966. The Bureau will continue its studies on surface temperature distribution in the eastern Pacific and the production of temperature charts.

\section{BUREAU OF MINES- $\$ 30,000$}

\section{Pacific}

Survey activity in the Pacific Ocean will be concentrated in the occurrence of minerals in the waters and under the seas. The major efforts will be in and on the Continental Shelf, although some effort may be directed toward the deep sea occurrence of manganese nodules and other related minerals.

\section{U. S. PUBLIC HEALTH SERVICE- $\$ 680,000$}

\section{Atlantic}

Continued studies of deterioration of water quality in coastal areas affected by urbanization and industrial development. Effects on food supply and recreational use will be studied. Surveys of Atlantic and Gulf Coasts will be directed from laboratories at. Kingston, Rhode Island and Dauphin Island, Alabama, respectively.

\section{Pacific}

Stuclies of coastal waters affected by urban and inclustrial development, and special study of problems of deterioration of water quality, to be directed from laboratory at Purdy, Washington.

\section{NATIONAL OCEANOGRAPHIC DATA CENTER: $\$ 1,054,000$}

To meet the need for a centralized respository of oceanographic data, the National Oceanographic Data Center has been established in Washington, D.C., under the guidance of an Advisory Board, representing six supporting agencies and the $\mathrm{Na}$ tional Academy of Sciences. NODC is a central clearing house for data received from government agencies, scientific institutions, and other nations engaged in research and survey work. NODC compiles, processes, and preserves data in a form permitting rapid retrieval. All ICO programs produce data for the NODC.

\section{International Oceanographic Programs}

The importance of international cooperation in oceanography has been recognized through the increased participation of the United States and other countries in several intergovernmental oceanographic programs. This growth is largely attributable to the work of UNESCO and the Intergovernmental Oceanographic Commission (IOC): The Commission was launched under the auspices of UNESCO, and currently includes fifty member governments from all parts of the world. The purpose of the Commission is to promote scientific investigation into the nature and resources of the oceans through the concerted action of its members. In bringing together the oceanographers of many countries, the Commission has focused attention on oceanographic problems beyond the capacity of individual nations to handle. Deliberations of the Commission have also been concerned with international problems of data exchange, standardization of equipment, intercalibration of techniques, allocation of radio frequencies for oceanographic use, exchange of scientists, and other problens fundamental to successful international coordination and cooperation.

\section{INTERNATIONAL INDIAN OCEAN EXPEDITION (IIOE)}

Although the Indian Ocean's 28,000,000 square miles cover over 14 percent of the earth's surface, relatively little was known or understood about the region prior to the initiation of the IIOE in 1960. The objective of the IIOE is to delineate the features of the ocean's topography, circulation, and distribution of living organisms. This goal will be attained by research efforts in air/sea interaction; studies of physical and chemical properties of the ocean's water; investigation of life in the sea; and, geological and geophysical studies of the ocean's basin. Most field aspects of the expedition will terminate in Fiscal Year 1965.

Nations participating with the United States include Australia, France, Germany, India, Indonesia, Japan, Pakistan, Portugal, South Africa, Thailand. and the United Kingdom. Nearly 40 ships, of which 12 are American, share responsibility for the field operations.

The U. S. buclget for FY 1965 for the IIOE amounts to nearly 4.0 million. The United States has contributed slightly over one third the total support for this expedition, with most of the re- 
mainder coming from Japan, U.K., Australia. U.S.S.R., Germany, France, and India.

An interesting highlight of the IIOE has been the establishment of two data centers: the International Meteorological Center, Bombay, India; and, the Indian Ocean Biological Center, Ceylon, India. Both centers may become permanent establishments after the completion of the IIOE.

\section{INTERNATIONAL COOPERATIVE INVESTIGATIONS OF THE TROPICAL ATLANTIC (ICITA)}

The objective of the ICITA is the detailed investigation of the marine environment in the Tropical Atlantic, for purposes of efficient exploitation of its fisheries resources. This program was conceived and planned in 1961 and 1962. Other participating nations include the Soviet Union, Brazil, Argentina, Ivory Coast, Nigeria, Republic of Congo (Brazzaville), Spain, Japan, and Poland.

Field operations commenced February 15, 1963, as Equalant I and continued through March 18, 1963. Equalant $I I$ took place August 1 to August 15,1963 . These phases have been successfully completed.

Thirteen and 11 vessels participated in Equalant $I$, and Equalant $I I$, respectively. Many foreign and American scientists and students participated in the program, with the U.S.A. and U.S.S.R., each contributing from $1 / 4$ to $1 / 3$ of the total support of the program. Significant information on the fluctuation and physical-chemical properties of the equatorial undercurrent were obtained. In addition, effective data exchange arrangements, communications, and standardization techniques were estab lished. Based on the results of the achievements of the first two phases, the IOC Bureau in October 1963 approved a further extension of the program. Equalant III will be a more loosely coordinated program with scientists free to explore leads developed during Equalant's $I$ and $I I$, but, as in the other phases, will include a quasi-synoptic program. It will be conducted in the spring of 1964, and it is expected that several additional countries will participate. Data from Equalant $I$ are scheduled for publication in early 1964. Equalant II data were being processed at the end of 1963 . The $\$ 3$ Million costs (to date) to U.S. agencies, are split among the research categories wherein the work has been reported.

The ICITA program has been closely coordinated with the Guinean Trawling Survey which is exploring the near shore fishery resources of the Gulf of Guinea. The Survey is primarily supported by the U.S. Agency for International Development (AID).

\section{U.S.-JAPAN INVESTIGATIONS OF THE PACIFIC}

The National Science Foundation is coordinating the U.S. participation in the U.S.-Japan Cooperative Science Programs. The overall aim of the program is the fostering of close working relations between the two governments and the pooling of their resources toward solution of common scientific problems. Work in two areas has been initiated in the Pacific: "Earth Sciences of the Pacific" and "Geography and Ecology of Plants and Organisms"; and this work involves four on-going oceanographic projects. It is probable that this number will be in creased somewhat in FY 1965.

\section{U.S.-LATIN AMERICAN PROGRAMS}

As a result of the National Academy of Sciences' Inter-American Conference on the Marine Sciences, several small programs in oceanography will be undertaken between the United States and various South American nations. The first to be initiated will be a cooperative effort between Panama, Colombia, Equador, Peru, and the United States to investigate the "EI Nino" phenomenon. Other programs, notable in the exchange of teaching and research personnel, are being considered.

Numerous smaller international programs will be undertaken cooperatively between the United States and other nations-principally the Latin American countries. In general, these will be informal programs arranged between the scientists of individual institutions. An example of these are the joint in vestigations in the South Atlantic by the Lamont Geological Observatory and the Argentine Navy Hydrographic Office. This cooperative effort has been continuing in an effective manner for nearly a decade.

\section{COOPERATIVE STUDY OF THE KUROSHIO}

A multi-nation investigation of the Kuroshio current has been proposed for commencement in FY 1965. The objectives are the:

a. detailed description of the Kuroshio current proper and the water masses of the surrounding regions;

b. examination of the living populations of the region; 
c. study of the interaction between the ocean and atmosphere.

The United States has been urged to cooperate in this study, but has not yet committed any funds or effort. Countries committed to date include Vietnam, Hong Kong, Philippines, Nationalist China, Korea, Japan, and the U.S.S.R. Periods of $30-45$ days each have been proposed for actual field operations to occur during the summer and winter of 1965 and 1966.

\section{PROGRAM FOR WORLD OCEANOGRAPHIC STUDY}

A Long-term Comprehensive Program for World Ocean Study is being developed for the Intergov- ernmental Oceanographic Commission (IOC), by the Special Committee on Oceanic Research (SCOR) of the International Council of Scientific Unions (ICSU), IOC's advisory body on the general scientific aspects of oceanography. SCOR is drawing up a General Scientific Framework around which the comprehensive study will be built. The initial phases of this program are planned for FY 1965.

The following categories of scientific problems are being examined: near shore processes and relationships, biology of the open ocean, geology of the sea floor and the earth beneath the sea; hydrodynamics of ocean waters, physics and chemistry of ocean waters, interactions between sea and air, and applications of oceanic research. 


\section{Chapter II}

\section{OCEANOGRAPHIC RESOURCES}

Oceanographic resources consist of the capabilities needed to support the oceanographic effort: A. Ships; B. Instrumentation; C. Facilities; and D. Manpower and Training.

\section{A. Ships: $\$ 21,350,000$}

For FY 1965, the ICO is recommending funding for construction of five new ships, for the outfitting of one other to provide a capability for oceanographic work, and for design studies for a ship planned for future construction.

The budget is down sharply from the shipbuilding budgets for FY 1963 and 1964; the drop in budget will have the effect of delaying the creation of a fully effective oceanographic observing program as outlined in the Ten Year Plan. The level has been chosen as the minimum building program needed to maintain the momentum in oceanographic research developed in the last few years; that is, the minimum needed to replace obsolete ships and to keep research groups working at an effective and efficient pace. A listing of 100 oceanographic survey/research ships is offered in the Appendix.

The various agencies contribute to the oveanographic ship building program in the following way:

\section{Coast and Geodetic Survey: $\$ 9,000,000$}

The C\&GS will build one survey ship of approximately 2,800 tons which will be largely self-sustaining in its operations and capable of carrying out hydrographic and oceanographic surveys anywhere in the world. It will have a wide range of datacollecting capability and will work primarily in support of the Ocean Survey Program. Capabilities for servicing oceanographic buoys and supporting deep research vehicles are being included in the design of this ship.

\section{Coast Guard: $\$ 50,000$}

The CG will design an oceanographic ship to replace EVERGREEN in International Ice Patrol and other CG oceanographic research and surveys. This vessel, to be constructed with funds planned for FY 1966, will be ice strengthened and completely equipped for oceanographic research in arctic and subarctic waters.

\section{Bureau of Commercial Fisheries: $\$ 1,700,000$}

$\mathrm{BCF}$ will build a replacement for an exploratory fishing and oceanographic research vessel used in the tropical Atlantic and Gulf of Mexico. Funds are also being requested to equip a new ship (whose construction was funded in FY 1964) for high-sea salmon investigations and related oceanographic studies in the Bering Sea and the North Pacific.

National Science Foundation: $\$ 1,500,000$

NSF must be responsive to scientific proposals received; its program, therefore, is not as firm as those of other agencies. NSF expects to provide about $\$ 1.5$ Million for ships, for university and other private laboratories. It is estimated that this will include one small vessel for general oceanographic research.

Navy: $\$ 9,100,000$

Navy is requesting two ships to support the aims of the National Oceanographic Program.

A 1,320 ton survey ship will be built to work with the larger vessels or carry out independent surveys and to assist in research projects in support of military requirements. This ship will replace the USS REQUISITE, a 23 year old converted mine sweeper, which is being decommissioned in early calendar year 1964.

One of the Navy's 1,350 ton oceanographic research ships will also be built for assignment to a private research institution, for use on research projects supporting Navy needs. Three of the AGOR Class oceanographic research ships are now used by the Navy and by research institutions. The new AGOR will incorporate improvements gained in experience from the preceding three. Since none of these ships is in the FY 1964 shipbuilding program, the Navy is using this period to update the design and firm-up an improved "second generation" of the class. This will be accomplished by utilizing the results of a complete canvass of both current and anticipated AGOR-users in order to ascertain experience and requirements data.

\section{B. Instrumentation: $\$ 9,110,000$}

Oceanographic instrumentation remains a critical factor in improving quality and increasing quantity of oceanographic data. Replacement of slow, manual handling methods for data collection; and the development of new, automatic, and rapid collection and computing methods is most promising. Present instrument development is directed toward improving the accuracy, sensitivity, dura- 
bility, and versatility of existing instruments, developing new instruments where existing gear is inadequate, and the use of automatic measurement, recording, analysis, and computation wherever possible and practical. Plans for FY 1965, by agency, are as follows: *

\section{Bureau of Commercial Fisheries: $\$ 150,000$}

The Bureau is developing biological sampling and measuring devices applicable to fishery science, such as semiautomatic fish scale readers to determine the race and age of North Pacific salmon, New England haddock, and South Atlantic and GuIf Coast menhaden. This instrument will improve accuracy and objectivity, standardize procedures, and reduce costs of scale reading. Another device under development is a towed vehicle which will follow and record a given parameter, such as temperature or salinity, while carrying a sampling device or another sensor. A high-speed plankton sampler which can be towed for long periods of time is also under development.

\section{Geological Survey: $\$ 150,000$}

The USGS is developing and testing instrument systems for: (a) Automatic collection of samples and continuous recording of information concerning the physical and chemical properties of water in streams, estuaries, and bays; (b) Mapping relative bulk densities, radioactivity, and other properties of recent ocean sediments; (c) Laboratory analyses of textural, mineralogic, and chemical characteristics of ocean sediments; (d) Collection of bottom samples from the ocean floor in cooperation with Coast and Geodetic Survey and other offices; and (e) Procurement of geophysical data pertinent to geological structures beneath the ocean floor.

\section{Bureau of Mines: $\$ 48,000$}

The USBM is continuing its studies of equipment for the successful sampling, evaluation, and economical recovery of mineral resources from in and on the ocean floor. All aspects will be considered.

Coast Guard: $\$ 1,218,000$

The CG will continue the outfitting of its oceanstation vessels with oceanographic winches, laboratories, and basic instruments for the collection of time series data. New winches and laboratories will be installed on three WIND Class icebreakers.

- Additional funding for instrumentation is included under research categories.

\section{Coast and Geodetic Survey: $\$ 850,000$}

C\&GS is acquiring modern oceanographic, hydrographic, and tide instrumentation, including signal processing and automated recording equipment to replace obsolete and cumbersome devices and to increase the automation of shipboard processing operations. A buoy system will be developed for estuarine and Continental Shelf studies. Deep-sea tsunami sensors will supplement the shore-based sensors and will provide basic physical data for studies of tsunami wave theory. The deep-sea sensors may also provide an early warning capability to the existing network. In support of the Survey's study of basic tidal theory, the development of a special tide gage for offshore use to determine tidal characteristics at sea will be continued. Development of the automated current measuring system, to replace the present system, will be completed.

\section{Office of Naval Research: $\$ 740,000$}

The ONR is sponsoring development of large oceanographic and meteorological buoys. Two prototype deep-sea buoys with high-speed telemetering capabilities for long-range communications will be developed during FY 1965. This continuation of a 2-year buoy-development program includes construction of two discus-shaped hulls, 40 feet in diameter, tests of electrical power supplies and radio communication over distances as great as 2,500 miles, investigations of mooring techniques, development of sensors, and engineering of telemetering and recording systems for buoys and shore command stations.

\section{Naval Oceanographic Office: $\$ 5,909,000$}

The NavOceano will continue to expand its test and evaluation capabilities and pursue the development of oceanographic recording systems from sensor to computer. The present program for testing, calibrating, and evaluating of both standard and newly developed instruments will be accelerated. The Shipboard Survey System now under development will be carried to the field testing phase. This system which consists of an underwater subsystem, a hoist subsystem, and a data handling subsystem, will be the first truly integrated shipboard survey system with seismic, magnetic, gravity, and bathymetric, as well as oceanographic recording capabilities. Data will be read out in a format for direct use by the National Oceanographic Data Center. In FY 1965 the Office plans to develop more advanced sensors, capable 
of much greater accuracy, sensitivity, and reliability for this and other systems. Efforts toward development of standard synoptic instrumentation will be increased. This will include continued work with ONR in buoy systems, i.e., development of anchoring and moving techniques for both submerged and surface models and appropriate instrument packages for them.

Public Health Service: $\$ 45,000$

PHS is planning to modify present fresh-water instruments for use in estuarine and near-shore waters. In the first stages of this program, efforts are being largely directed towards development of instruments for automatic measurements of water quality. In addition, automatic recording meters will be utilized in estuarine waters.

\section{Facilities: $\$ 8,420,000$}

Construction and improvement of shore facilities in FY 1965 will continue at about the same funding level as in FY 1964. About 65 per cent of this effort will enlarge the research and training capacity of private institutions. The remainder will be used for the modernization of existing Federal laboratories and for the financing of a limited program of new Federal construction. Outlines of programs by agency follow.

Coast and Geodetic Survey: $\$ 360,000$

The C\&GS has scheduled development of the Norfolk Ship Base in FY 1965 as outlined in Phase $\mathrm{V}$ of its master plan. This stage will complete the conversion of the base to a modern facility for ship support and data processing. The channel is to be dredged and the administrative office constructed.

\section{Office of Naval Research: $\$ 2,000,000$}

The ONR is sponsoring the construction of docking facilities at the Narragansett Marine Laboratory of the University of Rhode Island to expand the present pier to accommodate the new 180 foot research vessel. Increased pier space is also being provided for the Woods Hole Oceanographic Institution where present space is inadequate.

\section{Bureau of Commercial Fisheries: $\$ 2,500,000$}

The BCF proposes to build a $\$ 1.5$ million laboratory at Miami, Florida, which will serve as headquarters for research in the tropical Atlantic. Extensive work in exploratory fishing, oceanography, and biology will be needed to develop the food resources of this area, making the establishment of the laboratory basic to a successful program. A new
$\$ 1$ million biological laboratory is planned for Milford, Connecticut, to replace the present one which is old and inadequate. It will be concerned with specialized large-scale studies on the artificial culture of shellfish and on the control of shellfish predators.

\section{Geological Survey: $\$ 30,000$}

The USGS is establishing a marine research facility in the San Francisco Bay Area of California. This installation will serve as a base for marine geological, geophysical, and hydrological studies of the Pacific Ocean floor.

\section{Coast Guard: $\$ 30,000$}

The CG is continuing structural additions to two light towers now under construction to permit oceanographic measurements to be made. Surveys from CG light towers will be made in conjunction with the Fish and Wildlife Service, C\&GS, Weather Bureau, Corps of Engineers, and private research laboratories.

\section{National Science Foundation: $\$ 3,500,000$ (Estimate)}

NSF will invest about $\$ 3.5$ million in shore facilities at universities and other nongovernment research institutions. Precisely what facilities will be built and for whom, will be decided after proposals are received and evaluated by NSF.

\section{Manpower and Training: (\$1.6 Million)*}

Achievement of the long range goal in oceanography depends critically on (a) the training in our universities of an adequate number of high caliber scientists to direct and carry out a research program which is certain to become technically and scientifically more complex, and (b) the training of technicians capable of carrying out much of the observational and laboratory program and of manning the needed expansion of ocean engineering.

\section{Sources of Trained Oceanographers}

A 1962 study by the ICO reported that 35 institutions offer courses in the "marine sciences," 29 institutions offer graduate courses, and graduate degrees are granted by 17 institutions. A study conducted by the Office of Education, summarized in the following table, shows that between 1959 and

- This is included in the tabulations of research budgets. The figures reported here include federal support of fellowships and employee training programs in oceanography, but do not include stipends paid to student research assistants (which are also included under the appropriate research categories) . 
1962 the number of undergraduate and graduate degrees granted in oceanography failed to increase significantly. At the same time, graduate enrollment did increase steadily and significantly, so that it is reasonable to expect a marked increase in graduate degrees within the next ferv years.

University enrollment and degree statistics represent only in part the sources of oceanographers. According to the National Register, scientists reporting first specialties in oceanography hold their highest degrees in that subject. Other fields from which oceanographers come in significant numbers are:

Biology: 21\%; Geology: 20\%; Engineering: 14\%; Physics: $7 \%$.

\section{ADVANCED DEGREE ENROLLMENTS AND DEGREES GRANTED* IN OCEANOGRAPHY BY U.S. UNIVERSITIES} 1959-1962

\begin{tabular}{lrrrr} 
& \multicolumn{4}{c}{ Academic } \\
& 1959 & 1960 & 1961 & 1962 \\
Advanced degree enrollments & n.a. & 111 & 159 & 191 \\
Full-time & n.a. & 92 & 105 & 126 \\
Part-time & n.a. & 19 & 54 & 65 \\
Degrees & 27 & 21 & 29 & 36 \\
Bachelors & 2 & 6 & 6 & 2 \\
Masters & 15 & 9 & 14 & 22 \\
Doctorates & 10 & 6 & 9 & 12
\end{tabular}

These fields provide a large and diversified pool from which oceanographers will continue to be recruited. However, competition from the parent fields and from other developing science programs is severe, so that it is doubtful that manpower adequate for the expanded program of the Ten Year Plan can be recruited without special efforts.

\section{The Need for Engineers and Technicians}

Attainment of the goals of the Long Range Plan and profitable exploitation of the sea requires that the field of ocean engineering be expanded and strengthened. Instruments must be designed and built to withstand the adverse environment of the

- Source: Office of Education-From Office of Education earned degree study, which defines oceanography as a physical science. Degrees in closely related fields of marine biology, geology, geochemistry, etc., not included. sea, new types of structures and vehicles must be built, and man must learn to work effectively within the sea. Capable engineers and technicians who have first-hand acquaintance with the sea and its special difficulties are scarce, and this lack of available manpower inhibits industry from entering a field in which it should play a large role. It becomes the responsibility of the federal government, therefore, to encourage industry to turn its attention to ocean engineering and to stimulate and support the training of technicians for the wide variety of skilled tasks which are needed.

\section{Agency Support of Education and Training}

Fellowships are available to qualified graduate students of oceanography in competition with other fields through the broad programs of the National Science Foundation, the Public Health Service, and the Office of Education (National Defense Education Act). The Bureau of Commercial Fisheries supports fellowships in oceanography through grants for this purpose to selected universities. Roughly one-third of the graduate student population in oceanography is supported by fellowshipsand the total federal expenditure for this purpose is estimated for FY 1965 as $\$ 0.4$ million or $25 \%$ of the total manpower funds in oceanography.

Research grants and contracts provide financial support for about half the graduate students. These students normally devote 20 hours per week to research under the supervision of a faculty member; this not only provides them with an income, but in most cases the research experience which they gain is a most important part of their training. The National Science Foundation, Office of Naval Research, Navy Oceanographic Office, Bureau of Ships, Bureau of Naval Weapons, Atomic Energy Commission, Public Health Service, and the Smithsonian provide contract and grant support of this sort. Stipends paid to graduate students for research is included under the appropriate research budget.

Substantial employee training programs in oceanography are conducted by the Navy (Naval Academy and Post-graduate School), Coast and Geodetic Survey, and the Coast Guard. Other agencies provide limited support for employee training. An estimated $\$ 1.2$ million or $75 \%$, of the total manpower funds will be allocated to all employee training programs in FY 1965. 


\author{
Chapter III \\ NATIONAL OCEANOGRAPHIC PLAN \\ BUDGET
}

Based on a 1958 study of the potential of oceanography to contribute to the national welfare by the National Academy of Sciences, the Executive Branch and the Congress, concerted steps were taken to elevate this field from its comparatively primitive state of resources and activity to one in healthier balance with science and technology as a whole and more responsive to national needs.

The Federal oceanographic budget has grown from a FY 1959 level of $\$ 32$ million to $\$ 55$ million in FY 1960 and to $\$ 62$ million in FY 1961, with a budget supplement in FY 1962 totaling $\$ 105$ million. Growth to $\$ 124$ million in FY 1963 completely leveled off in FY 1964 as a result of Congressional action upon the President's Budget.

Although the FY 1965 budget has been kept to a minimum consistent with requisites, there is, nevertheless, some proposed growth. The research, instrumentation, and facilities components which form the cutting edge for scientific accomplishments will grow from $\$ 68.0$ million in FY 1964 to $\$ 86.7$ million, thus preserving the momentum already established. The program will thus continue progress toward goals set forth by the late President Kennedy in his message to the Congress in 1961 and the more detailed projection of the recently published long range Federal plan in oceanography. Ship construction, however, will be slowed.

A number of major program components have been previously identified as deserving further study and emphasis: deep sea research, and vehicles requisite for its accomplishment; a more vigorous study of air/sea interaction; and a detailed rationale for future survey operations. Such studies are now in progress, and will be elaborated upon in subsequent reports, explaining the basis for those budget elements in the FY 1965 budget and setting the stage for extension of this activity in future years.

\title{
NATIONAL OCEANOGRAPHIC PLAN BUDGET (Thousands)
}

\section{A. BY AGENCIES}

\section{Defense}

Commerce

Interior

National Science Foundation

Atomic Energy Commission

Health, Education and Welfare

Treasury

Smithsonian Institution

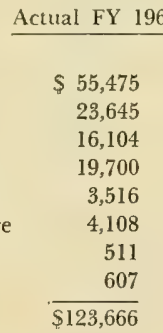

\section{B. BY FUNCTIONAL AREAS}

\begin{tabular}{lr} 
Research & \\
Instrumentation & 46,410 \\
Ships & 6,658 \\
Surveys & 37,250 \\
IIOE & 18,036 \\
Facilities & 5,802 \\
Data Center & 8,875 \\
& 635 \\
\cline { 2 - 2 } & $\$ 123,666$
\end{tabular}

Estimated FY 1964 President's Budget FY 1965

\begin{tabular}{rr}
$\$ 54,631$ & $\$ 66,619$ \\
23,752 & 20,486 \\
16,509 & 19,652 \\
20,200 & 20,600 \\
4,167 & 4,730 \\
2,855 & 3,280 \\
1,152 & 1,822 \\
605 & 881 \\
\hline 123,871 & $\$ 138,070$
\end{tabular}

\begin{tabular}{rr}
$\$ 58,722$ & $\$ 69,143$ \\
6,386 & 9,110 \\
27,387 & 21,350 \\
21,916 & 25,014 \\
5,582 & 3,979 \\
2,937 & 8,420 \\
941 & 1,054 \\
\hline$\$ 123,871$ & $\$ 138,070$
\end{tabular}


AGENCY-FUNCTION

DEFENSE-TOTAL

Navy-Total
Research
Instrumentation
Ship Construction
Surveys
IIOE
Facilities
Data Center
Army-Total
Research

COMMERCE-TOTAL

Coast \& Geodetic

Survey-Total

Research

Instrumentation

Ship Construction

Surveys

IIOE

Facilities

Data Center

Weather Bureau-Total

Research

Data Center

Maritime AdministrationTotal

Research
C. INDIVIDUAL AGENCY BUDGETS

\begin{tabular}{|c|c|c|}
\hline Actual FY 1963 & Estimated FY 1964 & President's Budget FY 1965 \\
\hline$\$ 55,475$ & $\$ 54,631$ & $\$ 66,619$ \\
\hline 54,850 & 53,557 & 65,506 \\
\hline 19,900 & 26,426 & 32,278 \\
\hline 5,500 & 4,455 & 6,649 \\
\hline 18,200 & 8,200 & 9,100 \\
\hline 9,600 & 12,944 & 14,704 \\
\hline 1,300 & 803 & 250 \\
\hline - & 233 & 2,000 \\
\hline 350 & 496 & 525 \\
\hline 625 & 1,074 & 1,113 \\
\hline 625 & $\overline{1,074}$ & 1,113 \\
\hline$\$ 23,645$ & $\$ 23,752$ & $\$ 20,486$ \\
\hline 23,412 & 23,519 & 20,203 \\
\hline$\overline{394}$ & $\overline{839}$ & $\overline{650}$ \\
\hline 768 & 973 & 850 \\
\hline 14,400 & 13,000 & 9,000 \\
\hline 7,505 & 8,109 & 9,101 \\
\hline - & 125 & 75 \\
\hline 265 & 332 & 360 \\
\hline 80 & 141 & 167 \\
\hline 183 & 183 & 233 \\
\hline 173 & 165 & 208 \\
\hline 10 & 18 & 25 \\
\hline 50 & 50 & 50 \\
\hline 50 & 50 & 50 \\
\hline
\end{tabular}


C. INDIVIDUAL AGENCY BUDGETS (Cont'd.)

\begin{tabular}{|c|c|c|c|}
\hline AGENCY-FUNCTION & Actual FY 1963 & Estimated FY 1964 & President's Budget FY 1965 \\
\hline INTERIOR-TOTAL & $\$ 16,104$ & $\$ 16,509$ & $\$ 19,652$ \\
\hline \multicolumn{4}{|l|}{ Bureau of Commercial } \\
\hline Fisheries-Total & 15,320 & 15,494 & 18,210 \\
\hline Research & 9,747 & 11,757 & 13,499 \\
\hline Instrumentation & 70 & 120 & 150 \\
\hline Ship Construction & 2,650 & 3,107 & 1,700 \\
\hline Surveys & 20 & 20 & 40 \\
\hline IIOE & 102 & 154 & 154 \\
\hline Facilities & 2,651 & 195 & 2,500 \\
\hline Data Center & 80 & 141 & 167 \\
\hline Geological Survey-Total & 496 & 498 & 998 \\
\hline Research & 476 & 474 & 778 \\
\hline Instrumentation & 20 & 24 & 150 \\
\hline Surveys & - & - & 20 \\
\hline Facilities & - & - & 30 \\
\hline Data Center & - & - & 20 \\
\hline \multicolumn{4}{|l|}{ Bureau of Sports Fisheries } \\
\hline \& Wildlife-Total & 238 & 464 & 262 \\
\hline Research & 238 & 257 & 262 \\
\hline Facilities & - & 127 & - \\
\hline Ship Construction & - & 80 & - \\
\hline Bureau of Mines-Total & 50 & 53 & 182 \\
\hline Research & 50 & 53 & 104 \\
\hline Instrumentation & - & - & 48 \\
\hline Ship Construction & - & - & - \\
\hline Surveys & - & - & 30 \\
\hline Data Center & - & - & - \\
\hline \multicolumn{4}{|l|}{ NATIONAL SCIENCE } \\
\hline FOUNDATION-TOTAL & $\$ 19,700$ & $\$ 20,200$ & $\$ 20,600$ \\
\hline Research & 9,200 & 10,600 & 12,000 \\
\hline Ship Construction & 2,000 & 3,000 & 1,500 \\
\hline IIOE & 4,400 & 4,500 & 3,500 \\
\hline Facilities & 4,000 & 2,000 & 3,500 \\
\hline Data Center & 100 & 100 & 100 \\
\hline
\end{tabular}




\section{INDIVIDUAL AGENGY BUDGETS (Cont'd.)}

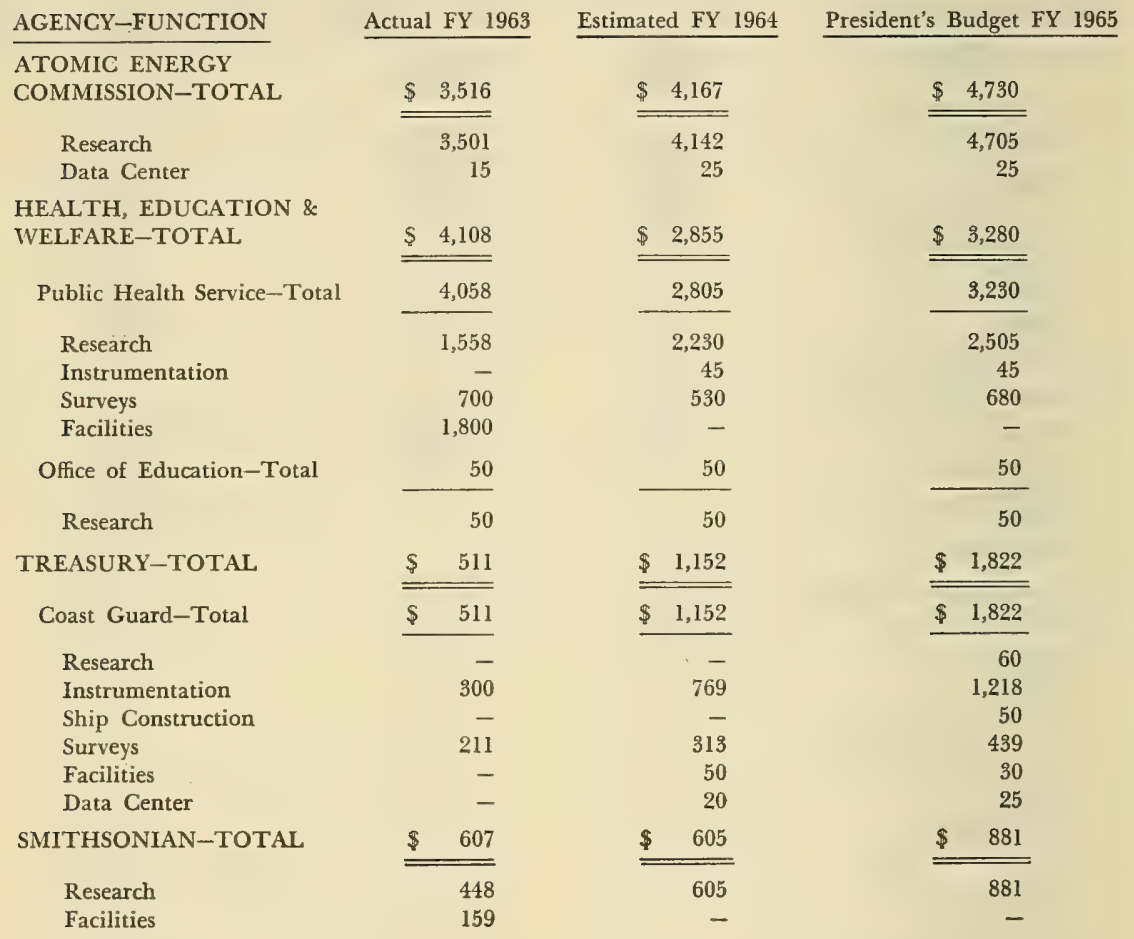


APPENDIX

ICO OCEANOGRAPHIC SURVEY/RESEARCH SHIPS 


\section{UNITED STATES NAVY}

\begin{tabular}{|c|c|c|c|c|c|c|}
\hline Name & \multicolumn{2}{|c|}{ Type } & Source & Built & Use & $\begin{array}{c}\text { Cost } \\
\text { Millions }\end{array}$ \\
\hline TANNER & Large & AGS & ex-AKA & 1944 & Coastal surveys, tender & \\
\hline MAURY & Large & & ex-AKA & 1943 & Coastal surveys, tender & \\
\hline TOWHEE & Large & AGS-28 & ex-AMS & 1941 & Coastal \& nearshore surveys & \\
\hline SHELDRAKE & Large & & ex-AMS & 1943 & Coastal \& nearshore surveys & \\
\hline SERRANO & Large & & ex-ATF & 1947 & Coastal \& nearshore surveys & \\
\hline SAN PABLO & Medium & AGS & ex-AVP & 1942 & Mid-Ocean surveys & \\
\hline REHOBOTH & Medium & & ex-AVP & 1942 & Mid-Ocean surveys & \\
\hline LITTLEHALES & Small & AGS & ex-YF & 1945 & Harbor surveys & \\
\hline ARCHERFISH & Medium & AGS & ex-SS & 1943 & Ocean surveys & \\
\hline BOWDITCH & Large & AGS & ex-Cargo & 1944 & Ocean surveys & \\
\hline DUTTON & Large & & ex-Cargo & 1944 & Ocean surveys & \\
\hline MICHELSON & Large & & ex-Cargo & 1944 & Ocean surveys & \\
\hline CONRAD & AGOR & & new const. & 1963 & Ocean research (Lamont) & $\$ 4.5$ \\
\hline GILLISS & AGOR & & new const. & 1963 & Ocean research (Navy) & 4.3 \\
\hline DAVIS & AGOR & & new const. & 1963 & Ocean research (Navy) & 4.3 \\
\hline SANDS & AGOR & & new const. & 1964 & Ocean research (Navy) & 4.3 \\
\hline LYNCH & AGOR & & new const. & 1964 & Ocean research (Navy) & 4.3 \\
\hline KELLAR & Small & AGS & new const. & 1964 & Coastal \& nearshore surveys & 4.4 \\
\hline AGOR-9 & AGOR & & new const. & 1965 & Ocean research (Scripps) & 4.4 \\
\hline AGOR-10 & AGOR & & new const. & 1965 & Ocean research (Univ, of Washington) & 4.4 \\
\hline AGS-26 & Medium & AGS & new const. & 1965 & Ocean surveys & 9.4 \\
\hline \multirow[t]{4}{*}{ AGS-27 } & Medium & AGS & new const. & 1966 & Ocean surveys & 8.2 \\
\hline & \multicolumn{4}{|c|}{ Proposed FY 1965 Program } & & \\
\hline & AGOR & & new const. & 1967 & Ocean research (Texas A\&M) & 4.5 \\
\hline & Small & AGS & new const. & 1967 & Coastal \& offshore surveys & 4.6 \\
\hline
\end{tabular}


UNITED STATES NAVY (cont'd)

\begin{tabular}{|c|c|c|c|c|c|c|c|c|c|}
\hline \multirow[t]{2}{*}{ NAME } & \multirow[t]{2}{*}{ LOA } & \multirow[t]{2}{*}{ DRAFT } & \multirow[t]{2}{*}{ BEAM } & \multirow[t]{2}{*}{ DISPL } & \multicolumn{2}{|c|}{ COMPLEMENT } & \multirow[t]{2}{*}{ SOURCE } & \multirow[t]{2}{*}{ AGE } & \multirow[t]{2}{*}{ MISSION } \\
\hline & & & & & CREW & SC & & & \\
\hline $\begin{array}{l}\text { TANNER CLASS } \\
\text { TANNER } \\
\text { MAURY }\end{array}$ & 426 & 17 & 53 & 6500 & 930 & 8 & AKA & $\begin{array}{l}1944 \\
1943\end{array}$ & $\begin{array}{l}\text { Precise coastal surveys. Serve as } \\
\text { operating tender providing sup- } \\
\text { port for smaller ships, boats, and } \\
\text { shore parties. Equipped with } \\
\text { helicopters. Chart production } \\
\text { capability and electronic posi- } \\
\text { tioning equipment. }\end{array}$ \\
\hline
\end{tabular}

\begin{tabular}{llllllllll}
\hline SAN PABLO CLASS & 300 & 13 & 41 & 2600 & 174 & 8 & AVP & 1942 Deep-water oceanographic and
\end{tabular}
hydrographic data. Basic ships for collection of deep-ocean environmental data for pro- and anti-submarine warfare. Conduct the "ocean-wide survey" to meet the VCS and national requirements for a widespread knowledge of the oceans.

\begin{tabular}{lllllllll}
\hline $\begin{array}{l}\text { BOWDITCH } \\
\text { BOWDITCH }\end{array}$ & 455 & 24 & 62 & 13,000 & 80 & 15 & CARGO 1944 Deep ocean surveys for special \\
fleet requirements.
\end{tabular}

DUTTON

MICHELSON

\begin{tabular}{|c|c|c|c|c|c|c|c|c|c|}
\hline $\begin{array}{l}\text { REQUISITE CLASS } \\
\text { TOWHEE } \\
\text { SHELDRAKE } \\
\text { SERRANO }\end{array}$ & 221 & 15 & 32 & 1250 & 82 & 2 & AMS & 1941 & $\begin{array}{l}\text { Nearshore, shallow and medium } \\
\text { depth hydrographic and oceano- } \\
\text { graphic work, either for charter } \\
\text { surveys or for special military } \\
\text { projects such as mining and } \\
\text { mines counterneasures work. } \\
\text { Mid-deep equipment, test and } \\
\text { evaluation by shipborne and } \\
\text { bottomed sonar arrays. }\end{array}$ \\
\hline
\end{tabular}

\begin{tabular}{|c|c|c|c|c|c|c|c|c|c|}
\hline LITTLEHALES & 136 & 11 & 31 & 600 & 19 & 1 & YTB & 1945 & $\begin{array}{l}\text { Shallow water oceanography for } \\
\text { military requirements. }\end{array}$ \\
\hline ARCHERFISH & 311 & 17 & & 2200 & 55 & 4 & SS & 1943 & Project SEASCAN \\
\hline $\begin{array}{l}\text { GILLISS CLASS } \\
\text { (AGOR) } \\
\text { GILLISS } \\
\text { CONRAD } \\
\text { DAVIS } \\
\text { SANDS } \\
\text { LYNCH } \\
\text { AGOR } \\
\text { AGOR }\end{array}$ & 209 & 14 & 41 & 1320 & 26 & 15 & NEW & $\begin{array}{l}1964 \\
1964 \\
1965 \\
1965\end{array}$ & $\begin{array}{l}\text { Basic and applied oceanography. } \\
\text { Acoustic test of environmental } \\
\text { effects on instruments. } \\
\text { SPECIAL FEATURES: } \\
\text { Lab and office space, } \\
\text { acoustic silencing, } \\
\text { oceanographic winch, } \\
\text { deep anchoring, bow propellor, } \\
\text { antiroll tanks, van storage. }\end{array}$ \\
\hline $\begin{array}{l}\text { KELLAR CLASS } \\
\text { (Small AGS) }\end{array}$ & 209 & 14 & 41 & 1320 & 26 & 15 & NEW & 1964 & Same as REQUISITE Class. \\
\hline
\end{tabular}


U.S. COAST AND GEODETIC SURVEY

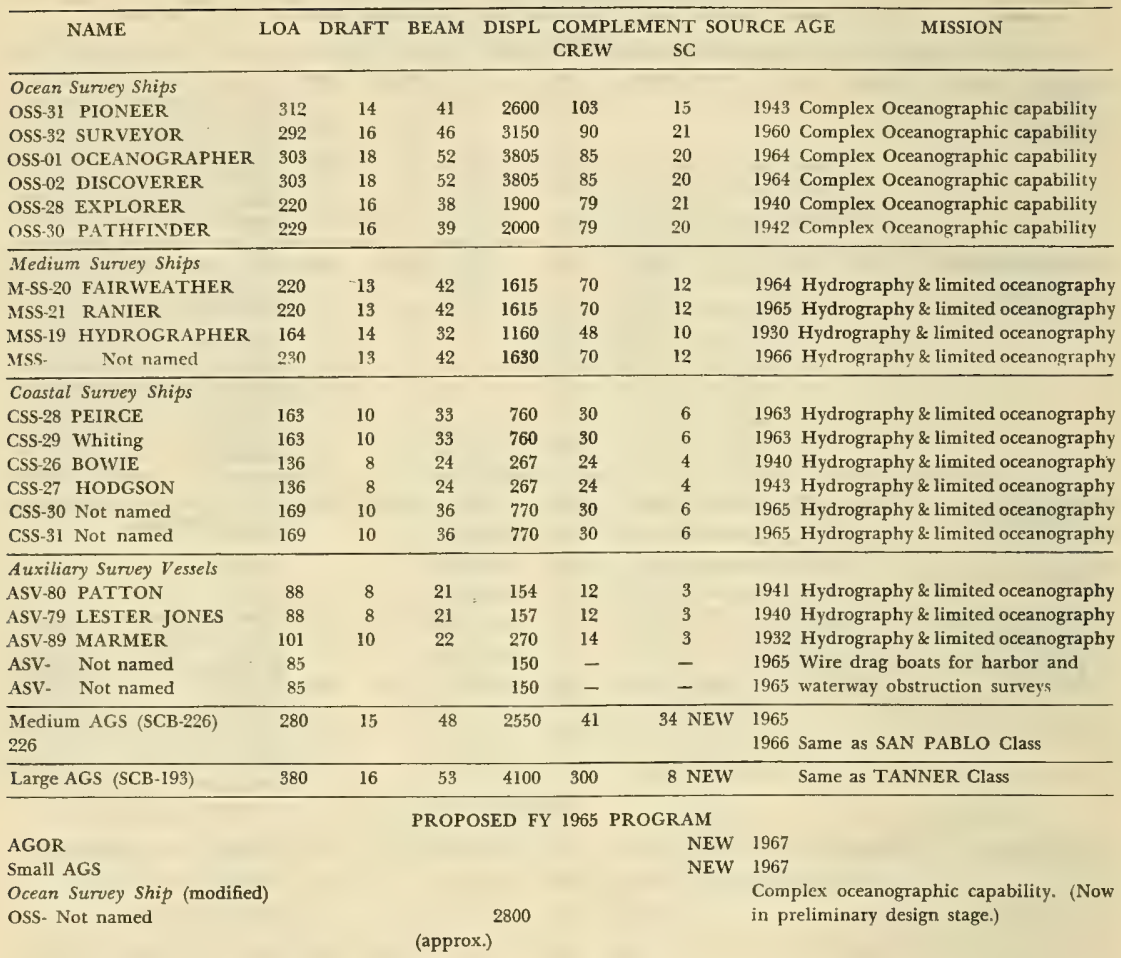


U. S. COAST GUARD

SHIPS WITH OCEANOGRAPHIC CAPABILITY-EXISTING (FY-64) AND PLANNED (FY-65) PROGRAMS

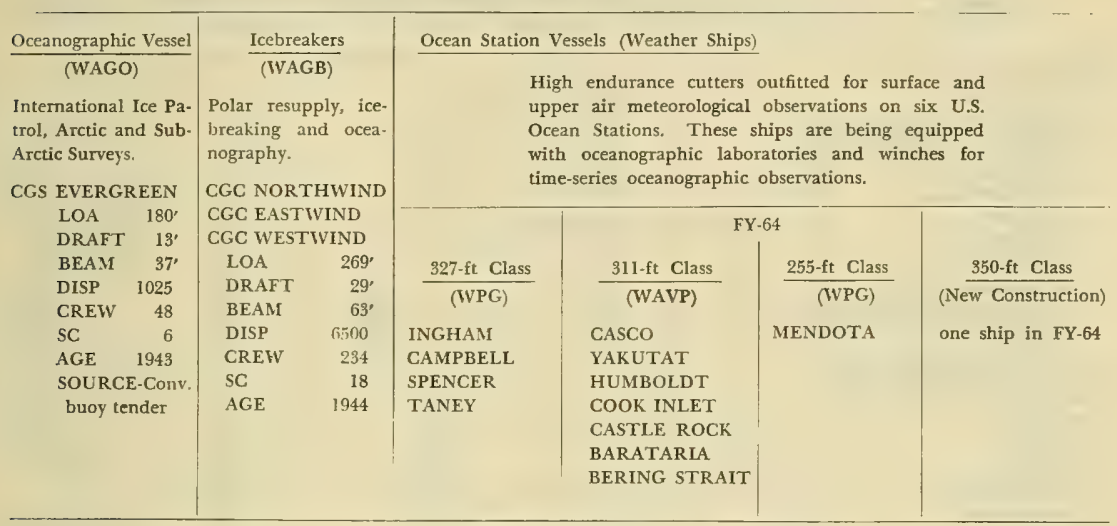

FY 65 PROGRAM

\begin{tabular}{|c|c|c|c|c|}
\hline $\begin{array}{l}\text { In } 1965 \text { a new vessel } \\
\text { will be designed to } \\
\text { replace EVER - } \\
\text { GREEN. New ship to } \\
\text { be approximately }\end{array}$ & $\begin{array}{l}\text { In } 1965 \text { new and } \\
\text { larger laboratories } \\
\text { will be installed on } \\
\text { icebreakers. New oce- } \\
\text { anographic winches }\end{array}$ & $\begin{array}{l}\text { BIBB } \\
\text { DUANE }\end{array}$ & $\begin{array}{l}\text { HALF MOON } \\
\text { ABSECON } \\
\text { MACKINAC } \\
\text { ROCKAWAY } \\
\text { CHINCO- }\end{array}$ & $\begin{array}{l}\text { ESCANABA } \\
\text { OWASCO } \\
\text { WINNEBAGO } \\
\text { CHAUTAUGUA } \\
\text { MINNETONKA }\end{array}$ \\
\hline $\begin{array}{l}200 \text {-ft long@1500 } \\
\text { tons. To have ice- } \\
\text { breaking capability. }\end{array}$ & to be provided. & & TEAGUE & \\
\hline
\end{tabular}

NAIIONAL SCIENCE FOUNDATION

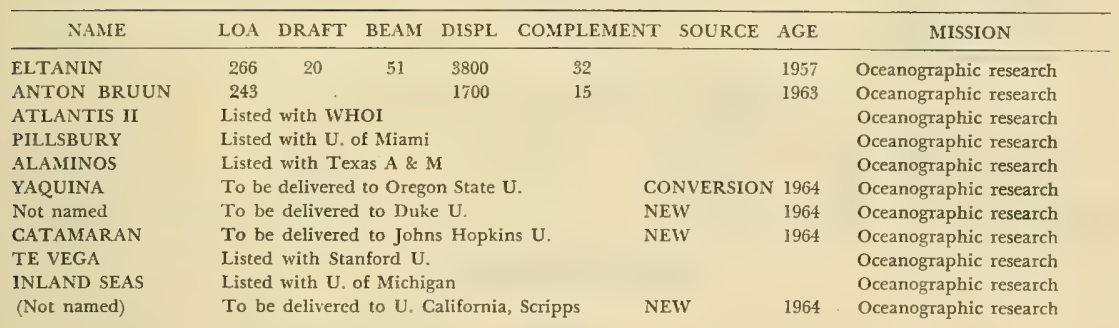


BUREAU OF COMMERCLAL FISHERIES

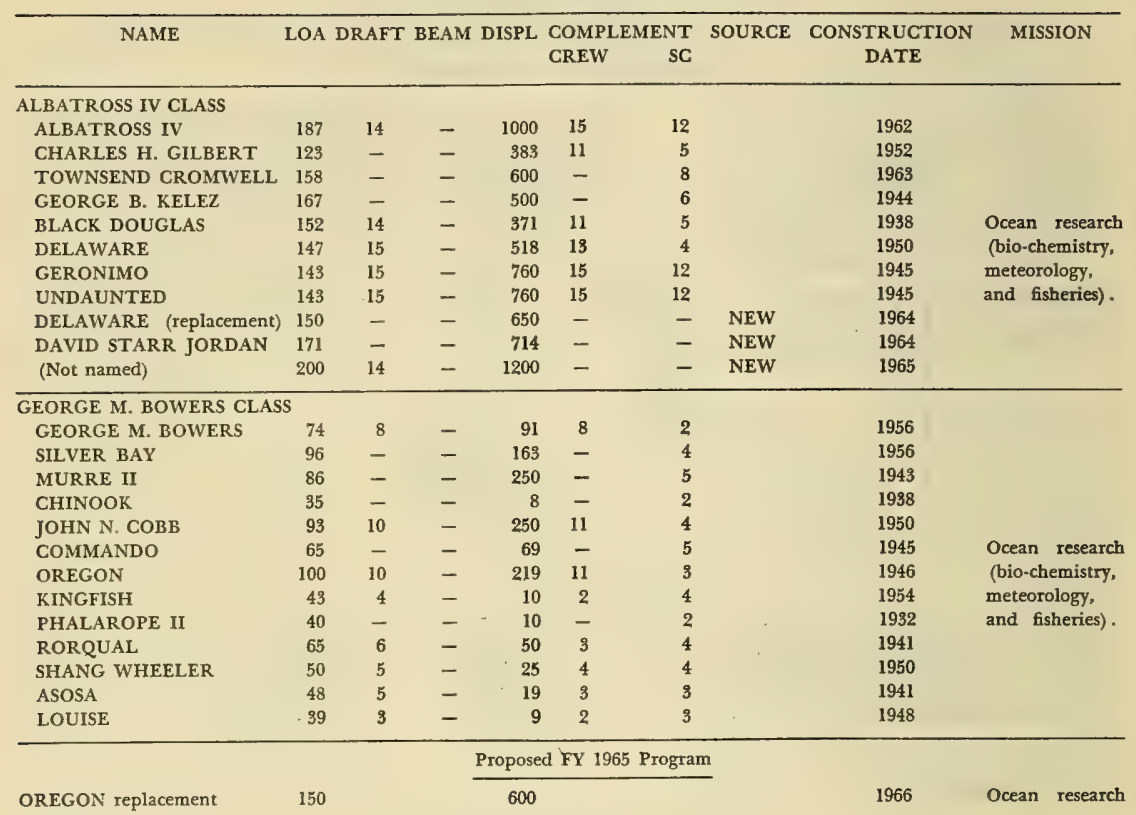


PRIVATE INSTITUTIONS

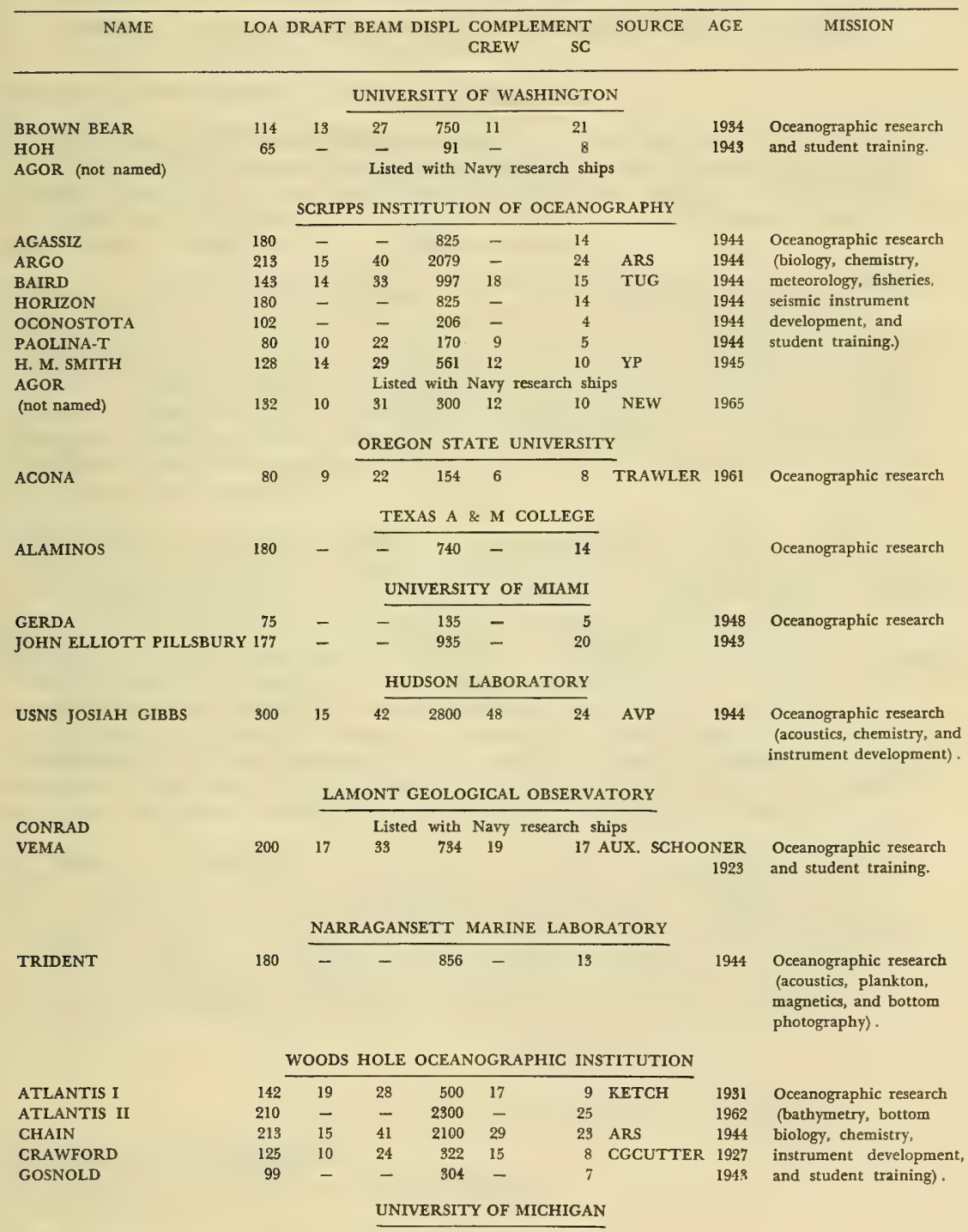

INLAND SEAS 
PRIVATE INSTITUTIONS (cont'd)

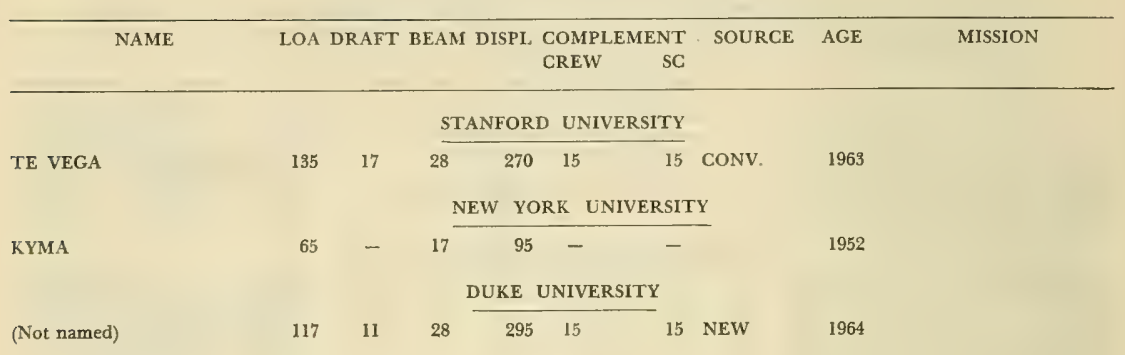




\section{THE WHTTE HOUSE} WASHINGTON

March 19, 1964

Dear Mr. President: (Dear Mr. Speaker:)

Recognizing the continued interest by the Congress in advancing this Nation's program in oceanography, I arn pleased to forward advance copies of two publications of the Federal Counc1l for Sience and Technology that set forth Government-wide plans and budget details.

These reports, entitled "National Oceanographlc Program, Fiscal Year 1965, Parts I and II, "contain an account of oceanic research to meet national goals, in keeping with the long range considerations previously submitted to the Congress. Information is also included concerning proposed funding for research, surveys, new ship and laboratory construction, and zoncerning program planning and coordination by the Counctl's Interagency Committee on Oceanography (ICO), to minimize unwitting duplication and program gaps.

The proposed Federal budget in oceanography is $\$ 138$ million. This is 11\% more than Fiscal Year 1964 appropriations, which in turn equalled those for Fiscal Year 1963. This proposed growth is on absolute minimum if the country is to maintain the momenturn necessary to achieve those objectives in oceanic research which have been previously enunciated by both President Kennedy and the Congress to enhance our military defense; to develop marine mineral and fisheries resources to control pollution; to predict more accurately storms and tides that endanger life and property; to assist state, national and international bodies in wise legislation and regulation of conmerce on the sea; and to extend scientirlc knowledge generally.

I especially should like to cali ettention to the Governmentwide character of this program. Statutory responsibility for the conduct of related sectors are vested in a number of separate agencies. Special measures are thus being continued by the office of Sclence and Technology and the Federal Coundi for Sufence and Technology, with the assistance of the ICO, to achieva effective interagency planning and coordination.

Sincerely yours,

/s/ Lyndion B. Johnson

Honorable Carl Heyden

President pro Tempore of the Senate

Washington, D, C.

Honorable John W. MeCormack

Speaker of the House of Representatives

Weshington, D. C. 



\section{APPENDIX 8}

ANNUAL REPORT OF THE NATIONAL OCEANOGRAPHIC

DATA CENTER-FISCAL YEAR 1962, SUBMITTED BY MR.

HAROLD W. DUBACH, DEPUTY, NODC 



\section{NATIONAL OCEANOGRAPHIC DATA CENTER}

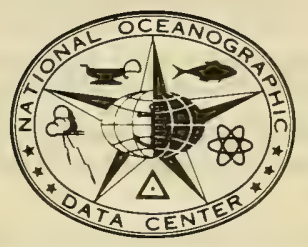

\section{ANNUAL REPORT}

OF THE

NODC

(JULY 1961-JUNE 1962) 


\section{ANNUAL REPORT OF THE NATIONAL OCEANOGRAPHIC DATA CENTER}

(July 1961 through June 1962)

On January 16, 1962 the National Oceanographic Data Center completed its first full year of operation and on June 30, 1962 finished its first full Fiscal Year. Some of the work in Fiscal Year 1962 was a continuation of the task begun in 1961 of completing the organization of the NODC. In addition to this task the NODC has made a number of significant accomplishments during this period.

In the area of physical-chemical data, the computational capability of the NODC in the processing of oceanographic station data was speeded up by a factor of 25 to 1 by conversion to the new 1401-7070 computer system.

A new format for listing oceanographic station data which eliminates the need for separate wiring boards was developed. Both publication listings and regular listings now can be run by using the same wiring board.

During Fiscal Year 1962 the NODC staff developed a standard form for recording physicalchemical data. This form was designed to incorporate most of the suggestions of the oceanographic community, so that it would adequately serve consumer needs. This form has been adopted by the International Indian Ocean Expedition, and will be especially printed for participants in that expedition. The first Working Group of the Intergovernmental Oceanographic Commission has recommended to the Commission that this same form be used by participants in the forthcoming International Cooperative Investigations of the Tropical Atlantic Ocean.

A new punch card format for physical-chemical data was also developed by the NODC staff. The format was developed concurrently with the recording form to eliminate coding operations when data are submitted on the NODC form. A provisional bathythermograph log was printed and distributed. After a period of testing by components of the U.S. Navy Fleet the log is currently undergoing revision. The $\log$ is also currently used by other nations.

Work has begun on the development of a BT punch card to digitize both data in the NODC archives and future BT data. This card is being developed concurrently with the BT log and in concert with the oceanographic community.

In the area of publications the NODC released, in December 1961, the joint IGY WDC-ANODC publication Oceanographic Vessels of the World. This publication has stimulated such great interest that a supplement is currently in work. The first publication in the catalog series, Reference Sources for Oceanographic Station Data, was also released in FY-62. By the end of FY-62 the first two publications in the Manual Series, M-1, Oceanographic Conversion Tables for Use by the International Indian Ocean Expedition, and M-2, Processing Physical and Chemical Data from Oceanographic Stations, were in press and will be released early in FY- 63. 
During FY-62 NODC has published a monthly NEWSLETTER, consisting of approximately 8 pages and containing information on activities of NODC and items of interest to the entire scientific community. The NODC has provided back-up information for articles appearing in magazines and journals; namely, Rockets and Missiles magazine, the Bulletin of the American Meteorological Society, the Mariners Weather Log, and the U.S. Naval Institute Proceedings. The NODC also prepared an article which appeared in the March issue of Transactions of the American Geophysical Union.

Papers on the work of the NODC were presented at numerous meetings of scientific and related societies such as, the Joint Government-Industry Symposium on Oceanographic Instrumentation, the American Society of Computer Machinery, the Research Society of America, and the Special Libraries Association.

In the field of research and investigations the NODC has been working on the development of a geological-geophysical data holding-recall system and presented its findings to the Ad Hoc Committee on Geology and Geophysics in June 1962. A similar program for biological data is also under development.

An analysis of bathythermograph data has also been begun to evaluate the data in NODC archives and to evaluate incoming BT data.

A new computer program was written to detect instabilities in physical-chemical data from oceanographic stations. This has considerably cut down premonitoring work necessary in quality control procedures. Work is progressing on reprogramming for the computation of sound velocity according to Wilson's method and test runs of this program have been made for special projects.

In order that the NODC will truly represent an interagency concept, three additional agencies with an interest in oceanography have been invited to participate in the support of NODC. These agencies are the U.S. Coast Guard, The Department of Health, Education, and Welfare, and the U.S. Geological Survey. During FY-62 the Coast Guard and the Geological Survey responded favorably to this invitation and have agreed to support the NODC beginning in FY-64. The other agency had made no definite committment by the end of FY- 62. 
The sponsoring agencies and their representatives on the Interagency Advisory Board are:

\author{
ATOMIC ENERGY COMMISSION \\ Dr. Vincent Schultz \\ BUREAU OF COMMERCIAL FISHERIES \\ Mr. Howard Eckles \\ COAST AND GEODETIC SURVEY \\ Dr. Harris B. Stewart, Jr.
}

NATIONAL SCIENCE FOUNDATION

Dr. John Lyman

NAVAL OCEANOGRAPHIC OFFICE

$\mathrm{Mr}$. Boyd E. Olson

OFFICE OF NAVAL RESEARCH

Dr. Arthur E. Maxwell

WEATHER BUREAU

Mr. Robert Schloemer

NATIONAL ACADEMY OF SCIENCES:

Dr. Milner B. Schaefer

Inter-American Tropical Tuna Commission

Dr. Donald Pritchard

The Johns Hopkins University

\title{
NATIONAL OCEANOGRAPHIC DATA CENTER
}

Dr. Woodrow C. Jacobs

Director, ex officio Member of Board 


\section{POLICY DECISIONS BY THE NODC ADVISORY BOARD FOR FISCAL YEAR 1962}

The following items, quoted or paraphrased from the NODC Advisory Board Minutes, represent the policy decisions made by the Board during FY-62. These are arranged by subject, not in chronological order.

\section{BUDGET MATTERS}

The board established at the 18 January 1962 Meeting the following policy in regard to submission of NODC budgets: "(1) Budgets will be submitted two years in advance; (2) the NODC will submit the preliminary budget to the Board on 1 September [of each calendar year]; (3) The Board and the NODC staff [will] devote the period from September to January to budget review; $(4)$ at the first meeting in January of each year the Board will act on the budget for the Fiscal Year beginning 18 and 6 months in advance, respectively."

\section{EXCHANGES}

At the Meeting of 18 January 1962 the board set the following policy, " . . International exchanges other than those to which we are already authorized by the Board [are to] be handled under the IGY WDC-A \& - B agreements."

\section{REQUESTS FOR SERVICES}

At the Advisory Board meeting of 17 April 1962 two decisions were made on requests for services.

1. In order to expedite initiation of work requested by government controcting oceanographic institutions, a special allotment would be set up by the Office of Naval Research on which these institutions could draw. Authorization to begin work would be on verbal approval from ONR.

2. The NODC will volunteer the services of its personnel to assist in oceanographic surveys both at the national and international levels.

\section{WORLD DATA CENTER-A (OCEANOGRAPHY)}

On 5 July 1961, the Board decided that "WDC-A [should] not be terminated but instead moved physically to NODC; a component should be set up within NODC to permit its continuation, but functions of WDC-A would be carried by NODC."

At the meeting of 14 August 1961 it was decided that a letter to the NODC be prepared by the National Academy of Sciences "authorizing NODC to assume responsibility of the WDC-A and to insure that it carries out all aspects of its job." The NODC accepted responsibility for the WDC-A on 8 March 1962.

\section{PUBLICATIONS}

At the meeting of 30 October 1961 the Board made two decisions on policies governing publications of the NODC.

1. "Review of publications by the Board prior to publication is not required but members of the Board in the Washington area would . . . do so if requested by the Director."

2. Although NODC "publications have prices listed on them, [they] should be sent free of charge to contributing activities." 


\section{SUMMARY OF FUNDS}

DATA IN: This is a fiscal summary of funds received and expended in Fiscal Year 1962 covering the normal operating costs required to process oceanographic data into existing standard holdingrecall systems.

RECEIPTS

Supporting Agency

Atomic Energy Commission

Bureau of Commercial Fisheries

Coast and Geodetic Survey

National Science Foundation

Navy

Weother Bureau

Navy (for Facilities and Equipment)

EXPENDITURES

PERSONAL SERVICES

PERSONAL BENEFITS

TRAVEL

RENTALS

PRINTING

CONTRACTUAL SERVICES

JITCO

SANYO

Hydro Support

(Includes 1401-7070 Exp.)

Misc.

CONTRACTS (TOTAL)

SUPPLIES AND MATERIALS

FACILITIES, HOUSEKEEPING SERVICE

SUPPORT COST, EQUIPMENT

TOTAL

DATA OUT

RECEIVED

$\$ 60,410.48$
SPENT

$\$ 23,503.95$
Total Agency Support

Amount of Contribution for FY 62

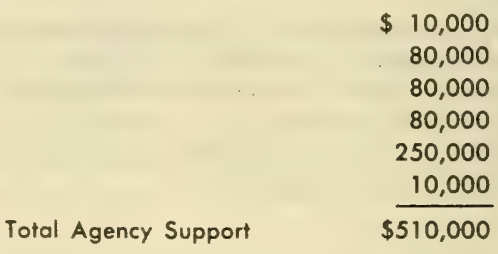

$$
\text { Total } \quad \frac{60,000}{\$ 570,000}
$$

$\begin{array}{ccc}\begin{array}{c}\text { ANNUAL } \\ \text { ALLOCATIONS }\end{array} & \begin{array}{c}\text { GROSS } \\ \text { OBLIGATIONS }\end{array} & \text { BALANCE } \\ \$ 355,150 & \$ 351,441 & \$ 3,709 \\ 28,000 & 27,420 & 580 \\ 4,150 & 3,977 & 173 \\ 16,850 & 16,723 & 127 \\ 5,400 & 5,230 & 170\end{array}$

$\$ 33,000$

22,385

$\$ 33,000$

$\$ 00$ $22,385 \quad 00$

24,015

1,200

23,828

187

1,200

00

$\$ 80,600$

$\$ 80,413$

$\$ 187$

$\$ 18,500$

$\$ 18,557$

$\$-57$

50,000

48,328

1,672

11,350

11,335

15

$\$ 570,000$

$\$ 563,424$

$\$ 6,576$

CARRIED FORWARD FY-63

UNSPENT

$\$ 30,845.04$

$\$ 6,061.49$ 


\section{PERSONNEL}

The NODC started Fiscal Year 1962 with 60 employees and completed the year with 65 full-time employees and 2 part-time employees. The "on board" count at the end of the year included 26 professionals ranging from GS-5 to GS-16, 20 scientific support personnel ranging from GS-4 to GS-7, and 21 administrative and other support personnel ranging from GS-3 to GS-9.

Status of personnel during FY 1962 is shown in Table 1 and Graph 1

\section{POSITION DESCRIPTIONS}

During the past year several key positions have been written and all Branch Head positions have been graded out with the exception of the position of the Head of the Information Branch.

\section{RECRUITMENT}

The NODC has had considerable trouble in recruitment of professional personnel at the GS-5 and GS-7 level. It is felt that a more vigorous recruitment program should be placed into effect to recruit these people when available and exceed ceiling if necessary. Experience shows about $85 \%$ of recruitment commitments in this category decline prior to their reporting date. 
TABLE 1

\section{SUMMARY OF POSITIONS}

POSITION (Grade)

FILLED VACANT

Oceanographer, GS-16 (PL 313) ..........

Oceanographer, GS-14 .............. 1

Oceanographer, GS-13 .............. 2

Oceanographer, GS-12 .............. 3

Oceanographer, GS-11 . . . . . . . . . . . 4

Oceanographer, GS-9............... 2

Oceanographer, GS-7 ............... 9

Oceanographer, GS-5 .............. 1

Oceanographer (Geol.), GS-12 . . . . . . . . . . 1

Oceanographer (Biol.), GS-11 ............. 1

Mathematician, GS-13 .................

Cartographer, GS-11 . . . . . . . . . . . . .

Geophysicist (Earth Physics), GS-11

Phys. Science Tech., GS-7 . . . . . . . . . . . . I

Phys. Science Tech., GS-6 . . . . . . . . . . . . 3

Phys. Science Tech., GS-5 . . . . . . . . . . . . . . 11

Phys. Science Tech., GS-4 . . . . . . . . . . . . 4

Administrative Asst., GS 9 . . . . . . . . . . . . 1

Statistical Clerk, GS-4 ................... 1

EAM Project Planner, GS-7 . . . . . . . . . . . . I

Student Trainee (Oceanography), GS-3 . . . . . . I 1

Scientific Illustrator, GS-6

Scientific lllustrator, GS-5

Tab. Equip. Operator, GS-4 . . . . . . . . . . 2

Tab. Equip. Operator, GS-3

Card Punch Operator, GS-4

Card Punch Operator, GS-3

Secretary (Steno.), GS-6

Secretary (Steno.), GS-5

Clerk (Steno.), GS-5

Secretary (Typing), GS-5 . . . . . . . . . . 2

Clerk-Typist, GS-4 . . . . . . . . . . . . . 3

Clerk-Typist, GS-3................ 5 
GRAPH 1

STATUS OF NODC PERSONNEL

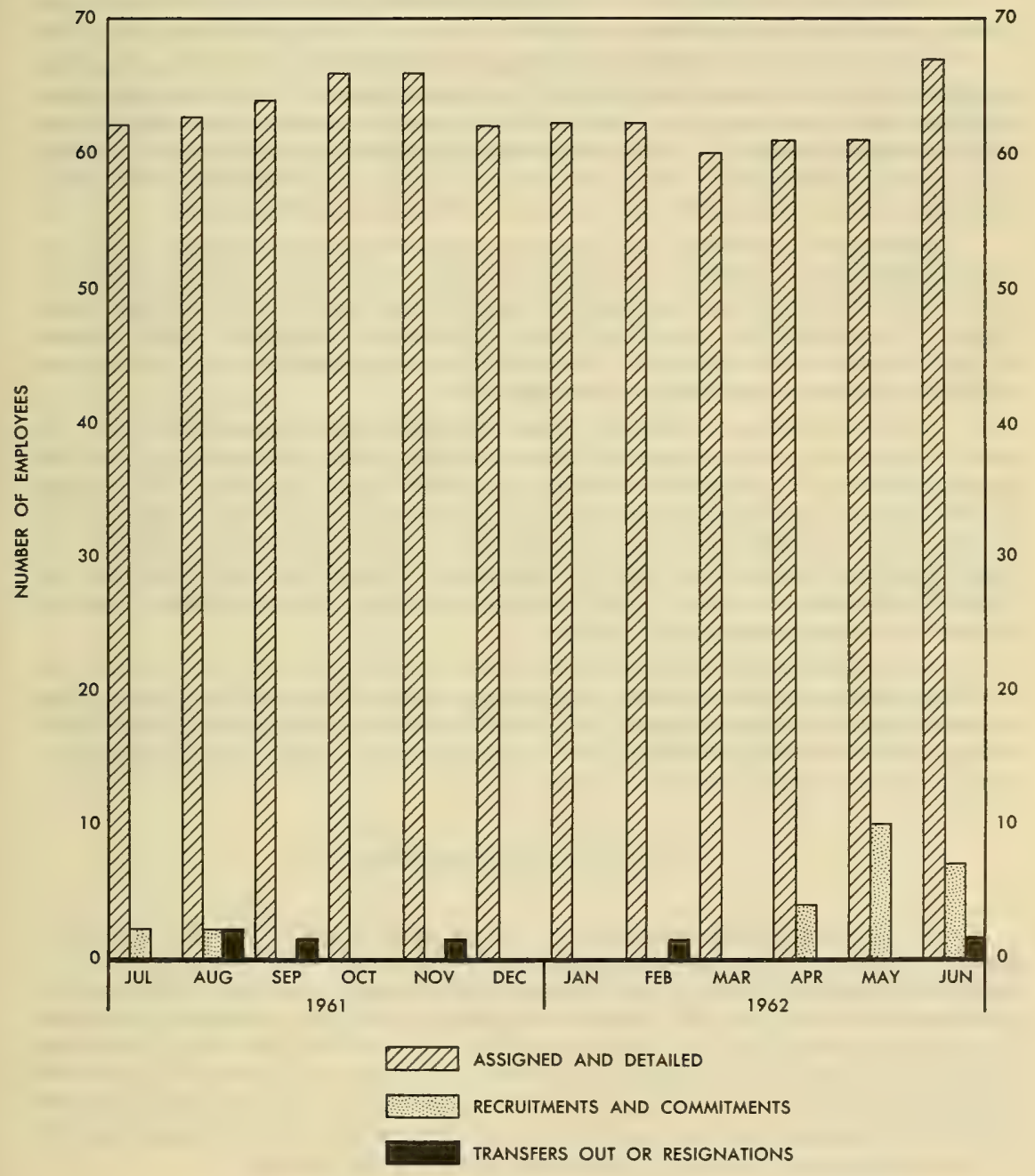




\title{
PRODUCTION WORK
}

\author{
Bathythermograph Data
}

Graph Number 2 shows the level of bathythermograph (BT) data processing and Graph Number 3 receipt of BT's during Fiscal Year 1962.

The contract let to John I. Thompson Company (JITCO) of Washington, D. C. to reduce the backlog of BT data was terminated January 1962. During the same month, the processing procedures of BT data were re-evaluated and certain quality control checks have been added to increase the quality and usability of the data. Other modifications are expected to follow in the near future. These revised procedures, along with loss of manhours to fulfill "data out" requests, have reduced our monthly production from 6,000 observations per month to about 1,500 per month.

The NODC has agreements with Scripps Institution of Oceanography (SIO) and Woods Hole Oceanographic Institution (WHOI) for exchange of BT data. Under the arrangement, NODC provides to $\mathrm{SIO}$ two prints of each completely processed BT observation for the Pacific and Indian Oceans; SIO provides NODC with one print of each SIO processed observation. NODC provides to WHOl one print of each processed BT observation for the North Atlantic Ocean; WHOI provides NODC with one print of each WHOI processed observation.

The NODC has been investigating means of automating the processing of BT data. At present, we are testing and evaluating on Automatic BT Slide Holding and Advancing System designed and built for us by the Instrumentation Division of the Oceanographic Office. It is estimated that this device may save up to 3.0 man years of work annually along with the elimination of considerable repetitive handling and sorting of glass BT slides. Additionally, IBM, Gulton Industries and Hytech Corporation have expressed interest in developing an automatic scanning device to read and digitize BT slide negatives or prints. Each has been supplied the necessary samples of data and material for the development of such a system.

Also planned for the near future are the construction and installation of an Automatic Film Feed and Cutting System to be adapted to the BT cameras and the conversion of the Ozalid machines to operate under the Anhydrous System. It is hoped that the automation of many of the BT processing procedures will reduce the time required for the digitization of the more than 750,000 bathythermograph observations in the NODC archives.

\section{Oceanographic Station Dafa}

Oceanographic station data production is shown by month and for the period covered by this report in Graph 4. The average production rate has been about 5,000 stations per month. A total of 60,619 stations (of which 11,537 were coded and keypunched under contract with the Sanyo Surveying Company of Japan, but computed and edited by the NODC) was processed during the past year; the oceanographic station data archives now total about 215,000 stations. The reduced production rate in the last quarter of Fiscal Year 1962 was caused by the transfer of personnel from production work to Data Out projects for NUOS, BCF and others. It was impossible to recruit the additional staff required to maintain work in both areas. Personnel shifts were made assigning priority to Data Out projects and temporarily de-emphasizing routine production work. 


\section{Oceanographic Station Data}

At the beginning of Fiscal Year 1962 the NODC archives consisted mainly of oceanographic station data for the North Atlantic Ocean area; during the year, increased emphasis has been given to processing data for the Pacific and Indian Oceans. To the best of our knowledge the only un. processed Indian Ocean data are recent observations which were received by NODC late in Fiscal Year 1962. The Indian Ocean Geo-Sort is completed and a listing is being readied for release.

Work has begun to adapt the existing holdings to the approved NODC Physical-Chemical Oceanographic Station Punch Card and recomputing sound velocity values according to Wilson's formulas. It has been definitely established that the basic NODC files will retain material in metric units insofar as feasible. 
GRAPH 2

\section{BT PRODUCTION}

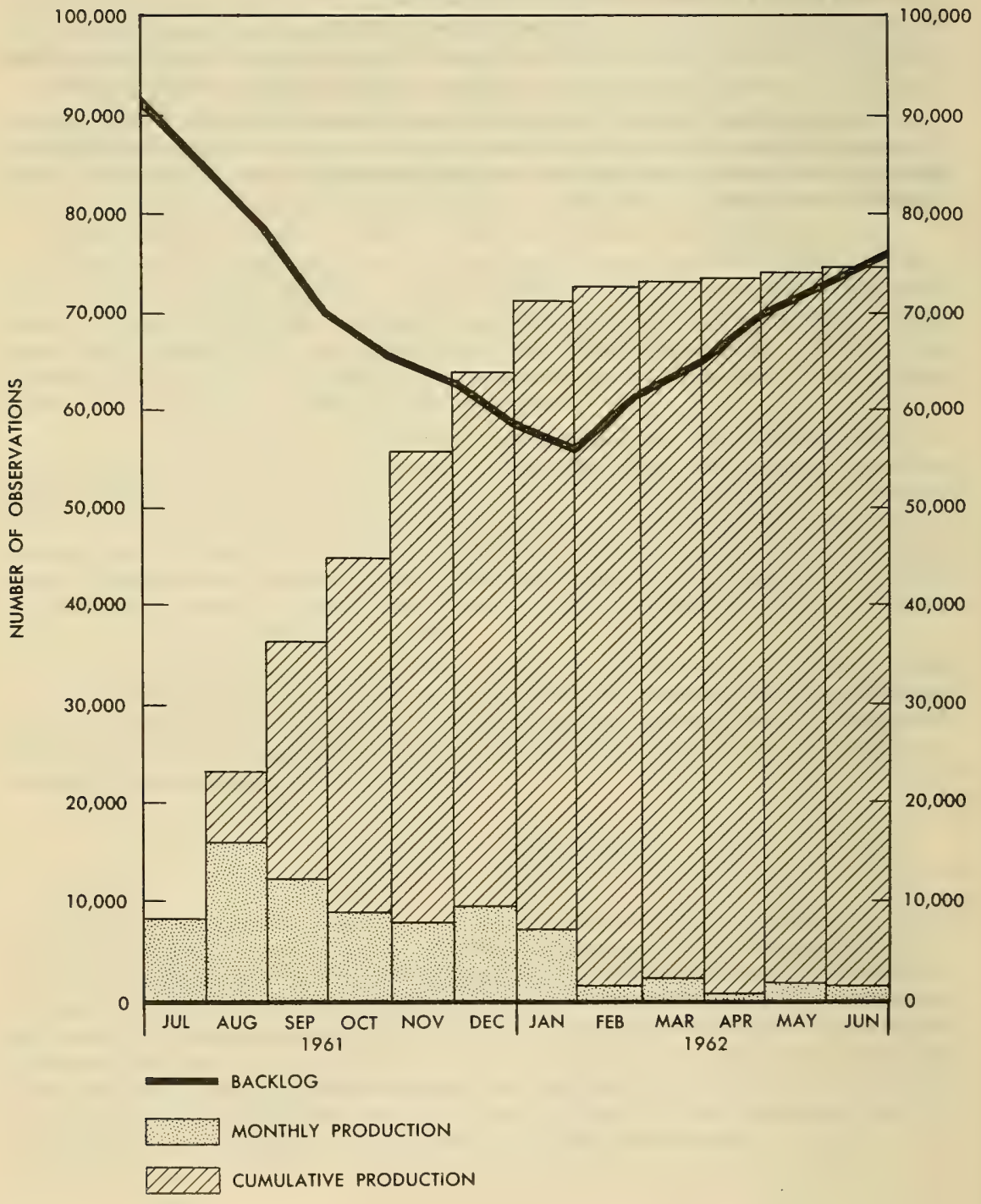


GRAPH 3

\section{BT RECEIPTS}

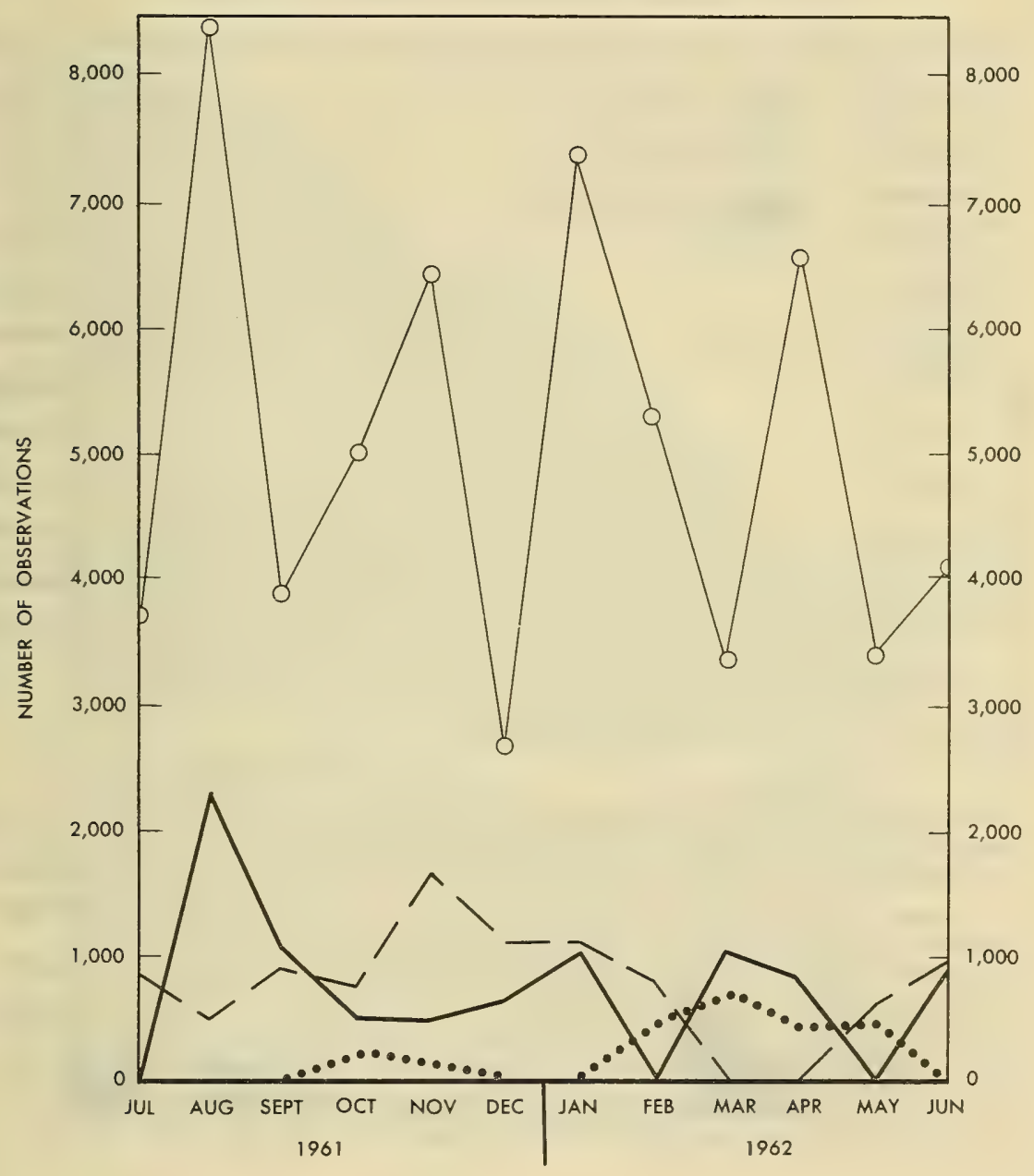

- - SCRIPPS INSTITUTION OF OCEANOGRAPHY WOODS HOLE OCEANOGRAPHIC INSTITUTION

........ OTHERS

○— UNPROCESSED SLIDES 
GRAPH 4

OCEANOGRAPHIC STATION DATA PRODUCTION CHART

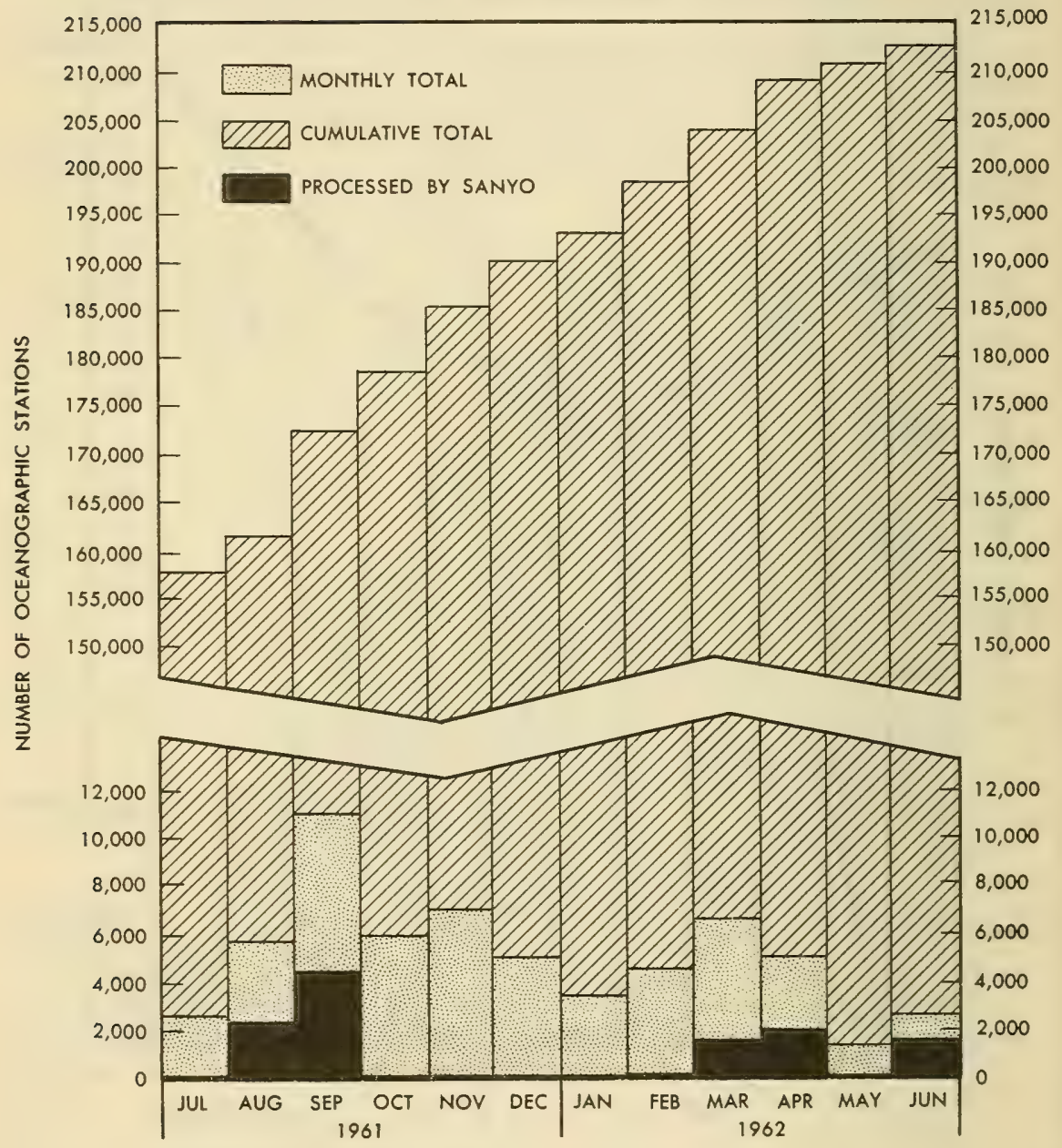




\section{MAJOR DATA OUT PROJECTS BUREAU OF COMMERCIAL FISHERIES PROJECT}

The NODC contribution ( 20 charts, 1 table, and a bibliography of oceanographic station data sources) to the BCF brochure "Provisional Oceanographic Charts, Tropical Atlantic" was prepared for use by the participants in the $10 \mathrm{C}$ Working Group Meeting on International Cooperative Investigations of the Tropical Atlantic, which was held at NODC on June 20-23, 1962. This document served as a review of existing information and was of assistance in the planning of cruises, particularly in positioning of the station lines and the spacing of the stations along these lines. In addition, the NODC "Proposal for Exchange and Publication of Data and Preparation and Publication of an Atlas" was accepted with minor modifications by the Working Group. With this proposal, NODC is obligated to participate in the EQUALANT I and EQUALANT II programs. The Data Center will accept, process and exchange data with the participants, and prepare and publish Data Reports after each synoptic survey; the proposal also included a requirement for the preparation and publication of an atlas of the Equatorial Atlantic under the guidance of an International Board of Editors.

\section{DATA EVALUATION PROJECTS}

During the last part of Fiscal Year 1962 the National Oceanographic Data Center undertook two data evaluation projects. The first, which is being done for the Office of Naval Research, is concerned with evaluations of data obtained during the hurricane CARLA from an unmanned weather buoy designated NOMAD (Navy Oceanographic and Meteorological Automatic Device) which was moored in the middle of the Gulf of Mexico. Work was begun at the end of Fiscal Year 1962.

The NODC will investigate data collected from this weather buoy during the passage of hurricane CARLA to assess the value of similar unmanned buoys in the prediction of oceanographic conditions during storm surges, abnormal tides, and other extreme oceanographic phenomeno resulting from hurricanes.

This project, which is expected to take approximately 9 to 12 months to complete, will have as its final product a summary report consisting of text, charts and graphs showing the relative contribution of a buoy system to the accuracy of analysis of enviromental conditions in an open marine area and a marine coastal area.

The first phase of the second data evaluation project, undertaken for the Navy Underwater Ordnance Station (NUOS), was completed during Fiscal Year 1962. This project consists of a thorough examination and comparative analysis of historical data and contemporary data collected in a deep sea area. Special techniques for manual interpolation of various oceanographic parameters at standard levels were devised. Some of the basic work which has been done manually will be programmed for machine plotting in Fiscal Year 1963. It is expected that this project will be extended at least 6 months into Fiscal Year 1963 depending on the exact specifications received. 


\section{DATA REQUESTS (Reimbursable)}

During the Fiscal Year 1962 the NODC completed 27 reimbursable requests for data at a cost of $\$ 23,503.95$. As the scientific community became increasingly aware of the facilities available at the Data Center, the diversity of requests increased. Although requests for basic data predominated, requests for information which require analysis and special handling were especially notable during the last quarter. It is expected that the need for these more complex "specialized" requests will increase significantly during the coming Fiscal Year. Funds expended during this Fiscal Year increased 6 times over Fiscal Year 1961. Reimbursable requests completed during Fiscal Year 1962 are summarized in Table 2 , and itemized in Table 3.

\section{EXCHANGE WORK (Non-Reimbursable)}

The NODC encouraged and developed oceanographic data exchange programs with all activities in any country indicating a desire to participate. Punch cards for about 8,000 Japanese oceanographic stations were added to the archives of Pacific holdings. Approximately 2,500 stations from the North Polar Front Survey were forwarded, in publication format, to the International Council for the Exploration of the Sea (ICES) in exchange for receipt of these data. The relocation of WDC-A for Oceanography, in facilities adjacent to.NODC in the last quarter of Fiscal Year 1962, will help in centralizing the United States foreign exchange effort. The survey activity in two international oceanographic programs (IIOE and ICITA) during the next fiscal year will significantly increase the amount of oceanographic station data to be exchanged; we also expect to begin the exchange of biological and geological data during Fiscal Year 1963. Exchanges of data are summarized in Table 4 , and given in detail in Table 5 .

\section{INFORMATIONAL ITEMS (Non-Reimbursable)}

About 35 inquiries requesting either small amounts of data or answers to single questions were answered during the fiscal year and were provided at no cost. In general, data and information costing less than $\$ 25.00$ to supply were provided at no cost.

Data inquiries involving only nominal costs are answered without reimbursement. 
TABLE 2

SUMMARY OF DATA REQUESTS (REIMBURSABLE)

(July 1961 - June 1962)

NO. OF
REQUESTS

27

Listings
Reproduction
Services
Research

$\$ 23,503.95$ 
TABLE 3

\section{DETAILED LIST OF DATA REQUESTS (REIMBURSABLE)}

\section{ACTIVITY}

Li. Kang, Republic of Korea

Lamont Geological

Observatory (Wüst)

NHO
Code 3000

NHO

Code 3500

\section{NHO}

Code 3412

NHO

Code 3300

Lamont Geological

Observatory (Heezen)

Western Electric

Naval Underwater

Ordnance Station

Naval Research

Laboratory (Stewart)
TYPE OF DATA

AND/OR

NO. OF OBS.

5500 BT prints

1036 stations oceano-

graphic station data

Listings oceonographic

station data

Services for survey

in TOTO

BT search and reproduction

Ocean station data and sea and swell listings and punch card reproduction

Ocean station data listings

417 stations

Oceanographic station dato

Analysis and supporting services of ocean data from TOTO

1874 BT prints

31 pages of sea surface temperatures
$\$ 10,428.09$

SERVICE PROVIDED

AND

COST TO CONSUMER

Reproduction

$\$ 343.07$

Listings

\$ 75.61

Listings

$\$ 1,051.89$

$\$ 211.43$

Listings

$\$ 1,056.64$

Listings

\$ 362.50

Listings

$\$ 97.84$

Services

$\$ 5,306.02$

Reproduction

$\$ \quad 69.16$ 


\section{TABLE 3 (CONT'D)}

\section{ACTIVITY}

ONR (LeSchack)

Scripps Institution

of Oceanography

Gulf Coast Research

Underseas Cable Corp.

Loral Electronics

Socony Mobil Oil Co.

Aretic Institute of

North America

Colorado State Univ.

(Riehl)

Tufts University

(Mac Donald)

New York University

University of

California

\author{
TYPE OF DATA \\ AND \\ NO. OF OBS.
}

Ocean station data

225 stations

754 stations

Ocean station dato

150 stations

Ocean station data

50 stations

Ocean station data

BT and ocean station data listings

Heat flow search and abstracts

Ocean station data listings

502 obs

BT prints

544 stations

Ocean station data

Ocean station data listings

876 photo copies Vityaz Cruise

\author{
SERVICE PROVIDED \\ AND \\ COST TO CONSUMER
}

Listings

$\$ 17.07$

Listings

$\$ 25.15$

Listings

$\$ 9.23$

Listings

$\$ 65.53$

Listings

$\$ 79.63$

Research

$\$ 96.22$

Listings

$\$ 75.08$

Reproduction

$\$ 20.93$

Listings

$\$ 19.23$

Listings

$\$ 142.97$

Reproduction

$\$ 53.20$ 


\section{TABLE 3 (CONT'D)}

\section{ACTIVITY}

University of Southern

California (Malkus)

\section{University of \\ California (Reid)}

Harvard University

(Stommel)

Coast and Geodetic

Survey

Bureau of Commercial

Fisheries (Wash. Lab.)

Bureau of Commercial

Fisheries (Hawaii, $\mathrm{HBL}$ )

\author{
TYPE OF DATA \\ AND \\ NO. OF OBS.
}

1400 obs

BT prints

Duplicate ocean station data listings

993 stations

Ocean station data

Ocean station data-all data submitted in FY62

Supporting services for ICITA

30,000 stations ocean station data; punch card reproduction and listings
SERVICE PROVIDED

AND

COST TO CONSUMER

Pub. Listings 78.78

Services

$\$ 1,449.59$

Listings

$\$ 2,134.28$ 
TABLE 4

\section{SUMMARY OF DATA EXCHANGES}

(July 1961-June 1962)

NO. OF EXCHANGES

13

1

1

Grand

Total 15
TYPE OF DATA

BT prints

Computed punch cards
111,559

3,281

$\$ 180.00$

$\$ 5,606.35$

$\$ 17,967.00$

114,840

$\$ 23,753.35$ 


\section{TABLE 5}

\section{DETAILED LIST OF DATA EXCHANGES}

(July 196.1-June 1962)

ACTIVITY

Argentina

Canada

Great Britain

India

Japan

Netherlands

New Zealand

SIO

WHOI
TYPE OF DATA

AND

NO. OF OBS

82 BT prints

20 BT prints

5,931 BT prints

700 stations

2,100 BT prints

Computed punch

cards

94 BT prints

754 BT prints

17,214 BT prints

28,485 BT prints
$\$ 296.00$

$\$ 17,967.00$

$\$ \quad 38.00$

$\$ 3,560.00$

SERVICES PROVIDED

AND

COST TO NODC

$\$ \quad 4.00$

$\$ \quad 135.00$

$\$ \quad 5.00$

$\$ 1,424.00$ 


\section{TABLE 5 (CONT'D)}

\section{ACTIVITY}

\author{
TYPE OF DATA \\ AND \\ NO. OF OBS.
}

C\&GS

18 BT prints

$\$ 1.00$

F \& WS

529 BT prints

$\$ 26.00$

NHO

Chile

ICES

Union of South Africa
2325 BT prints

4 BT prints

$\$ \quad .20$

2,581 stations

$\$ 180.00$

3 BT prints

$\$ \quad .15$ 


\section{DEVELOPMENT OF INFORMATION RETRIEVAL SYSTEM AND PUNCH CARD FORMATS}

\section{GEOLOGICAL, GEOPHYSICAL, AND BIOLOGICAL DATA}

During FY-62 NODC began its investigation of various possible information and data storage and retrieval systems that might prove suitable for adaptation to geological, geophysical and biological oceanography material. A system has been proposed and a pilot project begun; it includes a potential for location and recall of both digital and non-digital types of material.

In addition to investigating various storage-retrieval systems, some study of useful supporting equipment will be required.

Concurrently, the NODC is developing proposed digitization schemes and punch cards for geological, geophysical, biological, ice and other physical data for presentation to the oceanographic community. A few preliminary test cases have been put on punch cards; upon completion of the test the results will be circulated to the scientific community for comments and further recommendations.

Dr. Harris B. Stewart, Jr. has been appointed chairman of the ad hoc NODC Advisory Committee on Geophysical and Geological Dato; its purpose is to advise and to provide technical guidance to NODC in the developing of the marine geophysical and geological storage retrieval problem (s). The ad hoc Committee on Geological Data met on 25 June 1962; those in attendance were:

CHAIRMAN-Dr. Harris B. Stewart, Jr.

MEMBERS:

Mr. Jack Kofoed-U.S. Coast and Geodetic Survey

Mr. James Trumbull-U.S. Geological Survey

Mr. George Keller-U.S. Naval Oceanographic Office

Dr. Robert Schmalz-Pennsylvania State University

Dr. H.G. Goodell-Florida State University

Dr. Joe S. Creager-University of Washington

Mr. John Hathaway-USGS Denver, Colorado

OTHERS:

Dr. Woodrow C. Jacobs-National Oceanographic Data Center

Mr. Harold W. Dubach-National Oceanographic Data Center

Mr. Robert V. Ochinero-National Oceanographic Data Center

Mr. Robert W. Taber-National Oceanographic Data Center

Dr. Anthony R. Picciolo-National Oceanographic Data Center

Mr. Franklin D. Derenge-National Oceanographic Data Center 
The ad hoc Committee on Geophysical Data met on 26 June 1962; those in attendance were:

CHAIRMAN-Dr. Harris B. Stewart, Jr.

MEMBERS:

Mr. Hyman Orlin-U.S. Coast and Geodetic Survey

Mr. Michael Smalet-U.S. Naval Oceanographic Office

Dr. J. Lamar Worzel-Lamont Geological Observatory

Mr. Martin Kane-U.S. Geological Survey

\section{OTHERS:}

Dr. Woodrow C. Jacobs-National Oceanographic Data Center Mr. Harold W. Dubach-National Oceanographic Data Center Mr. Robert V: Ochinero-National Oceanographic Data Center Mr. Robert W. Taber-National Oceanographic Data Center

Dr. Anthony R. Picciolo-National Oceanographic Data Center Mr. Franklin D. Derenge-National Oceanographic Data Center

Items considered by both Committees were:

1. Items to be included on punch card format.

2. Units and codes for punch cards.

3. Plans for an information retrieval system for data reports.

4. Adequacy of plans and timing as outlined on action milestone charts.

Based upon the recommendations of the geological-geophysical ad hoc committe, the NODC plans to proceed on the programs as follows:

1. Preliminary punch cards for bottom sediments and gravity will be developed.

2. Preliminary formats will be circulated throughout the marine geological and geophysical community for comments.

3. Revised proposed formats will be submitted to the NODC Advisory Board for approval.

4. Development will continue on punch card formats for other geophysical and geological projects.

5. Development will begin on a system for bathymetric data as soon as a subject specialist is recruited.

6. Data Reports in IGY WDC-A for Oceanography will be indexed.

7. Data Reports in IGY WDC-A for Geomagnetism, Gravity and Seismology will be indexed. 


\section{DEVELOPMENT OF SYSTEMS FOR PHYSICAL AND CHEMICAL DATA}

\section{OCEANOGRAPHIC STATION DATA}

The punch card format for recording oceanographic station data was revised and approved by the NODC Advisory Board on 12 May 1961. This card format was designed in conjunction with the recommendations of the EPOC Committee on Machine Processing of Oceanographic Data and others in the oceanographic commmunity.

\section{AUTOMATIC DATA PROCESSING}

Procedures for processing data into the new Oceanographic Station Card were in the final stages of development by the end of the fiscal year. In Fiscal Year 1963 these procedures will be implemented; new cruises will be reduced and processed in accordance with the requirements of the new card format.

A new routine has been added to the computer program (IBM 7070) to compute the velocity of sound in sea water according to the formulas developed by Wayne D. Wilson. Suitable codes have been set up for the punch cards and listings to identify stations containing velocities computed by Wilson's formulas.

During Fiscal Year 1963 it is planned to convert the EAM system of archiving these data (punched cards) to an EDP system (magnetic tape). The EDP archiving system will greatly increase NODC capability for processing (updating, inventorying, arranging, analyzing and evaluating, selecting, disseminating, etc.) these data to meet user requirements and will provide greater flexibility and responsiveness. In addition, improved computer interpolation, computation, and quality control techniques are planned.

\section{BATHYTHERMOGRAPH (BT) DATA}

In addition to conducting studies on the validity of BT observational and processing procedures, the NODC staff has been working on a revision of the Provisional Bathythermograph Log and a digitization scheme for putting BT data on machine punched cards. Considerable progress has been made on the development of a BT card format, and NODC expects to submit its format for comment to the oceanographic community early in Fiscal Year 1963. 


\section{PUBLICATIONS}

NODC Publications in print and available for distribution are as follows:

Publication G-2, Oceanographic Vessels of the World

Publication C-1, Reference Sources for Oceanographic Station Data (Provisional)

Publications in draft are as follows:

Publication G-1, Introduction to the National Oceanographic Data Center

Publication C-2, Catalog of BT Data, World Wide (will replace SP-12 Part lla which is now out of print)

Publication C-4, Catalog of Oceanographic Data, Indian Ocean

Publication C-5, Catalog of Oceanographic Data, North Pacific Ocean

Publication M-1, Conversion Tables for Use by the International Indian Ocean Expedition

Publication M-2, Processing Physical and Chemical Data from Oceanographic Stations

The NODC NEWSLETTER is now forwarded to approximately 520 recipients; some of these receive several copies. Judging from letters received concerning this NEWSLETTER it appears to be well accepted throughout the oceanographic community and by private industry and international activities. The NEWSLETTER is published at the end of each month, and contributions on work and activities of scientists which seem to be of general interest are included in the NEWSLETTER. 


\section{IGY WORLD DATA CENTER A, OCEANOGRAPHY}

The World Data Center A, Oceanography, was officially relocated in Building 160, Washington 25, D. C. on 8 March 1962, at which time Dr. Jacobs assumed its directorship. The bulk of the reference material from the Department of Oceanography and Meteorology of Texas A \& M was delivered on that day; the remaining materials were transferred before the end of June 1962 .

At the time of the transfer the WDC-A holdings included data from about 25,000 oceanographic stations plus a variety of other data in various forms. Since this transfer, 763 stations have been added to the holdings; two shipments of documents have been received from WDC-B. A crossindex reference system of WDC-A and NODC assigned oceanographic cruise numbers has been established. 


\section{FUTURE PLANS}

During the last half of Fiscal Year 1963 the NODC plans to initiate a pilot program to develop techniques and procedures for direct communication between NODC and survey ships so that raw observations can be serviced by NODC during the course of survey activities. By use of computer programs, NODC could perform the thermometric corrections and further process the data, refurning the results to the ship's scientists for use in modifying survey plans as may be required for the research investigation underway.

The NODC will continue the functions of WDC-A; it will continue to contribute to major international programs such as IIOE and the International Cooperative Investigations of the Tropical Atlantic as the opportunities to be of service present themselves. A direct communications link with the Canadian Oceanographic Data Center, its east and west coast oceanographic laboratories, and an Arctic laboratory is in prospect.

The NODC expects to obtain, by the end of Fiscal Year 1964, a total picture of the processing problems related to satellite recorded oceanographic information (radiation and ice data). This program will be done in cooperation with NASA and the Weather Bureau.

By the end of Fiscal Year 1964 the NODC plans to have schemes for processing, holding and retrieving some types of marine geological, geophysical and biological data available for presentation to the oceanographic community.

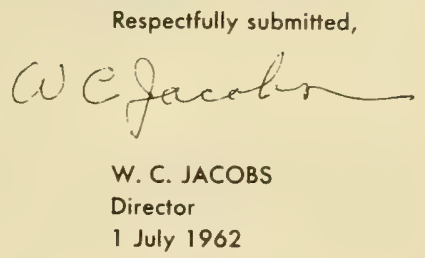

Approved by NODC Interagency Advisory Board

af meeting of 20 July 1962 



\section{APPENDIX 9}

ANNUAL REPORT OF THE NATIONAL OCEANOGRAPHIC DATA CENTER-FISCAL YEAR 1963, SUBMITTED BY MR.

HAROLD W. DUBACH, DEPUTY, NODC 



\title{
NATIONAL OCEANOGRAPHIC DATA CENTER
}

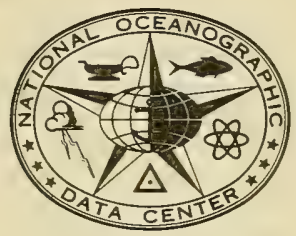 \\ ANNUAL REPORT \\ OF THE \\ NODC
}

(JULY 1962-JUNE 1963)

Washington 25, D. C. 


\section{TABLE OF CONTENTS}

Resume of Work

Sponsoring Agencies of the NODC and Representatives on the Interagency Advisory Board ...................... 3

Summary of Funds . . . . . . . . . . . . . . . 4

FY-63 Policy Decisions of the NODC Advisory Board . . . . . . . . . . . 5

Production Work ............................ 6

Major Data Requests. . . . . . . . . . . . . . . . . . . .

Summary of Data Requests. . . . . . . . . . . . . . . . . . 9

Exchange Work . . . . . . . . . . . . . . .

Development of Systems and Punch Card Formats .............. 16

Development of Systems for Physical and Chemical Data . . . . . . . . . 18

NODC Publications. . . . . . . . . . . . . . . . . . . . 19

IGY World Data Center A, Oceanography. . . . . . . . . . . . . . 20

World Data Center A, Publications. . . . . . . . . . . . . . 21

Administrative Motters. . . . . . . . . . . . . . 22

Future Plans. . . . . . . . . . . . . . . 


\section{ANNUAL REPORT OF THE NATIONAL OCEANOGRAPHIC DATA CENTER}

Fiscal Year 1963 has been an outstanding year for the growth and development of the NODC despite many obstacles and the increasing pressure of data collected during numerous oceanographic surveys. The emphasis on production was somewhat shifted during the year in the interest of maintaining quality of deta rather than quantity of data. Much effort had to be devoted to developmental areas for streamlining the processing procedures for oceanographic station data and BT data, to in. crease the quality of the latter, to handle the current flow of data, and to anticipate the increased receipts of the data. The NODC undertook several studies on the problems of quality in BT's and their digitization. In addition to these studies, numerous commercial organizations have presented proposals for automation of BT processing. For a special request, the NODC undertook a manual digitization program of BT's; however, a manual system would never be able to cope with the present archived analog BT's nor incoming dato, so this interest and cooperation from industry improves the outlook on the BT problem. Investigations are already under way to provide for greater automation of the oceanographic station data processing system.

The scientific community has become increasingly aware of the NODC and the services and data which it can provide; for example, the reimbursable requests for data and services represented a monetary increase of about 10 times more than those for FY-62. Indicative of the trend of services being requested of the NODC is the fact that of these reimbursable requests over $50 \%$ of their dollar value was for data evaluation and analysis.

The data services for which there has been no charge have also increased significantly. The exchange activities of the NODC have increased and will probably continue to increase over the next few years with the involvement of NODC as a contributor of services to international oceanographic expeditions. Minor requests for which there has been no charge have increased to about 15 times the number for FY-62.

To increase the capability of some of the younger and less experienced NODC staff members, we have taken advantage of several training programs and training opportunities; for example, each year, new employees at the GS-5 or -7 level enter a technical orientation-training program under the Civil Service Training Agreement. During FY -63 , the NODC sent two employees to the Woods Hole Oceanographic Institution for an advanced course in oceanography; personnel from NODC served on five different oceanographic survey cruises.

To enable the NODC to process data other than physical-chemical data, the programs for developing holding-recall systems for geological-geophysical and biological data have been given added impefus. Ad hoc committees have been convened for these types of data to review the work of the Data Center to date in these areas and to provide guidance.

The publications of the NODC and presentations of the Director, Deputy Director, and staff before various scientific groups have considerably publicized the Data Center and its work. The NODC NEWSLETTER, for example, now has a distribution of over 1,000 copies in the Unifed States and abroad. The Director of NODC has made presentations to such groups as the Federal Council for Science and Technology, the Navy Research and Development Clinic, and the Eastern Pacific Oceanic Conference. 
In addition to his presentations to these groups, the Director has served as Chairman of the Joint ICO -ICAS (Interagency Committee on Oceanography - Interdepartmental Committee on Atmospheric Sciences) ad hoc Panel on Ocean-Atmosphere Research, has been an observer on many of the committees of the ICO and has served as a member of the Intergovernmental Oceanographic Commission (IOC) working group on data exchanges. Members of the staff have presented papers to the Novy Research and Development Clinic, the American Society of Limnology and Oceanography Sixth Conference on Great Lakes Research, and the Atlantic Estuarine Research Society. Members of the staff have contributed or have started articles or material for such publications as the Mariners Weather Log, the American Zoologist, the McGraw-Hill Encyclopedia of Science and Technology Yearbook, a book on hydrospace, and the Hidaka Memorial Volume. The Director and two members of the staff were asked by the American Geophysicai Union to edit technically English translations of three Russian scientific volumes.

Letters have been sent to those government agencies with an interest in oceanography, but which are not sponsors of the NODC, inquiring as to the possibility of their becoming sponsors. By the end of Fiscal Year 1963, three had responded affirmatively. The Coast Guard and the Geological Survey will become sponsors beginning in FY-64, and the Beach Erosion Board will become one of the sponsors of the NODC in FY-65. 
The sponsoring agencies and their representatives on the Interagency Advisory Board are:

ATOMIC ENERGY COMMISSION

Dr. Vincent Schuliz

BUREAU OF COMMERCIAL FISHERIES

Mr. Howard Eckles

COAST AND GEODETIC SURVEY

Dr. Harris B. Stewart, Jr.

NATIONAL SCIENCE FOUNDATION

Dr. John Lyman

NAVAL OCEANOGRAPHIC OFFICE

Mr. Boyd E. Olson

OFFICE OF NAVAL RESEARCH

Dr. Arthur E. Maxwell

WEATHER BUREAU

Mr. Robert Schloemer

NATIONAL ACADEMY OF SCIENCES

Dr. Milner B. Schaefer

Institute of Marine Resources

Dr. Donald Pritchard

The Johns Hopkins University

NATIONAL OCEANOGRAPHIC DATA CENTER

Dr. Woodrow C, Jacobs

Director, ex officio Member of Board 


\section{SUMMARY OF FUNDS}

DATA IN: This is a fiscal summary of funds received and expended in Fiscal Year 1963 covering the normal operating costs required to process oceanographic dato into existing standard holdingrecall systems.

RECEIPTS

Supporting Agency

Atomic Energy Commission

Bureau of Commercial Fisheries

Coast and Geodetic Survey

National Science Foundation

Navy

Weather Bureau

Total Agency Support

Navy (for Facilities and Equipment)

Total

EXPENDITURES

PERSONNEL SERVICES

PERSONNEL BENEFITS

TRAVEL

TRANSPORTATION

RENTALS

PRINTING

CONTRACTUAL SERVICES

\section{SANYO}

Hydro Support (Includes 1401-7070 Exp.) Misc.

ANNUAL
ALLOCATIONS
$\$ 380,300$
36,000
8,300
200
15,700
4,000

$\$ 18,000$

32,834

3,666

$\$ 54,500$

CONTRACTS (Total)

SUPPLIES AND MATERIALS

FACILITIES, HOUSEKEEPING SERVICE

EQUIPMENT

RESERVE

TOTAL

DATA OUT (REIMBURSABLE MONEY) RECEIVED

$\$ 220,234$

19,500

3,000

$\$ 575,400$
SPENT

$\$ 170.720$

Amount of Contribution for FY-63

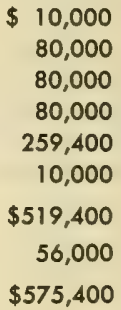

$\begin{array}{cr}\begin{array}{c}\text { GROSS } \\ \text { OBLIGATIONS }\end{array} & \text { BALANCE } \\ \$ 386,531 & \$-6,231 \\ 37,004 & -1,004 \\ 6,963 & 1,337 \\ 315 & -115 \\ 13,735 & 1,965 \\ 4,873 & -873\end{array}$

$\$ 18,000 \$ \$ 00$ $34,042-1,208$

$3,666 \quad 00$

$\$ 55,708 \quad \$-1,208$

$11,048 \quad 2,852$

$32,467 \quad 7,533$

$16,401 \quad 3,099$

3,000

$\$ 565,045$

$\$ 10,355$

CARRIED FORWARD FY-64 $\$ 49,514$ 


\section{POLICY DECISIONS BY THE NODC ADVISORY BOARD FOR FISCAL YEAR 1963}

The following items, quoted or paraphrased from the NODC Advisory Board Minutes, represent the policy decisions made by the Board during FY-63.

At the meeting of 15 January, the Advisory Board decided that it was not mandatory that the Chairmanship and Vice-Chairmanship be rotated each year. Both Chairman and Vice-Chairman may serve consecutive terms.

It was the Advisory Boord's decision at the meeting of 20 July that the reciprocity in dato exchange be left to the discretion of the Director of the World Data Center-A (WDC-A), Oceanography; the Board felt that the distinction between NODC and WDC-A and the respective areas of obligation and responsibility should be clearly set forth by the Intergovernmental Oceanographic Commission (IOC). 


\section{PRODUCTION WORK}

\section{BATHYTHERMOGRAPH DATA ANALOG PRODUCTION}

During Fiscal Year 1963, the NODC received 61,714 bathythermograph (BT) observations. It is estimated that approximately $20 \%$ of these BT's were recieved from ships involved in survey operations.

A total of 12,184 BT observations were processed and archived; 48,736 ozolid analog copies of these data were distributed to the contributors and to others having a standing requirement. Emphasis was placed on the processing of survey and exchange type data primarily because more usable BT data could be archived per man-hour and because a greater percentage of these observations are taken in "sparse data lones."

Processing procedures for BT data were evaluated and revamped in order to increase the processing rate without an undue sacrifice of quality. Indications are that an average of approximately 3,000-4,000 BT observations can be processed (as analog cards) monthly using the revised methods during the first quarter of FY- 64 .

The agreements that the NODC has with Scripps Institution of Oceanography (SIO) and Woods Hole Oceanographic Institution (WHOI) for the exchange of analog BT data continues. However, negotiations were started with SIO to receive their BT dato in a digitized format rather than in the conventional analog form. It is planned to approach WHOI with a similar proposal.

\section{DIGITIZATION}

BT data, as currently archived at the NODC, are at best "unsatisfactory" from the standpoint of usability. These data must be digitized according to the common need of all for efficient utilization by the oceanographic community. Impetus (including funds) for initiating the "standard" digitization of BT data was provided by the Navy Electronics Laboratory (NEL); approximately 40,000 digitized BT observations were requested for an area in the Pacific Ocean. A total of 8,204 was completed; 15,242 additional observations were in different phases of production at the close of the fiscal year.

During FY-63, five unsolicited proposals were received for an automated reader-digitization system; it is anticipated that eight others will be received during July and August 1963 . Full implementation of automated BT processing direct from the slide is planned for Fiscal Year 1964.

\section{OCEANOGRAPHIC STATION DATA}

Oceanographic station data were processed at an average rate of about 1,600 stations per month. The production for Fiscal Year 1963 totaled about 20,000 stations. (Of these 8,000 were coded and keypunched under contract with the Sanyo Surveying Company of Japan, but computed and edited by the NODC.) The NODC Publication M-2, "Processing Physical and Chemical Data from Oceanographic Stations," and new coding forms were used by about 15 domestic and foreign contributors in submitting about 1,500 stations to the NODC for processing; it is hoped that the number of contributors using the new coding forms will increase from about $7 \%$ in $\mathrm{FY}-63$ to $50 \%$ during FY-64.

The archives of ocean station data now totals about 235,000 stations; most of the station data added to the archives were from the Pacific, Indian, and South Atlantic Oceans. Additionally, approximately 25,000 stations for these same oceans were in various phases of completion at the end of the fiscal year. 


\section{MAJOR DATA REQUESTS}

During FY-63, the NODC completed or begon work on ten major $(\$ 2,500$ or more) data requests. These were largely from government agencies which included the Bureau of Commercial Fisheries (BCF), the Navy Electronics Laboratory (NEL), the Naval Underwater Ordnance Station (NUOS), the Naval Oceanographic Office (NAVOCEANO), the Naval Air Development Center (NADC), and the Office of Naval Research (ONR). Private institutions and commercial organizations that made major use of the NODC's data and services consisted of the Scripps Institution of Oceanography, the Raytheon Corporation, and the Martin-Marietta Corporation.

The requirements of all the major requestors made each project mutually beneficial to the requestor and the NODC. The requestor was able to obtain services and data which might not have been available otherwise, and the NODC was able to increase its capability in various phases of data handling and analysis.

Projects summarized below are given by subject rather than individually.

\section{DATA SELECTION}

The requests from the Raytheon Corporation and the Martin-Marietta Corporation required the selection of certain oceanographic station data and special studies of sound velocity. The selection for Martin-Marietta was based on areas which are quasi-homogeneous with respect to oceanographic conditions. The requestor was provided with a listing of stations and special magnetic tapes for further computational work on sound velocity analyses.

For the Raytheon Corporation, selection of data was made by analysis of specific areas with characteristic sound velocity structures; they were provided with listings and punch cards of selected data.

\section{DATA SELECTION AND SPECIAL PROCESSING}

At the request of the Naval Air Development Center (NADC), the NODC has begun a selection of oceanographic stations suitable for sound velocity studies in particular ocean areas. At the end of FY- 63 , the initial data selection was about $30 \%$ complete. After the data selection is completed, graphics will be generated by high speed automated plotting equipment. These graphics will be analyzed to define and delimit oceanic regions with basically similar sound velocity structures.

\section{DATA DIGITIZATION}

In November 1962 the NODC began work in answer to a request from the Naval Electronics Laboratory (NEL) for all available physical and chemical data for the period 1949 through 1959 in specific areas of the Pacific Ocean. Inasmuch as the requirement was for all data to be in digital form, preliminary work was required to develop an adequate "all-purpose" digitization scheme to provide BT data on punch cards rather than in the analeg form.

On the basis of previous studies on digitization by the NODC, it was agreed to record the temperatures from the BT trace at constant intervals of 10 feet or 5 meters. The temperatures were read from the NODC archive analog prints. At the end of FY- 638,204 of approximately 40,000 BT analog prints were coded, digitized, and punch cards and listings delivered.

Other data forwarded in answer to this request consisted of approximately 290,000 punch cards of surface temperature data and about 80,000 cards for approximately 11,000 oceanographic stations. 


\section{DATA ANALYSIS}

A special study begun in FY-62 was continued during FY-63 for the Naval Underwater Ordnance Station (NUOS). This request required the development of special data processing, interpolation, quality control, and computational techniques for oceanographic station data. The NODC has prepared for NUOS numerous special graphs, analyzed plots, and computed products based on 900 oceanographic stations. In addition, the NODC has been analyzing various aspects of the physical environment for this study. A final report on this work request will be submitted to NUOS at the end of the first quarter of FY- 64 .

During the last quarter of FY-63 the NODC was requested by the Bureau of Commercial Fisheries (BCF) to conduct a special analysis of maximum and minimum bottom temperatures on George's Bank. All available oceanographic station, BT, sea surface temperature, and air temperature data were investigated and a search was conducted for descriptive literature on bottom temperatures in the area. Data were selected and plotted on base charts and analyzed for expected maximum and minimum temperatures. The contours which have been constructed will be drafted and these final products and a brief text will be provided to the BCF.

\section{DATA EVALUATION}

During the second quarter of FY-63 the NODC was able to recruit personnel with oceanographic/meteorological background to work on a project requested by the Office of Noval Research (ONR) late in FY-62. The project consists of collecting data from the transmissions of the Navy Oceanographic Meteorological Automatic Device (NOMAD), inspecting and comparing these data with other independent data collections, and evaluating the data for use in oceanographic and meteorological applications.

All the data concerned with NOMAD have been collected, collated, and plotted for analytical purposes. A pilot study has been completed and an evaluation by comparison with independent data is about one-half completed. A final report on the evaluation will be submitted to ONR during the second quarter of FY- 64 .

In addition to the evaluation of the data, the NODC has been requested to provide an "optimum placement of NOMAD buoys" design.

\section{COMPUTER PROGRAMMING}

The Scripps Institution of Oceanography has requested the NODC to develop a computer program for surface current data. This program will summarize the H1-9 surface current data by one-degree squares and month. The computer program will provide resultant vector speed, direction, and the $V_{N}$ and the $V_{E}$ components. The average speed will be computed without consideration of direction. If, however, observations number less than four, only the individual current observations will be printed out.

The program was begun late in June. The work is scheduled for completion in August 1963.

\section{DATA REPRODUCTION}

The Naval Oceanographic Office (NAVOCEANO) has requested a major amount of data for particular ocean areas for various geographic and operational studies. For the Indian Ocean, the NODC has provided the sea, swell, and sea surface temperature data properly arranged for magnetic taping. By the end of FY- 63 approximately one-half of the station data requested had been provided. For a specified area of the Eastern Atlantic the NODC has provided to the NAVOCEANO all BT's (analog), summaries of sea surface temperatures, sea, and swell, and station data for approximately 10,000 stations of 30,000 stations in the area. 


\section{SUMMARY OF ALL DATA REQUESTS}

\section{(REIMBURSABLE WORK)}

During FY 63 , the NODC completed 51 reimbursable requests for data from 25 different activities; 10 additional requests were in work at the close of the fiscal year. In addition, reimbursable funds for such projects as WDC-A, Oceanography, personnel assisting on surveys, and other "special" funds were received. These are not included as "request" items. Funds received for the projects totaled about $\$ 220,000$. This represents a monetary increase of about 10 times the reimbursable monies received for requests in Fiscal Year 1962. The following table shows by percentage the types of services provided.

TABLE 1

\section{SUMMARY OF TYPES OF DATA SERVICES}

\section{TYPE OF SERVICE}

Station Data Reproduction and Search

Data Evaluation and Analysis

BT Search and Reproduction

Combined ( 2 or more types of data for a specified geographic area)

Surface Data Reproduction (Currents, Waves, Sea Surface Temperatures)

Miscellaneous
NO. OF REQUESTS

44

17

13

13

10

3
$\%$ OF TOTAL

DOLLAR RE =EIPTS

(approx.)

\section{2}

56

2

35

4

1

The trend toward more complex analytical or interpretive requests which was expected in Fiscal Year 1962 developed in Fiscal Year 1963; however, the expected diversification in the types of data requests did not materialize. It is expected that as processed geological and biological data become available in future years, requests for these types of data will grow. Reimbursable items received during the Fiscal Year are summarized in Table 2, and completed requests are itemized in Table 3. 
TABLE 2

\section{SUMMARY OF DATA REQUESTS (REIMBURSABLE)}

(July 1962-June 1963)

NO. OF
REQUESTS
CONT TO

Completed

In Work

"Special Projects"

TOTAL

- Carried forward to FY-64
51

$\$ 130,792$

10

* \$49,154

$\$ 40,288$

$\$ 220,234$

"Special Projects" include funds for World Data Center-A, Oceanography; for abstracting and bibliographic work by the American Meteorological Society; and for the training of foreign naval personnel in Data Center procedures.

At its meeting on 16 October 1962 the NODC Avisory Board recognized the desirability of supporting the abstracting of the oceanographic literature as part of an overall data/information retrieval program. After a briefing by Mr. Malcolm Rigby of the American Meteorological Society it was decided to support the Society as the most logical organization to accomplish this work. AEC offered funds for the initial support of this work in FY 1963, providing the work would continue to receive support after FY 1963 in the NODC's regular budget.

The abstracts of the American Meteorological Society are published in Meteorological and Geoastrophysical Abstracts. A special bibliography (including abstracts) on Oceanographic Instrumentation appeared in the April-May 1963 issues. Future issues will contain special bibliographies on the Indian Ocean, Subsurface Currents, and Heat Flow through the Bottom of the Ocean. In addition, oceanographic abstracts appear routinely in each issue.

For a description of the work of World Data Center-A, see pages 20 and 21 . The NSF provides support for this function. 
TABLE 3

DETAILED LIST OF DATA REQUESTS (REIMBURSABLE) BY ACTIVITIES

\section{ACTIVITY}

Raytheon Corporation (Paster)

Bureau of Commercial Fisheries, Sandy Hook, New Jersey

(Walford)

Bureau of Commercial Fisheries, Wushington Laboratory

(Ch:amberlain)

Naval Oceanographic Office

Code 3300

Noval Oceanographic Office

Code 3400

Naval Oceanographic Office

Code 3500

Naval Oceanographic Office

Code 3800

American Miscellaneous Society (Petrie)

Naval Weapons Laboratory

Coast and Geodetic Survey (Starr)

Sikorsky Aircraft Company (Withington)

University of Miami (Burke)

Woods Hole Oceanographic Institution (Yensch)

\author{
TYPE OF DATA \\ AND/OR \\ NO. OF OBS.
}

Sound Velocity Analysis

Temperature and salinity

data-Gulf of Mexico

Maximum \& minimum temperatures George's Bank

Ocean station data; sea and swell listings and punch card reproduction

BT search and reproduction; station data; sea and swell listings; punch cards

Ocean station date and publication listings

Ocean station data publication listings and punch cards; statistical summaries

Wave, wind, temperature data

$\triangle 82$ BT prints in Gulf Stream

Ocean station data listings; listings of Caribbean Geosort

Selected BT dato

Ocean station data

BT and ocean station data

\section{SERVICE PROVIDED}

Computed $V_{f}$ and analysis

Search and reproduction

Research \& analysis

Data reproduction

Search \& reproduction

Data reproduction

Data services and reproduction

Search \& reproduction

Reproduction

Reproduction

Analysis \& reproduction

Sorting \& reproduction

Reproduction 
TABLE 3 (CONT'D)

\section{DETAILED LIST OF DATA REQUESTS (REIMBURSABLE) BY ACTIVITIES}

\section{ACTIVITY}

\section{Colorado State University}

(Riehl)

University of Washington

(Coochman)

Naval Research Laboratory

(Stewart)

Bell Telephone Laboratory

(Taylor)

Naval Electronics Laboratory

San Diego (Anderson)

Lamont Geological Observatory (Donn)

Marine Advisors (Horrer)

Ocean Science and

Engineering, Inc. (Volkmann)

Bureau of Commercial Fisheries, Washington Lab. (Austin)

Martin-Marietta Company (Webb)

American Telephone and Telegraph Company (Magruder)

Lockheed-California Co.

University of Miami (Rinkel)

\section{TYPE OF DATA \\ AND/OR \\ NO. OF OBS.}

5,091 BT prints

Ocean station data and punch cards

Ocean station data

Ocean station data $(1,000$ stations)

Oceanstation and BT data

Ocean station data

Wave roses and wave observations

Surface currents, MS 042 and 079

Ocean station data in ICITA area, 2-part listings

Sound velocity selection; station data for TOTO on magnetic tape

Bottom temperature dato between Vero Beach and St. Thomas

Ocean station data listings and punch cards

Ocean station listings and punch cards of Tropical Atlantic

\section{SERVICE PROVIDED}

Reproduction

Reproduction

Search \& reproduction

Search \& reproduction

Search \& reproduction

Analysis and reproduction

Reproduction

Sorting and reproduction

Reproduction

Analysis and reproduction

Search

Reproduction

Reproduction 


\section{EXCHANGE WORK (Non-Reimbursable)}

The NODC continued to encourage and develop oceanographic data exchange programs with all activities. Punch cards for 5,233 Japanese oceanographic stations were added to the archives of Pacific holdings. Approximately 1,220 stations were forwarded, in publication format, to the International Council for the Exploration of the Sea (ICES) in exchange for receipt of the same data in raw form.

The establishment of data centers in Canada and Australia should facilitate and, to some degree, increase the exchange of data with these countries. It is expected data centers will also be organized in the near future in Japan and Great Britain. Exchange was initiated through World Data Center A (WDC-A) for Oceanography with the International Indian Ocean Expedition (IIOE) and International Investigations of the Tropical Atlantic (ICITA). It is expected that practically all data from international expeditions in the future will be acquired through WDC.A. It is also likely that all oceanographic data for declared national programs from 1960 onwards will be acquired through WDC-A. When this is an officially recognized requirement the work load in WDC-A will probably double.

On 7-10 August 1962, the Intergovernmental Oceanographic Commission (IOC) Working Group on Data Exchange met at the NODC. Dr. Jacobs attended as representative for WDC-A. This meeting and its accomplishments are further discussed under "IGY World Dato Center A, Oceanogrophy" in this report.

Table 5, Detailed List of Data Exchanges, shows the countries and institutions with which NODC exchanged station and bathythermograph data. The cost to NODC is also itemized. It should be pointed out that one of the chief advantages to the exchange program is a financial one; namely, the high ship/observer costs involved to obtain data vs. the low cost to process data taken by and available from others. It has been estimated, for example, that acquisition of station data through the exchange program pays off on a ratio of 100:1 (observing costs: processing costs).

\section{TABLE 4}

\section{SUMMARY OF DATA EXCHANGES}

NO. OF EXCHANGES

9

16

1

GRAND

TOTAL

\section{TYPE OF DATA}

Ocean stations

BT prints

Computed punch cards (stations)

\author{
NO. OF \\ OBSERVATIONS
}

10,973

45,620

5,233

56,593
COST TO NODC

$\$ 649.00$

$2,281.10$

250.00

$\$ 3,180.10$ 


\section{TABLE 5}

\section{DETAILED LIST OF DATA EXCHANGES}

\section{COUNTRY \\ OR \\ ACTIVITY}

Argentina

Canada

Chile

Denmark (ICES)

Great Britain

Japan

New Zealand

Peru

Poland

Union of South Africa

USSR

Venezuela

Yugoslavia

U.S. Coast and Geodetic

Survey

Columbia U. (Hudson Lab.)

Miami, Univ. of

Naval Oceanographic Office
TYPE OF DATA

AND

NO. OF OBS

3,053 stations

5,000 stations

3,312 BT prints

2,210 BT prints

1,220 stations

877 BT prints

3,596 BT prints

5,233 station (punch card)

2,383 BT prints

130 stations

See WDC-A Section (Exchange through WDC-A channel)

178 stations

181 BT prints

See WDC-A Section (Exchange through WDC-A channel)

1,000 stations

See WDC-A Section (Exchange through WDC-A channel)

4,008 BT prints

15 BT prints

33 BT prints

292 stations

7,432 BT prints
75.00

200.00

COST TO NODC

OF

SERVICES PROVIDED

$\$ 270.00$

200.00

165.60

110.50

49.00

44.00

180.00

250.00

119.00

15.00

25.00

9.00

1.00

2.00

12.00

372.00 
TABLE 5 (CONT'D)

\section{DETAILED LIST OF DATA EXCHANGES}

\section{COUNTRY \\ OR} ACTIVITY

\author{
TYPE OF DATA \\ AND \\ NO. OF OBS
}

65 stations

1,408 BT prints

35 stations

2,868 BT prints

90 BT prints

11,092 BT prints

47 BT prints

6,068 BT prints

\section{COST TO NODC \\ OF \\ SERVICES PROVIDED}

2.00

70.00

1.00

143.00

5.00

555.00

2.00

303.00

Woods Hole Oceanographic

Institution

\section{INFORMATIONAL ITEMS (Non-Reimbursable)}

About 460 inquiries requesting small amounts of data, publications, literature data references, and general information queries were answered during the fiscal year and were provided at no cost to the requestor. This represents an increase of about 15 times the number reported for Fiscal Year 1962. Although the majority of these items concern subsurface physical oceanography, nearly all phases of the marine environment are covered.

Data inquiries involving only nominal costs (under $\$ 30$ ) are onswered without reimbursement. 


\section{DEVELOPMENT OF SYSTEMS AND PUNCH CARD FORMATS}

\section{GEOLOGICAL, GEOPHYSICAL, AND BIOLOGICAL DATA}

The investigatory work began in FY-62 concerning possible information and data storage and retrieval systems suitable for adaptation to geological, geophysical, and biological oceanography material continued during FY-63. The status of development follows.

\section{GEOLOGICAL-GEOPHYSICAL DATA}

During FY-63, the geological-geophysical program developed according to guidance by the ad hoc Committee for Geological and Geophysical Data under the chairmanship of Dr. Harris B. Stewart, Jr. The committee indicated that the most valuable initial contribution of NODC would be the development of a system of recording and disseminating information on core, grab, and dredge samples taken by government and non-government institutions with emphasis on non-government sources. Accordingly, NODC submitted for final approval, a master geological station card for core, grab, and dredge data to the ad hoc Committee for Geology. We plan to complete during FY-64 detail cards for specific geological analysis to be tied into the master card.

A master geophysical station card and associated specific analysis cards are being studied; it is hoped that approval of these cards can be obtained early in FY-64.

Collections for a thesourus of geological-geophysical terms for the purpose of developing a non-digital storage and retrieval system have begun but efforts in this direction will not be concentrated until digital procedures are well established.

\section{BIOLOGICAL DATA}

During FY-63, major oceanographic institutions were personally contacted and correspondence was exchanged with interested scientists from the United States and foreign countries with the purpose of establishing punch card formats for several classes of biological data.

Upon receipt of comments and suggestions from the scientific community, NODC presented the following proposed cards to a specially selected ad hoc committee, chaired by Dr. Bostwick $\mathrm{H}$. Ketchum, for review:

1. Identification card (location, vessel, institution, cruise, time, etc.)

2. Station Index card

3. Environmental card

4. Phytoplankton card

5. Primary Productivity and Phytoplankton Pigment card

6. Zooplankton card

7. Benthos card 
The ad hoc committee, which met on 8 March 1963, included the following:

Dr. Bostwick H. Ketchum-Woods Hole Oceanographic Institution

(Chairman)

Dr. Robert J. Menzies-Duke University

Dr. John M. Sieburth-University of Rhode Island

Dr. Donald F. Squires-Smithsonion Institution

Dr. I. Eugene Wallen-Smithsonian Institution

Mrs. Beatrice Burch-Smithsonian Institution

Dr. Milner B. Schaefer-Scripps Institution of Oceanography

Dr. Elbert H. Ahlstrom-Bureau of Commercial Fisheries

Mr. Joseph E. King-Bureau of Commercial Fisheries

Dr. O. E. Sette-Bureau of Commercial Fisheries

Mr. Kenneth W. Kaye-U.S. Naval Oceanographic Office

Dr. Robert Holmes-Scripps Institution of Oceanography

Mr. Thomas Austin-Bureau of Commercial Fisheries

Recommendations of the ad hoc committee included:

1. Development of coding instructions

2. Development of a microbiological card format as outlined by Dr. J. Sieburth

3. Development of preliminary formats for a nekton card, a systematics and biogeographical card, and a bioacoustical card

4. Reconvention of the ad hoc committee to provide further guidance for the NODC biological program

The NODC accomplished some work in the preparation of a thesourus of terms to be used for the retrieval of published and unpublished sources of biological information archived in the NODC. Additionally, at the request of the Atomic Energy Commission, the NODC conducted a survey of the status and availability of radiological data pertaining to marine biota and the marine environment. 


\section{DEVELOPMENT OF SYSTEMS FOR PHYSICAL AND CHEMICAL DATA}

\section{OCEANOGRAPHIC STATION DATA}

Although no new systems per se were developed during FY-63, a letter was sent out on 18 January 1963 inviting certain oceanographers to serve on the NODC ad hoc Committee for Physical and Chemical Data. This committee will be asked to provide advice and guidance on such matters as ice data, current data (both surface and subsurface), surface observations, and the processing of oceanographic data from unmanned buoys.

In conjunction with the International Cooperative Investigations of the Tropical Atlantic (ICITA), the NODC established an experimental communications system during the first phase (EQUALANT I) of this program. Depth, temperature, salinity, and oxygen data were transmitted by radio on a daily basis from the Argentine research vessel COMODORO AUGUSTO LASERRE. The messages were immediately processed and analyzed under simulated conditions of a return message containing completed computed station data with precision evaluations, adequacy of sample spacing, possible station relocation, etc. The success achieved in this system has introduced a number of very interesting possibilities for future investigations in oceanographic data radio transmissions.

A second communication system was attempted which made use of a modified International Ship Weather Code (FM21.A, Surface Report from Ship in Full Form). The goal of this system was the production of synoptic layer depth charts. Unfortunately, due to unforeseen circumstances, only two ships were able to transmit layer depth values.

\section{AUTOMATIC DATA PROCESSING}

During FY-63, new computer programs for processing data into the NODC Oceanographic Station Card were written and are in operation. In addition to the improvements in the punched card for recording station data, several significant improvements were made to the revised IBM 7070 program. A few of these are: interpolation for additional standard depths $(125,700,900,1,100$, $1,300,1,400$, and 1,750 meters); improved modification to the 3-point Lagrange interpolation method to eliminate "nose-outs" (linearly interpolates a section of the curve); sound velocity routine (Wilson's method) was revised to record values in meters/second and also to compute sound velocity starting at any observed depth (surface or subsurface).

A list of computer programs in use at various oceanographic institutions was compiled with the assistance of the EPOC Committee on Machine Processing of Oceanographic Data and disseminated with the June NEWSLETTER. NODC plans to continue this computer program library service on a continuing and improved basis to facilitate communication among oceanographers of the various ADP applications and techniques developed and in use for handling dato.

\section{BATHYTHERMOGRAPH (BT) DATA}

Work continued on the evaluation and validity of BT observational and processing procedures. A comparision was made of various BT digitization schemes as well as a comparison of sea surface BT reference temperatures measured by different instrumentation aboard the same ship. The BT card developed during Fiscal Year 1962 for the digitization of BT data was distributed to the oceanographic community for comments and final approval. These cards presently are being used at the NODC and it is hoped will be used by SIO for their digitization in FY- 64. 


\section{PUBLICATIONS}

NODC Publications in print and available for distribution are as follows:

Publication G.1, Introduction to the National Oceanographic Data Center

Publication G-2, Oceanographic Vessels of the World

Publication M-1, Conversion Tables for Use by the International Indian Ocean Expedition

Publication M-2, Processing Physical and Chemical Data from Oceanographic Stations

Publications in draft are as follows:

Publication C-2, Catalog of BT Data, World Wide (will replace SP-12, Part IIA which is now out of print)

Publication C-3, Catalog of Oceanographic Data, North Atlantic Ocean

Publication C-4, Catalog of Oceanographic Data, Indian Ocean

Publication C-5, Catalog of Oceanographic Data, North Pacific Ocean

Publications in press are as follows:

Publication G-2, Oceanographic Vessels of the World, Vol. II

Publications being reviewed are as follows:

Publication C-1, Reference Sources for Oceanographic Station Data

The NODC NEWSLETTER is now being forwarded to approximately 950 recipients $(1,025$ copies); a gain of 400 over FY-62. There has been continued favorable response to the publication.

A series of Progress Reports is being formulated "in-house" to summarize the more important development and analysis work, and to report on the work status for various major projects and requests placed on NODC. 


\section{IGY WORLD DATA CENTER A, OCEANOGRAPHY}

On 7-10 August 1962, the Intergovernmental Oceanographic Commission (IOC) Working Group on Data Exchange met at the NODC.

Attending were:

Dr. W. S. Wooster

Commodore K. P. Ryzhkov

Dr. P. H. Kutschenreuter

Dr. R. R. Revelle

RADM. E. C. Stephan

Dr. J. R. Rossiter

Dr. J. W. Smed

Dr. W. C. Jacobs
United Nations Educational and Cultural Organization/Intergovernmental

Oceanographic Commission (UNESCO/IOC)

World Data Center-B (WDC-B)

World Meteorological Organization (WMO)

Scientific Committee on Oceanic Research (SCOR)

International Hydrographic Bureau (IHB)

Permanent Service for Mean Sea Level (PSMSL)

International Council for the Exploration of the Sea (ICES)

World Data Center-A (WDC-A)

The Working Group prepared a Provisional Guide for Exchange of Oceanographic Data (NS/1OC/2-5(c)) which was endorsed by the 2nd Session of the 1OC, Paris, 20-28 September 1962 (UNESCO/NS/180). As a result of recommendations of the Working Group and those of the earlier 20-22 June 1962 IOC Working Group meeting at NODC (WP/WDC/62-2/Final, Appendix C), the duties and responsibilities of WDC-A, Oceanography, have been increased to make it the central collection agency for oceanographic data from international programs, currently the International Indian Ocean Expedition (IIOE) and ICITA. Since WDC-A has traditionally handled only processed data far cataloguing and dissemination, the receipt and handling of unprocessed (raw) data, and coordinating the processing of these data, impose additional technical and administrative problems and workloads not heretofore budgeted.

The preliminary draft of the final catalogue of data for the IGY/IGC period; i. e. July 1957December 1959, was received from WDC-B late in December. It required six montbs of intensive work to verify the data holdings, edit the catalogue and prepare 216 pages of typescript copy of text, catalogue materials, charts and indices, for final photo-reproduction and printing as part of the Annals of the International Geophysical Year, Pergamon Press, London.

The 10 th and 11 th 6-monthly catalogues of data were also completed during FY- 63 and forwarded to the WDC-A Coordination Office for printing in the IGY General Report Series. The 10th 6-monthly catalogue was printed and distributed in October 1962, as IGY General Report No. 17. The 11 th 6 -monthly catalogue is currently in press.

During the period 1 July 1962 and 31 December 1962, data for 8,225 stations were provided to WDC-B. 


\section{WDC-A PUBLICATIONS}

No. 1. Atlas of Track Charts of IGY Cruises, Part I; North Atlantic, compiled by J. R. Lumby. 46 Pp., Aug. 1960.

No. 2. Hydrological Observations in the Southern Oceans, compiled by Luis R. A. Capurro. 386 pp., May 1961.

Oceanographic Vessels of the World, compiled by Luis R. A. Capurro, Albert M. Bargeski, and William H. Meyers. Looseleaf, 1961.

No. 3. Oceanographic Observations in the Intertropical Region of the World Ocean, compiled by Luis R. A. Capurro. Part I: Atlantic and Indian Oceans, Parts lla and IIb, Pacific Ocean. September 1961.

No. 4. Productivity Observations in the World Ocean, Part I and Part II, compiled by Maxwell S. Doty and Luis R. A. Capurro. 625 pp., Sept. 1961. 


\section{ADMINISTRATIVE MATTERS}

The NODC started Fiscal Year 1963 with 60 employees and completed the year with 89 full-time employees and 7 part-time employees. The "on board" count at the end of the year included 47 professionals, 18 technicians and scientific support personnel, and 31 administrative, clerical, and other support personnel.

A request has been forwarded to the U. S. Naval Oceanographic Office for the reorganization of the Data Preparation Branch. The reorganization would permit more flexible use of personnel within the Branch and consolidate the work program under the three major subject areas of specialization. The present organization of the Branch has, from the outset, been considered a temporary arrangement; the two sections being incorporated in the Branch as originally approved in January of 1961. The revised arrangement should be better suited to the total obligation of NODC service to the oceanographic community.

Recruitment for Oceanographers (Physical) at the GS-5 through the GS-7 level is very slow due to lack of applicants on existing registers. A more active recruitment program whereby more colleges through the mid-West and West may be contacted has been suggested and will be pursued.

The NODC provided training for several foreign officers during the past year. Among this group were two Chinese officers who worked "on the job training" for seven weeks and received private instruction pertaining to the NODC operation. Numerous briefings were provided Naval Reserve Officers and guest oceanographers.

Two NODC Oceanographers were accepted for a summer course in advanced physical oceanography by Woods Hole Oceanographic Institution. It is hoped that at least one oceanographer will be available to attend this excellent course each summer.

The NODC provided personnel for training purposes on three survey cruises during the year under the supervision of the Naval Oceanographic Office.

The NODC provided pesonnel to assist on the Bureau of Commercial Fisheries Ship GERONIMO for two different cruises during the year. One of these cruises was related to EQUALANT I.

During the year, eleven oceanographers were assigned to the Civil Service Training Agreement Program for oceanographers; all successfully completed the training. Eleven summer students and several new employees (recent graduates) are participating in a 10 -week ( 4 hours/week) orientation course to acquaint them with the oceanographic work being done by the various activities in the Washington crea.

During the year, four physical science technicians were reclassified as oceanographers as a result of their completing additir, nal required studies and course work to meet the qualification requirements.

Approximately 250 visitors from the civilian and Government scientific community were received during the past year. Many of these visitors are renowned scientists; no attempt was made to record the frequent "visitors" from the local activities and laboratories who used the study room facilities (some for an hour, others for several days) to peruse, select, and otherwise use the data available. 


\section{FUTURE PLANS}

\section{DATA OBSERVING AND RECORDING}

Continue development of and promote world-wide use of standard or compatible coding forms and/or cards to expedife automatic processing of data.

Evaluate data output of instruments to provide advice on new instrumentation and choice of instrumentation in view of the precision of the instrument, quality of data obtained from the instrument, and the requirements to be placed on the data.

\section{COMMUNICATIONS}

Expand mechanisms to facilitate the acquisition of all oceanographic data.

Continue data exchange with domestic organizations, international organizations, and future foreign national oceanographic data centers and promote standardization of exchange mechanisms.

Continue function of WDC-A.

Establish effective communication and liaison with oceanographic institutions and orgar.1zations for survey planning, survey operations, and receipt of data.

\section{DATA PROCESSING AND ANALYSIS}

Continue development of NODC standardized processing routines, and storage media, with special emphasis on automation of quality control techniques and integrated data reading computer systems.

Investigate and develop adequacy of present-day statistical techniques in light of future observational procedures and requirements.

Determine the interrelationship of the various processes controlling the marine environment.

Conduct pilot studies and/or special analy ses concerning anticipated oceanographic problems of mutual interest to the oceanographic community.

Using total archives and total computer capability, develop oceanographic control models (selfmodifying) based on basic dynamic oceanographic controls. These will provide a field quality control service as well as NODC quality control.

\section{DATA STORAGE AND RETRIEVAL}

Continue development of holding-recall systems for digital and nondigital data and investigate outomatic indexing and abstracting techniques.

Establish oceanographic systems; e. g., a temperature system. Possible establishment of merged files for particular end products. 


\section{DATA DISPLAY AND REPORTS}

Develop automatic controls for desired data outputs or formats according to specific user requirements.

Investigate and develop data display techniques; e. g., in-line or off-line devices for plotting and/or contouring.

Publish a series of atlases, but give emphasis to the development of the types of charts required; e. g., quasi-isentropic charts. These will be used for in-house quality control and also for the use of the oceanographic community.

Compile and reproduce lists of publications containing information relating to the marine environment; produce series of manuals on data processing techniques and catalogs of holdings; make routine distribution of summarized and analyzed products.

\section{NODC FACILITY AND SERVICES}

Provide specialized personnel for surveys, projects, studies, etc.

Arrange for translation services, manual or automatic.

Establish a computer program library.

Continue and increase NODC's role in participation in National and international expeditions and foster the use of NODC as the clearing house for the National effort in oceanographic data collecfion and the medium of exchange with other national oceanographic centers.

Establish adequate library facilities integrated with the data storage-retrieval system.

Respectfully submitted,

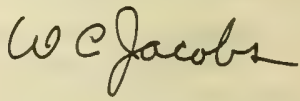

W. C. Jacobs

Director

1 July 1963

Approved by NODC Interagency Advisory Board at meeting of 15 July 1963 


\section{APPENDIX 10}

U.S. OCEANOGRAPHY-A BOLD NEW VENTURE, ARTICLE APPEARING IN THE EXPLORERS JOURNAL, DECEMBER 1963, BY DR. HARRIS B. STEWART, JR., DEPUTY ASSISTANT DIRECTOR, U.S. COAST AND GEODETIC SURVEY, IN THE OFFICE OF OCEANOGRAPHY 

[Explorers Journal, December 1963]

\section{U.S. Oceanography-a Bold New Venture}

(By Harris B. Stewart, Jr.)

While the exploration of space has been getting most of the headlines, an unacclaimed acceleration of the exploration of the world ocean has quietly been taking place. Marine science may lack the appeal to the popular press which has typified our space effort-certainly oceanography would be hard pressed to match the public excitement generated by the manned orbital flights-but those of us involved in oceanography are convinced that the future of man's existence on this planet is inextricably linked to his globe-girding sea. Our utilization of this sea for our economic growth, for the improvement of our general welfare, and perhaps even for our continuation as a species all depends on increasing our basic understanding of the sea, its contents, and the dynamic processes that cause the variations we can measure.

But what of this increased effort in oceanography? What are we actually doing? Perhaps the best way to illustrate the accelerated tempo of our marine exploration is to list several very recent and apparently unrelated events which are in fact part of a carefully worked out plan to provide the knowledge that is needed if we are to understand the ocean in all its magnificent complexity.

This past March the Soviet oceanographic ship Lomonosov rendezvoused with the Explorer of the U.S. Coast and Geodetic Survey along the Equator about midway between South America and Africa. The Soviets had planted a buoy for measuring subsurface currents, but poor visibility prevented them from getting a good position for it. The Americans stayed in the area using the Soviet buoy as a starting point for their own work in tracing the current eastward; and when the skies cleared, they obtained a good position for the buoy and radioed the position verification to the Lomonosov. This was no casual meeting of two scientific ships in midocean. It was instead part of a whole network of operational plans developed at an intergovernmental meeting held the year before at the new National Oceanographic Data Center in Washington, D.C. These two ships were part of an armada of 13 oceanographic ships that were carrying out a detailed synoptic survey of the tropical Atlantic. There were ships from Argentina, Brazil, Congo (Brazzaville), Ivory Coast, U.S.S.R., and the United States all working together on a carefully worked out plan to take a simultaneous look at the structure and properties of the water masses extending across the entire stretch of ocean from Brazil to the Ivory Coast.

This past spring the 2,500-ton Atlantis $I I$, a new oceanographic research ship, was delivered by the National Science Foundation to the Woods Hole Oceanographic Institution. In early July the research vessel Pillsbury, a converted Navy ship, was commissioned by the Marine Laboratory of the University of Miami, and later that same month the keel was laid for the USCGS ship Oceanographer, a 3,800-ton oceanographic ship being built from the keel up specifically for the study of the sea. This ship and her sister ship, the USCGS ship Discoverer, will be the largest oceanographic ships this country has ever built. The Navy has two new ships for marine surveys and research, the Davis and Gillis, and two more are in the early stages of construction. The Bureau of Commercial Fisheries has just recently commissioned the Albatross $I V$ which will do oceanographic work related primarily to fisheries, the University of Rhode Island's Graduate School of Oceanography has a converted Navy ship renamed the Trident which recently completed its maiden oceanographic voyage in the Atlantic, and new oceanographic ships are slated for other U.S. universities carrying out research and teaching in the marine sciences.

In early May four young American Government oceanographers journeyed to Moscow to meet for 4 days with scientists from Argentina, Brazil, Canada, France, Great Britain, Japan, and the U.S.S.R. They were meeting to report on what their respective governments had done on such topics as oceanographic data exchange, standardization and intercalibration of techniques and equipment for oceanography, to discuss international expeditions such as the International Indian Ocean Expedition and the International Cooperative Investigations of the Tropical Atlantic, and to iron out the many difficulties that invariably develop whenever scientists representing different governments try to work out agreements and arrangements to further governmental involvement in international endeavors. This meeting was merely a precursor to the full-scale 
meeting of the Intergovernmental Oceanographic Commission under UNESCO scheduled to be held in Paris next June.

Nothing was printed in the press about the really exciting cooperative expedition in the tropical Atlantic, only the local papers picked up the stories of the various keellavings and ship commissionings, and the one small release from Paris about the Moscow meetings was totally ignored by the wire services. It is little wonder that practically no one is aware of the marine "great awakening" taking place in this country. Even if these various items had received the public notice they deserved, there is little chance that their relevance to an overall scheme would have been apparent. Ye't there is such a scheme, and these events and many others are part of this Nation's bold new venture in oceanography.

Thus the meeting of the Lomonosov and the Explorer in midocean, the construction of new ships for oceanography, and the trip of those four Americans to Moscow were all part of a well thought out and carefully planned program being put forward by the United States to insure that this Nation gets the information it so vitally needs for the full utilization of the world ocean as our last great resource on this earth. This new approach to learning about the ocean is indeed a bold new venture, but it is just getting started. The mechanisms to accomplish the task are newly formed, and scientists and governments are feeling their way slowly-and rightfully so. This is no endeavor to be undertaken on the "crash" basis. New ships must be designed and their construction planned well in advance so that they will be able to do tomorrow's job as well as today's, so that they will not come off the ways any faster than men can be trained to man them and to interpret the data they bring home, and so that their continuing operating costs will not bankrupt the relatively small budget allotted this aspect of the Nation's overall scientific effort. New facilities must be constructed for training and research, and these must be planned at a rate commensurate with the demand for the people they must train. The various research activities should not in any way be controlled by a dictum of the Federal Government, for the very essence of research is the unfettered quest for knowledge, a quest that loses its challenge and with it its effectiveness when it is closely directed. But the research projects underway should have an input to the design of the survey program, the requirements of the researchers must be considered in the design of new ships and in the development of new instruments and equipment, and the researchers must be apprised of work others are doing and of the overall needs of the country in the field of marine science.

The Interagency Committee on Oceanography within the United States and the Intergovernmental Oceanographic Commission on the international level are both currently involved with the formulation of national and international programs in oceanography and with the coordination of the various elements that must work together if the task is to be accomplished successfully. However, the real excitement is in the work at sea. This has begun, but just barely. As the new ships become operational, as new facilities are built to train new scientists in oceanography, and as the research activity is stepped up, then the bold new venture will in fact be well underway.

All of this may sound in'teresting-even if somewhat administrative-but why is the United States so concerned with developing new knowledge about the oceans that a "bold new venture" was necessitated in the first place? Probably it was the report of the National Academy of Sciences Committee on Oceanography entitled "Oceanography-1960-70" that awakened this Government to our real need for an expanded program in the marine sciences. The need, however, had been there for years. Since the publication of the NASCO Report, as it has come to be known, much has been written on the reasons for increasing the U.S. effort in oceanography. However, most of it has appeared in budget justifications for the Federal agencies involved, in reports of congressional committee hearings, or in equally obscure publications. What little has appeared in the popular press has either been overglamorized or else slanted toward the particular aspect in which the writer had a personal interest. Perhaps the reasons why the United States is embarking on an accelerated effort in oceanography can be summarized most briefly as curiosity, economics, and defense.

Man is an innately curious creature, and in an age of general pragmatism we often tend to downgrade sheer curiosity as a legitimate motivation for the actions of men and of nations. Certainly it is this motive, which is primary in attracting scientists to the field of oceanography. Man has been to both poles, 
has conquered Everest, and has penetrated to the remotest portions of the land. Only the oceans are left as the last great unexplored part of the éarth. The fact that knowledge of the seas will be of great value to mankind is probably secondary in the minds of most oceanographers. To them the challenge is the challenge of the unknown, the lure of new discoveries, the chance to glimpse previously unseen things, to learn and through learning to understand things previously unknown. It is the same challenge that caused men to want to reach the poles or find a Northwest Passage, and it is the same challenge that caused their governments to support their endeavors. Bare unrationalized curiosity is indeed a valid motive for an increased program of marine exploration.

But as President Kennedy said in his message to Congress in March of 1961, "Knowledge of the oceans is more than a matter of curiosity." And indeed it is. The United States is seriously deficient in reserves of such strategic resources as manganese, cobalt, nickel, and copper. Yet we know that these very minerals are to be found in profusion as potato-shaped concretions littering parts of the ocean floor. These so-called manganese nodules have been dredged up from depths generally on the order of 1 to 2 miles, and assays of their mineral content show them to be high in just these metals. The questions now are how extensive are these deposits and how do we get them up and recover the minerals. But these are only a few of the minerals found on the ocean floor Diamonds are now being dredged from the sea floor off South Africa, a lease for the recovery of phosphorite has recently been granted off the coast of California, and one for the recovery of gold has been let off the mouth of an Alaskan river known to contain gold-bearing gravels. These, however, are merely exploitation of minerals on or in the sea floor. Sea water itself has been described as a dilute solution of almost everything, and the definition is not too far from the truth. The salts of the sea have been recovered through evaporation since before the Christian era. More recently magnesium and bromíne have been commercially extracted from sea water. More minerals are there, it is primarily a question of determining how they can be concentrated and recovered cheaper than they can be obtained on land. The living resources of the sea have been used since man first tasted fish and found that it was good. But when people are dying of malnutrition anywhere on earth, the marine food resources are obviously not being adequately utilized. Man is still a hunter in the seas. It is not until he is able to pass out of the hunting stage and into the farming stage that he will be utilizing the marine food resources to the utmost. The word "aguaculture" is new to our vocabulary now, but with sufficient knowledge of the interrelationships between oceanic food stocks and their environment, it may indeed be possible to raise fish as we now raise livestock on land.

Seventy-one percent of the incoming solar radiation falls on the surface of the sea. Because we as yet know so little of the heat budget of the oceans, we know little of the quantitative role of the sea in the generation of our weather and climate. Currently weather forecasts for 2 or 3 days in advance are possible, but if the total role of the air-sea interaction in the generation of our weather were known, it is highly probable that the weather could be predicted far in advance. Perhaps we could even cause Mark 'Twain's famous statement to be changed to read: "Everybody talks about the weather, and at last somebody is doing something about it." This is not so farfetched as it at first might seem. It has been proposed, for example, that large barges carrying nuclear powered heat generators be anchored awash off the coast of California near Los Angeles. The rising moist warm air would move eastward with the prevailing westerlies, would be forced upward over the California mountains, be cooled below the dew point, and drop much needed rain on parched southern California. At the same time, the circulation generated by the rising air over the barges would pull the smog-filled air out of the Los Angeles basin leaving that city with the constant view of the Santa Ynez, San Gabriel and San Bernadino Mountains it once had. Sea bottom atomic generators could be utilized to create rising ocean currents in coastal areas. Not only would this affect the local climate, but also it would cause an upwelling of the nutrient-rich bottom waters to act as a fertilizer for the local fishing industry. Such schemes obviously cannot even be considered until we know a great deal more about the oceans than we now do. Such hot air generators or upwelling machines might do much more harm than good. The point to be made is that if we ever expect to utilize advanced ideas such as these, we must first have the basic oceanographic knowledge to predict accurately what will happen once they are put into operation. Such knowledge does not yet exist. 
Nature has a way of making fools of men who tamper with her without first arming themselves with knowledge of her reactions.

Improvements of transportation, protection against coastal erosion, improved ship design, protection of life and property at sea, better marine navigation through better charts, protection against natural hazards such as seismic sea waves (the misnamed "tidal waves"), marine storms, coastal flooding, and icebergs, all of these things depend for their final solution on increased knowledge of the ocean and the processes that go on within it. These are mainly economic benefits that can be expected from an increased effort in oceonography.

Perhaps the most apparent aspect of oceanography, and certainly the aspect currently capable of obtaining the most support, is that of military defense. In any conflict, the side that is most familiar with the environment in which the fighting is taking place has a decided advantage over the other. It is primarily for this reason that the Navy is supporting a strong and diversified effort in marine science. More specifically, the effort is related to hiding our submarines and finding those of a hostile porver, to having our ships equipped with the best knowledge and predictions of the marine conditions they will encounter, having our naval forces utilize the sea to their advantage and to the disadvantage of any antagonist. Since any future conflict will in large part be waged over, on, and under the sea, it is imperative that the United States know more about the sea than anyone else. It is that simple and that urgent.

The point to be made from all this is that man has at last come to realize the importance of knowledge of the sea to his future survival. Within the United States we have made our first attempt to establish a program whereby this knowledge will be realized effectively and efficiently. The bold new venture has in fact commenced. 


\section{APPENDIX 11}

MAN AND THE SEA, BY JOEL W. HEDGPETH. A SERIES

OF LECTURES DELIVERED OVER KPFA, BERKELET, CALIF., APRIL 7-13, 1964 

Man and the Sea

by

Joel W. Hedgpeth

A series of lectures delivered over KPFA,

Berkeley, California, April 7 - 13, 1964

Distributed by Pacific Marine Station

Dillon Beach, California 
On the Pacific coast of North America, from Juneau to Ensenada, there are some fifteen establishments which in one way or another are known as marine biological stations. Some of these operate all year, others open their doors only in the sumer time. In the North America alone there are at least 34 marine laboratories associated with Universities. What goes on at these stations? Why are they where they are--or, why do we have these institutions? These are anong the many questions asked by interested visitors to marine laboratories, and the announcements that there is to be a new marine laboratory at Bodega Head and that there are plans for a biggest and best one on Catalina Island have stirred up more public interest. Sometimes there are strange notions about the work done at marine laboratories--something mysterious is being done with starfish or crabs or something like that--or the comically serious notion that rats were being raised for scientific torture in the basement at Stanfords Hopkins Marine Station at Pacific Grove. We say this rumor was comically serious because while it did suggest some misunderstanding of the activities at Pacific Grove, the most casual inquiry would have revealed that there is no basement at Hopkins anyhow.

To answer such questions as what marine biology is all about and why people work at marine stations, it seems best to go back to the beginnings with a little history of marine biology and marine stations.

Marine stations, as places-usually some building or another, of course at some seaside location, are not very old. The first one was started about 1859 at Concarneau in France, and is still going. We always say that Aristotle was the first marine biologist, and of course he was, and Charles Singer, the great historian of science, wrote an imaginative description of Aristotle at work:

n---we see Aristotle, the first and in many ways the greatest of all naturalists, actually watching the creatures he loves. He is leaning out of a boat in the great gulf that indents the Island of Lesbos, intent on what is going on at the bottom of the shallow water. In the bright sun, and in the still, clear water of the Mediterranean every detail, every movement, can be discerned. Hour after hour he lies there, motionless, watching, absorbed, and he has left for us his imperishable account of the things that he has seen with his own eyes."

It is to be noted that Aristotle did not use a microscope; another part of the description should also be noted--undoubtedly Aristotle spent a lot of time observing -- just looking. Too often our modern biologists don't spend enough time in just looking.

Marine biology -- and many other branches of biology, did not really become a serious field of inquiry until the invention of the microscope -- the first good lens systems for microscopes were invented around 1827 and it was not until a few years after that that microscopes became generally available.

One of the first people to make use of such an instrument was evidently a medical inspector at Cork, Ireland, J. Vaughan Thompson. We actually do not know much about this man, other than that he was an army surgeon for many years, who was obviously at heart a naturalist. Between 1823 and 1830 Vaughan Thompson published four papers at his own expense. He worked out the life cycles of 
barnacles, crabs and hydroids -- these latter are related to sea anemones. To do this he not only used a microscope, he also used a net of fine silk towed through the water to capture the minute immature or larval forms of these organisms. Thus was born the plankton net, still the indispensable apparatus for capturing the minute life of the sea. Some professional scientists did not think too highly of this work -- he was not, as the saying goes, "a man of authority".

The man of authority, who got credit for devising the plankton net, was Johannes Muller, the Professor at Berlin. It was Johannes Muller who set the pattern for trips to the seashore for the study of material, and who advocated the establishment of marine stations. It is often said that Johannes Millier was one of the last great universal naturalists, who tried to keep up with everything and it is suspected that he died in 1858 from what we would call an overdose of sleeping pills. Be that as it may, Millier should be remembered for one endearing gesture -- in his later years, distressed by his doctoral dissertation, he would steal copies back from library shelves and destroy them.

Vaughan Thompson was a highly competent amateur, and Mulller was a marine biologist because he was a universal naturalist. The first professional marine biologist, who worked with the creatures of the sea exclusively, was Edward Forbes, the Manx naturalist who lived from 1815 to 1854 . His posthumously published Natural History of the European Seas was the first book on marine biology as such.

At the same time a contemporary of Forbes, Philip Henry Gosse (1801-1888) published some of the first popular books on seashore life -- thus starting that type of book that has done so much to attract people of all ages and interests to the sea shore. His books set a fashion in England (and there were similar books by Frenchman and Germans) that stimulated an amateur enthusiasm that has never waned. One must remember another economic factor -- just as the microscope made many studies of seashore life possible, so the building of railroads made it possible for people to reach the shore easily -- and what may be more significant, return in good time to their homes with their specimens. For a while it seemed that no well ordered Victorian parlour was complete without a marine aquarium, and young gentlemen accompanied their ladies to the seashore armed with a handbook to seaweeds or zoophytes and spent the outing learning the names for their mutual edificatioi. There wasn't much else that could be done in those innocent days, evidently.

Some idea of the lengths to which this passion for seashore studies could go can be had from on George Henry Lewes, best remembered by posterity as the principal man in George Eliot's life. In a book titled "Seaside studies at Ilfracombe, Tenby and the Scilly Isles and Jersey", published in 1858, we find this passage:

\footnotetext{
"The fact is, the sea is a passion. Its fascination, like all true fascination, makes us reckless of consequences. The sea is like a woman; she lures us and we run madly after her; she ill uses us, and we adore her; heautiful, capricious, tender and terrible! There is no satiety in this love; there never is satiety in true affection. The sea is the first thing which meets my eyes in the morning, placidly suming herself under my window; her many voices beckoning me, her gently heaving breast alluring me, her face beaming with unutterable delight. All through the day I wanton with her; and the last thing at night, I see the long shimmering track of light from the distant beacon
} 


\begin{abstract}
thrown across her tranquil surface -- dark now, and solemn, made more desolate by the dark and silent hulls of anchored vessels, but beautiful even in her somber and forlorn conditinn. I hear her mighty sighs answering the wailing night winds. She lures me to her. I cannot go to bed."
\end{abstract}

One wonders what George Eliot thought of this passage, written a few years after they ran off together. So much for $\mathrm{Mr}$. Lewes, who was actually a rather good physiologist -- he was not alone as a master of the purple passage -- for as recently as a year or so ago an eminent witness before a congressional committee described the ocean as the placental fluid of the globe. Perhaps a better quotation to remember our Victorian forkears by is that of the Reverend $\mathrm{Mr}$. George Tugwell -- one of several reverend gentlemen who became enthusiastic students of seashore life and authors of books about it -- the Rev. Mir. Tugwell remarked in his little book about the English sea anemones: "But I must add as we stroll homeward, that one great benefit to be derived from the pursuit of natural history at the seaside, is the intense relief and the renewed buoyancy which it grants to a mind wearied and overtasked by the realities of daily life. $M$

Who, in this time of overcrowded daily life, has stated the justification better for such an enterprise as the Pt. Reyes National Seashore?

But let us get back to marine stations and their reasons for existance.

The first impetus for the establishment of marine stations was the great interest in learning more about the plants and animals of the sea, many of them too delicate to be transported away from shore. The early studies soon brought forth much evidence, especially through the identification of developing stages, concerning the relationships of the major groups of animals we call phyla. Most of these major groups are best represented in the sea, and some of them like starfishes and their relatives, occur nowhere else. From the beginning marine stations became necessary adjuncts to university training in zoology, and most of them still serve this function. Many inland institutions require the degree candidates in zoology undergo at least one exposure to seashore life, and the sumer enroliment of virtually all marine stations in the United States is filled because of the demand for courses by students from all over the country.

In Sweden this requirement is applied to those who wish to become high school biology teachers -- every candidate must take a course at a marine station. Perhaps we will come to this someday.

But also from the beginning there was a practical motivation for marine stations as well -- the need to understand and improve fisheries and the culture of marine organisms for food. The oldest still functioning marine laboratory, that at Concarneau, was established to study oysters.

Probably the classical laboratory in the sense of pure science is that at Naples, established in 1874 by Anton Dohrn, a german professor. Dohrn started his study of marine life at Helgoland, but after being nearly drowned in a storm, sought a more kindly climate. The Naples station established on an international basis, and is still essentially an international station, receiving some of its support from the United States. People go there to study particular animals and plants, follow specific lines of study such as the function of squid nerves or the learning behavior of the octopus, and the station is still essentially an international service institution. One rents a "table" which may actually be a 
small room, and makes his needs known. The scientific fishermen associated with the station usually manage to have the needed animals waiting for the investigator the next morning. One of the early fishermen for the station became so interested that he developed into a first rate speçialist in his own right - Salvatore lo Bionco. A season at Naples is considered an essential part of the life of marine biologists, and there are few who have not done some research at the famous Stazione Zoologica.

\section{There is only one such station as Naples.}

About ten years after the establishment of Naples the English established The Laboratory at PIynouth. As to be expected, this was peculiarly British, and from its inception, was a mingling of pure and applied science, for one of the patrons was the Royal Fishmonger's Company. Until the last few years, there was no large permanent staff at Naples, but Plymouth has always had resident naturalists, who have worked on problems of fisheries, interrelations of plants and animals in the sea and similar problems which are considered by many to be the stuff of marine biology. The Staff at PIymouth numbers 17 or 20 resident scientists at this time, exploring not only the venerable classical lines of zoology at the seasizure, but the problems of life in the sea.

In 1886 the principal marine laboratory in North America was established at Woods Hole. This was actually the successor of sumer seaside laboratories started by Louis Agassiz -- perhaps at the instigation of a geologist, Nathaniel Southgate Shaler, a decade or so before. Woods Hole again is a different institutition administered by a private corporation and not directly affiliated with any single university, although students and faculty members from many universities go there during the summer. The summer population consists of hundreds of people. The rest of the year the great buildings are for the most part nnoccupied, although this last year a resident staff was added to undertake studies of the abundances and changes of marine life in the area and to continue the still incompleted task of systematics -- identifying and cataloging the kinds of animals and plants.

Woods Hole has become so crowded that serious consideration has heen given to the idea of a "Woods Hole of the Westi. There are many advantages to the Woods Hole idea, especially the opportunity for investigators to meet and exchange ideas -- although some of them do not study marine organisms at all, but there is also some concern about the advisability of another such establishment which would have so much unoccupied space for a large part of the year.

The nearest counterpart to Woods Hole on the Pacific Coast is the Friday Harbor Laboratory of the University of Washington, located on San Juan island in Pugest Sound. This is actually the second marine station to be established on the Pacific coast, founded about nine years later than the Hopkins Marine Station of Stanford University at Pacific Grove. The original idea behind this station was somewhat similar to that of Woods Hole, -- it was to be a joint enterprise of several institutions. However, it is now essentially a part of the zoology department of the University of Washington. Unfortunately its incular location has made it difficult to undertake year round operations, and it remains primarily a sumer teaching and research station.

Stanford's marime station, founded in 1892, is a year round station. This laboratory has a permanent staff of half a dozen investigators and has recently gone to sea in a spectacular way with the TeVega, a sort of scientific school ship for marine biologists. Currently in the Indian Ocean, TeVega carries a dozen 
students who take course work en route and participate in the first hand experience of working at sea.

We could go on with an itemized list of our Pacific coast marine stations, but in so doing it would be easy to lose sight of the essentials. Marine stations are where they are for several reasons -- usually the location is the best available one nearest the main base - - be it university or fisheries board -- that shows most promise of remaining in a reasonably undisturbed condition. Friday Harbor, for example, is a secluded region with many kinds of organisms and several kinds of environments - muddy, sandy and rocky bottoms, and not too remote from Seattle. It has no open, wave swept shores. The laboratories at Charleston Oregon and Dillon Beach were located at those localities because of the accessibility of several basic kinds of sea and shore environments. Some laboratories, located many years ago, now find themselves surrounded by towns - these are Hoplins, Cal Tech's lab at Corona del Mar and the great Scripps Institution of Oceanography at Ia Jolla. But one way or another all afford scientific access to the sea, and to as diversified suite of environments and organisms as possible.

Let us return to the subject of marine biology. While each station serves a slightly differert, nurpose, depending on the institution that supports it and the people that stail, all have one common aim: to gain a better understanding of the organisms and the nrocesses of the sea. It might be remarked that this does not sound very different from oceanography, but there are differences. Marine biologists at marine stations do not necessarily go to sea, and marine biological stations do not depend on large vessels, nor are they involved in major expeditions. The line cannot always be clearly drawn between marine biology and what some people regard as biolopical oceanography, nor should it be. But for the most part the scientific effort at marine biological stations is related to the shore and shallow sea, and to the phenomena of organisms that happen to live in the sea. They work from the shore whereas oceanographers work from the sea.

There is work enough for everyone - or, we should say, questions for all. One of the principal questions is how -.- and how much do the animals of the sea eat? It is not easy to examine this question on ship board, as precise measurements have to be made not only of microscopically small amounts of food material, but of the amount of oxygen consumed, and carbon dioxide give off, and so on. We have a pretty good idea how much grain it takes to produce a hog for market, or how much fertilzer we must use to grow corn in Iowa, but we know virtually nothing about such matters for the fish, crabs and mollusks of the sea which are major contributors to our fisheries, to say nothing of all the diverse inedible or uneaten organisms along the shore. But we must understand these processes if we are to get anywhere with increasing our harvest of the sea. In recent years we have become aware that our capacity to pollute our environment has increased ten or perhaps a hundredfold in the last twenty years, and we have found detergents in fish livers at sea and radioactive isotopes in oysters far from the sources of the pollution. So we must know much more about how organisms feed in the sea and how various kinds of substances are transferred from one organism to another.

Some of this work is carried on by establishments supported by such organizations as the United States Fish and Wildlife service, but the economic - or practical - orientation of such laboratories often allows little time for the study of problems whose immediate application to the economic problem is not apparent. It is often from disinterested or uneconomic - if we may use the word in that sense - questions that unexpectedly useful knowledge may come. 
A famous example of this is the study of the poisonous nature of the Portuguese man-of-war. The French researcher Richet, who was a guest of the Prince of Monaco, was curious about the nature of this poison, and made tests on various animals. He found that sometimes there was no effect until the second test, and thereby discovered twe phenomenon of allergy -- which he called anaphylaxis. And who isn't allergic to something or another these days? This is also one of the few discoveries in marine biology to be honored on a postage stamp.

The study of sea urchin eggs -- a perennial favorite for the summer habituees of Woods Hole -- and of Bodega to be, no doubt, has yielded much significant information about the fertilization process -- in fact a current school movie on sex for teen agers shows the fertilization of sea uchin eggs in lieu of the human process -- without, it must be said, making it clear that they are not watching the beginning of human babies. Somewhere in the study of sea urchin embryology may lie a Nobel prize, but in the meanwhile we have leamed much about the initial stages of development from this line of inquiry.

Other marine biologists study nerves of squid -n which has some of the largest of all known nerves -- giant telegraph systems that enable the animal to react swiftly, as anyone who has observed squid in an aquarium will remember. Such studies give us insight into the mechanism of nerves -- how they work. Still other marine biologists are interested in the ways by which marine and brackish water organisms -- the creatures of bays and river mouths -- can adjust their salt balance to the changing environment.

As for the plants of the sea, they present many fascinating problems. We have all heard of chlorophyll, perhaps as something that is used to make green toothpaste. But there are different kinds of chlorophyll in different kinds of seaweed, wich may have something to do with the circumstance that some kinds of seaweed grow best near high tide while others grow only beneath low tide levels. The efficiencies of these substances is a question of particular interest to those concerned with harvesting seaweeds or hoping to understand the efficiency of the plants of the sea as converters of energy.

These are some of the studies that go on at marine stations. Others are concerned with the more general aspects of the plants and animals in the artual environment -- the broad field known as ecology. Surprisingly little has yet been done on the year to year changes in life along the seashore which may in turn help us understand such spectacular changes as the great sardine collapse of two decades ago, but beginnings of this sort of study have been made at Pacific Marine Station in Tomales Bay and have just been startan nt, Bodega. Without such long range studies we cannot really say what the effects of man's tampering with nature may be.

In these days of governmental support of science, many organizations are actively interested in supporting and fostering marine biological studies at marine stations and university laboratories. Although its primary concern is the application of information to naval problems, the Office of llaval Research has supported many projects which might be considered pure science in addition to supporting research on the habits of creatures that destroy pilings and docks and foul ships and buoys. The navy's interest in developing artificial breathing systems for people and submarines has led to the support of studies of respiration in gills in marine organisms and even such matters as how some types of jellyfish maintain gas in floats. The ability of many marine animals - shrimp, fish, and whales to produce sounds, some of which sound like machinery, is inter- 
esting in their own right, is somewhat disturbing to the navy. One interesting byproduct of the study of sounds is a record of the various squeaks, rattles and whistlings made by the different kinds of whales and porpoises. Yet, in spite of its concern for practical problems, the Office of Naval Research is one of the most enlightened supporters of research in the sea for its own sake. Research for its own sake is often called "basic research" ... perhaps it would be better to characterize it as inquiry into phenomena without a goal of immediate and specific practical application.

In recent years the Atomic Energy Comission has become an active supporter of such research, especially in ecology, since it has become obvious that if we are to increase our use of radioactive materials, we need to know much more about the present environment of coastal waters in particular. One of the greatest gaps in our knowledge is that of the genetics of marine organisms -- what characters may be inherited and the mechanisms involved. A modest beginning has been made in this.field by Victor I. Loosanoff with clams, but until we know much more about the genetics of marine organisms, we are not prepared for the atomic age.

Other agencies, such as the National Science Foundation and National Institutes of Health, support many specific projects in marine biology.

Indeed, the present support and future of marine biology seem to be ahead of the recruitment of able workers. In 1961 over 250 students were turned away from marine laboratories because there was not space enough for them, and 88 were unable to find financing to continue their studies. It is also interesting to note that more than 600 were rejected because of lack of qualification for graduate study - inadequate scholarship is probably the greatest single reason for this rejection. The many young people who have been inspired by films, television and popular articles on marine biology should ponder this unfortunate circumstance, and remember that as in all other fields, the competition is getting rougher every day. But for those who survive, there are few more rewarding careers (except perhaps in actual money) than to be the member of a staff at a marine station -- providing of course that you love the sea and the smell of the shore at low tide and the salt water gurgling gently through your laboratory.

Joel W. Hedgpeth 


\section{Oceanography}

Oceanography, the scientific study of the seas and of all that is in and beneath them, is comparatively recent as a formal branch of science. Although mankind has been interested in the sea since before the days of Aristotle, and oceanographic ships have been exploring the seas now for ninety odd years, it. is only in the last twenty years that the study of the seas has become a daily way of life for so many scientists and that this endeavor has been supported on such a large scale by governments and universities. Whether or not this support is adequate for the problems that confront man in his hopes for understanding and utilizing the seas is a matter to be taken up later in this series. In any event, growth of interest in and activity in oceanography has been exponential in the past two decades. There are many reasons for this -- some of them related to the war, and the need at that time to understand waves and currents along strange tropical shores, some of them related to the increasing concern over the future of major oceanic fisheries and not least to the increasing popular interest inspired by such inventions as the self contained diving apparatus, which some call aqua lung and others know by its unlovely acronym SCUBA -..- short for self contained underwater breathing apparatus -- and the atomic submarines that may move about like fish, almost perpetually beneath the surface.

Today, more people than ever seem to be interested in knowing something about the ocean and about the ways that it is being studied by scientists. Now and then we get the impression that some of these people think the oceanographer -- or oceanologist, as some would call him -- is a different and unique kind of scientist following a very special sort of science only slightly less mysterious than atomic physics. No one has ever defined oceanography in a way that satisfies most oceanographers, because oceangraphy is really not a science in its own right, dealing with a limited suite of phenomena, but simply the scientific study of the ocean and its physical and biological contents. Specialists in many different disciplines are oceanographers -- mathematicians who derive equations for wave patterns or analyse tides, biologists who study the abundance and distribution of plankton - the floating life of the sea - geologists who analyse the composition of the mud at the bottom, and the man who tows a sea going tape recorder through a herd of whales to record their conversation. AIl these and many others are oceanographers, and some of them do not understand what the others are up to. But they all have one tining in common -- they go to sea for their data.

We usually date the formal beginning of oceanography as Dec. 30 1872, when Her Majesty's Ship Challenger made her first station after leaving Portsmovth on a cruise that was to last more than three years and circumnavigate the globe... A station, incidentally, is simply a spot at which observations are made -- in this case, at Iat $41^{\circ} 57^{\prime} \mathrm{N}$, Long $9^{\circ} 42^{\prime} \mathrm{W}$. The depth was 71.25 fathoms. Nothing very remarkable was discovered as the dredge did not work quite right and came up half empty - but with enough ice cold bottom mud nevertheless to chill a bottle of champagne to drink to the success of the expedition.

What did we know about the oceans in 1872 that prompted such an expedition? It must not be forgotten that this was not an expedition to chart passages and shoals and rocks for commerce, although some of that work was done, nor was it an expedition to find new lands for the Crown, for there were no unknown lands left. Nor did anyone expect to find fold, spices or other such things. This was an expedition -- and the first such -- sent out to satisfy the curiosity of man. 
Exploration of the seas of course did not begin abruptly with the cruise of the Challenger - for almost twenty years jefore 1872 British and Scandanavian naturalists had been dredging in deeper and deeper water to find strange and unknown animals. One of the greatest marine naturalists was Edward Forbes - or $4 \mathrm{~B}^{\prime} \mathrm{s}$, as he pronounced his name. Forbes studied the waters of the Aegean Sea, but was unable to find anything on the bottom below about 300 fathoms -- 1800 feet, and postulated there was no life on the sea at depths. This of course stimulated others to go deeper and deeper. At this time, in the mid 19th century a new piece of apparatus was developed that made study of the deep sea possible -- the steam donkey engine. Fishermen were quick to adapt this engine to the hauling of larger nets. It was a successor of Forbes. C. Wyville Thomson, who became the prime mover for the study of the deepest parts of the ocean. It was his enthusiasm from the British admiralty, which made survey ships available to him -- vessels named H. M. S Lightning and Porcupine, for the study of the waters north of Scotland.

It was soon apparent that some sort of life was to be found at all depths that could be reached by the bulky rope hawsers and donkey engines of the day, and further questions concerning the oceans were aroused by these preliminary studies carried out during the late 1860's. Furthermore, the advent of steam power to the fisheries greatly increased the haul of fish from the sea, and the beginning of telegraphic communication made it necessary to understand more about the nature of the bottom of the sea, across which the cables must be laid.

Thus was born the Challenger expedition. Although the name of the vessel was singularly apt, it does not appear that the ship was selected because of its name, but because it was available and suitable for the purpose. The Challenger was an early version of a surplus naval vessel, so many of which are now in use as oceanographic vessels in this country. She was a steam corvette, displacing 2,300 tons, which is about equal to some of the medium sized oceanographic vessels now in use, such as the Chain at Woods Hole and the Argo of Scripps Institution. Sixteen of the ships 1868 pound guns were removed and the ship was converted for use of a floating laboratory. While the officers and crew were regular navy, considerable care was taken to select officers with surveying experience and interest in scientific matters. The Scientific staff consisted of six persons, including the director, C. Wyville Thomson, and the staff artist. Only one of this staff, the german biologist Willemoes-Suhm, had the doctor's degree. The man who was selected at the last minute after another candidate could not accept, became one of the great names in Oceanography. This was John Murray, who succeeded Wyville Thomson as direetor of the collections and studies and saw the publication of results through to a successful conclusion in 1895 , twenty years after the completion of the voyage.

When she returned from her long cruise in the cause of science, the Challenger was decommissioned, and ended up ingloriously as a coal barge. However, her name has been revived from time to time for survey ships, although currently no ship by the name of Challenger is in the oceanographic register.

The Challenger spent more than three years at sea, returning to England on May 24 1876. It was a long and fruitful voyage, expecially for the scientific staff -- except for the loss of Willemoes Suhm, who died at sea. Wyville Thomson survived the expedition by several years, and the remaining young men went on to distinguished and fruitful careers -- John Murray as director of the Challenger Office in Edinburgh, J Y Buchanan the chemist as oceanographer to the Prince of Monaco (in those days the prince of Monaco was a great patron of oceanography), 
and H N Moseley became Professor at Oxford. Moseley, the son of a mathematician, became an eminent zoologist and one of the founders of the Harine Biological Association of the United Kingdom. It was his son, H. G. J. Moseley who was considered one of the most promising young men of his generation -. in his twenties he determined that the properties of the atom were determined by its nuclear charge. The loss of this young man at the age of 27 in the Gallipoli campaign may have delayed the atomic age by a generation -- certainly this loss had much to do with deferment policies for men of science in the second world war.

The Challenger's track included two crossings of the North Atlantic, a meandering line down the south Atlantic and across to the Cape of Good Hope, Thence to Kerguelen Island and to the edge of the Antarctic continent, north to Australia, through the East Indies, north to Japan and across the north Pacific to the Hawaiian Islands and southward to Chile, around the horn and back through the Atlantic to England. In all, the Challenger logged 68,890 nautical miles on her cruise. For some reason the Challenger did not touch any Unjted States port. In this long cruise she made 362 official stations, lost about 28 thermometers and broke her dredging line eleven times. This is a remarkable record, not often equalled by modern research vessels.

What were the questions that the men of the Challenger - and those who stayed at home - hoped to find answers for in their long exploration of the deeps? First, no one knew how deep the ocean was, or what was on its bottom. It was thought that perhaps the great chalk formation of the Cretaceous period was being actively formed nowadays at the bottom by the activity of organisms -- this idea was known as "the continuity of the chalk" Then it was hoped by some that the expedition would finc in the great deeps the survivors of the past -- the trilobites and primitive echinoderms of the paleozoic times, and there was Bathybius, the primordial life substance, a sort of giant amoeba like creature that had been found in the sediment samples made by some of early telegraph cable survey ships. Professor Huxley had named this creature Bathybius haeckeli for his eminent German colleague and there was lively anticipation by some naturalists that this organism might be found in abundance at the bottom. Among the other questions was that concerning the nature of sea water itself -- whether it was uniform the world over, or differed from place to place. But most of all the question was -.- what was on the bottom of the sea?

To answer these questions the Challenger dredged the bottom by dragging a net modified from commercial fishing gear, dropped long sounding lines to the bottom, captured water from the depths and took its temperature.

The Challenger found that there was life at the bottom almost everywhere, although she did not achieve the greatest depths -- these were not dragged until 1950 or so by the Galathea - that bottom temperatures were uniformly old, and that sea water was pretty much the same everywhere. No living fossils were discovered - no trilobites or other now extinct forms. Bathybius was never found -- the chemist discovered that Bathybius was a colloidal precipitate of impure sulphate of lime in sea water and bottom mud from the interaction of preserving alcohol and sediment. Thus Bathybius turned out to be an error - as Huxley remarked, it had not fulfilled the promise of its youth. Nevertheless, as the chemist Buchanan said in his report on the true nature of this mysterious primordial plasm, it "should not be allowed to pass into oblivion". Like Forbes" notion of the lifeless nature of the deep sea, it was an error that stimulated thought and research. It does not necessarily follow, of course, that bad ideas are better than good ones, but sometimes a bad idea is better than none at all. Unfortu- 
nately some people -- especially brash young one trying to get ahead -- get the notion that they should produce ideas and theories without foundation simply to stir things up. The lesson to be learned from the examples of the lifeless deeps and bathybius is that there was some evidence at the time for these ideas, enough evidence in fact to justify more careful investigation.

One of the major contributions of the Challenger expedition was the report on the sediments -- in which the broad outlines of the deep sea deposits were determined -. and the doctrine of the continuity of the chalk also fell by the wayside. The prime result of the Challenger was the fifty large quarto volumes of reports, whose familiar green bound covers are the cornerstone of every oceanographic library. Most of these concern the life of the sea -- the animals found on the bottom -- and at the surface. Not much was collected in between because the gear was not suitable. The other great contributions are on the chemistry of sea water and the bottom sediments. As far as these aspects of oceanography go, we have been filling in the details so broacly outlined by the Challenger reports. Iittle was contributed to our knowledge of the circulation of the oceans, because of lack of instruments and the necessary hydrodynamic theories on which to infer circulation from the characteristics of the water, Such theories were not developed until early in this century, primarily by Scandanavian and German oceanographers.

We are still seeking more refined answers to many of the questions raised by those who went on the Challenger expedition, but many more have occured to us as our knowledge has improved.

Now we want to know how many fish there are in the sea, not as kinds, but as populations, and how much the sea can produce as compared to the land .. in terms of plant production and rate of overturn in the food cycles. When the Challenger sailed, ecology had barely begun, with the studies of the oyster banks of Helgoland by the german fisheries biologist Karl Moebius. We often hear from our Sunday supplement literature that as our population increases we must turn more and more to the sea for food and raw materials -- but if we are to do this, we must realise how nrimitive our knowledge is. It is often stated, for example, that there is no plant activity, or no active synthesis of food in the sea below the depths to which light can penetrate. Yet we are becoming aware that this may not be quite true -- some types of plant like organisms may well be actively producing nutrient material in a different manner. We are also beginning to realise that there is a marvelously complex and interrelated group of rather small organisms in the sediments of the deep seas.

The questions we now ask of the chemistry of the sea water, concern elements and substances not dreamed of by the Challenger's chemist, for now we need to know about the distribution of radium, of artificial isotopes, and other substances of man's careless devising in the sea. Much more refined chemistry is needed now.

Our studies of the sediments go deeper than those of the Challenger's geologists, for now we sink long tubes into the mud and study the layers in these cores to gain some idea of what has gone on in the past. By method the layers of ash that fell into the Mediterranean when Pompei was buried have been identified.

We are vitally concerned about ocean currents and circulation, both as an aid to understanding the populations of fishes and other creatures of the sea, and also as a necessary adjunct to controlling our potential pollution of the sea 
by radioactive materials and other vast-r. While the broad outlines of oceanic circulation have been dram since the Challenger's time, we may still have such startling discoveries before us that that of the Cronwell Current, a broad thin current flowing beneath the surface in the reverse direction across the Pacific toward the Galapagos Islands -.- the existance of this current was not denonstrated until 1950, and the mechanism that drive it is still not well understood. Indeed, there was no provision for such a current in oceanographic theory.

In methods and types of gear we have advanced beyond the Challenger era -at that time wire cable had just been developed by Lord Kelvin, and was not considered reliable enough -- so the Challenger used hemp lines for sounding and enormous ropes for dredging. The steam donkey engine has been replaced by electric motors. But still the operation takes time -- many hours for a dredge haul. Thermometers are better, and all sorts of electronic gadgets to measure the chemicals in sea water have been covised. Most useful of all have been the echo sounders and similar devices that not only measure the depth beneath the ship but in some cases the thickness of the bottom sediments, producing useful geological profiles. Positioning is of course more accurate. But the prime instrument in oceanography is the oceanographer, whether he be basically a physicist, chemist, biologist or geologist, and the people that help him ashore: It has been estimated that for every researcher on ship, there should be ten ashore to work on the data. But most of these shore people are the indians of oceanography - we need them desperately, but of course most young people who want to become oceanographers want to be chiefs.

Lately we have been trying to decide just what -- or who -- an oceanographer is. In these days of IBM cards and record keeping, everything must be classified properly. There is a federal register of scientific talent, and all working scientists are asked to fill out rather complicated forms for this register. Somebody converts these things to little rectangular holes on IBM cards. RecentIy in an attempt to estimate the total number of oceanographers, these cards were fed through the machine, and about 5,000 cards fell out. There are nothing like 5,000 oceanographers, even if we count all the cooks and bottle washers. There may be 5,000 people who have something to do with things in, about or from the ocean. For example, I do not consider myself an oceanographer, but a marine biologist, who happens to specialize in the study of a group of animals found only in the sea. But I have become recently involved in trying to promulgate a fool proof questionnaire that will produce only the real oceanographers, those who work actively with problems in the sea and who go to sea. So our questionnaire asks how many months have you been to sea this last year, and what research papers have you published about the sea, and so on. I am not qualified to fill out this questionnaire -- or at least I have managed to do so in such a way that I probabIy will not be numbered among the salt water oceanographers -- this time my IBM card should fa.ll out in the miscellaneous pile at the end.

There ia a serious aspect to this attempt at classification, since the support of oceanography must depend in part on the estimated roster of available people. There are probably not more than 350 or at most 500 people in the US who really ought to be considered oceanographers. Yet we have plans for adding more and more ships to the scientific fleet and some of us are not too sure that we are going to have enough oceanographers to man these ships, especially at the present rate of recruitment from universities.

An oceanographer is not only a scientific sailor, he is something of a jack of at least several trades. A good many of the senior oceanographers have come 
from other fields of study, carrying their special problems to the sea. Because of its three dimensional nature, the ocean presents many complications even for the simplest problem, such as going back to exactly the same place on the bottorn of the sea to take a second sample of mud or worms. As a result, more knowledge of oceanic processes is expected of the next generation by those whc have learned some of these things the hard way. It has been facetiously said -- but perhaps not so facetiously after all -- that present degree requirements are such that many of the people who now hold degrees in oceanography would not now be eligible for admission to graduate schools in oceanography. This is perhaps more simply understood as a result of the increasing numbers of people who want to go on to graduate school, and the correspondingly larger number of those who can meet more stringent requirements - in other words, as in many other fields, the competition is getting keener.

We often get requests from students in high school, and sometimes even from grade school children, about a future in oceanography, and how to study for it. Sometimes we get inquiries from their teachers as well, who seem to want to take to sea to get out of the classroom. Often these questions include inquiries about working hours and salaries. At the outset, it should be realized that oceanography -- like any other scientific endeavor, does not observe union hours and that the principal compensation is not the salary but the privilege of doing what you really want to do and incidentally getting paid for it. As the Greek poet Oppian said so long ago of the fisherman, the oceanographer should be daring, dauntless, willing to lose sleep, and must be keen of sight, wakeful and open eyed. "He must bear well the wintry weather and the thirsty season of Sirius -. he must be fond of labor and he must love the sea."

Preparation for career in oceanography is not enst -. love of the sea is not quite enough. Oceanography is such a mingling of $c \ldots \ldots i n$ disciplines and specialities that it is necessary for an oceanographer to know a little bit about almost everything in addition to knowing a fair amount about some particular field.

In other words, there is really no "major" in oceanography. A student should be basically a physicist, biologist, geologist or whatever, interested in the processes of the sea as they pertain to his central field of study. As a result virtually all institutions that offer degrees in oceanofraphy require first of all a major in a particular field, and a broad background in related fields. For example, a biology major who desires to become an oceanographer must also have laboratory courses in chemistry and physics, and at least one course in geology. All oceanographers are expected to have mathematics through calculus. Since oceanography is one of the most international of the sciences, foreign languages are essential and are becoming increasingly more so. The two preferred ones for degree candidates are Russian and German.

The beginner in college should not hope -- or expect -- to start right in with the ocean. Few institutions offer undergraduate majors in marine biology, and only one -- the University of Washington -- offers an undergraduate major in oceanography. But the requirements are so many that the course is really a five year one anyhow. $\hat{A}_{n}$ oceanographer should begin his preparation back in high school, learning his own language -- English in our case -- mathematics and the start of his foreign languages. The best college training for oceanography -as for any other branch of science -- is to get into the toughest undergraduate school possible, and to work hard. Although oceanography does call for a diverse background training, the diversity can be overdone. There is the sad story of the young man who tried to do everything in his undergraduate years that was hoped 
for by a comittee of oceanographers who published a brochure on the ideal education for an oceanographer. Unfortunately this young man overlooked the essential requirement that he have at least one solid field of specialization. As a result, when he presented himself for admission to graduate school, he was unacceptable for admission because no professor would concede that he had the background for any one subject. Perhaps the story is apocryphal -- but it does serve as a warning that diversity of knowledge must not be confused with diffusion of effort. Anything in excess is bad for the system -- including too much salt or water.

While no one wants to discourage young people, it is only fair to remind them that many are called but few are chosen -- but if the call is strong and the response adequate, there is a good chance of being chosen. It is inevitable that our national effor' in oceanography will increase, for we have barely begun to study the reeans and our future will depend much more on our understanding of ihe coeans the: it will upon bringing back samples of moon dust.

Joel W. Hedgpeth 
III The ways and means of Oceanography

Public understanding of oceanography - what it does and how it operates is not always in pace with popular interest in the subject. Too often, questions are asked which suggest that the questioner understands no more than that oceanog raphy involves going out on the ocean with a boat, or down to the bottom in a bathyscaphe, or perhaps drilling a hole through the bottom of the sea. The drilling of a hole in the bottom is only incidentally related to oceanography -. if it is to be done at all, it has to be somewhere in the sea where the earth's crust is thinner, and the budget for the Mohole is separate from oceanographic budgets. Oceanography, is more, of course than people who study the ocean, although the people are the most essential part of oceanography. Oceanography is ships, shore bases, instruments and logistics.

According to the 1961 compilation called Oceanographic Vessels of the world, some 161 vessels of all types were in use as oceanographic research vessels all over the world. The list was probably incomplete before it was published, and some vessels are included which can hardly be considered oceanographic in the fullest sense of the word since they are 39-40 feet long and probably seldom get very far from land. Of the 161 research vessels listed, 43 are in the United States, and only 12 are listed for the Soviet Union. According to a more recent listing of new oceanographic vessels, some 31 new vessels are now in service or will be in the next few years in the United States alone. This however includes some rather special objects, like FLIP, which is a long tube with a cabin on one end that is towed to sea and upended to form a sort of floating submerged tower to study the acustic properties of sea water, and a small two man submarine. Another 43 vessels are conversions. While there is some duplication in the lists, and some of the new ships or conversions will replace others now in service, it. is nevertheless evident that the United States is doubling its oceanographic fleet in about ten years time or less. A good part of this increase is due to the socalled Navy Tenoc (Ten years oceanography) program. Each year the Navy is supplying two or more vessels, generally termed AGOR, which is short for Auxiliary General Oceanographic Research. These are not all constructed to a uniform plan, although they are usually 200 feet or more in length. Some are conversions -adaptations of existing vessels, others are new, specially ocnstructed ships. New research vessels cost between 2 and 3 million dollars to construct, and conversion of an existing ship may cost a half million dollars. Among the AGOR ships is the Eltanin, operated in Antarctic waters by the National Science Foundation as part of the Antarctic Research Program. The Davis, used primarily by the Navy, is based in San Francisco. Another is the Conrad, operated by Lamont Geological Observatory. This is not named for Joseph Conrad, but for Robert Dexter Conrad, who had much to do with the Office of Naval Research in its early, formative years. Another group of large research vessels is operated by the Bureau of Commercial Fisheries of the Fish and Wildlife Service. It was the predecessor agency, the U. S. Fish Commission, which built and mintained the first vessel specifically built for the oceanographic research, the Albatross. The name is now carried by the Albatross IV at Woods Hole. A few research vessels are maintained by industries for special purposes such as testing instruments or classified research related to military contracts. In all, it is possible that by 1970 the United States alone will have an oceanographic fleet equal to the world fleet of 1960 .

As anyone who owns a boat -- even a fibreglass job with a trailer that is towed out to a lake on weekends -- knows, it's not the initial cost, it's the upkeep, that runs into money. The cost of oceanographic ships is high - good sized 
vessels cost around 1,000 to 2,500 per day at sea, and the annual ship operating budget of Scripps Institution of Oceanography alone is 2.5 million dollars. These costs include maintenance, but cost of operating ships does account for a large part of the national oceanographic budget. Yet the total budget is not very large. Just how it will work out for 1964 is uncertain, but it will probably be around $\$ 2140,000,000$. This is of course the Federal budget, and includes the share of the Navy, the Bureau of Commercial Fisheries and Coast and Geodetic Survey, Atomic Energy Commission and National Science Foundation. It does not include the money from states and private industry, but this is a small fraction of the total anyhow. It is difficult to estimate the total world wide budget for oceanography, but it seems to be in the order of perhaps $250,000,000$ per year.

Even without expansion of effort, oceanography is not going to cet less expensive. The cost of operating ships increases steadily -- despite the careless statements of one local oceanographic entrepreneur, universities do not use students as crew to operate research vessels, but unionization of crews on research vessels will produce difficult financial problems. Oceanographic instrumentation is becoming more expensive as the instruments become more complicated -- or sophisticated, and we have now reached the stage where no major oceanographic institution feels properiy equipped unless it has a computer. Indeed, one of the latest major research vessels has a computer on board to process results under way. All that is now needed is an attachment that will produce the finished progress reports for distribution when the ship docks. Somebody attempted to reduce the costs of oceanography to specific details and came up with the estimate that each figure, such as a temperature measurement, cost about $\$ 7$ a number, and a sample of sea water captured in a bottle cost \$11 a fifth. Loss of gear is inevitable, and instruments must be replaced. When one remembers that oceanographic vessels often must be at sea in rather rough weather (although of course observations are impossible in heavy seas), it is remarkable that no major oceanographic vessel has been lost at sea in the last twenty five years, and only two since 1929. The French exploring vessel Pourquoi Pas?, a veteran of Antarctic exploration, was wrecked on the shore of Iceland in 1936 with the loss of all but one of her crew, including the commander, Captain Charcot, and the non-magnetic research vessel Carnegie was destroyed in 1929 by fire in Apia harbor, Samoa, with the loss of her captain and a cabin boy. In view of the hazards involved, the safety record of oceanography is much better than driving down the highway. The most disastrous loss to oceanography is recent years was the airplane accident in Mexico which took the lives of Townsend Cromwell and Bell Shimada while en route to join an oceanographic cruise in 1958. A few years ago a vessel from the University of Tokyo was destroyed by a volcano, with the loss of all on board, including some well known students of volcanos, but this is not a usual hazard of research vessels.

The estimated world oceanographic budget of approximately 250 million a year may sound like a lot of money to some people, but it is infinitesimal along side the $\$ 5$ billion approved for space projects by Congress for fiscal 64 . The National Academy of Sciences committee on oceanography recommends an annual budget of 600 million for USA by 1970. While a large part of the oceanopraphy money may be spent for engineering and keeping ships going, a still larger percentage of our space budget is not strictly speaking science -- it is hardware. And there is no comparison of the practical benefits to be obtained by a fuller knowledge of the ocean as compared with finding whether or not there is really life on Mars. Let us say we do find that life is constructed of something other than DNA on Mars - very interesting, but so what? We still. have to live on earth, and the ocean is the largest part of our earth. 
As a distinguished British gentleman, Sir Frederick Brundett has remarked: "The World must be mad to spend more in a year on space research than has been spent in studying the oceans in the last hundred years".

Ships, of course, are the primary capital investment of oceanography. But there are also buildings, Oceanographers do not spend all their time at sea, but must process data, analyze results and prepare reports. It has been said that for every day at sea there are ten days of work on land. Another way of putting this is that there should be nine or ten researchers and technicians ashore for each man at sea. This requires buildings, and one of the most striking aspects of our oceanographic institutions is their crowded condition. Nobody seems to have enough space to work in and everybody needs more buildings. Sometimes a close mingling of people has an advantage -- more ideas get exchanged. But there is some limit to this, beyond which people simply get in each other's way.

Our oceanographic effort is not however, overstaffed, even if the buildings are crowded. Indeed, we are not sure where all the people are coming from to staff the vessels and the shore facilities for our expanding oceanographic fleet. Recruitment, in spite of all the public interest, is not as fast as we would like it to be. We think there are about 500 - at the most - real oceanographers in the business in the United States and the shortage is already acute in two fields -straight physical oceanography (which alls for more rigorous mathematical background than other phases of the field), and taxonomy -- the people who must identify all the kinds of plant and animals found in the ocean, or at least those which are most abundant. According to one federal agency, the manpower requirement for taxonomy is much smaller than for physical oceanography. This was evidently written by someone who did not know what he was talking about, for the identification of organisms is not amenable to computer techniques, and it has taken years to get some of the most important animals identified. Our most critical need is biological oceanographers - good ones, who are specialists in various critical groups of organisms.

At any rate, we have ships -- perhaps more than we need - buildings, but, not enough for the people we do have in most places, and people - critically short in some fields. What are we doing with what we.have?

There are two broad aspects of oceanographic effort. The first is what is known as surveys -- this is essentially similar to the mission of the Weather Bureau-continuous retaking of observations at the sea to gather data for the changing environment, and to find out what is there at present. One of the great international efforts of this character is currently in progress, the International Indian Ocean Expedition. This involves ships of many nations including USA and USSR. Much of the work of the US Navy's Oceanographic Office, the Coast and Geodetic Survey ships and the Bureau of Fisheries is essentially survey in nature. This must be kept up year after year, although some aspects of it maybe processed by computers for more rapid results. Promising steps in this direction have been taken by the Navy. An adjunct to the survey function of oceanography is the National Oceanographic Data Center, where all data that can be reduced to square holes on IBM Cards is being assembled. The Soviet Union operates a similar data center, and the two are exchanging information.

The other aspect of oceanography is that involving research into special phases or problems -- sometimes this involves surveys as well, but often expeditions are undertaken to explore special problems or phases. Some of these have 
come to attention because the routine data gathering has brought out problems. So it is not always easy to separate these functions. A survey of fishery areas in the mid Pacific revealed the Crápwell Current or equatorial undercurrent running against the grain, so to speak, just under the equator from west to east. An immediate result of this discovery has been not only intensified study of the oceanic region involved, but a lively reappraisal of basic oceanographic theory, since it did not have any explanation for this observed phenomenon. The intensive, repeated surveys off the California coast, set in motion by the decline of the sardine, have brought to light oceanic fluctuations still not adequately explained, and provided data for a new and critical approach to the organization of groups of planktonic or floating organisms. We even have the glimmer of an idea of what may have happened to the sardines, but cannot say confidently that the "average" or "normal" conditions of the waters along the California coast are conditions of sardine abundance or sardine scarcity. It may take twenty five years of surveys and data to get an answer to that question.

What oceanography should do, at least in this country, has been considered by a number of national committees. In fact, from its beginning oceanography has been organized by committees. A committee of the Royal Society determined the course and scope of the Chalienger Expedition that explored the oceans from 1872 to 1876. The oldest committee that still functions is known as the Conseil Internationale pour l'exploration de la Mer, a comittee of representatives from various countries of northern Europe, including the Soviet Union -. Russian scientists were among the charter members in 1901. It has confined most of its interest to the North Sea and the North Atlantic, with emphasis on fisheries problems. It is now more familiarly known as ICES, from its English title, International Council for the Exploration of the Sea.

In the United States the course of oceanography has been charted -- or should one say plotted -- by two successive committees of the National Academy of Sciences. The first of these committees flourished in the decade 1927-37. As a result of its deliverations and reports, Scripps Institution was started on its way as a major center of oceanographic research and new establishment was recommended for the Atlantic Coast. Accordingly Woods Hole Oceanographic Institution (not to be confused with the much older Marine Biological Laboratory there) was founded in 1931. At the present time there are four research establishments at Woods Hole, employing in all hundreds of people. It is a town whose chief industry is science. And tourists in summer time -- scientific and otherwise.

The present comittee on Oceanography of the National Academy, familiarly known as NASCO, was established in 1957, and is responsible for much of the stimulus that has prompted Congress and the various granting and contracting agencies of the Federal Government to support oceanography.

ICES and NASCO are not the only committees. There is a veritable galaxy of committees, both international and in each maritime country. Attempts to coordinate oceanographic effort in the United States, at least in the Federal bureaus, are made through ICO, the Interagency Committee on Oceanography, not to be confused with IOC, the Intergovernmental Oceanographic Commission, and SCOR, the special Comittee on Oceanic Research. Both of the latter are part of UNESCO. A recent publication of the United Nations lists some 45 committees involved in one way or another in oceanography. In spite of all the multiplicity, there is a sort nf nceanography establishment. The same eminent individuals serve on ceveral committees and shift about in a sort of game of musical chairs from one comittcu meeting to another. Now and then our committees seem to get a bit 
weary, and the last joint meeting of NASCO and ICO could only approve what was already decided and funther recommend air-sea interface studies as the most inportant thing yet to do.

From the sense of all these meetings has come statements of the broad aims of oceanography. The ICO has surmarized these in terms of five objectives: One - to describe the distribution of physical and chemical properties of the oceans and to understand the dynamic processes which affect this distribution; two - to increase knowledge of interactions between sea and atmosphere; three - to determine the kinds, distribution, adaptations and productivity of the living populations of the sea and to understand the interactions of the marine organisms to each other and to the physical and chemical properties of the sea. This is to many of us the ultimate and most essential mission of oceanography, and all other objectives relate directly to it. Already the potential backlog of specimens that must be handled from our increasing oceanographic effort has resulted in the establishment of anew division of the Smithsonian Institution to sort the specimens and see that they are placed in the hands of those who will study them. The fourth objective is to describe and understand the geological, geochemical and geophysical nature of the sea floor, including its relation to the adjoining land masses. Insofar as the Mohole can be considered oceanography, it will fulfill a small part of this objective. The fifth and last major objective is to determine the modification of the ocean resulting from man's activities. It is reassuring that at the highest levels of our committee establishment this problem is recognized. Nor too many years ago the possibility that man could alter the ocean was not seriously considered at a.ll.

These objectives are carried out not only by the large government agencies such as branches of the navy, coast and geodetic survey -- and the army, which because of its charge for harbor engineering, studies beaches and harbors, and the Fish and Wildife Service, but by universities and private research institutions. There are three big oceanographic institutions as such in this country, Scripps Institution (not Institute, please) at Ia Jolla, the Woods Hole Oceanographic Institution at Woods Hole and the Institute of Marine Science at Miami. There are quite a few other oceanographic institutions and departments of universities, and there is even an oceanography department at Ann Arbor, Michigan.

The work, of course, is actually done by oceanographers and the people at the shore bases. The usual procedure is for those who actually want to do the work to propose their project. Funding is provided in one way or another, through grants or contracts. But the growing problem is that ship time eats up so much of these budgets (since usually ship time is charged against each project) that serious concern is now being expressed. It seems inevitable that ways must be found to operate ships separately from specific missions as well as developing more realistic accounting systems. One oceanographic ship operated, according to the books, 13 months in one year!

In any event, the broad mission has filtered down from the establishment, and a lesser committee somewhere has approved the project and the money. FinalIy the oceanographer can go to sea.

The Iife of an oceanographer at sea is not much different from that of the commercial fisherman -- getting good data or observations is often as uncertain as making a good catch of fish. Nor is it always certain that instruments will work properly. Most of them do, but there is always the peril of a parted cable -- and the valuable gadget sinks to the bottom. Une of the informal standard 
rules of oceanography is that you should photograph'a new piece of apparatus before you lower it in the ocean, because that is the last you may see of it. Data must be gathered at all hours of the day and night, and sometimes the process takes most of a day. Some samples must be analyzed. immediately and others properIy stored for later analysis ashore.

But data alone is not science. It is not enough to do something that hasn't been done before -- to sail to an unknown spot on the ocean just because no one else has got there yet. The critical need in oceanography, as in all branches of science, is for keen analytical minds to make useful summaries of data and draw meaningful inferences.

Without people of this sort, our national oceanographic effort can become constipated with data. So far, however, provisions for education of oceanographers are the smallest part of our budgetary thinking. It is to be hoped that this will not continue to be so.

Joel W. Hedgpeth 
IV The Inexhaustible Sea

The title of our discourse is taken from a recent magazine article, but it illustrates an opinion about our future expectations from the ocean that many informed scientists view with some reservation. It is true that the seas of the world cover the greater portion of the globe and that much can be expected from them in the future. But our knowledge of the seas is only slightly less fragmentary than that of the moon, and some of the schemes and imaginative devices proposed for obtaining resources from the ocean are only slightly less fanciful that the devices suggested for bringing a sample of moon dust back to earth, and almost as expensive.

The optimism of those who speak of the inexhaustible sea had best be tempered by a remembrance of how we have regarded our terrestrial resources. It was not much more than 60 years ago that men still spoke of the boundless wealth and inexhaustible resources of the North American continent. Now we seem to have transferred this attitude to the sea, but we have no real justification for doing so. In short, our estimate of the inexhaustible resources of the sea is based on our lack of understanding of the sea. It is also part of man's blithe optimism that the future will always be taken care of, somehow. But the gloomy prophets of the plundered planet school (as some have disdainfully called them) are right in one essential: mankind cannot always hope that the future is assured, unless he limits his numbers so that they do not exceed the carrying canacity of the earth. The solution to Los Angeles is not to commit all the water of the western United States to its unlimited growth, but to stop Los Angeles from growing. One of the plans for moving water to Los Angeles would be so devastating to fish life, especially what is left of the salmon, that the Fish and Game people have categorically recommended against the scheme. Thus what we propose to do on land may affect the life of the sea and our expectation of future harvest.

sut there is also the implicit notion that we can do almost anything we wish to our native environment, the land, as long as we have the sea to fall back on. But because we are creatures of the land, the sea rill always to our secondary reserve -- and what will it avail us to reduce our land to a vast denaturalized desert of houses, highways, power plants and turn to upporting ourselves on fish meal and plankton soup -- if indeed that is possible? Man will not be able to live on fish meal alone.

The eminent fisheries biologist Sir Alister Hardy has pointed out that apparently several times in the history of life on earth certain animals have been forced back into the sea to make their living. Porpoise and whale like dinosaurs evolved, and in later epochs the mamalian whales, seals and such birds as auks and penguins evolved from terrestrial relatives. Perhaps this was due to competition for food. Sir Alister goes on to remark that man's increasing populations will force him back to the sea as well -- and he proposes a few fanciful devices of his own -- underwater fish herding gadgets and perfected diving apparatus that will enable us to stroll about in far deeper water than we can now reach. At any rate, it is to be noted that this return to the sea wiII not be the result of competition from another, more successful terrestrial mammal, but from man's own pressure of numbers. Are we justified in the comfortable notion that the sea is our ultimate safety valve?

The problem was concisely put some 1800 years ago by the greek poet Oppian, 
who said:

But, since the sea is infinite and of unmeasured depth, many things rme hidden, and of these dark things none that is mortal can tell; for small are the understanding and the strength of men. The briny sea feeds not, I think, fewer hords nor lesser tribes than earth, mother of many. But whether the tale of offspring be debatable between them both, or whether one excels the other, the gods know certainiy; but we must make our reckoning by our human wits.

Indeed the must, and one of the liveliest arguments among oceanographers and marine biologists is precisely the question nut by Oppian around 180 AD: does production in the sea equal or excel that on land? At least we hope that our understanding and our wit have been sharpened since Oppian's day, and we may not be too far from some sort of answer to this basic question of the productivity of the sea. In the meanwhile, popular writers and TV script artists oversimplify the problems and raise hopes whose fulfillment we cannot guarantee. article:

Consider, for example, the following statement from a recent magazine

"--- the sardine population dwindled, and it never recovered, because by the time the environment improved in 1957, the feeding grounds has been pre-empted by a kind of anchovy that has a limited market as a food fish in the United States. Had the anchovies been fished intensively during the lean year, Cannery Row might still be thriving."

There are so many oversimplifications in this statement that it is hard to know where to begin. However, it should first be pointed out that at the peak of the California sardine fishery - around 1936-39 - the greater part of the catch was not used for human food but for the production of fish meal for livestock food and oil for industrial purposes. The same thing is happening to the herring fisheries of Europe. The peak production of California sardines has now equalled or surpassed by the menhaden fishery of the South Atlantic and Gulf states, which in 1961 accounted for about $45 \%$ of the entire fish catch of the United States and Alaska. Menhaden are used exclusively for fish meal and it is obvious that menhaden have replaced sardines in the economy. It is doubtful, should the sardines return this month, that Cannery Row could ever catch up. The State of California controls the percentages of whole fish that may be used for reduction purposes, and at this tire virtually the entire sardine -. and anchovy-catch is canned for food. 1961 was the lowest sardine pack in history. Of course, some people might say that Cannery Row is thriving again - - as a tourist trap.

The most serious misstatement is perhaps the idea that had we been as fond of anchovies as of sardines as food, the fish canneries would have been able to continue at something near their peak by simply switching fish and labels on the cans. The idea that anchovies are replacing sardines is at best a hypothesis, and I am not aware that anyone who has studied the situation would be willing to say that this was an instantaneous replacement of fish stocks, like changing the guard at Buckingham Palace. It will be interesting to see what happens if tho menhaden population collapses -- what will happen then to the cannery rows of the Atlantic and Gulf coast communities? When the herring disappeared fruil the 
baltic in the mid 15th century, the Hanseatic league of cities that depended on them faded and the Dutch became the premier fishmongers of Europe for their turn. No one knows why the herring of the Baltic disappeared -- perhaps some change of conditions in the sea -- and they have never returned.

As yet, we have no way of adjusting to these fluctuations in natural populations of fishes in the sea. For example, while it is generally believed that the sardines of the California coast declined because of changes in the temperature of the ocean, brought about perhaps by changes in the currents, it is also suspected that a very heavy fishery at a period of unfavorable environmental change contributed to the decline of the fish stocks. Conversely, however, we have some evidence that a fairly heavy fishery of adults during favorable years might have the reverse effect -- that is, removing the mature large fisi makes it possible for the young fishes to grow faster and replace the older ones that have been removed.

Whatever happens in nature, it is doubtful that major population changes are as simple as driving cattle off a range and turning sheep loose on it. Less than r hunired years ago it was believed by many eminent authorities on fisheries problems $t$ t the sea was so vast and the populations of fishes so immense that the efforts of man, however intense, could have no effect on the populations. It needed only a minute fraction of the population to replace the entire stock, so abundant is the spawn of most fishes. Now we have evidence concerning the extraordinary vulnerability of hatching and larval fish to changes in the enviroment, -how a drop of a degree or so of temperature may delay hatching perhaps several days, so that the egg drifts beyond the point of no return, or hatches at a time when other creatures that would eat it are just a little larger than they should be, and thus eat more fish. These small changes apparently have a way of piling up to produce unexpectedly large effects. And we have the example of the Baltic herring to suggest that the process may not always be reversible.

Mankind has had two great lessons concerning the effect of his fishing activities on the stock of fishes. The bottom fish of the North Sea and waters around the British Isles had been fished intensively up to 707/, and the catches were dropping off, and the average size of the fish was decreasing. Fishing had gone beyond that stage in the fishery when a harvest of the old mature fish enabled the smaller and younger ones to grow up to take their place -- the rhole fisheries curve was dropping. But the war of 1911-18 made fishing impossible, and imposed a closed season on the stocks of the North Sea. When fishing was resumed in 1919, the fish were more abundant and larger. But man did not learn the lesson, and by 1938 things were back to where they were in 1914 -- or perhaps worse. Then World War 2 imposed another long closed season, and the stocks again improved. Now many nations that depend on the north sea fisheries have regulations requiring that the mesh of the nets be large enough for the smaller fish to excape, but in no field of international relations is uniformity and compliance so difficult to achieve as in fishery regulations.

When success is apparently attained, as in the halibut fishery of the United States and Canada, the suspicion arises in some minds that the fishery is not being regulated so much on conservation grounds as on lines to maintain the highest price for the fish. In any event, it was impossible for the fisheries experts to be certain that the halibut was being fished to capacity in the east Bering sea grounds, so in 1963 the Americans and Canadians grudgingly opened these grounds to Japanese fishing. 
As we can see from the papers these days, we seem to be on the verge of some sort of crab war in the Bering sea with the Russians. More such controversies are inevitable as we increase our fisheries efforts, and it is certain that we will not be able to achieve a rational exploitation of the valuable fisheries stocks of the world ocean as long as the efforts of any one nation cannot be restricted. The efforts of those who agree to conserve Antarctic whales are futile as long as other fishing nations sneak into the waters and capture whales of all species and sizes. The United States cannot piously point the finger at another nation, especially in the matter of whales, for the memarial to the great nods of sperm whales, now forever gone from the seas, is New Bedford, Massachusetts. At least we have made some modest beginuings toward the sort of international accord that must be achieved in our cooperative intemational oceanographic endeavours. The most striking of these is now under way, the Internaional Indian Ocean Expedition. Under the auspices of the UN, this expedition which involves the ships and scientists of many nations, has as one of its aims the increase of knowledge about the resources of the Indian Ocean, primarily for the benefit of the countries bordering on the Indian Ocean. Some of these, like India, do not have the resources in research ships and talent to undertake such studies without this assistance.

It is difficult to predict which essential step toward greater reliance on the seas will come first -- complete international ccord or scientific understanding at such a level of sophistication that we can reasonably predict fisheries stocks from year to year. One suspects the latter will come first. Yet it is a difficult task, to understand the combined effects of man and nature in the sea. One of the greatest fisheries investigations in the history of man was that undertaken along the Califormia and Oregon coast since about 1949 to find out what had happened to the sardines. As already mentioned, we are not sure how much of the change was brought about by nature and how much by man.

But we suspect most of the change was due to nature. This is based partly on the analogy of such past events as the 15th century disappearance of thr Baltio herring, the great tilefish catastrophe of 1882, but in particular on the ci: stance that while conditions seem to be improving for sardines and the fishing effort is minimal, the sardines are not coming back. Perhaps they will come back, but as yet we lack the information to predict if or when. We cannot even answer the question tiat we may have this whole business the wrong way around, that actually the great sardine catches of the 1930's were made during an unusual period and that the usual -- normal z- or average state of affairs is indeed one of colder waters, stronger winds and fewer sardines. So far, at least, we have no indication of regularity in this process -. cycles of 7,9 or 11 years or whatever. That we do know is that the warming up of the ocean in $1957-60$ is not a unique event -- something like it apparently occurred a hundrec years before.

We are often asked about the waming of the ocean water, especially since this period seemed to coincide with more sharks. Perhaps it was simply that more people expose themselves to sharks these days. It is misleading to think of the ocean as warming up -- what actually happened was a shift in surface water, brought about by some change in the wind and pressure system over the entire Pacific basin. Decreased wind force reduces the upwelling of cold water near shore, and even results in somewhat higher sea level along the shore. If we try to understand the process as an actual warming up, we have to think of the amount of heat required -- something like four times the heat of the sun that actually reached the ocean in 1956-57. So evidently there was a shifting pattern in the ocean, and the sharks, out in the warmer waters away from shore all the time, 


\section{simply moved in closer.}

The changes we are talking about are of small magnitude as compared with the almost daily fluctuations on land -- the temperature rise in 1957-58 along central California was only about 3 degrees above the established average condition. The observed changes in marine life offer some evidence in support of what many naturalists have long suspected -- the life chains of the sea - from the floating diatoms to the great fish stocks are to be considered a system that is turning over at a rather high rate of speed - some of the smaller organisms have life cycles of a day or a few days, and the great blue whale, largest animal on earth, attains its full size in three or four years. But each level of the chain decreases in total mass as we proceed form the first producers to the last carnivores. There appears to be a great deal of lost energy in this system of turn over, and now and then the suggestion has been made that we should harvest our food from the lower levels -- the plankton -- instead of going to all the expense and uncertainty of catching fish. People who suggest this apparently do not realise that the plankton may be as equally spotty and uncertain.

Much more practical are the suggestions for the culture of these types of organisms that we can utilize at the second step -- such animals as clams and oysters. Oyster culture is our oldest marine industry -- practiced by the Romans. But shellfish and alga culture - such as the green Chlorella for which so much was hoped a few years ago -- must be done in bays. We have given very little heed to the use of our bays except as cloaca maxima. If we should ever want to return San Francisco bay to a condition adequate for oyster culture, we would have an almost impossible clean up job on our hands. Some of the future proposals for water to Los Angeles, which include bypassing of unsatisfactory water from farmlands and industries into San Francisco Bay would make the possibility even more remote. San Francisco bay is gone -- as a scene for shellfish and seaweed culture. This is a local example of what we may allow to happen on a world wide basis while at the same time we talk about increasing our food supplies.

Another possibility is that we may domesticate whales and seals and a fanciful novel has been written about the great herds of whales controlled by electronic fences and of the divers that shepherd them about. It may be more practical to increase the nutrient content of shallow waters by stirring up the bottom with compressed air jets, or eliminating by chemical means some of the hordes of useless bottom animals like starfish that consume the greater part of the available food material that might instead support fish. Something along these lines has been suggested by Sir Alister Hardy, but admittedly we must be much more certain about the significance of these animals to the economy of the sea as a whole before we can proceed with confidence. Men's continuing war with the agricultural pests on land is in large part a problem of his own making -by the intense cultivation of uniform crops he has set up attractive conditions for insects and viruses which in a state of undisturbed nature are only a small part of the system.

Today we have added a new variable to the uncertainties of the sea -- radioactive waste polution. Some of our Russian colleagues are of the opinion, and they may have some evidence for this -- that any degree of disposal of radioactive waste in the sea is potentially harmful, especially if it reaches the sea at those times when fish eggs are developing. This problem needs far more intensive study than it has so far received, even in England where studies are under way in the Irish Sea around the outfall of their infamous isotope sewer at Windscale. 
We have such an isotope sewer of our own in the Columbia River, but the studies that should be made -- of the structure of fishes -- conditions of glands -- numbers of scales -- fin rays and vertebrae -- are yet to be made. It means nothing to catch a fish and measure its radioactivity if we do not look for possible damage. To take a fishes' background count and conclude it is not affected because it still swims around is misleading; we do know that fish get thyroid cancers or tumors from radioactivity. In examing the published work on the effects of radioactivity on marine organisms, one is struck by the preliminary -- progress report sort of atmosphere of these reports. When are we going to get down to some serious work on this problem? The editors of the Bulletin of Atomic Scientists may be justified in getting the hands of their clock back a few minutes, but this clock of pollution cannot be set back or halted, unless we are willing to accept our obligation to our environment more seriously than we so far done.

I have discussed the biological aspects of the inexahustible sea because I am a biologist. I can say little about other hopes expressed for man's future from the oceans -- the mining of manganese nodules from the deep, or of phosphorite from the waters around Los Angeles. A large chenical corporation did take out a lease to go after this material but found that its costs estimates were off by a factor of perhaps ten, and abandoned the effort. While the difficulties may not be unsurmountable, some of the desired resources must be in much shorter supply on land than they are now to make reclamation from the sea justifiable. our best success so far has been with evaporating salt (another ancient industry), and obtaining magnesium from sea water. This is done on such a scale that the incidental fresh water obtained is now the principal water supply of an entire town in Texas. We have great hopes for fresh water from the sea -- or should we say Los Angeles has. But the prospect of economical fresh water from the sea is still so far off that we seriously discuss reducting most of the major rivers of this state to a shambles of dans and ditches to deliver water South of the Tehachapi. If we do manage to produce fresh water from the sea, will we tear up all these waterworks?

As for many of the fanciful submarine tractors, self prepelled nets and the like that have been suggested it must be remembered that the sea is a very difficult medium for machinery. It has enough salt to corrode but not enough to be a good conductor, and pressure makes it necessary to fill potentially collapsible spaces with incompressible fluids or construct heavy reinforcing against it. Most of the elaborate devices of the Sunday supplements have yet to leave the drawing boards, and the few that have been built, such as a self propelled submarine tractor, have been plagued with difficulties. The sea has long been a graveyard of fancy instmuments. Someday, of course, our ingenuity will solve most of these problems and some of the fancy gadgets will go forth to find out how inexhaustible the sea really is. In the meanwhile we spend our money on atomic submarines -- how many of these things do we have now, anyway - - and on rockets to the moon. But, as one gentleman on a national scientific comittee put it, it is still more essential for us to study the ocean's bottom rather than to scratch the moon's behind.

The National Research Council thinks our oceanographic budget. should be 600 million by 1970; at present it is probably not more than 150 million per year and it is probable that the efforts by other countries are correspondly financed. This brings us to the final consideration in this notion concerning the inexhaustible sea -- we are not going to get much for nothing out of the sea. Man never has, for he has fished the sea at the peril of his life and loss of ships and gear. So far, in all the long history of fishing, we have used essentially the same gear 
that was used 1800 years ago. When we do devise some different way of catching fish than towing nets or dropping baited hooks, we will still face the essentially inhospitable environment of the sea, and will still remember the words of that first author on fishing concerning the lot of the fisherman:

But for the toilsome fishermen their labors are uncertain, and unstable as a dream is the hope that flatters their hearts. For not upon the moveless land do they labor, but always they have to encounter the chill and wildly raging water.

Joel W. Hedgpeth 

